\title{
A FORMAL TOTAL SYNTHESIS OF THE MARINE DITERPENOID DIISOCYANOADOCIANE
}

\author{
A Thesis Submitted for \\ the Degree of \\ Doctor of Philosophy \\ of
}

The Australian National University

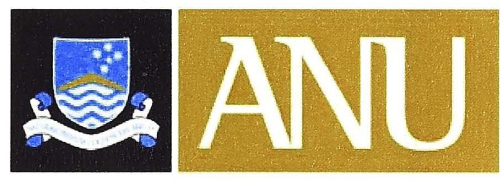

THE AUSTRALIAN NATIONAL UNIVERSITY

by

Kelly Ann Fairweather

Research School of Chemistry

July 2006 


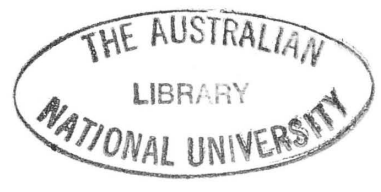

- ii - 
This thesis contains no material previously submitted for a degree in any other University, and to the best of my knowledge and belief, contains no material previously published or written by another person, except where due reference is made in the text.

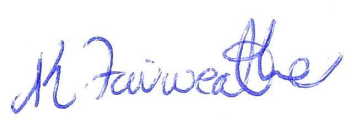

Kelly Ann Fairweather 
- iv - 
The chemists are a strange class of mortals, impelled by an almost maniacal impulse to seek, their pleasures amongst smoke and vapour, soot and flames, poisons and poverty, yet amongst all these evils I seem to live so sweetly that I would rather die than change places with the King of Persia.

Johann Joachim Becher, Physica Subterranea (1667) 
- vi - 
I would like to thank my supervisor, Professor Lewis N. Mander for his support and encouragement during my doctoral studies. It has been a pleasure to work in the Mander research group on such a challenging project.

I thank my colleagues in the Mander group over the years for their friendship and advice. In particular, my lab mate for most of my studies, Oliver Hutt, also to Matthew McLachlan, Regan J. Thomson, Patrick O'Connor, Matthew McDonough, and Giuseppe Del Signore. I am grateful to my current lab mate Lorraine Axford for the proof reading of this manuscript. I am indebted to Bruce Twitchin for the synthesis of starting materials and early intermediates in my synthetic sequence.

I would like to thank the technical staff at the RSC. Thanks to Chris Blake for his help with numerous high field NMR experiments, Gordon Lockhart and his team at Mass Spectrometry, Dr Tony Willis for obtaining X-ray crystal structures and Tony Herlt for help with the HPLC purification of my final compound. I am grateful to all my friends and colleagues at the RSC for making it a great place to work.

I am grateful to Professor Mary Garson from the University of Queensland for the provision of authentic samples of diisocyanoadociane and its diamine derivative, also to Dr Jamie Simpson from Monash University for helpful advice in dealing with these compounds.

I gratefully acknowledge the receipt of an Australian Postgraduate Award, the Alan Sargeson Scholarship and an RSC supplementary scholarship.

Thanks to my family in NZ, in particular my parents Jacqueline and Gavan Fairweather for their constant encouragement and regular purchase of airfares to visit me in Australia. Thanks also to Michaela and Howard Tipson for making me feel at home in Canberra.

Finally I would like to thank Shaun for help with the proof reading and formatting of this manuscript, but more importantly for his love and support over the last three years. 
This thesis describes a formal total synthesis of the marine diterpenoid, diisocyanoadociane (1.10).

Chapter 1 provides a brief survey of isonitrile marine natural products, including the isolation, biological function, biosynthesis and previous synthetic studies of these compounds. A strategy for the synthesis of diisocyanoadociane is also introduced.

Chapter 2 covers our problems with the previous synthetic sequence to ketone 1.95, and our efforts to improve it by utilising an epoxidation to install the required carbonyl group.

The first half of Chapter 3 discusses the Birch reduction of the A-ring, and investigations into the proposed reductive acylation and alkylation reactions. The second half covers an alternative approach to elaboration of the A-ring, and a successful synthesis of an intermediate (3.36) bearing a quaternary centre with the correct stereochemistry for $\mathrm{C}-7$ in the natural product.

Chapter 4 discusses an improved synthesis of aldehyde 1.98, in particular an alternative method for cyclopropanation. This chapter will also cover the Birch reduction of the Aring, and a successful synthesis of an intermediate (4.17) bearing both quaternary centres with the correct stereochemistry for C-7 and C-20 in the natural product.

Chapter 5 covers the difficulties encountered with the intramolecular Michael reaction, and the successful synthesis of a tetracyclic precursor (1.87) to diisocyanoadociane $(1.10)$.

Chapter 6 discusses our studies towards the deoxygenation and dealkylation to obtain dicarboxylic acid 1.62. The second part of this chapter will discuss the use of the Curtius rearrangement to complete the stereocontrolled formal total synthesis of Diisocyanoadociane (1.10). 
$-x-$ 
The following abbreviations have been used throughout this thesis:

Ac Acetyl

$\mathrm{AcOH}$

Acetic acid

AIBN 2,2'-azobisisobutyronitrile

APT

Attached Proton Test

$\mathrm{Bn}$

Benzyl

$\mathrm{Bu}$

Butyl

$t$ - $\mathrm{Bu}$

tert-Butyl

m-CPBA meta-Chloroperoxybenzoic Acid

d

Days

DBU

1,8-Diazabicyclo[5.4.0] undec-7-ene

DCM Dichloromethane

DEPT Distortionless Enhancement by Polarisation Transfer

DMAP 4-(Dimethylamino)pyridine

DMF Dimethylformamide

DMP Dess-Martin Periodinane

EI Electron Impact

Et Ethyl

EtOAc Ethyl Acetate

$\mathrm{h}$

Hours

HMPA Hexamethylphosphoramide

HPLC High Performance Liquid Chromatography

HRMS High Resolution Mass Spectrometry

IR

Infrared

Coupling Constant

LiHMDS Lithium Hexamethyldisilazane

LDA Lithium Diisopropylamide

LRMS Low Resolution Mass Spectrometry

Me Methyl

$\mathrm{MgSO}_{4} \quad$ Anhydrous Magnesium Sulfate

Min Minutes

MOM Methoxymethyl

m.p. Melting Point

NaHMDS Sodium Hexamethyldisilazane 


$\begin{array}{ll}\text { NMR } & \text { Nuclear Magnetic Resonance } \\ \text { nOe } & \text { Nuclear Overhauser Effect } \\ \mathrm{Ph} & \text { Phenyl } \\ \text { ppm } & \text { Parts Per Million } \\ i \text {-Pr } & \text { Isopropyl } \\ \text { Py } & \text { Pyridine } \\ \text { rt } & \text { Room Temperature } \\ \text { TBAF } & \text { Tetrabutylammonium Fluoride } \\ \text { TBDMS } & \text { tert-Butyldimethylsilyl } \\ \text { Tf } & \text { Triflyl } \\ \text { TFA } & \text { Trifluoroacetic Acid } \\ \text { THF } & \text { Tetrahydrofuran } \\ \text { TLC } & \text { Thin Layer Chromatography } \\ \text { TMS } & \text { Trimethylsilyl } \\ \text { Ts } & \text { para-Toluenesulfonyl } \\ \end{array}$




\section{INTRODUCTION}

1.1 Isolation 3

1.2 Biological Activity 6

1.2.1 Synthetic Antimalarial Analogues of Isonitrile Diterpenoids 9

$\begin{array}{lll}1.3 & \text { Biosynthesis } & 10\end{array}$

1.4 Previous Synthetic Studies 12

1.4.1 Total Synthesis of a Diisonitrile Tricyclic Diterpene 12

1.4.2 Total Synthesis of a Member of the Kalihinane family 13

1.4.3 Total Synthesis of Diisocyanoadociane (1.10) 14

1.5 ANU Strategy for the Synthesis of Diisocyanoadociane (1.10) 15

$\begin{array}{ll}\text { 1.5.1 Work Carried Out by Crabtree } & 16\end{array}$

$\begin{array}{ll}\text { 1.5.2 A Revised Approach } & 20\end{array}$

1.6 Current Study 23

2. IMPROVED SYNTHESIS OF KETONE 1.95 29

3. BIRCH REDUCTION AND ELABORATION OF THE A-RING

3.1 Birch Reduction 37

3.2 Reductive Acylation of Enone 3.7

3.3 Stereochemistry at the $\beta$-position of the Reductive Acylation Products 43

3.4 Attempted Alkylation of $\beta$-keto ester 3.16 44

3.5 A New Approach 46

3.6 Synthesis of Enone 3.34 47

3.7 Regioselective Acylation and Alkylation $\quad 48$

4. ELABORATION OF THE D-RING AND A COHESIVE SYNTHESIS $\quad \mathbf{5 3}$

4.1 Improved Synthesis of Aldehyde 1.98

4.2 Birch Reduction of the A-ring 55

4.3 Elaboration of the A-ring $\quad 57$

4.3.1 Synthesis of Enone 4.12 57

$\begin{array}{ll}\text { 4.3.2 Regioselective Acylation and Alkylation } & 60\end{array}$

5. INTRAMOLECULAR MICHAEL ADDITION REACTION

5.1 Introduction 65

5.2 Model Studies towards the Intramolecular Michael Addition 66

5.2.1 Formation of Dione 5.1 66

5.2.2 Intramolecular Michael Reaction 67

5.3 Michael Addition on a Model Lacking the $\beta$-keto Ester Function 72

5.3.1 Acylation of 5.11 and Attempted Alkylation 72

5.4 The Key Intramolecular Michael Addition Reaction 75 
6. DEOXYGENATION AND THE CURTIUS REARRANGEMENT $\quad 83$

6.1 Introduction 83

6.2 Deoxygenation 83

6.3 Dealkylation of the two Ester Groups 89

6.4 The Curtius Rearrangement 90

6.4.1 Model Studies 90

6.4.2 The Key Curtius Rearrangement 92

7. SUMMARY AND CONCLUSIONS 99

8. EXPERIMENTAL 105

$\begin{array}{lll}8.1 & \text { General Experimental } & 105\end{array}$

$\begin{array}{ll}\text { 8.1.1 Notes on Nomenclature } & 107\end{array}$

8.2 Chapter 2 Experimental 109

8.3 Chapter 3 Experimental 125

8.4 Chapter 4 Experimental 143

8.5 Chapter 5 Experimental 161

8.6 Chapter 6 Model Studies Experimental 180

8.7 Chapter 6 Experimental 186

\begin{tabular}{lr} 
REFERENCES & 195 \\
\hline
\end{tabular}

APPENDIX ONE - ORGANIC LETTERS PUBLICATION 199

APPENDIX TWO - X-RAY CRYSTAL STRUCTURE REPORTS 


\section{CHAPTER 1}

\section{Introduction}

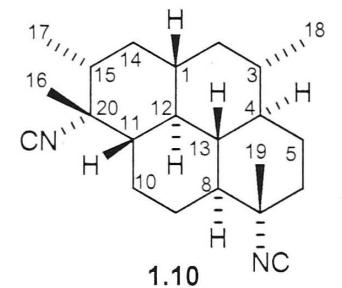


Chapter 1 


\section{Introduction}

The search for new antimalarial agents has become increasingly important over the last two decades, since malaria has regained its status as an extremely serious threat to the health and economic well-being of the human race in tropical and semitropical regions. ${ }^{l}$ Of particular concern is the increasing resistance of the malaria parasite Plasmodium falciparum against the drugs currently in clinical use.

\subsection{Isolation}

Since the discovery of the antimalarial activity of axisonitrile- $31.1,{ }^{2}$ much research has been focused on the isolation of compounds known to contain isonitrile and related functionalities, in order to determine whether structurally similar natural products demonstrate similar biological activity. Interestingly, the isonitrile group is rarely observed in terrestrial metabolites, ${ }^{3}$ and as such the focus has been on the isolation of these compounds from marine organisms. Approximately 80 marine diterpenoids from three classes of isonitriles and isothiocyanates have been isolated to date from marine sponges, including three acyclic diterpenes, e.g. 1.2, 46 derivatives based on the kalihinane skeleton $\mathbf{1 . 3}$ and 30 derivatives based on, the amphilectane skeleton 1.4 and its derivatives, namely cycloamphilectane $\mathbf{1 . 5}$ and isocycloamphilectane $\mathbf{1 . 6}$. $^{3}$
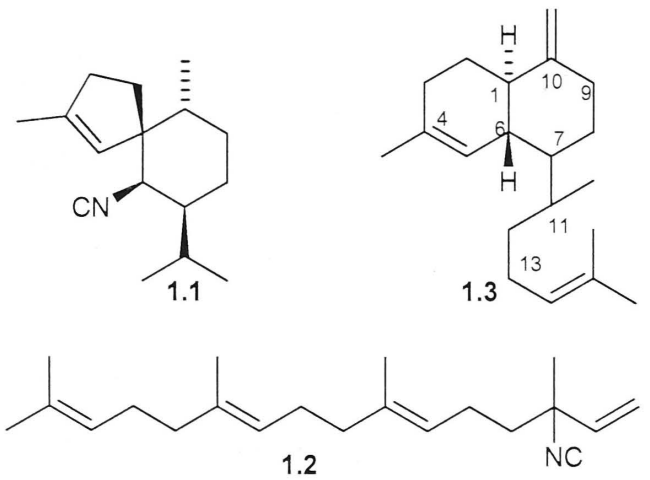
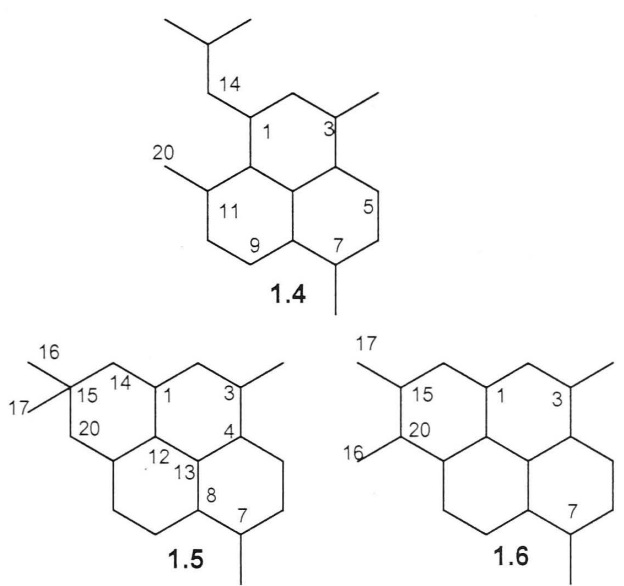

The first marine isocyano diterpene (1.2) was isolated from a mixture of cyclic sesquiterpenoids found in a Halichondria species, by Burreson et al. in $1974 .{ }^{4}$ The corresponding isothiocyanate and formamide were also isolated. These three compounds now appear to be an exception, as the majority of diterpenoid isonitriles are polycyclic.

In 1983 Scheuer and coworkers ${ }^{5,6}$ isolated several novel multifunctional isonitriles from marine sponges in the genus Acanthella. Compounds 1.7 and 1.8 are two such 
examples isolated from Acanthella sponges in Guam. Recently, $\mathbf{1 . 7}$ and similar compounds were demonstrated to have significant in vitro antimalarial activity. ${ }^{1,7}$
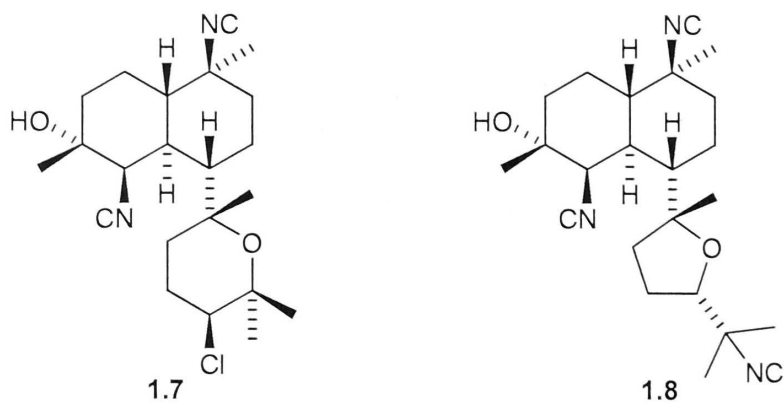

Wells and coworkers ${ }^{8,9}$ isolated diisocyanoadociane $\mathbf{1 . 1 0}$ along with five other isonitriles in 1976 from a marine sponge belonging to the genus Amphimedon (ex. Adocia) $)^{3,8,10}$ collected near Townsville, Australia on the Great Barrier Reef. Subsequently $\mathbf{1 . 1 0}$ and other diterpenoids have been isolated from the marine sponge Cymbastela hooperi. ${ }^{11}$

In 1996 Wright and coworkers ${ }^{11}$ isolated the series of 15 diterpenes 1.9-1.23 from the marine sponge Cymbastela hooperi, which were found to contain isocyanate, isothiocyanate and isonitrile functionalities (Figure 1.1). The biological activity of these compounds has since been investigated. Of these 15 diterpenes, all, with the exception of 1.9, demonstrated significant antiplasmodial activity when tested for biological activity in vitro against two clones of the malaria parasite Plasmodium falciparum. The activity of the compounds towards the mammalian KB cell line was also tested in order to calculate an experimental selectivity index (SI), which indicates whether the observed antiplasmodial activity is a specific or general toxic effect. Results showed that compounds $\mathbf{1 . 1 0}$ and $\mathbf{1 . 1 3}$, in particular, display antiplasmodial potency and selectivity that rivals the in vitro results obtained with some clinically-used antimalarial drugs. ${ }^{11}$ Surprisingly, the closely related compounds 1.11 and 1.12 show considerably less activity than compounds $\mathbf{1 . 1 0}$ and $\mathbf{1 . 1 3}$, and much lower selectivity indexes (Table 1.1). 

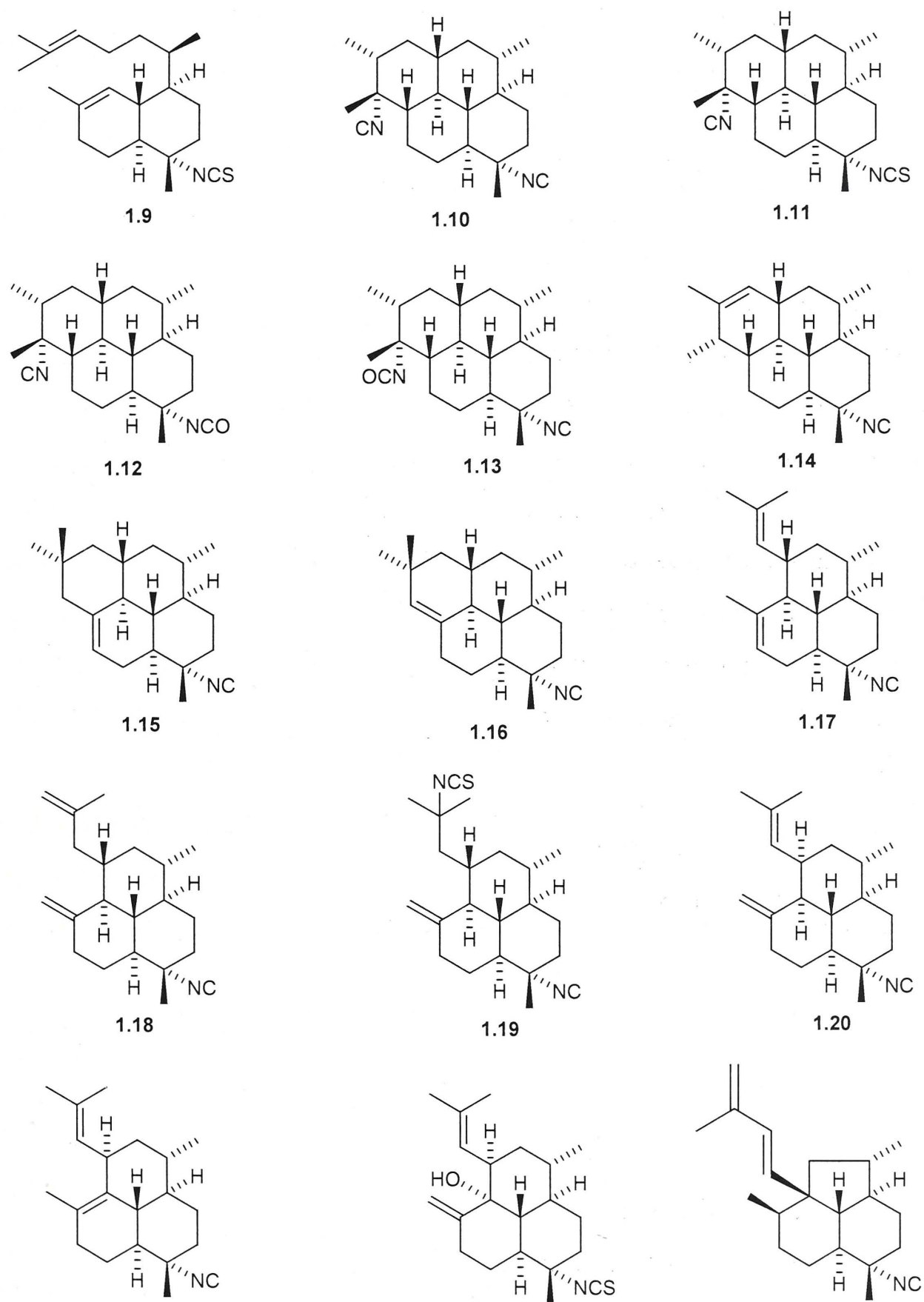

1.21
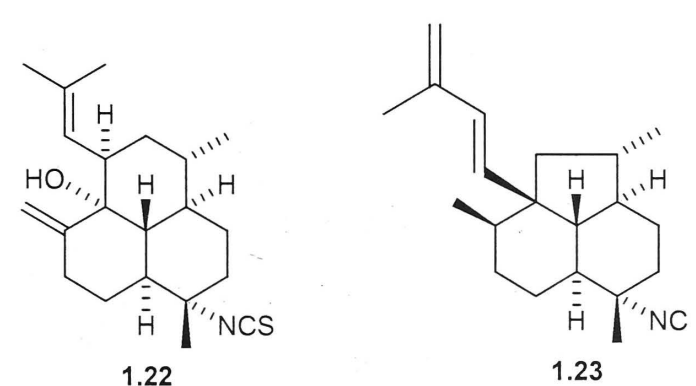

Figure 1.1: Diterpenes Isolated from the Marine Sponge Cymbastela Hooperi 


\begin{tabular}{|c|c|c|c|c|c|}
\hline Compound & $\begin{array}{l}\mathrm{KB} \text { cells } \mathrm{IC}_{50} \\
(\mathrm{ng} / \mathrm{mL})\end{array}$ & $\begin{array}{c}\text { Clone D6 IC } 50 \\
(\mathrm{ng} / \mathrm{mL})\end{array}$ & Clone D6 SI & $\begin{array}{c}\text { Clone W2 } \mathrm{IC}_{50} \\
(\mathrm{ng} / \mathrm{mL})\end{array}$ & $\begin{array}{c}\text { Clone W2 } \\
\text { SI }\end{array}$ \\
\hline 1.10 & 4700 & 4.7 & 1000 & 4.3 & 1100 \\
\hline 1.11 & 1600 & 45.1 & 35.5 & 28.5 & 56.1 \\
\hline 1.12 & 2000 & 74.9 & 26.7 & 56.1 & 35.7 \\
\hline 1.13 & 4300 & 3.2 & 1340 & 2.5 & 1710 \\
\hline loroquine $\mathbf{1 . 2 5}$ & 17400 & 3.8 & 4600 & 50.5 & 340 \\
\hline quinine & $>20000$ & 19.4 & $>1030$ & 54.6 & $>370$ \\
\hline mefloquine & 3500 & 11.5 & 300 & 3.8 & 920 \\
\hline artemisinin & $>20000$ & 2.8 & $>7140$ & 2.1 & $>9400$ \\
\hline
\end{tabular}

Table 1.1 Cytotoxicity of Compounds 1.10-1.13 and Antimalarial Standards to KB Cells and P.

Table 1.1 shows that compound $\mathbf{1 . 1 0}$ demonstrates antiplasmodial potency to $P$. falciparum clones D6 and W2 with $\mathrm{IC}_{50}$ values of 4.7 and $4.3 \mathrm{ng} / \mathrm{mL}$, respectively. By comparison, the antimalarial drug, chloroquine (CQ) (1.25), shows antiplasmodial potency to $P$. falciparum clones D6 and W2 with $\mathrm{IC}_{50}$ values of 3.8 and $50.5 \mathrm{ng} / \mathrm{mL}$, respectively. Thus, although compound $\mathbf{1 . 1 0}$ exhibits a somewhat less potent activity than that of CQ against the growth of CQ-sensitive D6 clones of P. falciparum, compound 1.10 exhibits a much more potent activity than CQ against the growth of CQresistant W2 clones of $P$. falciparum. In contrast, compound $\mathbf{1 . 1 3}$ exhibits more potent activity than $\mathrm{CQ}$ against both $\mathrm{D} 6$ and $\mathrm{W} 2$ clones of $P$. falciparum, with $\mathrm{IC}_{50}$ values of 3.2 and $2.5 \mathrm{ng} / \mathrm{mL}$, respectively.

More recently a new diterpene $\mathbf{1 . 2 4}$ was isolated from the apolar extract of the Vanuatu sponge Axinella sp. ${ }^{12}$ This diterpenoid has a tetracyclic carbon skeleton characterized by a rarely found cis-A,B ring junction, and a double bond between the 11 and 12 positions.

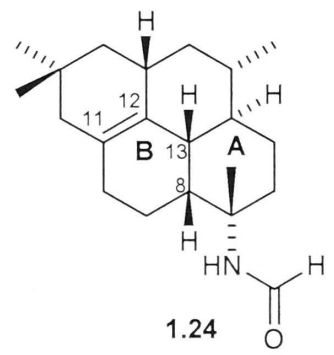

\subsection{Biological Activity}

The malaria parasite feeds by degrading haemoglobin in an acidic food vacuole, producing free heme (FP) moieties as a by-product. At the $\mathrm{pH}$ of the food vacuole, the FP in oxyhemoglobin is oxidised from the Fe(II) state to the Fe(III) state with the 
consequent production of a 0.5 molar equivalent of hydrogen peroxide. Both FP and hydrogen peroxide are toxic molecules that the parasite needs to destroy or neutralize. If allowed to accumulate, high levels of the FP molecules would destroy the parasite membranes. The parasite disposes of the FP partly by sequestration into a crystalline form, know as hemozoin, and partly by non-enzymatic degradation processes. ${ }^{13}$ Chloroquine (CQ) $\mathbf{1 . 2 5}$ and a number of other quinoline antimalarial drugs exert their activity by inhibiting FP detoxification, causing a build-up of toxic FP molecules that eventually destroy the integrity of the malaria parasite membranes.

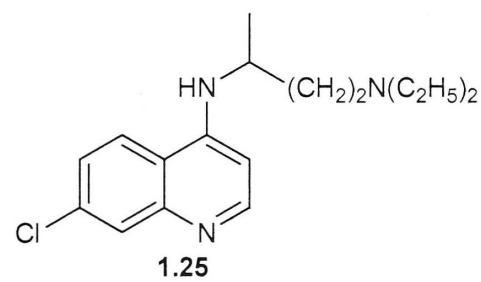

In an attempt to understand why a series of diterpene isonitriles and isothiocyanates (1.9-1.23, Figure 1.1) had differential antiplasmodial activity ${ }^{1}$ and also to derive a more detailed structure-activity relationship (SAR) for them, Wright and coworkers ${ }^{13}$ undertook a quasi-atomistic receptor modelling study to generate a $3 \mathrm{D}$ pseudoreceptor envelope about the molecular ensemble of interest. Following the modelling study, the axisonitrile-3 1.1 and three of the diterpene isonitriles $1.10,1.15$ and 1.16 isolated from the marine sponge Cymbastela hooperi were used to gain an understanding of the molecular basis of the antimalarial action of these compounds. The isonitrile compounds $\mathbf{1 . 1}$ and $\mathbf{1 . 1 0}$, having the most potent antimalarial activity, were shown to interact with FP and prevent its destruction and conversion to $\beta$-hematin (the form of FP present in hemozoin).

Diisocyanoadociane (1.10) and $\mathbf{1 . 1 3}$, which display the most potent antimalarial activity of the diterpenes 1.9-1.23, possess an isonitrile (in the case of $\mathbf{1 . 1 0}$ ) or an isocyanate (in the case of 1.13) group in the $\alpha$-orientation at C-20 (Figure 1.2) ${ }^{*}$. All compounds lacking these potentially interacting functionalities are at least 10-fold less active. However, compounds $\mathbf{1 . 1 1}$ and $\mathbf{1 . 1 2}$ also possess an isonitrile group at C-20, and their activity is approximately 10 -fold less than compounds $\mathbf{1 . 1 0}$ and $\mathbf{1 . 1 3}$ (Table 1.1). Therefore, the functionality at C-20 cannot be solely responsible for the biological activity.

\footnotetext{
${ }^{*}$ These structures are based on the isocycloamphilectane skeleton 1.6, the numbering of which derives from the amphilectane skeleton $1.4 .^{3}$
} 


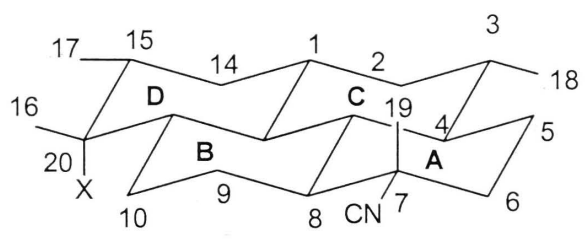

$$
\begin{gathered}
1.10 x=N C \\
1.13 X=N C O \\
\text { Figure } 1.2
\end{gathered}
$$

From their molecular modelling studies, Wright and coworkers ${ }^{13}$ were able to conclude that the most significant structural feature for receptor complementarity of the active diterpenes was the overall lipophilic rigid molecular core comprising at least a tricyclic framework with an equatorial-oriented isonitrile group at C-7. An additional electrostatic-governed interaction close to $\mathrm{C}-20$ of the common ring framework is also essential for activity, as well as a further hydrophobic region above the ring plane. This suggests that the 'receptor' for these isonitriles within the malaria parasite is hydrophobic in nature but capable of forming electrostatic interactions with functional groups on the drug surface.

The interaction of some terpene isonitriles with FP was also investigated. First, the effect of the isonitrile compounds on the visible absorption spectrum of FP was examined. The mixing of FP with compounds $\mathbf{1 . 1}$ and $\mathbf{1 . 1 0}$ produced a marked effect on the absorption spectrum of FP, which is consistent with the formation of mono- or bis-coordinated drug-FP complexes. In addition, $\mathbf{1 . 1 5}$ and 1.16, two isonitrile compounds that show little antimalarial activity, showed little effect on the FP absorption spectrum, indicating that no coordination complex was formed between the FP and $\mathbf{1 . 1 5}$ or $\mathbf{1 . 1 6}$. Thus, the ability to form a coordination complex with FP appears to correlate with the antimalarial activity of the compounds.

To investigate further the nature of the complex formed between the isonitrile compounds and FP, 1: 1 mixtures were subjected to electrospray ionisation mass spectrometry (ESI-MS). It was found that $\mathbf{1 . 1 0}$ preferentially forms a $2: 1$ complex with FP, while 1.1 preferentially binds in a $1: 1$ complex with FP. The binding in the complexes most likely occurs via a coordinate bond between the axially-oriented group (-NC in the case of $\mathbf{1 . 1}$ and 1.10) and the iron within the porphyrin. The resultant complexes are further stabilised by van der Waals-type interactions between the porphyrin and the respective ligands. 
From the studies carried out by Wright and coworkers ${ }^{13}$ it appears that the active isonitriles exert their activity by interfering with a range of FP detoxification processes, analogous to that of quinoline antimalarial drugs. These processes include: inhibiting the decomposition of hydrogen peroxide, inhibiting the peroxidative destruction of FP and the glutathione-mediated break down of FP, and interfering with $\beta$-hematin formation. These combined effects appear to lead to a build up of toxic moieties which irreversibly damage proteins and lipids within the parasite.

\subsubsection{Synthetic Antimalarial Analogues of Isonitrile Diterpenoids}

In the course of research exploiting the chemistry of arene tricarbonyl chromium (0) complexes, Schmalz and coworkers ${ }^{14}$ were able to synthesis analogues of marine isonitrile diterpenoids based on natural products. $\mathbf{1 . 2 6}$ and $\mathbf{1 . 2 7}$ are examples based on the amphilectane skeleton $\mathbf{1 . 4 .}$
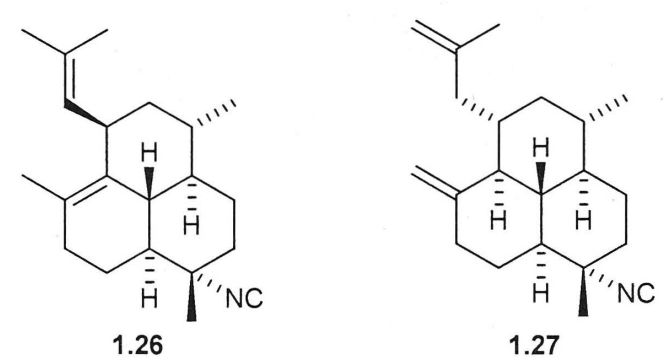

The samarium (II) iodide mediated cyclisation of an imine possessing an arene tricarbonylchromium complex such as in $\mathbf{1 . 2 8}$ gives rise to tricyclic products such as 1.29 and 1.30. These products were then converted into the corresponding isonitriles 1.31 and $\mathbf{1 . 3 2}$ by standard procedures, after oxidative decomplexation to remove the chromium species and hydrogenolysis to remove the benzyl nitrogen protecting group (Scheme 1.1).

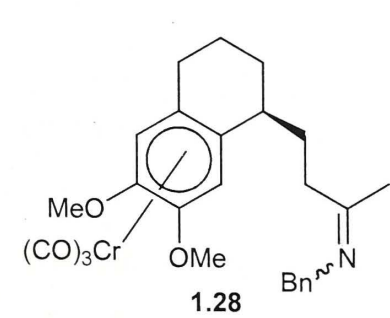

1.28

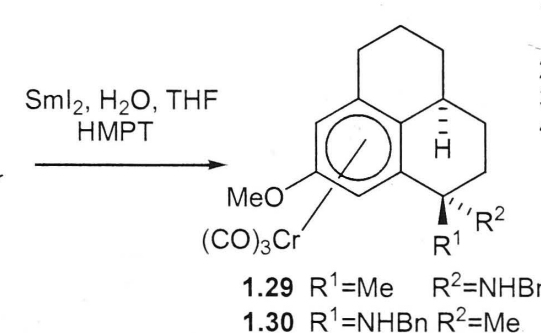

Scheme 1.1: Samarium lodide Mediated Cyclisation

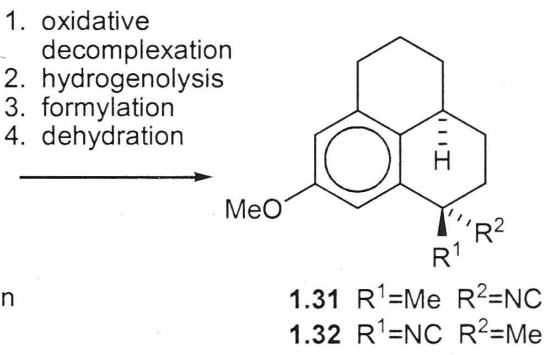

$1.32 \mathrm{R}^{1}=\mathrm{NC} \mathrm{R}^{2}=\mathrm{Me}$ 
An analogue with an unsaturated side-chain, as found in some of the natural products (such as 1.27), was also synthesised. In this case, to avoid any undesired hydrogenation of the side-chain double bond under the hydrogenolysis conditions, an $O$-allyl oxime derivative was used, rather than the benzyl protected derivative. Under similar conditions as seen in Scheme 1.1, both cyclisation and the $N$-deprotection proceeded in a single synthetic operation. The resulting amine (1.34) could be converted into the corresponding isonitrile (1.35) by standard procedures (Scheme 1.2).

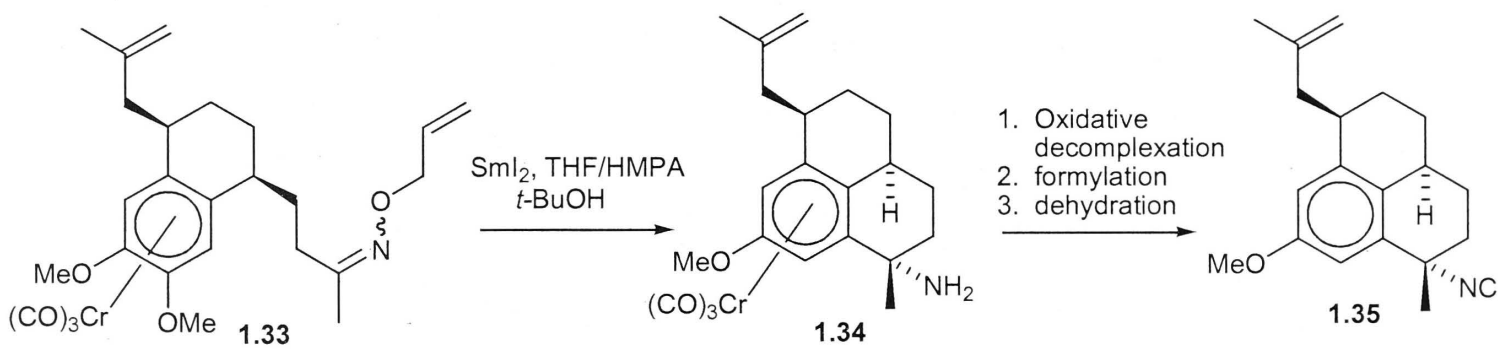

Scheme 1.2: Synthesis of 1.35

The synthetic analogues $\mathbf{1 . 3 1}, \mathbf{1 . 3 2}$ and $\mathbf{1 . 3 5}$, as well as a nitrile derivative of $\mathbf{1 . 3 5}$, were entered into an in vitro assay using the well known antimalarial compounds chloroquine (1.25) and artemisinin as standards. Antiplasmodial activity was then determined using two strains of P. falciparum (NF54 and KI). All of the isonitriles were tested and found to exhibit significant antimalarial activity. By comparison, the nitrile derivative was found to be virtually inactive, thus confirming the importance of the isonitrile group for biological activity.

The synthetic analogues $\mathbf{1 . 3 1}, \mathbf{1 . 3 2}$ and $\mathbf{1 . 3 5}$ when tested had activities one order of magnitude lower than those of their natural counterparts. Compound $\mathbf{1 . 3 1}$, in which the isonitrile group has the configuration of that seen in the natural product, was almost twice as active as its diastereomer 1.32. Interestingly, the introduction of the unsaturated side-chain resulted in minimal increase in biological activity.

These results reveal the general antimalarial potential of structurally simplified analogues.

\subsection{Biosynthesis}

The biosynthesis of diisocyanoadociane is not straightforward. It has been postulated that $\mathbf{1 . 1 0}$ is terpene-derived and results from methyl migration during a unique 
cyclisation of a $\mathrm{C}_{20}$ precursor. ${ }^{8,10,15}$ At least three different foldings of the $\mathrm{C}_{20}$ precursor lead to the desired skeleton (Figure 1.3). ${ }^{15}$

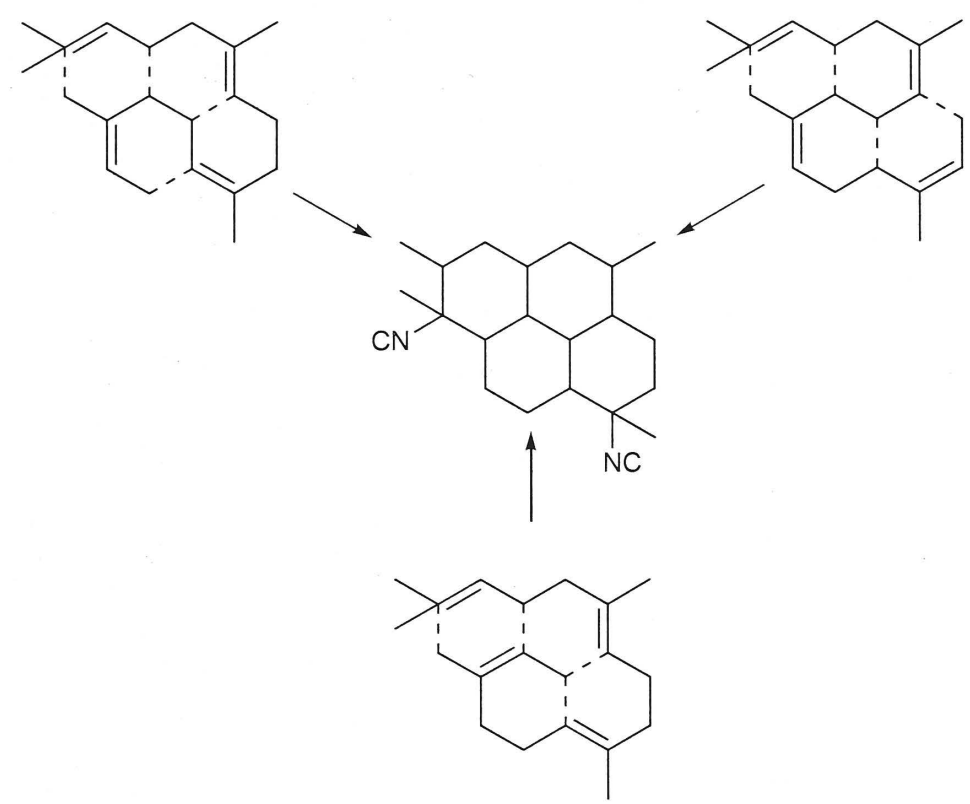

Figure 1.3

The biochemical origin of the isocyanide groups in $\mathbf{1 . 1 0}$ and other isocyanide containing marine natural products has been an area of much investigation since their isolation. It has been established through incorporation studies with sodium $\left[{ }^{14} \mathrm{C}\right]$ cyanide that the isonitrile carbons are derived by functionalisation of a terpene precursor using inorganic cyanide. ${ }^{10}$ In more recent studies it has been shown through labelling with sodium $\left[{ }^{14} \mathrm{C}\right]$ thiocyanate that inorganic thiocyanate in addition to cyanide is utilised by $A$. terpensis for isocyanide biosynthesis, confirming that cyanide and thiocyanate are used interchangeably in marine sponges for terpene functionalisation (Figure 1.4). Furthermore, organic isothiocyanates are utilised by A. terpensis as precursors to isocyanides. $^{16}$
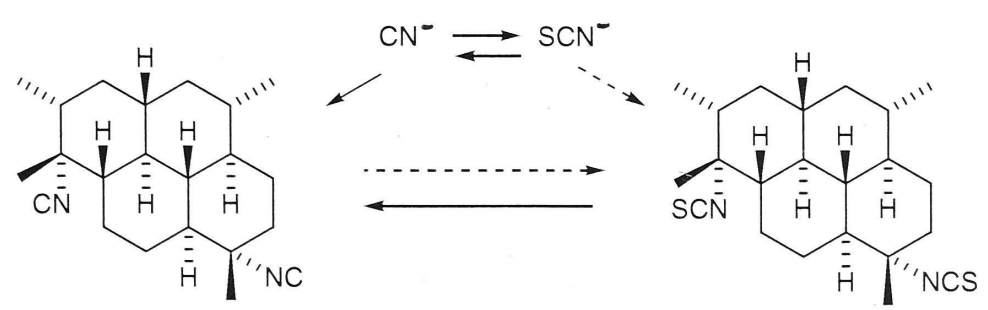

Figure 1.4

It is surprising that a marine invertebrate would utilise cyanide in view of the known role of cyanide as a potent cytochrome oxidase inhibitor. Since Amphimedon sp., like many other sponges, contains bacterial symbionts, it is not clear whether the animal host or the bacterial symbiont is responsible for the uptake of cyanide. Many strains of 
bacteria are known to have developed cyanide insensitive respiratory chains, or to generate inorganic cyanide from amino acids. However, other isocyanide-producing sponges are known to contain negligible amounts of symbionts, which is consistent with the uptake of the cyanide directly into the sponge cells. Demonstration of the functionalisation of $\mathbf{1 . 1 0}$ also fits with the uptake of cyanide directly into the sponge cells. $^{17}$

The origin of the cyanide accumulated in $\mathbf{1 . 1 0}$ by Amphimedon $s p$. has been investigated. The concentration of cyanide in sea water is presumably negligible, except perhaps in industrially polluted waters. Hence, by analogy with terrestrial metabolic processes such as the biosynthesis of cyanogenic glycosides or ethylene, the ultimate source of the cyanide may be an amino acid. Several amino acids have been tested as potential precursors of diisocyanoadociane, including $\left[\mathrm{U}_{-}{ }^{14} \mathrm{C}\right]$ alanine, [U$\left.{ }^{14} \mathrm{C}\right]$ leucine, $\left[2-{ }^{14} \mathrm{C}\right]$ glycine, and [guanidino- ${ }^{14} \mathrm{C}$ ]arginine. In each case, precursor uptake could be demonstrated both by loss of ${ }^{14} \mathrm{C}$ from the incubation medium and subsequent detection of ${ }^{14} \mathrm{C}$ in the sponge tissue. However, none of these precursors generated labelled diisocyanoadociane. Sponges contain many unusual amino-acids along with the common protein amino-acids, and it is highly plausible that one of these specific amino acids may act as a cyanide precursor. ${ }^{15}$

\subsection{Previous Synthetic Studies}

\subsubsection{Total Synthesis of a Diisonitrile Tricyclic Diterpene}

A member of the isonitrile diterpene family, 1.46, an analogue of the tricyclic diterpene 1.19, has been synthesised by Piers and Llinas-Brunet in a 20 step synthesis from stannane 1.38 (Scheme 1.3). ${ }^{18}$ The bicyclic intermediate was obtained by the one-pot conversion of $\mathbf{1 . 3 8}$ into the corresponding trifluoromethane sulfonate, followed by a Pd (0)-catalysed intramolecular coupling reaction. A Diels-Alder reaction was then used to give the tricyclic compund $\mathbf{1 . 4 0}$ as the major product after base-catalysed equilibration. A dissolving metal reduction on compound $\mathbf{1 . 4 1}$ was employed to give the all trans-ring system 1.42, as required for the natural product. Worthy of note in this synthesis is the stereospecific incorporation of the isonitrile groups into $\mathbf{1 . 4 6}$. This was achieved in four steps from the diacid $\mathbf{1 . 4 3}$, via the corresponding dicarbamate $\mathbf{1 . 4 4}$ and diformamide 1.45 (Scheme 1.3). 

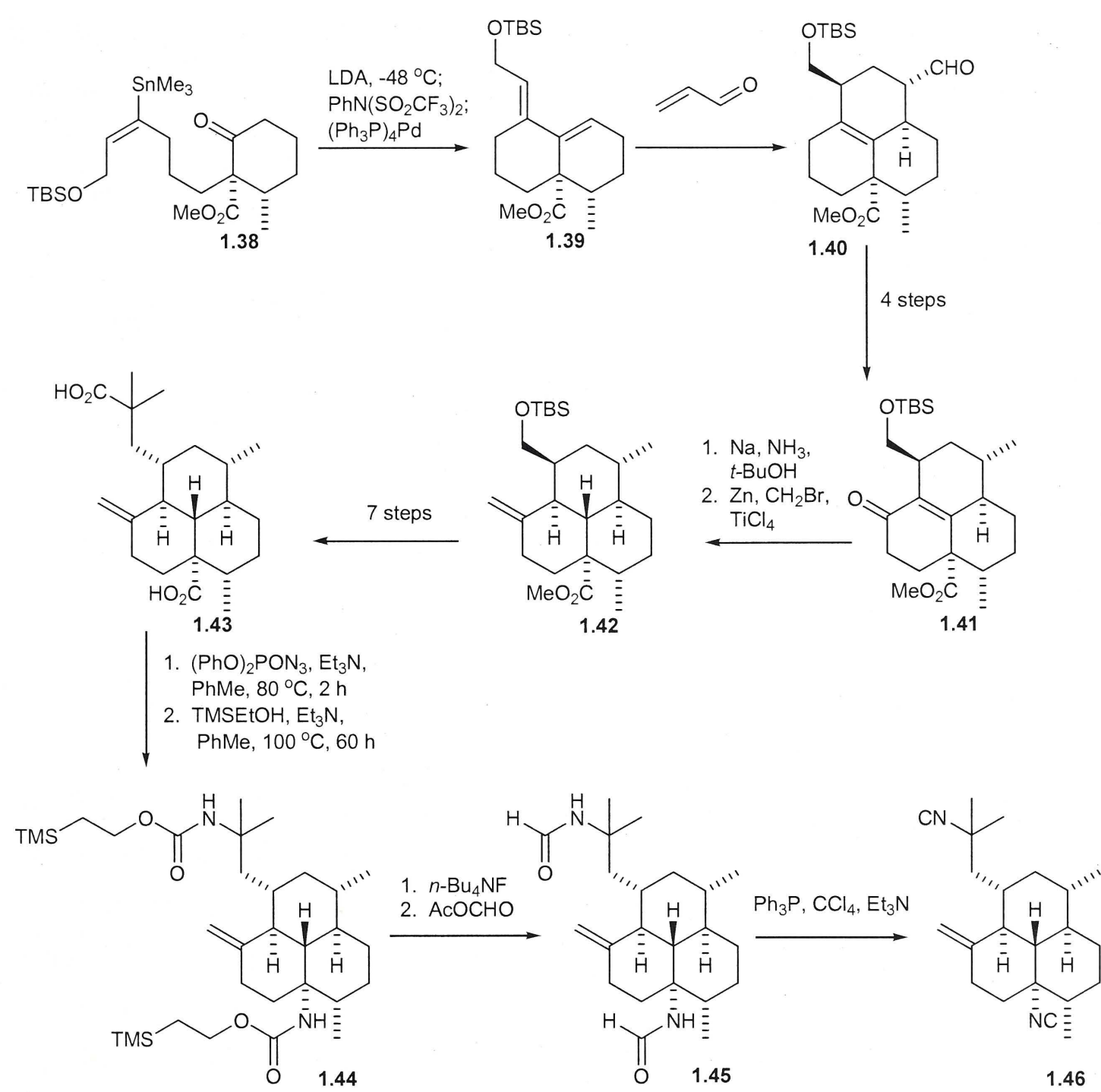

Scheme 1.3: Total Synthesis of 1.46

\subsubsection{Total Synthesis of a Member of the Kalihinane family}

The first total synthesis of Kalihinol C (1.52), a member of the Kalihinane family of marine diterpenoids, has recently been reported by Wood and coworkers. ${ }^{19}$ Of interest in this synthesis is the installation of the equatorial nitrogen at $\mathrm{C}-10$ by aziridination of the exo-methylene derivative 1.47. The desired aziridine $\mathbf{1 . 4 8}$ was formed with $5: 1$ diastereoselectivity. Later in the sequence this terminal aziridine could be treated with Super-Hydride ${ }^{\circledR}$ to give the corresponding tertiary amine, and subsequent treatment with ammonium azide gave the azido-alcohol 1.50. Treatment of intermediate $\mathbf{1 . 5 0}$ with sodium metal then resulted in simultaneous tosyl deprotection and azide reduction to afford the bisamine 1.51. Formylation and dehydration were then employed to give Kalihinol C (1.52) in 39\% over the three steps (Scheme 1.4). 


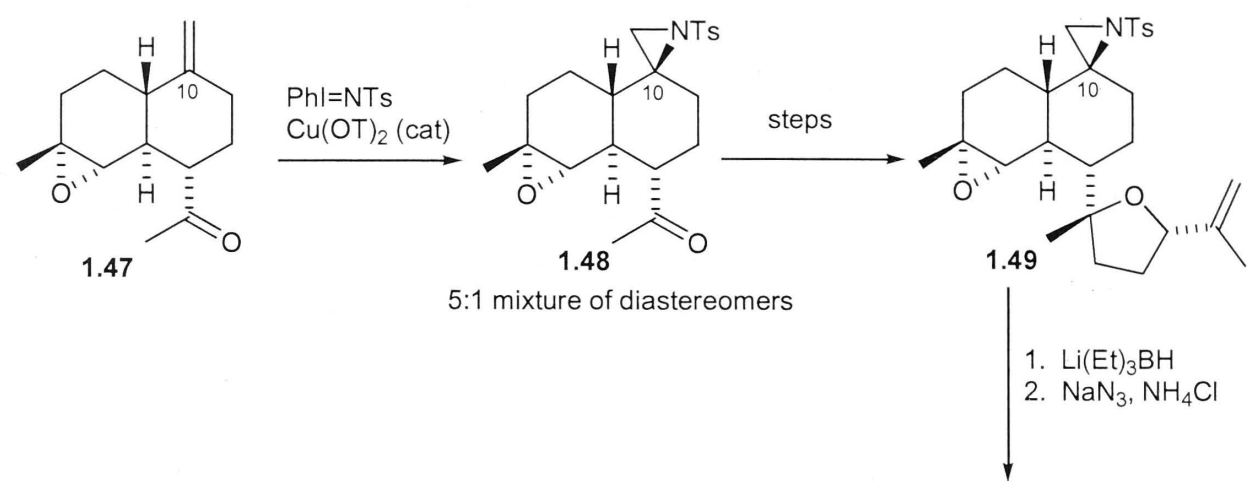

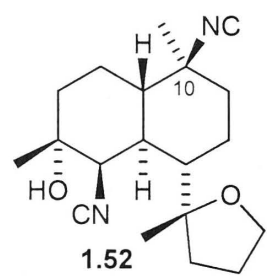

Kalihinol C

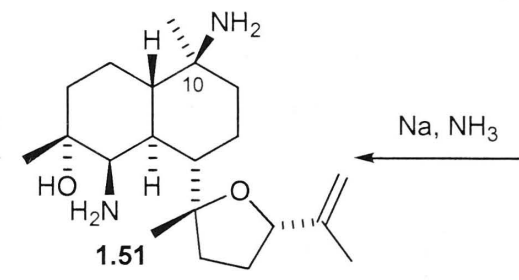

Scheme 1.4: Total Synthesis of Kalihinol C

\subsubsection{Total Synthesis of Diisocyanoadociane (1.10)}

As previously mentioned, diisocyanoadociane (1.10) was the first of the unusual diterpene isonitriles from the sponge Amphimedon to be isolated. The skeleton of the molecule consists of four cyclohexane rings, all trans-fused and in a chair conformation, with two isonitrile groups. The skeleton is unusual in that the rings have no angular methyl substituents. The unusual structure, biosynthesis, and potent biological activity of this compound have given rise to a great deal of interest amongst chemists and biochemists. Interestingly, only one total synthesis of diisocyanoadociane (1.10) exists to date. Corey and Magriotis achieved an enantioselective (60\% e.e.) total synthesis of $\mathbf{1 . 1 0}$ in 27 steps from the acid chloride $\mathbf{1 . 5 3}$ (Scheme 1.5), thus allowing assignment of the absolute configuration. ${ }^{20}$ The observed enantiomeric excess of $60 \%$ was in accordance with that determined for the first chiral intermediate, which was obtained via a diastereoselective Michael addition to convert the ethylene ketal $\mathbf{1 . 5 4}$ to the diester 1.55, using menthol as a chiral auxiliary. The tetracyclic skeleton was then obtained from two intramolecular Diels-Alder cycloadditions. The first of these reactions occurred stereoselectively, resulting in the trans-fused adduct $\mathbf{1 . 5 7}$, which has the correct stereochemistry for the natural product. The second intramolecular Diels-Alder reaction gave two diastereomeric products resulting from cis addition to each of the two faces of the dienophile 1.58, with a ratio of $1.5: 1$ in favour of the desired adduct $\mathbf{1 . 5 9}$. The more stable all trans-fused tetracyclic skeleton $\mathbf{1 . 6 0}$ was obtained at a later stage in the synthesis through base catalysed epimerisation. The two isocyanide groups were 
then introduced in a single biomimetic operation on the bistrifluoroacetate $\mathbf{1 . 6 1}$, by treatment with trimethylsilyl cyanide and titanium tetrachloride. A mixture of four diastereomeric diisonitriles was obtained in a total overall yield of $70 \%$, including $\mathbf{1 . 1 0}$ in unspecified yield (Scheme 1.5).

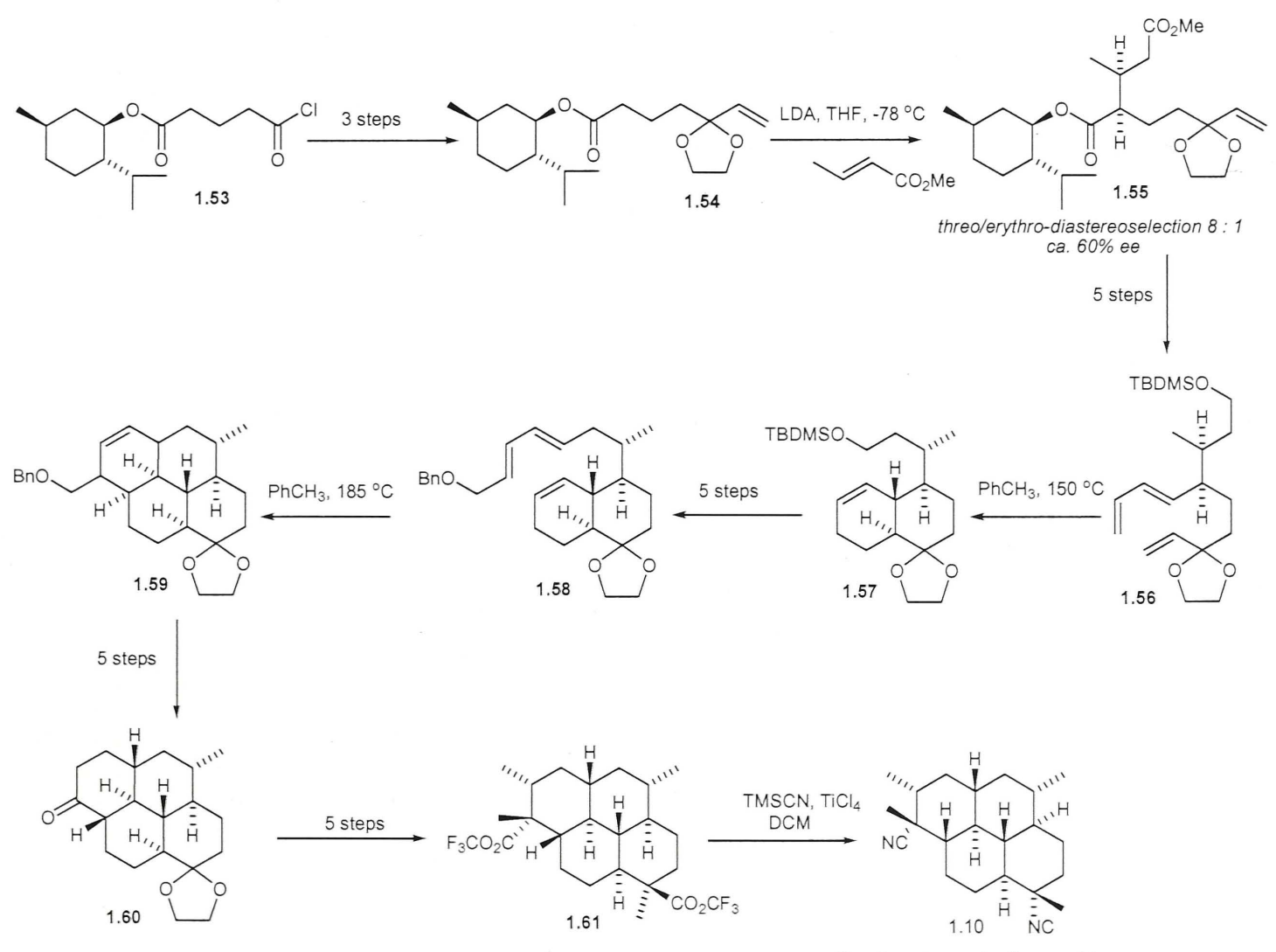

Scheme 1.5: Total Synthesis of Diisocyanoadociane (1.10)

\subsection{ANU Strategy for the Synthesis of Diisocyanoadociane (1.10)}

As in the Piers synthesis (Section 1.4.1) ${ }^{18}$ we planned to utilise the Curtius rearrangement of the corresponding acyl azide of dicarboxylic acid $\mathbf{1 . 6 2}$ for the stereoselective incorporation of the isonitrile groups (Scheme 1.6).

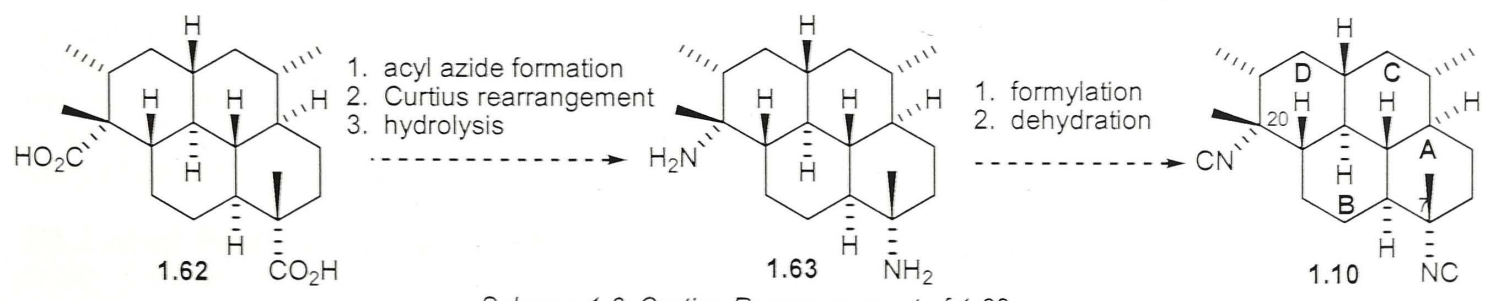

Scheme 1.6: Curtius Rearrangement of 1.62

Worthy of note is that Garson and coworkers ${ }^{15,21}$, during the course of $\left[{ }^{14} \mathrm{C}\right]$-labelling studies into the biochemical origin of the isocyanide groups, obtained amine 1.63 by 
direct hydrolysis of diisocyanoadociane (1.10). Subsequently they were able to carry out formylation and dehydration reactions to reconstitute the natural product $\mathbf{1 . 1 0}$.

To prepare the dicarboxylic acid 1.62 Mander and Crabtree devised the following plan (Scheme 1.7).
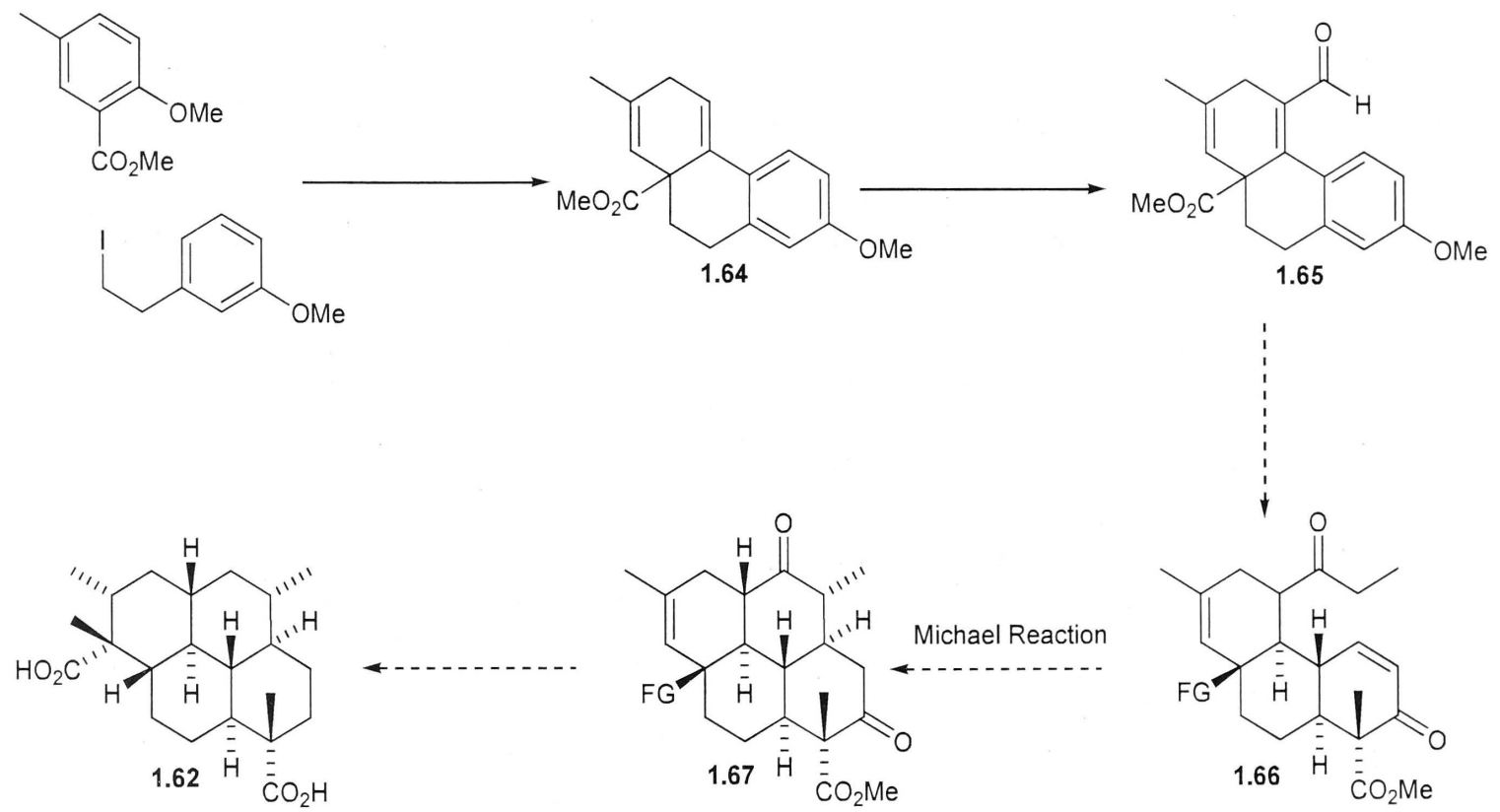

Scheme 1.7: Synthetic Plan for Diacid 1.62

Methodology towards the tricyclic aldehyde $\mathbf{1 . 6 5}$ had been well established previously in the group. ${ }^{22,23}$ It was envisaged that the tetracyclic skeleton (1.67) of the natural product could be obtained by an intramolecular Michael reaction on an all trans-fused tricyclic enone intermediate 1.66. As this reaction is reversible, the thermodynamically most stable trans-fused product would be expected.

\subsubsection{Work Carried Out by Crabtree}

In work by Crabtree ${ }^{24}$ a tetracyclic skeleton $\mathbf{1 . 6 9}$ with the desired trans-anti-transstereochemistry at all but two bridgehead carbons (labelled *), and the quaternary centre with the correct stereochemistry in the A-ring, was completed in 18 steps from aldehyde

1.65. The key intramolecular Michael addition produced a $70 \%$ yield of $\mathbf{1 . 6 9}$ from $\mathbf{1 . 6 8}$ (Scheme 1.8). 


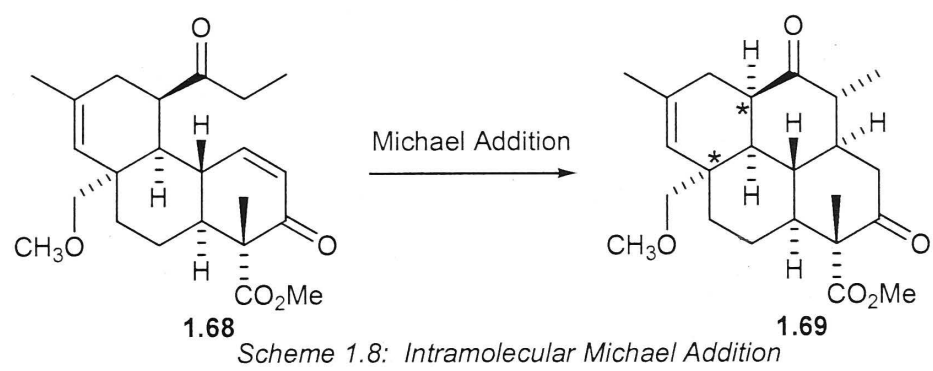

Starting with aldehyde $\mathbf{1 . 6 5}$ as a building block, a 1,4-dissolving metal reduction was carried out on the corresponding ester 1.70 to give the cis-fused product 1.71 , a result that was unexpected (Scheme 1.9).

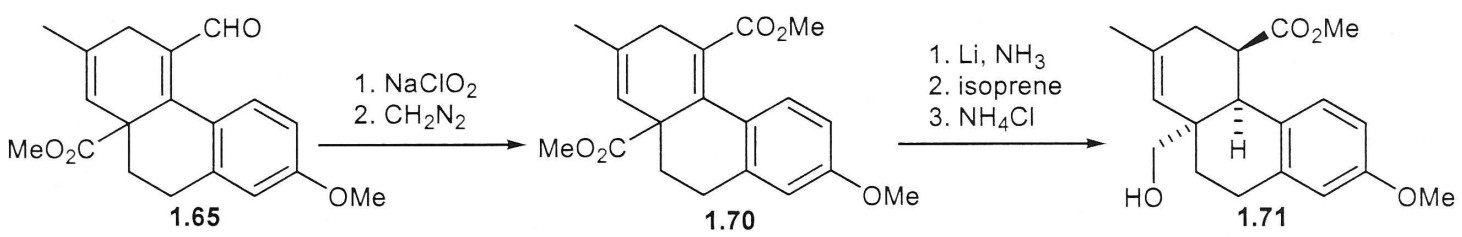

Scheme 1.9: Dissolved Metal Reduction

The 1,4-reduction of octalones to give a trans-ring fusion, by contrast, is well precedented. $^{25}$ The observed cis-ring fusion in compound 1.71 can be explained by analysis of the possible conformations of the radical benzylic anion intermediate that result on conjugate reduction (Figure 1.5).
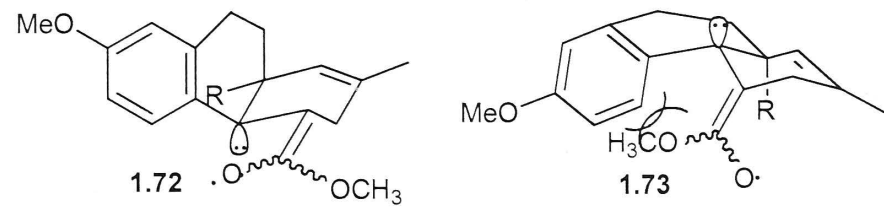

Figure 1.5

Only the two radical benzylic anion intermediates $\mathbf{1 . 7 2}$ and $\mathbf{1 . 7 3}$ satisfy the orbital overlap requirements between the $\beta$-carbon and the enolate system. In the case of $\mathbf{1 . 7 3}$, which would lead to a trans-fused product, the exocyclic ester function is in the plane of the aromatic ring, resulting in a severe peri interaction. In the conformation $\mathbf{1 . 7 2}$, that acts as the precursor to the cis-fused product, this destabilising peri interaction is avoided. Thus, the product with a cis-ring fusion is observed in the above dissolving metal reduction.

Also worthy of note is the reduction of the angular ester group in $\mathbf{1 . 7 0}$ to the corresponding hydroxymethyl derivative. This reduction is not expected in the absence of an alcohol. It was presumed that the ammonia in the reaction must act as a proton 
source for this reduction as well as the $\beta$-protonation of the benzylic anion intermediate formed from the 1,4-reduction of the enone system.

Elaboration of the ester group in compound $\mathbf{1 . 7 1}$ was then carried out in order to install the side chain required for formation of the fourth ring. A Birch reduction, followed by careful control of the double bond isomerisation, formed the $\alpha, \beta$-enone $\mathbf{1 . 7 6}$ without removal of the acid sensitive protecting group (Scheme 1.10).

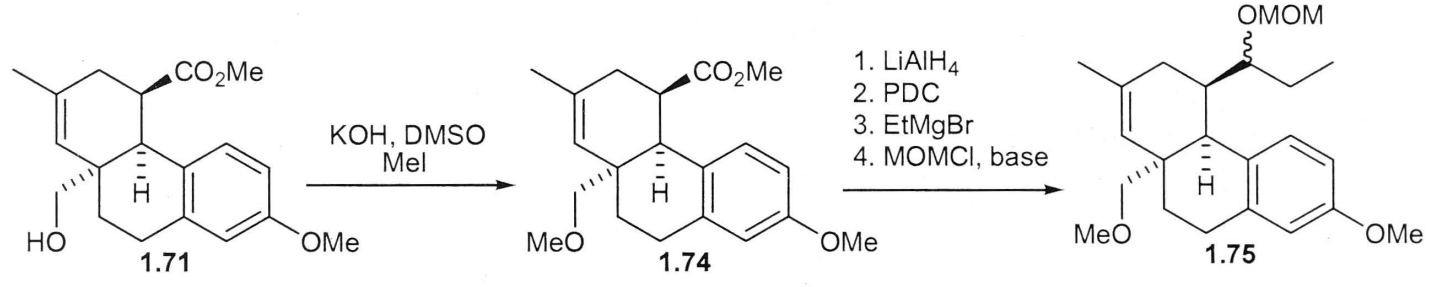

Scheme 1.10: Birch Reduction of the A Ring

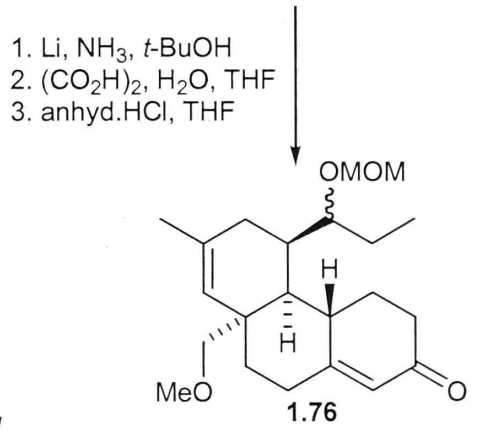

Reductive acylation then resulted in the formation of the required A,B-trans ring fusion and gave a modest yield of the $\beta$-keto ester $1.77 .^{26}$ Alkylation followed to introduce the desired axial methyl group in compound $\mathbf{1 . 7 8}$ (Scheme 1.11).

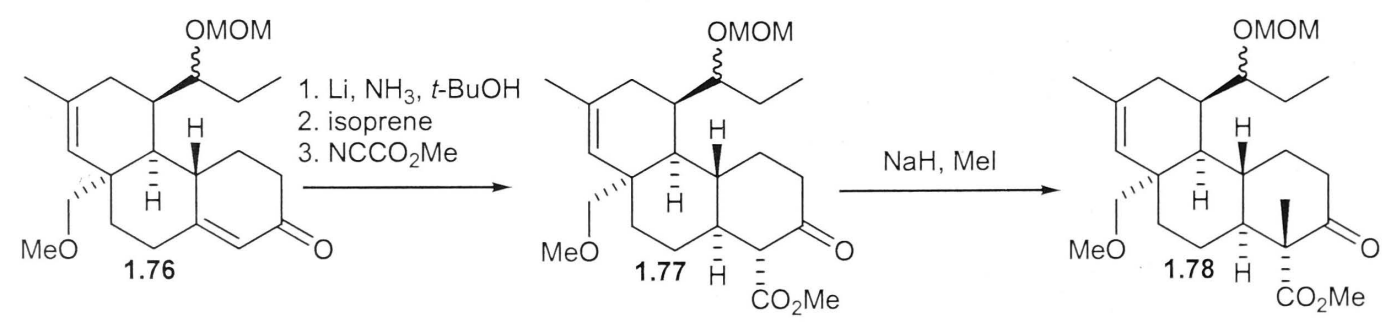

Scheme 1.11: Reductive Acylation and Alkylation

Alkylation along the axial vector under stereoelectronic control (Figure 1.6) for this type of compound is well precedented, ${ }^{27}$ provided that there is no undue steric hindrance. $^{28,29}$ 


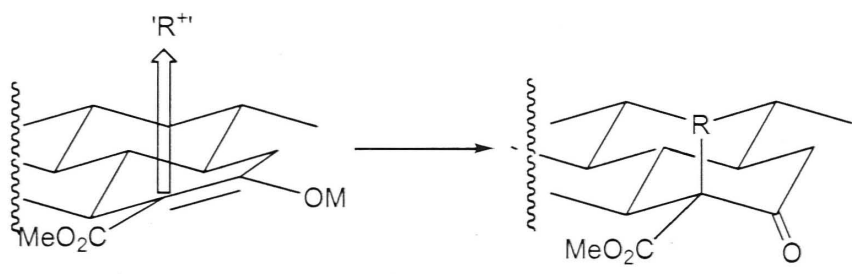

Figure 1.6

The introduction of the enone double bond was the next step in the reaction sequence. Selenium based chemistry was utilised for this transformation, but the yields were poor. Furthermore, in order to avoid the formation of the cyclic ether 1.81 , it was necessary to remove the $\mathrm{MOM}$ ether protecting group before the enone function could be installed. Nevertheless, a small quantity of enone $\mathbf{1 . 6 8}$ was obtained (Scheme 1.12).

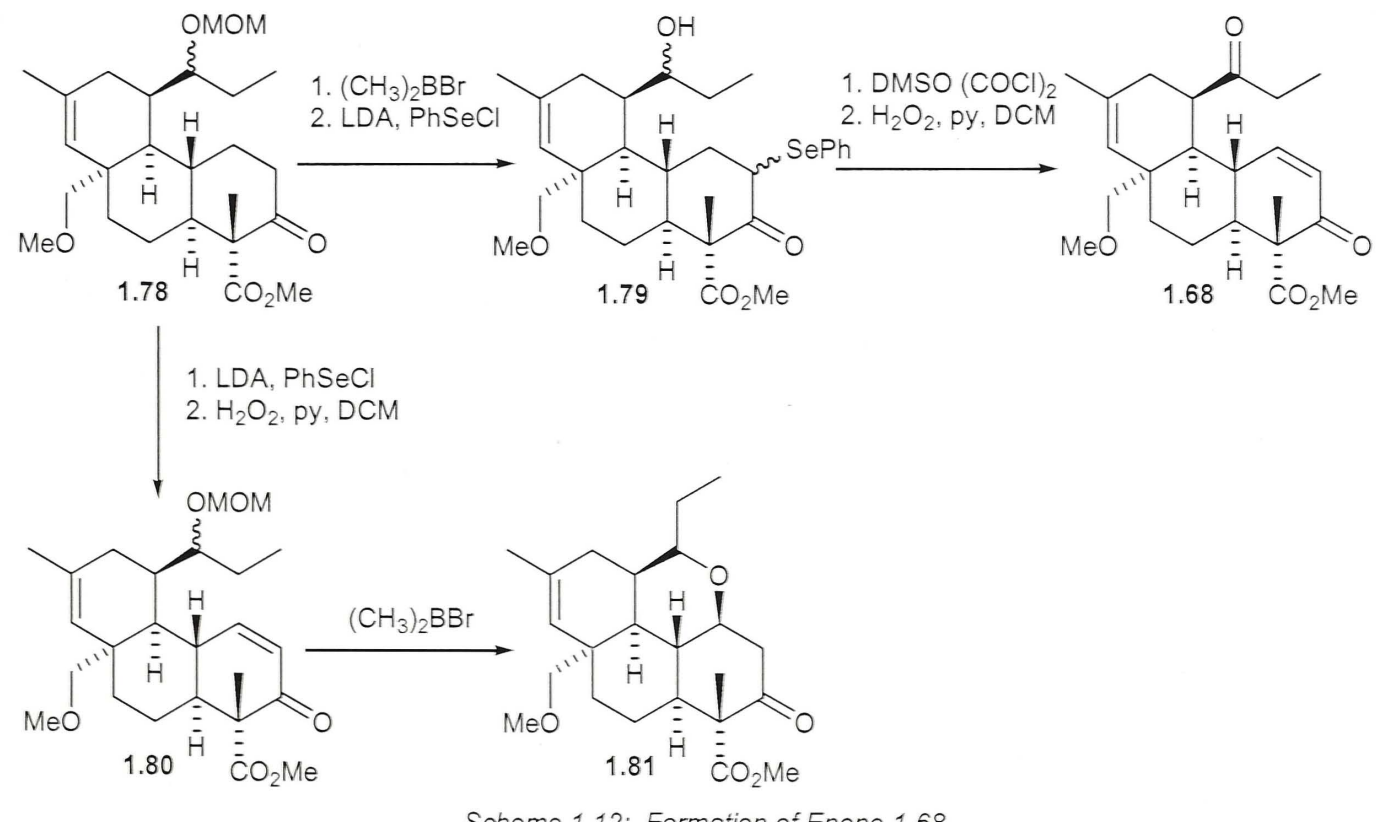

Scheme 1.12: Formation of Enone 1.68

Initial attempts to perform the base catalysed intramolecular Michael reaction utilising DBU, and potassium $t$-butoxide in $t$-butyl alcohol, were unsuccessful, but potassium carbonate in methanol, was found to give the tetracycle 1.69 in $71 \%$ yield (Scheme $1.13)$.

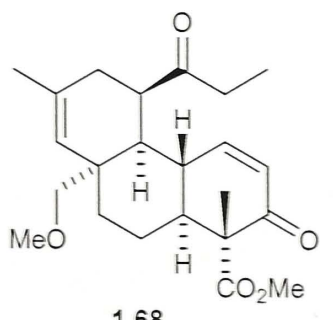

1.68
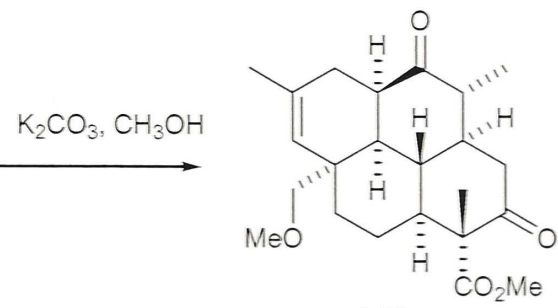

1.69

Scheme 1.13: Intramolecular Michael Addition 
A major problem with the route outlined above is the formation of the cis-ring fusion between the $\mathrm{B}$ and $\mathrm{D}$-rings early in the reaction sequence. In order to correct the stereochemistry to give the all trans-fused tetracycle, epimerisation would need to occur at two bridgehead carbons (labelled *). The oxidation of the olefinic bond to the corresponding ketone $\mathbf{1 . 8 2}$ and deprotection of the angular methoxymethyl group has the potential to allow for both removal of the angular group (retro-aldol reaction) and epimerisation on treatment with base. However, in order to allow for the concomitant epimerisation at the other bridgehead carbon, the other ketone group must also remain. This presents an additional problem, as if the epimerisation is successful, both ketone groups will have identical local environments within the product (1.83). Thus, differentiation between the two ketone groups may be difficult if not impossible (Scheme 1.14).
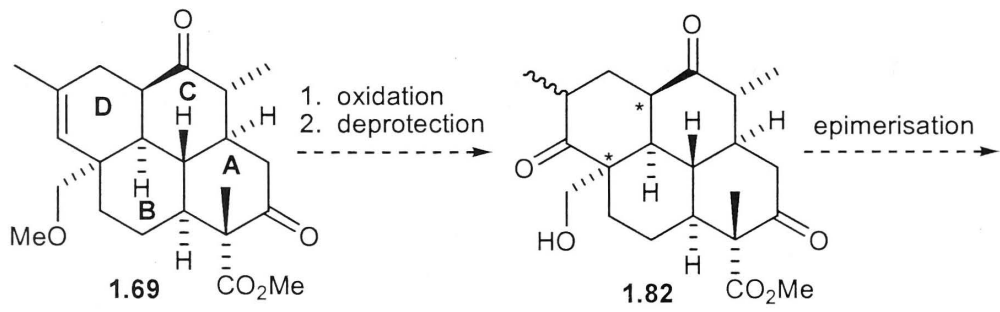

Scheme 1.14: Correction of cis-Ring Fusion

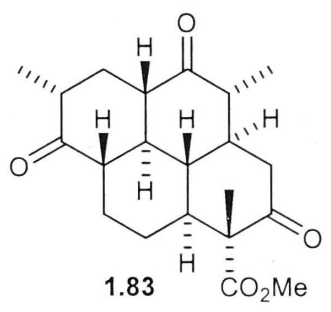

\subsubsection{A Revised Approach}

In order to avoid the problems associated with the B,D cis-ring fusion, a new approach was devised, in which the B,D trans-ring fusion could be established by means of a retro-Claisen reaction, before the key intramolecular Michael addition (Scheme 1.15).
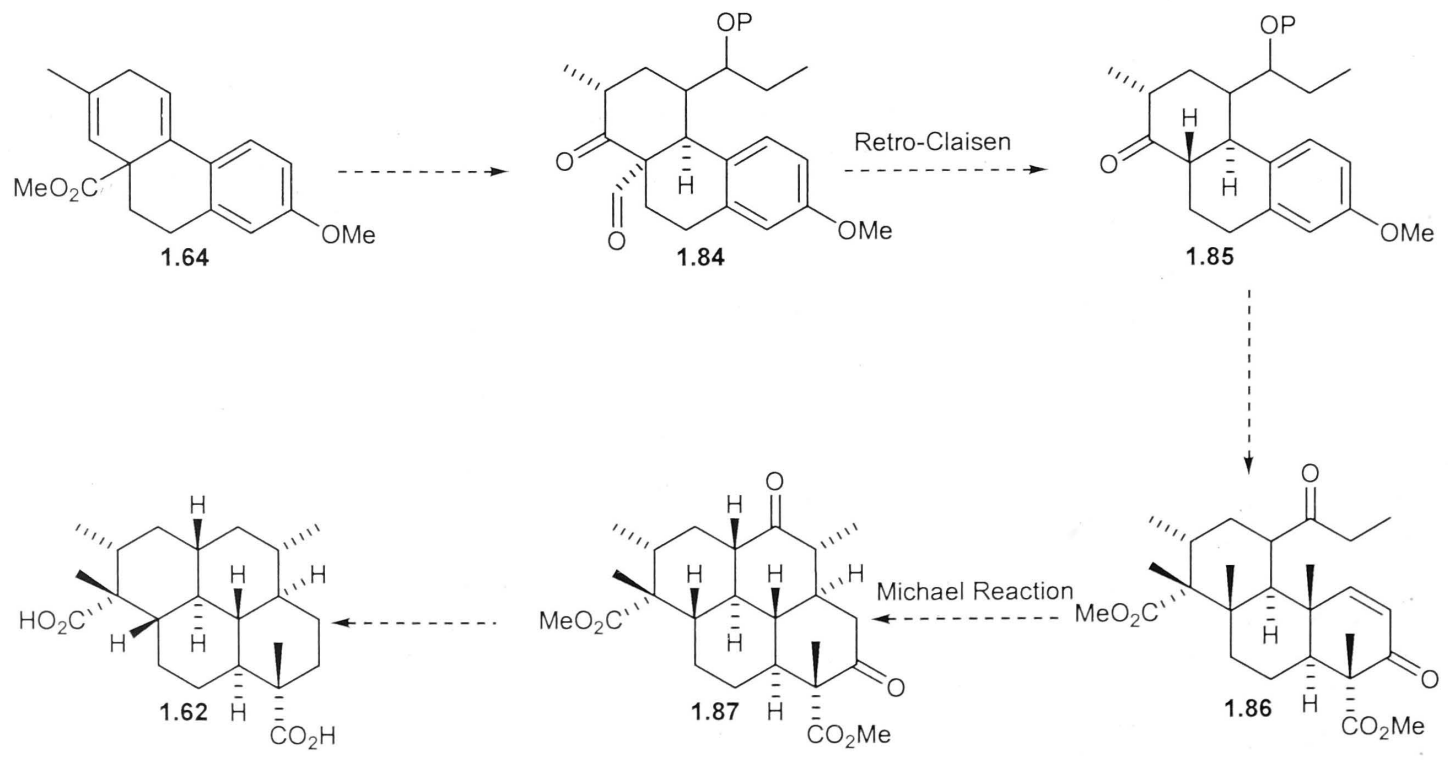

Scheme 1.15: Revised Synthesis of Diacid 1.62 
As a prelude to the current research, ${ }^{30}$ an analogue of ketone $\mathbf{1 . 8 5}$ was synthesised in a 12 step sequence, shown in Scheme 1.16. Tricyclic precursor $\mathbf{1 . 8 8}$ was synthesised according to methodology developed previously in the group. ${ }^{22-24}$ Alcohol $\mathbf{1 . 8 8}$ was then protected as the TBDMS ether $\mathbf{1 . 8 9}$, and a hydroboration reaction was carried out on the less sterically hindered double bond to produce the alcohol 1.90. After further manipulations, the tetrasubstituted double bond in enone $\mathbf{1 . 9 1}$ was reduced by means of a 1,4-conjugate reduction affording the cis-ring fused product $\mathbf{1 . 9 2}$, although in poor yield. The cis-ring fusion was later corrected to give the desired trans-ring fused product 1.95 via a retro-Claisen reaction on keto-aldehyde 1.94. Although the benzoate bearing side chain in $\mathbf{1 . 9 5}$, which was eventually to be used in the formation of the fourth ring to complete the tetracycle, has the incorrect stereochemistry (confirmed by $\mathrm{X}$-ray crystallography ${ }^{30}$ ) for the formation of the natural product, it was believed that this stereocentre could be corrected by epimerisation at a later stage in the synthesis.

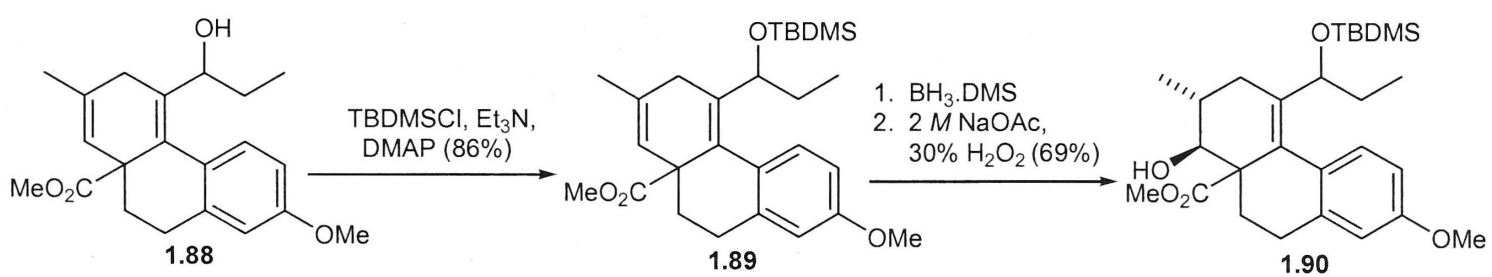<smiles>CCC(OC(=O)P)C1C[C@@H](C)C(OC)[C@]2(COC)CCc3cc(OC)ccc3C12c1ccccc1</smiles>
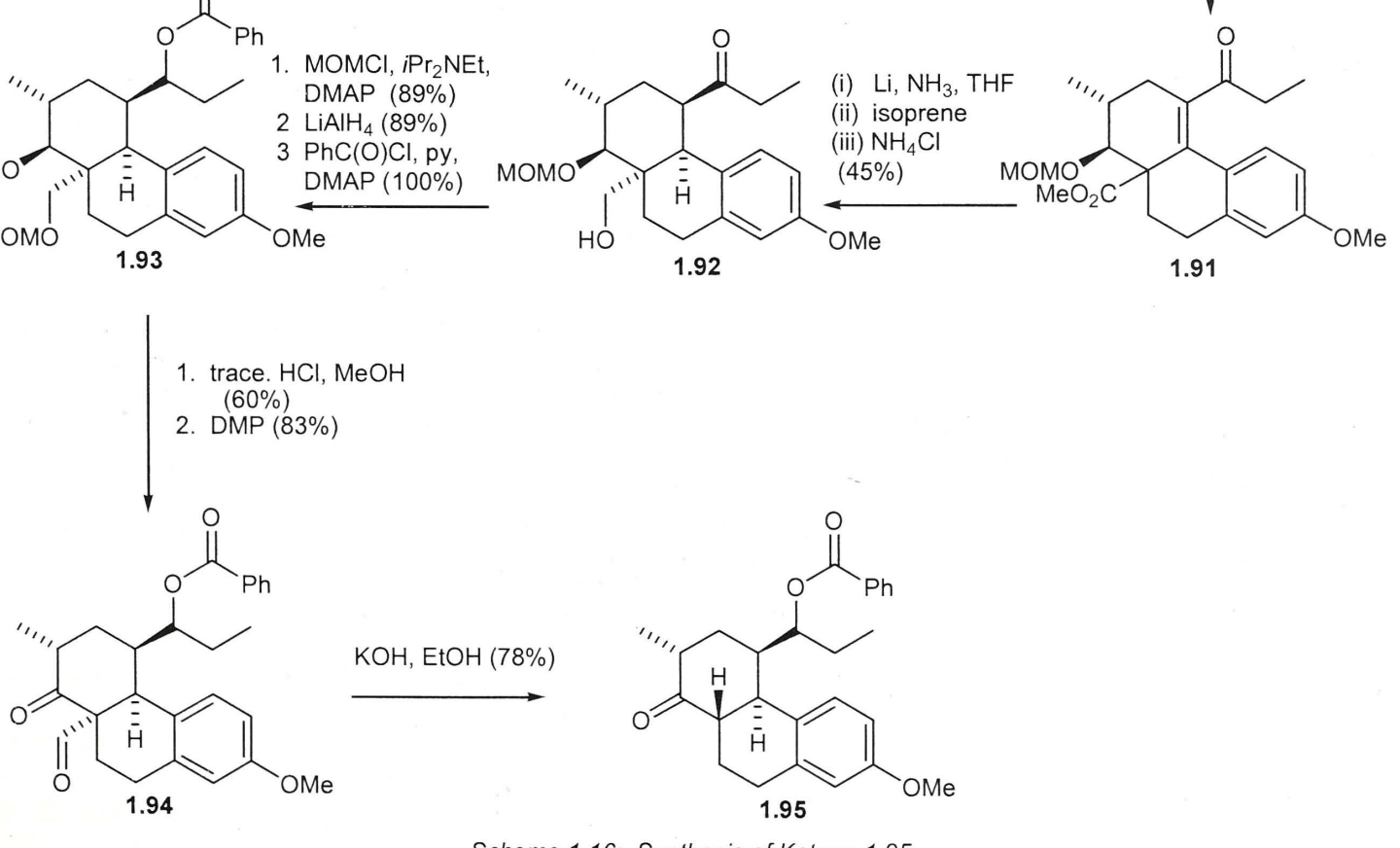

Scheme 1.16: Synthesis of Ketone 1.95 
Ketone 1.95 was further elaborated with the formation of the quaternary centre which becomes the isonitrile bearing centre in the D-ring (C-20) of $\mathbf{1 . 1 0}$ (Scheme 1.17). We hoped to obtain intermediate $\mathbf{1 . 9 8}$ via the methylation of the exocyclic enolate of aldehyde 1.97, which could be obtained after a Wittig reaction on ketone $\mathbf{1 . 9 5}$. We expected alkylation of aldehyde $\mathbf{1 . 9 7}$ to occur along the less sterically crowded equatorial vector, ${ }^{31}$ but unfortunately, our attempts to incorporate an equatorial methyl group at $\mathrm{C}-1$ (C-20 in the natural product) in the D-ring by alkylation of aldehyde $\mathbf{1 . 9 7}$ were unsuccessful (Scheme 1.17).

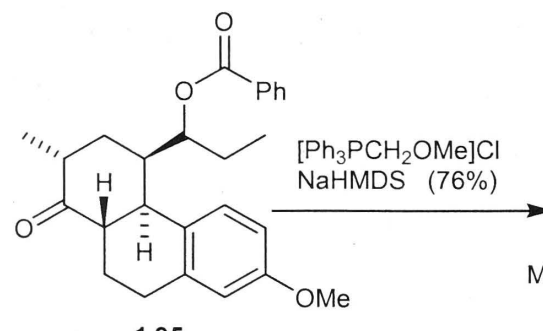

1.95

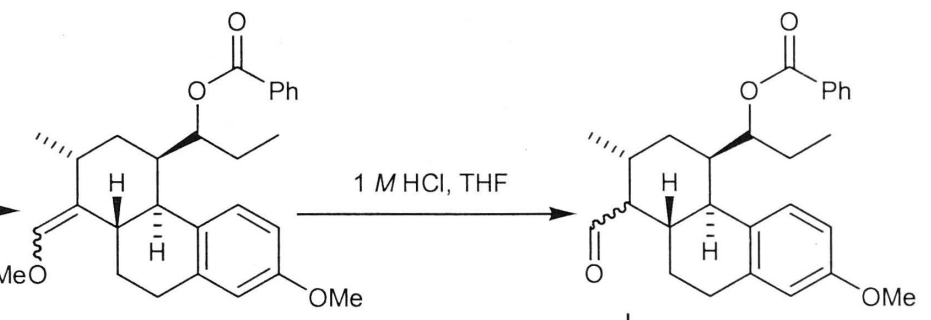

1.96

1.97
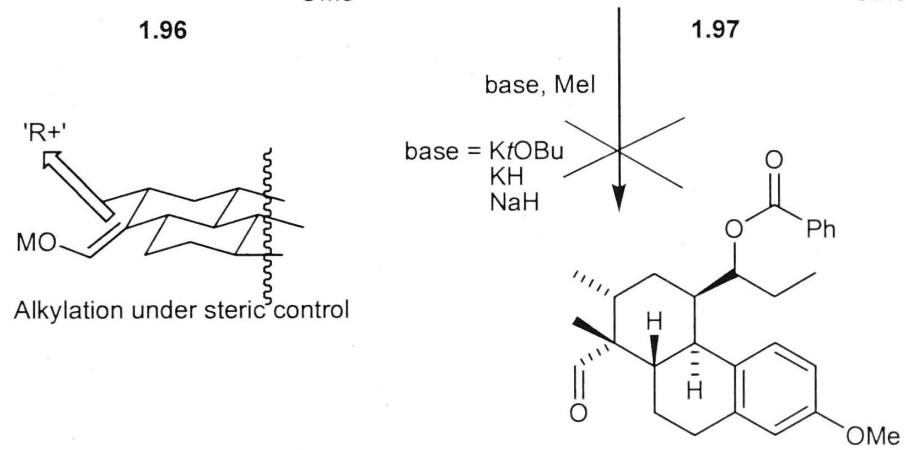

Scheme 1.17: Attempted Alkylation of Aldehdye 1.97

1.98

The required equatorial methyl group in 1.98, however, was installed by an acidcatalysed-ring-opening reaction of the methoxy cyclopropane moiety in $1.99 .^{32}$ This intermediate was obtained from ketone $\mathbf{1 . 9 5}$ via the enol ether $\mathbf{1 . 9 6}$ by employing a Wittig reaction followed by subjecting the resulting enol ether $\mathbf{1 . 9 6}$ to Simmons-Smith conditions, or treating with diazomethane and a catalytic amount of palladium acetate. The methoxy cyclopropane $\mathbf{1 . 9 9}$ was then treated with concentrated hydrochloric acid in acetone at reflux to obtain the methylated derivative $\mathbf{1 . 9 8}$ with the required stereochemistry, as confirmed by one dimensional nuclear Overhauser enhancement (nOe) NMR experiments ${ }^{30}$ (Figure 1.18). 


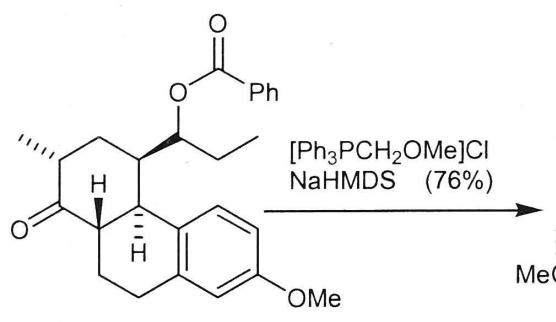

1.95

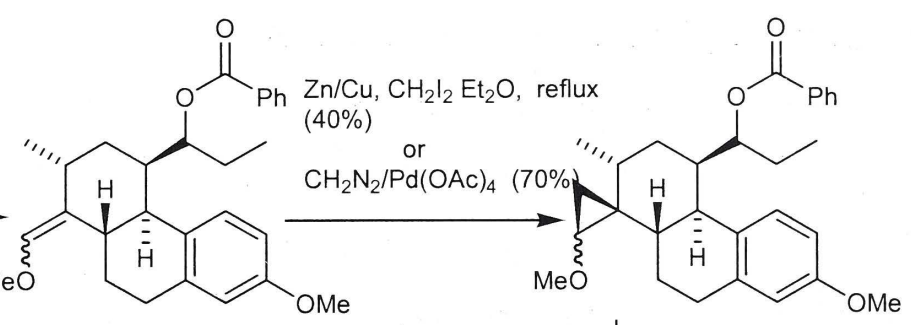

1.96

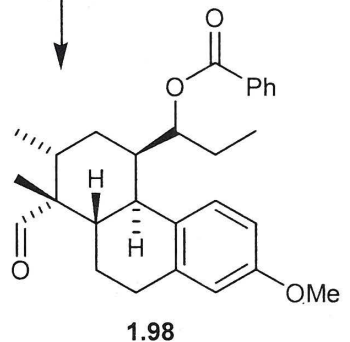

In view of this result, the methoxy cyclopropanated precursor 1.99 must have been formed by addition of the methylene unit to the exo face of the enol ether $\mathbf{1 . 9 6}$ (Figure 1.7).

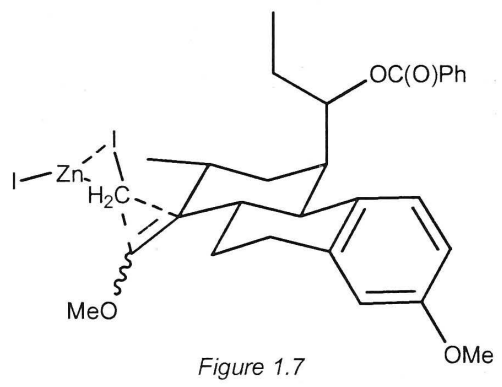

\subsection{Current Study}

The aim of the current study has been to blend and improve the procedures established thus far into a cohesive route to diisocyanoadociane (1.10).

The formation and relative stereochemistry of the two isonitrile bearing quaternary carbons, C-7 and C-20 in the A and D-rings respectively of diisocyanoadociane (1.10), has previously been established separately on similar tricyclic intermediates as discussed. ${ }^{24,30}$ As mentioned above, a synthetic route to aldehyde 1.98, with the correct stereochemistry for the quaternary centre at C-20 and the desired trans-fusion between the B and D-rings, had been achieved. We envisaged applying the Birch derived methodology developed by Crabtree (Scheme 1.10 and 1.11) to afford the carboxylic 
acid 1.101, with the consequential elaboration of the quaternary centre in the A-ring. Based on this work, the $\beta$-keto ester $\mathbf{1 . 1 0 2}$ would be obtained via a reductive acylation ${ }^{26}$ of the enone $\mathbf{1 . 1 0 1}$ corresponding to $\mathbf{1 . 1 0 0}$ after a Birch reduction of the aromatic ring. The axial methyl group at C-7 could then be introduced by alkylation of the corresponding enolate of the $\beta$-keto ester 1.102, under stereoelectronic control (Figure 1.6), to give compound $\mathbf{1 . 1 0 3}$ (Scheme 1.19). The use of a dissolving metal reduction in order to facilitate the regioselective installation of the required acyl group would also result in the formation of the A,B-trans ring fusion required in our target $\mathbf{1 . 1 0 2}$.
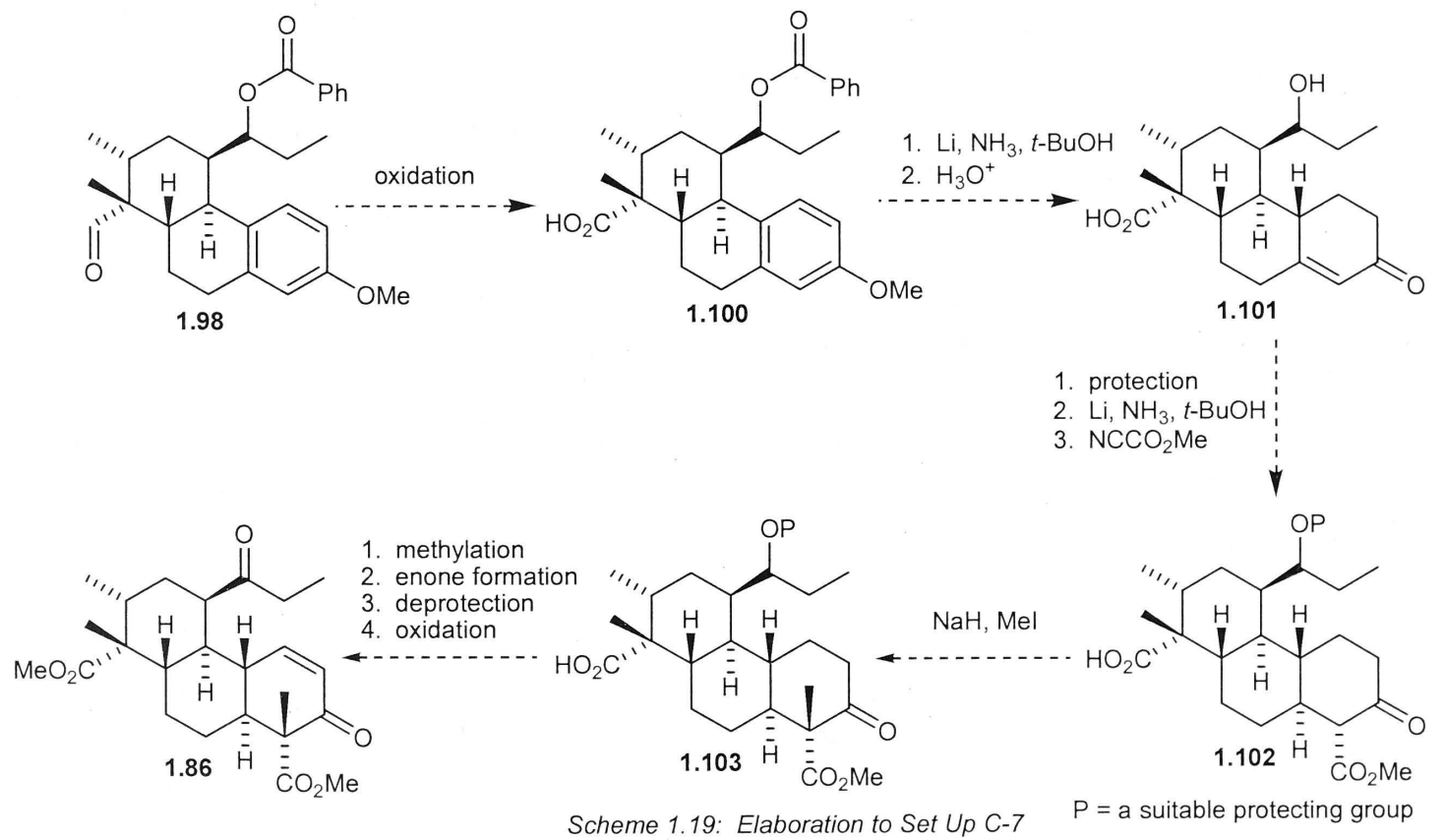

Following on from work carried out by Crabtree $^{24}$ it was envisaged that the tetracyclic skeleton $\mathbf{1 . 8 7}$ of the natural product could be obtained by an intramolecular Michael reaction on an all trans-fused tricyclic enone intermediate 1.86. As this reaction is reversible, the thermodynamically most stable trans-fused product, with an equatorial methyl group next to the carbonyl function, would be expected. As mentioned above, from earlier work $^{30}$ we expected the ketone bearing side chain to have the incorrect stereochemistry for the formation of the all trans-fused tetracycle. However, it appeared plausible to invert the configuration at $\mathrm{C}-1$ at the same time as inducing the planned intramolecular Michael reaction. Deoxygenation and demethylation would then follow to give the dicarboxylic acid $\mathbf{1 . 6 2}$ (Scheme 1.20). 


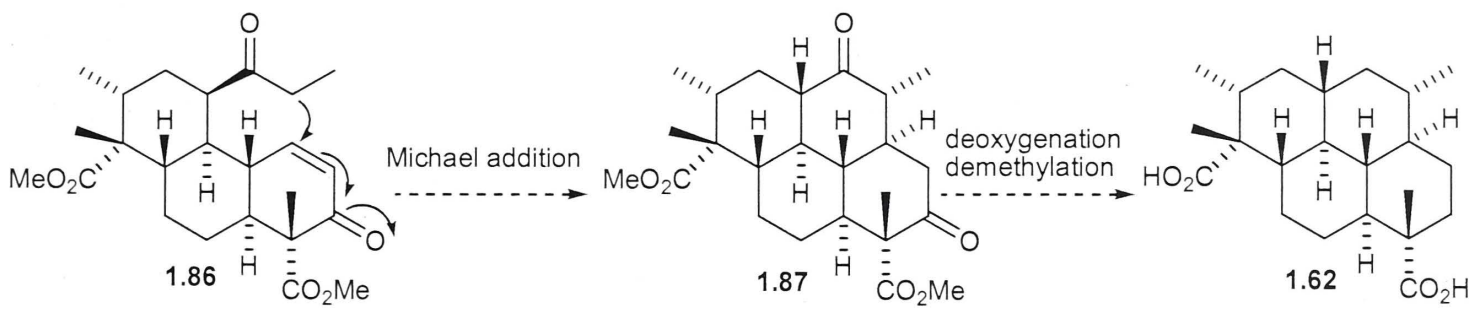

Scheme 1.20: Proposed Intramolecular Michael Reaction 
Chapter 1 


\section{CHAPTER 2}

\section{Improved synthesis of Ketone 1.95}

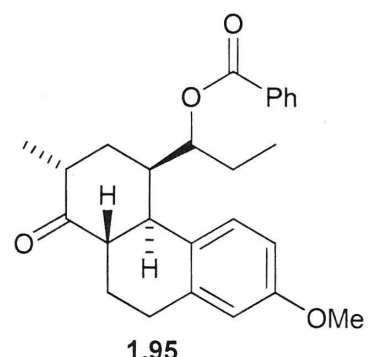


Chapter 2 


\section{Improved Synthesis of Ketone $\mathbf{1 . 9 5}$}

This chapter will cover our problems with the previous synthetic sequence to ketone 1.95, and our efforts to improve it by utilising an epoxidation to install the required carbonyl group.

As already discussed, ketone $\mathbf{1 . 9 5}$ was previously synthesised by a 12 step sequence from alcohol $\mathbf{1 . 8 8}$ (Scheme 1.16, Chapter 1). ${ }^{30}$ A major problem with this route to $\mathbf{1 . 9 5}$ is the many additional steps required, owing to numerous protecting group manipulations, oxidations and reductions. Furthermore, there are steps in the sequence with unacceptable yields. For example, the best yield that could be obtained in the hydroboration reaction to form $\mathbf{1 . 9 0}$, even after extensive attempts to optimize the reaction, was at best $69 \%$, but more commonly $45-55 \%$. By far the most problematic step in the sequence, however, was the 1,4-conjugate reduction of 1.91 , which gave a dismal yield (45\%) of the required intermediate $\mathbf{1 . 9 2}$.

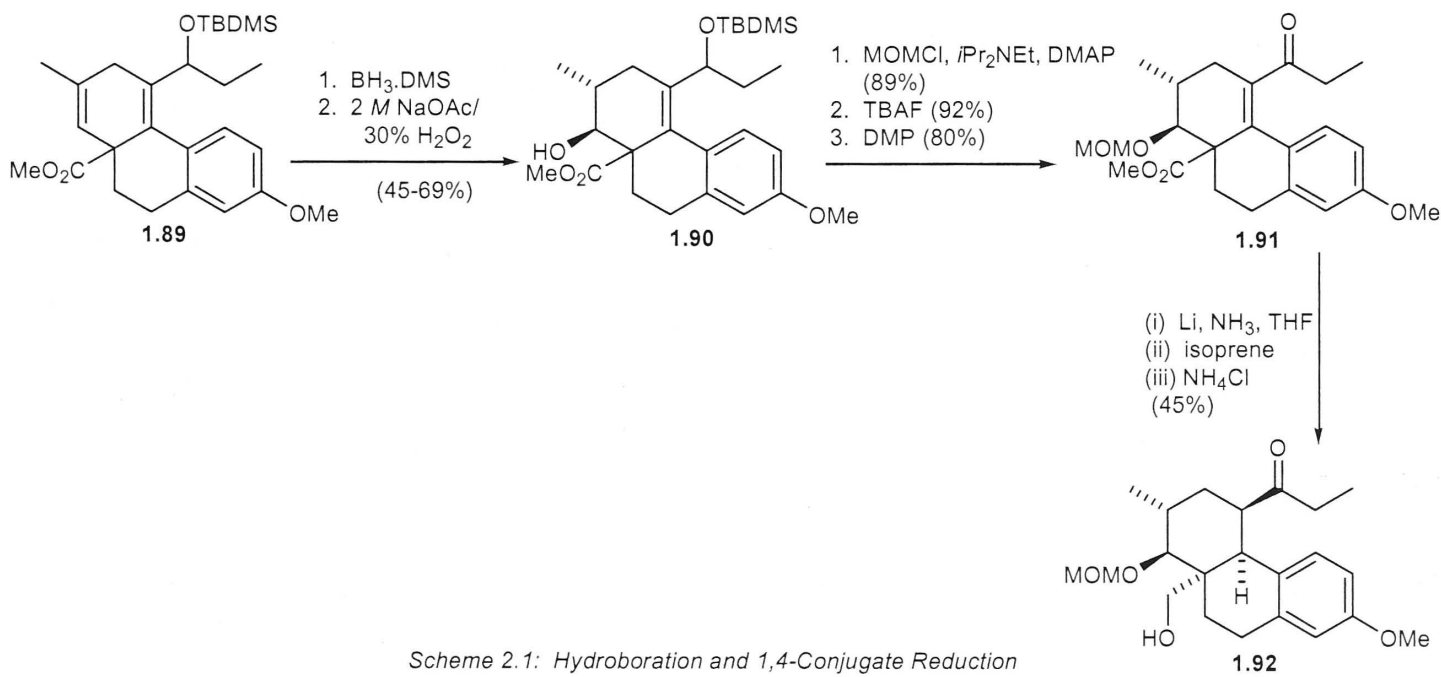

In contrast, when this reaction was applied to the simpler enone 2.1, the reduced product 2.2 was obtained in $75 \%$ yield (Scheme 2.2 ).

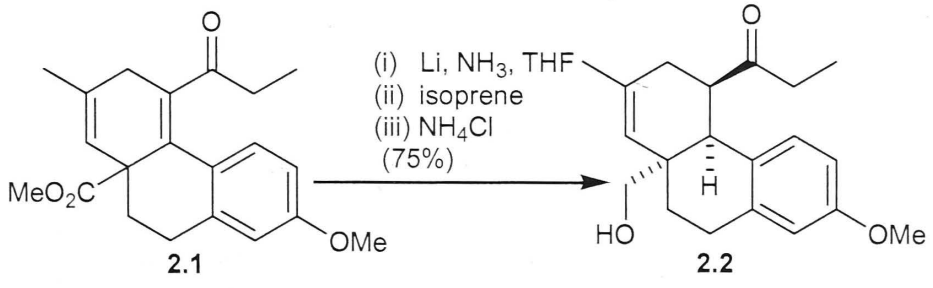

Scheme 2.2: 1,4 Conjugate Reduction of Enone 2.1

In view of the higher yield, it was decided to reduce the tetrasubstituted double bond before elaboration of the less sterically hindered double bond. To this end, attention 
was focused on the synthesis of enone $\mathbf{2 . 1}$, which was previously obtained by a three step procedure shown in scheme 2.3 .
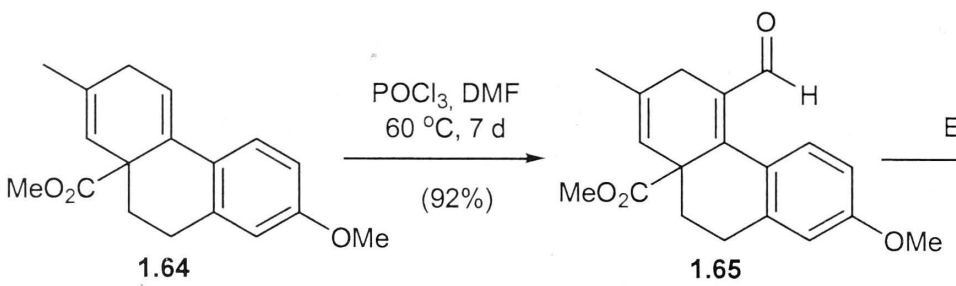<smiles>CCC(O)C1=C2c3ccc(OC)cc3CCC2(C(C)=O)C=C(C)C1</smiles>

Scheme 2.3: Synthesis of Enone 2.1

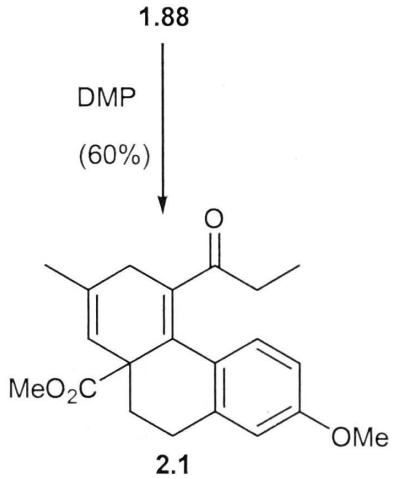

The allylic alcohol $\mathbf{1 . 8 8}$ could be obtained in high yield as a single diastereomer of unspecified stereochemistry from 1.65, as previously reported by Crabtree, ${ }^{24}$ then oxidation with Dess-Martin periodinane (DMP) ${ }^{33}$ gave enone $\mathbf{2 . 1}$ in modest yield.

In the present study, it was found that enone $\mathbf{2 . 1}$ could be synthesised in one step by Friedel Crafts acylation ${ }^{34,35}$ of the styrene bond in 1.64, using aluminum chloride as the Lewis acid and propionyl chloride at $-78^{\circ} \mathrm{C}$ in DCM. Not only were two steps saved by utilising the acylation reaction, but the reaction time for acylation was also reduced from 7 days to 20 minutes (Scheme 2.4).

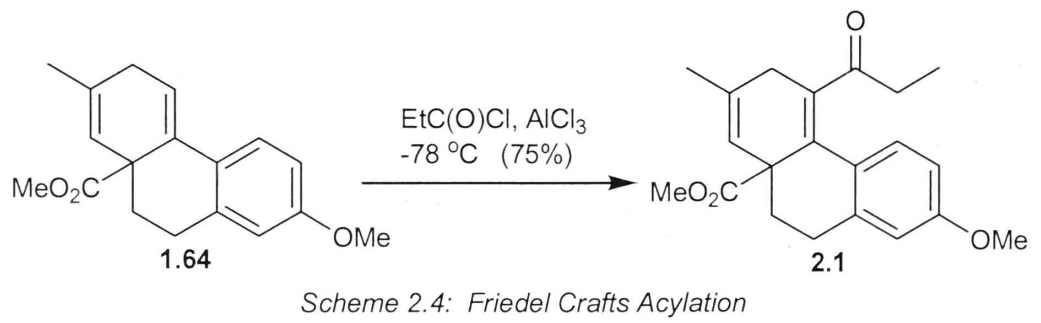

We ascertained that it is important to carry out the Friedel Crafts acylation reaction at $-78^{\circ} \mathrm{C}$. Initially the reaction was attempted at room temperature, whereupon none of the desired enone was obtained. Instead, a puzzling tetracyclic compound was isolated, and eventually assigned the structure 2.3. The ${ }^{1} \mathrm{H}$ NMR spectrum exhibited a doublet at $2.21 \mathrm{ppm}$ and a quartet at $6.61 \mathrm{ppm}$, each with a coupling constant of $7.6 \mathrm{~Hz}$ which could be attributed to the methyl group and proton respectively on the exocyclic double bond. It was thought that the desired acylated compound $\mathbf{2 . 1}$ was formed initially, then 
the aromatic ring cyclised onto the carbonyl carbon, followed by dehydration to form the external double bond. A proposed mechanism is outlined in Scheme 2.5.

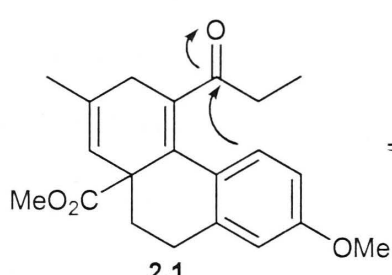

2.1
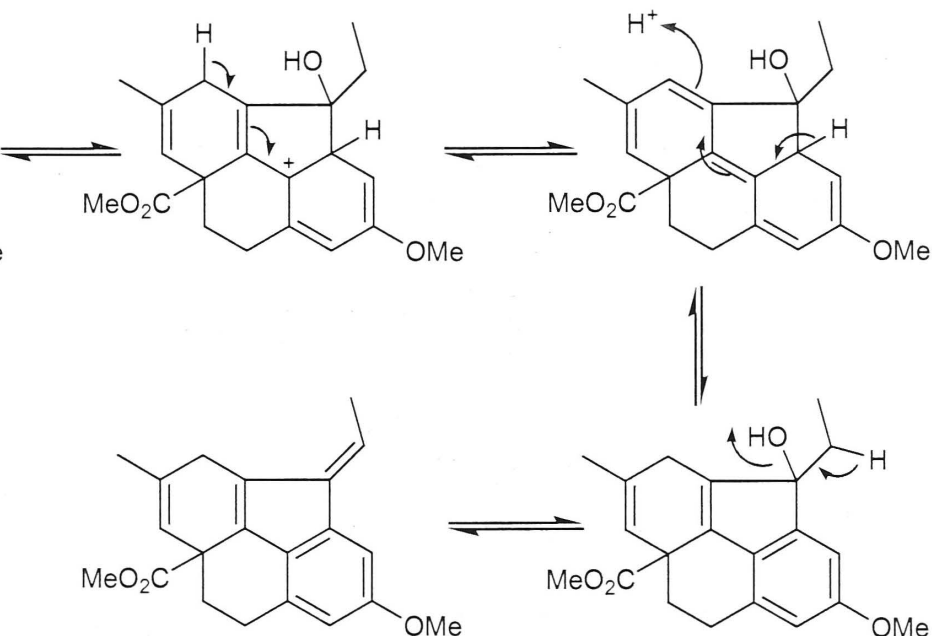

2.3
1

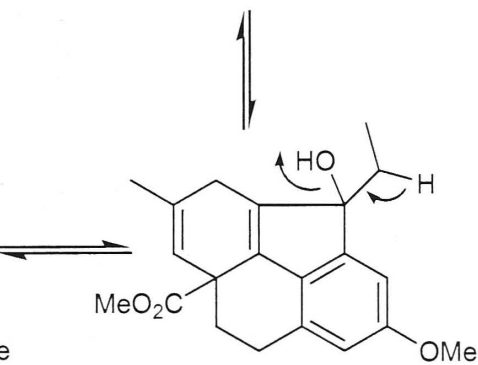

$\mathrm{OMe}$

Scheme 2.5: Proposed Mechanism for the Formation of 2.3

The 1,4-reduction was then carried out as before by the addition of enone $\mathbf{2 . 1}$ to lithium metal dissolved in freshly distilled ammonia, followed by quenching with isoprene, then treatment with aqueous ammonium chloride after removal of ammonia to give $\mathbf{2 . 2}$ in $75 \%$ yield (Scheme 2.2 ).

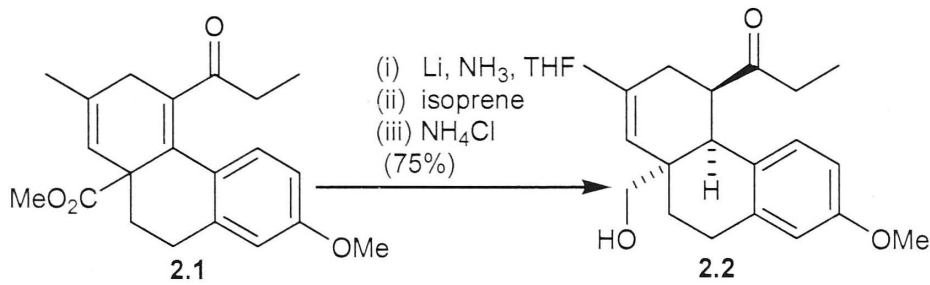

Scheme 2.2: 1,4 Conjugate Reduction of Enone 2.1

Like the example shown in Scheme 1.9, (Chapter 1), the enone 2.1 underwent reduction of the angular methoxycarbonyl group, to the corresponding hydroxymethyl derivative, and gave the product $\mathbf{2 . 2}$ assumed to have a cis-ring fusion by analogy with the Crabtree example (1.71, Scheme 1.9 and Figure 1.5). Once the required reduced product 2.2 was synthesised in large quantities with acceptable yields, our focus turned to improving the "oxygenation" of the double bond. In view of the lack of success in producing high yields of the alcohol 1.90 utilising a hydroboration reaction, Scheme 2.1 (discussed in Chapter 1, Section 1.5.2), we went in search of an alternative approach.

To this end, we decided to explore an epoxidation based route. In preparation for the planned epoxidation reaction, compound $\mathbf{2 . 4}$ was synthesised bearing suitable protecting 
groups. The free hydroxy group in $\mathbf{2 . 2}$ was first protected as the MOM ether, followed by reduction of the ketone group with lithium aluminum hydride. Protection of the resulting free alcohol as the benzoate gave compound $\mathbf{2 . 4}$ as one epimer in $90 \%$ yield over the three steps. An epoxidation reaction was then carried out by treatment of olefin 2.4 with $m$-CPBA, using sodium bicarbonate as a buffer, to give the epimeric epoxides 2.5 in $60 \%$ yield. The formation of the epoxides was evident by analysis of the ${ }^{1} \mathrm{H}$ NMR spectrum, from the presence of two new singlets at $2.82 \mathrm{ppm}$ due to the major epoxide epimer and $2.90 \mathrm{ppm}$ due to the minor epoxide epimer; also the singlet due to the double bond proton in the starting material at $5.04 \mathrm{ppm}$ had disappeared. We then attempted to perform a 1,2-hydride shift using the Lewis acid boron trifluoride diethyl etherate at $0{ }^{\circ} \mathrm{C}$. Rather than the desired ketone, however, a mixture of products was formed. The structure of the major product appeared to be $\mathbf{2 . 6}$ (Scheme 2.6). The 1,2hydride shift of compound 2.5 was also attempted at $-78^{\circ} \mathrm{C}$, but no reaction occurred.
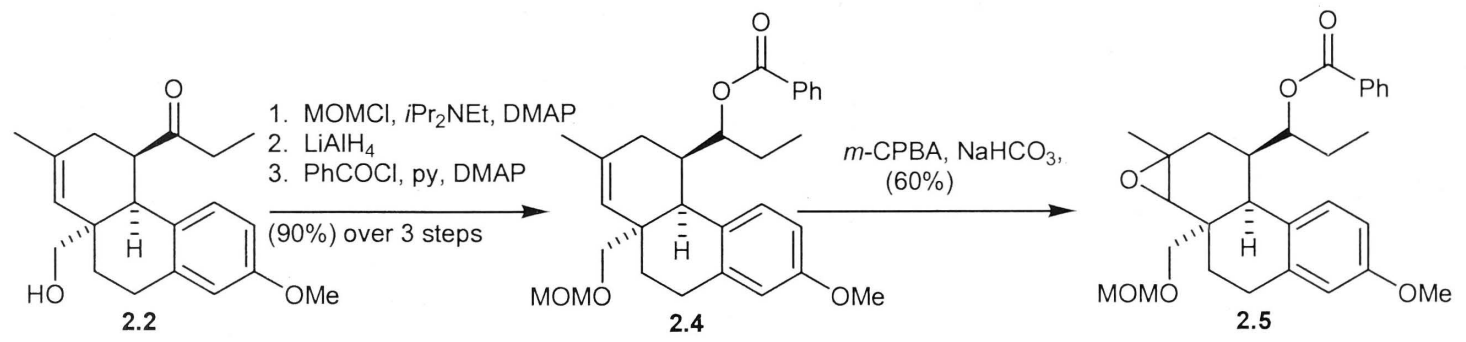

Scheme 2.6: Epoxidation of 2.4

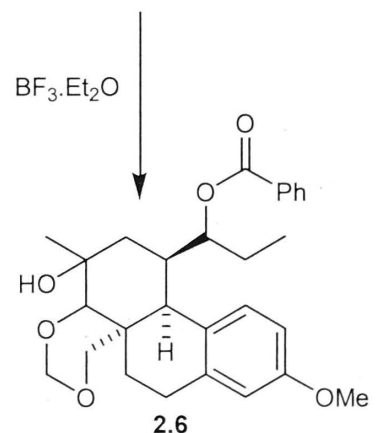

The product 2.6 can be derived from cyclisation of the angular MOM ether onto the Dring with the consequential opening of the epoxide to give a tertiary alcohol and loss of a methyl group (Scheme 2.7).
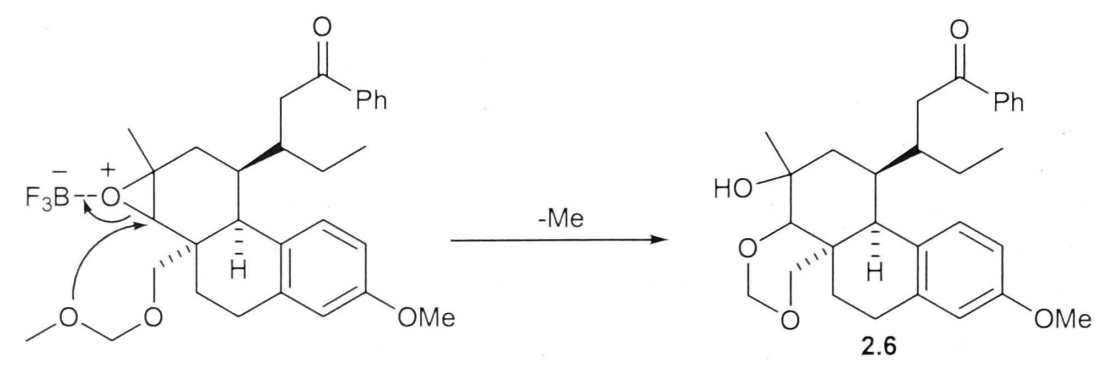

Scheme 2.7: Formation of 2.6 
In view of this result, it was decided to replace the MOM protecting group with an acetate function. Initially the hydroxymethyl substituent of compound $\mathbf{2 . 2}$ was protected as the acetate, but, on reduction of the ketone (sodium borohydride in this case), two epimeric alcohol products in a ratio of $1: 5$ were obtained. It appeared that the steric bulk of the MOM protecting group was such that it allowed hydride to approach only one face. Therefore, compound $\mathbf{2 . 4}$ was synthesised as described above, followed by removal of the MOM protecting group by heating in methanol with hydrochloric acid to afford the parent alcohol, which was subsequently protected as the acetate $\mathbf{2 . 7}$ in $81 \%$ yield over the two steps. With the acetate installed, the epoxidation was carried out as before to give the epimeric epoxides $\mathbf{2 . 8}$ in $85 \%$ yield. In this case, the 1,2-hydride shift occurred smoothly on treatment with boron trifluoride diethyl etherate at $0{ }^{\circ} \mathrm{C}$, to give $\mathbf{2 . 9}$ as a mixture of 2 -C epimers in $75 \%$ yield (Scheme 2.8 ).
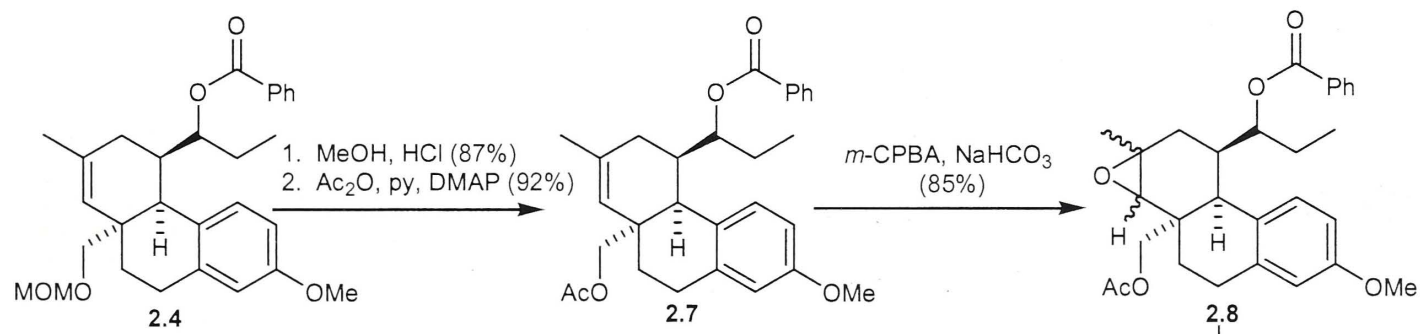

Scheme 2.8: Successful Ring Opening of Epoxide 2.8

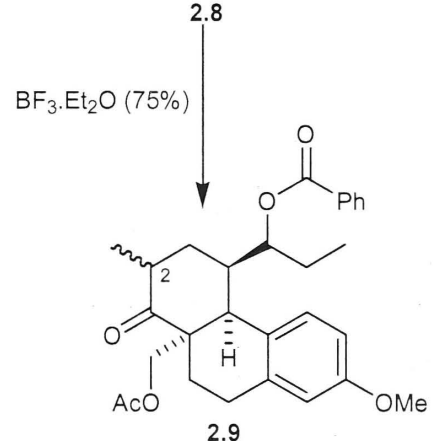

Next, ketone 2.9 was treated with potassium hydroxide in ethanol to remove the acetoxymethyl group and establish the required trans-ring fusion at the carbon alpha to the ketone group by a retro-aldol reaction. ${ }^{36}$ Under these conditions, the C-2 centre also underwent epimerisation thereby affording $\mathbf{1 . 9 5}$ in 70\% yield (Scheme 2.9).<smiles>CCC(OC(=O)c1ccccc1)[C@H]1C[C@H](C)C(=O)[C@]2(COC(C)=O)CCc3cc(OC)ccc3[C@H]12</smiles>

2.9
$\mathrm{KOH}, \mathrm{EtOH}(70 \%)$

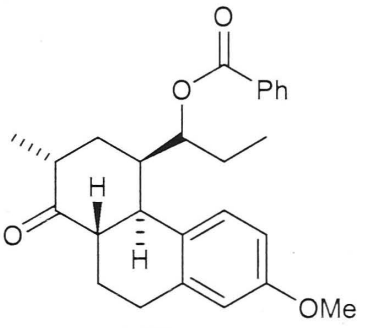

1.95

Scheme 2.9: Retro Aldol Reaction 
In summary, by the use of the above methodology, we were able to improve the synthetic sequence to ketone $\mathbf{1 . 9 5}$ to produce acceptable yields and a reduction in the total number of steps. 


\section{CHAPTER 3}

\section{Birch Reduction and Elaboration of the A-Ring}

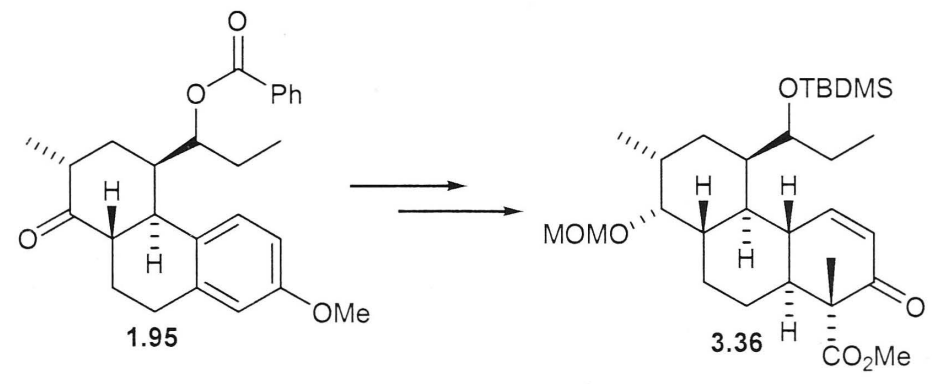


Chapter 3 


\section{Birch Reduction and Elaboration of the A-ring}

The first half of this chapter will discuss the Birch reduction of the A-ring, and investigations into the proposed reductive acylation and alkylation reactions. The second half covers an alternative approach to the elaboration of the A-ring, and a successful synthesis of an intermediate (3.36) bearing a quaternary centre with the correct stereochemistry at $C-1$ (equivalent to $C-7$ in the natural product).

\subsection{Birch Reduction}

We decided to explore the Birch reduction, and the ensuing chemistry to install the quaternary centre in the A-ring, on the readily accessible intermediate $\mathbf{1 . 9 5}$. This compound has the required trans-ring fusion for the D and B rings, but it lacks the functionality at $\mathrm{C}-1$ (equivalent to the $\mathrm{C}-20$ quaternary centre in the natural product).

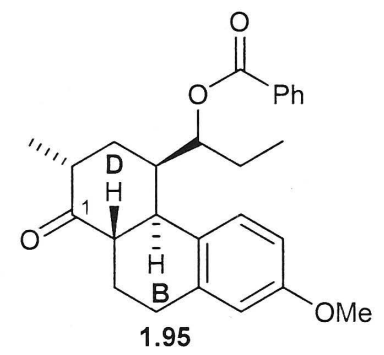

Thus, ketone $\mathbf{1 . 9 5}$ was reduced with L-selectride ${ }^{\circledR 37}$ to afford $88 \%$ of the alcohol $\mathbf{3 . 1}$ as one epimer.* Reduction with the less bulky reducing agent, sodium borohydride, gave two epimeric alcohols in a $2: 1$ ratio. The alcohol $\mathbf{3 . 1}$ was then converted to the MOM ether 3.2 in $86 \%$ yield. Because of concerns over the stability of the benzoate function in the Birch reduction, replacement by the TBDMS group was undertaken. Thus, the benzoate group was removed by heating $\mathbf{3 . 2}$ with sodium ethoxide in ethanol, affording alcohol 3.3 in 95\% yield. We then attempted to install the desired TBDMS group using TBDMSCl in DMF and a catalytic amount of imidazole, a method commonly used for this conversion. ${ }^{38}$ Unfortunately, even after stirring this reaction mixture for 2 days, only 52\% of the desired TBDMS ether $\mathbf{3 . 4}$ was obtained, based on recovered starting material. However, we were pleased to find that a good yield of $\mathbf{3 . 4}$ could be obtained within 20 minutes by using a method developed by Corey $^{39}$, whereby the alcohol $\mathbf{3 . 3}$ was treated with TBDMSOTf and 2,6-lutidine in DCM (Scheme 3.1).

\footnotetext{
* The stereochemistry of the alcohol 3.1 was confirmed at a later stage in the synthesis by Xray crystallography (see Figure 5.3, Chapter 5)
} 


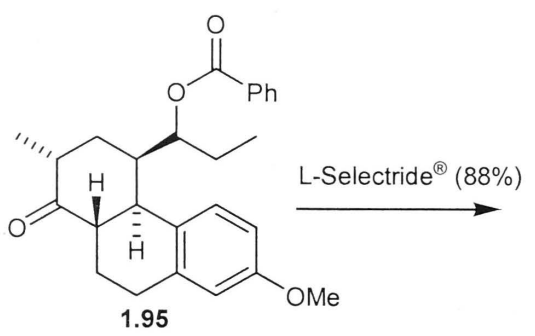

1.95

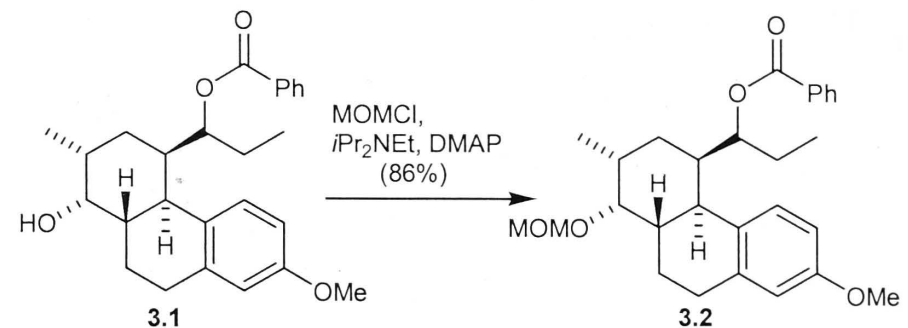

3.1 $\mathrm{NaOEt}, \mathrm{EtOH}$
$(95 \%)$
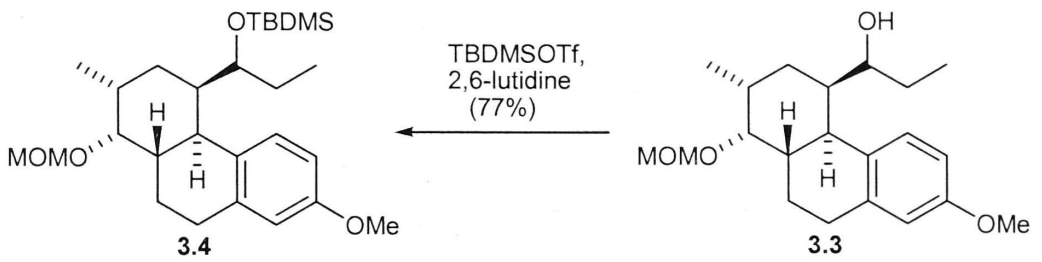

3.3

Scheme 3.1: Formation of a Suitable TBDMS Ether

The Birch reduction of $\mathbf{3 . 4}$ proved to be stubborn. We attempted the reduction of $\mathbf{3 . 4}$ to 3.5 with both methanol and ethanol as the proton sources, but no reaction occurred. We believed that in both the above cases, the respective alcohol was reacting faster with the dissolved lithium metal than compound 3.4. We hypothesised that better results could be obtained using the less reactive reagent, $t$-butyl alcohol, as the proton source. Acting on this hypothesis, we repeated the Birch reduction on a small scale (ca. $100 \mathrm{mg}$ ) using $t$-butyl alcohol as the proton source, and stirring for 40 minutes gave $100 \%$ conversion of compound $\mathbf{3 . 4}$ to the dihydroanisole moiety 3.5. Unfortunately, on a larger scale this reaction resulted in a large amount of recovered starting material. After having tried a range of reaction times and conditions, it was finally found that the best results could be obtained by stirring at $-40{ }^{\circ} \mathrm{C}$ for 3 hours with $t$-butyl alcohol as the proton source and a large excess (50 equivalents) of lithium metal. Presumably, the bulky side chain interferes with solvation of the intermediate aromatic radical-anion.

The dihydroanisole moiety $\mathbf{3 . 5}$ was then isolated, and on treatment with a mixture of acetic acid, THF and water $(4: 2: 1),{ }^{40}$ the $\beta, \gamma$-enone $\mathbf{3 . 6}$ was obtained. Conversion to the desired $\alpha, \beta$-enone $\mathbf{3 . 7}$ occurred on treatment with anhydrous hydrogen chloride gas in THF to give a yield of $71 \%$ over the three steps. The conversion of $\mathbf{3 . 6}$ to $\mathbf{3 . 7}$ needed to be followed closely, as when the reaction was left for longer than 20 minutes we started to see more polar products by TLC, which could be attributed to deprotection of the MOM and TBDMS ethers (Scheme 3.2). 

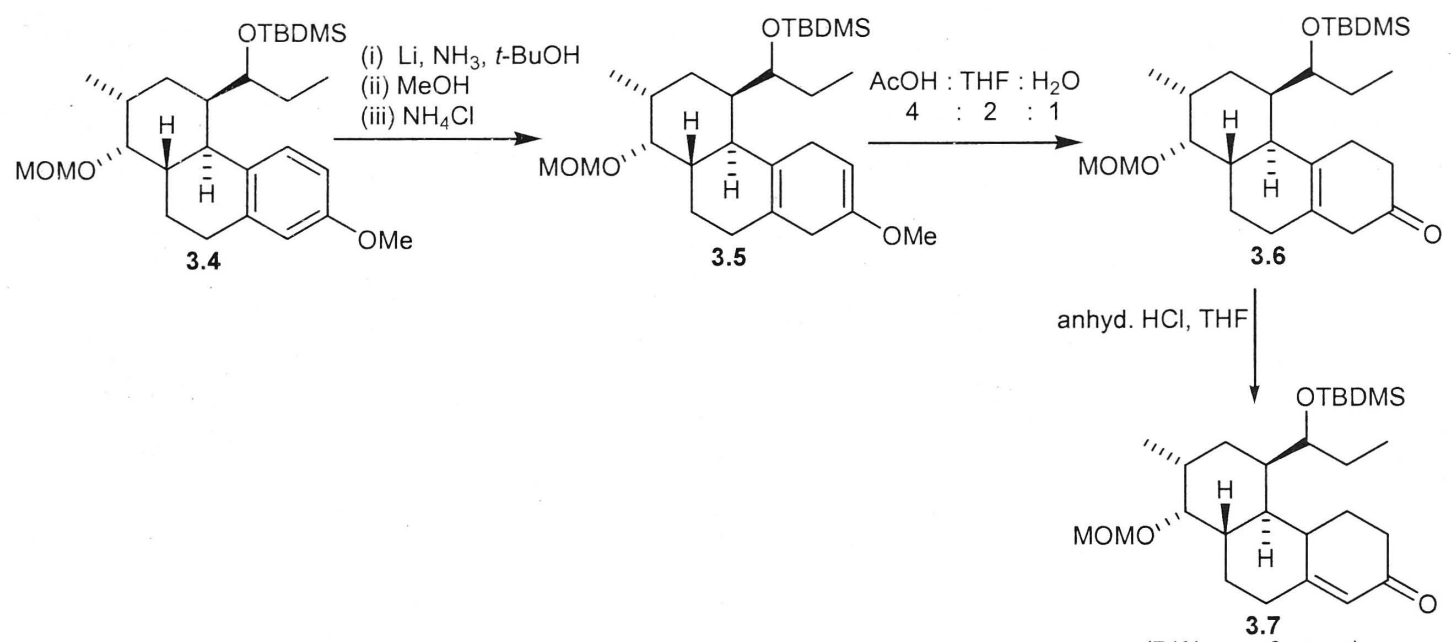

Scheme 3.2: Birch Reduction of 3.4

The formation of the $\alpha, \beta$-enone $\mathbf{3 . 7}$ was evident by a distinctive singlet in the ${ }^{1} \mathrm{H}$ NMR spectrum at $5.81 \mathrm{ppm}$ owing to the proton on the carbon-carbon double bond.

\subsection{Reductive Acylation of Enone 3.7}

It was planned to set up the $\mathrm{C}-1$ (equivalent to $\mathrm{C}-7$ in the natural product) quaternary centre in the A-ring by reductive acylation of a suitable enone, followed by alkylation of the resulting $\beta$-keto ester. We expected this alkylation to occur under stereoelectronic control to give the required axial methyl group for the natural product, as for the conversion of $\mathbf{1 . 7 7}$ to $\mathbf{1 . 7 8}$ by Crabtree shown in Scheme 1.11 (discussed in Section $1.5 .1)$.

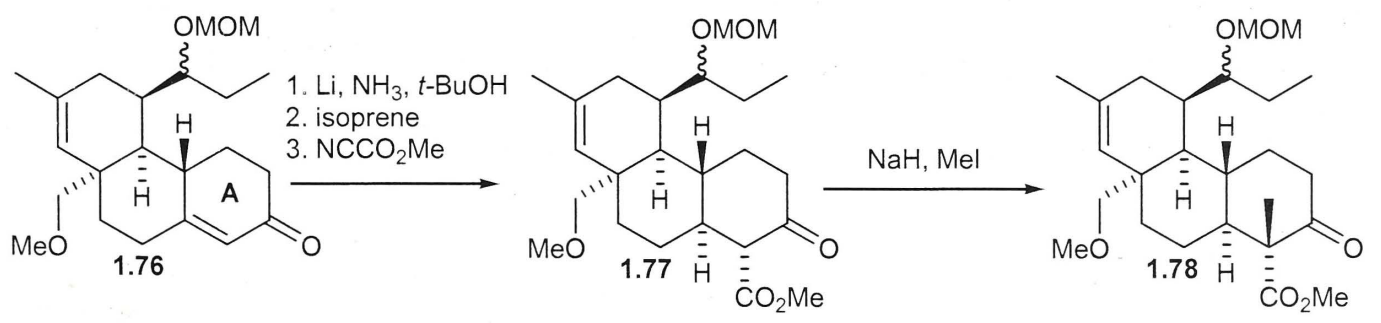

Scheme 1.11: Reductive Acylation and Alkylation by Crabtree

Reductive acylation has been a topic of extensive studies previously in our laboratories. $^{26,41}$ During these studies a relatively mild, reliable method for preparing $\beta$ keto esters with good ambidoselectivity was established. This methodology involves forming the required enolate by reduction with dissolved lithium metal in ammonia, followed by trapping the enolate at $-78^{\circ} \mathrm{C}$ in ether with methyl cyanoformate, then warming to $0{ }^{\circ} \mathrm{C}$ before quenching with water. Greater than $95 \%$ ambidoselectivity had been displayed by the reagent for the $C$-terminus of the enolate using this procedure, 
although in earlier studies, varying amounts of the enol carbonate products were isolated, using THF instead of ether as the solvent. Examples of reactions utilising this methodology are shown in Scheme 3.3.<smiles>O=C1C=C2CCCC[C@H]2CC1</smiles>

3.8<smiles>C[C@]12CCCCC1=CC(=O)CC2</smiles>

3.11

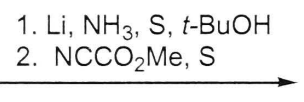

$S=$ Diethyl ether $S=T H F$

1. $\mathrm{Li}, \mathrm{NH}_{3}, \mathrm{~S}, t-\mathrm{BuOH}$ 2. $\mathrm{NCCO}_{2} \mathrm{Me}, \mathrm{S}$

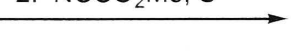

$\mathrm{S}=$ Diethyl ether $S=T H F$<smiles>C[C@H]1C(=O)CC[C@H]2CCCC[C@H]21</smiles>

3.9 $100(74 \%)$ 25

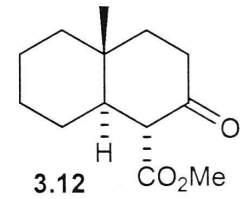
$100(82 \%)$ 4<smiles>CC(=O)OC1=C[C@H]2CCCC[C@H]2CC1</smiles>

3.10

$$
0
$$$$
1
$$<smiles>COC(=O)C1=C[C@H]2CCCC[C@]2(C)CC1</smiles>

3.13

Scheme 3.3: Examples of Reductive Acylations

It was suggested in mechanistic studies carried out by Crabtree $^{24}$ that the acylation proceeds via an aldol type intermediate. If these aldol intermediates were relatively long-lived under the reaction conditions, equilibrium would be set up between the ortho complex $\mathbf{3 . 1 4}$ and the aldol intermediate 3.15. The aldol derivative $\mathbf{3 . 1 5}$ would then be stabilised by chelation of the lithium cation between the carbonyl oxygen and the alkoxy anion. However, in the case of $\mathbf{3 . 1 4}$, the lithium cation can only co-ordinate to the oxygen anion. Therefore, the aldol intermediate 3.15 would be stabilised relative to the ortho intermediate $\mathbf{3 . 1 4}$, displacing the equilibrium in the desired direction, and yielding the $\beta$-keto ester (3.12) as the major product on work-up (Scheme 3.4).

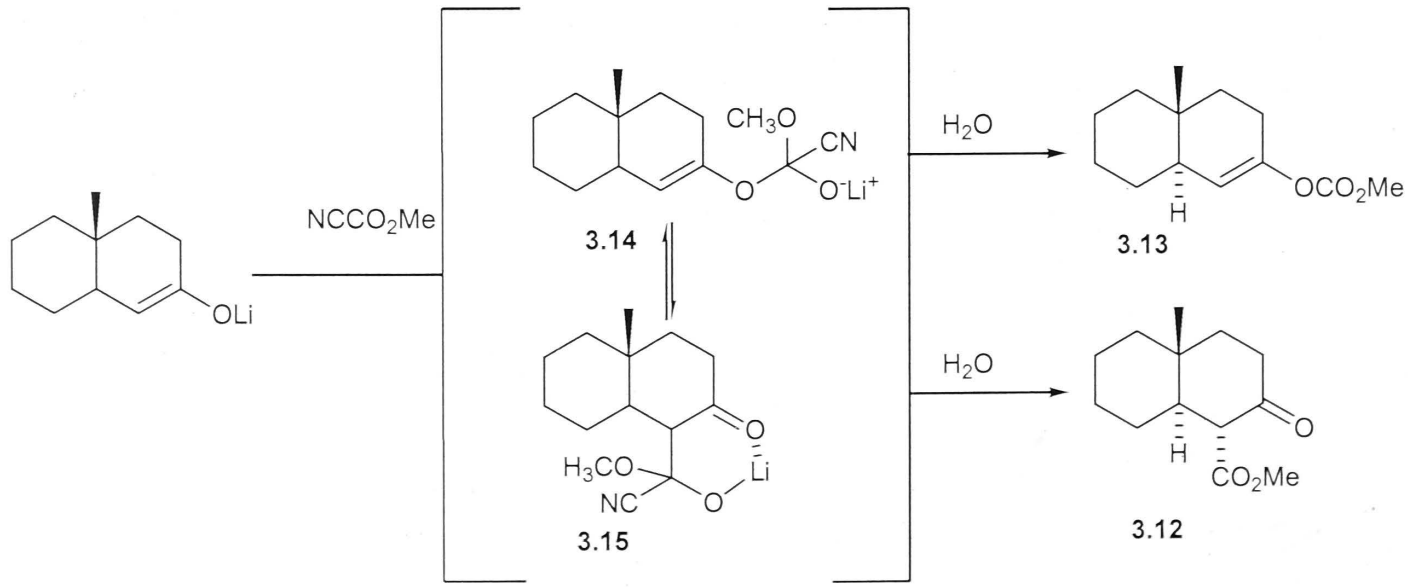

Scheme 3.4: Intermediates in the Reductive Acylation 
The increased ambidoselectivity in ether relative to THF was also explained by the fact that diethyl ether is a poor solvating medium for the lithium cation. This poor solvation allows a relatively strong chelate to form between the $C$-acylated aldol intermediate and the cation, displacing the equilibrium in Scheme 3.4 in favour the desired $C$-acylated product. However, THF solvates the lithium cation to a greater extent, so the chelate is less stable.

Reductive acylation was attempted on enone $\mathbf{3 . 7}$ following the methodology described above. The first reaction was attempted on a small scale (ca. $20 \mathrm{mg}$ ), and gave the $\beta$ keto ester $\mathbf{3 . 1 6}$ in less than $20 \%$ yield. The reaction was repeated on a larger scale to give three products in poor yield; the desired product $\mathbf{3 . 1 6}$ was formed, but we also isolated its regioisomer (in its enol form 3.17) and the product of simple 1,4-reduction 3.18 (Scheme 3.5).

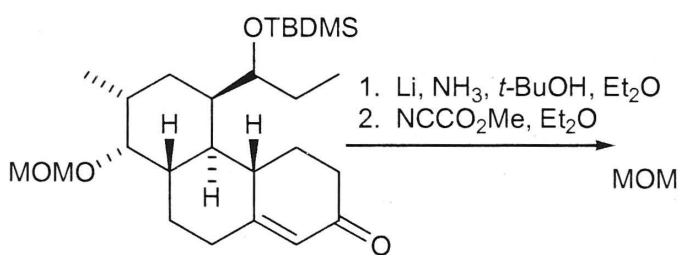

3.7
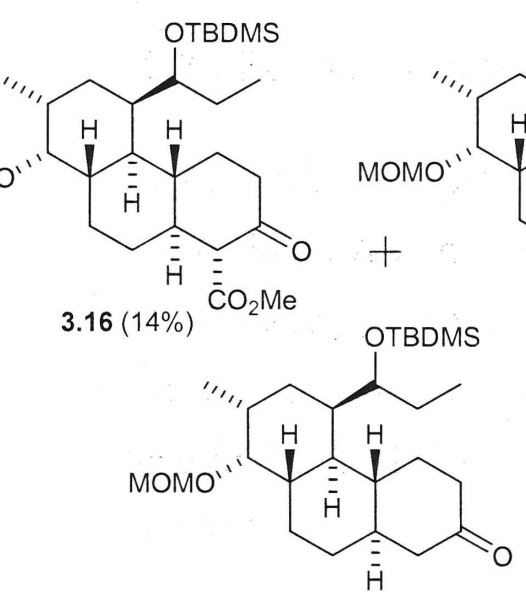

$3.18(13 \%)$

Scheme3.5: Reductive Acylation of Enone 3.7

Analysis by ${ }^{1} \mathrm{H}$ NMR spectroscopy provided evidence for the formation of $\mathbf{3 . 1 6}$, in that a doublet arising from the proton on the carbon bearing the ester group was present at 3.12 ppm with a diaxial coupling constant of $11.7 \mathrm{~Hz}$. Furthermore a singlet at 3.75 ppm due to the ester group was observed. On the other hand, the regioisomer 3.17 exhibited a singlet at $3.73 \mathrm{ppm}$ due to the ester group, and a singlet at $12.08 \mathrm{ppm}$ due to the enol proton.

In view of the poor results obtained so far in this reaction, some model studies were undertaken on the simpler enone $\mathbf{3 . 1 1}$, which has been previously acylated in high yield

\footnotetext{
- The location of the ester function was confirmed by 2D NMR studies on the methylated derivative (see section 3.2.2).
} 
(as shown in Scheme 3.3). The reductive acylation of 3.11, following the previously developed methodology, resulted in none of the desired $\beta$-keto ester 3.12, but rather its regioisomer $\mathbf{3 . 1 9}$ and the $O$-acylated product 3.13. This reaction was followed by TLC analysis, and a great change was noticed after warming to $0{ }^{\circ} \mathrm{C}$. After this observation, the experiment was repeated, quenching with water at $-78{ }^{\circ} \mathrm{C}$. From this experiment the desired $\beta$-keto ester $\mathbf{3 . 1 2}$ was obtained in 12\% yield, plus two cyanohydrin compounds $\mathbf{3 . 2 0}$ and $\mathbf{3 . 2 1}$ in $21 \%$ and $31 \%$ yield respectively. The cyanohydrin compounds were converted to the $\beta$-keto ester $\mathbf{3 . 1 2}$ when treated with mild base. However, in order to avoid the isolation of these cyanohydrin compounds the experiment was repeated, quenching at $-78{ }^{\circ} \mathrm{C}$ with $2 M$ lithium hydroxide rather than water, and followed until only one compound could be seen by TLC analysis. To our delight this resulted in the isolation of the desired $\beta$-keto ester $\mathbf{3 . 1 2}$ in $70 \%$ yield (Scheme 3.6).

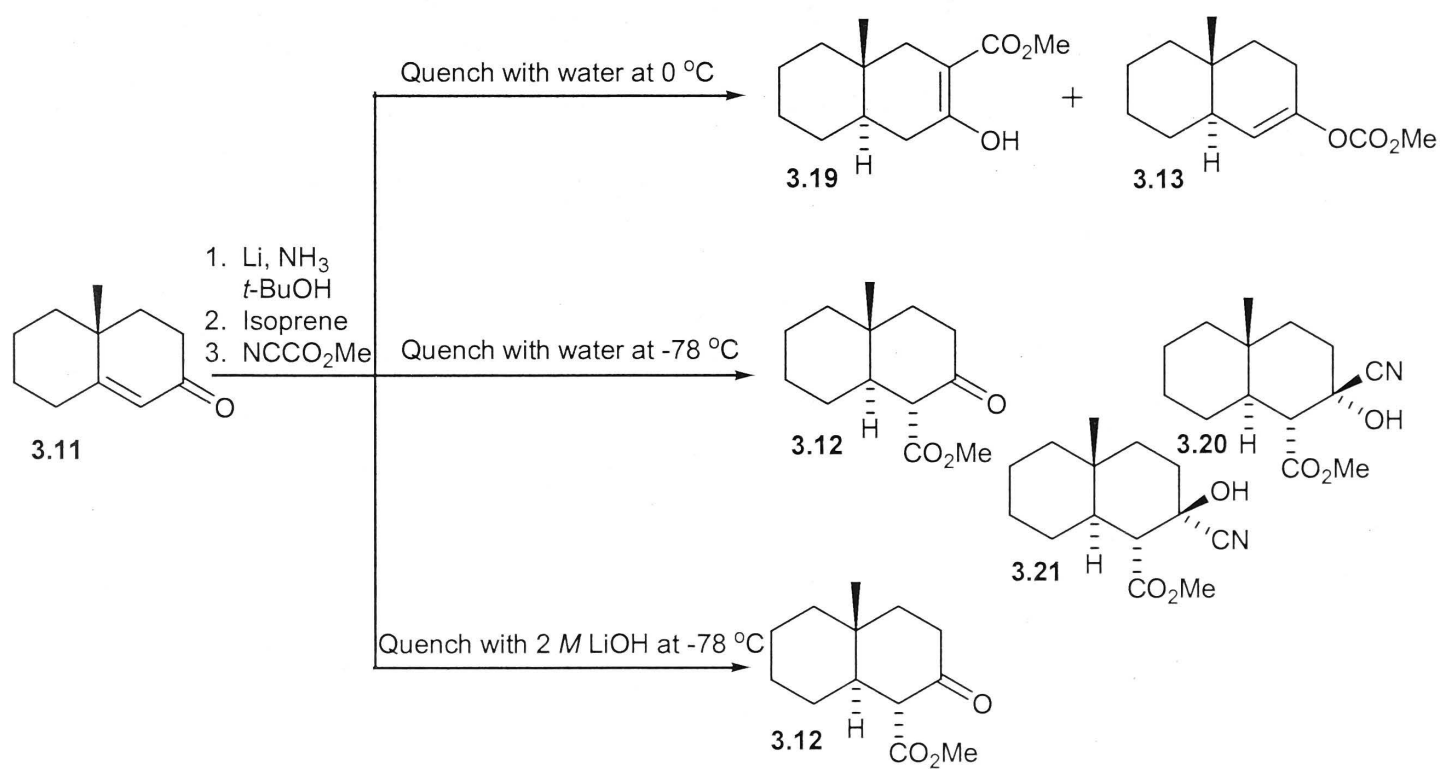

Scheme 3.6: Model Studies on Reductive Acylation Reaction

This new methodology was then applied to enone 3.7, and the desired $\beta$-keto ester $\mathbf{3 . 1 6}$ was obtained in $40 \%$ yield. Although the yield of $\mathbf{3 . 1 6}$ was still quite low, it was a vast improvement on the previous attempts (Scheme 3.7).

^ The NMR data for compounds shown in Scheme 3.6 are in accordance to that previously recorded by S.R. Crabtree, Ph.D. thesis, ANU, 1990. 


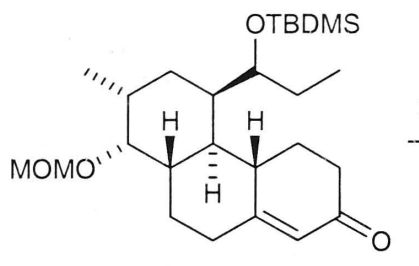

3.7
1. $\mathrm{Li}, \mathrm{NH}_{3}, t-\mathrm{BuOH}, \mathrm{Et}_{2} \mathrm{O}$

2. $\mathrm{NCCO}_{2} \mathrm{Me}, \mathrm{Et}_{2} \mathrm{O}$

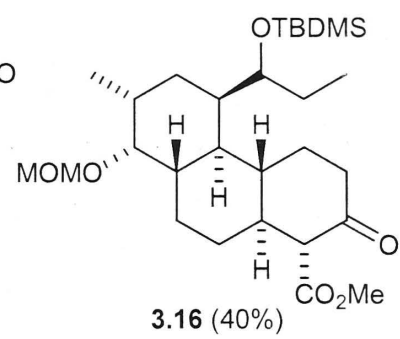

$3.16(40 \%)$

Scheme 3.7: Improved Reductive Acylation of Enone 3.7

In an attempt to improve the methodology further, a two step procedure was investigated. The enolate resulting from the dissolving metal reduction was first trapped as the TMS enol ether. ${ }^{42}$ The enolate was then liberated in the second step on treatment with $n$-butyllithium and finally trapped with methyl cyanoformate. Applying this procedure to enone $\mathbf{3 . 7}$ gave ester $\mathbf{3 . 1 7}$ and a poor yield of the desired acylated product $\mathbf{3 . 1 6}$ (Scheme 3.8).

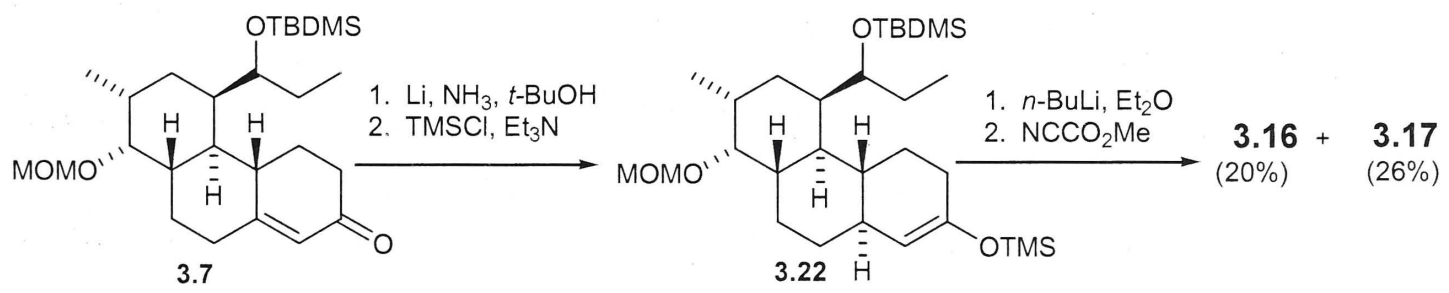

Scheme 3.8: Two Step Acylation Procedure

The best result we were able to obtain for the reductive acylation to give $\mathbf{3 . 1 6}$ was, despite our best efforts, a yield of only $40 \%$. However, we were able to obtain enough acylated material to investigate the subsequent alkylation reaction.

\subsection{Stereochemistry at the $\beta$-position of the Reductive Acylation Products}

As briefly mentioned in Chapter 1, the 1,4-reduction of octalones to give a trans-ring fusion is well precedented. ${ }^{25}$ The stereochemistry at the $\beta$-position is established by the protonation of an allylic anion intermediate. In the reduction step of the conversion of $\mathbf{3 . 7}$ to $\mathbf{3 . 1 6}$, there are two possible allylic anion intermediates, $\mathbf{3 . 2 3}$ and $\mathbf{3 . 2 4}$, which satisfy the orbital overlap requirements between the $\beta$-carbon and the enolate system.

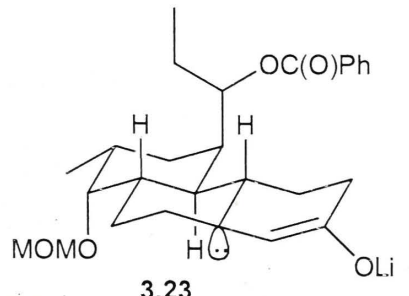

3.23

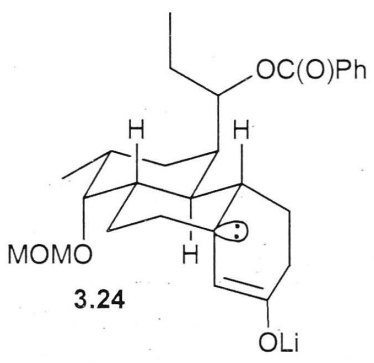


Intermediate $\mathbf{3 . 2 3}$ has less severe 1,3-diaxial interactions than $\mathbf{3 . 2 4}$, so it can be assumed that the kinetically favoured transition state structure will be based on the more stable conformation 3.23, which leads to the observed trans-ring fusion. ${ }^{\vee}$

\subsection{Attempted Alkylation of $\beta$-keto ester 3.16}

There are numerous methods for the alkylation of $\beta$-keto esters. The methods we attempted for the alkylation of $\mathbf{3 . 1 6}$ to $\mathbf{3 . 2 5}$ are listed below:

- Sodium hydride and iodomethane in THF at room temperature. Alkylations of substrates very similar to that of the $\beta$-keto ester $\mathbf{3 . 1 6}$ have been carried out previously using this method. ${ }^{24}$ When this methodology was applied to $\mathbf{3 . 1 6}$, a complex mixture of products was obtained which contained none of the methylated product $\mathbf{3 . 2 5}$.

- Sodium hydride and iodomethane in toluene at $80{ }^{\circ} \mathrm{C} .{ }^{43}$ When applied to 3.16, only a trace amount of the product $\mathbf{3 . 2 5}$ was obtained.

- Potassium carbonate and iodomethane in acetone at reflux. ${ }^{44}$ Only starting material was recovered using this procedure.

- Potassium t-butoxide in benzene and t-butanol at room temperature. ${ }^{45}$ The best result was produced using this procedure, but only a small amount of the alkylated product $\mathbf{3 . 2 5}$ was obtained (Scheme 3.9).

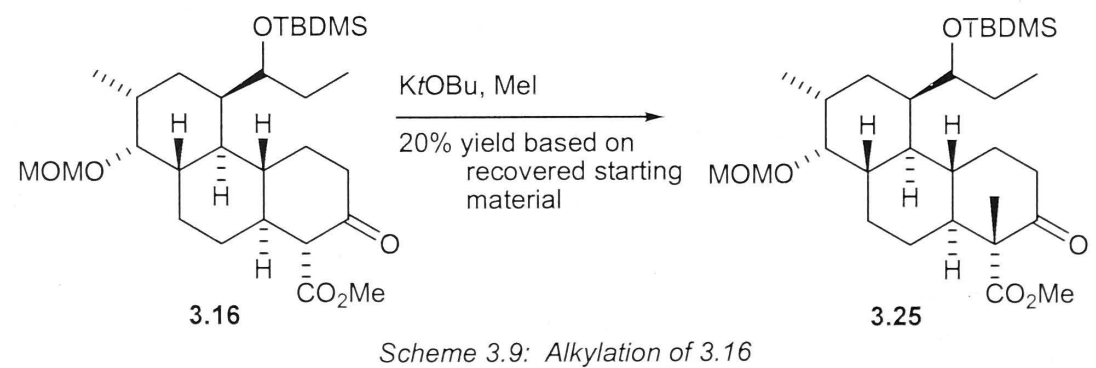

The results for the alkylation of $\mathbf{3 . 1 6}$ were disappointing, especially considering that the alkylation of $\mathbf{3 . 1 7}$ (the regioisomer of $\mathbf{3 . 1 6}$ ) proceeded smoothly on treatment with sodium hydride and iodomethane to afford $\mathbf{3 . 2 6}$ in 65\% yield (Scheme 3.10).

\footnotetext{
- The trans relationship of the two bridgehead protons in the A-ring was later confirmed by X-ray crystallography on the advanced intermediates $\mathbf{1 . 8 7}$ and $\mathbf{5 . 2}$ (Chapter 5).
} 


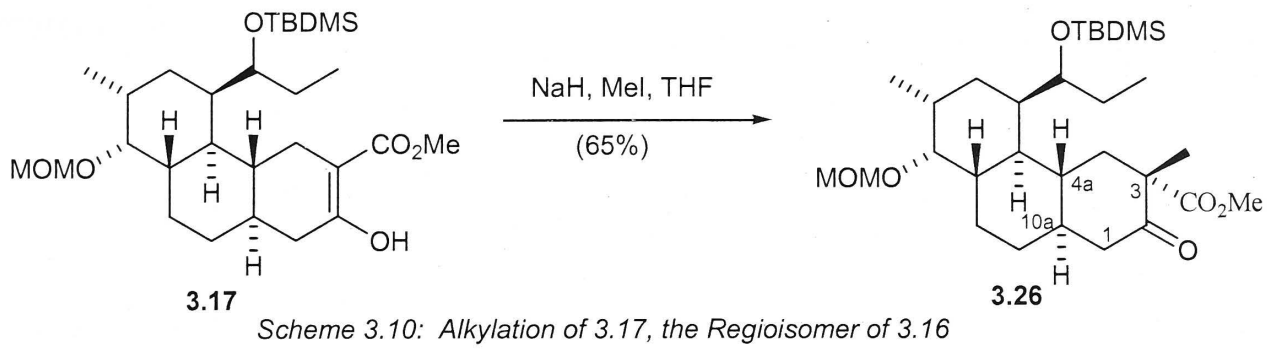

The regiochemistry of acylation and stereochemistry of alkylation leading to $\mathbf{3 . 2 6}$ was determined by two dimensional NMR studies. The ${ }^{1} \mathrm{H}$ NMR spectrum of $\mathbf{3 . 2 6}$ exhibits a multiplet between 2.24-2.35 ppm due to the two protons on $\mathrm{C}-1$ alpha to the carbonyl group. Upfield of this, a multiplet between 2.04-2.13 ppm was observed representing the two protons on $\mathrm{C}-4$ and the proton on C-4a. Analysis of the COSY spectrum showed the $\mathrm{C}-1$ protons were only coupled to themselves and one other proton at C-10a, therefore providing evidence of the observed regiochemistry of 3.26. Accordingly, no relationship was observed between the protons on C-1 and C-4, which we would have expected if we had the other regioisomer (3.25). Analysis of the NOESY spectrum showed a correlation between a C-1 proton (presumably the axial proton) and the methyl group at C-3. An enhancement was also observed between the other proton at C-1 (presumably the equatorial proton) and the proton at C-10a. Furthermore, an enhancement was observed between the methyl group at C-3 and the proton at C-4a. Thus, the axial stereochemistry of the methyl group at C-3 was confirmed (Figure 3.1).

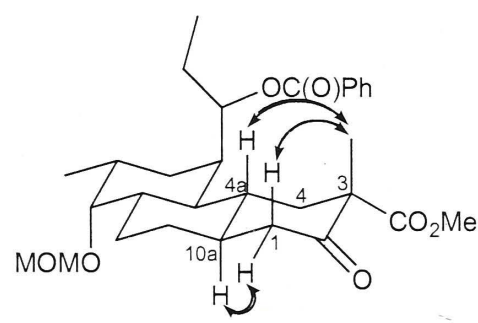

Figure 3.1

In summary, even after optimisation, the reductive acylation reaction provided a poor yield of the $\beta$-keto ester 3.16. Furthermore, progress with the alkylation of $\mathbf{3 . 1 6}$ had not been encouraging thus far. 


\subsection{A New Approach}

The following plan was devised as an alternative to installing the required quaternary centre in the A-ring (Scheme 3.11).
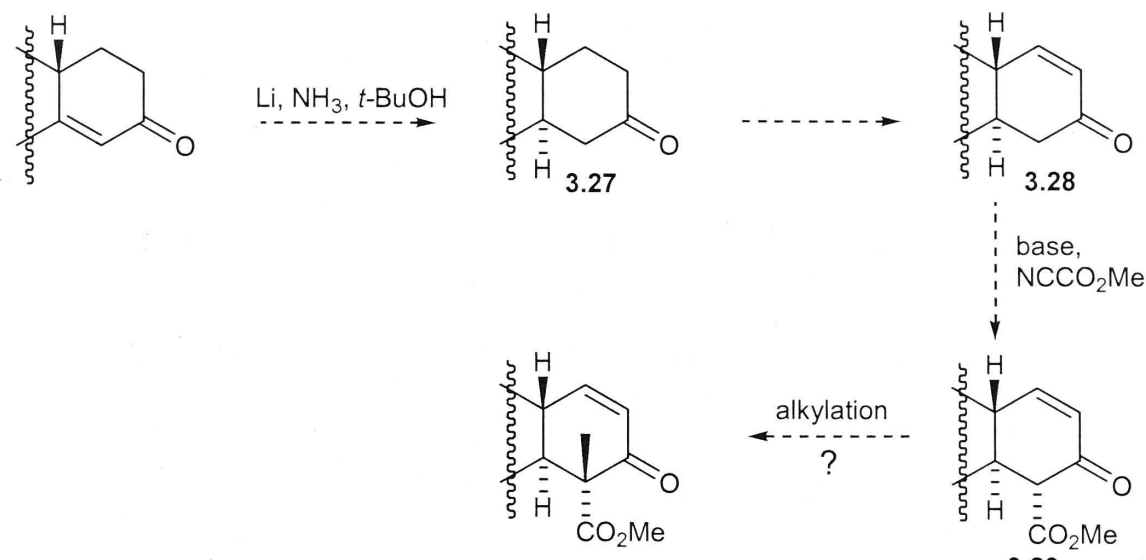

Scheme 3.11: New Strategy

A dissolving metal reduction would result in the saturated product with the A, B transring fusion (3.27). Installing the $\alpha, \beta$-enone $\mathbf{3 . 2 8}$ (which we require at a later stage for the intramolecular Michael reaction, see Chapter 5) would then "mask" C-3, allowing for regioselective acylation to form the $\beta$-keto ester 3.29.

In methodology developed by Mander and Sethi, ${ }^{46}$ a number of $\beta$-keto ester substrates have been prepared regioselectively from the lithium enolates of the parent ketones and methyl cyanoformate. The parent ketones were treated with LDA to form the lithium enolate, then subsequently trapped at $-78{ }^{\circ} \mathrm{C}$ with methyl cyanoformate in the presence of HMPA. An example of the acylation of a steroidal compound, bearing similar structural characteristics to our tricyclic intermediates, is shown below (Scheme 3.12).

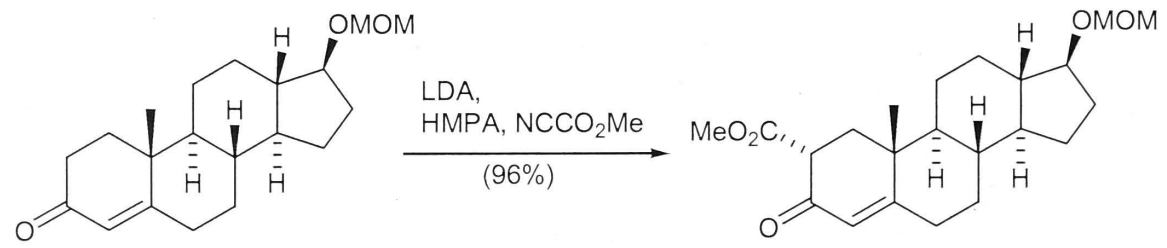

Scheme 3.12: Acylation of a Steroid

In another example, Fraser-Reid and coworkers applied the above procedure to the acylation of $(R)-(-)$-carvone $\mathbf{3 . 3 0}$ to afford ester $\mathbf{3 . 3 1}$ in quantitative yield ${ }^{47}$ (Scheme 3.13). 


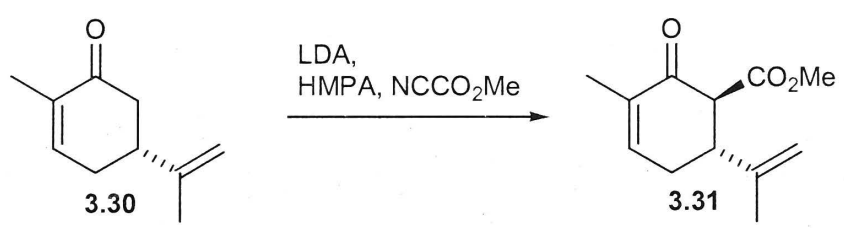

Scheme 3.13: Acylation of (R)-(-)-Carvone

\subsection{Synthesis of Enone 3.34}

In order to install the enone in the required position, we first needed to reduce the enone $\mathbf{3 . 7}$ to set up the A, B trans-ring fusion. To this end, 1,4-reduction of $\mathbf{3 . 7}$ with lithium metal dissolved in ammonia, followed by an aqueous work up, gave the trans-fused product $\mathbf{3 . 1 8}$ in 92\% yield (Scheme 3.14).

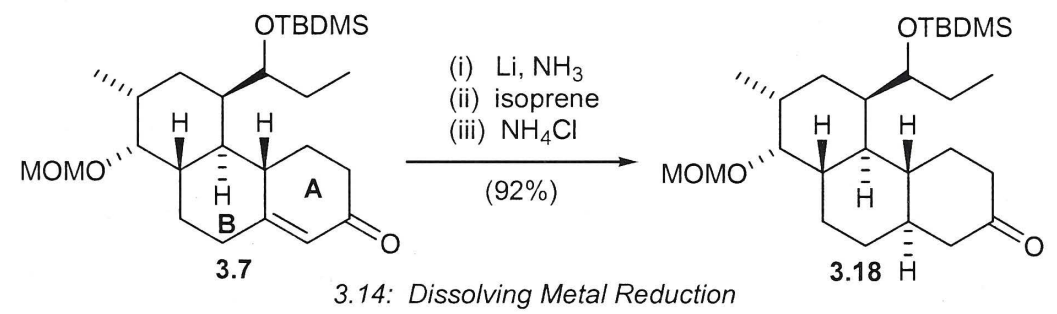

In previous work by Crabtree the introduction of an enone double bond was carried out using selenium based chemistry, but the yields were poor (see Scheme 1.12). ${ }^{24}$ However, a versatile method for the preparation of $\alpha, \beta$-unsaturated carbonyl compounds was reported in 1978 by Saegusa and coworkers. ${ }^{48}$ Saegusa's procedure involves the reaction of silyl enol ethers with palladium (II) acetate in acetonitrile to give regiospecific introduction of an $\alpha, \beta$-carbon-carbon double bond to unsymmetrical ketones. It is believed an oxo- $\pi$-allyl palladium (II) complex (3.32) may be involved (Scheme 3.15).

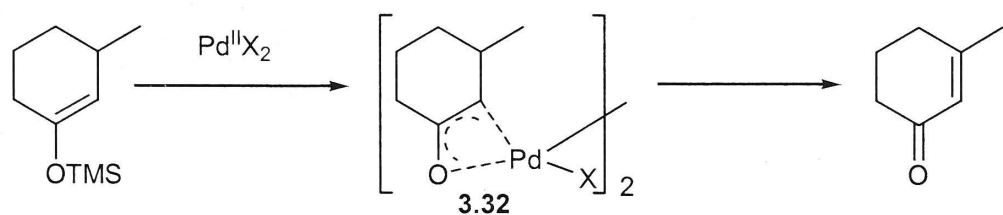

Scheme 3.15: Saegusa Oxidation

It was decided to use the Saegusa oxidation to synthesis enone 3.34. Ketone 3.18 was treated with LDA, and trapping the resulting enolates with $\mathrm{TMSCl}$ gave a $2: 1$ ratio of silyl enol ethers in favour of the required product 3.33. The crude mixture was then treated with palladium (II) acetate in the presence of $p$-benzoquinone in acetonitrile to give an excellent combined yield of the enones $\mathbf{3 . 3 4}$ and $\mathbf{3 . 7}$ (Scheme 3.16). The 
presence of $p$-benzoquinone in the reaction mixture appears to regenerate an active palladium (II) species. ${ }^{48}$

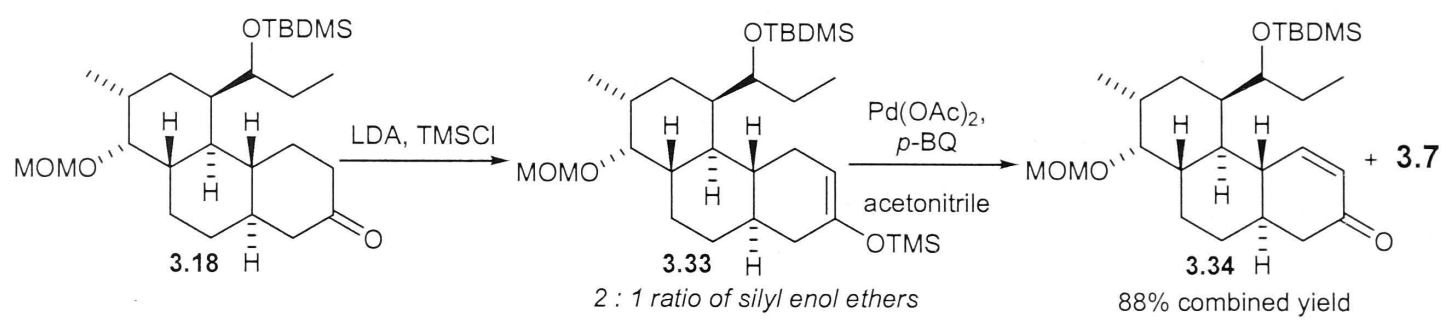

Scheme 3.16: Application of the Saegusa Oxidation

The formation of enone $\mathbf{3 . 7}$ was inconvenient, but this was not an insurmountable problem, since the enone could be easily separated from enone $\mathbf{3 . 3 4}$ and recycled.

\subsection{Regioselective Acylation and Alkylation}

With enone $\mathbf{3 . 3 4}$ in hand, the next step involved regioselective acylation to form the required $\beta$-keto ester 3.35. We were delighted to find that treating the lithium enolate of 3.34 with methyl cyanoformate, in the presence of HMPA at $-78^{\circ} \mathrm{C}$, gave a good yield of $\beta$-keto ester 3.35 with no by-products (Scheme 3.17).

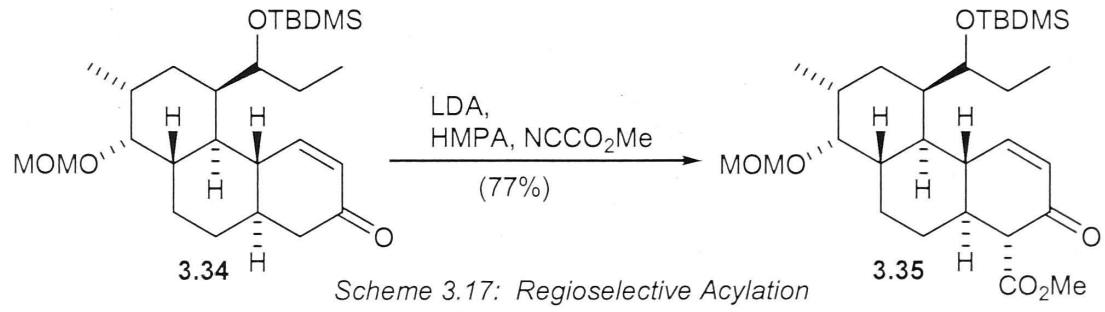

As discussed (Section 3.2.1), the results from alkylation studies of $\beta$-keto ester $\mathbf{3 . 1 6}$ had not been encouraging (Scheme 3.9). Nevertheless, we decided to investigate the alkylation of ester 3.35, which only differs from $\mathbf{3 . 1 6}$ in that it possesses an $\alpha, \beta$-carboncarbon double bond. We were pleased to find that when $\mathbf{3 . 3 5}$ was treated with sodium hydride and iodomethane in THF at room temperature, the methylated product $\mathbf{3 . 3 6}$ was obtained in reasonable yield (Scheme 3.18).

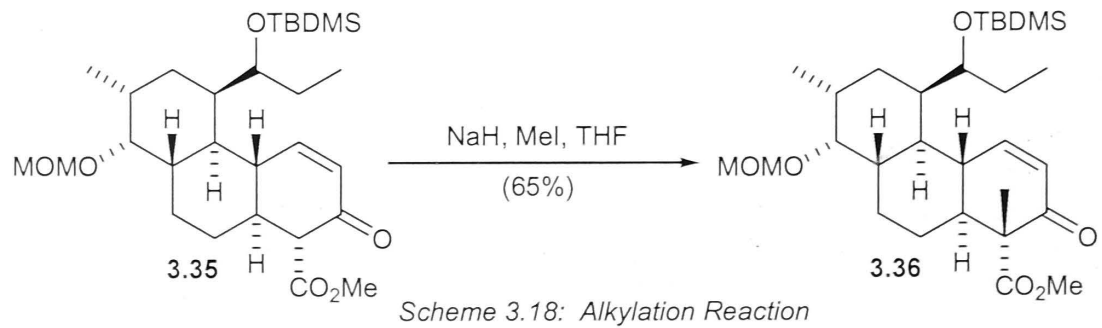


Although we expected the alkylation of $\mathbf{3 . 1 6}$ to occur under stereoelectronic control to give the required axial methyl group for the natural product (Figure 1.6, discussed in Chapter 1), we were unsure how the presence of the carbon-carbon double bond in the six-membered-ring of $\mathbf{3 . 3 5}$ would affect the stereochemical outcome of the alkylation.

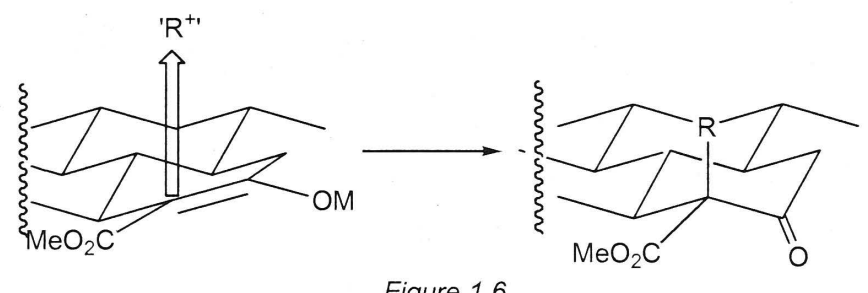

Figure 1.6

In order to confirm the stereochemistry at C-1, the product $\mathbf{3 . 3 6}$ was subjected to one dimensional nuclear Overhauser enhancement (nOe) NMR experiments. An nOe enhancement was observed between the methyl group at C-1 and the proton at C-4a. This observation is only possible if the methyl group is axial ${ }^{*}$ (Figure 3.1).

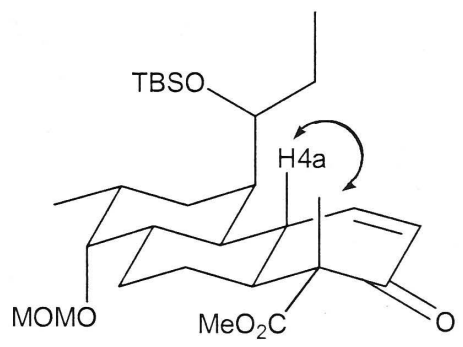

Figure 3.1

Thus, elaboration of the A-ring was successfully achieved (compound 3.36), with the stereochemistry at six centres correct.

\footnotetext{
* The stereochemistry of $\mathbf{3 . 3 6}$ was further confirmed by X-ray crystallography on the advanced intermediate 5.2, Chapter 5.
} 
Chapter 3 


\section{CHAPTER 4}

\section{Elaboration of the D-ring and a Cohesive Synthesis}
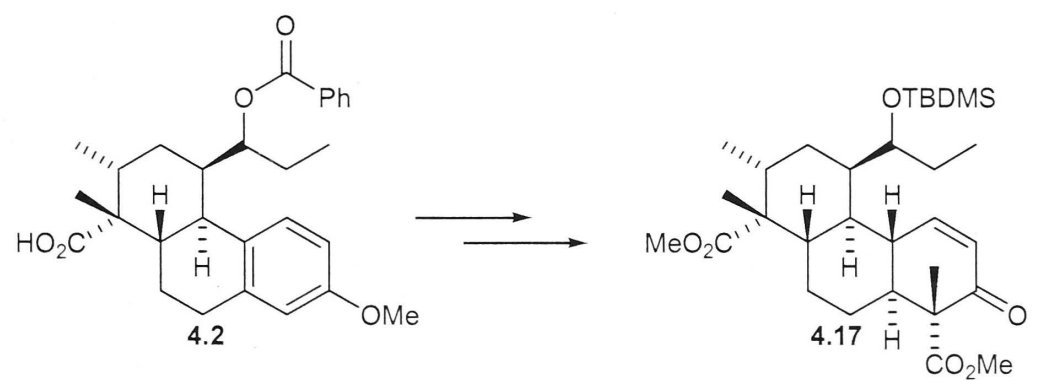
Chapter 4 


\section{Elaboration of the D-ring and a Cohesive Synthesis}

The first part of this chapter will discuss an improved synthesis of aldehyde 1.98, including an alternative method for cyclopropanation. The second and third parts with cover the Birch reduction of the A-ring, and a successful synthesis of an intermediate (4.17) bearing both quaternary centres with the correct stereochemistry at $C-1$ (C-7 in the natural product) and C-8 (C-20 in the natural product).

\subsection{Improved Synthesis of Aldehyde 1.98}

As discussed (Section 1.5.2), aldehyde 1.98 with the required equatorial methyl group for the quaternary centre at $\mathrm{C}-1$ (equivalent to $\mathrm{C}-20$ in the natural product) in the $\mathrm{D}$-ring was previously synthesised (Scheme 1.18).`

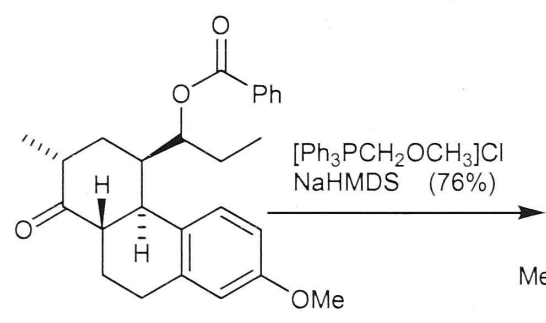

1.95

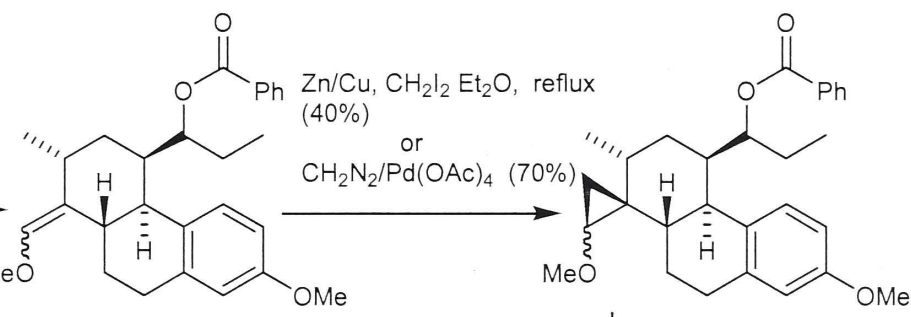

1.96

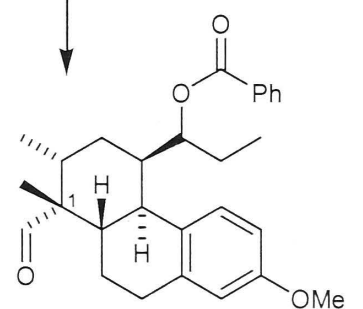

1.98

The synthesis of $\mathbf{1 . 9 8}$ was achieved by employing an acid-catalysed-ring-opening reaction of a cyclopropyl precursor, ${ }^{32}$ which was obtained by a Simmons-Smith reaction. $^{30}$ A problem with this sequence was the low yielding Simmons-Smith reaction, which even after long reaction times would not go to completion. The Simmons-Smith reaction as initially carried out gave only $40 \%$ of the desired methoxy cyclopropane 1.99. Under the initial conditions the zinc/copper couple from zinc dust and cuprous chloride was heated under reflux, then treated with methylene iodide to form the iodomethylzinc reagent. ${ }^{49}$ The method developed by Furukawa and coworkers $^{50,51}$, whereby diethyl zinc is treated with methylene iodide to generate the iodomethylzinc reagent was also attempted, but was unsuccessful. We had also formed the methoxy cyclopropane 1.99 by treatment of the enol ether 1.96 with diazomethane

- This Scheme is repeated from Chapter 1. 
and a catalytic amount of palladium acetate. ${ }^{52}$ However, while the yield of this reaction was a vast improvement (70\%) on previous attempts, a large excess of diazomethane was needed, and even then the reaction still could not be forced to completion. Given the poor yield of the Simmons-Smith reaction we decided to investigate alternative reagents.

In a recent publication by Yang, Lorenz and $\mathrm{Shi}^{53}$ a new reactive species for cyclopropanation was reported. The iodomethylzinc reagent 4.1 was generated by the reaction of diethyl zinc with trifluoroacetic acid, followed by treatment of the resulting species with methylene iodide (Scheme 4.1).

$$
\mathrm{Et}_{2} \mathrm{Zn}+\mathrm{CF}_{3} \mathrm{CO}_{2} \mathrm{H} \longrightarrow \mathrm{EtH}+\mathrm{CF}_{3} \mathrm{CO}_{2} \mathrm{ZnEt} \stackrel{\mathrm{CH}_{2} \mathrm{I}_{2}}{\longrightarrow} \underset{4.1}{\mathrm{CF}_{3} \mathrm{CO}_{2} \mathrm{ZnCH}_{2} \mathrm{I}}+\mathrm{Etl}
$$

Scheme 4.1: Formation of Reactive lodomethylzinc Reagent

The reaction sequence to form the iodomethylzinc reagent 4.1 is carried out at $0{ }^{\circ} \mathrm{C}$ using DCM as the solvent, and the olefin is added directly to the reagent. The authors reported that the reaction is completed within 30 minutes at room temperature on a variety of olefin substrates.

When the above discussed cyclopropanation conditions were applied to the enol ether 1.96, the reaction proceeded to completion within one hour at room temperature, affording the desired methoxy cyclopropane $\mathbf{1 . 9 9}$ in $80 \%$ yield after purification. However, a better result was achieved if purification was left to a later stage in the synthesis. To this end, the crude cyclopropane $\mathbf{1 . 9 9}$ was treated with hydrochloric acid to obtain the aldehyde $\mathbf{1 . 9 8}$, followed by oxidation with sodium chlorite ${ }^{54}$ to give the carboxylic acid $\mathbf{4 . 2}$ in $80 \%$ yield over the three steps (Scheme 4.2). 
<smiles>CCC(OC(=O)c1ccccc1)[C@H]1C[C@H](C)/C(=C/OC)[C@H]2CCc3cc(OC)ccc3[C@@H]21</smiles>

1.96

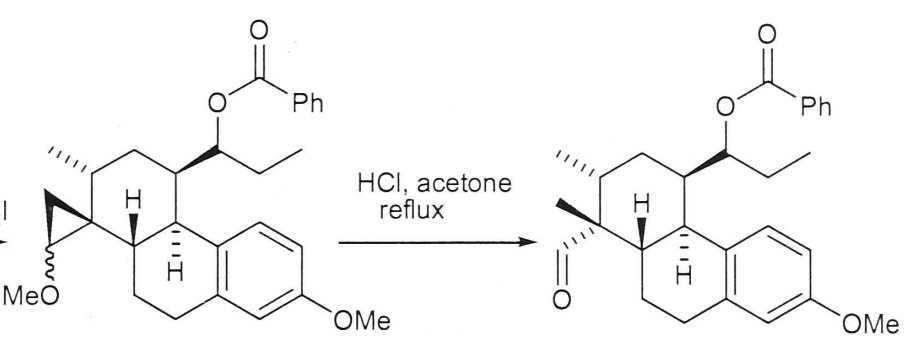

1.99

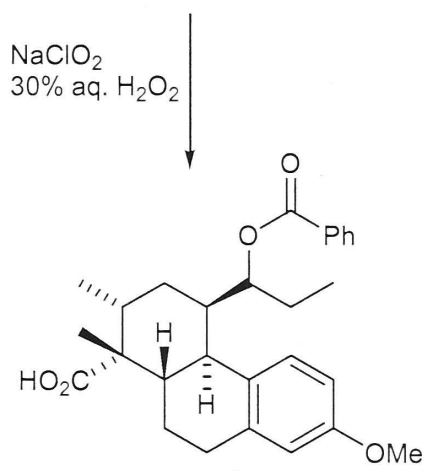

4.2

Scheme 4.2: Improved Cyclopropanation and Synthesis of Carboxylic Acid $4.2 \quad 80 \%$ over 3 steps

The problems that we had previously encountered with the Simmons-Smith reaction were therefore overcome. An alternative reagent for the cyclopropanation reaction was found that can be used to produce large quantities of carboxylic acid $\mathbf{4 . 2}$.

\subsection{Birch Reduction of the A-ring}

The Birch reduction discussed in Chapter 3 was carried out on an intermediate $\mathbf{3 . 4}$ with a TBDMS ether in place of the initial benzoate protecting group (Scheme 4.3).

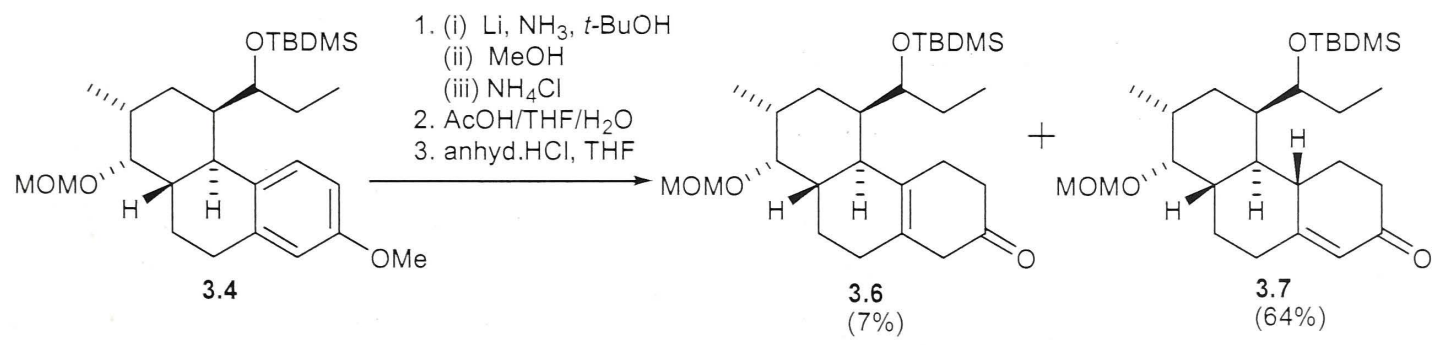

Scheme 4.3: Birch Reduction of 3.4

To replace the benzoate group of $\mathbf{4 . 2}$ with a TBDMS protecting group, the protection of the carboxylic acid group as the TBDMS ester is inevitable. The consequence of carrying out a Birch reduction in the presence of an ester group is that they are readily reduced under the reaction conditions, thus resulting in a cycle of changing oxidation states at the quaternary centre in the D-ring. We considered the possibility of carrying out the unavoidable bis-protection followed by a hydrolysis reaction to remove the 
TBDMS ester, but this would result in an additional step to our sequence. Thus, we decided to attempt the Birch reduction on the benzoate 4.2, in order to avoid the extra steps associated with changing the protecting group. The Birch reduction was carried out using lithium metal in ammonia, and $t$-butyl alcohol as the proton source (as discussed in Chapter 3.1), with the expectation that the benzoate protecting group would be lost in this reaction to give alcohol 4.3 (Scheme 4.4). Unfortunately, alcohol 4.3 was not obtained, but a small amount of a compound in which it appeared that the aromatic ring of the benzoate group had been reduced as well as the A-ring.

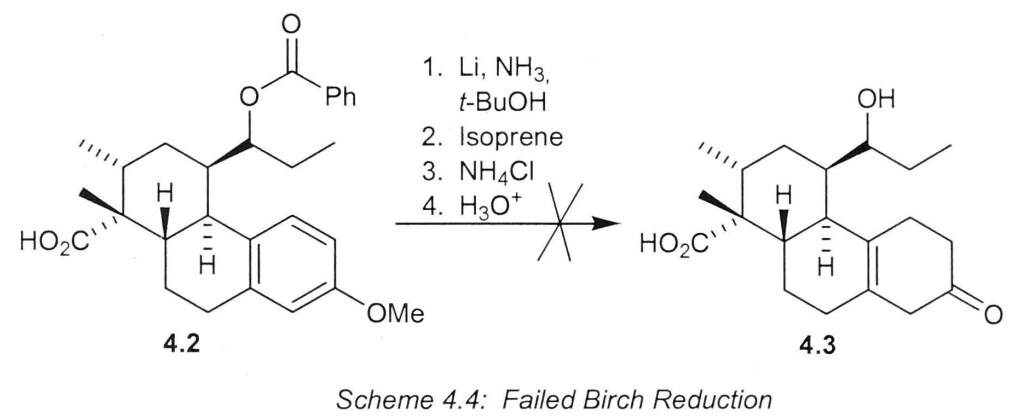

We also attempted the Birch reduction on the free alcohol 4.4. Thus, treatment of $\mathbf{4 . 2}$ with sodium ethoxide in ethanol gave alcohol 4.4 in good yield. The alcohol 4.4 was then subjected to Birch conditions, but rather than obtaining the expected $\beta, \gamma$-enone, compound $\mathbf{4 . 5}$ was obtained in poor yield (Scheme 4.5). It was believed that this product formed via indiscriminate internal protonation from the free alcohol function.

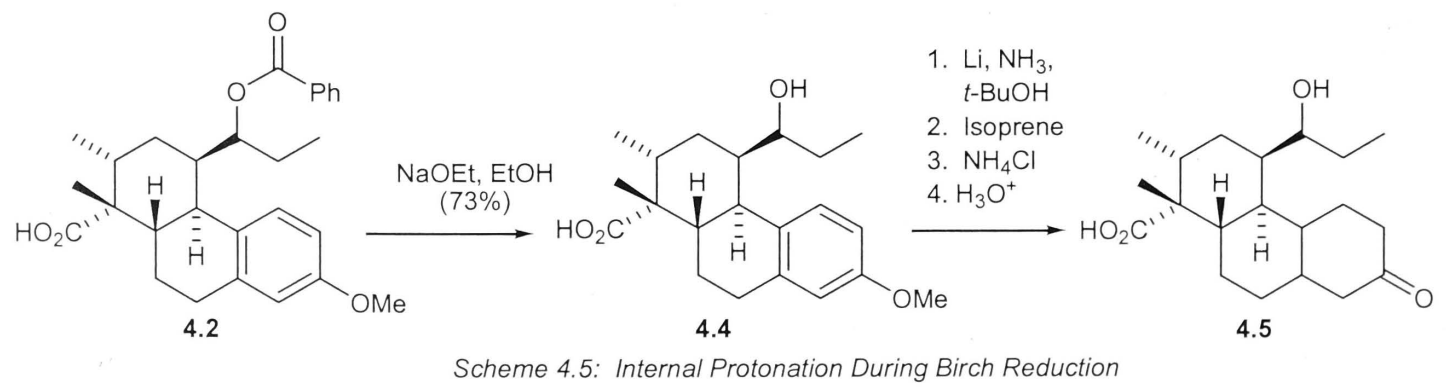

Given the lack of success thus far, we decided to protect the alcohol $\mathbf{4 . 4}$ as the TBDMS ether. Treatment of alcohol 4.4 with TBDMSOTf and 2,6-lutidine gave the bisprotected product $\mathbf{4 . 6}$ as expected. Fortunately, the selective hydrolysis of $\mathbf{4 . 6}$ proceeded smoothly on treatment with potassium carbonate in aqueous methanol to obtain a good yield of the TBDMS ether $\mathbf{4 . 7}$ over the two steps (Scheme 4.6). 


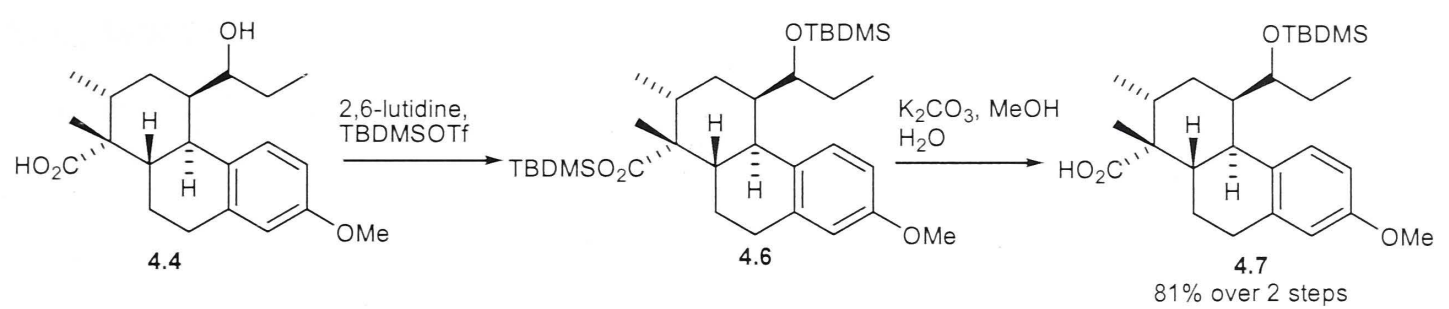

Scheme 4.6: Silyl Ether Formation

The aromatic moiety in $\mathbf{4 . 7}$ underwent Birch reduction on treatment with lithium in ammonia and $t$-butyl alcohol at $-40^{\circ} \mathrm{C}$ for 3 hours. The initially formed dihydroanisole product was treated with a solution of acetic acid, THF and water $(4: 2: 1)$ to obtain the $\beta, \gamma$-enone 4.8, which could be converted on treatment with hydrogen chloride gas to a 1 : 1 mixture of $\mathbf{4 . 8}$ and the $\alpha, \beta$-enone 4.9 in good yield. The two enone products were easily separated and 4.8 converted to additional $\alpha, \beta$-enone 4.9 (Scheme 4.7).

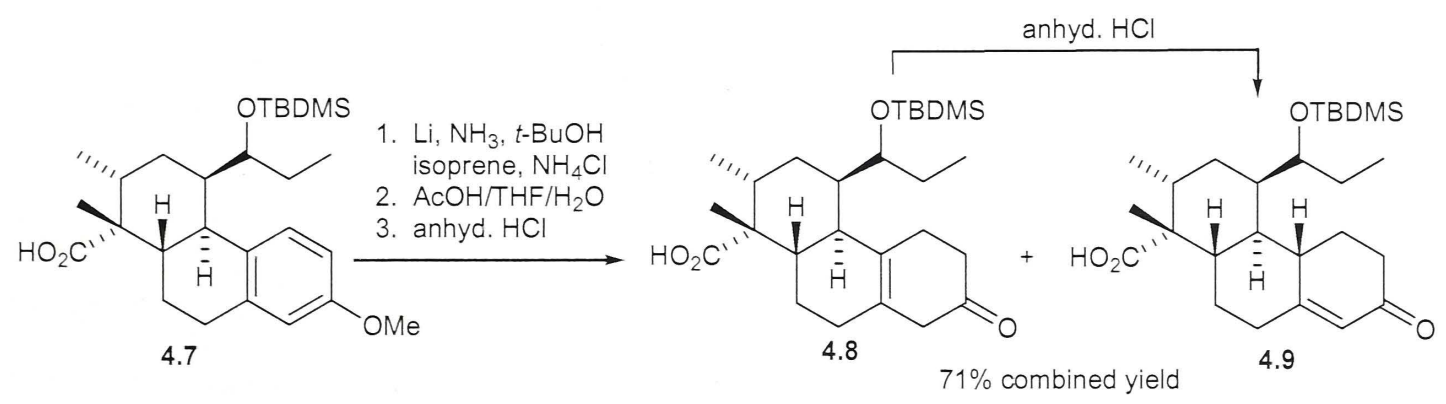

Scheme 4.7: Birch Reduction of 4.7

\subsection{Elaboration of the A-ring}

\subsubsection{Synthesis of Enone 4.12}

The methodology outlined in Chapter 3 (Section 3.3) was now applied to enone 4.9 so as to install the required enone functionality and quaternary centre in the A-ring. To this end, the enone 4.9 was subjected to 1,4-reduction with dissolved lithium metal in ammonia, followed by methylation of the carboxylic acid with diazomethane to give the trans-fused product 4.10. The alcohol 4.11 was also obtained, but was easily oxidised with DMP to give ketone 4.10 (Scheme 4.8). 


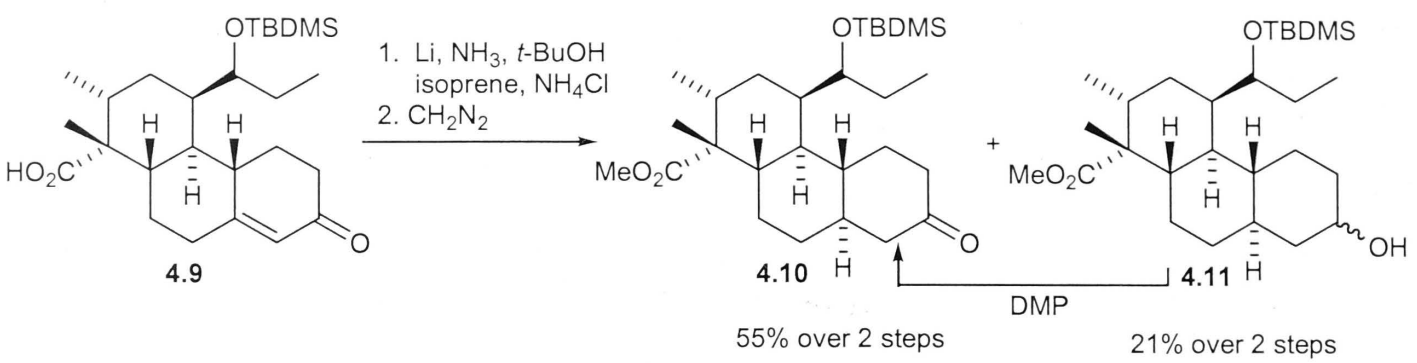

Scheme 4.8: Dissolving Metal Reduction of 4.9

The next step required the Saegusa oxidation of $\mathbf{4 . 1 0}$ to furnish enone 4.12. Previously, for the conversion of ketone $\mathbf{3 . 1 8}$ to enone $\mathbf{3 . 3 4}$ (Scheme 3.16) the silyl enol ether intermediates were synthesised in a 2:1 ratio in favour of the intermediate leading to the required enone 3.34. Although enone $\mathbf{3 . 7}$ was also formed in this process (derived from the minor silyl enol ether intermediate), it could be easily recycled to form more of the required enone $\mathbf{3 . 3 4}$.

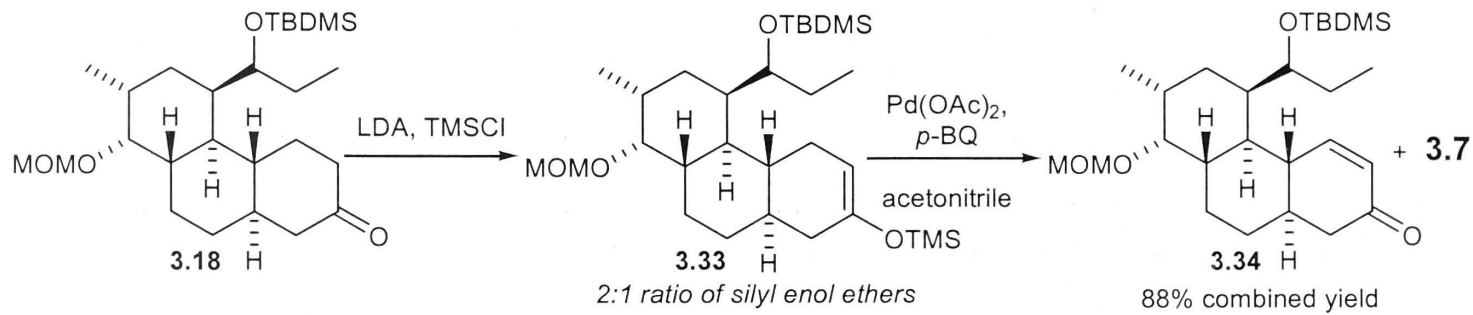
Scheme 3.16: Application of the Saegusa Oxidation

In the case of ketone $\mathbf{4 . 1 0}$, in order to recycle the unwanted enone (4.9a) formed after the Saegusa oxidation, the methyl ester group would initially need to be hydrolysed before the dissolving metal reduction, only to be re-esterified in the following step (Scheme 4.9).
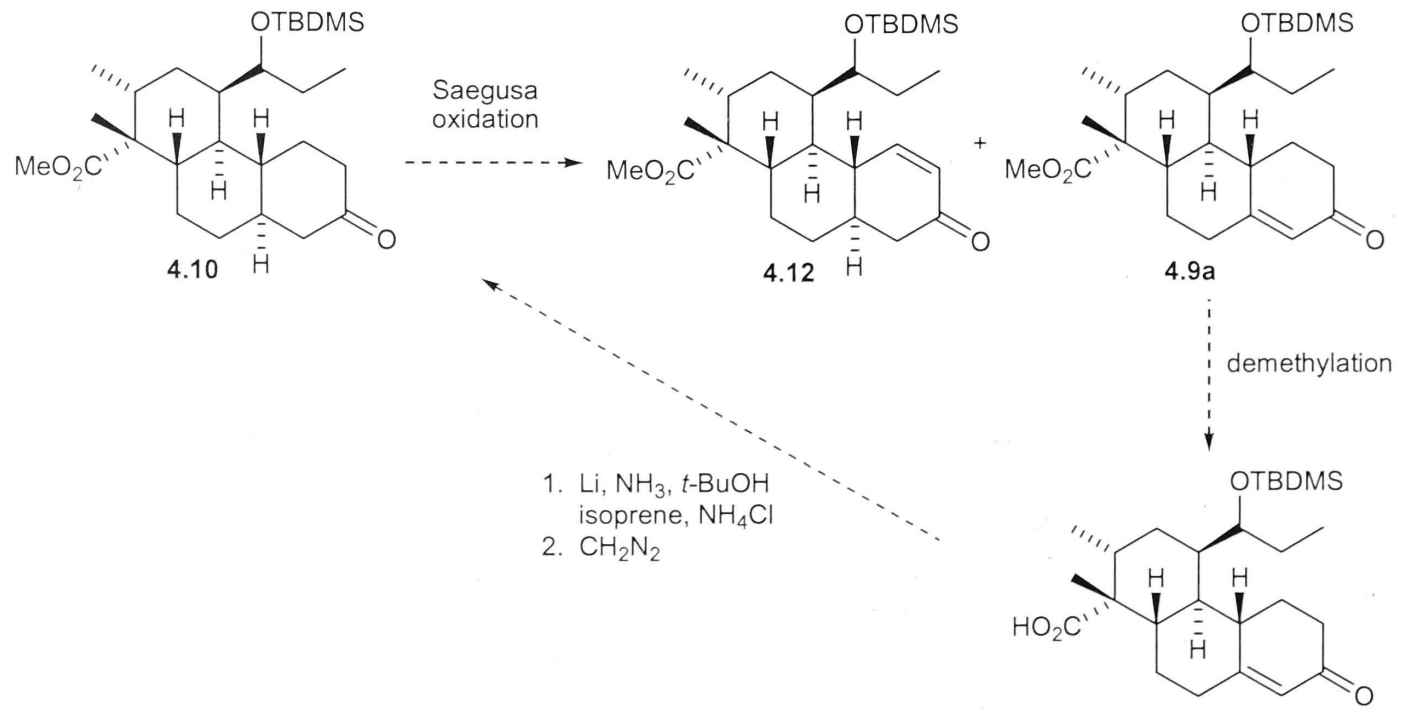
Thus, our attention was focused on finding conditions to improve the ratio of silyl enol ether intermediates. The results from our studies are summarised in Table 4.1.

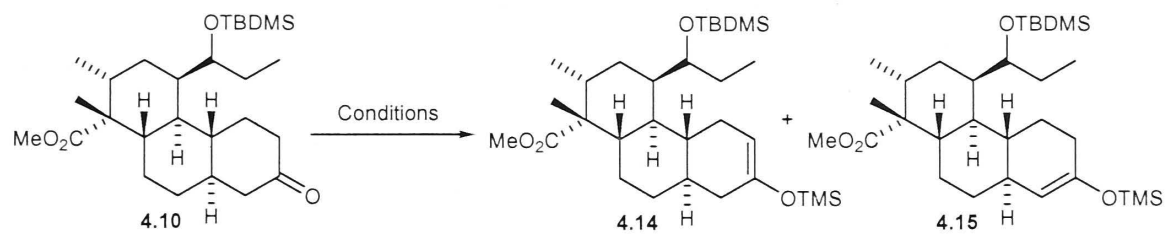

\begin{tabular}{|c|c|c|}
\hline Base & Silylating Reagent & Ratio $\mathbf{4 . 1 4}: \mathbf{4 . 1 5}$ \\
\hline LDA & TMSCl & $2: 1$ \\
\hline LiTMP & TMSCl & $2: 1$ \\
\hline LICA & TMSCl & $5: 1$ \\
\hline Triethylamine & TMSOTf & $20: 1$ \\
\hline 2,6 - Lutidine & TMSOTf & \multicolumn{2}{|c|}{} \\
\hline
\end{tabular}

Table 4.1: Silylation Studies

Table 4.1 shows that forming the enolate of $\mathbf{4 . 1 0}$ with LDA gives a $2: 1$ ratio of silyl enol ethers. It is well known that highly hindered bases, such as LDA, favour the formation of the kinetic, less substituted silyl enol ether. ${ }^{55}$ Therefore, it was hypothesised that the use of even bulkier bases would increase this ratio. Acting on this hypothesis LDA was substituted by the bulkier bases lithium tetramethyl piperidine (LiTMP) and lithium isopropylcyclohexyl amide (LICA), respectively. In both cases a ratio of $2: 1$ was observed. Better ratios of $4.14: 4.15$ were observed when TMSOTf was used as the silylating reagent. Thus, ketone 4.10 was treated with triethylamine and TMSOTf to give a $5: 1$ ratio of the silyl enol ethers. We were pleased, however, to find that using 2,6-lutidine as the base increased the ratio to $20: 1$ in favour of the required silyl enol ether $\mathbf{4 . 1 4}$.

The crude mixture of $\mathbf{4 . 1 4}$ and $\mathbf{4 . 1 5}$ obtained thus was then treated with palladium (II) acetate in the presence of $p$-benzoquinone to give a good yield of enone 4.12 , and a small amount of enone 4.9a (Scheme 4.10). 


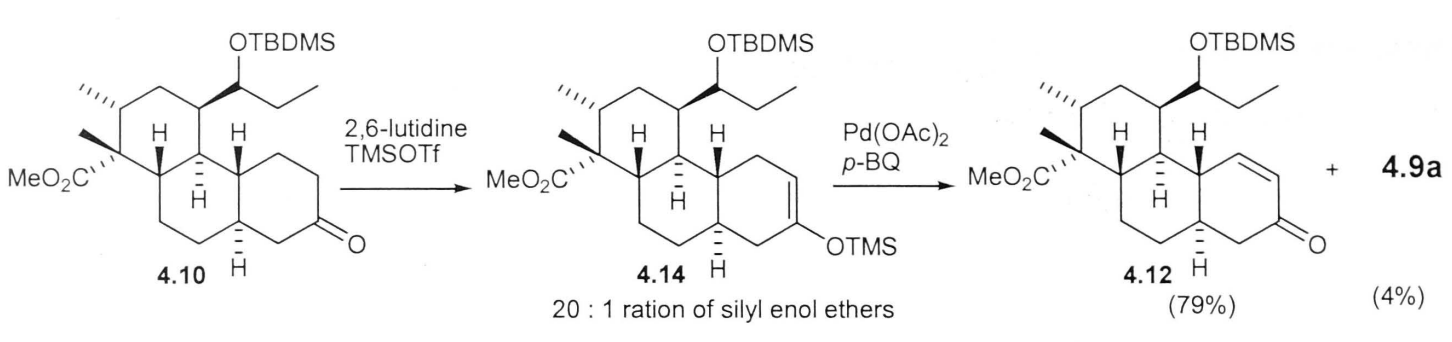

Scheme 4.10: Saegusa Oxidation of 4.10

\subsubsection{Regioselective Acylation and Alkylation}

The acylation reaction of enone $\mathbf{4 . 1 2}$ was carried out as described in chapter 3 (Section 3.3.2). Thus, the lithium enolate of $\mathbf{4} .12$ was treated with methyl cyanoformate, in the presence of HMPA at $-78{ }^{\circ} \mathrm{C}$ to give the $\beta$-keto ester 4.16 in $83 \%$ yield. The $\beta$-keto ester 4.16 was then treated with sodium hydride and iodomethane to obtain the methylated product $\mathbf{4 . 1 7}$, possessing the required axial methyl group* (Scheme 4.11).

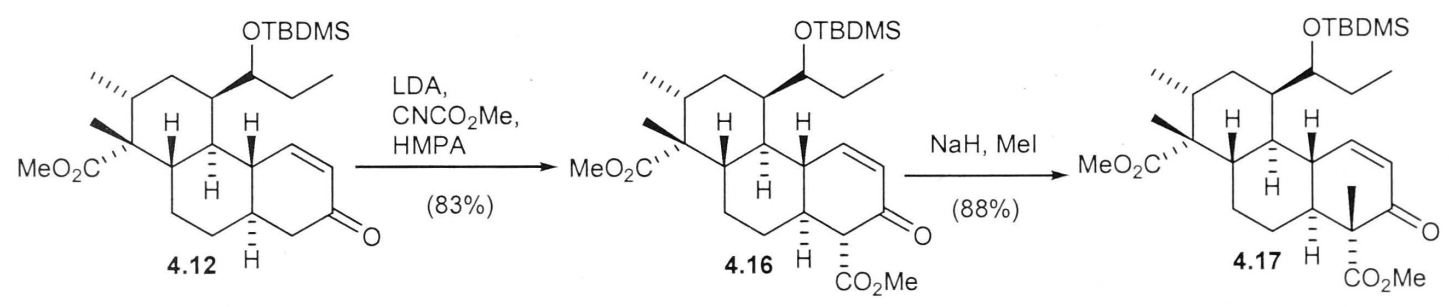

Scheme 4.11: Regioselective Acylation and Alkylation to Form 4.17

We were pleased to find that the acylation of $\mathbf{4 . 1 2}$ and the alkylation of $\mathbf{4 . 1 6}$ proceeded in higher yields than that of their respective models $\mathbf{3 . 3 4}$ and $\mathbf{3 . 3 5}$ (Section 3.3.2).

\footnotetext{
* The stereochemistry was confirmed later by X-ray crystallography of the advanced intermediate 1.87; Chapter 5 .
} 
The $300 \mathrm{MHz}{ }^{1} \mathrm{H}$ NMR spectrum obtained for the diester 4.17 is shown in Figure 4.1.
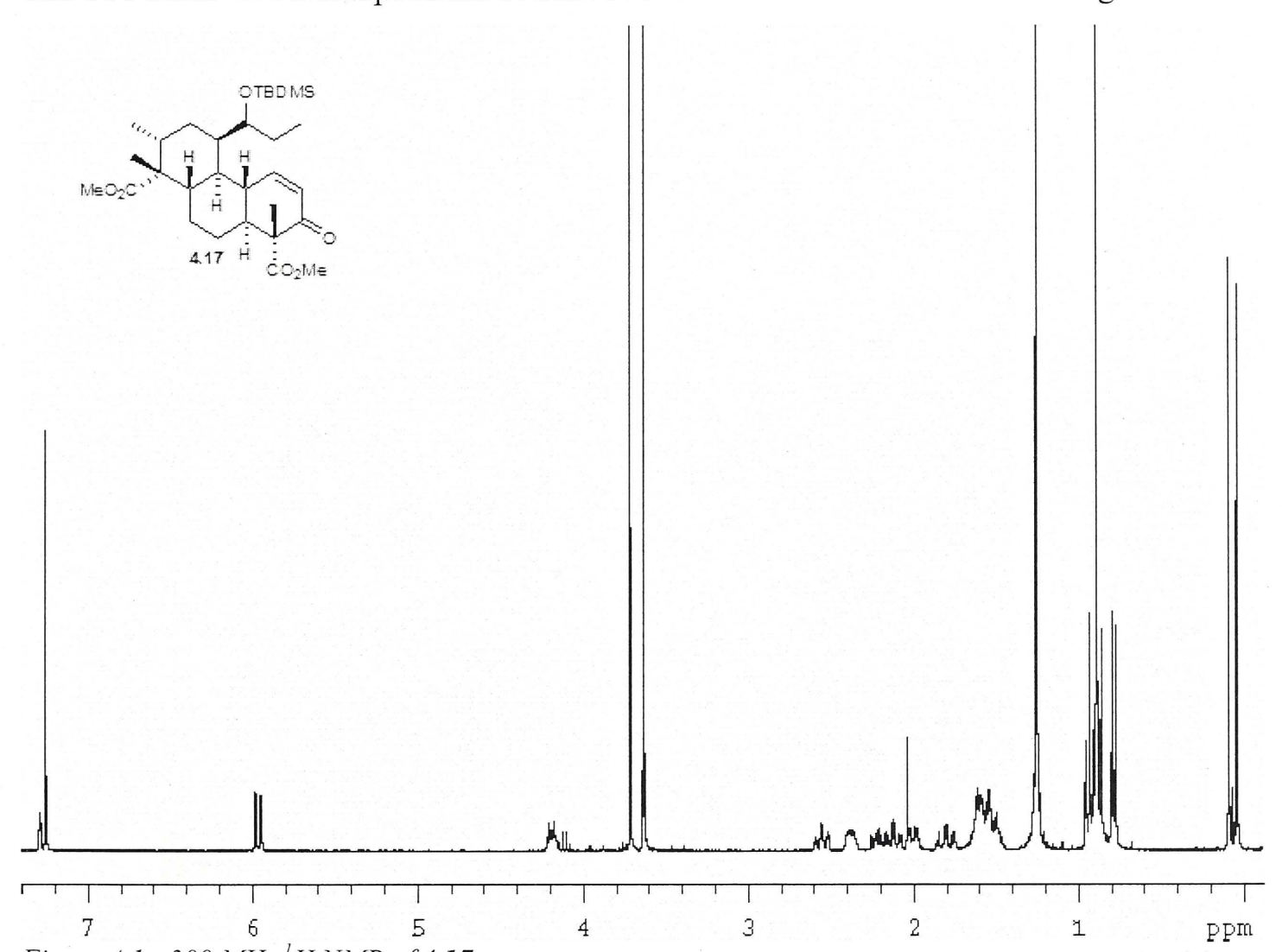

Figure 4.1: $300 \mathrm{MHz}^{1} \mathrm{H}$ NMR of 4.17

Assignment of the characteristic peaks shown in Figure 4.1 are as follows: the two methyl groups at the quaternary centres occur as singlets at the same chemical shift, $1.26 \mathrm{ppm}$; the two ester groups at the quaternary centres in the D-ring and the A-ring occur as singlets at $3.64 \mathrm{ppm}$ and $3.72 \mathrm{ppm}$ respectively; the carbon-carbon double bond protons occur as two doublet of doublets at $5.96 \mathrm{ppm}$ and $7.28 \mathrm{ppm}$.

Thus, we had achieved the synthesis of intermediate 4.17 with the correct stereochemistry at seven centres, including both the quaternary centres in the A and the D-rings. 
Chapter 4 


\section{CHAPTER 5}

\section{Intramolecular Michael Addition Reaction}

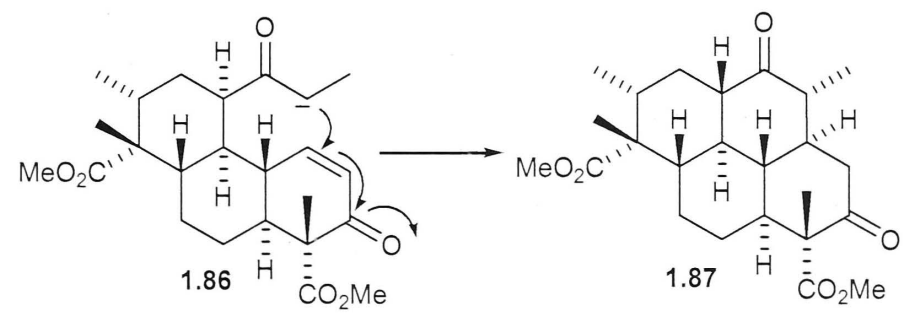


Chapter 5 


\section{Intramolecular Michael Addition Reaction}

This chapter will cover the difficulties encountered with the intramolecular Michael reaction, and the successful synthesis of a tetracyclic precursor (1.87) to diisocyanoadociane (1.10).

\subsection{Introduction}

As discussed in Chapter 1, it was envisaged that the tetracyclic skeleton 1.87 of the natural product (1.10) could be obtained by an intramolecular Michael reaction on an all trans-fused tricyclic enone intermediate 1.86. As this reaction is reversible, the thermodynamically most stable trans-fused product would be expected (Scheme 5.1).

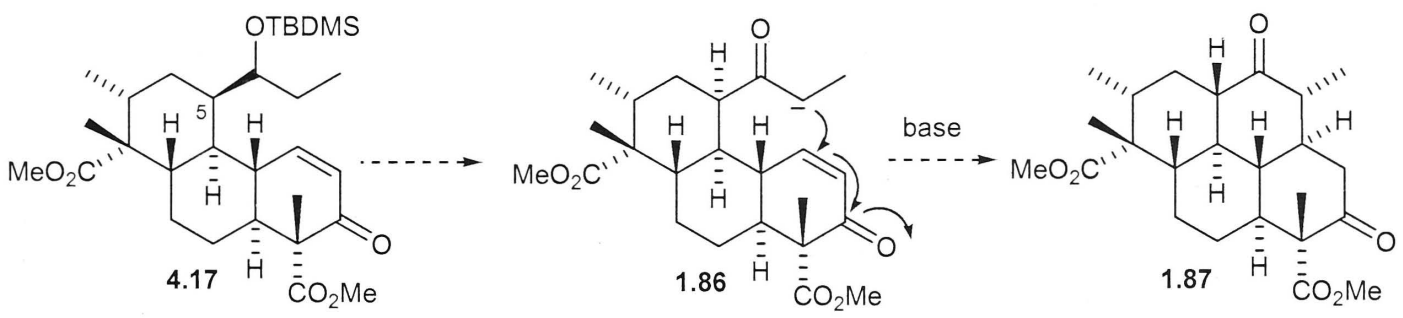

Scheme 5.1: Proposed Michael Reaction

We knew from previous work ${ }^{30}$ that the centre at $\mathrm{C}-5$ bearing the side chain has the incorrect stereochemistry for the Michael reaction to occur giving the all trans-fused tetracycle. However, it was believed that due to the presence of base, epimerisation of C-5 would readily occur and the Michael addition would follow. ${ }^{*}$

We decided to test the methodology on compound $\mathbf{3 . 3 6}$, which should be an ideal model for ester 4.17 (Scheme 5.2).

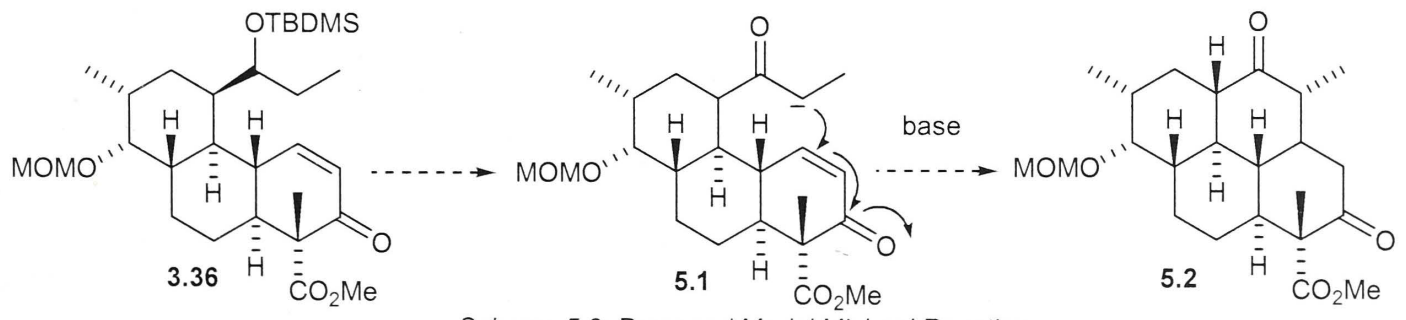

Scheme 5.2: Proposed Model Michael Reaction

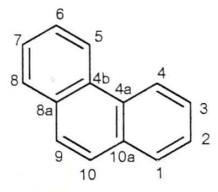

phenanthrene

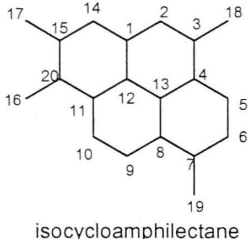

isocycloamphilectane
}

* Thus far numbering of the tricyclic derivatives has been based on phenanthrene. The tetracyclic structures that follow in Chapter 5 and 6 are numbered according to the isocycloamphilectane skeleton. 


\subsection{Model Studies towards the Intramolecular Michael Addition}

\subsubsection{Formation of Dione 5.1}

In order to complete the synthesis of dione 5.1, the removal of the TBDMS protecting group was required, followed by the oxidation of the resulting hydroxyl function to the ketone group. Removal of the TBDMS protecting group in the presence of the enone function, however, was not possible. For example, when ester $\mathbf{3 . 3 5}$ was treated with TBAF a mixture was produced, the major product isolated being the tetracyclic ether 5.3 (Scheme 5.3).

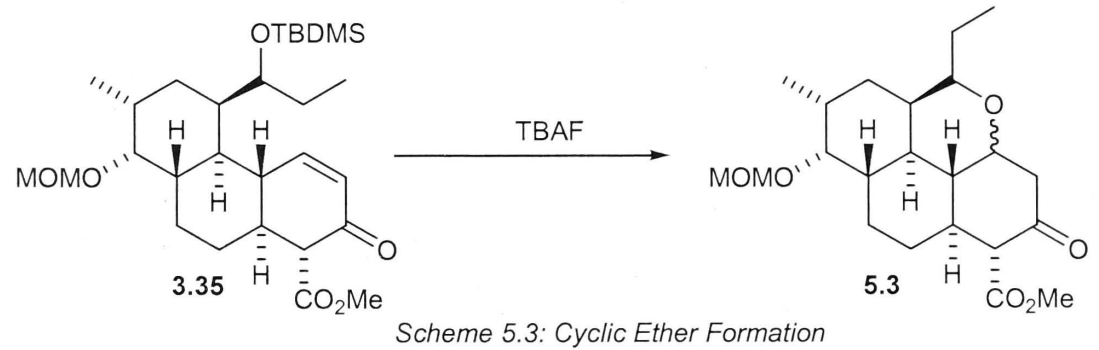

Thus, the enone function needed to be "deactivated" before removal of the TBDMS protecting group. To this end, reduction of enone $\mathbf{3 . 3 6}$ under Luche conditions ${ }^{56}$ resulted in formation of epimeric allylic alcohols $\mathbf{5 . 4}$ in 91\% yield (Scheme 5.4).

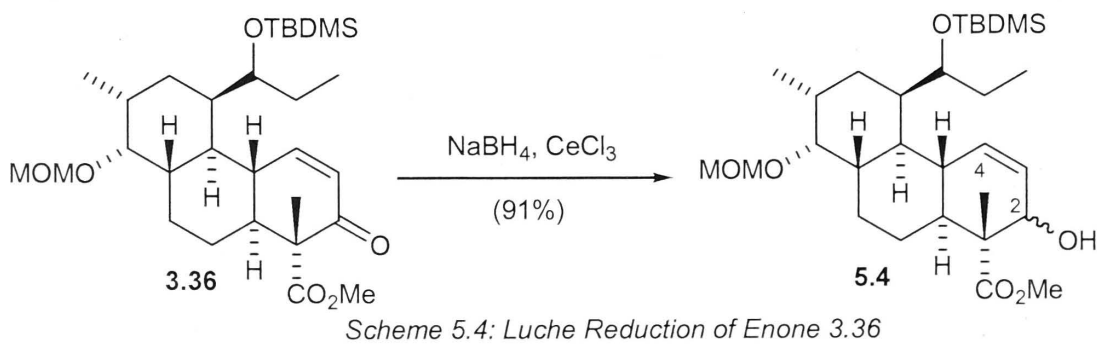

The reduction of $\mathbf{3 . 3 6}$ was characterised by a significant up field shift in the double bond proton at C-4 in the ${ }^{1} \mathrm{H}$ NMR spectrum, from $7.18 \mathrm{ppm}$ to $5.96 \mathrm{ppm}$. Furthermore, a new peak was observed as a multiplet at $4.73 \mathrm{ppm}$ due to the proton at C-2.

Allylic alcohol 5.4 was treated with $\mathrm{TBAF}$ at $65^{\circ} \mathrm{C}$ in the presence of $4 \AA$ powdered molecular sieves to obtain the diol $\mathbf{5 . 5}$ in good yield (Scheme 5.5). Although deprotection could be conducted at room temperature, the reaction was very slow. 


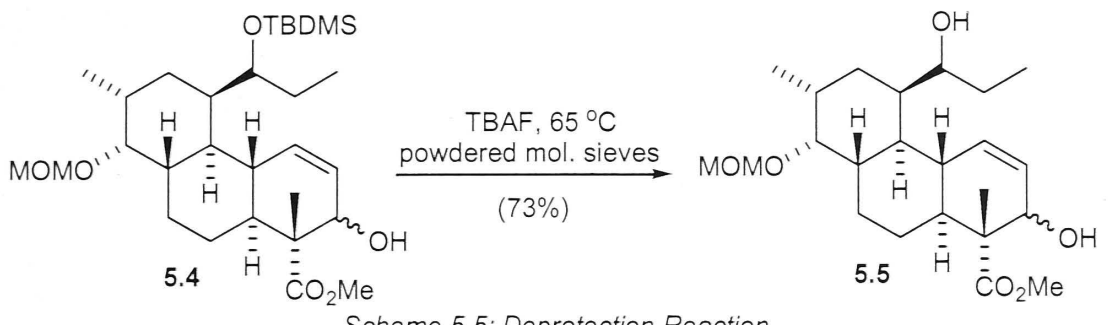

All that remained in order to complete the synthesis of $\mathbf{5 . 1}$ was the oxidation of the hydroxyl groups. Thus, treatment of diol $\mathbf{5 . 5}$ with an excess of DMP gave the required dione $\mathbf{5 . 1}$ in $81 \%$ yield (Scheme 5.6).

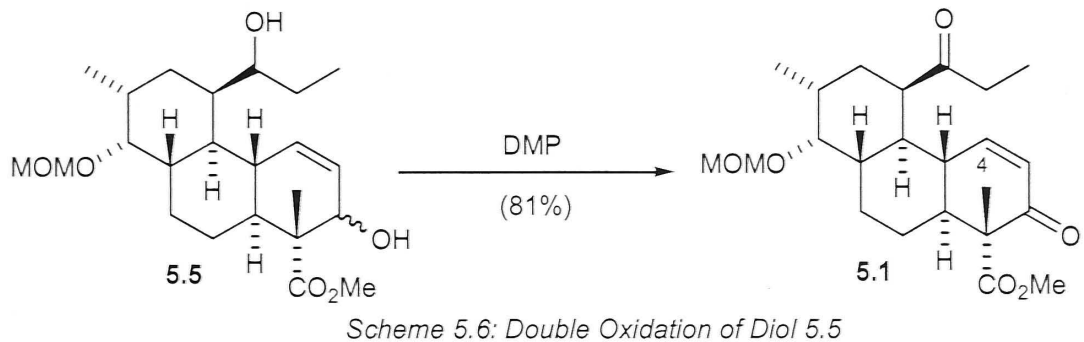

The formation of the dione $\mathbf{5 . 1}$ was evident by two new carbonyl peaks in the ${ }^{13} \mathrm{C}$ NMR spectrum at $198.9 \mathrm{ppm}$ and $213.6 \mathrm{ppm}$, as well as the shift of $\mathrm{H}-4$ to $6.85 \mathrm{ppm}$.

\subsubsection{Intramolecular Michael Reaction}

The intramolecular Michael reaction of compound $\mathbf{5 . 1}$ proved problematic. Initially we utilised Crabtree's conditions, i.e. potassium carbonate in methanol (see Chapter 1, Section 1.5.1), but no reaction occurred. The reaction was also attempted under reflux, but only starting material was recovered. The reaction was then attempted under the range of reaction conditions summarised in Table 5.1 below.

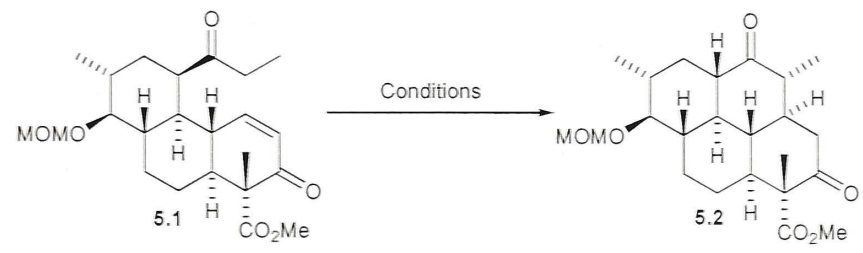

\begin{tabular}{|l|l|l|}
\hline Conditions & Time & Result \\
\hline $\mathrm{K}_{2} \mathrm{CO}_{3} / \mathrm{MeOH}$ r.t and $\Delta$ & $24 \mathrm{~h}$ & No reaction \\
\hline $\mathrm{DBU} / \mathrm{MeOH}$ r.t and $\Delta$ & $24 \mathrm{~h}$ & No reaction \\
\hline $\mathrm{KO} t \mathrm{Bu} / t-\mathrm{BuOH}$ & $24 \mathrm{~h}$ & Complex mixture \\
\hline $\mathrm{KH} / \mathrm{THF}$ & $24 \mathrm{~h}$ & No reaction \\
\hline $\mathrm{KH} / \mathrm{DMF}$ & $24 \mathrm{~h}$ & Complex mixture \\
\hline $\mathrm{HCl} / \mathrm{MeOH}$ & $24 \mathrm{~h}$ & MOM deprotection \\
\hline
\end{tabular}

Table 5.1: Results for attempted intramolecular Michael Addition 
The results shown in Table 5.1 were disappointing. Substituting DBU for potassium carbonate had no effect on the outcome of the reaction, both at room temperature and at reflux. Potassium hydride in THF also gave only recovered starting material. We hoped to increase the reactivity by substituting THF for the polar aprotic solvent DMF, but unfortunately this resulted in a complex product mixture, as did treatment with potassium $t$-butoxide in $t$-butyl alcohol. Since by this point we had had no success with base we attempted the reaction with acid, but this only resulted in deprotection of the MOM ether.

We believed that the problems with the intramolecular Michael addition were arising from the difficulty of epimerisation at C-5. An inspection of molecular models indicated that the Michael reaction was unlikely to take place with the side chain of $\mathbf{5 . 1}$ in the axial orientation, as it would require the D-ring to adopt a boat conformation to bring the Michael donor within bonding distance of the Michael acceptor; even then, orbital overlap would be poor. If the ketone side chain was able to take up an equatorial orientation, however, it appeared that good orbital overlap would be achieved between the reacting centres (Figure 5.1).

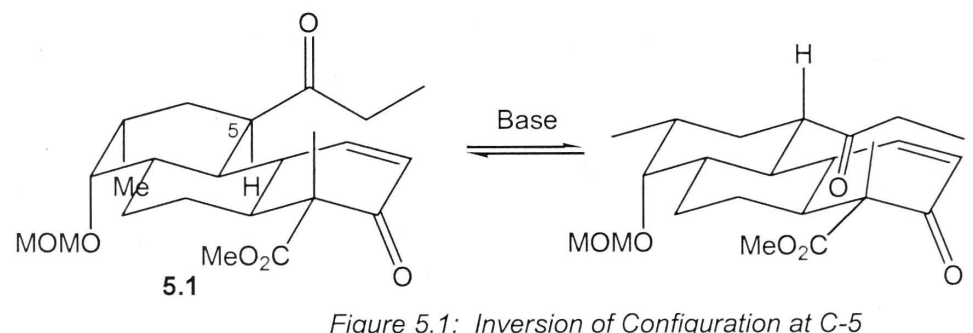

Figure 5.1: Inversion of Configuration at $\mathrm{C}-5$

Corey and coworkers ${ }^{57}$ encountered a difficult intramolecular Michael reaction in their work towards the synthesis of longifolene, shown in Scheme 5.7. Strong bases such as potassium $t$-butoxide and sodium methoxide led to extensive degradation of the starting material 5.6. Weaker bases, however, were without effect at both room temperature and up to $100{ }^{\circ} \mathrm{C}$. Eventually, it was discovered that treating $\mathbf{5 . 6}$ with triethylamine in ethylene glycol at $225^{\circ} \mathrm{C}$ for 24 hours gave the desired product $\mathbf{5 . 7}$ in $10-20 \%$ yield.
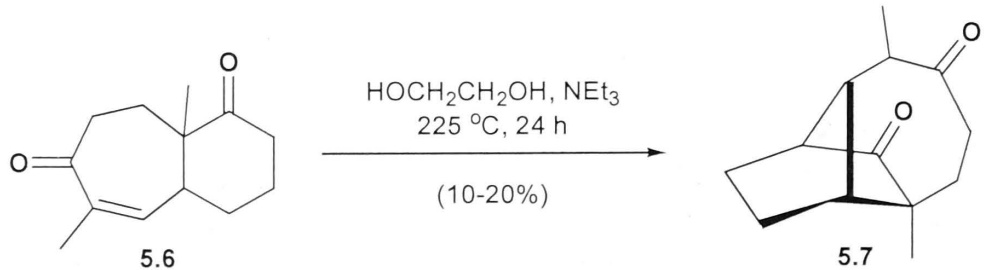

Scheme 5.7: Michael Addition used in the Synthesis of Longifolene 
These were not encouraging results, given that the yield of $\mathbf{5 . 7}$ was poor, and a number of other degradation products were obtained out of the reaction mixture. Nonetheless, we decided to apply this methodology to $\mathbf{5 . 1}$, but under less forceful conditions. Initially, we attempted the reaction in the lower boiling point alcohol, $n$-butanol, in the presence of triethylamine, but no reaction occurred. We then attempted the reaction in ethylene glycol, and we discovered that treatment of $\mathbf{5 . 1}$ with triethylamine in ethylene glycol at $150{ }^{\circ} \mathrm{C}$ for 20 hours gave the desired tetracycle $\mathbf{5 . 2}$ in $30 \%$ yield based on recovered starting material (Scheme 5.8).

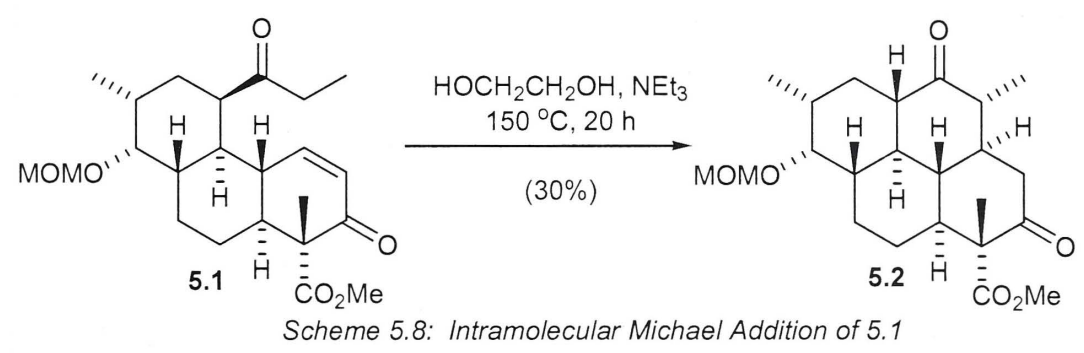

We terminated the reaction before the consumption of all of the starting material in order to avoid the formation of unwanted by-products. We also saw unwanted byproducts if the reaction mixture was heated to temperatures above $150{ }^{\circ} \mathrm{C}$, as revealed by the ${ }^{1} \mathrm{H}$ NMR spectrum. In the ${ }^{1} \mathrm{H}$ NMR spectrum of the crude product the integration of the $\beta$-keto ester peak at $3.76 \mathrm{ppm}$ in the desired product $\mathbf{5 . 2}$ was significantly less than the MOM group methyl ether peak (at $3.38 \mathrm{ppm}$ ). Therefore we concluded that the other products were resulting from decarboxylation processes. 
The $800 \mathrm{MHz}{ }^{1} \mathrm{H}$ NMR spectrum of $\mathbf{5 . 2}$ after purification is shown in Figure 5.2.
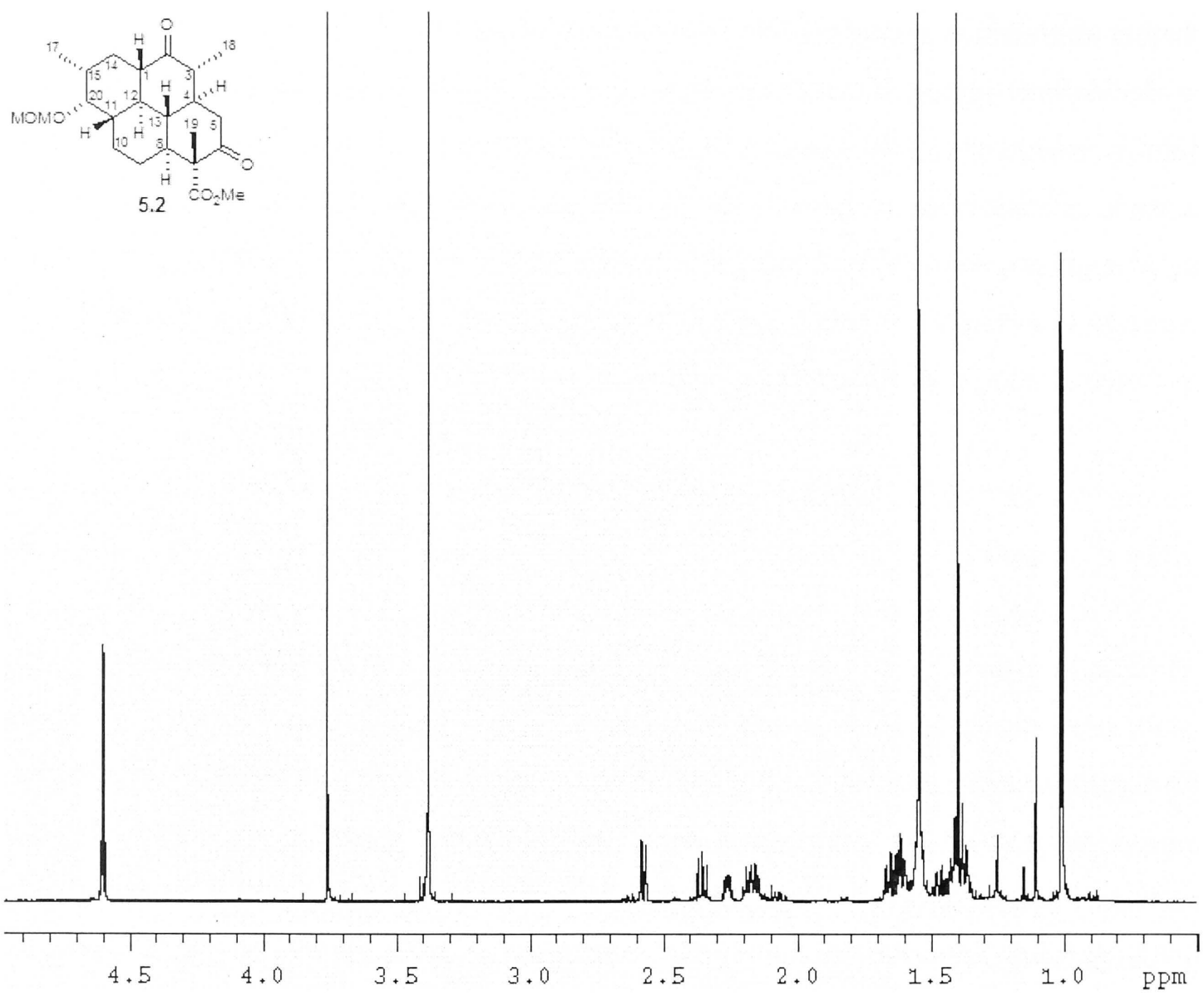

Figure 5.2: $800 \mathrm{MHz}{ }^{1} \mathrm{H}$ NMR spectrum of $\mathbf{5 . 2}$

We were surprised to find the two methyl groups C-17 and C-18 overlapped to appear as one doublet at $1.01 \mathrm{ppm}$. Analysis of the COSY and HMQC spectra, however, confirmed the presence of the two methyl groups at this chemical shift. The methyl group at C-7 occurs as a singlet at $1.40 \mathrm{ppm}$ and the ester group as a singlet at $3.76 \mathrm{ppm}$. The two protons on $\mathrm{C}-5$ can be seen as distinctive multiplets at $2.36 \mathrm{ppm}$ and $2.58 \mathrm{ppm}$.

The stereochemistry of $\mathbf{5 . 2}$ was confirmed by X-ray crystallography. Figure 5.3 shows that we had formed the all trans-fused tetracyclic required for the natural product. Furthermore, the quaternary centre in the A-ring possessed the desired axial methyl group, and the two secondary methyl groups were equatorial as required. ^

\footnotetext{
^ The numbering shown in the X-ray crystal structure of $\mathbf{5 . 2}$ is an arbitrary numbering system.
} 


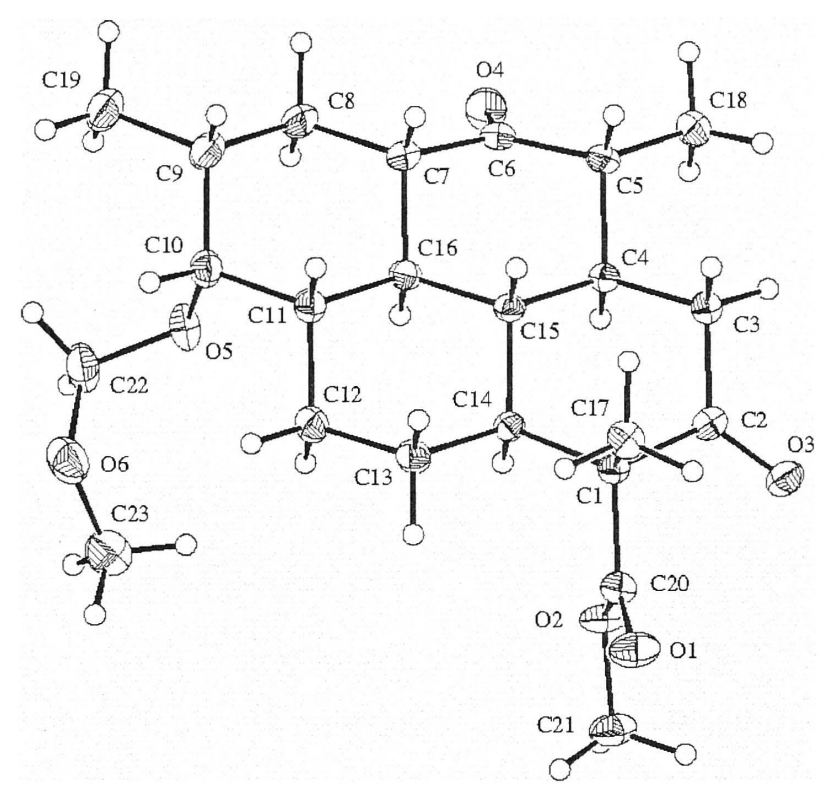

Figure 5.3: Crystal structure of $\mathbf{5 . 2}$

Although we were successful in synthesising $\mathbf{5 . 2}$ with the correct stereochemistry, the best yield we could obtain from the Michael reaction was 30\% based on recovered starting material. Thus, we attempted to further optimise the reaction conditions. One problem with the conditions utilised above was the difficulty of extracting the product from the ethylene glycol mixture at the end of the reaction. It was assumed that high heat was needed to activate the reaction, so ethylene glycol was substituted with the less polar high boiling point solvent xylene, but no reaction occurred. Using 1,2dimethoxyethane or digol as the solvent was also without effect.

We decided to attempt the Michael addition under high pressure in order to activate the reaction. The advantages of using high pressure as the activation method are that generally it is a mild non-destructive method, with excellent reproducibility. ${ }^{58} \mathrm{We}$ hoped to carry out the reaction in methanol. Thus, 5.1 in methanol and triethylamine were subjected to $19 \mathrm{kbar}$ of pressure at $25^{\circ} \mathrm{C}$ for 24 hours, after which time a complex product mixture resulted which appeared to contain none of the desired product 5.2.

In summary, despite our efforts to optimise the intramolecular Michael addition reaction, it appeared that the conversion of $\mathbf{5 . 1}$ to $\mathbf{5 . 2}$ required very specific reaction conditions, heating to at least $150{ }^{\circ} \mathrm{C}$ in ethylene glycol and triethylamine. The yield of $\mathbf{5 . 2}$ from this process was at best $30 \%$ based on recovered starting material, and it was postulated that the low yield was due to decarboxylation of the $\beta$-keto ester function. 


\subsection{Michael Addition on a Model Lacking the $\beta$-keto Ester Function}

It was hypothesised that a better yield could be obtained from the intramolecular Michael addition if it was carried out on an intermediate lacking the $\beta$-keto ester group. Thus, dione $\mathbf{5 . 1 0}$ was prepared by applying the methodology described in 5.2.1 to an intermediate produced earlier in the sequence (see Chapter 3), enone 3.34. Luche reduction of $\mathbf{3 . 3 4}$ gave epimeric allylic alcohols $\mathbf{5 . 8}$, which were treated with TBAF to give $87 \%$ yield of the diols $\mathbf{5 . 9}$ over the two steps. Diols $\mathbf{5 . 9}$ then underwent a double oxidation on treatment with DMP to give the required dione $\mathbf{5 . 1 0}$ (Scheme 5.9).<smiles>CCC([OH2+])[C@H]1C[C@H](C)[C@@H](OC)[C@H]2CC[C@@H]3CC(=O)C=C[C@H]3[C@H]12</smiles>

$3.34 \bar{H}$<smiles>CCC(=O)[C@H]1C[C@@H](C)[C@H](OC)[C@H]2CC[C@H]3CC(=O)C=C[C@H]3[C@H]12</smiles>

$5.10^{\mathrm{H}}$
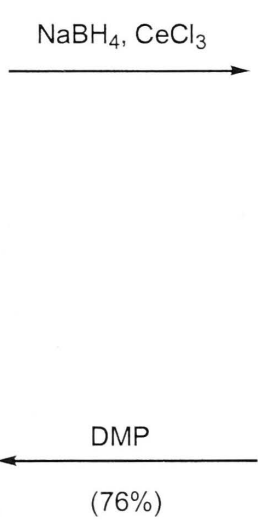

$(76 \%)$

Scheme 5.9: Synthesis of Dione 5.10

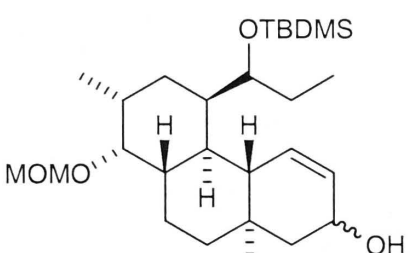

$5.8 \bar{H}$

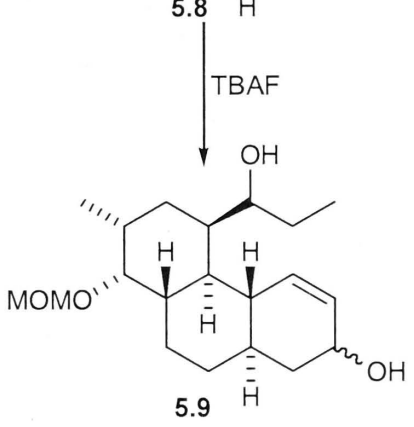

( $87 \%$ over 2 steps)

Treatment of $\mathbf{5 . 1 0}$ with triethylamine in ethylene glycol at $150{ }^{\circ} \mathrm{C}$ gave the desired tetracycle $\mathbf{5 . 1 1}$ in 68\% yield (Scheme 5.10).

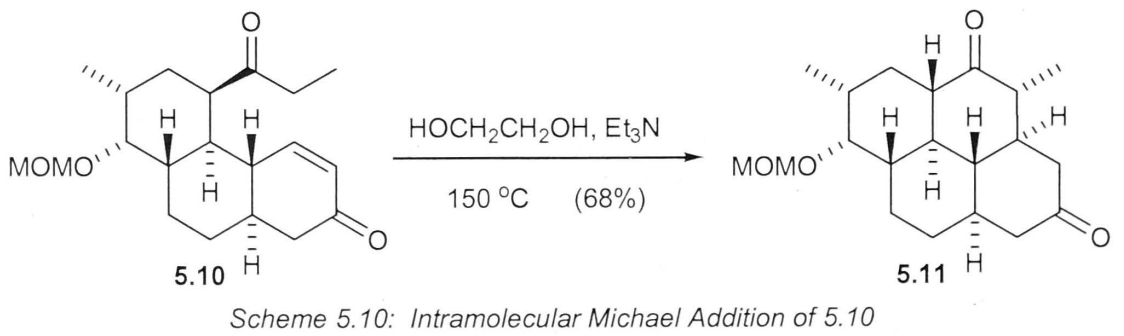

Thus, the intramolecular Michael addition on an intermediate lacking the $\beta$-keto ester group (5.10) exhibited a significant improvement in yield.

\subsubsection{Acylation of 5.11 and Attempted Alkylation}

Given the improvement in yield of the key intramolecular Michael addition reaction, we decided to investigate the regioselective acylation of the tetracycle $\mathbf{5 . 1 1}$. We hoped the 
methyl group at C-3 would induce enough steric hindrance to shield C-5, thereby directing the approach of the electrophile to C-7 (Figure 5.4).

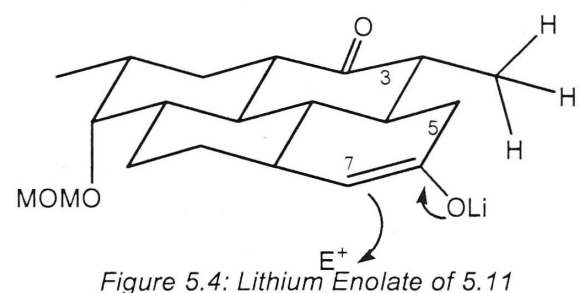

The lithium enolate of $\mathbf{5 . 1 1}$ was generated with LDA then treated with methyl cyanoformate in the presence of $\mathrm{HMPA}$ at $-78{ }^{\circ} \mathrm{C}$ to give a mixture of acylated products. A mixture of two inseparable regio-isomers $\mathbf{5 . 1 2}$ and $\mathbf{5 . 1 3}$ were isolated from the reaction mixture in $40 \%$ yield. On treatment with potassium carbonate in methanol, epimerisation of the ester group in $\mathbf{5 . 1 3}$ occurred to give $\mathbf{5 . 1 4}$. Esters $\mathbf{5 . 1 2}$ and $\mathbf{5 . 1 4}$ could then be easily separated by chromatography on silica gel (Scheme 5.11).

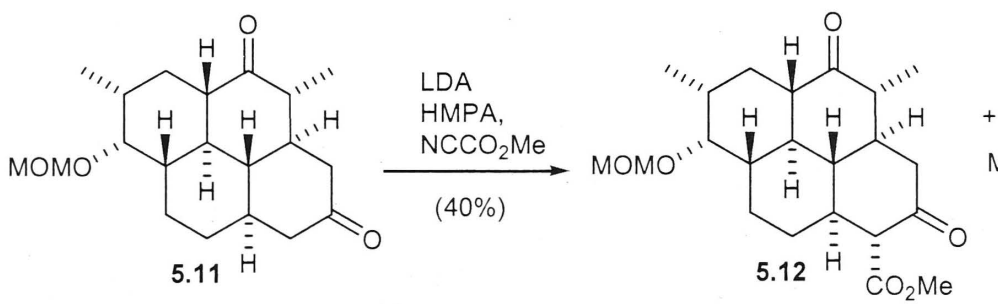

$\mathrm{K}_{2} \mathrm{CO}_{3}, \mathrm{MeOH}$

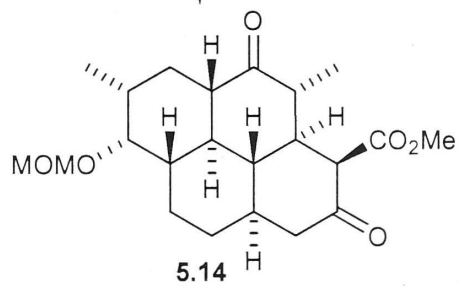

Scheme 5.11: Acylation of 5.11

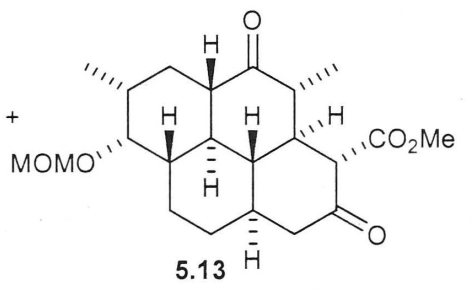

The structure and stereochemistry of both $\mathbf{5 . 1 2}$ and $\mathbf{5 . 1 4}$ were confirmed by one dimensional and two dimensional NMR studies. In the case of ester $\mathbf{5 . 1 2}$, the proton on C-7 occurs as a doublet at 3.19 ppm with a coupling constant of $12.6 \mathrm{~Hz}$, the size of this coupling to $\mathrm{H}-8$ confirming that $\mathrm{H}-7$ is axial. The stereochemistry was further confirmed by analysis of the NOESY spectrum. The proton on C-7 showed a correlation with the proton at $\mathrm{C}-13$, thus confirming the stereochemistry. The equatorial proton on C-5 showed a correlation with the axial proton on C-5, the methyl group C18 , and the proton at C-4. The enhancement between the equatorial proton on C-5 and the methyl group C-18 was further confirmation of the structure of $\mathbf{5 . 1 2}$ (Figure 5.5). 


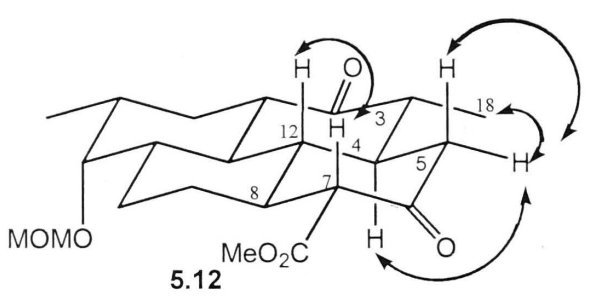

Figure 5.5: NOESY Correlations of Ester 5.12

On the other hand, ester $\mathbf{5 . 1 4}$ exhibited a doublet of doublets at $3.62 \mathrm{ppm}$ due to the proton on C-5 with coupling constants of 4.8 and $1.2 \mathrm{~Hz}$. The size of the coupling (4.8 $\mathrm{Hz})$ to $\mathrm{H}-4$ indicated that the proton at C-5 was equatorial, which was further confirmed by analysis of the NOESY spectrum. The proton at C-5 showed a correlation with the proton at C-4, and with the methyl group at C-18, therefore confirming the stereochemistry and location of the ester function in $\mathbf{5 . 1 4}$ (Figure 5.6). In contrast, the proton at C-5 in ester $\mathbf{5 . 1 3}$ was observed as a doublet at 3.30 ppm with a diaxial coupling constant of $3.2 \mathrm{~Hz}$.

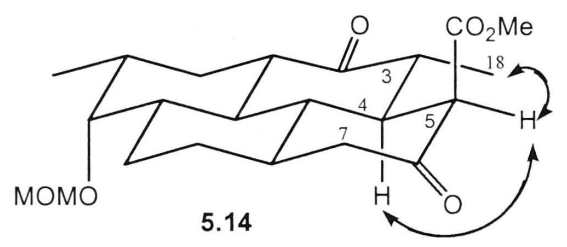

Figure 5.6: NOESY Correlations of Ester 5.14

It was somewhat surprising that $\mathbf{5 . 1 4}$ in which the ester substituent is axial was more stable than 5.13. Presumably the peri-interaction between the C-3 methyl group and the equatorial ester substituent destabilises $\mathbf{5 . 1 3}$.

It was hoped that utilising the bulkier base lithium tetramethyl piperidine (LiTMP) to form the lithium enolate would improve the regioselectivity of the acylation reaction, but this was not the case. On the other hand, using lithium hexamethyldisilazane (LiHMDS) to form the lithium enolate gave $\mathbf{5 . 1 2}$ as the only $\beta$-keto ester product (based on the crude ${ }^{1} \mathrm{H}$ NMR spectrum) (Scheme 5.12).

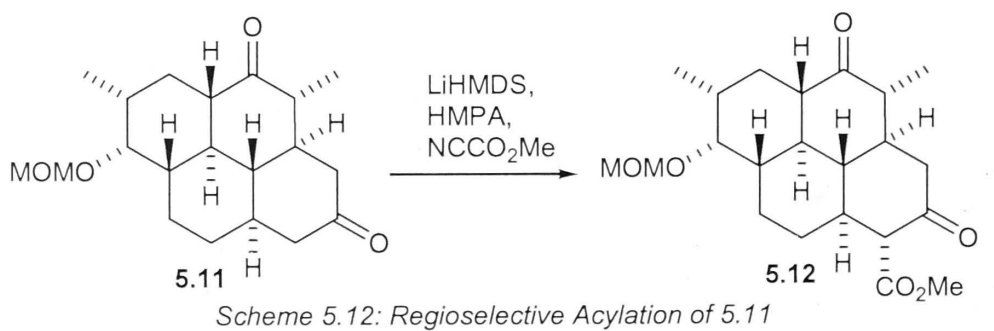


With $\beta$-keto ester $\mathbf{5 . 1 2}$ in hand, it remained for us to install the axial methyl group at C3 to complete the synthesis of the advanced intermediate 5.2. Unfortunately all attempts to alkylate 5.12, for example with sodium hydride and iodomethane (Scheme 5.13), were unsuccessful, resulting in complex product mixtures from which none of the desired product could be isolated.

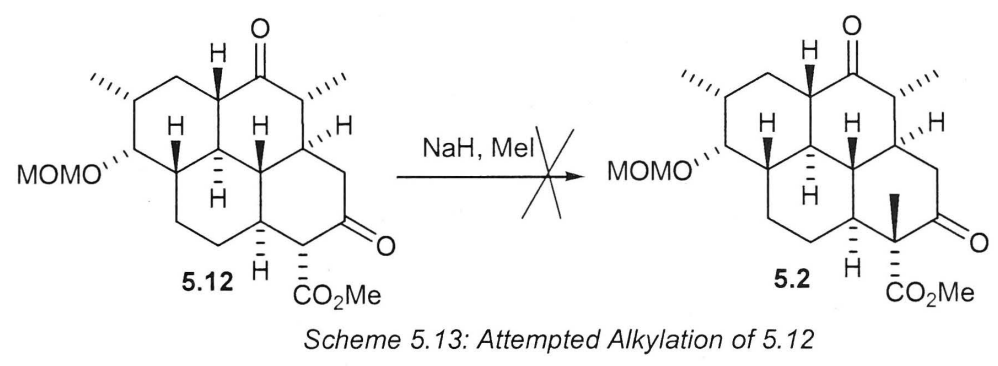

In summary, the intramolecular Michael addition reaction on an intermediate $(\mathbf{5 . 1 0})$ lacking the $\beta$-keto ester function proceeded in good yield (68\%) to give the tetracyclic intermediate 5.11. Acylation could be directed to the required position, C-7 of 5.11, utilising LiHMDS as the base, but all attempts to alkylate the $\beta$-keto ester $\mathbf{5 . 1 2}$ to form $\mathbf{5 . 2}$ were unsuccessful. This route was accordingly abandoned.

\subsection{The Key Intramolecular Michael Addition Reaction}

Having synthesised the tetracyclic intermediates $\mathbf{5 . 2}$ and $\mathbf{5 . 1 1}$, it was decided to apply the established methodology towards the intramolecular Michael reaction of $\mathbf{1 . 8 6}$ to form the tetracyclic compound $\mathbf{1 . 8 7}$ as previously outlined in Scheme 5.1.

Thus, as illustrated in Scheme 5.14, dione $\mathbf{1 . 8 6}$ was prepared by applying the established methodology to enone 4.17. Luche reduction of $\mathbf{4 . 1 7}$ gave epimeric allylic alcohols $\mathbf{5 . 1 5}$ in $80 \%$ yield, which were treated with TBAF to give the epimeric diols $\mathbf{5 . 1 6}$ in $84 \%$ yield, based on recovered starting material. The diol mixture $\mathbf{5 . 1 6}$ then underwent oxidation on treatment with DMP to give the required dione $\mathbf{1 . 8 6}$ in $81 \%$ yield. 

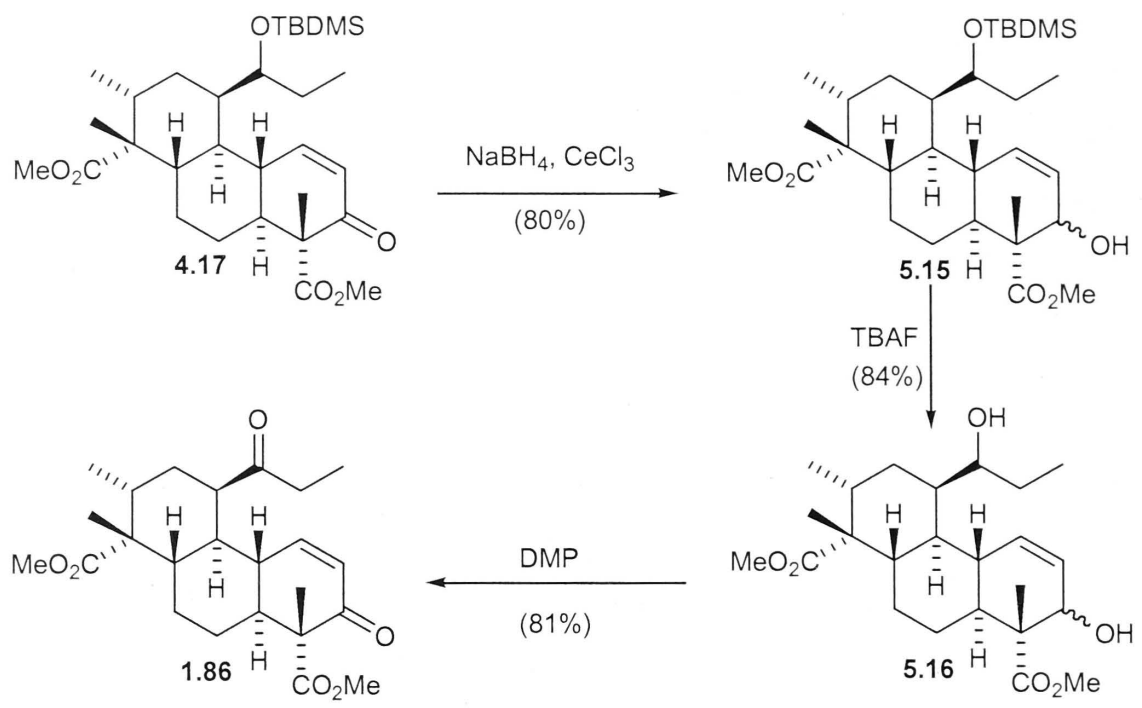

Scheme 5.14: Synthesis of Dione 1.86

The intramolecular Michael reaction was carried out as described previously. Thus, dione $\mathbf{1 . 8 6}$ was treated with triethylamine in ethylene glycol at $150{ }^{\circ} \mathrm{C}$. Surprisingly, after only four hours no starting material remained. Three products were obtained from the reaction in poor yield. A trace amount of a compound which appeared to have the structure 5.17, the desired product $\mathbf{1 . 8 7}$ in 7\% yield, and the transesterified compound $\mathbf{5 . 1 8}$ was formed as the major product with a dismal yield of $27 \%$ (Scheme 5.15).

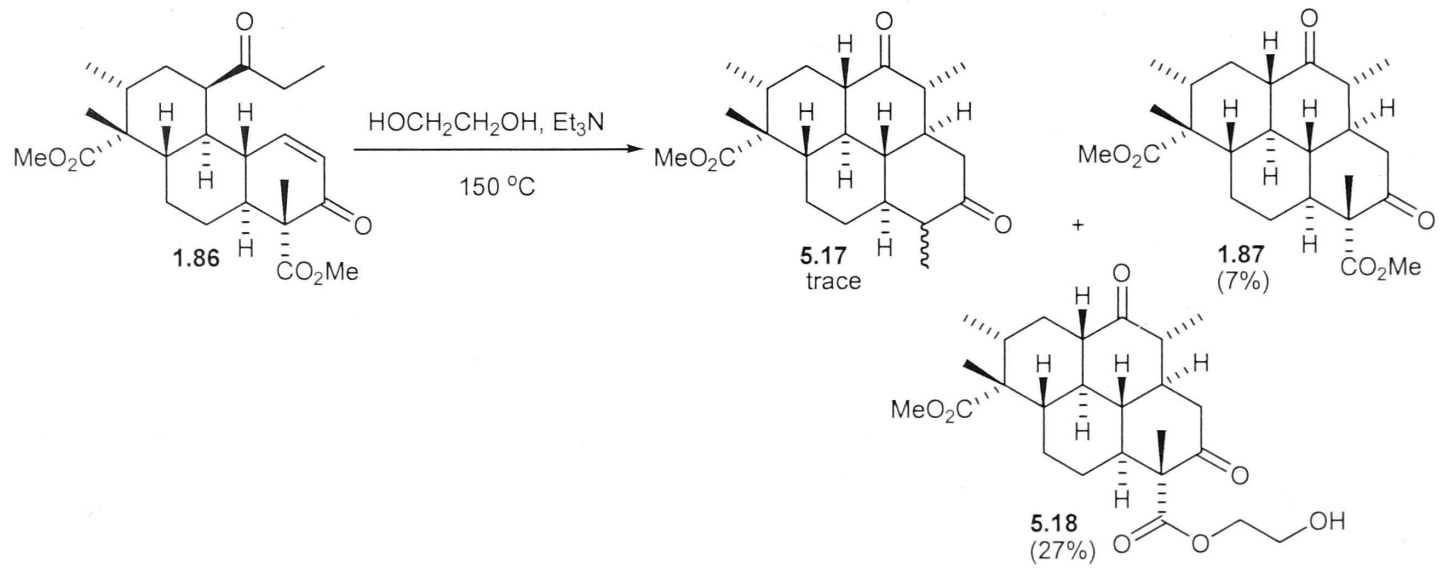

Scheme 5.15: Initial Intramolecular Michael Addition of 1.86

Due to the increased reactivity of $\mathbf{1 . 8 6}$ relative to enones $\mathbf{5 . 1}$ and $\mathbf{5 . 1 0}$, we decided to conduct the reaction at lower temperatures. It was found that at $100{ }^{\circ} \mathrm{C}$ and lower the formation of $\mathbf{5 . 1 7}$ was avoided, but unfortunately the formation of the transesterified product $\mathbf{5 . 1 8}$ could not be avoided. In fact at temperatures lower than $150{ }^{\circ} \mathrm{C}$ the transesterified enone $\mathbf{5 . 1 9}$ was also obtained as an inseparable mixture with $\mathbf{5 . 1 8}$. The results of reducing the reaction temperature are summarised in Table 5.2. 


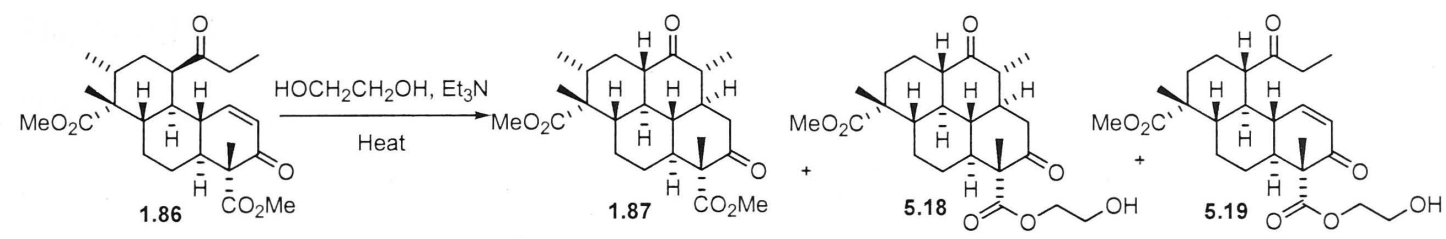

\begin{tabular}{|l|l|l|l|l|}
\hline Temperature & Reaction time & Recovered 1.86 & $\mathbf{1 . 8 7}$ yield $^{*}$ & $\mathbf{5 . 1 8}$ and 5.19 yield \\
\hline $150{ }^{\circ} \mathrm{C}$ & $4 \mathrm{~h}$ & 0 & $7 \%$ & $27 \%(\mathbf{5 . 1 8}$ only $)$ \\
\hline $100{ }^{\circ} \mathrm{C}$ & $18 \mathrm{~h}$ & $12 \%$ & $\begin{array}{l}17 \% \\
(20 \%)\end{array}$ & $\begin{array}{l}17 \% \\
(18 \%)\end{array}$ \\
\hline $70{ }^{\circ} \mathrm{C}$ & $4 \mathrm{~d}$ & $24 \%$ & $\begin{array}{l}22 \% \\
(30 \%)\end{array}$ & $\begin{array}{l}29 \% \\
(41 \%)\end{array}$ \\
\hline
\end{tabular}

Table 5.2: Effect of temperature on the Intramolecular Michael Reaction of 1.86

* Yields in brackets refer to yields based on recovered starting material.

Table 5.2 shows that as the temperature decreases the yield of $\mathbf{1 . 8 7}$ increases. However, decreasing the temperature of the reaction leads to a significant increase in reaction time, and over longer reaction times the formation of the transesterified compounds $\mathbf{5 . 1 8}$ and 5.19 could not be avoided. Treatment of $\mathbf{1 . 8 6}$ with triethylamine in ethylene glycol at $70{ }^{\circ} \mathrm{C}$ for four days resulted in the best yield of $\mathbf{1 . 8 7}$ (30\% based on recovered starting material). A mixture of $\mathbf{5 . 1 8}$ and $\mathbf{5 . 1 9}$ was also obtained in a $5: 1$ ratio in $41 \%$ yield, based on recovered starting material (Scheme 5.16).
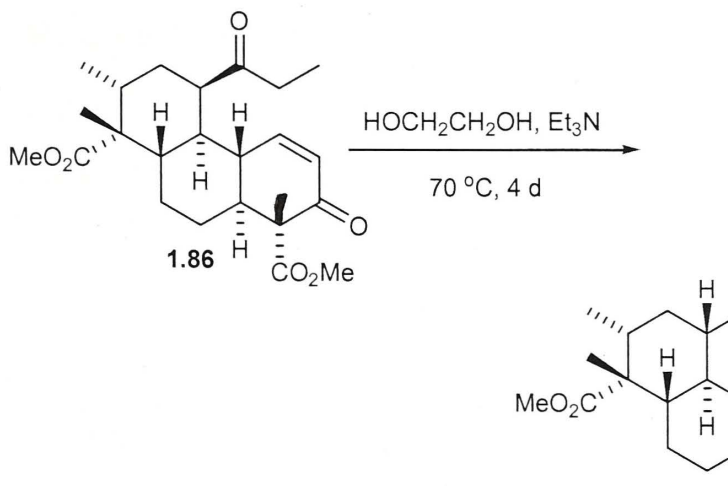

5.18

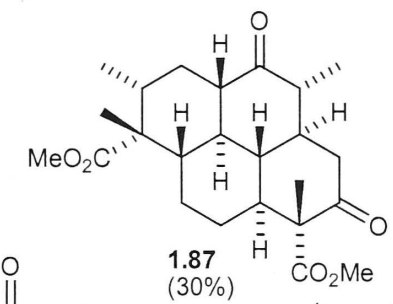

Scheme 5.16: Optimised Intramolecular Michael Addition of 1.86

The formation of the transesterified products $\mathbf{5 . 1 8}$ and $\mathbf{5 . 1 9}$ was inconvenient, but not an insurmountable problem, since the ester groups were eventually hydrolysed to the dicarboxylic acid 1.62. This conversion will be discussed further in Chapter $6^{\bullet}$ (Scheme 5.17).

- Originally we attempted a reverse transesterification with methanol to convert the mixture of $\mathbf{5 . 1 8}$ and 5.19 to the methyl diesters 1.86 and $\mathbf{1 . 8 7}$. However, the reaction was unreliable and produced low yields. 


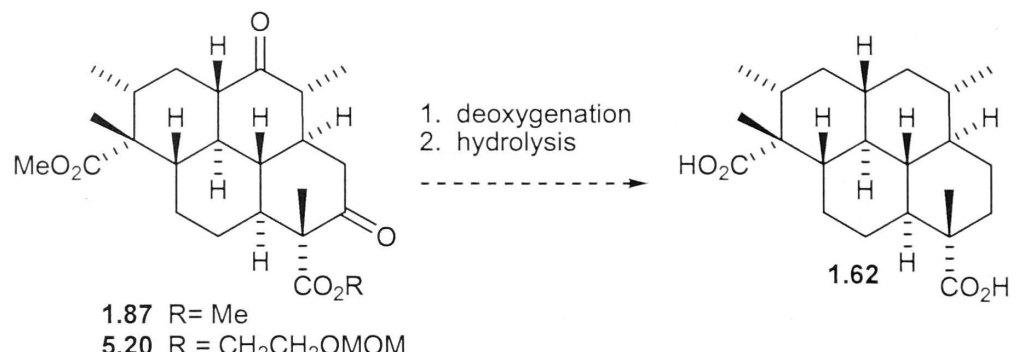

Scheme 5.17: Planned Synthesis of Dicarboxylic Acid 1.62

Thus, the mixture of $\mathbf{5 . 1 8}$ and $\mathbf{5 . 1 9}$ was converted to the MOM ethers $\mathbf{5 . 2 0}$ and $\mathbf{5 . 2 1}$, and then a reasonable amount of $\mathbf{5 . 2 0}$ could be isolated, although the separation was difficult and a pure sample of the minor product $\mathbf{5 . 2 1}$ could not be obtained (Scheme 5.18). The mixture of $\mathbf{5 . 2 1}$ and 5.20, however, could be recycled to obtain more of the required product $\mathbf{5 . 2 0}$.

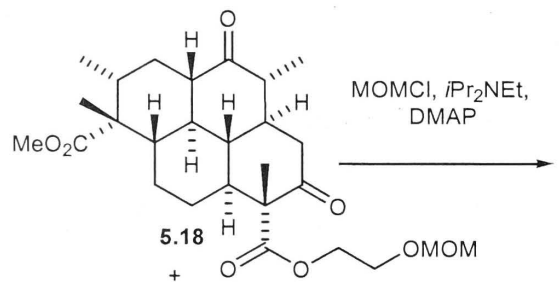

5.19

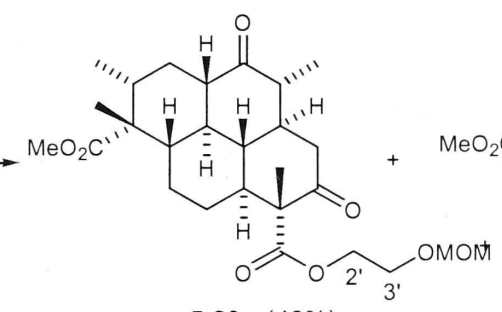

$5.20(43 \%)$

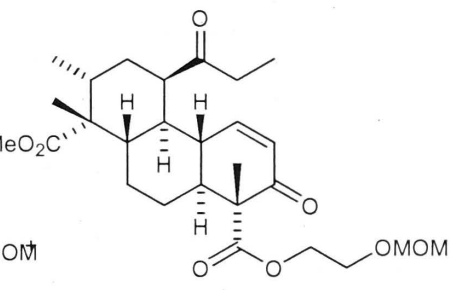

5.21 with $5.20(31 \%)$

Scheme 5.18: MOM Protection of 5.18 and 5.19

The protons on $\mathrm{C}^{-2}$ ' and $\mathrm{C}-3^{\prime}$ in $\mathbf{5 . 2 0}$ appeared as two characteristic multiplets, representing two protons each in the ${ }^{1} \mathrm{H}$ NMR spectrum, one between 3.72-3.75 ppm and the other between 4.33-4.36 ppm. The peaks for $\mathrm{C}-2^{\prime}$ and $\mathrm{C}-3^{\prime}$ in the ${ }^{13} \mathrm{C}$ NMR were observed at $64.2 \mathrm{ppm}$ and $65.5 \mathrm{ppm}$ respectively. 
The $800 \mathrm{MHz}{ }^{1} \mathrm{H}$ NMR spectrum of the desired tetracyclic product 1.87 is shown in figure 5.7 .

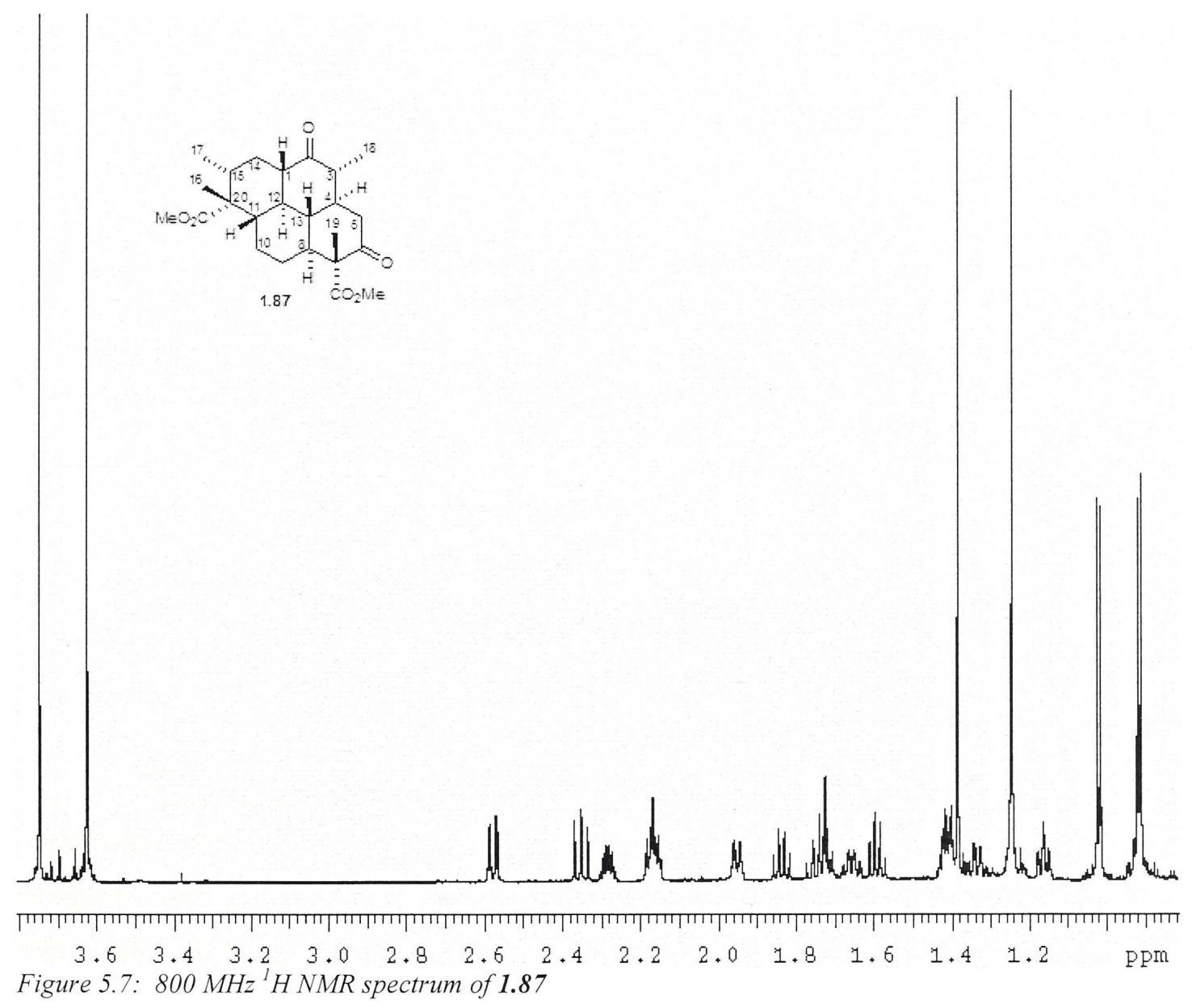

The methyl groups C-17 and C-18 occur as doublets at 0.92 and 1.02 ppm respectively. The methyl group at C-20 occurs as a singlet at $1.25 \mathrm{ppm}$ and the methyl group at C-7 occurs as a singlet at $1.39 \mathrm{ppm}$. The ester group at C-20 was observed as a singlet at $3.63 \mathrm{ppm}$ and the $\beta$-keto ester peak at C-7 was observed at $3.75 \mathrm{ppm}$. The multiplets exhibited at 2.35 and $2.56 \mathrm{ppm}$ were assigned to the two protons on $\mathrm{C}-5$.

The stereochemistry of $\mathbf{1 . 8 7}$ was confirmed by X-ray crystallography. Figure 5.8 shows that we had formed the all trans-fused tetracycle required for the natural product. Furthermore the quaternary methyl group in the A-ring was axial, and the quaternary methyl group in the D-ring was equatorial as required. 


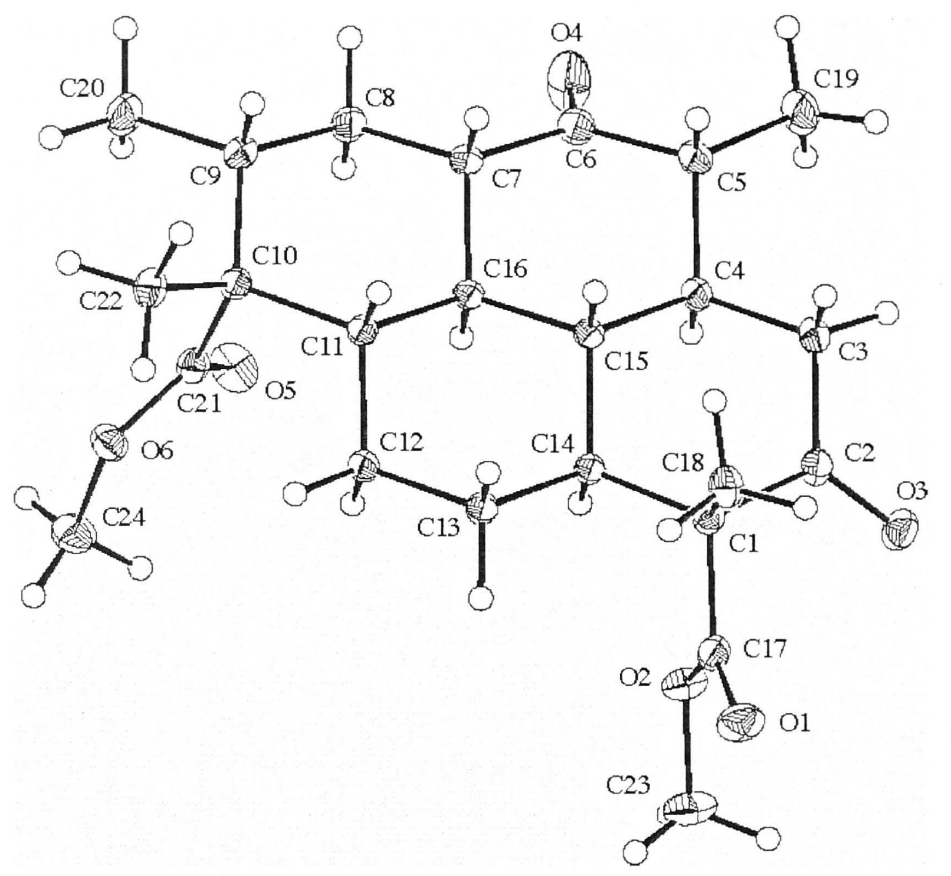

Figure 5.8: X-ray Structure of 1.87

In summary, the best yield of $\mathbf{1 . 8 7}$ obtained in the intramolecular Michael addition was $30 \%$ based on recovered starting material; however, $41 \%$ of useable transesterified intermediates (5.18 and 5.19) were also obtained. Thus, the synthesis of the tetracyclic skeleton of diisocyanoadociane (1.87) was successfully achieved, with the stereochemistry at all ten centres correct. 


\section{CHAPTER 6}

\section{Deoxygenation and the Curtius Rearrangement}

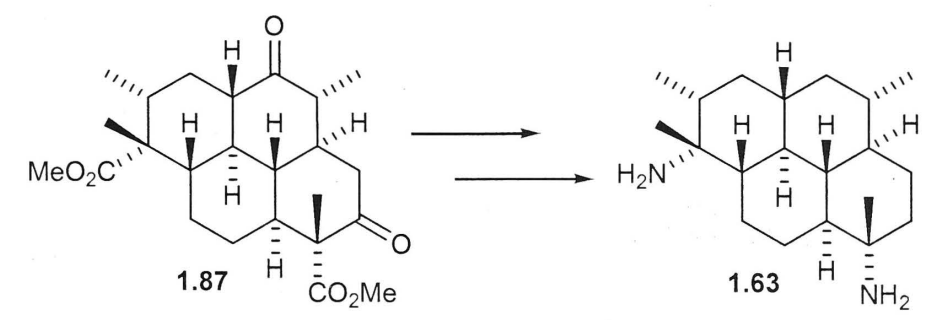


Chapter 6 


\section{Deoxygenation and the Curtius Rearrangement}

The first part of this chapter will discuss our studies towards the deoxygenation and dealkylation to obtain dicarboxylic acid 1.62. The second part will discuss the planned Curtius rearrangement to complete the formal total synthesis of Diisocyanoadociane (1.10).

\subsection{Introduction}

As mentioned in Chapter 1 (Section 1.5, Scheme 1.6) it was planned to utilise the Curtius rearrangement of the corresponding acyl azide of dicarboxylic acid $\mathbf{1 . 6 2}$ for the stereoselective incorporation of the isonitrile groups in $\mathbf{1 . 1 0}$.

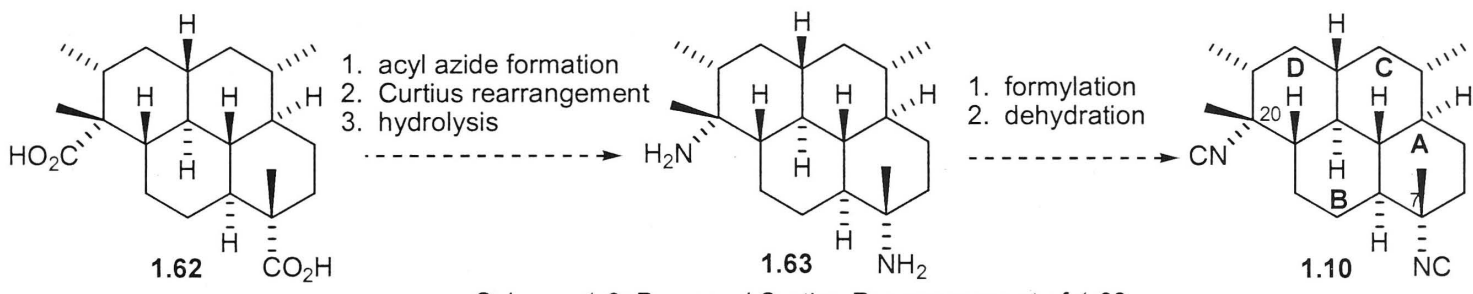

Scheme 1.6: Proposed Curtius Rearrangement of 1.62

In order to complete the synthesis of the skeleton of diisocyanoadociane (1.10) and to prepare for the Curtius rearrangement, we first needed to synthesise dicarboxylic acid 1.62. It was envisaged that the dicarboxylic acid $\mathbf{1 . 6 2}$ could be obtained after a double deoxygenation and ester hydrolysis of the Michael products $\mathbf{1 . 8 7}$ and $\mathbf{5 . 2 0}$ (Scheme 6.1).

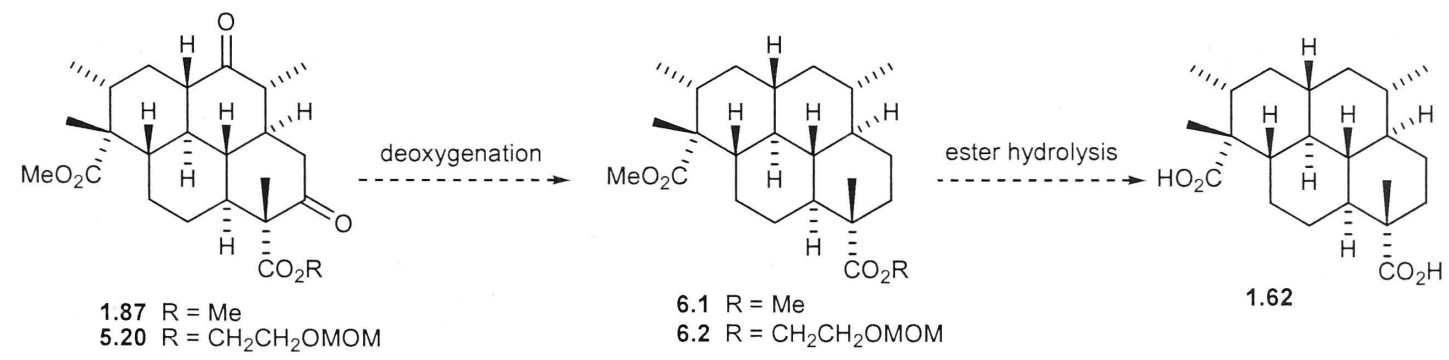

Scheme 6.1: Planned Synthesis of Dicarboxylic Acid 1.62

\subsection{Deoxygenation}

The Wolff-Kishner reduction is a well known reaction for the reduction of carbonyl compounds to hydrocarbons. Two different variations of the method were discovered independently by Kishner in $1911^{59}$ and by Wolff in $1912 .^{60}$ Early procedures described

\footnotetext{
- This Scheme is repeated from Chapter 1.
} 
the addition of preformed hydrazones to hot solid potassium hydroxide, or by heating with sodium ethoxide in ethanol in a sealed tube at $180{ }^{\circ} \mathrm{C}$. In general, heating at 180 ${ }^{\circ} \mathrm{C}$ for six to eight hours is adequate to achieve complete reduction. ${ }^{61}$ Numerous modifications of the Wolff-Kishner reduction have been introduced over the years. ${ }^{61}$ For example, the modification discovered by Huang-Minlon ${ }^{62}$ in 1946, which involved heating the crude hydrazone to $180-200{ }^{\circ} \mathrm{C}$ for three to four hours with sodium or potassium hydroxide in diethylene or triethylene glycol. In $1962 \mathrm{Cram}$ and coworkers ${ }^{63}$ reported a modified Wolff-Kishner reduction that could be conducted at room temperature. The authors reported that the slow addition of hydrazones to a solution of sublimed potassium $t$-butoxide in anhydrous dimethyl sulfoxide at $25^{\circ} \mathrm{C}$ gave the corresponding hydrocarbons in good yields. The main by-product from this procedure was an azine, whose formation is favoured by the rapid addition of hydrazone to the reaction mixture. Azine formation is a well documented side reaction of the Wolff Kishner reduction. ${ }^{61}$ (Scheme 6.2)
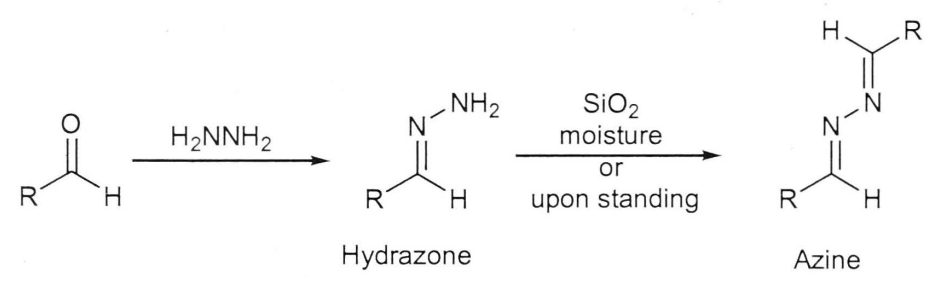

Scheme 6.2: Azine formation

Henbest and coworkers ${ }^{64}$ reported an alternative to Cram's procedure, in which the hydrazones were added in a single portion to a suspension of potassium $t$-butoxide in toluene at $100-110^{\circ} \mathrm{C}$ to obtain the corresponding hydrocarbons.

In 2004, these reduced temperature modifications of the Wolff-Kishner reduction were exploited by Myers and Furrow ${ }^{65}$ for the reduction of $N$-silylhydrazones. $N$-t.Butyldimethylsilylhydrazones were prepared by treating the parent aldehydes or ketones with 1,2-bis(t-butyldimethylsilyl)hydrazine (BTBSH) and a catalytic amount of scandium trifluoromethanesulfonate. An example is shown in Scheme 6.3. ${ }^{65}$

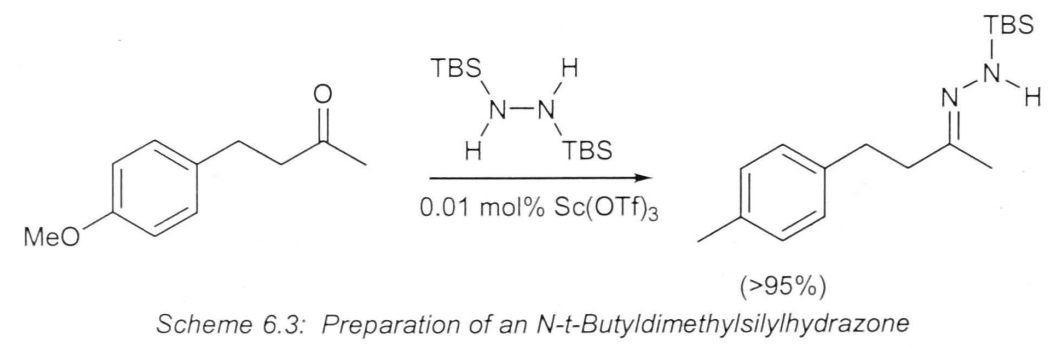


The crude hydrazones were then subjected to Cram-type conditions at $23{ }^{\circ} \mathrm{C}$ or $100{ }^{\circ} \mathrm{C}$ with $t$-butyl alcohol added as a proton source. Outstanding yields of reduction products were achieved, and some examples of these reductions are shown in Scheme 6.4.<smiles>COc1ccc(CCC(C)=O)cc1</smiles>

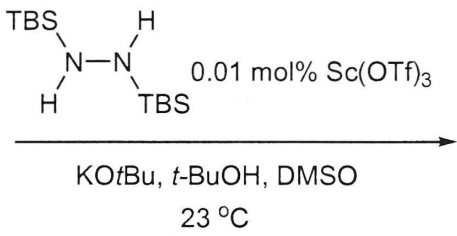<smiles>CCCCc1ccc(C)cc1</smiles><smiles>O=Cc1cccc(Oc2ccccc2)c1</smiles>

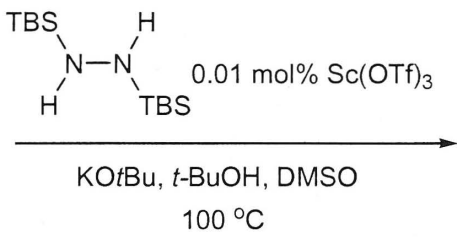<smiles>Cc1cccc(Oc2ccccc2)c1</smiles>
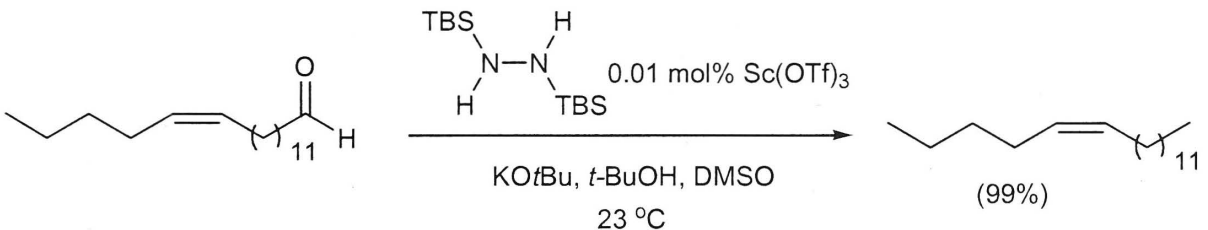

Scheme 6.4: Modified Wolff-Kishner Reduction

Several features of the Myers modified Wolff-Kishner reduction demonstrate it to be advantageous. First, the azine formation was not observed in the process and the two steps could be conducted in a single reaction vessel without compromising the yield of the reduction products. Second, it is milder than traditional Wolff-Kishner reactions in that reductions in most cases can be carried out at room temperature. Furthermore, the $N$-silylhydrazones exhibit improved stability over standard hydrazones with respect to handling and storage.

We decided to apply the methodology described by Myers to the model compound, $\mathbf{6 . 3}$. Unfortunately, after treatment of the initially formed $N$-silylhydrazone with potassium $t$ butoxide in dimethyl sulfoxide and $t$-butyl alcohol at room temperature overnight, none of the desired product $\mathbf{6 . 4}$ was formed (Scheme 6.5).

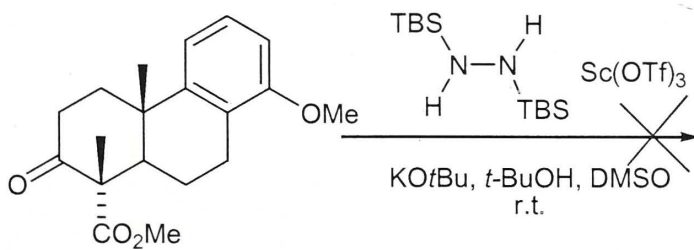

6.3<smiles>COc1cccc2c1CCC1[C@@](C)(C(C)=O)CCC[C@@]21C</smiles>

6.4

Scheme 6.5: Attempted Deoxygenation of Model 6.3 
Analysis of the crude ${ }^{1} \mathrm{H}$ NMR showed that the ester group had been lost in the operation. Thus, given the apparent sensitivity of the $\beta$-keto ester function to strong base, this methodology was abandoned.

In 1971 Hutchins and coworkers ${ }^{66}$ reported the mild reduction of tosylhydrazones to hydrocarbons using sodium cyanoborohydride in a $1: 1$ mixture of DMF and sulfolane at $100-105{ }^{\circ} \mathrm{C}$. The authors reported that keto esters could be converted to the corresponding hydrocarbons without decomposition of the ester function. In 1985 Kim et al. ${ }^{67}$ discovered that reduction of aldehydes and ketones could be achieved in one pot by treating with tosylhydrazine then zinc-modified cyanoborohydride in methanol at reflux. Several tosylhydrazones were converted cleanly into the corresponding hydrocarbons after three hours in good yield. Examples of ketone reduction with tosylhydrazine and zinc-modified cyanoborohydride have subsequently been carried out in THF at reflux. ${ }^{68}$ We decided to test this two-step one pot procedure for the conversion of model $\beta$-keto ester $\mathbf{6 . 5}$ to ester 6.6. Thus, keto ester $\mathbf{6 . 5}$ was treated with tosylhydrazine in THF at reflux for 16 hours, before the addition of zinc chloride and sodium cyanoborohydride and heating at reflux for an additional 16 hours to obtain ester 6.6 in 66\% yield (Scheme 6.6).
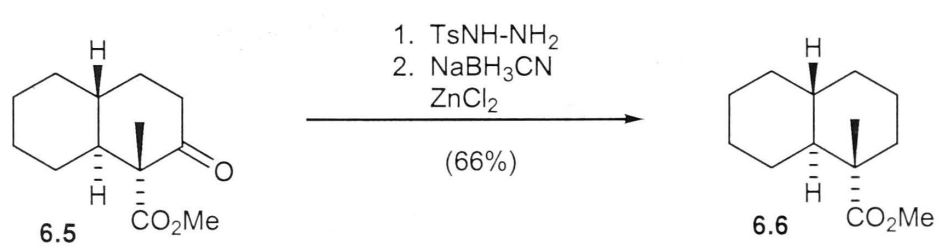

Scheme 6.6: Deoxygenation of Model Ester 6.5

Given the success on model compound $\mathbf{6 . 5}$ we attempted the deoxygenation of compound 1.87. To this end, dione $\mathbf{1 . 8 7}$ was treated with tosylhydrazine for 16 hours in THF at reflux. Zinc chloride and sodium cyanoborohydride were then added and the mixture was heated at reflux for an additional 24 hours to obtain a complex product mixture, from which hydrocarbon 6.1 was separated, although in the dismal yield of 5\% (Scheme 6.7).
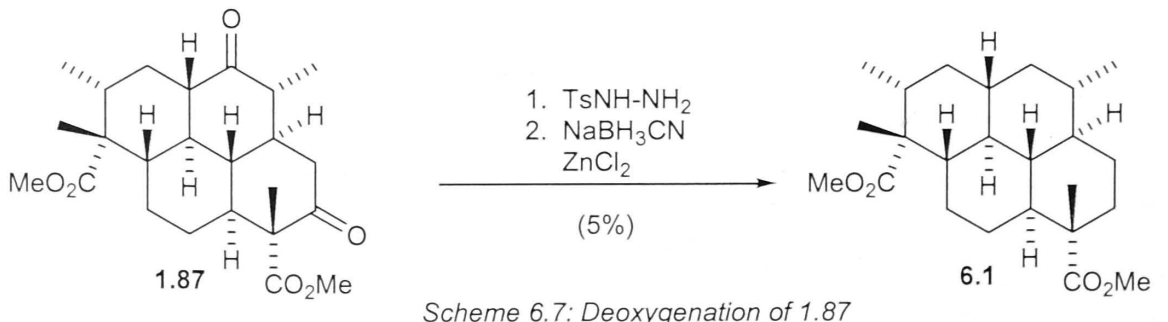
In view of the lack of success thus far for the deoxygenation of dione $\mathbf{1 . 8 7}$ utilising a modified Wolff-Kishner reduction, we turned our attention to alternative deoxygenation protocols.

Another method commonly used in the literature for the deoxygenation of secondary alcohols is the radical mediated Barton-McCombie reaction (Scheme 6.8). ${ }^{69}$ This deoxygenation involves reaction of tributylstannane with the thiocarbonate or xanthate ester derived from the parent secondary alcohol to give the corresponding hydrocarbon in good yield. The driving force for the reaction is the formation of the very stable S-Sn bond. An advantage of this protocol is that it takes place under neutral conditions, making it compatible with the presence of a number of functional groups.

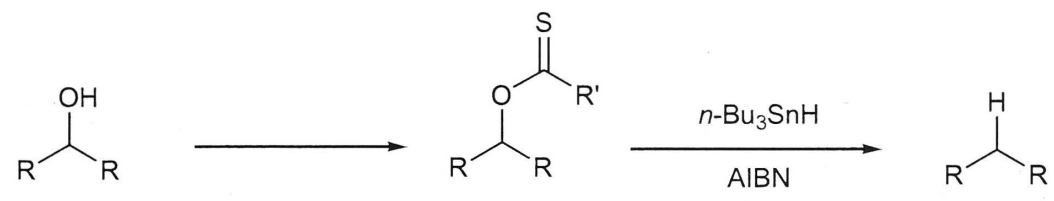

$\mathrm{R}=$ alkyl $\quad \mathrm{R}^{\prime}=\mathrm{H}, \mathrm{Me}, \mathrm{Ph}, \mathrm{OMe}, \mathrm{SMe}, \mathrm{OPh}$

Scheme 6.8: The Barton-McCombie Reaction

Thus, in order to test the Barton-McCombie reaction conditions on our model compound 6.5 we first needed to reduce the ketone group. We decided to carry out the reduction under Luche reaction conditions ${ }^{56}$, as we hoped that by binding the carbonyl group with cerium trichloride reduction would occur at only one face of the molecule, therefore avoiding the formation of epimeric products. However, this was not the case and instead reduction of ketone $\mathbf{6 . 5}$ under Luche reaction conditions gave the epimeric alcohols 6.7 in a $4: 1$ ratio, although in quantitative yield. Treatment of the alcohols with NaHMDS followed by carbon disulfide then iodomethane over six hours gave the epimeric xanthate esters 6.8. Finally the xanthate esters 6.8 were treated with tributylstannane in the presence of AIBN as the radical initiator, then heated to $80^{\circ} \mathrm{C}$ over five hours to obtain the ester $\mathbf{6 . 6}$ in 70\% yield over the three steps (Scheme 6.9). 

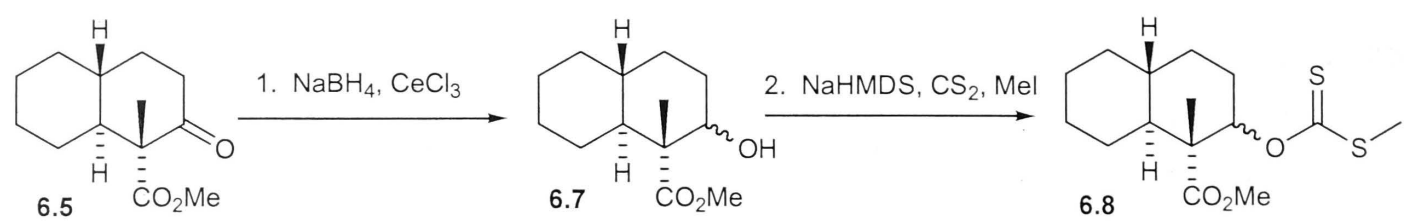

Scheme 6.9: Barton-McCombie Deoxygenation of Model Ester 6.5

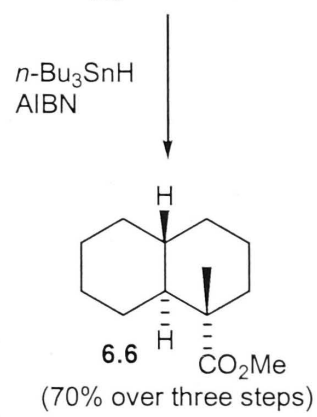

The conditions for the Barton-McCombie reaction established on compound $\mathbf{6 . 5}$ were then applied to the synthesis of ester 6.1. Thus, dione $\mathbf{1 . 8 7}$ was treated with sodium borohydride and cerium trichloride to give the corresponding mixture of epimeric diols. The diols were then treated with NaHMDS, carbon disulfide and iodomethane over six hours to form the corresponding epimeric xanthate esters, which could then be treated with tributylstannane in the presence of AIBN to obtain the desired hydrocarbon $\mathbf{6 . 1}$ in $47 \%$ yield over the three steps (Scheme 6.10).
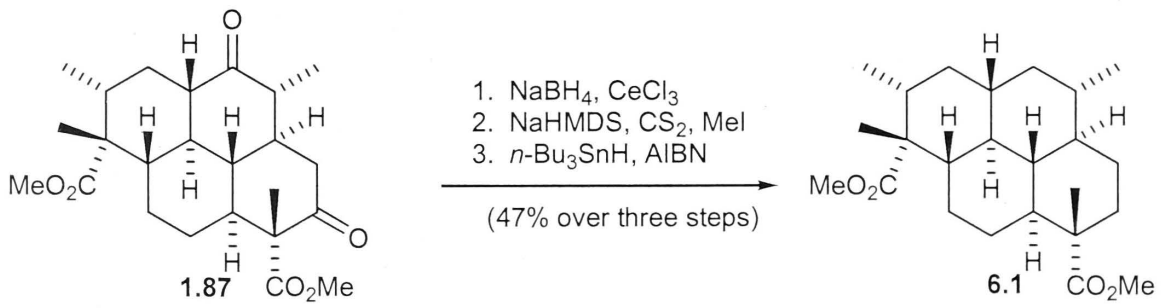

Scheme 6.10: Barton-McCombie Deoxygenation of 1.87

The Barton-McCombie deoxygenation procedure could also be applied to the transesterified derivative $\mathbf{5 . 2 0}$ to give the corresponding hydrocarbon $\mathbf{6 . 2}$ in $39 \%$ yield over three steps (Scheme 6.11).

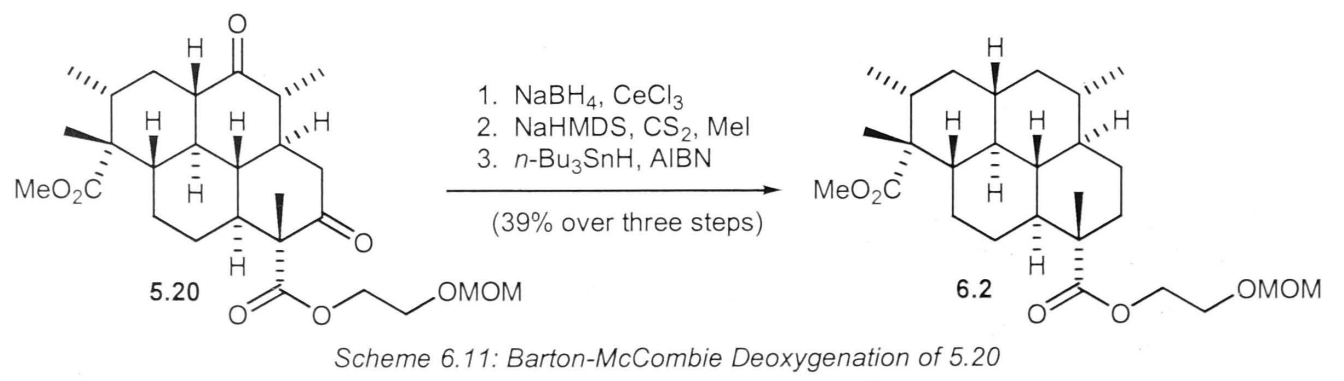

In both of the above cases, each time the reaction was carried out a mono-deoxygenated compound was also obtained in varying yields, which could be recovered and submitted 
to the reaction conditions a second time to obtain more of the respective hydrocarbons 6.1 and 6.2.

In summary, the Barton-McCombie reaction was identified to be the best method to achieve the deoxygenation of diones $\mathbf{1 . 8 7}$ and 5.20. By using this reaction, the tetracyclic skeleton of the natural product (1.10) was successfully completed.

\subsection{Dealkylation of the two Ester Groups}

In order to complete the synthesis of dicarboxylic acid $\mathbf{1 . 6 2}$ we needed to carry out the dealkylation of the diesters $\mathbf{6 . 1}$ and 6.2. Initially we attempted to remove the ester groups of 6.2 by base hydrolysis. Thus, treatment of 6.2 with lithium hydroxide in methanol : water $(3: 1)^{38}$ at reflux overnight gave two products: 6.9 and 6.1 . The two products arose from mono-dealkylation (6.9) and transesterification (6.1), but even after prolonged reaction time, the axial ester group in the D-ring remained untouched. Thiolate mediated demethylation is known to proceed under mild conditions, and is especially suited to the dealkylation of hindered methyl esters. By employing this methodology, we were able to obtain the dicarboxylic acid $\mathbf{1 . 6 2}$ after treatment of the mixture of 6.9 and $\mathbf{6 . 1}$ in an HMPA solution of sodium propane thiolate at room temperature for 24 hours, although in low yield (Scheme 6.12). ${ }^{70}$
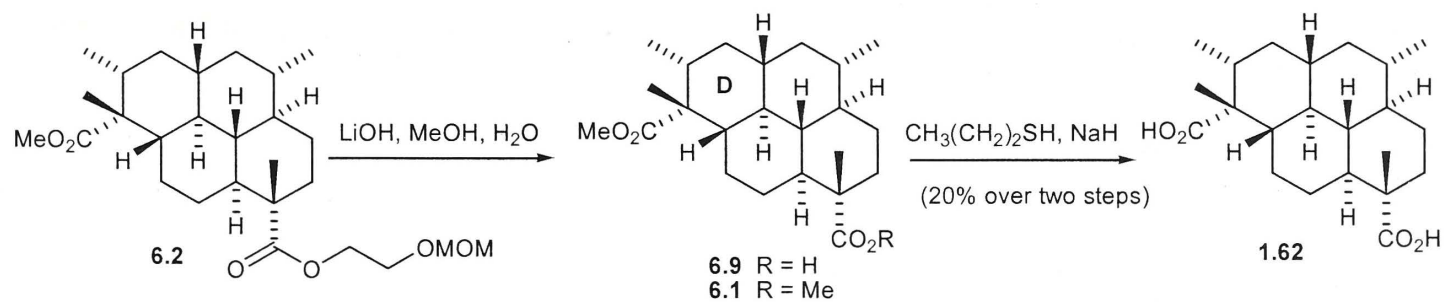

Scheme 6.12: Dealkylation of 6.2

A better yield was obtained for the one step thiolate mediated double demethylation of the diester 6.1. Thus, treatment of $\mathbf{6 . 1}$ with a freshly prepared solution of sodium propanethiolate in HMPA over 1.5 days gave the required dicarboxylic acid $\mathbf{1 . 6 2}$ in $87 \%$ yield (Scheme 6.13).

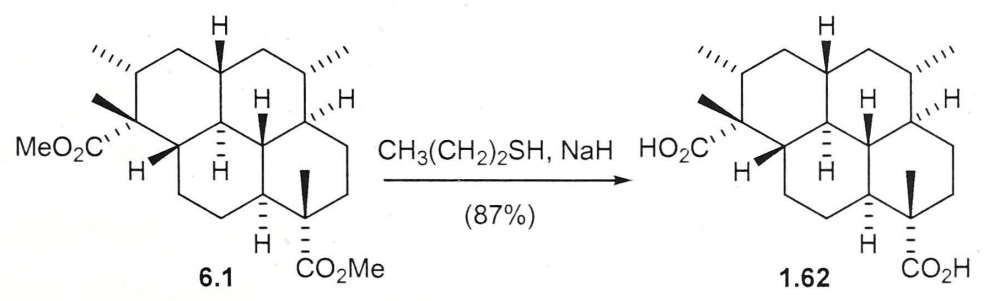

Scheme 6.13: Thiolate Mediated Demethylation of 6.1 
Worthy of note is that demethylation of the ester $\mathbf{6 . 6}$ proceeded under both base hydrolysis and thiolate mediated conditions, although a much higher yield of $\mathbf{6 . 1 0}$ was obtained from the latter procedure (Scheme 6.14).

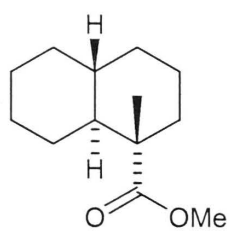

6.6

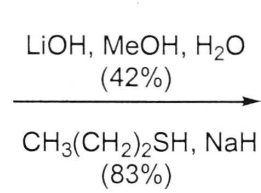

$(83 \%)$

Scheme 6.14: Dealkylation of 6.6

$\mathrm{O}$

6.10

\subsection{The Curtius Rearrangement}

The Curtius rearrangement is a commonly used reaction for the replacement of a carboxyl group by an amino group. The reaction proceeds via the rearrangement of an acyl azide derivative to an isocyanate. The amine is then obtained by hydrolysis of the isocyanate group (Scheme 6.15).

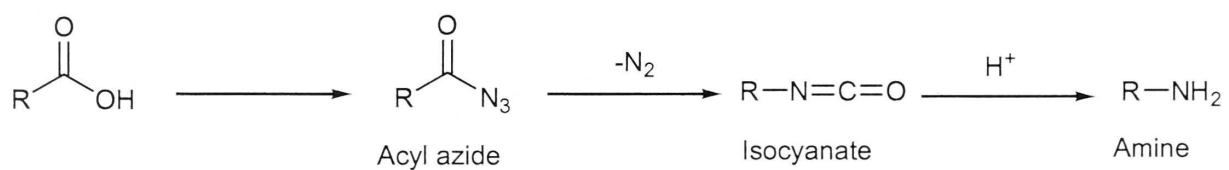

Scheme 6.15: The Curtius Rearrangement to Form Amines

A side reaction from the hydrolysis of isocyanates to amines is the formation of ureas. ${ }^{71}$ Thus, model studies were undertaken in order to ensure that we could avoid any urea formation in the hydrolysis step.

\subsubsection{Model Studies}

We initially attempted the acyl azide formation and the subsequent Curtius rearrangement on two model carboxylic acids; $\mathbf{6 . 1 0}$ and $\mathbf{4 . 2}$.

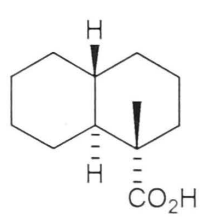

6.10

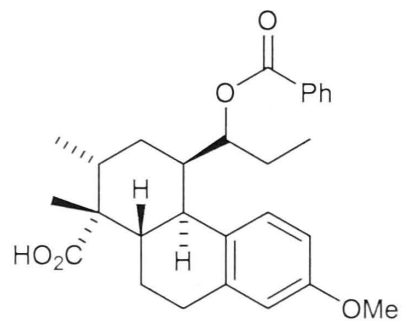

4.2

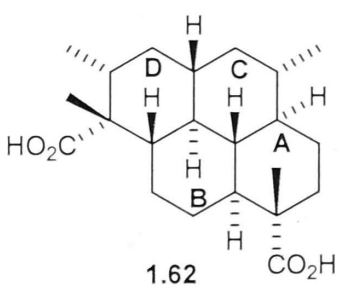

1.62

Compound 6.10 contains an equatorial carboxylic acid at the quaternary centre, and is representative of the $\mathrm{A}$ and $\mathrm{B}$-rings of compound 1.62. Compound 4.2, on the other 
hand, possesses an axial carboxylic acid group at the quaternary centre and is representative of the D-ring in compound $\mathbf{1 . 6 2}$.

Acyl azide formation was first tested on the equatorial model compound 6.10. We were delighted to find that on treatment with oxalyl chloride in DCM the corresponding acid chloride was obtained after less than one hour at room temperature. The DCM was removed and the crude acid chloride immediately treated with sodium azide in THF at room temperature for 18 hours to obtain the acyl azide 6.11. Evidence for the formation of the acyl azide was provided by IR spectroscopy, which showed that a strong $v(\mathrm{~N}=\mathrm{N}=\mathrm{N})$ absorption was visible at $2130 \mathrm{~cm}^{-1}$. The Curtius rearrangement then occurred rapidly on heating $\mathbf{6 . 1 1}$ in toluene at reflux for 15 minutes to obtain isocyanate 6.12. The reaction could again be followed by IR spectroscopy as the absorption at $2130 \mathrm{~cm}^{-1}$ had disappeared and a new strong $v(\mathrm{~N}=\mathrm{C}=\mathrm{O})$ absorption was visible at 2256 $\mathrm{cm}^{-1}$. The crude isocyanate in toluene was then treated with concentrated hydrochloric acid and heated at reflux for 20 hours to obtain the amine 6.13 in $48 \%$ yield over the four sequential steps (Scheme 6.16).

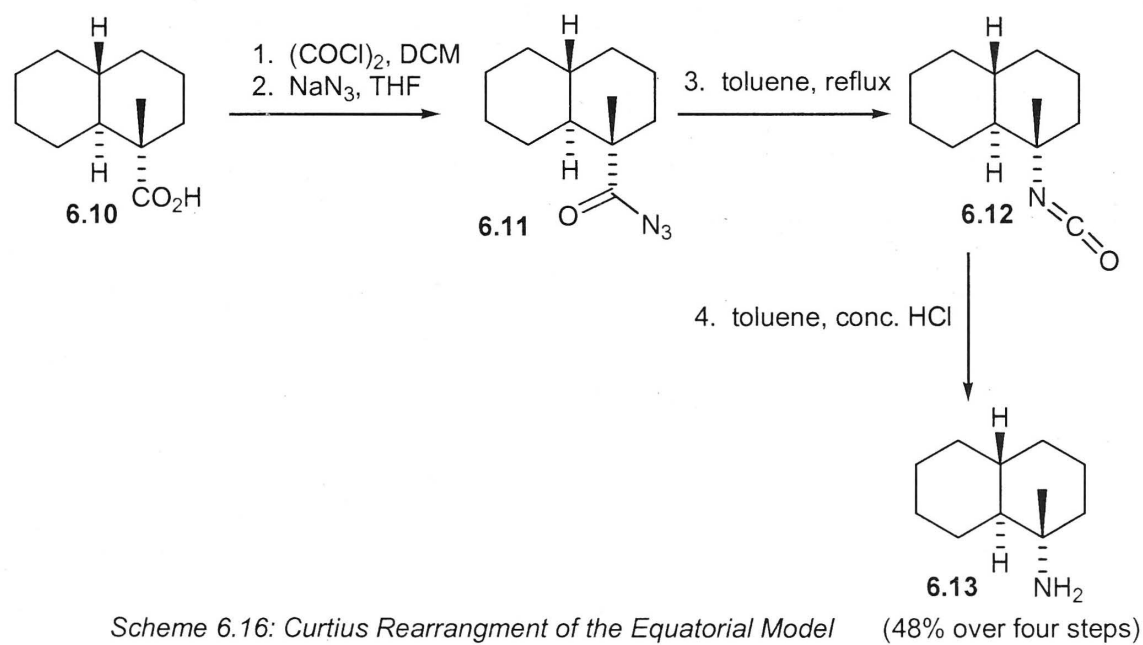

Next, we repeated the methodology on the more sterically demanding axial model $\mathbf{4 . 2}$. To this end, treatment of $\mathbf{4 . 2}$ with oxalyl chloride in DCM, followed by sodium azide in THF at room temperature for 24 hours gave the acyl azide 6.14. Heating $\mathbf{6 . 1 4}$ in toluene at reflux for 15 minutes then gave the isocyanate 6.15. The conversion of $\mathbf{6 . 1 4}$ to $\mathbf{6 . 1 5}$ could again be followed by IR spectroscopy, which showed that a strong $v(\mathrm{~N}=\mathrm{N}=\mathrm{N})$ absorption was seen at $2129 \mathrm{~cm}^{-1}$ for 6.14. This absorption disappeared on conversion to $\mathbf{6 . 1 5}$ and a $v(\mathrm{~N}=\mathrm{C}=\mathrm{O})$ absorption was seen at $2259 \mathrm{~cm}^{-1}$. Hydrolysis of $\mathbf{6 . 1 5}$ to the amine 6.16 was slow, and even after heating the isocyanate with concentrated hydrochloric acid in toluene at reflux for 24 hours, only $29 \%$ of the substrate was 
converted to the amine 6.16. Nevertheless, we could extract the amine from the mixture and repeat the hydrolysis reaction on the recovered isocyanate $\mathbf{6 . 1 5}$ (Scheme 6.17).

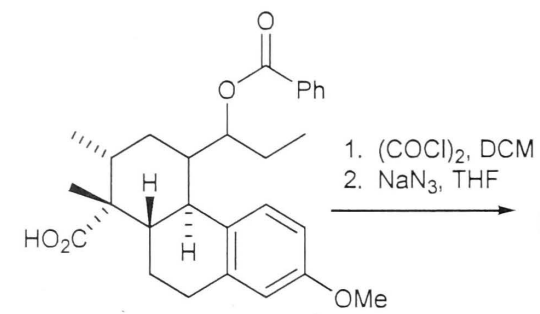

4.2

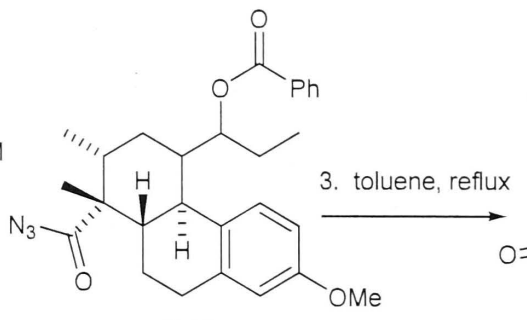

6.14

Scheme 6.17: Curtius Rearrangement of the Axial Model

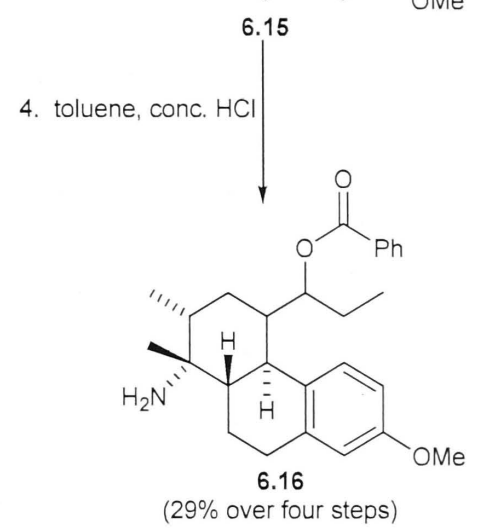

In summary, the acyl azide formation and the subsequent Curtius rearrangement was successfully carried out on two model compounds: $\mathbf{6 . 1 0}$ bearing an equatorial carboxyl group, and $\mathbf{4 . 2}$ bearing an axial carboxyl group. In both cases no urea by-products were observed.

\subsubsection{The Key Curtius Rearrangement}

We then applied the methodology established for the formation of amines $\mathbf{6 . 1 3}$ and $\mathbf{6 . 1 6}$ to the double Curtius rearrangement to form the diamine 1.63. Thus, dicarboxylic acid 1.62 was treated with oxalyl chloride in DCM to obtain the corresponding diacid chloride, which was treated immediately with sodium azide in THF. Analysis by IR spectroscopy after 18 hours revealed that the absorption for the diacid chloride at 1781 $\mathrm{cm}^{-1}$ had disappeared, and a new absorption was observed at $2131 \mathrm{~cm}^{-1}$ due to the diacyl azide 6.17. On heating the crude azide 6.17 in toluene at reflux for 15 minutes the double Curtius rearrangement proceeded smoothly to give diisocyanate 6.18. Analysis of 6.18 by IR spectroscopy revealed an absorption at $2260 \mathrm{~cm}^{-1}$ which was assigned to the $v(\mathrm{~N}=\mathrm{C}=\mathrm{O})$ stretch. Further characterization by E.I. mass spectrometry confirmed the structure of 6.18. Diisocyanate 6.18 was finally treated with concentrated hydrochloric acid in toluene for 18 hours to obtain the diamine $\mathbf{1 . 6 3}$ in 39\% yield over the four steps (Scheme 6.18). 


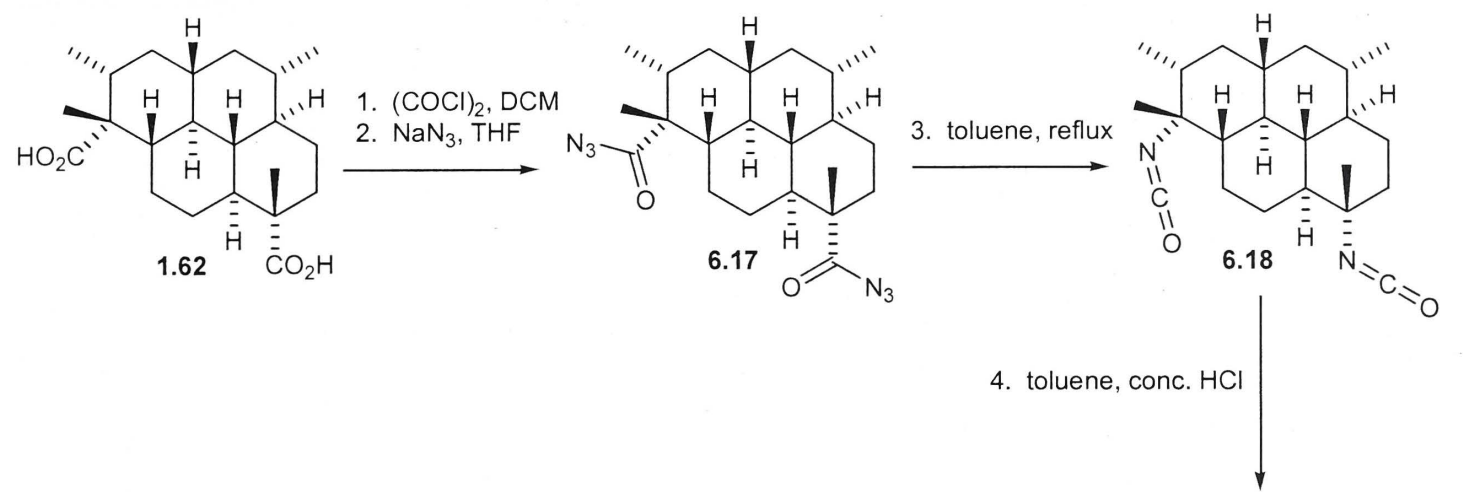

Scheme 6.18: Curtius Rearrangement of 1.62

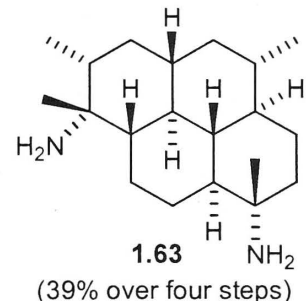

Diamine 1.63 was further purified by reverse phase HPLC, and was found to give identical mass spectra, and ${ }^{1} \mathrm{H}$ and ${ }^{13} \mathrm{C}$ NMR spectra (measured on the trifluoroacetate salts in $\mathrm{CD}_{3} \mathrm{OD}$ ), to those obtained from an authentic sample derived from hydrolysis of diisocyanoadociane (1.10). ${ }^{72}$ The $600 \mathrm{MHz}{ }^{1} \mathrm{H}$ NMR spectra for the synthetic and authentic samples of the diamine $\mathbf{1 . 6 3}$ are shown in Figure 6.1, and the ${ }^{13} \mathrm{C}$ NMR spectra (obtained at $800 \mathrm{MHz}$ for the synthetic sample and at $600 \mathrm{MHz}$ for the authentic sample) are shown in Figure 6.2. 
$600 \mathrm{MHz}{ }^{i} \mathrm{H}$ NMR spectrum of the TFA salt of 1.63 (synthetic sample)
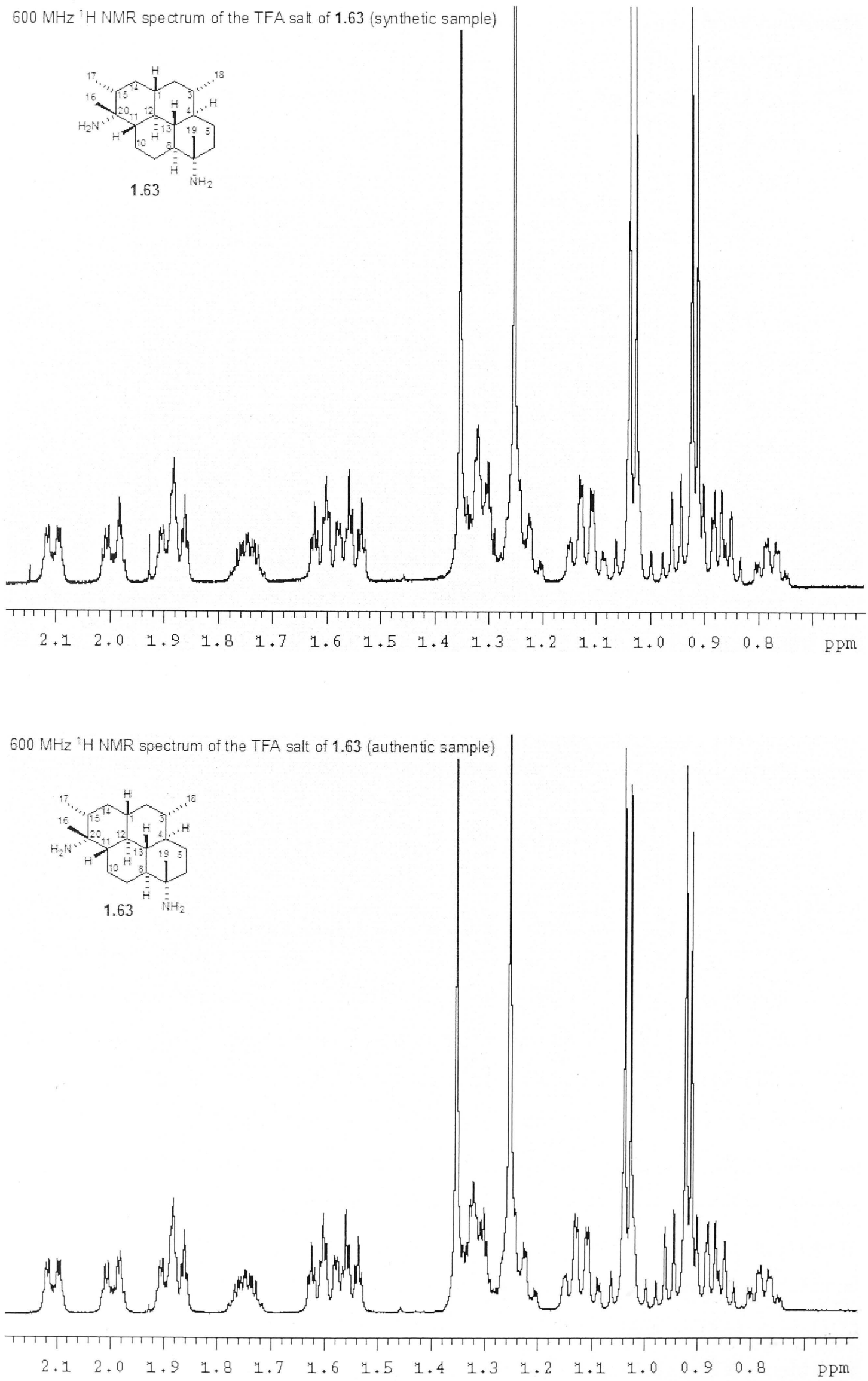

Figure 6.1: 'H NMR Spectra of synthetic and authentic samples of 1.63 
$800 \mathrm{MHz}{ }^{13} \mathrm{C}$ NMR spectrum of the TFA salt of 1.63 (synthetic sample)
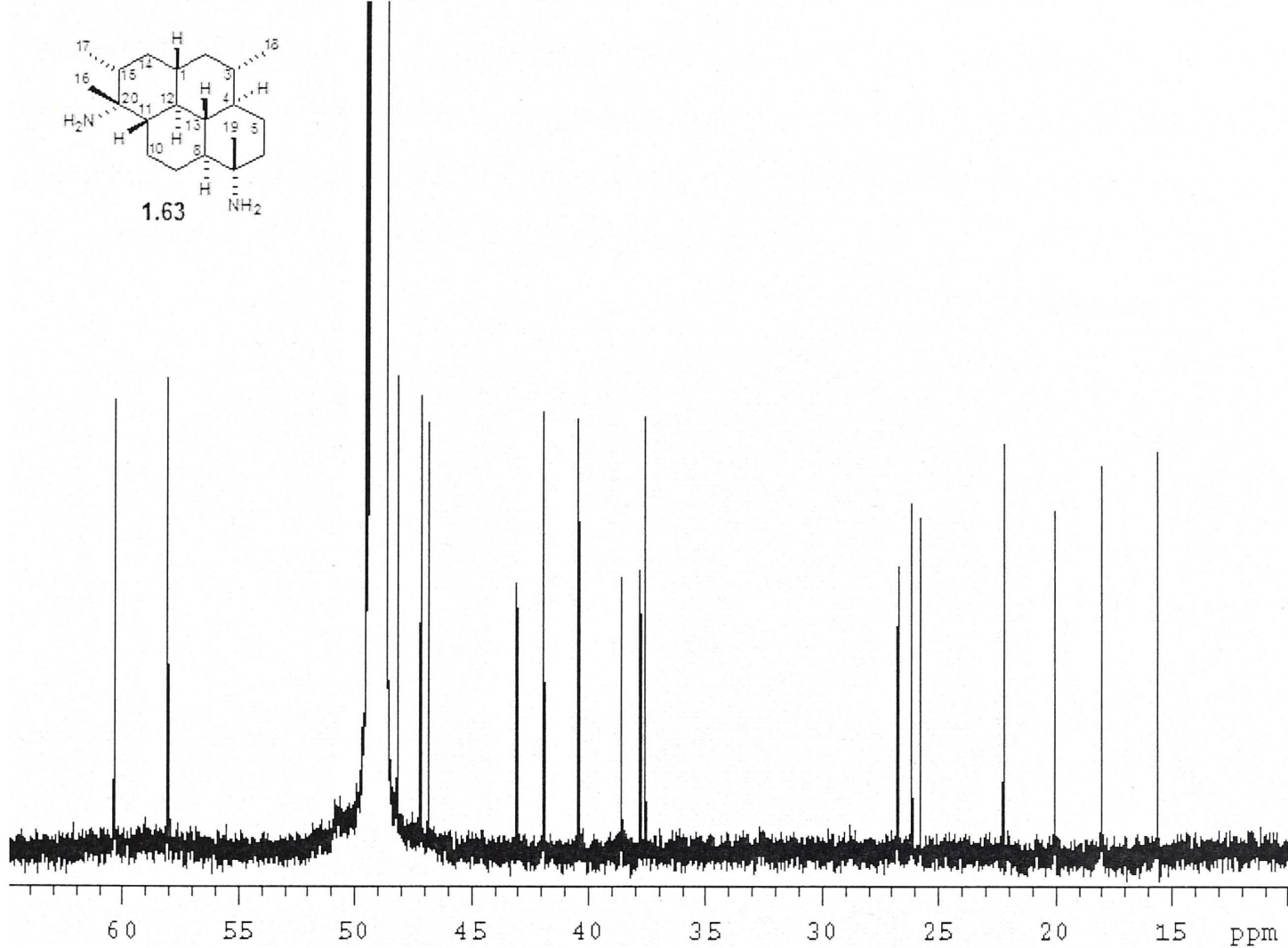

$600 \mathrm{MHz}{ }^{13} \mathrm{C}$ NMR spectrum of the TFA salt of 1.63 (authentic sample)
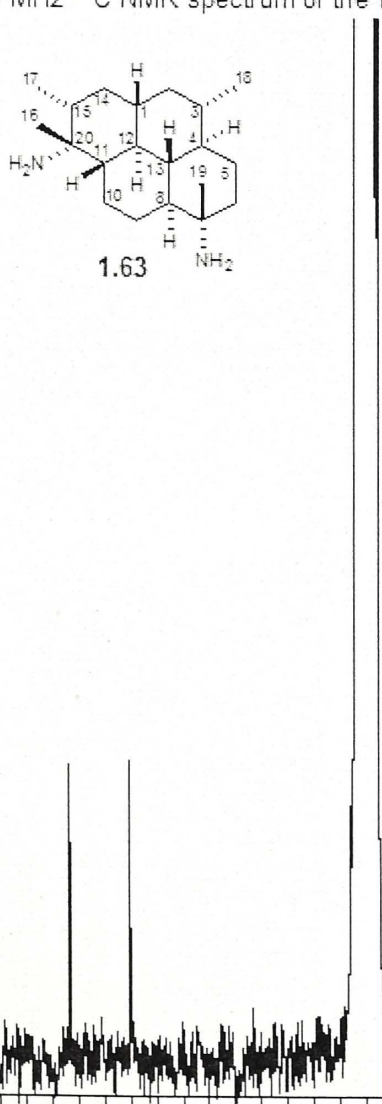

60

55

50

45

40

35

Figure 6.2: ${ }^{13}$ C NMR Spectra of synthetic and authentic samples of 1.63 
In Chapter 1 we outlined the synthetic strategy to diisocyanoadociane (1.10) and in that chapter we also referred to the work of Garson and coworkers, ${ }^{72}$ who obtained diamine 1.63 during the course of their biosynthetic studies, and subsequently were able to carry out formylation and dehydration reactions to reconstitute 1.10 (Scheme 6.19). Thus, the chemistry outlined in this chapter completes a formal total synthesis of diisocyanoadociane (1.10).
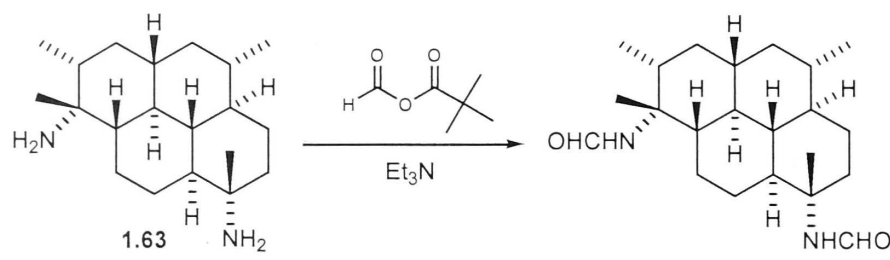

p-TsCl, py

Scheme 6.19: Reconsitution of 1.10 by Garson and Coworkers

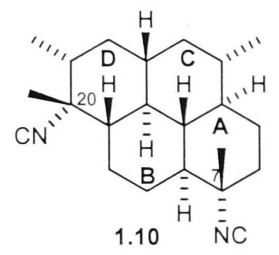




\section{CHAPTER 7}

\section{Summary and Conclusions}
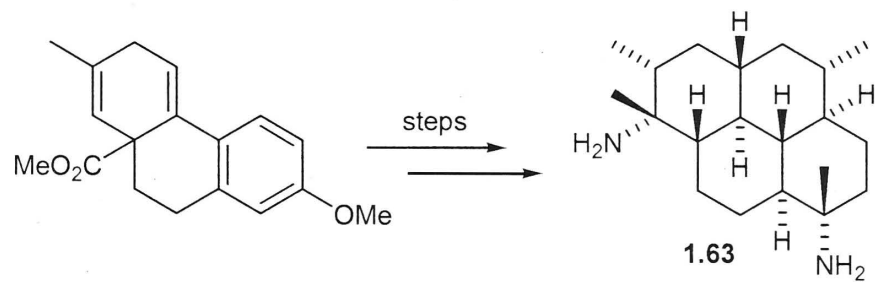
Chapter 7 


\section{Summary and Conclusions}

In conclusion, we have successfully completed a formal total synthesis of diisocyanoadociane (1.10). The 35 step sequence to diamine $\mathbf{1 . 6 3}$ is outlined in Scheme 7.1. The sequence begins with a phenanthrenoid (1.64) precursor which undergoes extensive elaboration before transformation into a pyrene derived intermediate (1.87) by means of an intramolecular Michael reaction. Finally the nitrogen functionality is introduced via a double Curtius rearrangement.

As discussed in Chapter 1 (Section 1.4.3) Corey and Magriotis ${ }^{20}$ have to date achieved the only other total synthesis of diisocyanoadociane (1.10). Our synthetic sequence outlined in Scheme 7.1 and Corey's sequence (summarised in Chapter 1, Scheme 1.5) are of a similar number of steps, but in our sequence additional steps were required due to compatibility problems with protecting groups and oxidation state changes. Worthy of note is that in Corey's sequence the two isonitrile groups were introduced in a single biomimetic operation to generate four diastereomeric diisonitriles, including $\mathbf{1 . 1 0}$ in unspecified yield. In our work, however, we have achieved the stereoselective incorporation of nitrogen at the two quaternary centres by utilising the Curtius rearrangement, thus theoretically facilitating the production of the natural product (1.10) as a single isomer at the final step. 
<smiles>COc1ccc(C)cc1C(C)=O</smiles><smiles>CCCc1cccc(OC)c1</smiles>

$(57 \%$<smiles>COC1=CCC(C)=CC1(CCc1cccc(OC)c1)C(C)=O</smiles>

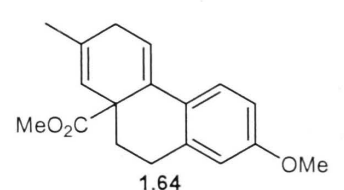

3. $\mathrm{EtC}(\mathrm{O}) \mathrm{Cl}, \mathrm{AlCl}_{3}$ $-78^{\circ} \mathrm{C}(75 \%)$<smiles></smiles>

5. $\mathrm{MOMCl}, \mathrm{Pr}_{2} \mathrm{NEt}$, DMAP

6. $\mathrm{LiAlH}_{4}$

7. $\mathrm{PhCOCl}$, py, DMAP (90\% over 3 steps)

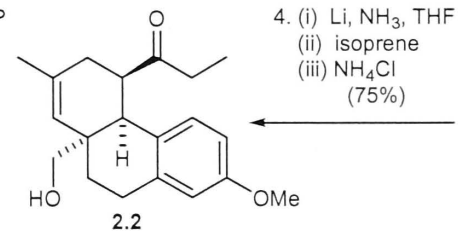

(ii) isoprene

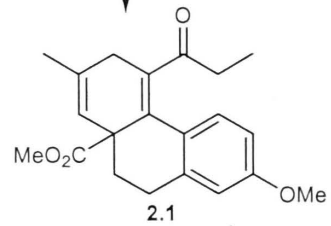

8. $\mathrm{MeOH}, \mathrm{HCl}(87 \%)$

9. $\mathrm{Ac}_{2} \mathrm{O}, \mathrm{py}, \operatorname{DMAP}(92 \%)$

10. $m-\mathrm{CPBA}, \mathrm{NaHCO}_{3}(85 \%)$

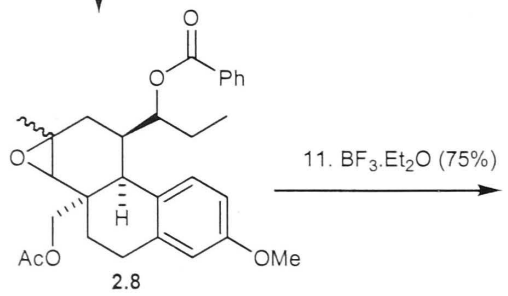<smiles>CCC(OC(=O)P)C1C[C@@H](C)C(=O)[C@]2(CO)CCc3cc(OC)ccc3[C@@H]12</smiles>

12. $\mathrm{KOH}, \mathrm{EtOH}(70 \%$<smiles>CCC(OC(=O)c1ccccc1)[C@H]1C[C@@H](C)C(=O)[C@H]2CCc3cc(OC)ccc3[C@@H]21</smiles>

1.95

13. $\left[\mathrm{Ph}_{3} \mathrm{PCH}_{2} \mathrm{OCH}_{3}\right] \mathrm{Cl}$ NaHMDS $(76 \%)$<smiles>CCC(OC(=O)c1ccccc1)C1C[C@H](C)[C@](C)(C=O)[C@H]2CCc3cc(OC)ccc3[C@H]12</smiles>

1.98

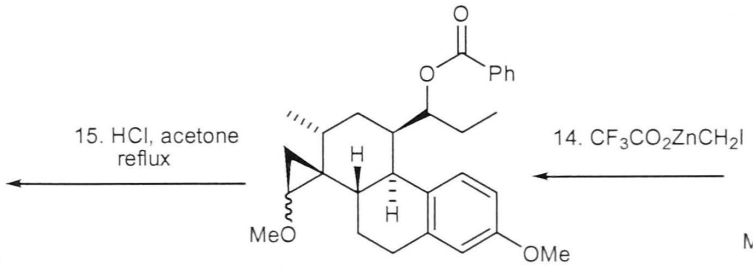

1.99

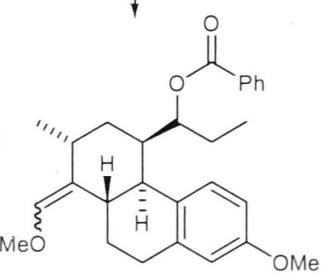

1.96<smiles>CCC(OC(=O)Pc1ccccc1)[C@H]1C[C@H](C)[C@](C)(C(=O)O)[C@H]2CCc3cc(OC)ccc3[C@H]12</smiles>

4.2

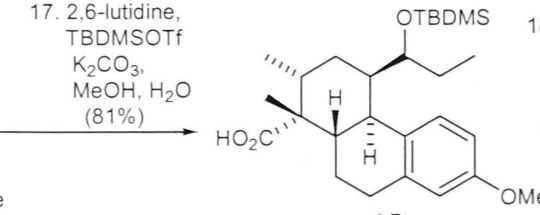

4.7

8. (i) $\mathrm{Li}, \mathrm{NH}_{3}, t-\mathrm{BuOH}$

isoprene, $\mathrm{NH}_{4} \mathrm{Cl}$

(ii) $\mathrm{AcOH} / \mathrm{THF} / \mathrm{H}_{2} \mathrm{O}$

(iii) anhyd. $\mathrm{HCl}(71 \%)$

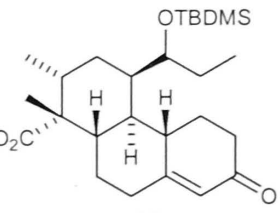

4.9 


\section{Scheme 7.1: Continued}
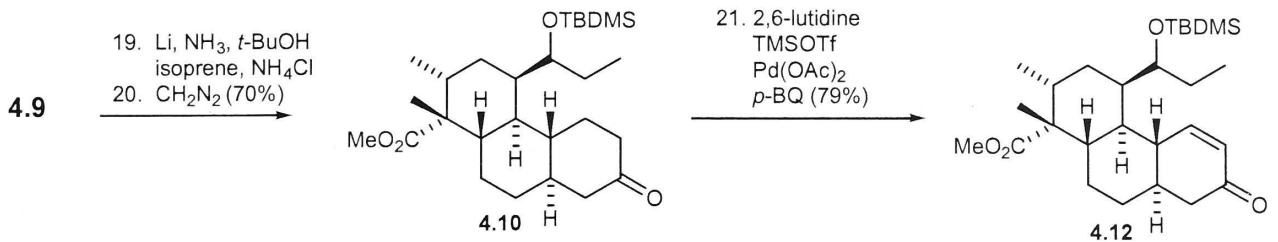

$4.12 \bar{H}$

22. LDA $\mathrm{CNCO}_{2} \mathrm{Me}$ HMPA $(83 \%)$

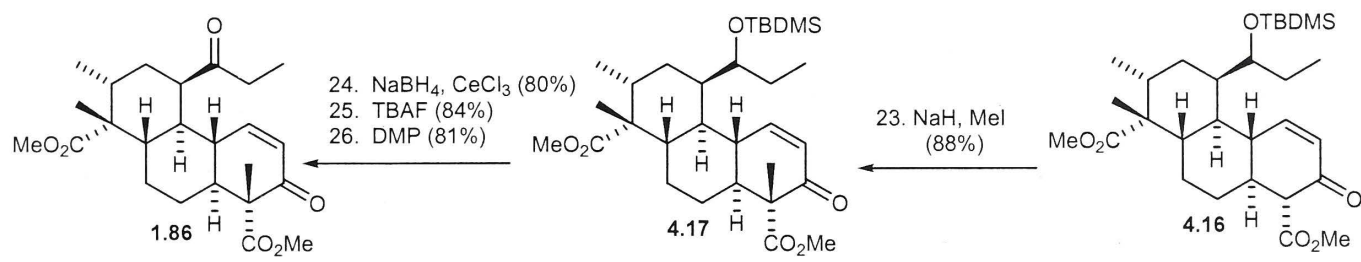
27. $\mathrm{HOCH}_{2} \mathrm{CH}_{2} \mathrm{OH}, \mathrm{Et}_{3} \mathrm{~N}$ $70{ }^{\circ} \mathrm{C}, 4 \mathrm{~d}(71 \%)$

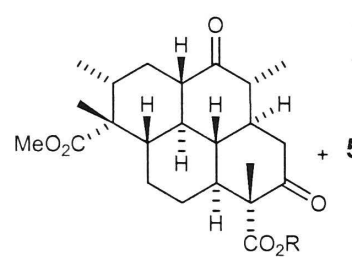

$1.87 \mathrm{R}=\mathrm{Me}$

- $5.18 \mathrm{R}=\mathrm{CH}_{2} \mathrm{CH}_{2} \mathrm{OH}$

$5.20 \mathrm{R}=\mathrm{CH}_{2} \mathrm{CH}_{2} \mathrm{OMOM}$

28. $\mathrm{NaBH}_{4}, \mathrm{CeCl}_{3}$

29. NaHMDS, $\mathrm{CS}_{2}$, Mel

30. $n-\mathrm{Bu}_{3} \mathrm{SnH}, \mathrm{AIBN}$

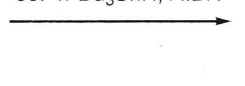

$6.2 \mathrm{R}=\mathrm{CH}_{2} \mathrm{CH}_{2} \mathrm{OMOM}(39 \%)$

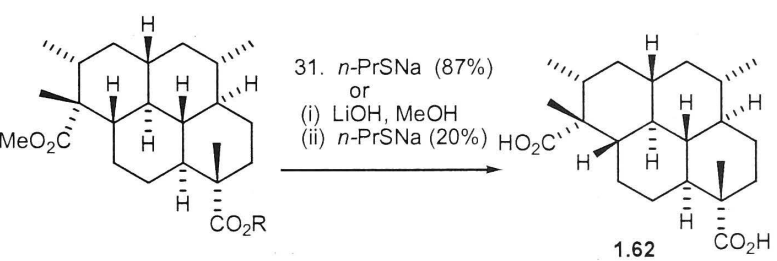

1.62
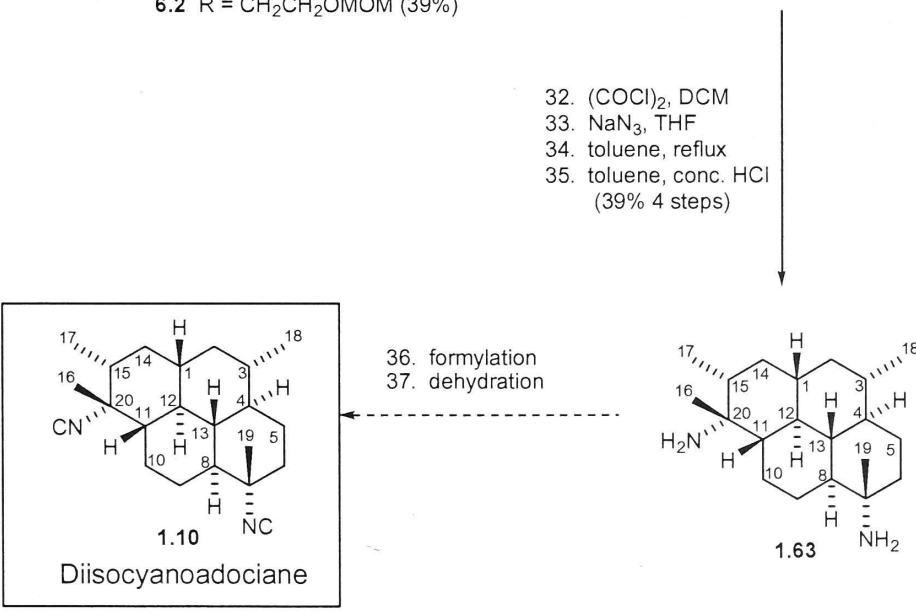

All ten stereocentres in the skeleton of $\mathbf{1 . 1 0}$ have been introduced with the correct relative stereochemistry, but we are yet to address the issue of enantioselectivity. However, the initial Birch reductive alkylation (step 1, Scheme 7.1), if carried out on an appropriate chiral benzamide ${ }^{73}$ should resolve this remaining stereochemical issue. An 
alternate approach would be an asymmetric Heck reaction ${ }^{74,75}$ to obtain a chiral phenanthrenoid. (Scheme 7.2)
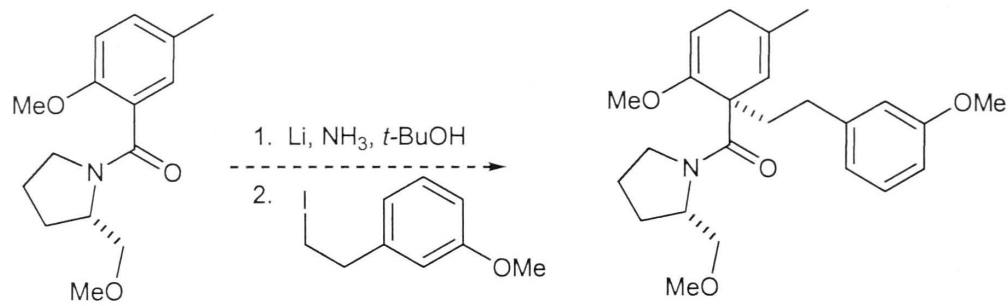

Birch Reductive Alkylation on a Chiral Benzamide

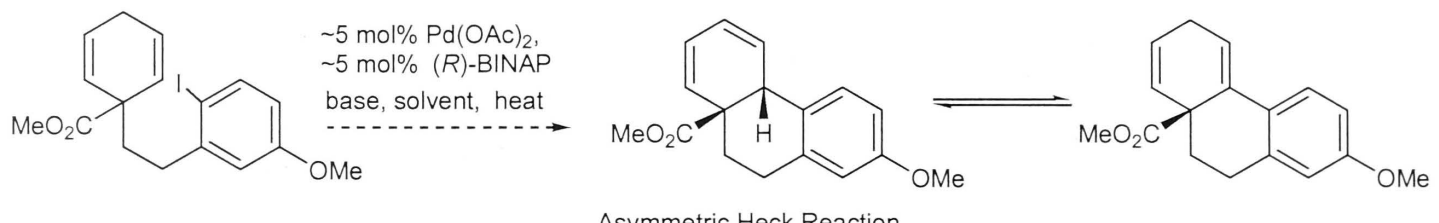

7.2: Possible Approaches to an Enatioselective Synthesis

If successful this would open the gateway to an enantioselective total synthesis of diisocyanoadociane (1.10) and a number of other diterpene natural products with significant in vitro anti-malarial activity, such as 1.11, 1.12 and 1.13.
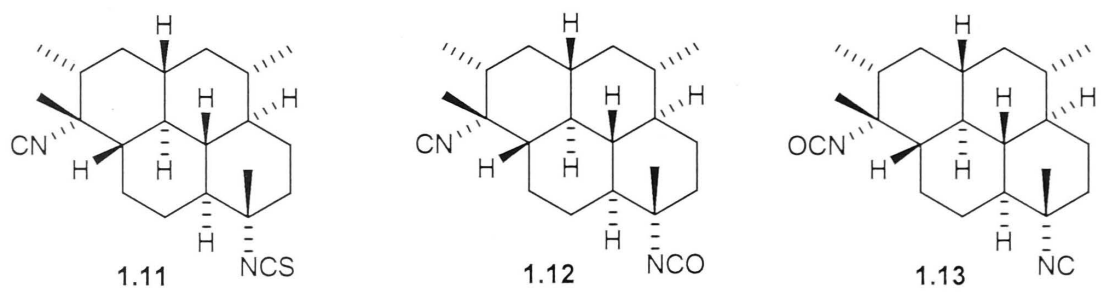
CHAPTER 8

\section{Experimental}


Chapter 8 


\section{Experimental}

\subsection{General Experimental}

Melting points (m.p.) were recorded on a Reichert hot-stage and are uncorrected. Microanalyses were carried out by the Australian National University Analytical Services Unit, Canberra.

Infrared (IR) spectra $\left(v_{\max }\right)$ were recorded on a Perkin-Elmer 683 Infrared spectrophotometer on $0.25 \mathrm{~mm} \mathrm{NaCl}$ solution cells. Data are recorded as follows: wavenumber $\left(\mathrm{cm}^{-1}\right)$, s (strong), br (broad).

Proton nuclear magnetic resonance $\left({ }^{1} \mathrm{H}\right.$ NMR) spectra were recorded on three different instruments operating at the following frequencies: (a) Varian Mercury 300 spectrometer at $300 \mathrm{MHz}$. (b) Varian Inova 600 spectrometer at $600 \mathrm{MHz}$. (c) Bruker Avance 800 spectrometer at $800 \mathrm{MHz}$. Carbon-13 nuclear magnetic resonance $\left({ }^{13} \mathrm{C}\right.$ NMR) spectra were also recorded on three different instruments operating at the following frequencies: (a) Varian Mercury 300 spectrometer at $75 \mathrm{MHz}$. (b) Varian Inova 600 spectrometer at $150 \mathrm{MHz}$. (c) Bruker Avance 800 spectrometer at $200 \mathrm{MHz}$. The instrument each sample was run on is stated. For proton spectra recorded in deuterated chloroform, the residual $\mathrm{CHCl}_{3}$ peak was used as the internal reference $(7.26$ $\mathrm{ppm})$, while the central peak of $\mathrm{CDCl}_{3}(77.0 \mathrm{ppm})$ was used as the reference for carbon spectra. For proton spectra recorded in deuterated methanol, the residual $\mathrm{HCD}_{2} \mathrm{OD}$ peak was used as the internal reference $(3.31 \mathrm{ppm})$, while the central peak of $\mathrm{CD}_{3} \mathrm{OD}(49.0$ ppm) was used as the reference for carbon spectra. Data are recorded as follows: chemical shift (ppm), multiplicity ( $\mathrm{s}$ : singlet, d: doublet, t: triplet, q: quartet, m: multiplet, dd: doublet of doublets, ddd: double doublet of doublets, dt: doublet of triplets, dq: doublet of quartets, s (br): broad singlet), coupling constant $J$ (Hz), intensity as number of protons, and assignment (based on chemical shifts). Distortionless enhancement by polarisation transfer (DEPT) and attached proton test (APT) experiments were used in the assignment of carbon spectra.

One dimensional Nuclear Overhauser spectroscopy was conducted using the 1DNOESY pulse sequence. Two dimensional NMR experiments were recorded on a 
Varian Inova 600 spectrometer. Proton-proton correlation spectroscopy was conducted using the gCOSY pulse sequence. Short range carbon-hydrogen correlation experiments were conducted via indirect detection using the gHMQC pulse sequence. Two dimensional nuclear Overhauser spectroscopy experiments were conducted with a pulse field gradient using the NOESY pulse sequence.

Low resolution (LRMS) EI mass spectra $(70 \mathrm{eV})$ and high resolution (HRMS) EI mass spectra were recorded on a Fisons VG autospec double focusing mass spectrometer. The molecular ion $\left(\mathrm{M}^{+}\right)$, if present, significant high mass ions and the more intense low mass ions are reported. Data are recorded as follows: $\mathrm{m} / \mathrm{z}$ value, relative intensity as a percentage of the base peak.

Analytical thin layer chromatography (TLC) was carried out on Merck aluminum TLC plates precoated with $\mathrm{KG}_{60} \mathrm{~F}_{254}$ silica. The developed plates were visualised under shortwave ultraviolet light and stained with PMA dip (15 g phosphomolybdic acid, $2.5 \mathrm{~g}$ cerium sulfate, $15 \mathrm{~mL}$ conc. sulfuric acid, $500 \mathrm{~mL}$ water). or a solution of potassium permanganate $(3 \mathrm{~g})$ and potassium carbonate $(20 \mathrm{~g})$ in sodium hydroxide $(5 \%$, aqueous, $5 \mathrm{~mL})$ and water $(200 \mathrm{~mL})$. After staining, the plates were developed by heating to $180{ }^{\circ} \mathrm{C}$. Flash chromatography was conducted according to the method of Still and coworkers, ${ }^{76}$ with Merck Kieselgel 60 used as the adsorbent. All solvents used for elution were analytical reagent $(A R)$ grade, and were used without further purification.

High performance liquid chromatography (HPLC) was carried out using Waters alliance 2695 HPLC pumps, and a Waters 2996 photodiode array detector set at $210 \mathrm{~nm}$. Novapack C18 columns were supplied by Waters.

Reagents used in reactions were obtained commercially from the Merck or Aldrich Chemical Companies, and were used without further purification unless otherwise indicated. Tetrahydrofuran (THF), diethyl ether (ether) and benzene were purified by distillation from sodium benzophenone ketyl under nitrogen. Toluene and dichloromethane (DCM) were purified by distillation from calcium hydride under nitrogen. Triethylamine and diisopropylamine were purified by distillation from calcium hydride under nitrogen and stored over potassium hydroxide. Ethylene glycol was purified by distillation from $\mathrm{MgSO}_{4}$ under reduced pressure and stored over $3 \AA$ 
molecular sieves. Ammonia was dried with sodium metal and $\mathrm{FeNO}_{3}$ and then distilled under an inert atmosphere as required. Sodium hydride $(60 \%$ in mineral oil) was washed twice with dry petroleum ether before use. Dess-Martin periodinane was prepared by the method of Dess and Martin. ${ }^{77-79}$ Ethanol-free ethereal diazomethane was prepared from Diazald ${ }^{\circledR}\left(N\right.$-methyl- $N$-nitroso- $p$-toluenesulfonamide). ${ }^{80}$

All moisture-sensitive reactions were conducted in flame-dried glassware under a positive pressure of dry nitrogen, unless otherwise stated. Reaction temperatures refer to the external oil bath temperatures. All organic extracts were dried with anhydrous magnesium sulfate. After filtration, the bulk of the solvent was removed using a Büchi rotary evaporator with a water aspirator. Final traces of solvent were removed under high vacuum.

\subsubsection{Notes on Nomenclature}

Chemical Abstracts nomenclature has been used throughout the experimental section, which are generally in accordance with the rules published by the International Union of Pure and Applied Chemistry (IUPAC).

The tricyclic compounds have been named as derivatives of phenanthrene with two possible numbering systems.

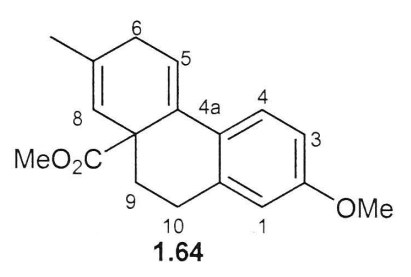

For example compound $\mathbf{1 . 6 4}$ is named as; (8aRS) Methyl 9,10-Dihydro-2-methoxy-7methylphenanthrene- $8 \mathrm{a}(6 H)$-carboxylate.

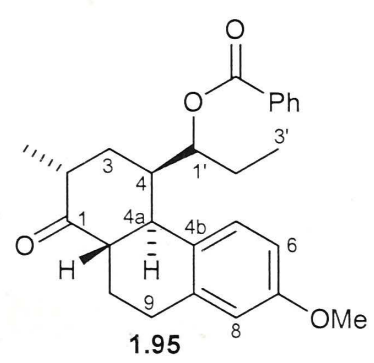


For example compound $\mathbf{1 . 9 5}$ is named as; (2RS, 4RS, 4aRS, 10aSR, 1'SR) 4-(1'Benzoyloxypropyl)-7-methoxy-2-methyl-3,4,4a,9,10,10a-hexahydrophenanthren-1(2H)one.

The tetracyclic compounds $\mathbf{5 . 2}, \mathbf{5 . 1 1}, \mathbf{5 . 1 2}$ and $\mathbf{5 . 1 4}$ have been named as derivatives of pyrene.
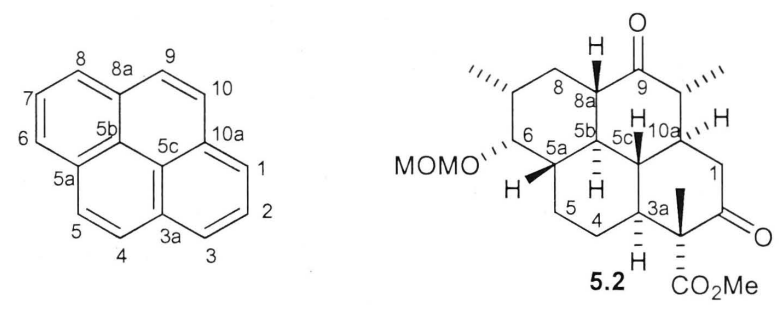

For example compound $\mathbf{5 . 2}$ is named as; (3RS, 3aSR, 5aSR, 5bSR, 5c $S R, 6 R S, 7 R S$, 8aSR, 10RS, 10aSR) Methyl-2,9-dioxo-6-methoxmethoxy-1, 3a, 4, 5, 5a, 5b, 5c, 6, 7, 8, 8a, 10, 10a-tridecahydro-3,7,10-trimethylpyrene-3(2H)-carboxylate.

The tetracyclic compounds $1.87,5.20,6.1,6.2,1.62$ and 1.63 are named as derivatives of isocycloamphilectane.
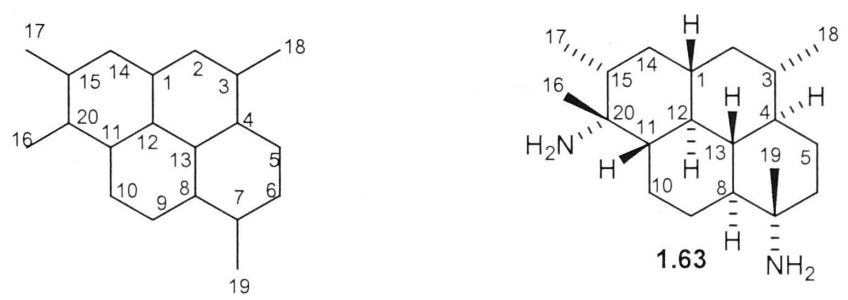

For example compound $\mathbf{1 . 6 3}$ is named as; Isocycloamphilectane-7,20-diamine. 


\subsection{Chapter 2 Experimental}

(1RS) Methyl 2-Methoxy-1-(2'-(3"-methoxyphenyl)ethyl)-5-methylcyclohexa-2,5diene-1-carboxylate $(8.1)$
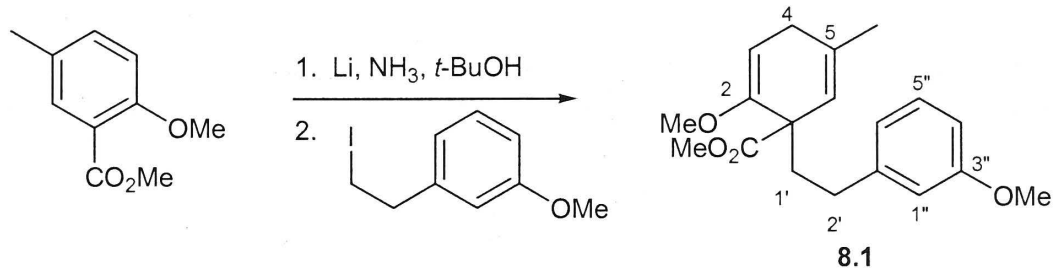

Preparation in accordance to that previously recorded by S.R. Crabtree, Ph.D. thesis, ANU 1990. ${ }^{24}$

A flame dried 3-necked flask, fitted with a dry ice condenser was charged with 2methoxy-5-methylbenzoate $(2.0 \mathrm{~g}, 11.1 \mathrm{mmol})$, THF $(20 \mathrm{~mL})$ and $t$-butyl alcohol $(2.1$ $\mathrm{mL}, 22.2 \mathrm{mmol})$ under nitrogen. Dry ammonia $(100 \mathrm{~mL})$ was then distilled into the flask cooled to $-78{ }^{\circ} \mathrm{C}$, and small pieces of freshly cleaned lithium wire $(0.19 \mathrm{~g}, 27.8$ mg/atom) were added. The resulting blue solution was warmed to $-33{ }^{\circ} \mathrm{C}$ and stirred for $15 \mathrm{~min}$, before adding isoprene until the blue colour dispersed. The ammonia was then boiled off under a stream of nitrogen and the residue cooled to $-78{ }^{\circ} \mathrm{C}$. 2- $\left(3^{\prime \prime}-\right.$ Methoxyphenyl)-ethyl iodide (3.2 g, $12.2 \mathrm{mmol})$ in THF $(8.5 \mathrm{~mL})$ was then added drop wise over $10 \mathrm{~min}$ and the resulting reaction mixture was stirred at $-78{ }^{\circ} \mathrm{C}$ for $30 \mathrm{~min}$, before warming to room temperature and stirring for an additional $16 \mathrm{~h}$. Water $(25 \mathrm{~mL})$ was then added and the reaction mixture extracted with ethyl acetate $(2 \times 100 \mathrm{~mL})$. The combined organic extracts were washed with water $(20 \mathrm{~mL})$, brine $(20 \mathrm{~mL})$, dried over anhydrous $\mathrm{MgSO}_{4}$, and concentrated in vacuo to give a yellow oil. Purification by flash column chromatography on silica gel using ethyl acetate : hexane (1:9) as eluant gave the title compound $\mathbf{8 . 1}(2.0 \mathrm{~g}, 57 \%)$ as a yellow oil.

IR (thin film) $\mathbf{c m}^{-1}: 2937 \mathrm{~s}(\mathrm{C}-\mathrm{H}), 1731 \mathrm{~s}(\mathrm{C}=\mathrm{O}), 1695 \mathrm{~s}, 1665 \mathrm{~s}, 1601 \mathrm{~s}, 1584 \mathrm{~s}, 1491 \mathrm{~s}$ $(\mathrm{C}=\mathrm{C}), 1384 \mathrm{~s}, 1365 \mathrm{~s}, 1230 \mathrm{br}, 1168 \mathrm{~s}, 1045 \mathrm{~s}(\mathrm{C}-\mathrm{O})$.

${ }^{1} \mathbf{H}$ NMR (300 MHz, $\left.\mathbf{C D C l}_{3}\right)$ ): $1.77\left(\mathrm{~s}, 3 \mathrm{H}, 5-\mathrm{CH}_{3}\right), 2.00\left(\mathrm{~m}, 1 \mathrm{H}, \mathrm{H}-1^{\prime}\right), 2.31-2.44$ (m, 3H, H-1', H-2'), 2.78 (m, 2H, H-4), 3.56 (s, 3H, - $\mathrm{CO}_{2} \mathrm{CH}_{3}$ ), 3.67 (s, 3H, 2-OCH $)$, $3.78\left(\mathrm{~s}, 3 \mathrm{H}, 3^{\prime \prime}-\mathrm{OCH}_{3}\right), 4.88$ (t, $\left.J=3.6 \mathrm{~Hz}, 1 \mathrm{H}, \mathrm{H}-3\right), 5.16$ (s (br), 1H, H-6), 6.68-6.76 (m, 3H, H-2", H-4", H-6"), 7.16 (dd, $\left.J=8.4, J=7.5 \mathrm{~Hz}, 1 \mathrm{H}, \mathrm{H}-5^{\prime \prime}\right)$. 
${ }^{13} \mathrm{C}$ NMR (75 MHz, $\left.\mathbf{C D C l}_{3}\right)$ ): $22.6\left(5-\mathrm{CH}_{3}\right), 30.8\left(\mathrm{CH}_{2}, \mathrm{C}-1^{\prime}\right), 31.3\left(\mathrm{CH}_{2}, \mathrm{C}-4\right), 36.1$ $\left(\mathrm{CH}_{2}, \mathrm{C}-2^{\prime}\right), 52.3\left(1-\mathrm{CO}_{2} \mathrm{CH}_{3}\right), 52.5(\mathrm{C}, \mathrm{C}-1), 54.4\left(2-\mathrm{OCH}_{3}\right), 55.1\left(3^{\prime \prime}-\mathrm{OCH}_{3}\right), 93.8$ (CH, C-3), 110.8 (CH, C-4"), 113.9 (CH, C-2"), 120.7 (CH, C-6"), $121.6(\mathrm{CH}, \mathrm{C}-6)$, $128.9\left(\mathrm{CH}, \mathrm{C}-5^{\prime \prime}\right), 134.7$ (C, C-5), 144.1 (C, C-1"), 152.3 (C, C-2), 159.3 (C, C-3"), $174.1(1-\mathrm{CO})$.

LRMS (m/z): $316\left(\mathrm{M}^{+}, 31 \%\right), 257$ (29), 195 (18), 181 (46), 149 (70), 135 (100), 121 (43), 105 (40), 91 (43), 77 (32).

HRMS: $\mathrm{C}_{19} \mathrm{H}_{24} \mathrm{O}_{4}\left(\mathrm{M}^{+}\right)$requires 316.1675 , found 316.1677

(8aRS) Methyl 9,10-Dihydro-2-methoxy-7-methylphenanthrene-8a(6H)carboxylate (1.64)

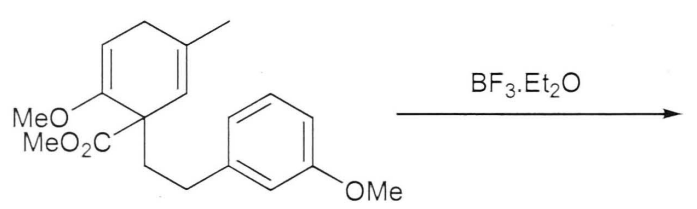

8.1

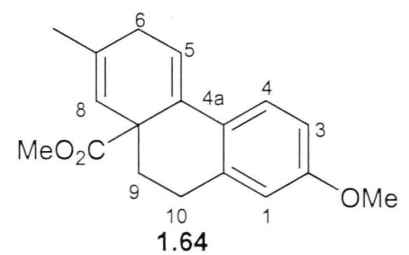

Preparation in accordance to that previously recorded by S.R. Crabtree, Ph.D. thesis, ANU 1990. ${ }^{24}$

Boron trifluoride diethyl etherate $(5.6 \mathrm{~mL}, 43.9 \mathrm{mmol})$ was added drop wise to a solution of ester 8.1 (12.6 g, $39.9 \mathrm{mmol})$ in DCM $(250 \mathrm{~mL})$ at $-24{ }^{\circ} \mathrm{C}$ under nitrogen. The reaction mixture was warmed to room temperature and stirred for $1 \mathrm{~h}$. Water (60 $\mathrm{mL}$ ) was then added and the resulting mixture stirred vigorously for $10 \mathrm{~min}$. The organic phase was separated and the aqueous phase further extracted with DCM $(2 \times 50$ $\mathrm{mL}$ ). The combined organic extracts were dried over anhydrous $\mathrm{MgSO}_{4}$, and concentrated in vacuo to give a yellow solid. Trituration with hexane gave the title compound $1.64(9.64 \mathrm{~g}, 85 \%)$ as a cream powder. A sample was crystallised from methanol to give white needle-like crystals.

m.p.: $135-138^{\circ} \mathrm{C}$

IR (thin film) $\mathrm{cm}^{-1}$ : 2948s (C-H), 1720s (C=O), 1606s, 1572s, 1497s, 1444, 1230s, $1167,1072$. 
${ }^{1} \mathbf{H}$ NMR (300 MHz, $\left.\mathbf{C D C l}_{3}\right) \delta: 1.78\left(\mathrm{~s}, 3 \mathrm{H}, 7-\mathrm{CH}_{3}\right), 1.80(\mathrm{~m}, 1 \mathrm{H}, \mathrm{H}-9), 2.45$ (ddd, $J_{g e m}$ $\left.=13.0, J_{9,10}=5.7, J_{9,10}=1.6 \mathrm{~Hz}, 1 \mathrm{H}, \mathrm{H}^{\prime}-9\right), 2.73-3.00(\mathrm{~m}, 4 \mathrm{H}, \mathrm{H}-6, \mathrm{H}-10), 3.57(\mathrm{~s}, 3 \mathrm{H}$, $\left.8 \mathrm{a}-\mathrm{CO}_{2} \mathrm{CH}_{3}\right), 3.78\left(\mathrm{~s}, 3 \mathrm{H}, 2-\mathrm{OCH}_{3}\right), 5.40$ (s (br), $\left.1 \mathrm{H}, \mathrm{H}-8\right), 6.21$ (dd, $J=4.4, J=3.2 \mathrm{~Hz}$, $1 \mathrm{H}, \mathrm{H}-5), 6.56\left(\mathrm{~d}, J_{1,3}=2.6 \mathrm{~Hz}, 1 \mathrm{H}, \mathrm{H}-1\right), 6.74\left(\mathrm{dd}, J_{3,4}=8.8, J_{3,1}=2.6 \mathrm{~Hz}, 1 \mathrm{H}, \mathrm{H}-3\right)$, $7.53\left(\mathrm{~d}, J_{4,3}=8.8,1 \mathrm{H}, \mathrm{H}-4\right)$.

${ }^{13} \mathbf{C}$ NMR (75 MHz, CDCl 3 ) $8: 23.2\left(7-\mathrm{CH}_{3}\right), 27.7\left(\mathrm{CH}_{2}, \mathrm{C}-10\right), 32.6\left(\mathrm{CH}_{2}, \mathrm{C}-9\right), 34.2$ $\left(\mathrm{CH}_{2}, \mathrm{C}-6\right), 48.9$ (C, C-8a), $52.6\left(8 \mathrm{a}-\mathrm{CO}_{2} \mathrm{CH}_{3}\right), 55.5\left(2-\mathrm{OCH}_{3}\right), 113.1(\mathrm{CH}, \mathrm{C}-3), 113.2$ (CH, C-1), 118.3 (CH, C-5), 123.6 (CH, C-4), 125.7 (C, C-4a), 128.1 (CH, C-8), 133.3 (C, C-7), 133.8 (C, C-10a), 136.4 (C, C-4b), 158.7 (C, C-2), 174.5 (8a-CO).

LRMS (m/z): $284\left(\mathrm{M}^{+}, 58 \%\right), 226$ (36), 225 (100), 224 (45), 210 (37), 209 (23), 193 (20), 179 (23), 178 (26), 166 (23), 165 (34), 152 (19).

HRMS: $\mathrm{C}_{18} \mathrm{H}_{20} \mathrm{O}_{3}\left(\mathrm{M}^{+}\right)$requires 284.1412 , found 284.1415 .

Microanalysis: Calcd. for $\mathrm{C}_{18} \mathrm{H}_{20} \mathrm{O}_{3}: \mathrm{C}, 76.03 \% ; \mathrm{H}, 7.09 \%$. Found: $\mathrm{C}, 75.92 \%$; $\mathrm{H}$, $6.82 \%$.

(8aRS) Methyl 9,10-Dihydro-5-(1'-oxopropyl)-2-methoxy-7-methylphenanthrene$8 \mathrm{a}(6 H)$-carboxylate $(2.1)$

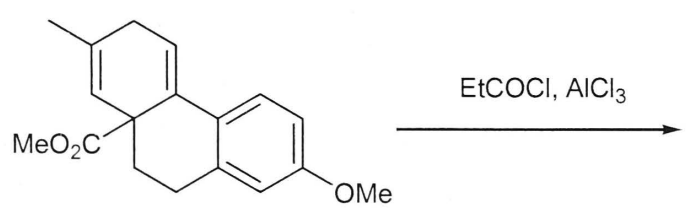

1.64

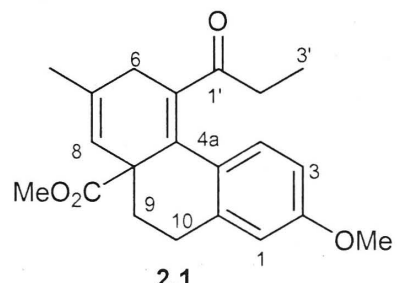

2.1

Aluminum chloride $(9.4 \mathrm{~g}, 70.4 \mathrm{mmol})$ was added to a solution of olefin $1.64(5.0 \mathrm{~g}$, $17.6 \mathrm{mmol})$ and propionyl chloride $(4.6 \mathrm{~mL}, 53.8 \mathrm{mmol})$ in $\mathrm{DCM}(150 \mathrm{~mL})$ at $-78{ }^{\circ} \mathrm{C}$ under nitrogen. The resulting reaction mixture was stirred for $20 \mathrm{~min}$ then quenched by pouring over iced water with vigorous stirring. The organic phase was separated and the aqueous phase extracted with DCM $(2 \times 30 \mathrm{~mL})$. The combined organic extracts were washed with water, aqueous potassium dihydrogen orthophosphate, dried over anhydrous $\mathrm{MgSO}_{4}$ and concentrated in vacuo to give a cream solid. Trituration with hexane gave the title compound $\mathbf{2 . 1}(4.5 \mathrm{~g}, 75 \%)$ as a cream powder. A sample was crystallised from ethyl acetate and hexane to give white crystals. 
m.p.: $139-144^{\circ} \mathrm{C}$

IR (thin film) $\mathbf{c m}^{-1}$ : 2936s $(\mathrm{C}-\mathrm{H}), 1729 \mathrm{~s}(\mathrm{C}=\mathrm{O}), 1679 \mathrm{~s}(\mathrm{C}=\mathrm{O}), 1605 \mathrm{~s}, 1498 \mathrm{~s}, 1445$, $1264,1239,1166,1070$.

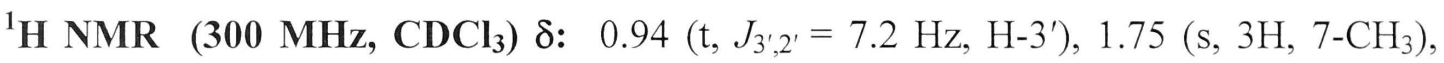
$1.90\left(\mathrm{ddd}, J_{\text {gem }}=13.5 \mathrm{~Hz}, J_{9,10}=10.8 \mathrm{~Hz}, J_{9,10}=7.0 \mathrm{~Hz}, 1 \mathrm{H}, \mathrm{H}-9\right), 2.23$ (dq, $J=17.7$ $\left.\mathrm{Hz}, J=7.2 \mathrm{~Hz}, 2 \mathrm{H}, \mathrm{H}-2^{\prime}\right), 2.57$ (m, 1H, H'-9), 2.56 (d, J $\left.J_{\text {gem }}=21.9 \mathrm{~Hz}, 1 \mathrm{H}, \mathrm{H}-6\right), 2.87$ $\left(\mathrm{ABdd}, J_{g e m}=17.9 \mathrm{~Hz}, J_{10,9}=6.0 \mathrm{~Hz}, 1 \mathrm{H}, \mathrm{H}-10\right), 3.01\left(\mathrm{ddd}, J_{g e m}=17.9 \mathrm{~Hz}, J_{10,9}=10.8\right.$ $\left.\mathrm{Hz}, J_{10,9}=7.0 \mathrm{~Hz}, 1 \mathrm{H}, \mathrm{H}^{\prime}-10\right), 3.24\left(\mathrm{~d}, J_{\text {gem }}=21.9 \mathrm{~Hz}, 1 \mathrm{H}, \mathrm{H}^{\prime}-6\right), 3.44$ (s, 3H, 8a$\mathrm{CO}_{2} \mathrm{CH}_{3}$ ), 3.76 (s, 3H, 2-OCH 3 ), 5.33 (s (br), 1H, H-8), 6.60-6.63 (m, 2H, H-1, H-3), $6.97\left(\mathrm{~d}, J_{4,3}=8.7 \mathrm{~Hz}, 1 \mathrm{H}, \mathrm{H}-4\right)$.

${ }^{13} \mathrm{C}$ NMR (75 MHz, $\left.\mathbf{C D C l}_{3}\right)$ 8: $8.7\left(\mathrm{CH}_{3}, \mathrm{C}-3\right.$ ') $, 22.6\left(7-\mathrm{CH}_{3}\right), 26.7\left(\mathrm{CH}_{2}, \mathrm{C}-9\right), 34.3$ $\left(\mathrm{CH}_{2}\right), 34.3\left(\mathrm{CH}_{2}\right), 35.6\left(\mathrm{CH}_{2}\right) 50.7(\mathrm{C}, \mathrm{C}-8 \mathrm{a}), 52.2\left(8 \mathrm{a}-\mathrm{CO}_{2} \mathrm{CH}_{3}\right), 55.1\left(2-\mathrm{OCH}_{3}\right)$, 111.7 (CH, C-3), 113.2 (CH, C-1), 122.3 (CH, C-4), 126.9 (C, C-4a), 130.4 (C, C-8), 131.0 (C, C-5), 132.7 (C, C-7), 135.2 (CH, C-4b), 137.8 (C, C-10a), 159.5 (C, C-2), 173.5 (8a-CO), 211.8 (1'-CO).

LRMS (m/z): $340\left(\mathrm{M}^{+}, 40 \%\right), 311$ (10), 281 (62), 263 (26), 251 (30), 223 (39), 209 (19), 178 (14), 165 (26), 57 (100).

HRMS: $\mathrm{C}_{21} \mathrm{H}_{24} \mathrm{O}_{4}\left(\mathrm{M}^{+}\right)$requires 340.1675 , found 340.1670 .

Microanalysis: Calcd. for $\mathrm{C}_{21} \mathrm{H}_{24} \mathrm{O}_{4}$ : C, 74.09\%; H, 7.11\%. Found: C, 73.97\%; H, $6.97 \%$

(7aRS) Methyl 4-ethylidene-5,7a,8,9-tetrahydro-2-methoxy-6-methyl-4Hcycopenta[def]phenanthrene-7a-carboxylate (2.3)

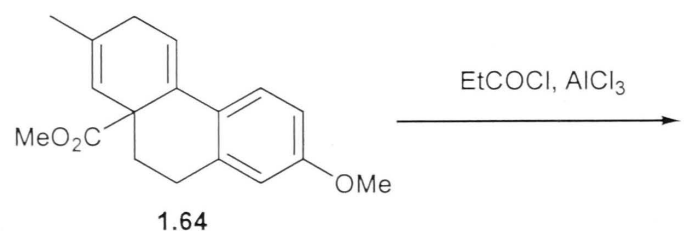

1.64

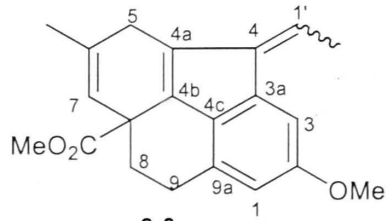

2.3 
Aluminum (III) chloride $(0.05 \mathrm{~g}, 0.35 \mathrm{mmol})$ was added to a solution of olefin $\mathbf{1 . 6 4}$ (0.05 g, $0.18 \mathrm{mmol})$ and propionyl chloride $(0.03 \mathrm{~mL}, 0.35 \mathrm{mmol})$ in DCM $(2 \mathrm{~mL})$ at room temperature under nitrogen. The resulting reaction mixture was stirred for $18 \mathrm{~h}$ poured over iced water with vigorous stirring. The organic phase was separated and the aqueous phase extracted with ethyl acetate $(3 \times 10 \mathrm{~mL})$. The combined organic extracts were washed with water $(10 \mathrm{~mL})$, aqueous saturated sodium bicarbonate $(10 \mathrm{~mL})$, dried over anhydrous $\mathrm{MgSO}_{4}$ and concentrated in vacuo to give a yellow oil. Purification by flash column chromatography on silica gel using ethyl acetate : hexane (1:9) as eluant gave the title compound $\mathbf{2 . 3}(0.03 \mathrm{~g}, 52 \%)$ as a yellow oil.

IR (thin film) $\mathbf{c m}^{-1}: 2949(\mathrm{C}-\mathrm{H}), 1725 \mathrm{~s}(\mathrm{C}=\mathrm{O}), 1594,1477,1449,1269,1232,1148$, 1062.

${ }^{1} \mathbf{H}$ NMR (300 MHz, $\left.\mathbf{C D C l}_{\mathbf{3}}\right)$ \&: $1.88\left(\mathrm{~s}, 3 \mathrm{H}, 6-\mathrm{CH}_{3}\right), 2.21\left(\mathrm{~d}, J=7.6 \mathrm{~Hz}, 3 \mathrm{H}, 1^{\prime}-\mathrm{CH}_{3}\right)$, 2.56-2.92 (m, 4H, H-8, H-9), 3.22, 3.37 (2 x ABd, $J=21.5$ Hz, 2H, H-5), 3.62 (s, 3H, 7a- $\mathrm{CO}_{2} \mathrm{CH}_{3}$ ), 3.81 (s, 3H, 2- $\mathrm{OCH}_{3}$ ), 5.61 (s (br), 1H, H-7), 6.52 (s, 1H, H-1), 6.61 (q, J $\left.=7.6 \mathrm{~Hz}, 1 \mathrm{H}, 1^{\prime}-\mathrm{H}\right), 6.92(\mathrm{~s}, 1 \mathrm{H}, \mathrm{H}-3)$.

${ }^{13} \mathbf{C}$ NMR (75 MHz, $\left.\mathbf{C D C l}_{3}\right)$ 8: $15.3\left(\mathrm{C}-2^{\prime}\right), 23.7\left(6-\mathrm{CH}_{3}\right), 25.7\left(\mathrm{CH}_{2}, \mathrm{C}-9\right), 33.3(2 \mathrm{x}$ $\left.\mathrm{CH}_{2}, \mathrm{C}-8, \mathrm{C}-5\right), 46.9,52.3,54.2,55.9,104.6$ (CH, C-3), $110.1(\mathrm{CH}, \mathrm{C}-1), 122.2,126.4$, $128.0,129.6,131.4,137.4,137.6,140.2,158.8(\mathrm{C}, \mathrm{C}-2), 174.0\left(7 \mathrm{a}-\mathrm{CO}_{2} \mathrm{CH}_{3}\right)$.

$\left(4^{\prime} R S, 4 \mathrm{a}^{\prime} S R, 10 \mathrm{a}^{\prime} R S\right)$ 1-[10a'-Hydroxymethyl-7'-methoxy-2'-methyl$4 a^{\prime}, 9^{\prime}, 10^{\prime}, 10 a^{\prime}$-tetrahydrophenanthren-4' (3'H)-yl]-propan-1-one (2.2)
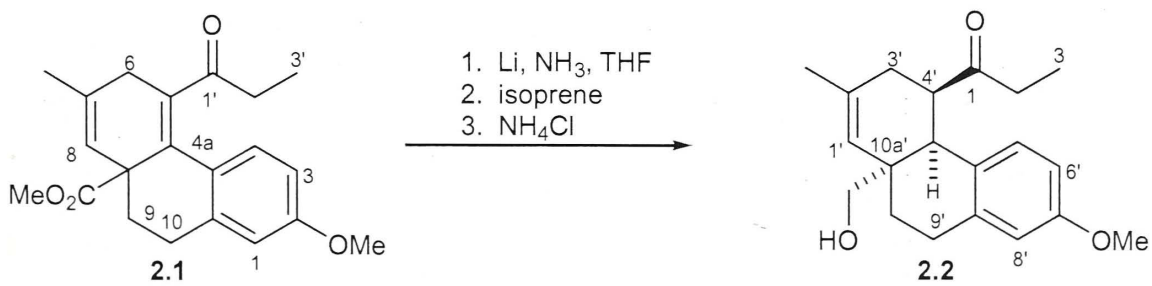

Preparation in accordance to that previously recorded by K.A. Fairweather, Honours thesis, ANU 2002. ${ }^{30}$

Dry ammonia $(480 \mathrm{~mL})$ was distilled into a 3-necked flask fitted with a dry ice condenser, under nitrogen. Small pieces of freshly cleaned lithium wire $(1.0 \mathrm{~g}, 152.7$ 
mmol) were added and the resulting blue solution was stirred at $-78{ }^{\circ} \mathrm{C}$ for $15 \mathrm{~min}$. A solution of ketone 2.1 (4.0 g, $11.7 \mathrm{mmol})$ in THF $(200 \mathrm{~mL})$ was then added drop wise over $5 \mathrm{~min}$ and the resulting reaction mixture was stirred for $15 \mathrm{~min}$ before adding isoprene drop wise until the blue colour dispersed. The ammonia was allowed to boil off under a stream of nitrogen and a saturated solution of aqueous ammonium chloride $(80 \mathrm{~mL})$ was added. After $15 \mathrm{~min}$, water $(50 \mathrm{~mL})$ was added and the aqueous phase extracted with ethyl acetate $(3 \times 100 \mathrm{~mL})$. The combined organic extracts were washed with water $(50 \mathrm{~mL})$, brine $(50 \mathrm{~mL})$ and dried over anhydrous $\mathrm{MgSO}_{4}$. Concentration of the organic phase in vacuo gave a yellow oil which was purified by flash column chromatography on silica gel using ethyl acetate : hexane $(2: 3)$ as eluant to give the title compound $\mathbf{2 . 2}(2.7 \mathrm{~g}, \mathbf{7 4 \%})$ as a white solid.

m.p.: $106-109^{\circ} \mathrm{C}$

IR (thin film) $\mathbf{c m}^{-1}$ : $3436 \mathrm{br}(\mathrm{C}-\mathrm{OH}), 2914 \mathrm{~s}(\mathrm{C}-\mathrm{H}), 1701 \mathrm{~s}(\mathrm{C}=\mathrm{O}), 1611 \mathrm{~s}, 1502 \mathrm{~s}, 1461$, 1278, 1236, 1075, 1038.

${ }^{1}$ H NMR (300 MHz, $\mathbf{C D C l}_{3}$ ) ): 1.04 (t, $\left.J_{3,2}=7.2 \mathrm{~Hz}, 3 \mathrm{H}, \mathrm{H}-3\right), 1.54$ (dt, $J_{\text {gem }}=13.2$ $\left.\mathrm{Hz}, J_{10^{\prime}, 9^{\prime}}=5.1 \mathrm{~Hz}, 1 \mathrm{H}, \mathrm{H}-10^{\prime}\right), 1.65\left(\mathrm{~s}, 3 \mathrm{H}, 2^{\prime}-\mathrm{CH}_{3}\right), 1.75\left(\mathrm{ddd}, J_{\text {gem }}=13.2 \mathrm{~Hz}, J_{10^{\prime}, 9^{\prime}}=\right.$ $\left.10.5 \mathrm{~Hz}, J_{10^{\prime}, 9^{\prime}}=5.1 \mathrm{~Hz}, 1 \mathrm{H}, \mathrm{H}^{\prime}-10^{\prime}\right), 1.94\left(\mathrm{~d}, J=6.9 \mathrm{~Hz}, 2 \mathrm{H}, \mathrm{H}-3^{\prime}\right), 2.35-2.56$ (m, 3H, H-2, H-9'), $2.74\left(\mathrm{ddd}, J_{\text {gem }}=16.2, J_{9^{\prime}, 10^{\prime}}=10.5 \mathrm{~Hz}, J_{9^{\prime}}, 10^{\prime}=5.1 \mathrm{~Hz}, \mathrm{H}^{\prime}-9^{\prime}\right), 2.91$ (s (br), 1H, -OH), 3.09 (ddd, $\left.J=10.2 \mathrm{~Hz}, J=6.9 \mathrm{~Hz}, J=3.3 \mathrm{~Hz}, 1 \mathrm{H}, \mathrm{H}-4{ }^{\prime}\right), 3.46,3.60(2 \mathrm{x}$ $\left.\mathrm{ABd}, J=11.1 \mathrm{~Hz}, 2 \mathrm{H}, 10 \mathrm{a}^{\prime}-\mathrm{CH}_{2}\right), 3.71\left(\mathrm{~d}, J_{4 \mathrm{a}^{\prime}{ }^{\prime}{ }^{\prime}}=3.3 \mathrm{~Hz}, 1 \mathrm{H}, \mathrm{H}-4 \mathrm{a}^{\prime}\right), 3.71\left(\mathrm{~s}, 3 \mathrm{H}, 7^{\prime}-\right.$ $\left.\mathrm{OCH}_{3}\right), 4.98$ (s (br), 1H, H-1'), 6.54 (d, $\left.J_{8^{\prime}, 6^{\prime}}=2.7 \mathrm{~Hz}, 1 \mathrm{H}, \mathrm{H}-8^{\prime}\right), 6.60$ (dd, $J_{6}{ }^{\prime}, 5^{\prime}=8.6$ $\left.\mathrm{Hz}, J_{6}{ }^{\prime}, 8^{\prime}=2.7 \mathrm{~Hz}, 1 \mathrm{H}, \mathrm{H}-6^{\prime}\right), 6.72\left(\mathrm{~d}, J_{5^{\prime}, 6^{\prime}}=8.6 \mathrm{~Hz}, 1 \mathrm{H}, \mathrm{H}-5^{\prime}\right)$.

${ }^{13} \mathrm{C}$ NMR (75 MHz, $\left.\mathbf{C D C l}_{3}\right)$ 8: $8.0\left(\mathrm{CH}_{3}, \mathrm{C}-3\right), 23.6\left(2^{\prime}-\mathrm{CH}_{3}\right), 26.5\left(\mathrm{CH}_{2}, \mathrm{C}-10^{\prime}\right), 28.5$ $\left(\mathrm{CH}_{2}\right), 29.6\left(\mathrm{CH}_{2}\right), 34.3\left(\mathrm{CH}_{2}\right), 39.2\left(\mathrm{C}, \mathrm{C}-10 \mathrm{a}^{\prime}\right), 42.0\left(\mathrm{CH}, \mathrm{C}-4 \mathrm{a}^{\prime}\right), 50.0\left(\mathrm{CH}, \mathrm{C}-4^{\prime}\right), 54.9$ $\left(7^{\prime}-\mathrm{OCH}_{3}\right), 69.3\left(\mathrm{Cl}^{\prime} \mathrm{a}^{\prime}-\mathrm{CH}_{2} \mathrm{OH}\right), 111.7\left(\mathrm{CH}, \mathrm{C}-6^{\prime}\right), 113.3\left(\mathrm{CH}, \mathrm{C}-8^{\prime}\right), 125.3\left(\mathrm{CH}, \mathrm{C}-1^{\prime}\right)$, $127.9\left(\mathrm{CH}, \mathrm{C}-5^{\prime}\right), 128.7$ (C, C-4b'), 136.9 (C, C-2'), 139.1 (C, C-8a'), 157.0 (C, C-7'), $215.1(1-\mathrm{CO})$.

LRMS (m/z): $314\left(\mathrm{M}^{+}, 60 \%\right), 283$ (74), 265 (26), 239 (24), 225 (84), 211 (63), 199 (16), 190 (63), 171 (44), 147 (19), 57 (100). 
HRMS: $\mathrm{C}_{20} \mathrm{H}_{26} \mathrm{O}_{3}\left(\mathrm{M}^{+}\right)$requires 314.1882 , found 314.1884 .

Microanalysis: Calcd. for $\mathrm{C}_{20} \mathrm{H}_{26} \mathrm{O}_{3}: \mathrm{C}, 76.40 \% ; \mathrm{H}, 8.33 \%$. Found: C, $76.30 \%$; $8.40 \%$.

$\left(4^{\prime} R S, 4 \mathrm{a}^{\prime} S R, 10 \mathrm{a}^{\prime} R S\right)$ 1-[10a'-Methoxmethoxy-7'-methoxy-2'-methyl$4 a^{\prime}, 9^{\prime}, 10^{\prime}, 10 a^{\prime}$-tetrahydrophenanthren-4'(3'H)-yl]-propan-1-one (8.2)
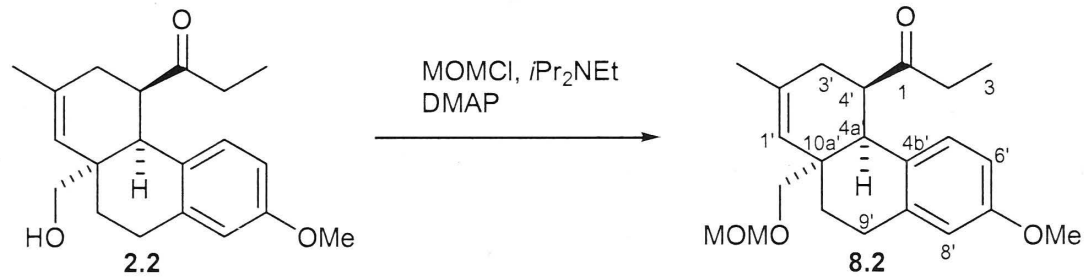

Hünig's base $(5.6 \mathrm{~mL}, \quad 32.1 \mathrm{mmol})$ was added to alcohol $\mathbf{2 . 2}$ (3.36 g, $10.7 \mathrm{mmol})$ in $\mathrm{DCM}(100 \mathrm{~mL})$ at $0{ }^{\circ} \mathrm{C}$ under nitrogen. Chloromethyl methyl ether (2.4 $\mathrm{mL}, 32.1 \mathrm{mmol}$ ) was added drop wise and the reaction mixture warmed to room temperature. DMAP (50 mg) was then added and the reaction was stirred for $24 \mathrm{~h}$. The reaction mixture was cooled to $0{ }^{\circ} \mathrm{C}$, saturated sodium bicarbonate $(50 \mathrm{~mL})$ was added, and stirring continued for $10 \mathrm{~min}$. The organic phase was then separated and the aqueous phase was extracted with DCM $(3 \times 50 \mathrm{~mL})$. The combined organic extracts were washed with water $(50 \mathrm{~mL}), 2 M$ hydrochloric acid $(50 \mathrm{~mL})$, saturated sodium bicarbonate $(50 \mathrm{~mL})$, brine $(50 \mathrm{~mL})$ and dried over anhydrous $\mathrm{MgSO}_{4}$. Concentration of the organic phase in vacuo gave the title compound $8.2(3.8 \mathrm{~g}, 100 \%)$ as a yellow gum, which was used directly in the next step without further purification.

IR (thin film) $\mathbf{c m}^{-1}$ : 2933s $(\mathrm{C}-\mathrm{H}), 1704 \mathrm{~s}(\mathrm{C}=\mathrm{O}), 1611 \mathrm{~s}, 1502 \mathrm{~s}, 1462,1377,1279$, $1236,1151,1108,1042$.

${ }^{1} \mathbf{H}$ NMR (300 MHz, $\left.\mathbf{C D C l}_{3}\right)$ \&: $1.11\left(\mathrm{t}, J_{3,2}=7.2 \mathrm{~Hz}, 3 \mathrm{H}, \mathrm{H}-3\right), 1.61\left(\mathrm{~m}, 1 \mathrm{H}, \mathrm{H}-10^{\prime}\right)$, 1.65 (s, 3H, 2'- $\left.\mathrm{CH}_{3}\right), 1.88\left(\mathrm{~m}, 1 \mathrm{H}, \mathrm{H}^{\prime}-10^{\prime}\right), 1.95$ (d, J = $\left.7.2 \mathrm{~Hz}, 2 \mathrm{H}, \mathrm{H}-3{ }^{\prime}\right), 2.39-2.69$ (m, $\left.3 \mathrm{H}, \mathrm{H}-2, \mathrm{H}-9^{\prime}\right), 2.79\left(\mathrm{ddd}, J_{g e m}=16.5, J_{9^{\prime}, 10^{\prime}}=11.4 \mathrm{~Hz}, J_{9^{\prime}}, 10^{\prime}=5.1 \mathrm{~Hz}, 1 \mathrm{H}, \mathrm{H}^{\prime}-9^{\prime}\right), 3.08$ (ddd, $J=10.5 \mathrm{~Hz}, J=7.2 \mathrm{~Hz}, J=3.0 \mathrm{~Hz}, 1 \mathrm{H}, \mathrm{H}-4$ '), 3.38 (s, 3H, 10a'-OCH $\mathrm{OCH}_{3}$ ), $3.39,3.60\left(2 \times \mathrm{ABd}, J=9.7 \mathrm{~Hz}, 2 \mathrm{H}, 10 \mathrm{a}^{\prime}-\mathrm{CH}_{2}\right), 3.69$ (d, $\left.J_{4 \mathrm{a}^{\prime},{ }^{\prime}}{ }^{\prime}=3.0 \mathrm{~Hz}, 1 \mathrm{H}, \mathrm{H}-4 \mathrm{a}^{\prime}\right), 3.75$

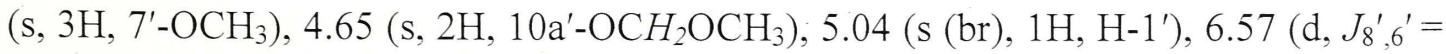


$\left.2.7 \mathrm{~Hz}, 1 \mathrm{H}, \mathrm{H}-8^{\prime}\right), 6.62\left(\mathrm{dd}, J_{6^{\prime}, 5^{\prime}}=8.4 \mathrm{~Hz}, J_{6^{\prime}, 8^{\prime}}=2.7 \mathrm{~Hz}, 1 \mathrm{H}, \mathrm{H}-6^{\prime}\right), 6.71\left(\mathrm{~d}, J_{5^{\prime}, 6^{\prime}}=8.4\right.$ $\left.\mathrm{Hz}, 1 \mathrm{H}, \mathrm{H}-5^{\prime}\right)$.

${ }^{13} \mathrm{C}$ NMR (75 MHz, $\left.\mathbf{C D C l}_{3}\right)$ 8: $8.2\left(\mathrm{CH}_{3}, \mathrm{C}-3\right), 23.6\left(2^{\prime}-\mathrm{CH}_{3}\right), 26.7\left(\mathrm{CH}_{2}, \mathrm{C}-10^{\prime}\right), 28.0$ $\left(\mathrm{CH}_{2}\right), 30.4\left(\mathrm{CH}_{2}\right), 33.9\left(\mathrm{CH}_{2}\right), 39.4\left(\mathrm{C}, \mathrm{C}-10 a^{\prime}\right), 41.2\left(\mathrm{CH}, \mathrm{C}-4 \mathrm{a}^{\prime}\right), 49.9\left(\mathrm{CH}, \mathrm{C}-4^{\prime}\right), 55.0$ $\left(10 a^{\prime}-\mathrm{OCH}_{2} \mathrm{OCH}_{3}\right), 55.2\left(7^{\prime}-\mathrm{OCH}_{3}\right), 74.7\left(\mathrm{ClOa}^{\prime}-\mathrm{CH}_{2} \mathrm{OH}\right), 96.6\left(10 a^{\prime}-\mathrm{OCH}_{2} \mathrm{OCH}_{3}\right)$, $111.7\left(\mathrm{CH}, \mathrm{C}-6^{\prime}\right), 113.5\left(\mathrm{CH}, \mathrm{C}-8^{\prime}\right), 125.1\left(\mathrm{CH}, \mathrm{C}-1^{\prime}\right), 127.8\left(\mathrm{CH}, \mathrm{C}-5^{\prime}\right), 128.7$ (C, C4b'), 136.2 (C, C-2'), 139.5 (C, C-8a'), 157.1 (C, C-7'), 214.2 (1-CO).

LRMS (m/z): $358\left(\mathrm{M}^{+}, 46 \%\right), 283$ (85), 265 (15), 239 (35), 225 (72), 211 (52), 195 (15), 171 (44), 147 (16), 57 (100).

HRMS: $\mathrm{C}_{22} \mathrm{H}_{30} \mathrm{O}_{4}\left(\mathrm{MH}^{+}\right)$requires 359.2217, found 359.2213.

$\left(4^{\prime} R S, 4 \mathrm{a}^{\prime} S R, 10 \mathrm{a}^{\prime} R S, 1 S R\right.$ or $\left.1 R S\right)$ 1-[10a'-Methoxmethoxy-7'-methoxy-2'-methyl$4 a^{\prime}, 9^{\prime}, 10^{\prime}, 10 a^{\prime}$-tetrahydrophenanthren-4' (3'H)-yl]-propan-1-ol (8.3)
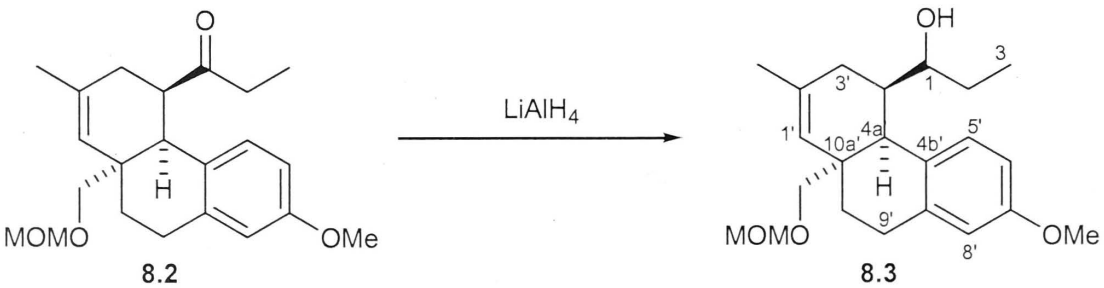

A solution of ketone 8.2 (3.8 g, $10.7 \mathrm{mmol})$ in diethyl ether $(40 \mathrm{~mL})$ was added to a suspension of lithium aluminum hydride $(0.8 \mathrm{~g}, 21.4 \mathrm{mmol})$ in diethyl ether $(40 \mathrm{~mL})$ at $0{ }^{\circ} \mathrm{C}$ under nitrogen. The resulting reaction mixture was warmed to room temperature and stirred for $1 \mathrm{~h}$. Water $(0.8 \mathrm{~mL})$ was added, followed by $1 M$ sodium hydroxide $(0.8$ $\mathrm{mL})$ and a further portion of water $(0.16 \mathrm{~mL})$. When a white precipitate formed, anhydrous $\mathrm{MgSO}_{4}$ was added and the reaction mixture was filtered through a plug of Celite $^{\circledR}$. Concentration of the organic phase in vacuo gave the title compound 8.3 (3.6 g, 93\%) as a white foam, which was used directly in the next step without further purification.

IR (thin film) $\mathbf{c m}^{-1}$ : 3478 br $(\mathrm{C}-\mathrm{OH}), 2923 \mathrm{~s}(\mathrm{C}-\mathrm{H}), 1609 \mathrm{~s}, 1500 \mathrm{~s}, 1464,1377,1272$, $1237,1151,1109,1044$. 
${ }^{1}$ H NMR (300 MHz, CDCl $\left.\mathbf{~}_{3}\right)$ \&: $0.97\left(\mathrm{t}, J_{3,2}=7.3 \mathrm{~Hz}, 3 \mathrm{H}, \mathrm{H}-3\right), 1.35$ (m, 1H, H-10'), 1.68 (s, 3H, 2'- $\left.\mathrm{CH}_{3}\right), 1.52-1.85$ (m, 5H, H'-10', H-3', H-2), 2.15 (m, 1H, H-9'), 2.53 $\left(\mathrm{ddd}, J_{\text {gem }}=16.5, J_{9^{\prime}, 10^{\prime}}=11.1 \mathrm{~Hz}, J_{9^{\prime}, 10^{\prime}}=5.7 \mathrm{~Hz}, 1 \mathrm{H}, \mathrm{H}^{\prime}-9^{\prime}\right), 2.86\left(\mathrm{~m}, 1 \mathrm{H}, \mathrm{H}-4^{\prime}\right), 3.31$ $\left(\mathrm{d}, J_{4 \mathrm{a}^{\prime},{ }^{\prime}}{ }^{\prime}=3.3 \mathrm{~Hz}, 1 \mathrm{H}, \mathrm{H}-4 \mathrm{a}^{\prime}\right), 3.36\left(\mathrm{~s}, 3 \mathrm{H}, 10 \mathrm{a}^{\prime}-\mathrm{OCH}_{2} \mathrm{OCH}_{3}\right), 3.36,3.53(2 \times \mathrm{ABd}, J=$ $\left.9.3 \mathrm{~Hz}, 2 \mathrm{H}, 10 \mathrm{a}^{\prime}-\mathrm{CH}_{2}\right), 3.77$ (s, 3H, 7'- $\left.\mathrm{OCH}_{3}\right), 3.79$ (m, 1H, H-1), 4.61 (s, 2H, 10a'$\mathrm{OCH}_{2} \mathrm{OCH}_{3}$ ), 5.12 (s (br), 1H, H-1'), 6.59 (d, $\left.J_{8^{\prime}, 6^{\prime}}=2.7 \mathrm{~Hz}, 1 \mathrm{H}, \mathrm{H}-8^{\prime}\right), 6.71\left(\mathrm{dd}, J_{6}{ }^{\prime}, 5^{\prime}=\right.$ $\left.8.4 \mathrm{~Hz}, J_{6^{\prime}, 8^{\prime}}=2.7 \mathrm{~Hz}, 1 \mathrm{H}, \mathrm{H}-6^{\prime}\right), 7.40\left(\mathrm{~d}, J_{5^{\prime}, 6^{\prime}}=8.4 \mathrm{~Hz}, 1 \mathrm{H}, \mathrm{H}-5^{\prime}\right)$.

${ }^{13} \mathbf{C}$ NMR (75 MHz, $\left.\mathbf{C D C l}_{3}\right)$ \&: $9.5\left(\mathrm{CH}_{3}, \mathrm{C}-3\right), 23.8\left(2^{\prime}-\mathrm{CH}_{3}\right), 26.9\left(\mathrm{CH}_{2}, \mathrm{C}-10^{\prime}\right), 29.2$ $\left(\mathrm{CH}_{2}\right), 30.4\left(\mathrm{CH}_{2}\right), 30.7\left(\mathrm{CH}_{2}\right), 37.9\left(\mathrm{C}, \mathrm{C}-10 \mathrm{a}^{\prime}\right), 40.5\left(\mathrm{CH}, \mathrm{C}-4 \mathrm{a}^{\prime}\right), 44.0\left(\mathrm{CH}, \mathrm{C}-4^{\prime}\right), 55.0$ $\left(10 \mathrm{a}^{\prime}-\mathrm{OCH}_{2} \mathrm{OCH}_{3}\right), 55.2\left(7^{\prime}-\mathrm{OCH}_{3}\right), 72.8(\mathrm{CH}, \mathrm{C}-1), 74.7\left(\mathrm{Cl}^{0} \mathrm{a}^{\prime}-\mathrm{CH}_{2}\right), 96.8\left(10 \mathrm{a}^{\prime}-\right.$ $\left.\mathrm{OCH}_{2} \mathrm{OCH}_{3}\right), 111.9\left(\mathrm{CH}, \mathrm{C}-6^{\prime}\right), 113.3\left(\mathrm{CH}, \mathrm{C}-8^{\prime}\right), 126.8\left(\mathrm{CH}, \mathrm{C}-1^{\prime}\right), 129.3\left(\mathrm{CH}, \mathrm{C}-5^{\prime}\right)$, $131.3\left(\mathrm{C}, \mathrm{C}-4 \mathrm{~b}^{\prime}\right), 135.4$ (C, C-2'), $140.1\left(\mathrm{C}, \mathrm{C}-8 \mathrm{a}^{\prime}\right), 157.1$ (C, C-7').

LRMS (m/z): $360\left(\mathrm{M}^{+}, 23 \%\right), 280$ (7), 267 (40), 239 (15), 227 (100), 212 (17), 173 (12), 147 (25), 84 (67).

HRMS: $\mathrm{C}_{22} \mathrm{H}_{32} \mathrm{O}_{4}\left(\mathrm{M}^{+}\right)$requires 360.2301 , found 360.2301 .

$\left(4^{\prime} R S, 4 \mathrm{a}^{\prime} S R, 10 \mathrm{a}^{\prime} R S, 1 S R\right.$ or $\left.1 R S\right)$ 1-[10a'-Methoxmethoxy-7'-methoxy-2'-methyl$4 \mathrm{a}^{\prime}, 9^{\prime}, 10^{\prime}, 10 \mathrm{a}^{\prime}$-tetrahydrophenanthren-4'(3'H)-yl]-propan-1-yl benzoate $(2.4)$

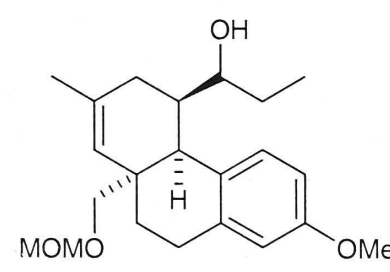

8.3

\section{PhCOCl, py, DMAP}

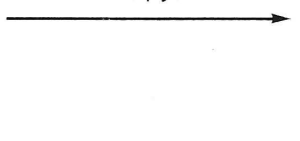

MOMO

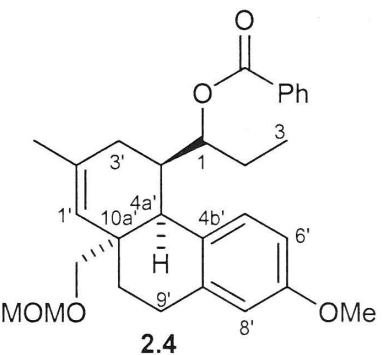

Benzoyl chloride $(3.5 \mathrm{~mL}, 29.9 \mathrm{mmol})$ was added to a solution of alcohol 8.3 (3.6 g, $9.96 \mathrm{mmol})$ in pyridine $(100 \mathrm{~mL})$ at room temperature under nitrogen. A catalytic amount of DMAP (5 mol \%) was added and the resulting reaction mixture was stirred for $24 \mathrm{~h}$. Water $(50 \mathrm{~mL})$ was then added, and the resulting mixture stirred for $10 \mathrm{~min}$ before extracting with ethyl acetate $(4 \times 50 \mathrm{~mL})$. The combined organic extracts were washed with a saturated aqueous solution of copper sulfate $(4 \times 50 \mathrm{~mL})$, water $(50 \mathrm{~mL})$, $1 \mathrm{M}$ hydrochloric acid $(50 \mathrm{~mL})$, water $(50 \mathrm{~mL})$, and dried over anhydrous $\mathrm{MgSO}_{4}$. 
Concentration of the organic phase in vacuo gave a cream solid, which was further purified by flash column chromatography on silica gel using ethyl acetate : hexane (1 : 9) as eluant to give the title compound $\mathbf{2 . 4}$ (4.2 g, 84\% over three steps) as a white wax.

IR (thin film) $\mathbf{c m}^{-1}$ : 2931s $(\mathrm{C}-\mathrm{H}), 1711 \mathrm{~s}(\mathrm{C}=\mathrm{O}), 1609 \mathrm{~s}, 1501 \mathrm{~s}, 1451,1314,1272$, $1237,1150,1110,1045$.

${ }^{1}$ H NMR (300 MHz, CDCl$\left.)_{3}\right)$ 8: $0.91\left(\mathrm{t}, J_{3,2}=7.3 \mathrm{~Hz}, 3 \mathrm{H}, \mathrm{H}-3\right), 1.64\left(\mathrm{~m}, 1 \mathrm{H}, \mathrm{H}-10^{\prime}\right)$, 1.74-1.94 (m, 4H, H'-10', H-3', H-2), 2.06 (m, 1H, H'-3'), 1.73 (s, 3H, 2'-CH CH $^{\prime}, 2.45-$ $2.76\left(\mathrm{~m}, 3 \mathrm{H}, \mathrm{H}-4^{\prime}, \mathrm{H}-9^{\prime}\right), 3.17\left(\mathrm{~d}, J_{4 \mathrm{a}^{\prime} 4^{\prime}}=3.0 \mathrm{~Hz}, 1 \mathrm{H}, \mathrm{H}-4 \mathrm{a}^{\prime}\right), 3.34$ (s, 3H, 10a'$\left.\mathrm{OCH}_{2} \mathrm{OCH}_{3}\right), 3.35,3.51\left(2 \times \mathrm{ABd}, J=6.6 \mathrm{~Hz}, 2 \mathrm{H}, 10 \mathrm{a}^{\prime}-\mathrm{CH}_{2}\right), 3.58\left(\mathrm{~s}, 3 \mathrm{H}, 7^{\prime}-\mathrm{OCH}_{3}\right)$, 4.60, $4.64\left(2 \times \mathrm{ABd}, J=9.3 \mathrm{~Hz}, 2 \mathrm{H}, 10 \mathrm{a}^{\prime}-\mathrm{OCH}_{2} \mathrm{OCH}_{3}\right), 5.26$ (s (br), 1H, H-1'), 5.53 $(\mathrm{ddd}, J=9.9 \mathrm{~Hz}, J=5.4 \mathrm{~Hz}, J=3.9 \mathrm{~Hz}, 1 \mathrm{H}, \mathrm{H}-1), 6.26\left(\mathrm{~d}, J_{8^{\prime}, 6^{\prime}}=2.7 \mathrm{~Hz}, 1 \mathrm{H}, \mathrm{H}-8^{\prime}\right)$, $6.68\left(\mathrm{dd}, J_{6^{\prime}, 5^{\prime}}=8.7 \mathrm{~Hz}, J_{6^{\prime}, 8^{\prime}}=2.7 \mathrm{~Hz}, 1 \mathrm{H}, \mathrm{H}-6^{\prime}\right), 7.20\left(\mathrm{~d}, J_{5^{\prime}, 6^{\prime}}=8.7 \mathrm{~Hz}, 1 \mathrm{H}, \mathrm{H}-5^{\prime}\right)$, 7.30-7.51 (m, 3H, H-3", H-4"), 7.74 (d, J=8.4 Hz, 2H, H-2").

${ }^{13} \mathrm{C}$ NMR (75 MHz, $\left.\mathbf{C D C l}_{3}\right)$ 8: $8.2\left(\mathrm{CH}_{3}, \mathrm{C}-3\right), 24.0\left(2^{\prime}-\mathrm{CH}_{3}\right), 26.0\left(\mathrm{CH}_{2}, \mathrm{C}-10^{\prime}\right), 26.4$ $\left(\mathrm{CH}_{2}\right), 29.1\left(\mathrm{CH}_{2}\right), 31.3\left(\mathrm{CH}_{2}\right), 39.1\left(\mathrm{C}, \mathrm{C}-10 a^{\prime}\right), 40.0\left(\mathrm{CH}, \mathrm{C}-4 \mathrm{a}^{\prime}\right), 40.4\left(\mathrm{CH}, \mathrm{C}-4^{\prime}\right), 54.7$ $\left(10 \mathrm{a}^{\prime}-\mathrm{OCH}_{2} \mathrm{OCH}_{3}\right), 55.0\left(7^{\prime}-\mathrm{OCH}_{3}\right), 74.2(\mathrm{CH}, \mathrm{C}-1), 75.4\left(\mathrm{Cl}^{\prime} \mathrm{a}^{\prime}-\mathrm{CH}_{2}\right), 96.6\left(10 \mathrm{a}^{\prime}-\right.$ $\left.\mathrm{OCH}_{2} \mathrm{OCH}_{3}\right), 111.9\left(\mathrm{CH}, \mathrm{C}-6^{\prime}\right), 112.8\left(\mathrm{CH}, \mathrm{C}-8^{\prime}\right), 127.3\left(\mathrm{CH}, \mathrm{C}-1^{\prime}\right), 127.6\left(\mathrm{CH}, \mathrm{C}-5^{\prime}\right)$, 129.3 (Ar), 129.4 (Ar), 130.1 (Ar), 130.2 (Ar), 132.3 (C, C-4b'), 133.6 (C, C-2'), 138.3 (C, C-8a'), $156.6\left(\mathrm{C}, \mathrm{C}-7^{\prime}\right), 165.7$ (1-OC(O)Ph).

LRMS (m/z): $464\left(\mathrm{M}^{+}, 37 \%\right), 432$ (5), 388 (8), 342 (8), 310 (15), 297 (16), 280 (32), 267 (100), 225 (25), 211 (17), 105(50).

HRMS: $\mathrm{C}_{29} \mathrm{H}_{36} \mathrm{O}_{5}\left(\mathrm{M}^{+}\right)$requires 464.2563 , found 464.2567 . 
$\left(4^{\prime} R S, 4 \mathrm{a}^{\prime} S R, 10 \mathrm{a}^{\prime} R S, 1 S R\right.$ or $\left.1 R S\right)$ 1-[10a'-Hydroxymethyl-7'-methoxy-2'-methyl$4 a^{\prime}, 9^{\prime}, 10^{\prime}, 10 a^{\prime}-$ tetrahydrophenanthren-4' $\left(3^{\prime} H\right)$-yl]-propan-1-yl benzoate $(8.4)$
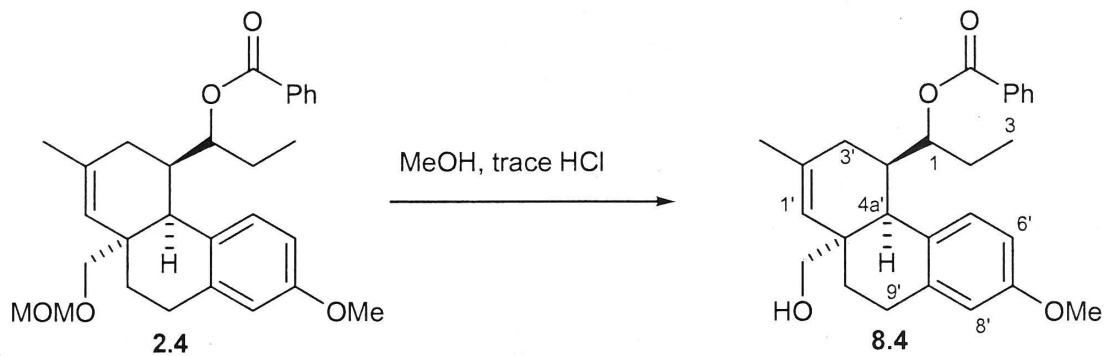

Concentrated hydrochloric acid (10 drops) was added to a solution of MOM ether $\mathbf{2 . 4}$ $(4.2 \mathrm{~g}, 9.04 \mathrm{mmol})$ in methanol $(80 \mathrm{~mL})$. The resulting reaction mixture was stirred at $70{ }^{\circ} \mathrm{C}$ for $18 \mathrm{~h}$, then a saturated solution of sodium bicarbonate was added and the methanol removed in vacuo. The residue was extracted with ethyl acetate $(3 \times 30 \mathrm{~mL})$ and the combined organic extracts were dried over anhydrous $\mathrm{MgSO}_{4}$. Concentration of the organic phase in vacuo gave the title compound 8.4 (3.6 g, 95\%) as a white foam, which was used directly in the next step without further purification.

IR (thin film) $\mathbf{c m}^{-1}$ : 2935s $(\mathrm{C}-\mathrm{H}), 1709 \mathrm{~s}(\mathrm{C}=\mathrm{O}), 1609 \mathrm{~s}, 1501 \mathrm{~s}, 1451,1315,1272 \mathrm{~s}$, $1114,1070,1041$.

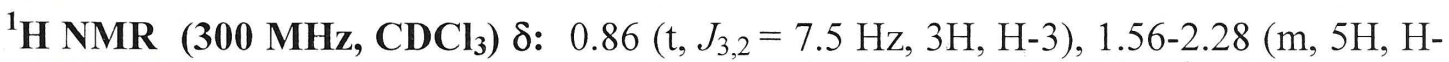
10', H-3', H-2), 1.77 (s, 3H, 2'-CH3), 2.24 (m, 1H, H'-3'), 2.47-2.54 (m, 2H, H-9'), 2.76 $\left(\mathrm{m}, 1 \mathrm{H}, \mathrm{H}-4^{\prime}\right), 3.22\left(\mathrm{~d}, J_{4 \mathrm{a}^{\prime} 4^{\prime}}=3.3 \mathrm{~Hz}, 1 \mathrm{H}, \mathrm{H}-4 \mathrm{a}^{\prime}\right), 3.37,3.42(2 \times \mathrm{ABd}, J=10.8 \mathrm{~Hz}$, $\left.2 \mathrm{H}, 10 \mathrm{a}^{\prime}-\mathrm{CH}_{2}\right), 3.52\left(\mathrm{~s}, 3 \mathrm{H}, 7^{\prime}-\mathrm{OCH}_{3}\right), 5.17$ (s (br), 1H, H-1'), 5.47 (ddd, $J=9.6 \mathrm{~Hz}, J=$ $5.4 \mathrm{~Hz}, J=3.3 \mathrm{~Hz}, 1 \mathrm{H}, \mathrm{H}-1), 6.12\left(\mathrm{~d}, J_{8^{\prime}, 6^{\prime}}=2.7 \mathrm{~Hz}, 1 \mathrm{H}, \mathrm{H}-8^{\prime}\right), 6.66\left(\mathrm{dd}, J_{6}^{\prime}, 5^{\prime}=8.6 \mathrm{~Hz}\right.$, $\left.J_{6^{\prime}, 8^{\prime}}=2.7 \mathrm{~Hz}, 1 \mathrm{H}, \mathrm{H}-6^{\prime}\right), 7.19\left(\mathrm{~d}, J_{5^{\prime}, 6^{\prime}}=8.6 \mathrm{~Hz}, 1 \mathrm{H}, \mathrm{H}-5^{\prime}\right), 7.25-7.48$ (m, 3H, H-3", H$\left.4^{\prime \prime}\right), 7.58$ (d, $\left.J=7.2 \mathrm{~Hz}, 2 \mathrm{H}, \mathrm{H}-2^{\prime \prime}\right)$.

${ }^{13} \mathrm{C}$ NMR (75 MHz, $\left.\mathbf{C D C l}_{3}\right)$ \&: $8.2\left(\mathrm{CH}_{3}, \mathrm{C}-3\right), 24.2\left(2^{\prime}-\mathrm{CH}_{3}\right), 26.0\left(\mathrm{CH}_{2}, \mathrm{C}-10^{\prime}\right), 26.1$ $\left(\mathrm{CH}_{2}\right), 28.6\left(\mathrm{CH}_{2}\right), 32.4\left(\mathrm{CH}_{2}\right), 39.0\left(\mathrm{C}, \mathrm{C}-10 \mathrm{a}^{\prime}\right), 40.8\left(\mathrm{CH}, \mathrm{C}-4 \mathrm{a}^{\prime}\right), 40.9\left(\mathrm{CH}, \mathrm{C}-4^{\prime}\right), 54.7$ $\left(7^{\prime}-\mathrm{OCH}_{3}\right), 68.8\left(\mathrm{Cl}^{\prime} \mathrm{a}^{\prime}-\mathrm{CH}_{2}\right), 75.3(\mathrm{CH}, \mathrm{C}-1), 112.4\left(\mathrm{CH}, \mathrm{C}-6{ }^{\prime}\right), 112.6\left(\mathrm{CH}, \mathrm{C}-8^{\prime}\right)$, $126.6\left(\mathrm{CH}, \mathrm{C}-1^{\prime}\right), 127.6\left(\mathrm{CH}, \mathrm{C}-5^{\prime}\right), 129.3$ (Ar), 129.7 (Ar), 129.9 (Ar), 130.4 (Ar), 132.3 (C, C-4b'), 135.7 (C, C-2'), 137.1 (C, C-8a'), 156.7 (C, C-7'), 165.7 (1-OC(O)Ph)。 
LRMS (m/z): 420 (M+, 33\%), 298 (21), 280 (12), 267 (100), 225 (35), 211 (20), 105 (61).

HRMS: $\mathrm{C}_{27} \mathrm{H}_{32} \mathrm{O}_{4}\left(\mathrm{M}^{+}\right)$requires 420.2295 , found 420.2298 .

$\left(4^{\prime} R S, 4 \mathrm{a}^{\prime} S R, 10 \mathrm{a}^{\prime} R S, 1 S R\right.$ or $\left.1 R S\right)$ 1-[10a'-Acetoxymethyl-7'-methoxy-2'-methyl$4 a^{\prime}, 9^{\prime}, 10^{\prime}, 10 a^{\prime}$-tetrahydrophenanthren-4'(3'H)-yl]-propan-1-yl Benzoate (2.7)
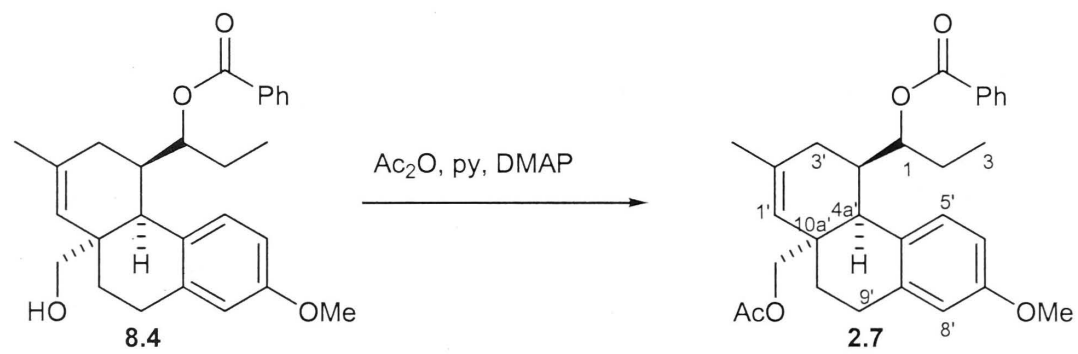

Acetic anhydride $(3.2 \mathrm{~mL}, 34.2 \mathrm{mmol})$ was added to alcohol 8.4 (3.6 g, $8.6 \mathrm{mmol})$ in $\operatorname{DCM}(90 \mathrm{~mL})$ and pyridine $(2.7 \mathrm{~mL}, 34.2 \mathrm{mmol})$ at $0{ }^{\circ} \mathrm{C}$ under nitrogen. A catalytic amount of DMAP was added and the resulting reaction mixture stirred for $1 \mathrm{~h}$. The reaction was quenched with water $(30 \mathrm{~mL})$, the organic phase separated and the aqueous residue was further extracted with DCM $(2 \times 20 \mathrm{~mL})$. The combined organic extracts were washed with a saturated aqueous solution of copper sulfate $(2 \times 20 \mathrm{~mL})$, water $(20$ $\mathrm{mL}), 1 \mathrm{M}$ hydrochloric acid $(20 \mathrm{~mL})$, saturated sodium bicarbonate $(20 \mathrm{~mL})$, and dried over anhydrous $\mathrm{MgSO}_{4}$. Concentration of the organic phase in vacuo gave a cream solid, which was further purified by flash column chromatography on silica gel using ethyl acetate : hexane $(1: 4)$ as eluant to give the title compound 2.7 (3.4 g, 81\% over two steps) as a white solid.

m.p.: $108-111^{\circ} \mathrm{C}$

IR (thin film) $\mathbf{c m}^{-1}$ : 2935s $(\mathrm{C}-\mathrm{H}), 1736 \mathrm{~s}(\mathrm{C}=\mathrm{O}), 1713 \mathrm{~s}(\mathrm{C}=\mathrm{O}), 1610 \mathrm{~s}, 1501 \mathrm{~s}, 1451$, 1380, 1314, 1271, 1112, 1070, 1038.

${ }^{1}$ H NMR (300 MHz, $\mathbf{C D C l}_{3}$ ) $\delta: 0.90$ (t, $\left.J_{3,2}=7.5 \mathrm{~Hz}, 3 \mathrm{H}, \mathrm{H}-3\right), 1.53-1.76$ (m, 4H, H10', H-2), 1.70 (s, 3H, 2'- $\mathrm{CH}_{3}$ ), 1.83-1.93 (m, 2H, H-3'), 1.99 (s, 3H, 10a'-OC(O)CH $\mathrm{CH}_{3}$ ), 2.44 (m, 1H, H-9'), 2.63-2.73 (m, 2H, H'-9', H-4'), 3.18 (d, $\left.J_{4 \mathrm{a}^{\prime} \mathbf{4}^{\prime}}=3.0 \mathrm{~Hz}, 1 \mathrm{H}, \mathrm{H}-4 \mathrm{a}^{\prime}\right)$, $3.60\left(\mathrm{~s}, 3 \mathrm{H}, 7^{\prime}-\mathrm{OCH}_{3}\right), 3.84,4.19\left(2 \times \mathrm{ABd}, J=10.8 \mathrm{~Hz}, 2 \mathrm{H}, 10 \mathrm{a}^{\prime}-\mathrm{CH}_{2}\right), 5.10$ (s (br), 
$\left.1 \mathrm{H}, \mathrm{H}^{-1}{ }^{\prime}\right), 5.50(\mathrm{ddd}, J=9.9 \mathrm{~Hz}, J=5.1 \mathrm{~Hz}, J=3.6 \mathrm{~Hz}, 1 \mathrm{H}, \mathrm{H}-1), 6.31\left(\mathrm{~d}, J_{8}^{\prime}, 6^{\prime}=2.4\right.$ $\left.\mathrm{Hz}, 1 \mathrm{H}, \mathrm{H}-8^{\prime}\right), 6.68\left(\mathrm{dd}, J_{6}{ }^{\prime}, 5^{\prime}=8.4 \mathrm{~Hz}, J_{6}{ }^{\prime}, 8^{\prime}=2.4 \mathrm{~Hz}, 1 \mathrm{H}, \mathrm{H}-6^{\prime}\right), 7.20\left(\mathrm{~d}, J_{5}{ }^{\prime}, 6^{\prime}=8.4 \mathrm{~Hz}\right.$, 1H, H-5'), 7.31-7.57 (m, 3H, H-3", H-4"), 7.80 (d, J=7.2 Hz, 2H, H-2").

${ }^{13} \mathbf{C}$ NMR (75 MHz, $\left.\mathbf{C D C l}_{3}\right)$ 8: $8.1\left(\mathrm{CH}_{3}, \mathrm{C}-3\right), 20.6\left(-\mathrm{OC}(\mathrm{O}) \mathrm{CH}_{3}\right), 23.6\left(2^{\prime}-\mathrm{CH}_{3}\right)$, $25.8\left(\mathrm{CH}_{2}, \mathrm{C}-10^{\prime}\right), 26.3\left(\mathrm{CH}_{2}\right), 29.4\left(\mathrm{CH}_{2}\right), 30.5\left(\mathrm{CH}_{2}\right), 38.0\left(\mathrm{C}, \mathrm{C}-10 \mathrm{a}^{\prime}\right), 39.7(\mathrm{CH}, \mathrm{C}-$ $\left.4 \mathrm{a}^{\prime}\right), 40.0\left(\mathrm{CH}, \mathrm{C}-4^{\prime}\right), 54.5\left(7^{\prime}-\mathrm{OCH}_{3}\right), 69.5\left(\mathrm{Cl}^{\prime} \mathrm{a}^{\prime}-\mathrm{CH}_{2}\right), 75.1(\mathrm{CH}, \mathrm{C}-1), 111.8(\mathrm{CH}, \mathrm{C}-$ 6'), $112.9\left(\mathrm{CH}, \mathrm{C}-8^{\prime}\right), 125.6\left(\mathrm{CH}, \mathrm{C}-1^{\prime}\right), 127.6$ (CH, C-5'), $128.4(\mathrm{Ar}), 129.1$ (Ar), 129.8 (Ar), 130.0 (Ar), 132.2 (C, C-4b'), 135.3 (C, C-2'), 138.3 (C, C-8a'), 156.6 (C, C-7'), $165.3(1-\mathrm{OC}(\mathrm{O}) \mathrm{Ph}), 170.4\left(-\mathrm{OC}(\mathrm{O}) \mathrm{CH}_{3}\right)$.

LRMS (m/z): $462\left(\mathrm{M}^{+}, 50 \%\right), 340$ (49), 297 (2), 280 (74), 267 (100), 225 (47), 187 (25), 105(71).

HRMS: $\mathrm{C}_{29} \mathrm{H}_{34} \mathrm{O}_{5}\left(\mathrm{M}^{+}\right)$requires 462.2406, found 462.2409 .

Microanalysis: Calcd. for $\mathrm{C}_{29} \mathrm{H}_{34} \mathrm{O}_{5}$ : C, 75.30\%; H, 7.41\%. Found: $\mathrm{C}, 75.38 \%$; $\mathrm{H}$, $7.64 \%$.

$\left(4^{\prime} R S, 4 \mathrm{a}^{\prime} S R, 10 \mathrm{a}^{\prime} R S, 1 S R\right.$ or $\left.1 R S\right)$ 1-(10a'-Acetoxymethyl-7'-methoxy-2'-methyl$1^{\prime}, 2^{\prime}$-epoxy-4a',9',10',10a'-tetrahydrophenanthren-4-yl)-propan-1-yl Benzoate (2.8)
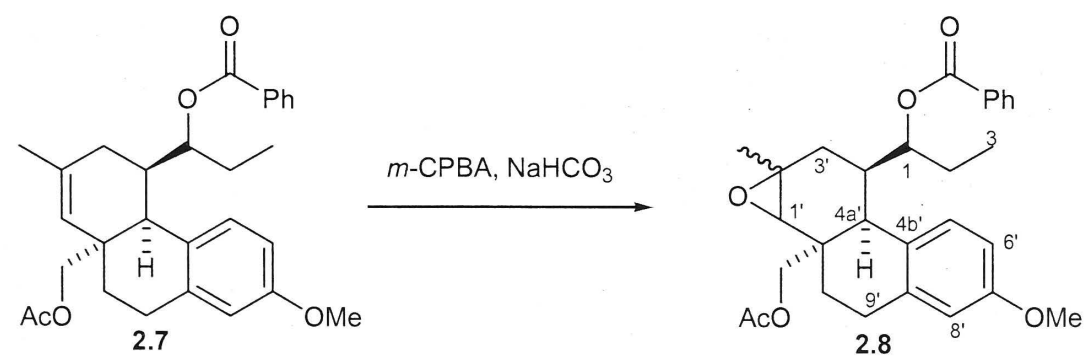

$m$-CPBA $(0.81 \mathrm{~g}, 4.70 \mathrm{mmol})$ was added to a mixture of olefin $2.7(1.08 \mathrm{~g}, 2.30 \mathrm{mmol})$ and $\mathrm{NaHCO}_{3}(1.70 \mathrm{~g})$ in $\mathrm{DCM}(20 \mathrm{~mL})$ at $0{ }^{\circ} \mathrm{C}$ under nitrogen. The resulting reaction mixture was warmed to room temperature and stirred for $2 \mathrm{~h}$ before $10 \% \mathrm{Na}_{2} \mathrm{SO}_{3}(10$ $\mathrm{mL}$ ) was added. After $5 \mathrm{~min}$, the organic phase was separated and the aqueous residue further extracted with DCM $(2 \times 15 \mathrm{~mL})$. The combined organic extracts were washed with $1 M$ sodium hydroxide and brine then dried over $\mathrm{MgSO}_{4}$. Concentration of the organic phase in vacuo gave a white foam which was further purified by flash column 
chromatography on silica gel using ethyl acetate : hexane $(1: 4)$ as eluant to give the title compound $\mathbf{2 . 8}(0.98 \mathrm{~g}, \mathbf{8 9 \%})$ as a white foam.

IR (thin film) $\mathbf{c m}^{-1}$ : 2938s $(\mathrm{C}-\mathrm{H}), 1743 \mathrm{~s}(\mathrm{C}=\mathrm{O}), 1713 \mathrm{~s}(\mathrm{C}=\mathrm{O}), 1610 \mathrm{~s}, 1583,1501 \mathrm{~s}$, $1451,1381,1364,1271,1176,1070,1039$.

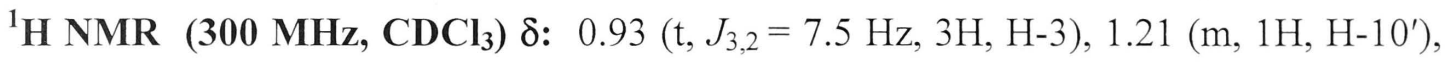
1.57-1.69 (m, 3H), 1.86-2.11 (m, 2H), $1.30\left(\mathrm{~s}, 3 \mathrm{H}, 2^{\prime}-\mathrm{CH}_{3}\right), 2.03\left(\mathrm{~s}, 3 \mathrm{H}, 10 \mathrm{a}^{\prime}-\right.$ $\mathrm{OC}(\mathrm{O}) \mathrm{CH}_{3}$ ), 2.50-2.92 (m, 4H, H-9', H-4', H-4a), 2.81 (s, 1H, H-1' major), 2.97 (s, 1H, H-1' minor), $3.74\left(\mathrm{~s}, 3 \mathrm{H}, 7^{\prime}-\mathrm{OCH}_{3}\right), 4.25\left(\mathrm{~s}, 2 \mathrm{H}, 10 \mathrm{a}^{\prime}-\mathrm{CH}_{2}\right), 5.38(\mathrm{~m}, 1 \mathrm{H}, \mathrm{H}-1)$, $6.57\left(\mathrm{~d}, J_{8^{\prime}, 6^{\prime}}=2.4 \mathrm{~Hz}, 1 \mathrm{H}, \mathrm{H}-8^{\prime}\right), 6.73\left(\mathrm{dd}, J_{6}{ }^{\prime}, 5^{\prime}=8.4 \mathrm{~Hz}, J_{6^{\prime}, 8^{\prime}}=2.4 \mathrm{~Hz}, 1 \mathrm{H}, \mathrm{H}-6^{\prime}\right), 7.10$ $\left(\mathrm{d}, J_{5^{\prime}, 6^{\prime}}=8.4 \mathrm{~Hz}, 1 \mathrm{H}, \mathrm{H}-5^{\prime}\right), 7.41-7.64$ (m, 3H, H-3", H-4"), 8.00 (d, J=7.2 Hz, 2H, H$\left.2^{\prime \prime}\right)$.

${ }^{13} \mathbf{C}$ NMR (75 MHz, $\left.\mathbf{C D C l}_{3}\right)$ 8: $8.2\left(\mathrm{CH}_{3}, \mathrm{C}-3\right), 20.9\left(-\mathrm{OC}(\mathrm{O}) \mathrm{CH}_{3}\right), 22.3\left(2^{\prime}-\mathrm{CH}_{3}\right)$, $25.0\left(\mathrm{CH}_{2}, \mathrm{C}-10^{\prime}\right), 26.5\left(\mathrm{CH}_{2}\right), 28.6\left(\mathrm{CH}_{2}\right), 31.3\left(\mathrm{CH}_{2}\right), 35.4\left(\mathrm{C}, \mathrm{C}-10 a^{\prime}\right), 36.2(\mathrm{CH}, \mathrm{C}-$ $\left.4 \mathrm{a}^{\prime}\right), 37.3\left(\mathrm{CH}, \mathrm{C}-4^{\prime}\right), 55.0\left(7^{\prime}-\mathrm{OCH}_{3}\right), 58.3\left(\mathrm{C}, \mathrm{C}-2^{\prime}\right), 64.3\left(\mathrm{CH}, \mathrm{C}-1^{\prime}\right), 68.0\left(\mathrm{C}^{\prime} \mathrm{a}^{\prime}-\right.$ $\mathrm{CH}_{2}$ ), 75.4 (CH, C-1), $111.7\left(\mathrm{CH}, \mathrm{C}-6^{\prime}\right), 113.5$ (CH, C-8'), $127.1\left(\mathrm{CH}, \mathrm{C}-5^{\prime}\right), 128.2(\mathrm{Ar})$, 129.3 (Ar), 130.1 (Ar), 130.4 (Ar), 132.8 (C, C-4b'), 139.5 (C, C-8a'), 157.0 (C, C-7'), $165.7(1-\mathrm{OC}(\mathrm{O}) \mathrm{Ph}), 170.7\left(-\mathrm{OC}(\mathrm{O}) \mathrm{CH}_{3}\right)$.

LRMS (m/z): $478\left(\mathrm{M}^{+}, 5 \%\right), 418$ (12), 356 (15), 296 (34), 267 (45), 226 (47), 173 (29), 105 (100).

HRMS: $\mathrm{C}_{29} \mathrm{H}_{34} \mathrm{O}_{6}\left(\mathrm{M}^{+}\right)$requires 478.2355 , found 478.2359 .

(4RS, 4aSR, 10aSR, $1 S R$ or $1 R S)$ 10a-acetoxymethyl-4-(1'-Benzoyloxypropyl)-7methoxy-2-methyl-3, 4, 4a, 9,10, 10a-hexahydrophenanthren-1(2H)-one (2.9)
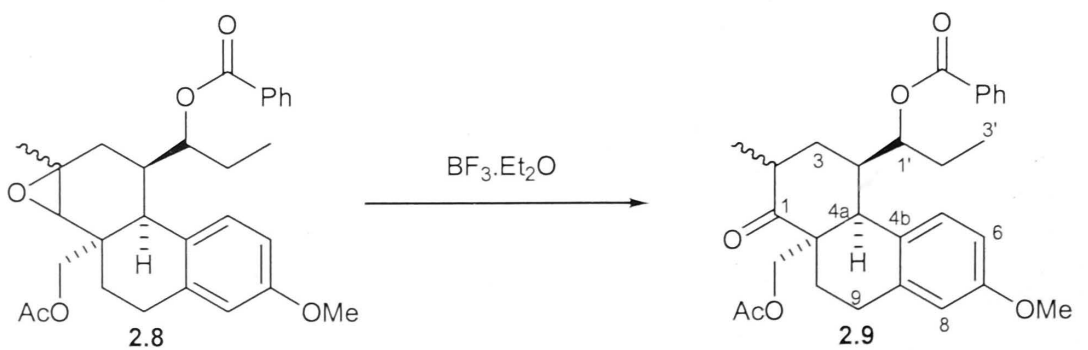
Boron trifluoride diethyl etherate $(0.52 \mathrm{~mL}, 4.10 \mathrm{mmol})$ was added drop wise to a solution of epoxide $2.8(0.98 \mathrm{~g}, 2.05 \mathrm{mmol})$ in DCM $(35 \mathrm{~mL})$ at $0{ }^{\circ} \mathrm{C}$ under nitrogen. The reaction mixture was stirred at $0{ }^{\circ} \mathrm{C}$ for 40 min before adding water $(15 \mathrm{~mL})$ and stirring vigorously for $10 \mathrm{~min}$. The organic phase was separated, and the aqueous phase extracted with DCM (2 x $15 \mathrm{~mL})$. The combined organic extracts were dried over anhydrous $\mathrm{MgSO}_{4}$ and concentrated in vacuo to give a white foam. Purification by flash column chromatography on silica gel using ethyl acetate : hexane (1:4) as eluant gave the title compound $2.9(0.72 \mathrm{~g}, 74 \%)$ as a white solid. A sample was crystallised from hexane to give white needle-like crystals.

m.p.: $121-123^{\circ} \mathrm{C}$

IR (thin film) $\mathbf{c m}^{-1}$ : 2967s $(\mathrm{C}-\mathrm{H}), 1739 \mathrm{~s}(\mathrm{C}=\mathrm{O}), 1709 \mathrm{~s}(\mathrm{C}=\mathrm{O}), 1611 \mathrm{~s}, 1584,1502 \mathrm{~s}$, 1452, 1378, 1337, 1314, 1271, 1174, 1108, 1038.

${ }^{1} \mathbf{H}$ NMR (300 MHz, $\left.\mathbf{C D C l}_{\mathbf{3}}\right)$ 8: $0.89\left(\mathrm{t}, J_{3^{\prime}, 2^{\prime}}=7.2 \mathrm{~Hz}, 3 \mathrm{H}, \mathrm{H}-3^{\prime}\right), 1.12(\mathrm{~d}, J=6.3 \mathrm{~Hz}$, $\left.3 \mathrm{H}, 2-\mathrm{CH}_{3}\right), 1.55-2.25$ (m, 6H, H-10, H-3, H-2'), 1.93 (s, 3H, 10a-OC $\left.(\mathrm{O}) \mathrm{CH}_{3}\right), 2.45-$ 2.76 (m, 4H, H-9, H-4, H-2), 3.42 (s, 3H, 7-OCH $), 3.46$ (d, J Ja, $=4.2$ Hz, 1H, H-4a), 3.94, $4.36\left(2 \times \mathrm{ABd}, J=10.8 \mathrm{~Hz}, 2 \mathrm{H}, 10 \mathrm{a}-\mathrm{CH}_{2} \mathrm{OH}\right), 5.75$ (ddd, $J=10.5 \mathrm{~Hz}, J=6.9 \mathrm{~Hz}$, $\left.J=3.6 \mathrm{~Hz}, 1 \mathrm{H}, \mathrm{H}-1^{\prime}\right), 6.18\left(\mathrm{~d}, J_{8,6}=2.7 \mathrm{~Hz}, 1 \mathrm{H}, \mathrm{H}-8\right), 6.55\left(\mathrm{dd}, J_{6,5}=8.6 \mathrm{~Hz}, J_{6,8}=2.7\right.$ $\mathrm{Hz}, 1 \mathrm{H}, \mathrm{H}-6), 7.17$ (d, $\left.J_{5,6}=8.6 \mathrm{~Hz}, 1 \mathrm{H}, \mathrm{H}-5\right), 7.26-7.50$ (m, 3H, H-3", H-4"), 7.66 (d, J $\left.=8.4 \mathrm{~Hz}, 2 \mathrm{H}, \mathrm{H}-2^{\prime \prime}\right)$.

${ }^{13} \mathrm{C}$ NMR (75 MHz, $\left.\mathbf{C D C l}_{3}\right)$ 8: $8.1\left(\mathrm{CH}_{3}, \mathrm{C}-3^{\prime}\right), 15.8\left(2-\mathrm{CH}_{3}\right), 20.6\left(-\mathrm{OC}(\mathrm{O}) \mathrm{CH}_{3}\right)$, $25.4\left(\mathrm{CH}_{2}, \mathrm{C}-10\right), 25.9\left(\mathrm{CH}_{2}\right), 28.0\left(\mathrm{CH}_{2}\right), 33.2\left(\mathrm{CH}_{2}\right), 38.2(\mathrm{C}, \mathrm{C}-10 \mathrm{a}), 40.7(\mathrm{CH}, \mathrm{C}-$ 4a), $41.6(\mathrm{CH}), 50.8(\mathrm{CH}), 54.3\left(7-\mathrm{OCH}_{3}\right), 67.2\left(\mathrm{C} 10 \mathrm{a}-\mathrm{CH}_{2} \mathrm{OH}\right), 74.0\left(\mathrm{CH}, \mathrm{C}-1^{\prime}\right), 112.4$ (CH, C-6), 112.7 (CH, C-8'), 127.4 (CH, C-5'), 127.6 (Ar), 129.0 (Ar), 129.3 (Ar), 130.0 (Ar), 132.2 (C, C-4b), 135.3 (C, C-8a), 156.9 (C, C-7), 165.1 (1'-OC(O)Ph ), $170.0\left(-\mathrm{OC}(\mathrm{O}) \mathrm{CH}_{3}\right), 214.2(1-\mathrm{CO})$.

LRMS (m/z): $478\left(\mathrm{M}^{+}, 11 \%\right), 418$ (50), 356 (53), 328 (22), 296 (50), 268 (35), 226 (47), 173 (65), 105(100).

HRMS: $\mathrm{C}_{29} \mathrm{H}_{34} \mathrm{O}_{6}\left(\mathrm{M}^{+}\right)$requires 478.2355, found 478.2362. 
Microanalysis: Calcd. for $\mathrm{C}_{29} \mathrm{H}_{34} \mathrm{O}_{6}$ : C, 72.78\%; H, 7.16\%. Found: C, 72.99\%; H, $7.25 \%$.

(2RS, 4RS, 4a RS, 10aSR, 1'SR) 4-(1'-Benzoyloxypropyl)-7-methoxy-2-methyl-3,4, 4a,9,10,10a-hexahydrophenanthren-1(2H)-one (1.95)
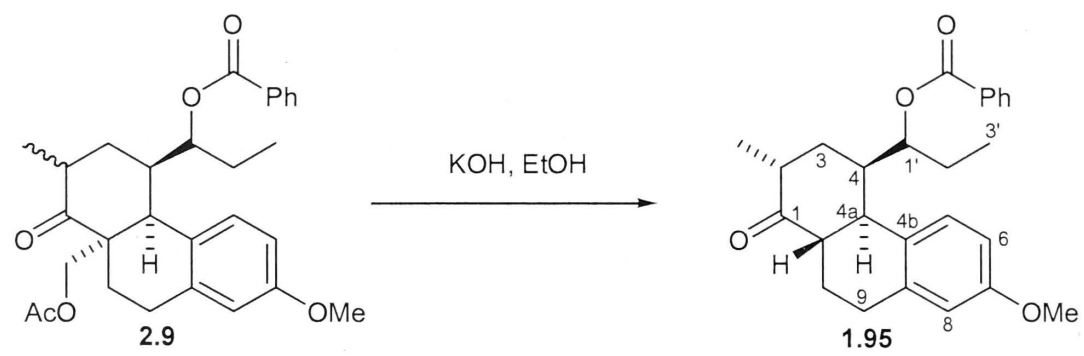

Acetate 2.9 (0.21 g, $0.44 \mathrm{mmol})$ was dissolved in ethanolic potassium hydroxide $(0.6 \mathrm{~g}$ per $20 \mathrm{~mL}$ ), and monitored by TLC until all the starting material had been consumed (ca. $1 \mathrm{~h}$ ). The reaction mixture was neutralised with $1 M$ hydrochloric acid, the ethanol removed in vacuo and the residue extracted with ethyl acetate $(3 \times 20 \mathrm{~mL})$. The combined organic extracts were washed with water $(20 \mathrm{~mL})$, brine $(20 \mathrm{~mL})$ and dried over anhydrous $\mathrm{MgSO}_{4}$. Concentration of the organic phase in vacuo gave a brown oil which was purified by flash column chromatography on silica gel using ethyl acetate : hexane (1:4) as eluant to give the title compound $\mathbf{1 . 9 5}(0.12 \mathrm{~g}, 70 \%)$ as a cream solid. A sample was crystallised from hexane to give white crystals.

m.p: $94-95^{\circ} \mathrm{C}$

IR (thin film) $\mathbf{c m}^{-1}$ : 2967s $(\mathrm{C}-\mathrm{H}), 1709 \mathrm{~s}(\mathrm{C}=\mathrm{O}), 1611 \mathrm{~s}, 1584 \mathrm{~s}, 1503 \mathrm{~s}, 1452 \mathrm{~s}, 1316$, $1275 \mathrm{~s}, 1111,1026$.

${ }^{1}$ H NMR (300 MHz, $\left.\mathbf{C D C l}_{3}\right)$ ): $0.95\left(\mathrm{t}, J_{3^{\prime}, 2^{\prime}}=7.3 \mathrm{~Hz}, 3 \mathrm{H}, \mathrm{H}-3^{\prime}\right), 1.11(\mathrm{~d}, J=6.3 \mathrm{~Hz}$, $\left.3 \mathrm{H}, 2-\mathrm{CH}_{3}\right), 1.48(\mathrm{~m}, 1 \mathrm{H}, \mathrm{H}-10), 1.70\left(\mathrm{dd}, J_{g e m}=14.1 \mathrm{~Hz}, J=4.5 \mathrm{~Hz}, 1 \mathrm{H}, \mathrm{H}-3\right), 1.81$ (m, 1H, H-2'), 1.95 (m, 1H, H'-2'), 2.17 (m, 1H, H'-10), $2.24\left(\mathrm{ddd}, J_{\text {gem }}=14.1 \mathrm{~Hz}, J=\right.$ 6.0, $\left.J=2.1 \mathrm{~Hz}, 1 \mathrm{H}, \mathrm{H}^{\prime}-3\right)$ 2.45-2.53 (m, 2H, H-9), 2.73 (m, 1H, H-2), 2.99-3.05 (m, $3 \mathrm{H}, \mathrm{H}-4, \mathrm{H}-4 \mathrm{a}, \mathrm{H}-10 \mathrm{a}), 3.46$ (s, 3H, 7-OCH 3$), 5.88$ (ddd, $J=10.8 \mathrm{~Hz}, J=8.4 \mathrm{~Hz}, J=$ $\left.3.3 \mathrm{~Hz}, 1 \mathrm{H}, \mathrm{H}-1^{\prime}\right), 6.02$ (d, $\left.J_{8,6}=2.7 \mathrm{~Hz}, 1 \mathrm{H}, \mathrm{H}-8\right), 6.52\left(\mathrm{dd}, J_{6,5}=8.7 \mathrm{~Hz}, J_{6,8}=2.7 \mathrm{~Hz}\right.$, 1H, H-6), 7.16-7.44 (m, 6H, H-5, H-2", H-3", H-4"). 


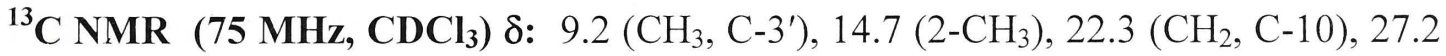
$\left(\mathrm{CH}_{2}, \mathrm{C}-2^{\prime}\right), 29.2\left(\mathrm{CH}_{2}, \mathrm{C}-9\right), 38.4\left(\mathrm{CH}_{2}, \mathrm{C}-3\right), 40.1(\mathrm{CH}, \mathrm{C}-2), 40.4(\mathrm{CH}, \mathrm{C}-10 \mathrm{a}), 46.8$ $(\mathrm{CH}, \mathrm{C}-4 \mathrm{a}), 47.3(\mathrm{CH}, \mathrm{C}-4), 54.6\left(7-\mathrm{OCH}_{3}\right), 72.7\left(\mathrm{CH}, \mathrm{C}-1^{\prime}\right), 112.4(\mathrm{CH}, \mathrm{C}-6), 112.6$ (CH, C-8), 127.2 (CH, C-5), 127.9 (Ar), 129.0 (Ar), 129.2 (Ar), 132.1 (C, C-4b), 137.1 (C, C-8a), 156.4 (C, C-7), 165.8 (1'-OC(O)Ph), 211.8 (1-CO).

LRMS (m/z): $406\left(\mathrm{M}^{+}, 90 \%\right), 284$ (51), 242 (56), 216 (30), 187 (87), 160 (76), 128 (13), 105 (100).

HRMS: $\mathrm{C}_{26} \mathrm{H}_{30} \mathrm{O}_{4}\left(\mathrm{M}^{+}\right)$requires 406.2144 , found 406.2148 .

Microanalysis: Calcd. for $\mathrm{C}_{26} \mathrm{H}_{30} \mathrm{O}_{4}: \mathrm{C}, 76.82 \%, \mathrm{H}, 7.44 \%$. Found: $\mathrm{C}, 76.47 \%, \mathrm{H}$, $7.37 \%$.

\subsection{Chapter 3 Experimental}

(1RS, 2RS, 4RS, 4aSR, 10aSR, 1'SR) 4-(1'-Benzoyloxypropyl)-7-methoxy-2-methyl$3,4,4 a, 9,10,10 a-h e x a h y d r o p h e n a n t h r e n-1(2 H)$-ol $(3.1)$
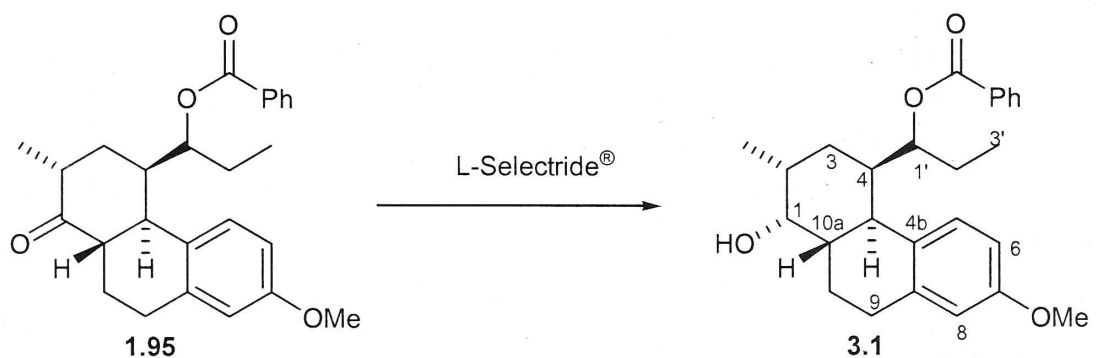

L-Selectride ${ }^{\circledR}(1.7 \mathrm{~mL}$ of a $1.0 \mathrm{M}$ solution in THF, $1.7 \mathrm{mmol})$ was added to ketone $\mathbf{1 . 9 5}$ $(0.50 \mathrm{~g}, 1.2 \mathrm{mmol})$ in THF $(5 \mathrm{~mL})$ at $-78{ }^{\circ} \mathrm{C}$ under nitrogen. The resulting reaction mixture was stirred for $20 \mathrm{~min}$ before warming to $0{ }^{\circ} \mathrm{C}$. $10 \%$ Aqueous sodium hydroxide $(7 \mathrm{~mL})$ and $30 \%$ aqueous hydrogen peroxide $(5 \mathrm{~mL})$ were added, the solution was warmed to room temperature and stirred overnight. The mixture was then extracted with ethyl acetate $(3 \times 30 \mathrm{~mL})$, washed with water $(2 \times 10 \mathrm{~mL})$, saturated sodium bicarbonate solution $(2 \times 10 \mathrm{~mL})$ and brine $(10 \mathrm{~mL})$. The organic phase was then dried over anhydrous $\mathrm{MgSO}_{4}$ and concentrated in vacuo. Purification by flash column chromatography on silica gel using ethyl acetate : hexane $(5: 95)$ as eluant gave the title compound $3.1(0.44 \mathrm{~g}, 88 \%)$ as a white foam. 
IR (thin film) $\mathbf{c m}^{-1}$ : $2526(\mathrm{C}-\mathrm{OH}), 2927 \mathrm{~s}(\mathrm{C}-\mathrm{H}), 1709 \mathrm{~s}(\mathrm{C}=\mathrm{O}), 1611 \mathrm{~s}, 1584,1502 \mathrm{~s}$, $1452 \mathrm{~s}, 1316,1275 \mathrm{~s}, 1112,1026$.

${ }^{1} \mathbf{H}$ NMR (300 MHz, $\left.\mathbf{C D C l}_{\mathbf{3}}\right)$ 8: $0.87\left(\mathrm{t}, J_{3^{\prime}, 2^{\prime}}=7.2 \mathrm{~Hz}, 3 \mathrm{H}, \mathrm{H}-3^{\prime}\right), 1.02(\mathrm{~d}, J=6.9 \mathrm{~Hz}$, $\left.3 \mathrm{H}, 2-\mathrm{CH}_{3}\right), 1.37-1.72(\mathrm{~m}, 5 \mathrm{H}), 1.75-1.87(\mathrm{~m}, 2 \mathrm{H}), 2.01(\mathrm{~m}, 1 \mathrm{H}), 2.16(\mathrm{~m}, 1 \mathrm{H}), 2.40-$ $2.70(\mathrm{~m}, 2 \mathrm{H}), 2.82(\mathrm{~m}, 1 \mathrm{H}, \mathrm{H}-4), 3.21$ (m, 1H, H-4a), $3.46\left(\mathrm{~s}, 3 \mathrm{H}, 7-\mathrm{OCH}_{3}\right), 3.78$ (m, $1 \mathrm{H}, \mathrm{H}-1), 5.63\left(\mathrm{ddd}, J=10.8 \mathrm{~Hz}, J=8.1 \mathrm{~Hz}, J=3.0 \mathrm{~Hz}, 1 \mathrm{H}, \mathrm{H}-1^{\prime}\right), 6.01$ (d, $J_{8,6}=2.7$ $\mathrm{Hz}, 1 \mathrm{H}, \mathrm{H}-8), 6.50$ (dd, $\left.J_{6,5}=8.7 \mathrm{~Hz}, J_{6,8}=2.7 \mathrm{~Hz}, 1 \mathrm{H}, \mathrm{H}-6\right), 7.17-7.42$ (m, 6H, H-5, H$\left.2^{\prime \prime}, \mathrm{H}-3^{\prime \prime}, \mathrm{H}-4^{\prime \prime}\right)$.

${ }^{13} \mathrm{C}$ NMR (75 MHz, $\left.\mathbf{C D C l}_{\mathbf{3}}\right)$ 8: $9.5\left(\mathrm{CH}_{3}, \mathrm{C}-3{ }^{\prime}\right), 18.5\left(2-\mathrm{CH}_{3}\right), 27.3\left(\mathrm{CH}_{2}\right), 27.4$ $\left(\mathrm{CH}_{2},\right), 30.9\left(\mathrm{CH}_{2}\right), 32.3\left(\mathrm{CH}_{2}\right), 32.6(\mathrm{CH}), 37.6(\mathrm{CH}), 39.8(\mathrm{CH}), 40.7(\mathrm{CH}), 55.0(7-$ $\left.\mathrm{OCH}_{3}\right), 73.7\left(\mathrm{CH}, \mathrm{C}^{\prime}{ }^{\prime}\right), 75.1(\mathrm{CH}, \mathrm{C}-1), 112.5(\mathrm{CH}, \mathrm{C}-6), 113.1(\mathrm{CH}, \mathrm{C}-8), 127.7(\mathrm{CH}$, C-5), 128.6 (Ar), 129.8 (Ar), 129.9 (Ar), 131.7 (Ar), 132.4 (C, C-4b), 137.9 (C, C-8a), 156.5 (C, C-7), 166.4 (1'-OC(O)Ph).

LRMS (m/z): $408\left(\mathrm{M}^{+}, 44 \%\right), 390$ (15), 284 (5), 268 (100), 239 (26), 226 (65), 189 (40), 105 (71).

HRMS: $\mathrm{C}_{26} \mathrm{H}_{32} \mathrm{O}_{4}\left(\mathrm{M}^{+}\right)$requires 408.2301, found 408.2301 .

$\left(1^{\prime} R S, 2^{\prime} R S, 4^{\prime} R S, 4 \mathrm{a}^{\prime} S R, 10 \mathrm{a}^{\prime} S R, 1 S R\right)$ 1-[7'-Methoxy-1'- methoxmethoxy -2'methyl-1',2',4a',9',10',10a'-hexahydrophenanthrene-4' $\left(3^{\prime} H\right)$-yl]-propan-1-yl benzoate $(3.2)$
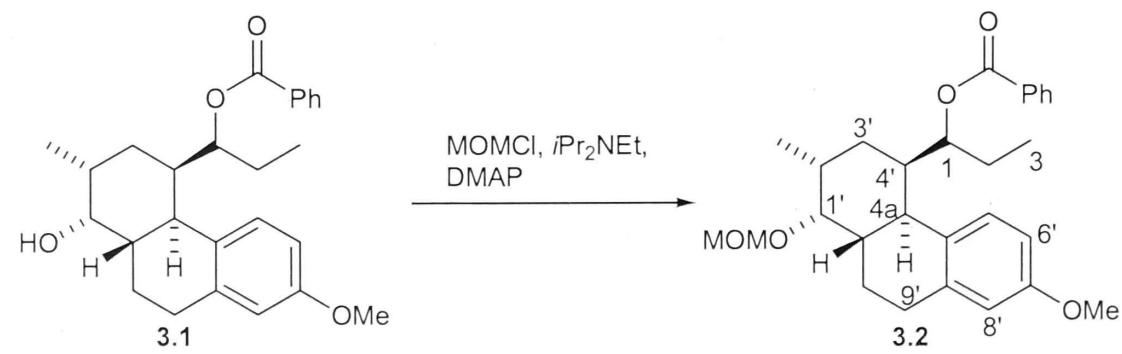

Hünig's base $(0.68 \mathrm{~mL}, \quad 3.88 \mathrm{mmol})$ was added to alcohol $\mathbf{3 . 1}$ (0.52 g, $1.29 \mathrm{mmol})$ in DCM $(10 \mathrm{~mL})$ at $0{ }^{\circ} \mathrm{C}$ under nitrogen. Chloromethyl methyl ether $(0.29 \mathrm{~mL}, 3.88 \mathrm{mmol})$ was added drop wise and the reaction mixture was warmed to room temperature. A catalytic amount of DMAP was then added and the mixture was stirred for $24 \mathrm{~h}$. The reaction was then cooled to $0{ }^{\circ} \mathrm{C}$, saturated sodium bicarbonate $(10$ 
$\mathrm{mL}$ ) was added, and the resulting mixture stirred for $10 \mathrm{~min}$. The organic phase was then separated and the aqueous phase was extracted with DCM $(3 \times 10 \mathrm{~mL})$. The combined organic extracts were washed with water $(10 \mathrm{~mL}), 2 M$ hydrochloric acid (10 $\mathrm{mL})$, saturated sodium bicarbonate $(10 \mathrm{~mL})$, brine $(10 \mathrm{~mL})$ and dried over anhydrous $\mathrm{MgSO}_{4}$. Concentration in vacuo gave the crude product as a yellow gum, which was further purified by flash column chromatography on silica gel using ethyl acetate : hexane $(5: 95-20: 80)$ as eluant to give the title compound $\mathbf{3 . 2}(0.50 \mathrm{~g}, 86 \%)$ as a colourless oil.

IR (thin film) $\mathbf{c m}^{-1}$ : 2929s $(\mathrm{C}-\mathrm{H}), 1709 \mathrm{~s}(\mathrm{C}=\mathrm{O}), 1611 \mathrm{~s}, 1584,1502 \mathrm{~s}, 1452 \mathrm{~s}, 1316$, 1274s, 1147, 1039.

${ }^{1}$ H NMR (300 MHz, $\left.\mathbf{C D C l}_{3}\right)$ 8: $0.87\left(\mathrm{t}, J_{3,2}=7.2 \mathrm{~Hz}, 3 \mathrm{H}, \mathrm{H}-3\right), 1.00(\mathrm{~d}, J=6.6 \mathrm{~Hz}$, $\left.3 \mathrm{H}, 2^{\prime}-\mathrm{CH}_{3}\right), 1.53-1.87(\mathrm{~m}, 7 \mathrm{H}), 2.01(\mathrm{~m}, 1 \mathrm{H}), 2.16(\mathrm{~m}, 1 \mathrm{H}), 2.39-2.62(\mathrm{~m}, 2 \mathrm{H}), 2.80$ (m, 1H, H-4'), 3.24 (m, 1H, H-4a'), 3.37 (s, 3H, 1'- $\left.\mathrm{OCH}_{2} \mathrm{OCH}_{3}\right), 3.46\left(\mathrm{~s}, 3 \mathrm{H}, 7^{\prime}-\mathrm{OCH}_{3}\right)$, 4.63, $4.67\left(2 \times \mathrm{ABd}, J=6.9 \mathrm{~Hz}, 2 \mathrm{H}, 1^{\prime}-\mathrm{OCH}_{2} \mathrm{OCH}_{3}\right), 5.63(\mathrm{~m}, 1 \mathrm{H}, \mathrm{H}-1), 6.00$ (d, $J_{8^{\prime}, 6^{\prime}}=$ $\left.2.7 \mathrm{~Hz}, 1 \mathrm{H}, \mathrm{H}-8^{\prime}\right), 6.50\left(\mathrm{dd}, J_{6^{\prime}, 5^{\prime}}=8.7 \mathrm{~Hz}, J_{6^{\prime}, 8^{\prime}}=2.7 \mathrm{~Hz}, 1 \mathrm{H}, \mathrm{H}-6^{\prime}\right), 7.17-7.41$ (m, 6H, $\left.\mathrm{H}-5^{\prime}, \mathrm{H}-2^{\prime \prime}, \mathrm{H}-3^{\prime \prime}, \mathrm{H}-4^{\prime \prime}\right)$.

${ }^{13} \mathbf{C}$ NMR (75 MHz, $\left.\mathbf{C D C l}_{3}\right)$ 8: $9.1\left(\mathrm{CH}_{3}, \mathrm{C}-3\right), 18.6\left(2^{\prime}-\mathrm{CH}_{3}\right), 27.0\left(\mathrm{CH}_{2}\right), 27.3\left(\mathrm{CH}_{2}\right)$, $30.4\left(\mathrm{CH}_{2}\right), 32.2\left(\mathrm{CH}_{2}\right), 33.1(\mathrm{CH}), 38.2(\mathrm{CH}), 39.7(\mathrm{CH}), 40.4(\mathrm{CH}), 54.5\left(1^{\prime}-\right.$ $\left.\mathrm{OCH}_{2} \mathrm{OCH}_{3}\right), 56.0\left(7^{\prime}-\mathrm{OCH}_{3}\right), 73.3(\mathrm{CH}, \mathrm{C}-1), 83.0\left(\mathrm{CH}, \mathrm{C}-1^{\prime}\right), 98.4\left(1^{\prime}-\mathrm{OCH}_{2} \mathrm{OCH}_{3}\right)$, 112.1 (CH, C-6'), 112.5 (CH, C-8'), 127.2 (CH, C-5'), 128.1 (Ar), 129.1 (Ar), 129.3 (Ar), 129.5 (Ar), 131.4 (Ar), 131.7 (Ar), 132.0 (C, C-4b'), 137.6 (C, C-8a'), 156.0 (C, C$\left.7^{\prime}\right), 165.9(1-\mathrm{OC}(\mathrm{O}) \mathrm{Ph})$.

LRMS (m/z): $452\left(\mathrm{M}^{+}, 25 \%\right), 420$ (40), 390 (30), 285 (60), 268 (100), 239 (26), 226 (65), $160(30), 105(85)$.

HRMS: $\mathrm{C}_{28} \mathrm{H}_{36} \mathrm{O}_{5}\left(\mathrm{M}^{+}\right)$requires 452.2563, found 452.2562 . 
$\left(1^{\prime} R S, 2^{\prime} R S, 4^{\prime} R S, 4 \mathrm{a}^{\prime} R S, 10 \mathrm{a}^{\prime} S R, 1 S R\right)$ 1-[7'-Methoxy-1'- methoxmethoxy -2'-

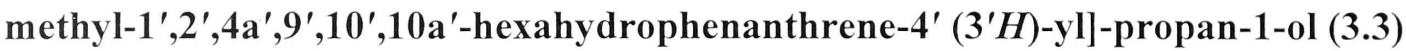
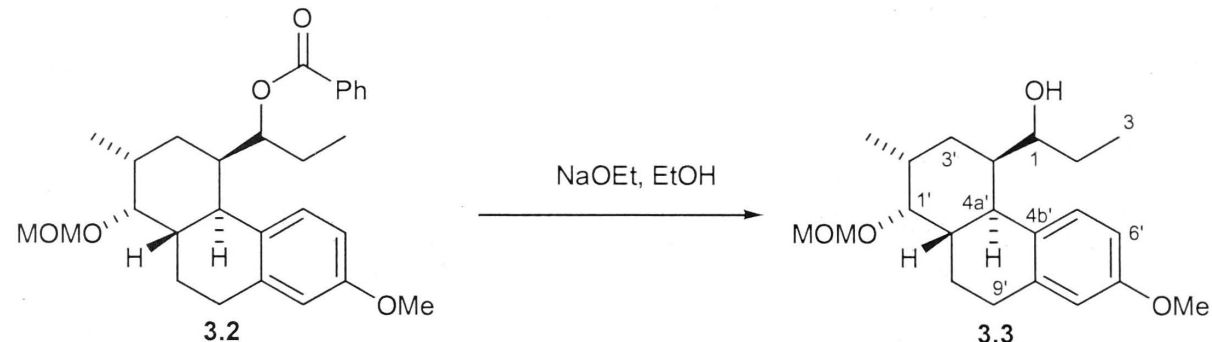

Small pieces of sodium metal $(0.4 \mathrm{~g}$ total) were added slowly to ethanol $(20 \mathrm{~mL})$ at room temperature under nitrogen. A solution of benzoate $3.2(0.50 \mathrm{~g}, 1.11 \mathrm{mmol})$ in ethanol $(5 \mathrm{~mL})$ was added and the resulting reaction mixture heated at reflux for $24 \mathrm{~h}$. The reaction mixture was warmed to room temperature, water $(10 \mathrm{~mL})$ was added and the ethanol removed in vacuo. The aqueous residue was extracted with ethyl acetate (3 x $20 \mathrm{~mL}$ ) and the combined organic extracts dried over anhydrous $\mathrm{MgSO}_{4}$. Concentration of the organic phase in vacuo gave a yellow gum which was purified by flash column chromatography on silica gel using ethyl acetate : hexane (1:9) as eluant to give the title compound $\mathbf{3 . 3}(0.36 \mathrm{~g}, 95 \%)$ as a white foam.

IR (thin film) $\mathbf{c m}^{-1}$ : $3576(\mathrm{C}-\mathrm{OH}), 2926 \mathrm{~s}(\mathrm{C}-\mathrm{H}), 1609 \mathrm{~s}, 1500 \mathrm{~s}, 1464,1256,1147$, 1038s.

${ }^{1}$ H NMR (300 MHz, $\left.\mathbf{C D C l}_{\mathbf{3}}\right)$ ): $0.91\left(\mathrm{t}, J_{3,2}=7.2 \mathrm{~Hz}, 3 \mathrm{H}, \mathrm{H}-3\right), 0.96(\mathrm{~d}, J=6.3 \mathrm{~Hz}$, $\left.3 \mathrm{H}, 2^{\prime}-\mathrm{CH}_{3}\right), 1.32(\mathrm{~m}, 1 \mathrm{H}), 1.48-1.87(\mathrm{~m}, 6 \mathrm{H}), 2.10(\mathrm{~m}, 1 \mathrm{H}), 2.49\left(\mathrm{~m}, 1 \mathrm{H}, \mathrm{H}-4^{\prime}\right), 2.71$ (m, 1H), $2.88(\mathrm{~m}, 1 \mathrm{H}), 3.28\left(\mathrm{~m}, 1 \mathrm{H}, \mathrm{H}-4 \mathrm{a}^{\prime}\right), 3.39$ (s, 3H, 1'- $\left.\mathrm{OCH}_{2} \mathrm{OCH}_{3}\right), 3.62(\mathrm{~m}, 1 \mathrm{H}$, H-1'), $3.75\left(\mathrm{~s}, 3 \mathrm{H}, 7^{\prime}-\mathrm{OCH}_{3}\right), 3.88\left(\mathrm{td}, J_{1,2}=9.0, J_{1,4^{\prime}}=3.0 \mathrm{~Hz}, 1 \mathrm{H}, \mathrm{H}-1\right), 4.65,4.68(2$ x ABd, $\left.J=6.9 \mathrm{~Hz}, 2 \mathrm{H}, 1^{\prime}-\mathrm{OCH}_{2} \mathrm{OCH}_{3}\right), 6.60\left(\mathrm{~d}, J_{8^{\prime}, 6^{\prime}}=2.6 \mathrm{~Hz}, 1 \mathrm{H}, \mathrm{H}-8^{\prime}\right), 6.73\left(\mathrm{dd}, J_{6^{\prime}, 5^{\prime}}\right.$ $\left.=8.6 \mathrm{~Hz}, J_{6^{\prime}, 8^{\prime}}=2.6 \mathrm{~Hz}, 1 \mathrm{H}, \mathrm{H}-6^{\prime}\right), 7.29\left(\mathrm{~d}, J_{5^{\prime}, 6^{\prime}}=8.6 \mathrm{~Hz}, 1 \mathrm{H}, \mathrm{H}-5^{\prime}\right)$.

${ }^{13} \mathrm{C}$ NMR (75 MHz, $\left.\mathbf{C D C l}_{3}\right)$ 8: $9.7\left(\mathrm{CH}_{3}, \mathrm{C}-3\right), 18.6\left(2^{\prime}-\mathrm{CH}_{3}\right), 27.3\left(\mathrm{CH}_{2}\right), 29.2\left(\mathrm{CH}_{2}\right)$, $30.9\left(\mathrm{CH}_{2}\right), 32.5\left(\mathrm{CH}_{2}\right), 32.9(\mathrm{CH}), 38.3(\mathrm{CH}), 40.3(\mathrm{CH}), 42.8(\mathrm{CH}), 55.1$ (1'$\left.\mathrm{OCH}_{2} \mathrm{OCH}_{3}\right), 56.1\left(7^{\prime}-\mathrm{OCH}_{3}\right), 72.8(\mathrm{CH}, \mathrm{C}-1), 83.0\left(\mathrm{CH}, \mathrm{C}-1^{\prime}\right), 98.4\left(1^{\prime}-\mathrm{OCH}_{2} \mathrm{OCH}_{3}\right)$, $112.3\left(\mathrm{CH}, \mathrm{C}-6^{\prime}\right), 114.3\left(\mathrm{CH}, \mathrm{C}-8^{\prime}\right), 128.5\left(\mathrm{CH}, \mathrm{C}-5^{\prime}\right), 130.8\left(\mathrm{C}, \mathrm{C}-4 b^{\prime}\right), 139.0(\mathrm{C}, \mathrm{C}-$ $\left.8 \mathrm{a}^{\prime}\right), 157.2\left(\mathrm{C}, \mathrm{C}-\mathrm{7}^{\prime}\right)$. 
LRMS (m/z): $348\left(\mathrm{M}^{+}, 25 \%\right), 316$ (35), 286 (48), 268 (23), 245 (50), 228 (100), 227 (75), $201(27), 186(40)$.

HRMS: $\mathrm{C}_{21} \mathrm{H}_{32} \mathrm{O}_{4}\left(\mathrm{M}^{+}\right)$requires 348.2301, found 348.2304.

(1'RS, 2'RS, 4'RS, 4a'SR, 10a'SR, 1SR) 1-[7'-Methoxy-1'- methoxmethoxy -2'methyl-1',2',4a',9',10',10a'-hexahydrophenanthrene-4' $\left(3^{\prime} H\right)$-yl]-propoxy-(t.butyl)dimethylsilane (3.4)

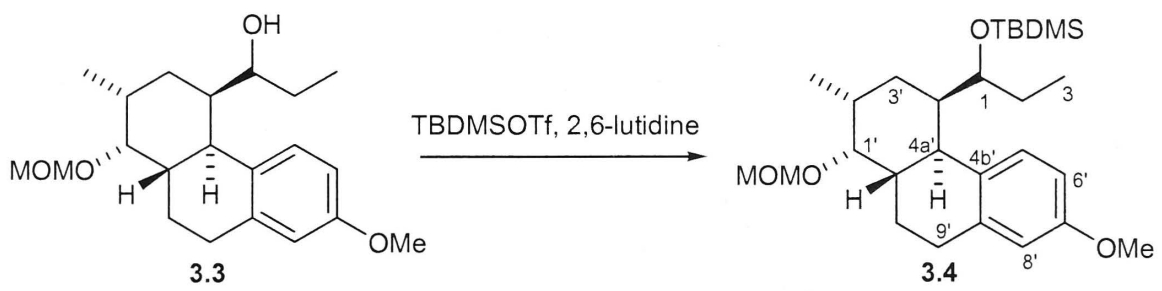

t.-Butyldimethylsilyl trifluoromethanesulfonate $(0.36 \mathrm{~mL}, 1.55 \mathrm{mmol})$ was added drop wise to alcohol $3.3(0.36 \mathrm{~g}, 1.03 \mathrm{mmol})$ and 2,6-lutidine $(0.24 \mathrm{~mL}, 2.06 \mathrm{mmol})$ in DCM $(6 \mathrm{~mL})$ at room temperature under nitrogen. The resulting reaction mixture was stirred for 15 min after which time TLC analysis revealed the consumption of all starting material. Water $(6 \mathrm{~mL})$ was added and the organic phase separated before further extraction with DCM $(2 \times 10 \mathrm{~mL})$. The combined organic extracts were washed with brine and dried over anhydrous $\mathrm{MgSO}_{4}$. Concentration of the organic phase in vacuo gave a yellow gum, which was purified by flash column chromatography on silica gel using ethyl acetate : hexane $(1: 9)$ as eluant to give the title compound $\mathbf{3 . 4}(0.38 \mathrm{~g}$, $77 \%$ ) as a white gum. A sample was crystallised from hexane to give white crystals.

m.p: $69-70{ }^{\circ} \mathrm{C}$

IR (thin film) $\mathbf{c m}^{-1}$ : 2929s (C-H), 1611, 1576, 1501s, 1464, 1278, 1256s, 1149, 1039s.

${ }^{1}$ H NMR (300 MHz, $\left.\mathbf{C D C l}_{3}\right)$ ): $-0.06\left(\mathrm{~s}, 3 \mathrm{H},-\mathrm{SiCH}_{3}\right),-0.04\left(\mathrm{~s}, 3 \mathrm{H},-\mathrm{SiCH}_{3}\right), 0.74$ (t, $\left.J_{3,2}=7.2 \mathrm{~Hz}, 3 \mathrm{H}, \mathrm{H}-3\right), 0.84\left(\mathrm{~s}, 9 \mathrm{H},-\mathrm{Si}^{\mathrm{t}} \mathrm{Bu}\right), 0.97$ (d, $\left.J=6.6 \mathrm{~Hz}, 3 \mathrm{H}, 2^{\prime}-\mathrm{CH}_{3}\right), 1.23-1.99$ (m, 8H), 2.62-2.88 (m, 3H), $3.26\left(\mathrm{dd}, J_{4 \mathrm{a}^{\prime}, 10 \mathrm{a}^{\prime}}=12.0 \mathrm{~Hz}, J_{4 \mathrm{a}^{\prime}, 4^{\prime}}=5.7 \mathrm{~Hz} 1 \mathrm{H}, \mathrm{H}-4 \mathrm{a}^{\prime}\right), 3.39$ $\left(\mathrm{s}, 3 \mathrm{H}, 1^{\prime}-\mathrm{OCH}_{2} \mathrm{OCH}_{3}\right), 3.57\left(\mathrm{~m}, 1 \mathrm{H}, \mathrm{H}-1^{\prime}\right), 3.78\left(\mathrm{~s}, 3 \mathrm{H}, 7^{\prime}-\mathrm{OCH}_{3}\right), 3.75(\mathrm{~m}, 1 \mathrm{H}, \mathrm{H}-1)$, 4.64, $4.67\left(2 \times \mathrm{ABd}, J=6.9 \mathrm{~Hz}, 2 \mathrm{H}, 1^{\prime}-\mathrm{OCH}_{2} \mathrm{OCH}_{3}\right), 6.56\left(\mathrm{~d}, J_{8^{\prime}, 6^{\prime}}=2.9 \mathrm{~Hz}, 1 \mathrm{H}, \mathrm{H}-8^{\prime}\right)$, $6.70\left(\mathrm{dd}, J_{6^{\prime}, 5^{\prime}}=8.4 \mathrm{~Hz}, J_{6^{\prime}, 8^{\prime}}=2.9 \mathrm{~Hz}, 1 \mathrm{H}, \mathrm{H}-6^{\prime}\right), 7.20\left(\mathrm{~d}, J_{5^{\prime}, 6^{\prime}}=8.4 \mathrm{~Hz}, 1 \mathrm{H}, \mathrm{H}-5^{\prime}\right)$. 
${ }^{13} \mathbf{C}$ NMR (75 MHz, $\left.\mathbf{C D C l}_{3}\right)$ 8: $-4.4\left(\mathrm{SiCH}_{3}\right),-3.8\left(\mathrm{SiCH}_{3}\right), 10.8\left(\mathrm{CH}_{3}, \mathrm{C}-3\right), 18.2$ (SiC), $19.1\left(2^{\prime}-\mathrm{CH}_{3}\right), 26.1\left(\mathrm{Si}{ }^{\mathrm{t}} \mathrm{Bu}\right), 28.0\left(\mathrm{CH}_{2}\right), 28.3\left(\mathrm{CH}_{2}\right), 29.3\left(\mathrm{CH}_{2}\right), 31.0\left(\mathrm{CH}_{2}\right), 34.2$ $(\mathrm{CH}), 37.2(\mathrm{CH}), 40.3(\mathrm{CH}), 41.0(\mathrm{CH}), 55.1\left(1^{\prime}-\mathrm{OCH}_{2} \mathrm{OCH}_{3}\right), 56.0\left(7^{\prime}-\mathrm{OCH}_{3}\right), 73.3$ $(\mathrm{CH}, \mathrm{C}-1), 83.5\left(\mathrm{CH}, \mathrm{C}-1^{\prime}\right), 98.4\left(1^{\prime}-\mathrm{OCH}_{2} \mathrm{OCH}_{3}\right), 111.7\left(\mathrm{CH}, \mathrm{C}-6{ }^{\prime}\right), 113.4\left(\mathrm{CH}, \mathrm{C}-8^{\prime}\right)$, $128.6\left(\mathrm{CH}, \mathrm{C}-5^{\prime}\right), 130.5$ (C, C-4b'), 138.3 (C, C-8a'), 156.7 (C, C-7').

LRMS (m/z): $462\left(\mathrm{M}^{+}, 2 \%\right), 405$ (27), 373 (20), 269 (7), 226 (7), 174 (14), 173 (100), $147(10), 117(15), 115(11)$.

HRMS: $\mathrm{C}_{27} \mathrm{H}_{46} \mathrm{O}_{4}\left(\mathrm{M}^{+}\right)$requires 462.3165 , found 462.3160 .

Microanalysis: Calcd. for $\mathrm{C}_{27} \mathrm{H}_{46} \mathrm{O}_{4} \mathrm{Si}: \mathrm{C}, 70.08 \%, \mathrm{H}, 10.02 \%$. Found: $\mathrm{C}, 69.82 \%$, $\mathrm{H}$, $10.10 \%$.

(4aSR, 4bSR, 5RS, 7RS, 8RS, 8aSR, 1'SR) 4-(1'-t.-Butyldimethylsilyloxypropyl)-8methoxmethoxy-7-methyl-,4,4a,4b,5,6,7,8,8a,9,10-decahydro-2(3H)phenanthrenone (3.7)

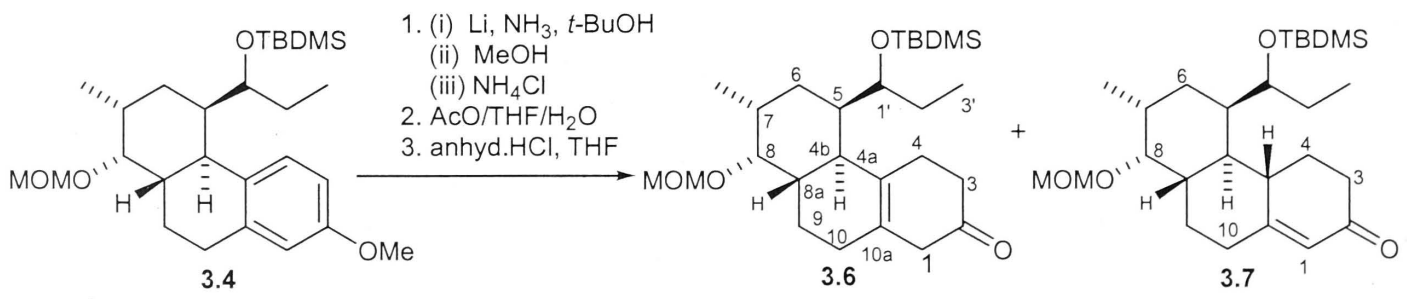

Dry ammonia $(100 \mathrm{~mL})$ was distilled into a 3-necked flask fitted with a dry ice condenser under nitrogen. Small pieces of freshly cleaned lithium wire $(0.70 \mathrm{~g}, 100$ mmol) were added at $-78{ }^{\circ} \mathrm{C}$ and the resulting blue solution was stirred for 15 min. Silyl ether 3.4 (0.93 g, $2.0 \mathrm{mmol})$ in THF (40 mL) was added over $10 \mathrm{~min}$, stirred for $15 \mathrm{~min}$, then $t$-butanol $(40 \mathrm{~mL})$ was added. The resulting blue reaction mixture was warmed to $-40{ }^{\circ} \mathrm{C}$ and stirred for $3 \mathrm{~h}$. The reaction was quenched with methanol and the ammonia allowed to boil off under a stream of nitrogen, before a saturated aqueous solution of ammonium chloride $(80 \mathrm{~mL})$ was added. Water $(50 \mathrm{~mL})$ was added after $15 \mathrm{~min}$ and the aqueous phase extracted with ethyl acetate $(3 \times 100 \mathrm{~mL})$. The combined organic extracts were washed with water $(50 \mathrm{~mL})$, brine $(50 \mathrm{~mL})$ and dried over anhydrous $\mathrm{MgSO}_{4}$. Concentration of the organic phase in vacuo gave a colourless oil, which was taken up in a solution of acetic acid : THF : water $(4: 2: 1,50 \mathrm{~mL})$ and stirred overnight under nitrogen. The solvent was removed in vacuo and the residue treated 
with $10 \%$ aqueous sodium hydroxide until $\mathrm{pH} 10$. The aqueous residue was then extracted with ethyl acetate $(3 \times 50 \mathrm{~mL})$, dried over anhydrous $\mathrm{MgSO}_{4}$ and concentrated in vacuo to give the crude $\beta \gamma$-enone $\mathbf{3 . 6}$ as a colourless oil, which was used directly in the next step without further purification.

Concentrated sulfuric acid was added drop wise to sodium chloride. The resulting hydrogen chloride gas was passed through concentrated sulfuric acid and then bubbled through THF (15 mL) for ca. 1 min. The crude $\beta \gamma$-enone 3.6 in THF (15 mL) was then added to the acidic THF and the reaction monitored by TLC. The reaction was quenched with saturated aqueous sodium bicarbonate $(5 \mathrm{~mL})$ when most of the starting material had been consumed and a new UV active spot was observed. The THF was removed in vacuo and the aqueous residue extracted with ethyl acetate $(3 \times 50 \mathrm{~mL})$. The combined organic extracts were washed with water $(20 \mathrm{~mL})$, brine $(20 \mathrm{~mL})$ and dried over anhydrous $\mathrm{MgSO}_{4}$. Concentration of the organic phase in vacuo gave a yellow gum, which was purified by flash column chromatography on silica gel using ethyl acetate : hexane $(1: 9)$ as eluant to give the $\beta \gamma$-enone $3.6(0.06 \mathrm{~g}, 7 \%)$ as a colourless oil, and the $\alpha \beta$-enone $3.7(0.58 \mathrm{~g}, 64 \%)$ as a white solid (71\% combined yield). A sample of the $\alpha \beta$-enone $\mathbf{3 . 7}$ was crystallised from hexane to give white crystals.

(4aSR, 4bSR, 5RS, 7RS, 8RS, 8a $S R, 1 ' S R)$ 4-(1'-t.-Butyldimethylsilyloxypropyl)-8methoxmethoxy-7-methyl-,4,4a,4b,5,6,7,8,8a,9,10-decahydro-2(3H)phenanthrenone (3.7)

m.p: $78-80{ }^{\circ} \mathrm{C}$

IR (thin film) $\mathbf{c m}^{-1}$ : 2930s (C-H), 1672s (C=O), 1621, 1472, 1463, 1360, 1256s, 1151, 1039s.

${ }^{1} \mathbf{H}$ NMR (300 MHz, $\left.\mathbf{C D C l}_{\mathbf{3}}\right)$ \&: $0.06\left(\mathrm{~s}, 3 \mathrm{H},-\mathrm{SiCH}_{3}\right), 0.08$ (s, 3H, - $\left.\mathrm{SiCH}_{3}\right), 0.90$ (s, $\left.9 \mathrm{H},-\mathrm{Si}{ }^{\mathrm{t}} \mathrm{Bu}\right), 0.92\left(\mathrm{t}, J_{3^{\prime}, 2^{\prime}}=7.5 \mathrm{~Hz}, 3 \mathrm{H}, \mathrm{H}-3^{\prime}\right), 0.89-0.92\left(\mathrm{~m}, 3 \mathrm{H}, 7-\mathrm{CH}_{3}\right), 1.35-1.92(\mathrm{~m}$, $10 \mathrm{H}), 2.08-2.46(\mathrm{~m}, 6 \mathrm{H}), 2.77(\mathrm{~m}, 1 \mathrm{H}), 3.38\left(\mathrm{~s}, 3 \mathrm{H}, 8-\mathrm{OCH}_{2} \mathrm{OCH}_{3}\right), 3.42(\mathrm{~m}, 1 \mathrm{H}, \mathrm{H}-8)$, $4.07\left(\mathrm{dt}, J_{1^{\prime}, 5}=7.5 \mathrm{~Hz}, J_{1^{\prime}, 2^{\prime}}=4.5 \mathrm{~Hz}, 1 \mathrm{H}, \mathrm{H}-1^{\prime}\right), 4.61,4.58(2 \times \mathrm{ABd}, J=6.9 \mathrm{~Hz}, 2 \mathrm{H}, 8-$ $\mathrm{OCH}_{2} \mathrm{OCH}_{3}$ ), 5.81 (s (br), 1H, H-1). 
${ }^{13} \mathrm{C}$ NMR (75 MHz, $\left.\mathbf{C D C l}_{3}\right)$ 8: $-4.0\left(\mathrm{SiCH}_{3}\right),-3.5\left(\mathrm{SiCH}_{3}\right), 8.6\left(\mathrm{CH}_{3}, \mathrm{C}-3{ }^{\prime}\right), 18.2$ ( $\mathrm{SiC}), 18.7\left(7-\mathrm{CH}_{3}\right), 26.1\left(\mathrm{Si}{ }^{\mathrm{t}} \mathrm{Bu}\right), 27.2\left(\mathrm{CH}_{2}\right), 28.4\left(\mathrm{CH}_{2}\right), 30.1\left(\mathrm{CH}_{2}\right), 30.5\left(\mathrm{CH}_{2}\right), 32.8$ $(\mathrm{CH}), 35.4\left(\mathrm{CH}_{2}\right), 36.3\left(\mathrm{CH}_{2}\right), 36.7(\mathrm{CH}), 38.3(\mathrm{CH}), 40.9(\mathrm{CH}), 44.1(\mathrm{CH}), 56.3(8-$ $\left.\mathrm{OCH}_{2} \mathrm{OCH}_{3}\right), 72.9\left(\mathrm{CH}, \mathrm{C}-1^{\prime}\right), 83.1(\mathrm{CH}, \mathrm{C}-8), 98.8\left(8-\mathrm{OCH}_{2} \mathrm{OCH}_{3}\right), 124.0(\mathrm{CH}, \mathrm{C}-1)$, 167.7 (C, C-10a), 200.2 (2-CO).

LRMS (m/z): $450\left(\mathrm{M}^{+}, 5 \%\right), 435$ (2), 421 (5), 393 (47), 361 (6), 331 (14), 318 (76), 256 (30), 224 (40), 192 (77), 173 (91), 170 (89), 141 (65), 73 (100).

HRMS: $\mathrm{C}_{26} \mathrm{H}_{46} \mathrm{O}_{4} \mathrm{Si}\left(\mathrm{M}^{+}\right)$requires 450.3165 , found 450.3158 .

Microanalysis: Calcd. for $\mathrm{C}_{26} \mathrm{H}_{46} \mathrm{O}_{4} \mathrm{Si}$ : C, 69.28\%, H, 10.29\%. Found: C, 68.94\%, H, $9.90 \%$.

(4bSR, 5RS, 7RS, 8RS, 8aSR, 1'SR) 4-(1'-t.-Butyldimethylsilyloxypropyl)-8methoxmethoxy-7-methyl-1,4,4b,5,6,7,8,8a,9,10-decahydro-2(3H)-phenanthrenone (3.6)

IR (thin film) $\mathbf{c m}^{-1}: 2930 \mathrm{~s}(\mathrm{C}-\mathrm{H}), 1721 \mathrm{~s}(\mathrm{C}=\mathrm{O}), 1677,1471 \mathrm{~s}, 1379,1254 \mathrm{~s}, 1151,1071$, $1037 \mathrm{~s}$.

${ }^{1} \mathbf{H}$ NMR $\left(300 \mathbf{M H z}, \mathbf{C D C l}_{3}\right)$ ): $-0.10\left(\mathrm{~s}, 3 \mathrm{H},-\mathrm{SiCH}_{3}\right),-0.02\left(\mathrm{~s}, 3 \mathrm{H},-\mathrm{SiCH}_{3}\right), 0.82(\mathrm{~s}$, $\left.9 \mathrm{H},-\mathrm{Si}^{\mathrm{t}} \mathrm{Bu}\right), 0.84\left(\mathrm{t}, J_{3^{\prime}, 2^{\prime}}=7.2 \mathrm{~Hz}, 3 \mathrm{H}, \mathrm{H}-3^{\prime}\right), 0.92\left(\mathrm{~d}, J=6.6 \mathrm{~Hz}, 3 \mathrm{H}, 7-\mathrm{CH}_{3}\right), 1.39-1.80$ (m, 10H), 2.20-2.32 (m, 2H), 2.38-2.48 (m, 3H), 2.68 (s(br), 2H, H-1), $2.74(\mathrm{~m}, 1 \mathrm{H})$, $3.40\left(\mathrm{~s}, 3 \mathrm{H}, 8-\mathrm{OCH}_{2} \mathrm{OCH}_{3}\right), 3.50(\mathrm{~m}, 1 \mathrm{H}, \mathrm{H}-8), 3.97\left(\mathrm{dt}, J_{1^{\prime}, 5}=9.0 \mathrm{~Hz}, J_{1^{\prime}, 2^{\prime}}=3.9 \mathrm{~Hz}\right.$, $\left.1 \mathrm{H}, \mathrm{H}-1^{\prime}\right), 466\left(\mathrm{~s}, 2 \mathrm{H}, 8-\mathrm{OCH}_{2} \mathrm{OCH}_{3}\right)$.

${ }^{13} \mathrm{C}$ NMR (75 MHz, CDCl 3 ) 8 : $-4.5\left(\mathrm{SiCH}_{3}\right),-3.5\left(\mathrm{SiCH}_{3}\right), 7.2\left(\mathrm{CH}_{3}, \mathrm{C} 3{ }^{\prime}\right), 18.2(\mathrm{SiC})$, $18.7\left(7-\mathrm{CH}_{3}\right), 26.2\left(\mathrm{Si}{ }^{t} \mathrm{Bu}\right), 26.8\left(\mathrm{CH}_{2}\right), 27.9\left(2 \times \mathrm{CH}_{2}\right), 29.9\left(\mathrm{CH}_{2}\right), 32.3\left(\mathrm{CH}_{2}\right), 32.5$ $(\mathrm{CH}), 37.2(\mathrm{CH}), 39.0\left(\mathrm{CH}_{2}, \mathrm{C} 3\right), 39.1(\mathrm{CH}), 40.5(\mathrm{CH}), 45.0\left(\mathrm{CH}_{2}, \mathrm{C}-1\right), 56.2(8-$ $\left.\mathrm{OCH}_{2} \mathrm{OCH}_{3}\right), 71.2\left(\mathrm{CH}, \mathrm{C}-1^{\prime}\right), 83.2(\mathrm{CH}, \mathrm{C}-8), 98.5\left(8-\mathrm{OCH}_{2} \mathrm{OCH}_{3}\right), 123.7(\mathrm{C}, \mathrm{C}-10 \mathrm{a})$, 132.7 (C, C-4a), 212.0 (2-CO).

LRMS (m/z): $450\left(\mathrm{M}^{+}, 6 \%\right), 435$ (6), 393 (47), 361 (20), 330 (20), 256 (22), 214 (21), 185 (15), 173 (100), 117 (31), 74 (90). 
HRMS: $\mathrm{C}_{26} \mathrm{H}_{46} \mathrm{O}_{4} \mathrm{Si}\left(\mathrm{M}^{+}\right)$requires 450.3165 , found 450.3157 .

$(1 R S, 4 \mathrm{a} R S, 4 \mathrm{~b} S R, 5 R S, 7 R S, 8 R S, 8 \mathrm{a} S R, 10 \mathrm{a} S R, 1 ' S R)$ Methyl 5-(1'-t. -

Butyldimethylsilyloxypropyl)-8-methoxmethoxy-7-methyl-2-oxo-3,4,4a,4b,5,6,7,8, 8a,9,10,10a-dodecahydrophenanthrene-1(2H)-carboxylate (3.16)

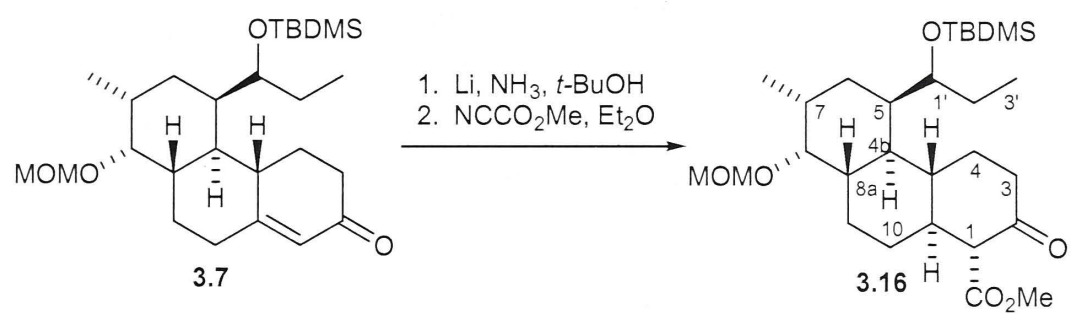

Dry ammonia $(10 \mathrm{~mL})$ was distilled into a 3-necked flask fitted with a dry ice condenser under nitrogen. Small pieces of freshly cleaned lithium wire $(0.005 \mathrm{~g}, 0.68 \mathrm{mmol})$ were added at $-78{ }^{\circ} \mathrm{C}$ and the resulting blue solution stirred for 10 min. A solution of enone $3.7(0.12 \mathrm{~g}, 0.27 \mathrm{mmol})$ in $t$-butyl alcohol $(0.020 \mathrm{~mL}, 0.27 \mathrm{mmol})$ and ether $(2 \mathrm{~mL})$ was added drop wise, and the resulting reaction mixture stirred for $15 \mathrm{~min}$. The reaction was quenched with isoprene until the blue colour dispersed, and the ammonia allowed to boil off under a stream of nitrogen. The residue was dried under high vacuum for 5 min then nitrogen was reintroduced. Ether $(5 \mathrm{~mL})$ was added and the reaction mixture was cooled to $-78{ }^{\circ} \mathrm{C}$. Methyl cyanoformate $(0.024 \mathrm{~mL}, 0.32 \mathrm{mmol})$ was added and the reaction mixture was stirred for $15 \mathrm{~min}$ before quenching with lithium hydroxide $(3 \mathrm{~mL}$, $2 M)$. The reaction mixture was warmed to room temperature and monitored by TLC until only one product was observed. The reaction mixture was extracted with ether (3 $\mathrm{x} 15 \mathrm{~mL})$ and the combined organic extracts were washed with water $(5 \mathrm{~mL})$, brine (5 $\mathrm{mL}$ ) and dried over anhydrous $\mathrm{MgSO}_{4}$. Concentration of the organic phase in vacuo gave a colourless oil which was purified by flash column chromatography on silica gel using ethyl acetate : hexane $(5: 95-20: 80)$ as eluant to give the title compound $\mathbf{3 . 1 6}$ $(0.054 \mathrm{~g}, 39 \%)$ as a colourless oil.

IR (thin film) $\mathbf{c m}^{-1}:$ 2930s $(\mathrm{C}-\mathrm{H}), 1749 \mathrm{~s}(\mathrm{C}=\mathrm{O}), 1716(\mathrm{C}=\mathrm{O}), 1462,1359,1254,1150$, $1071,1038$.

${ }^{1} \mathbf{H}$ NMR (300 MHz, $\left.\mathbf{C D C l}_{3}\right)$ \&: 0.06 (s, 3H, - $\left.\mathrm{SiCH}_{3}\right), 0.07$ (s, 3H, - $\left.\mathrm{SiCH}_{3}\right), 0.91$ (s, 9H, -Si $\left.{ }^{\mathrm{t}} \mathrm{Bu}\right), 0.88-0.95\left(\mathrm{~m}, 6 \mathrm{H}, \mathrm{H}-3^{\prime}, \mathrm{CH}_{3}\right), 1.13(\mathrm{~m}, 1 \mathrm{H}), 1.32-1.83(\mathrm{~m}, 12 \mathrm{H}), 2.12(\mathrm{~m}$, $1 \mathrm{H}), 2.27-2.42(\mathrm{~m}, 3 \mathrm{H}), 3.12\left(\mathrm{~d}, J_{1,10 \mathrm{a}}=11.7 \mathrm{~Hz}, 1 \mathrm{H}, \mathrm{H}-1\right), 3.35(\mathrm{~m}, 1 \mathrm{H}, \mathrm{H}-8), 3.39(\mathrm{~s}$, 
$\left.3 \mathrm{H}, 8-\mathrm{OCH}_{2} \mathrm{OCH}_{3}\right), 3.75\left(\mathrm{~s}, 3 \mathrm{H}, 1-\mathrm{CO}_{2} \mathrm{CH}_{3}\right), 3.92\left(\mathrm{~m}, 1 \mathrm{H}, \mathrm{H}-1^{\prime}\right), 4.59,4.62(2 \times \mathrm{ABd}, J$ $\left.=6.6 \mathrm{~Hz}, 2 \mathrm{H}, 8-\mathrm{OCH}_{2} \mathrm{OCH}_{3}\right)$.

${ }^{13} \mathrm{C}$ NMR (75 MHz, $\left.\mathbf{C D C l}_{3}\right)$ 8: $\quad-4.2\left(\mathrm{SiCH}_{3}\right),-3.2\left(\mathrm{SiCH}_{3}\right), 9.7\left(\mathrm{CH}_{3}, \mathrm{C}-3^{\prime}\right), 18.3$ ( $\mathrm{SiC}), 19.0\left(7-\mathrm{CH}_{3}\right), 26.1\left(\mathrm{Si}^{\mathrm{t}} \mathrm{Bu}\right), 28.7\left(\mathrm{CH}_{2}\right), 29.3\left(\mathrm{CH}_{2}\right), 29.9\left(\mathrm{CH}_{2}\right), 30.4\left(\mathrm{CH}_{2}\right), 31.5$, $33.1,37.3,40.4,40.7,41.1,41.5,45.8,51.9\left(1-\mathrm{CO}_{2} \mathrm{CH}_{3}\right), 56.3\left(8-\mathrm{OCH}_{2} \mathrm{OCH}_{3}\right), 63.7$ $(\mathrm{CH}, \mathrm{C}-1), 73.5\left(\mathrm{CH}, \mathrm{C}-1^{\prime}\right), 83.5(\mathrm{CH}, \mathrm{C}-8), 98.9\left(8-\mathrm{OCH}_{2} \mathrm{OCH}_{3}\right), 170.2\left(1-\mathrm{CO}_{2} \mathrm{CH}_{3}\right)$, $205.8(2-\mathrm{CO})$.

LRMS (m/z): $453\left(\left(\mathrm{M}^{\mathrm{t}}{ }^{\mathrm{B}} \mathrm{Bu}\right)^{+}, 73 \%\right), 373$ (10), 299 (9), 201 (10), 173 (100), 115 (17).

HRMS: $\mathrm{C}_{24} \mathrm{H}_{41} \mathrm{O}_{6} \mathrm{Si}\left(\mathrm{M}-{ }^{\mathrm{t}} \mathrm{Bu}^{+}\right)$requires 453.2672, found 453.2602.

(4a $\left.R S, 4 \mathrm{~b} S R, 5 R S, 7 R S, 8 R S, 8 \mathrm{a} S R, 10 \mathrm{a} R S, 1^{\prime} S R\right)$ Methyl 5-(1'-t.-

Butyldimethylsilyloxypropyl)-8-methoxmethoxy-7-methyl-2-hydroxy-

1,4,4a,4b,5,6,7,8, 8a,9,10,10a-dodecahydrophenanthrene-3(2H)-carboxylate $(3.17)$

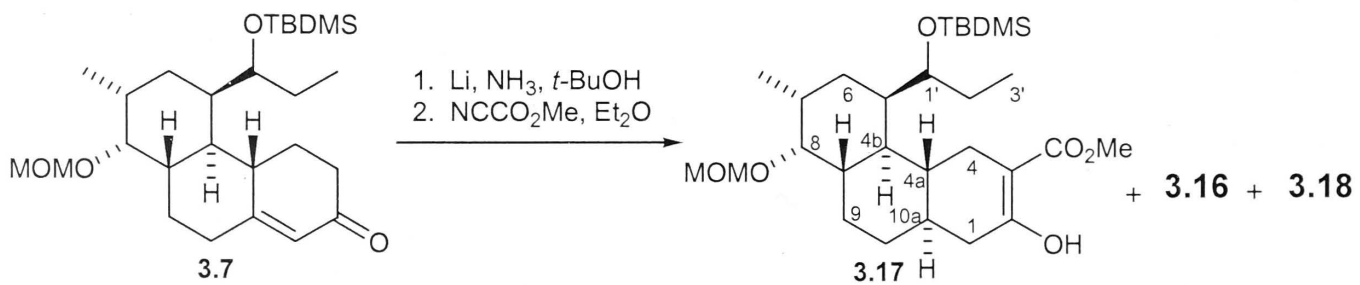

Dry ammonia $(10 \mathrm{~mL})$ was distilled into a 3-necked flask fitted with a dry ice condenser under nitrogen. Small pieces of freshly cleaned lithium wire $(0.004 \mathrm{~g}, 0.61 \mathrm{mmol})$ were added at $-78{ }^{\circ} \mathrm{C}$ and the resulting blue solution stirred for $10 \mathrm{~min}$. A solution of enone $3.7(0.11 \mathrm{~g}, 0.24 \mathrm{mmol})$ in $t$-butyl alcohol $(0.020 \mathrm{~mL}, 0.24 \mathrm{mmol})$ and ether $(2 \mathrm{~mL})$ was added drop wise, and the resulting reaction mixture stirred for $15 \mathrm{~min}$. The reaction was quenched with isoprene until the blue colour dispersed, and the ammonia allowed to boil off under a stream of nitrogen. The residue was dried under high vacuum for 5 min then nitrogen was reintroduced. Ether $(5 \mathrm{~mL})$ was added and the reaction mixture was cooled to $-78{ }^{\circ} \mathrm{C}$. Methyl cyanoformate $(0.020 \mathrm{~mL}, 0.26 \mathrm{mmol})$ was added and the reaction mixture was stirred for $15 \mathrm{~min}$ then warmed to $0{ }^{\circ} \mathrm{C}$ before quenching with water $(5 \mathrm{~mL})$. The reaction mixture was extracted with ether $(3 \times 15 \mathrm{~mL})$ and the combined organic extracts washed with water $(5 \mathrm{~mL})$, brine $(5 \mathrm{~mL})$ and dried over anhydrous $\mathrm{MgSO}_{4}$. Concentration of the organic phase in vacuo gave a yellow oil. The mixture was dissolved in methanol $(5 \mathrm{~mL})$ and potassium carbonate $(0.5 \mathrm{~g})$ was added. 
The reaction mixture was stirred for $2 \mathrm{~h}$, then the methanol removed in vacuo and the residue extracted with ethyl acetate $(3 \times 10 \mathrm{~mL})$. The combined organic extracts were dried over anhydrous $\mathrm{MgSO}_{4}$ and concentrated in vacuo to give a yellow oil which was purified by flash column chromatography on silica gel using ethyl acetate : hexane (1 : 9) as eluant to give the title compound $3.17(0.022 \mathrm{~g}, 19 \%)$ as a colourless oil. Further elution gave ketone 3.18 (0.014 g, 13\%) and ester $\mathbf{3 . 1 6}(0.017 \mathrm{~g}, 14 \%)$.

IR (thin film) $\mathbf{c m}^{-1}:$ 2929s (C-H), 1743, 1718, 1663s, 1623s, 1442, 1359, 1274, 1217 , $1150,1037$.

${ }^{1} \mathbf{H}$ NMR (300 MHz, $\left.\mathbf{C D C l}_{3}\right)$ 8: $0.02\left(\mathrm{~s}, 3 \mathrm{H},-\mathrm{SiCH}_{3}\right), 0.05\left(\mathrm{~s}, 3 \mathrm{H},-\mathrm{SiCH}_{3}\right), 0.88(\mathrm{~s}$, 9H, $\left.-\mathrm{Si}^{\mathrm{t}} \mathrm{Bu}\right), 0.88-0.93\left(\mathrm{~m}, 6 \mathrm{H}, \mathrm{H}-3^{\prime}, \mathrm{CH}_{3}\right), 1.12(\mathrm{~m}, 1 \mathrm{H}), 1.20-1.82(\mathrm{~m}, 13 \mathrm{H}), 1.91-$ $2.14(\mathrm{~m}, 2 \mathrm{H}), 2.29(\mathrm{~m}, 1 \mathrm{H}), 2.56(\mathrm{~m}, 1 \mathrm{H}), 3.35(\mathrm{~m}, 1 \mathrm{H}, \mathrm{H}-8), 3.41(\mathrm{~s}, 3 \mathrm{H}, 8-$ $\left.\mathrm{OCH}_{2} \mathrm{OCH}_{3}\right), 3.73\left(\mathrm{~s}, 3 \mathrm{H}, 1-\mathrm{CO}_{2} \mathrm{CH}_{3}\right), 3.84\left(\mathrm{~m}, 1 \mathrm{H}, \mathrm{H}-1^{\prime}\right), 4.63\left(\mathrm{~s}, 2 \mathrm{H}, 8-\mathrm{OCH}_{2} \mathrm{OCH}_{3}\right)$, $12.08(\mathrm{~s}, 1 \mathrm{H}, 2-\mathrm{OH})$.

${ }^{13} \mathrm{C}$ NMR (75 MHz, $\left.\mathbf{C D C l}_{3}\right)$ 8: $-4.4\left(\mathrm{SiCH}_{3}\right),-3.8\left(\mathrm{SiCH}_{3}\right), 10.7\left(\mathrm{CH}_{3}, \mathrm{C}-3^{\prime}\right), 18.2$ ( $\mathrm{SiC}), 19.2\left(7-\mathrm{CH}_{3}\right), 26.0\left(\mathrm{Si}{ }^{\mathrm{t}} \mathrm{Bu}\right), 28.4\left(\mathrm{CH}_{2}\right), 28.6\left(\mathrm{CH}_{2}\right), 28.7\left(\mathrm{CH}_{2}\right), 29.6\left(\mathrm{CH}_{2}\right), 32.5$, $33.636 .6,37.8,38.0,38.4,41.7,41.8,51.2\left(1-\mathrm{CO}_{2} \mathrm{CH}_{3}\right), 56.2\left(8-\mathrm{OCH}_{2} \mathrm{OCH}_{3}\right), 73.4$ $\left(\mathrm{CH}, \mathrm{C}-1^{\prime}\right), 83.9(\mathrm{CH}, \mathrm{C}-8), 97.1(\mathrm{C}, \mathrm{C}-3), 98.9\left(8-\mathrm{OCH}_{2} \mathrm{OCH}_{3}\right), 171.1\left(1-\mathrm{CO}_{2} \mathrm{CH}_{3}\right)$, $172.8(\mathrm{C}-1)$.

LRMS (m/z): 495 ((M-Me) $\left.{ }^{+}, 5 \%\right), 453$ (100), 435 (6), 346 (13), 333 (21), 284 (31), $173(82)$.

HRMS: $\mathrm{C}_{27} \mathrm{H}_{47} \mathrm{O}_{6} \mathrm{Si}\left(\mathrm{M}-\mathrm{Me}^{+}\right)$requires 495.3142, found 495.3140.

$(1 R S, 4 \mathrm{a} R S, 4 \mathrm{bSR}, 5 R S, 7 R S, 8 R S, 8 \mathrm{a} S R, 10 \mathrm{a} S R, 1 ' S R)$ Methyl 5-(1'-t.-

Butyldimethylsilyloxypropyl)-8-methoxmethoxy-1,7-methyl-2-oxo-3,4,4a,4b,5,6,7,8, $8 \mathrm{a}, 9,10,10 a-d o d e c a h y d r o p h e n a n t h r e n e-1(2 H)$-carboxylate $(3.25)$

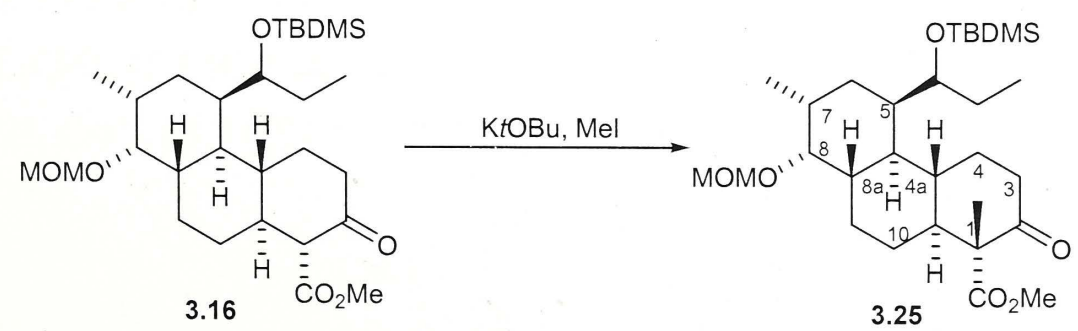


Potassium $t$-butoxide $(0.017 \mathrm{~g}, 0.15 \mathrm{mmol})$ in $t$-butyl alcohol $(1.5 \mathrm{~mL})$ was added to a solution of ester $3.16(0.039 \mathrm{~g}, 0.076 \mathrm{mmol})$ and iodomethane $(9.5 \mu \mathrm{L}, 0.15 \mathrm{mmol})$ in benzene $(1.5 \mathrm{~mL})$ at room temperature under nitrogen. The resulting reaction mixture was stirred for $18 \mathrm{~h}$, then partitioned between iced water and DCM (10 mL, 1: 1). The organic phase was separated and the aqueous phase extracted with DCM $(3 \times 5 \mathrm{~mL})$. The combined organic extracts were dried over anhydrous $\mathrm{MgSO}_{4}$ and concentrated in vacuo to give a yellow oil. Purification by flash column chromatography on silica gel using ethyl acetate : hexane (1:9) as eluant gave the title compound $\mathbf{3 . 2 5}$ (0.006 g, $22 \%$ ) as a colourless oil.

IR (thin film) $\mathbf{c m}^{-1}: 2927 \mathrm{~s}(\mathrm{C}-\mathrm{H}), 1744 \mathrm{~s}(\mathrm{C}=\mathrm{O}), 1713(\mathrm{C}=\mathrm{O}), 1463,1360,1260,1085$, 1038.

${ }^{1}$ H NMR (300 MHz, $\mathbf{C D C l}_{\mathbf{3}}$ ) ): 0.05 (s, 3H, - $\left.\mathrm{SiCH}_{3}\right), 0.06$ (s, 3H, - $\left.\mathrm{SiCH}_{3}\right), 0.91$ (s, $\left.9 \mathrm{H},-\mathrm{Si}{ }^{\mathrm{t}} \mathrm{Bu}\right), 0.88-0.96\left(\mathrm{~m}, 6 \mathrm{H}, \mathrm{H}-3^{\prime}, 7-\mathrm{CH}_{3}\right), 1.33\left(\mathrm{~s}, 3 \mathrm{H}, 1-\mathrm{CH}_{3}\right), 1.17-1.81(\mathrm{~m}, 13 \mathrm{H})$, 2.01-2.12 (m, 2H), 2.31-2.39 (m, 2H), 2.50 (m, 1H), 3.35 (m, 1H, H-8), 3.40 (s, 3H, 8$\left.\mathrm{OCH}_{2} \mathrm{OCH}_{3}\right), 3.74\left(\mathrm{~s}, 3 \mathrm{H}, 1-\mathrm{CO}_{2} \mathrm{CH}_{3}\right), 3.88\left(\mathrm{~m}, 1 \mathrm{H}, \mathrm{H}-1^{\prime}\right), 4.60,4.63(2 \times \mathrm{ABd}, J=6.6$ $\left.\mathrm{Hz}, 2 \mathrm{H}, 8-\mathrm{OCH}_{2} \mathrm{OCH}_{3}\right)$.

${ }^{13} \mathrm{C}$ NMR (75 MHz, $\left.\mathbf{C D C l}_{3}\right)$ 8: $-4.1\left(\mathrm{SiCH}_{3}\right),-3.4\left(\mathrm{SiCH}_{3}\right), 10.4\left(\mathrm{CH}_{3}, \mathrm{C}-3^{\prime}\right), 15.7$ (1$\left.\mathrm{CH}_{3}\right), 18.4(\mathrm{SiC}), 19.1\left(7-\mathrm{CH}_{3}\right), 26.1\left(\mathrm{Si}{ }^{\mathrm{t}} \mathrm{Bu}\right), 27.3\left(\mathrm{CH}_{2}\right), 28.9\left(\mathrm{CH}_{2}\right), 29.7\left(\mathrm{CH}_{2}\right), 29.8$ $\left(\mathrm{CH}_{2}\right), 30.5\left(\mathrm{CH}_{2}\right), 33.3(\mathrm{CH}), 35.6(\mathrm{CH}), 37.2\left(\mathrm{CH}_{2}\right), 37.5(\mathrm{CH}), 41.5(\mathrm{CH}), 42.2(\mathrm{CH})$, $48.1(\mathrm{CH}), 52.3\left(1-\mathrm{CO}_{2} \mathrm{CH}_{3}\right), 56.3\left(8-\mathrm{OCH}_{2} \mathrm{OCH}_{3}\right), 62.1(\mathrm{C}, \mathrm{C}-1), 74.1\left(\mathrm{CH}, \mathrm{C}-1^{\prime}\right), 83.5$ (CH, C-8), $98.9\left(8-\mathrm{OCH}_{2} \mathrm{OCH}_{3}\right), 173.3\left(1-\mathrm{CO}_{2} \mathrm{CH}_{3}\right), 210.4$ (2-CO).

LRMS (m/z): $467\left(\left(\mathrm{M}^{-}{ }^{\mathrm{t}} \mathrm{Bu}\right)^{+}, 12 \%\right), 387$ (13), 313 (12), 201 (12), 173 (100), 115 (20), $73(61)$.

HRMS: $\mathrm{C}_{25} \mathrm{H}_{43} \mathrm{O}_{6} \mathrm{Si}\left(\mathrm{M}-{ }^{\mathrm{t}} \mathrm{Bu}\right)^{+}$requires 467.2829, found 467.2837. 
(4a $\left.R S, 4 \mathrm{~b} S R, 5 R S, 7 R S, 8 R S, 8 \mathrm{a} S R, 10 \mathrm{a} R S, 1^{\prime} S R\right)$ Methyl 5-(1'-t.-

Butyldimethylsilyloxypropyl)-8-methoxmethoxy-3,7-methyl-2-hydroxy-

1,4,4a,4b,5,6,7,8, 8a,9,10,10a-dodecahydrophenanthrene-3(2H)-carboxylate $(3.26)$

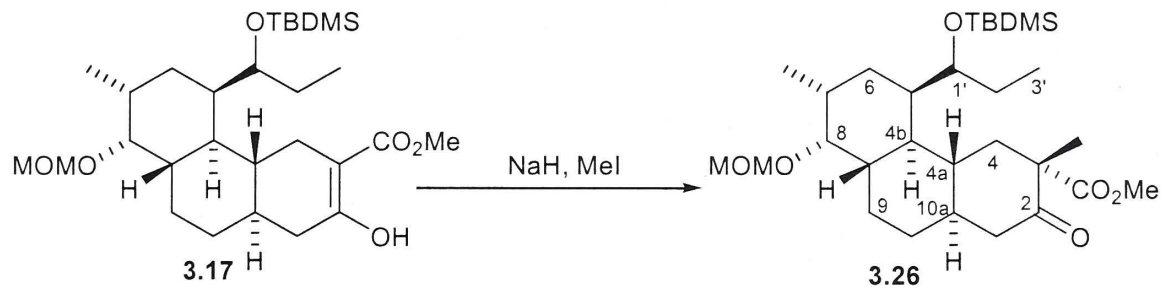

Sodium hydride $(0.001 \mathrm{~g}, 0.04 \mathrm{mmol})$ was added to $\beta$-keto ester $\mathbf{3 . 1 7}(0.022 \mathrm{~g}, 0.04$ $\mathrm{mmol})$ in THF $(1 \mathrm{~mL})$ at room temperature under nitrogen. After $5 \mathrm{~min}$, iodomethane $(0.003 \mathrm{~mL}, 0.05 \mathrm{mmol})$ was added and the reaction mixture stirred for $18 \mathrm{~h}$. The reaction was quenched with water, and extracted with ethyl acetate $(3 \times 10 \mathrm{~mL})$. The combined organic extracts were washed with water $(5 \mathrm{~mL})$, brine $(5 \mathrm{~mL})$ and dried over $\mathrm{MgSO}_{4}$. Concentration of the organic phase in vacuo gave a yellow oil, which was purified by flash column chromatography on silica gel using ethyl acetate : hexane (1 : $9)$ as eluant to give the title compound $\mathbf{3 . 2 6}(0.014 \mathrm{~g}, 65 \%)$ as a colourless oil.

IR (thin film) $\mathbf{c m}^{-1}:$ 2929s $(\mathrm{C}-\mathrm{H}), 1742 \mathrm{~s}(\mathrm{C}=\mathrm{O}), 1709(\mathrm{C}=\mathrm{O}), 1462,1379,1258,1087$, 1037.

${ }^{1} \mathbf{H}$ NMR (500 MHz, $\left.\mathbf{C D C l}_{3}\right)$ \&: $0.00\left(\mathrm{~s}, 3 \mathrm{H},-\mathrm{SiCH}_{3}\right), 0.04\left(\mathrm{~s}, 3 \mathrm{H},-\mathrm{SiCH}_{3}\right), 0.89$ (s, $\left.9 \mathrm{H},-\mathrm{Si}{ }^{\mathrm{t}} \mathrm{Bu}\right), 0.92\left(\mathrm{~d}, J=6.5 \mathrm{~Hz}, 3 \mathrm{H}, 7-\mathrm{CH}_{3}\right), 0.93\left(\mathrm{t}, J_{3^{\prime}, 2^{\prime}}=7.3 \mathrm{~Hz}, 3 \mathrm{H}, \mathrm{H}-3^{\prime}\right), 1.15(\mathrm{~m}$, $1 \mathrm{H}), 1.25-1.75(\mathrm{~m}, 10 \mathrm{H}), 1.34(\mathrm{~m}, 1 \mathrm{H}), 1.47\left(\mathrm{~s}, 3 \mathrm{H}, 3-\mathrm{CH}_{3}\right), 1.82(\mathrm{dd}, J=14 \mathrm{~Hz}, J=4.0$ $\mathrm{Hz}, 1 \mathrm{H}), 2.04-2.13$ (m, 3H, H-4, H-10a), 2.24-2.35 (m, 2H, H-1), 3.34 (m, 1H, H-8), $3.39\left(\mathrm{~s}, 3 \mathrm{H}, 8-\mathrm{OCH}_{2} \mathrm{OCH}_{3}\right), 3.74\left(\mathrm{~s}, 3 \mathrm{H}, 3-\mathrm{CO}_{2} \mathrm{CH}_{3}\right), 3.73\left(\mathrm{~m}, 1 \mathrm{H}, \mathrm{H}-1^{\prime}\right), 4.60,4.62$ (2 x $\mathrm{ABd}, J=7.3 \mathrm{~Hz}, 2 \mathrm{H}, 8-\mathrm{OCH}_{2} \mathrm{OCH}_{3}$ ).

${ }^{13} \mathbf{C}$ NMR (75 MHz, $\left.\mathbf{C D C l}_{3}\right)$ 8: $-4.3\left(\mathrm{SiCH}_{3}\right),-3.6\left(\mathrm{SiCH}_{3}\right), 11.9\left(\mathrm{CH}_{3}, \mathrm{C}-3^{\prime}\right), 18.2$ ( $\mathrm{SiC}), 19.2\left(7-\mathrm{CH}_{3}\right), 20.7\left(3-\mathrm{CH}_{3}\right), 26.0\left(\mathrm{Si}^{\mathrm{t}} \mathrm{Bu}\right), 28.2\left(\mathrm{CH}_{2}\right), 29.4\left(\mathrm{CH}_{2}\right), 29.8\left(\mathrm{CH}_{2}\right)$, $32.8\left(\mathrm{CH}_{2}\right), 33.9(\mathrm{CH}), 37.2(\mathrm{CH}), 38.2(\mathrm{CH} . \mathrm{C}-10 \mathrm{a}), 40.0\left(\mathrm{CH}_{2}, \mathrm{C}-4\right), 40.5(\mathrm{CH}), 42.0$ $(\mathrm{CH}), 43.0(\mathrm{CH}), 45.1\left(\mathrm{CH}_{2}, \mathrm{C}-1\right), 52.3\left(3-\mathrm{CO}_{2} \mathrm{CH}_{3}\right), 56.2\left(8-\mathrm{OCH}_{2} \mathrm{OCH}_{3}\right), 57.6(\mathrm{C}, \mathrm{C}-$ 3), $74.7\left(\mathrm{CH}, \mathrm{C}-1^{\prime}\right), 83.9(\mathrm{CH}, \mathrm{C}-8), 98.9\left(8-\mathrm{OCH}_{2} \mathrm{OCH}_{3}\right), 173.4\left(3-\mathrm{CO}_{2} \mathrm{CH}_{3}\right), 209.2$ (2$\mathrm{CO})$. 
LRMS (m/z): $467\left(\left(\mathrm{M}^{\mathrm{t}} \mathrm{Bu}\right)^{+}, 76 \%\right), 423$ (51), 352 (39), 308 (31), 271 (30), 229 (25), $173(100)$.

HRMS: $\mathrm{C}_{25} \mathrm{H}_{43} \mathrm{O}_{6} \mathrm{Si}\left(\mathrm{M}-{ }^{\mathrm{t}} \mathrm{Bu}{ }^{+}\right)$requires 467.2829, found 467.2827.

(4a $R S, 4 \mathrm{~b} S R, 5 R S, 7 R S, 8 R S, 8 \mathrm{a} S R, 10 \mathrm{a} R S, 1$ 'SR) 5-(1'-t.-

Butyldimethylsilyloxypropyl)-8-methoxmethoxy-7-methyl-1,4,4a,4b,5,6,7,8,8a,9,10, 10a-dodecahydro-2(3H)-phenanthrenone (3.18)

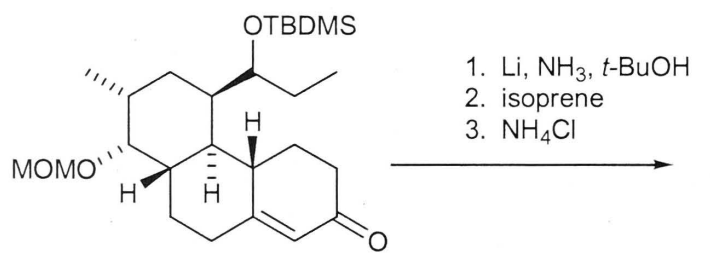

3.7

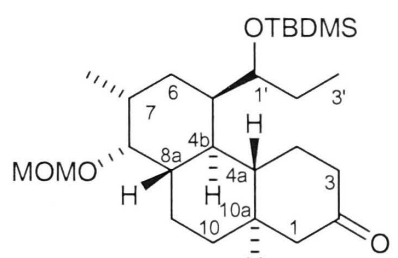

$3.18 \mathrm{H}$

Dry ammonia $(60 \mathrm{~mL})$ was distilled into a 3-necked flask fitted with a dry ice condenser under nitrogen. Small pieces of freshly cleaned lithium wire $(0.05 \mathrm{~g}, 7.59 \mathrm{mmol})$ were added at $-78{ }^{\circ} \mathrm{C}$ and the resulting blue solution stirred for $10 \mathrm{~min}$. A solution of enone 3.7 (1.14 g, $2.53 \mathrm{mmol})$ in $t$-butyl alcohol $(0.24 \mathrm{~mL}, 2.53 \mathrm{mmol})$ and THF (20 mL) was added drop wise, and the resulting reaction mixture stirred for $20 \mathrm{~min}$. The reaction was quenched with isoprene until and blue colour dispersed and the ammonia was allowed to boil off under a stream of nitrogen. A saturated solution of aqueous ammonium chloride $(20 \mathrm{~mL})$ was then added and stirring continued for a further $15 \mathrm{~min}$. Water (10 $\mathrm{mL}$ ) was added and the aqueous phase extracted with ethyl acetate $(3 \times 30 \mathrm{~mL})$. The combined organic extracts were washed with water $(20 \mathrm{~mL})$, brine $(20 \mathrm{~mL})$ and dried over anhydrous $\mathrm{MgSO}_{4}$. Concentration of the organic phase in vacuo gave the title compound $\mathbf{3 . 1 8}(1.06 \mathrm{~g}, 92 \%)$ as a colourless oil.

IR (thin film) $\mathbf{c m}^{-1}: 2929 \mathrm{~s}(\mathrm{C}-\mathrm{H}), 1718 \mathrm{~s}(\mathrm{C}=\mathrm{O}), 1463,1360,1254 \mathrm{~s}, 1150,1038 \mathrm{~s}$.

${ }^{1} \mathrm{H}$ NMR (300 MHz, $\left.\mathbf{C D C l}_{3}\right)$ \&: $0.04\left(\mathrm{~s}, 3 \mathrm{H},-\mathrm{SiCH}_{3}\right), 0.06\left(\mathrm{~s}, 3 \mathrm{H},-\mathrm{SiCH}_{3}\right), 0.90$ (s, $\left.9 \mathrm{H},-\mathrm{Si}{ }^{\mathrm{t}} \mathrm{Bu}\right), 0.86-0.92\left(\mathrm{~m}, 3 \mathrm{H}, 7-\mathrm{CH}_{3}\right), 0.93\left(\mathrm{t}, J_{3^{\prime}, 2^{\prime}}=7.2 \mathrm{~Hz}, 3 \mathrm{H}, \mathrm{H}-3^{\prime}\right), 1.10-1.76(\mathrm{~m}$, $14 \mathrm{H}), 2.04-2.22(\mathrm{~m}, 2 \mathrm{H}), 2.25-2.41(\mathrm{~m}, 4 \mathrm{H}), 3.35(\mathrm{~m}, 1 \mathrm{H}, \mathrm{H}-8), 3.39(\mathrm{~s}, 3 \mathrm{H}, 8-$ $\left.\mathrm{OCH}_{2} \mathrm{OCH}_{3}\right), 3.88\left(\mathrm{dt}, J_{1^{\prime}, 5}=5.4 \mathrm{~Hz}, J_{1^{\prime}, 2^{\prime}}=5.7 \mathrm{~Hz}, 1 \mathrm{H}, \mathrm{H}-1^{\prime}\right), 4.60,4.62(2 \times \mathrm{ABd}, J=$ $\left.6.9 \mathrm{~Hz}, 2 \mathrm{H}, 8-\mathrm{OCH}_{2} \mathrm{OCH}_{3}\right)$. 
${ }^{13} \mathbf{C}$ NMR (75 MHz, $\left.\mathbf{C D C l}_{3}\right)$ 8: $-4.3\left(\mathrm{SiCH}_{3}\right),-3.4\left(\mathrm{SiCH}_{3}\right), 10.4\left(\mathrm{CH}_{3}, \mathrm{C}^{\prime}\right), 18.3$ ( $\mathrm{SiC}), 19.1\left(7-\mathrm{CH}_{3}\right), 26.1\left(\mathrm{Si}{ }^{\mathrm{t}} \mathrm{Bu}\right), 28.8\left(\mathrm{CH}_{2}\right), 29.3\left(\mathrm{CH}_{2}\right), 29.7\left(\mathrm{CH}_{2}\right), 30.9\left(\mathrm{CH}_{2}\right), 33.3$ $\left(\mathrm{CH}_{2}\right), 33.4(\mathrm{CH}), 37.7(\mathrm{CH}), 41.0(\mathrm{CH}), 41.1(\mathrm{CH}), 41.5(\mathrm{CH}), 41.6(\mathrm{CH}), 43.7\left(\mathrm{CH}_{2}\right)$, $48.7\left(\mathrm{CH}_{2}\right), 56.2\left(8-\mathrm{OCH}_{2} \mathrm{OCH}_{3}\right), 73.8\left(\mathrm{CH}, \mathrm{C}-1^{\prime}\right), 83.8(\mathrm{CH}, \mathrm{C}-8), 98.9$ (8$\left.\mathrm{OCH}_{2} \mathrm{OCH}_{3}\right), 211.7$ (2-CO).

LRMS (m/z): $395\left(\left(\mathrm{M}-^{\mathrm{t}} \mathrm{Bu}\right)^{+}, 65 \%\right), 241(15), 201(10), 173(100), 115$ (17), 73 (57), 45 (66).

HRMS: $\mathrm{C}_{22} \mathrm{H}_{39} \mathrm{O}_{4} \mathrm{Si}\left(\left(\mathrm{M}-{ }^{\mathrm{t}} \mathrm{Bu}\right)^{+}\right)$requires 395.2618 , found 395.2613 .

$(4 \mathrm{a} S R, 4 \mathrm{~b} S R, 5 R S, 7 R S, 8 R S, 8 \mathrm{a} S R, 10 \mathrm{a} R S, 1 ' S R) 5$-(1'-t.-

Butyldimethylsilyloxypropyl)-8-methoxmethoxy-7-methyl-4a,4b,5,6,7,8,8a,9,10, 10a-decahydro-2(1H)-phenanthrenone (3.34)

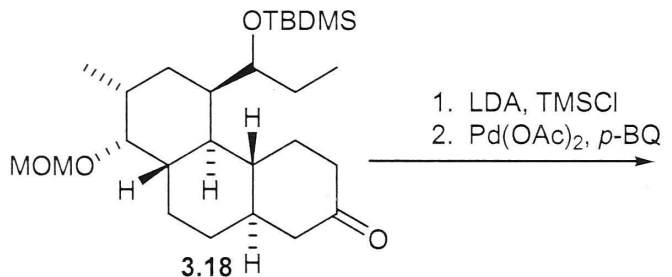

$3.18 \overline{\mathrm{H}}$

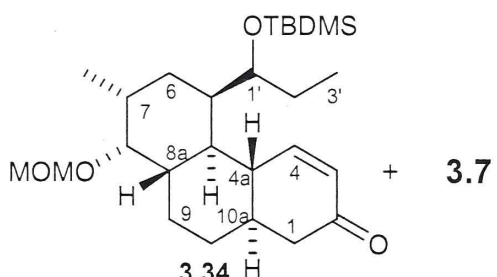

$3.34 \overline{\mathrm{H}}$

n-Butyllithium (1.30 mL of a $1.6 \mathrm{M}$ solution in hexanes, $2.12 \mathrm{mmol}$ ) was added to diisopropylamine $(0.30 \mathrm{~mL}, 2.12 \mathrm{mmol})$ in THF $(5 \mathrm{~mL})$ at $-20{ }^{\circ} \mathrm{C}$ under nitrogen. The reaction mixture was stirred for $20 \mathrm{~min}$, warmed to $0{ }^{\circ} \mathrm{C}$ and stirred for a further $30 \mathrm{~min}$. The solution was then cooled to $-78^{\circ} \mathrm{C}$ and $\mathrm{TMSCl}(0.94 \mathrm{~mL}, 7.42 \mathrm{mmol})$ was added, followed by the drop wise addition of ketone $\mathbf{3 . 1 8}(0.48 \mathrm{~g}, 1.06 \mathrm{mmol})$ in THF $(5 \mathrm{~mL})$. After $20 \mathrm{~min}$, the reaction was quenched by the addition of triethylamine $(2 \mathrm{~mL})$ and a saturated aqueous solution of sodium bicarbonate $(5 \mathrm{~mL})$. The mixture was extracted with ether $(3 \times 20 \mathrm{~mL})$, and the combined extracts washed with water $(5 \mathrm{~mL})$ and $1 \mathrm{M}$ citric acid $(5 \mathrm{~mL})$. The organic extracts were dried over anhydrous $\mathrm{MgSO}_{4}$ and concentrated in vacuo to give a mixture of two silyl enol ethers $(2: 1$ in favour of the desired isomer 3.33), which were used directly in the next reaction without further purification.

A solution of the crude crude silyl enol ethers in acetonitrile $(5 \mathrm{~mL})$ were added to palladium acetate $(0.24 \mathrm{~g}, 1.07 \mathrm{mmol})$ and $p$-benzoquinone $(0.06 \mathrm{~g}, 0.54 \mathrm{mmol})$ in acetonitrile $(5 \mathrm{~mL})$ at room temperature under nitrogen. The resulting reaction mixture 
was stirred for $30 \mathrm{~h}$, then filtered through a plug of Celite ${ }^{\circledR}$ and washed with ether (30 $\mathrm{mL}$ ). Concentration of the organic filtrate in vacuo gave a black gum which was further purified by flash column chromatography on silica gel using ethyl acetate : hexane (1 : 9) as eluant to give the title $\alpha \beta$-enone $3.34(0.31 \mathrm{~g}, 64 \%)$ as a white solid, and $\alpha \beta$-enone $3.7(0.11 \mathrm{~g}, 24 \%)$ as a white solid (88\% combined yield). A sample of the title $\alpha \beta-$ enone $\mathbf{3 . 3 4}$ was crystallised from hexane to give white crystals.

m.p: $65-67^{\circ} \mathrm{C}$

IR (thin film) $\mathbf{c m}^{-1}: 2930 \mathrm{~s}(\mathrm{C}-\mathrm{H}), 1684 \mathrm{~s}(\mathrm{C}=\mathrm{O}), 1472,1360,1255 \mathrm{~s}, 1148,1039 \mathrm{~s}$.

${ }^{1}$ H NMR (300 MHz, $\mathbf{C D C l}_{3}$ ) 8: $0.04\left(\mathrm{~s}, 3 \mathrm{H},-\mathrm{SiCH}_{3}\right), 0.06\left(\mathrm{~s}, 3 \mathrm{H},-\mathrm{SiCH}_{3}\right), 0.87$ (s, $\left.9 \mathrm{H},-\mathrm{Si}^{\mathrm{t}} \mathrm{Bu}\right), 0.91\left(\mathrm{~d}, J=6.3 \mathrm{~Hz}, 3 \mathrm{H}, 7-\mathrm{CH}_{3}\right), 0.87-0.92\left(\mathrm{~m}, 3 \mathrm{H}, \mathrm{H}-3^{\prime}\right), 1.24(\mathrm{~m}, 1 \mathrm{H})$, 1.39-1.81 (m, 12H), 2.13 (m, 1H, H-1), 2.26-2.52 (m, 2H, H-1, H-4a), 3.37 (m, 1H, H8), $3.40\left(\mathrm{~s}, 3 \mathrm{H}, 8-\mathrm{OCH}_{2} \mathrm{OCH}_{3}\right), 4.07\left(\mathrm{dt}, J_{1^{\prime}, 5}=6.9 \mathrm{~Hz}, J_{1^{\prime}, 2^{\prime}}=4.5 \mathrm{~Hz}, 1 \mathrm{H}, \mathrm{H}-1^{\prime}\right), 4.62(\mathrm{~s}$, $\left.2 \mathrm{H}, 8-\mathrm{OCH}_{2} \mathrm{OCH}_{3}\right), 5.97(\mathrm{dd}, J=9.9 \mathrm{~Hz}, J=1.5 \mathrm{~Hz}, 1 \mathrm{H}, \mathrm{H}-3), 7.19$ (d, $J=9.9 \mathrm{~Hz}, 1 \mathrm{H}$, $\mathrm{H}-4)$.

${ }^{13} \mathrm{C}$ NMR (75 MHz, $\left.\mathbf{C D C l}_{3}\right)$ 8: $-3.7\left(\mathrm{SiCH}_{3}\right),-3.4\left(\mathrm{SiCH}_{3}\right), 8.0\left(\mathrm{CH}_{3}, \mathrm{C}-3^{\prime}\right), 18.3$ (SiC), $18.9\left(7-\mathrm{CH}_{3}\right), 26.2\left(\mathrm{Si}{ }^{\mathrm{t}} \mathrm{Bu}\right), 27.8\left(\mathrm{CH}_{2}\right), 29.3\left(\mathrm{CH}_{2}\right), 30.7\left(\mathrm{CH}_{2}\right), 31.9\left(\mathrm{CH}_{2}\right), 32.9$ $(\mathrm{CH}), 36.5(\mathrm{CH}), 40.1(\mathrm{CH}), 41.6(\mathrm{CH}), 42.0(\mathrm{CH}), 42.9(\mathrm{CH}), 45.5\left(\mathrm{CH}_{2}, \mathrm{C}-1\right), 56.2(8-$ $\left.\mathrm{OCH}_{2} \mathrm{OCH}_{3}\right), 72.3\left(\mathrm{CH}, \mathrm{C}-1^{\prime}\right), 83.7(\mathrm{CH}, \mathrm{C}-8), 99.0\left(8-\mathrm{OCH}_{2} \mathrm{OCH}_{3}\right), 128.8(\mathrm{CH}, \mathrm{C}-3)$, 153.9 (CH, C-4), 200.4 (2-CO).

LRMS (m/z): $450\left(\mathrm{M}^{+},<1 \%\right), 393\left(\left(\mathrm{M}-{ }^{\mathrm{t}} \mathrm{Bu}\right)^{+}, 85 \%\right), 331$ (12), 318 (9), 273 (5), 257 (20), 199 (10), 173 (100), 115 (21).

HRMS: $\mathrm{C}_{26} \mathrm{H}_{46} \mathrm{O}_{4} \mathrm{Si}\left(\mathrm{M}^{+}\right)$requires 450.3165, found 450.3169 . $\mathrm{C}_{22} \mathrm{H}_{37} \mathrm{O}_{4} \mathrm{Si}\left(\left(\mathrm{M}-{ }^{t} \mathrm{Bu}\right)^{+}\right)$requires 393.2461, found 393.2460.

Microanalysis: Calcd. for $\mathrm{C}_{26} \mathrm{H}_{46} \mathrm{O}_{4} \mathrm{Si}$ : C, 69.28\%, H, 10.29\%. Found: C, 69.74\%, H, $10.15 \%$. 
$(1 R S, 4 \mathrm{a} R S, 4 \mathrm{bSR}, 5 R S, 7 R S, 8 R S, 8 \mathrm{a} S R, 10 \mathrm{a} S R, 1 ' S R)$ Methyl 5-(1'-t.-

Butyldimethylsilyloxypropyl)-8-methoxmethoxy-7-methyl-2-oxo-

$4 a, 4 b, 5,6,7,8,8 a, 9,10,10 a-d e c a h y d r o p h e n a n t h r e n e-1(2 H)$-carboxylate $(3.35)$

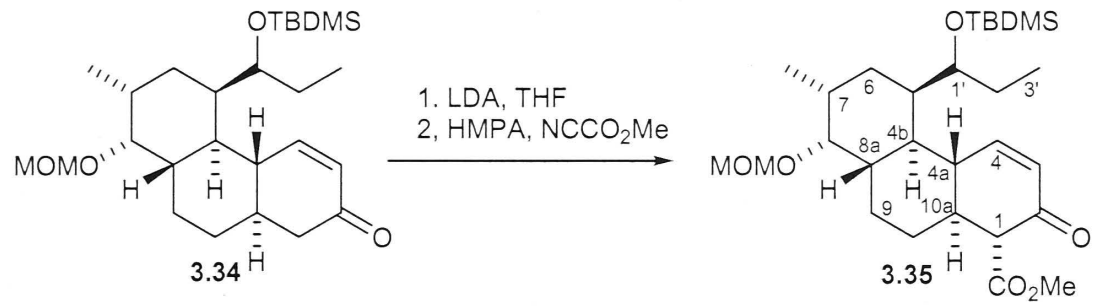

n-Butyllithium $(0.64 \mathrm{~mL}$ of a $1.6 \mathrm{M}$ solution in hexanes, $1.03 \mathrm{mmol})$ was added to diisopropylamine $(0.0 .14 \mathrm{~mL}, 1.03 \mathrm{mmol})$ in $\mathrm{THF}(6 \mathrm{~mL})$ at $-20^{\circ} \mathrm{C}$ under nitrogen. The reaction mixture was stirred for $20 \mathrm{~min}$, warmed to $0{ }^{\circ} \mathrm{C}$ and stirred for a further $30 \mathrm{~min}$. The solution was then cooled to $-78^{\circ} \mathrm{C}$, ketone $\mathbf{3 . 3 4}(0.31 \mathrm{~g}, 0.69 \mathrm{mmol})$ was added, and the reaction mixture warmed to $0{ }^{\circ} \mathrm{C}$ for $1 \mathrm{~h}$. After cooling to $-78{ }^{\circ} \mathrm{C}$, $\operatorname{HMPA}(0.12$ $\mathrm{mL}, 0.69 \mathrm{mmol})$ and methyl cyanoformate $(0.08 \mathrm{~mL}, 1.03 \mathrm{mmol})$ were added. After 20 min the reaction mixture was poured into water and extracted with ether $(3 \times 15 \mathrm{~mL})$. The combined organic extracts were washed with water $(10 \mathrm{~mL})$, brine $(10 \mathrm{~mL})$ and dried over anhydrous $\mathrm{MgSO}_{4}$. Concentration of the organic phase in vacuo gave a yellow oil which was purified by flash column chromatography on silica gel using ethyl acetate : hexane $(1: 9)$ as eluant to give the title compound $3.35(0.27 \mathrm{~g}, 77 \%)$ as a colourless oil.

IR (thin film) $\mathbf{c m}^{-1}: 2931 \mathrm{~s}(\mathrm{C}-\mathrm{H}), 1746 \mathrm{~s}(\mathrm{C}=\mathrm{O}), 1682 \mathrm{~s}(\mathrm{C}=\mathrm{O}), 1472,1463,1257 \mathrm{~s}$, 1151,1040 s.

${ }^{1}$ H NMR (300 MHz, $\left.\mathbf{C D C l}_{3}\right)$ ): 0.03 (s, 3H, - $\left.\mathrm{SiCH}_{3}\right), 0.05$ (s, 3H, - $\left.\mathrm{SiCH}_{3}\right), 0.86$ (s, 9H, -Si $\left.{ }^{\mathrm{t}} \mathrm{Bu}\right), 0.86-0.91\left(\mathrm{~m}, 3 \mathrm{H}, 7-\mathrm{CH}_{3}\right), 0.91$ (t, $\left.J_{3^{\prime}, 2^{\prime}}=7.2 \mathrm{~Hz}, 3 \mathrm{H}, \mathrm{H}-3^{\prime}\right), 1.17-1.82(\mathrm{~m}$, $11 \mathrm{H}), 2.02(\mathrm{~m}, 1 \mathrm{H}), 2.27(\mathrm{~m}, 1 \mathrm{H}), 2.62(\mathrm{~m}, 1 \mathrm{H}, \mathrm{H}-4 \mathrm{a}), 3.13\left(\mathrm{~d}, J_{1,10 \mathrm{a}}=13.2 \mathrm{~Hz}, 1 \mathrm{H}, \mathrm{H}-\right.$ 1), 3.60 (m, 1H, H-8), 3.39 (s, 3H, 8- $\left.\mathrm{OCH}_{2} \mathrm{OCH}_{3}\right), 3.76\left(\mathrm{~s}, 3 \mathrm{H}, 1-\mathrm{CO}_{2} \mathrm{CH}_{3}\right), 4.12(\mathrm{~m}$, $\left.1 \mathrm{H}, \mathrm{H}^{-1}{ }^{\prime}\right), 4.59,4.62\left(2 \times \mathrm{ABd}, J=6.9 \mathrm{~Hz}, 2 \mathrm{H}, 8-\mathrm{OCH}_{2} \mathrm{OCH}_{3}\right), 6.01$ (dd, $J=10.2 \mathrm{~Hz}$, $J=2.4 \mathrm{~Hz}, 1 \mathrm{H}, \mathrm{H}-3), 7.25$ (d, $J=10.2 \mathrm{~Hz}, 1 \mathrm{H}, \mathrm{H}-4)$.

${ }^{13} \mathrm{C}$ NMR (75 MHz, $\left.\mathbf{C D C l}_{3}\right)$ 8: $-3.7\left(\mathrm{SiCH}_{3}\right),-3.3\left(\mathrm{SiCH}_{3}\right), 7.3\left(\mathrm{CH}_{3}, \mathrm{C}-3^{\prime}\right), 18.3$ ( $\mathrm{SiC}), 18.9\left(7-\mathrm{CH}_{3}\right), 26.3\left(\mathrm{Si}{ }^{\mathrm{t}} \mathrm{Bu}\right), 27.6\left(\mathrm{CH}_{2}\right), 28.8\left(\mathrm{CH}_{2}\right), 29.9\left(\mathrm{CH}_{2}\right), 31.1\left(\mathrm{CH}_{2}\right), 32.6$ $(\mathrm{CH}), 36.1(\mathrm{CH}), 40.4(\mathrm{CH}), 41.3(\mathrm{CH}), 42.0(\mathrm{CH}), 44.1(\mathrm{CH}), 52.1\left(1-\mathrm{CO}_{2} \mathrm{CH}_{3}\right), 56.3$ 
$\left(8-\mathrm{OCH}_{2} \mathrm{OCH}_{3}\right), 61.2(\mathrm{CH}, \mathrm{C}-1), 71.9\left(\mathrm{CH}, \mathrm{C}-1^{\prime}\right), 83.3(\mathrm{CH}, \mathrm{C}-8), 99.0\left(8-\mathrm{OCH}_{2} \mathrm{OCH}_{3}\right)$, $127.6(\mathrm{CH}, \mathrm{C}-3), 154.4(\mathrm{CH}, \mathrm{C}-4), 170.6\left(1-\mathrm{CO}_{2} \mathrm{CH}_{3}\right), 194.8(2-\mathrm{CO})$.

LRMS (m/z): $451\left(\left(\mathrm{M}-{ }^{\mathrm{t}} \mathrm{Bu}\right)^{+}, 51 \%\right), 389$ (15), 331 (10), 269 (5), 255 (7), 199 (10), 173 (90), 115 (22), 73 (100).

HRMS: $\mathrm{C}_{24} \mathrm{H}_{39} \mathrm{O}_{6} \mathrm{Si}\left(\left(\mathrm{M}-{ }^{\mathrm{t}} \mathrm{Bu}\right)^{+}\right)$requires 451.2516 , found 451.2510 .

$\left(1 R S, 4 \mathrm{a} R S, 4 \mathrm{~b} S R, 5 R S, 7 R S, 8 R S, 8 \mathrm{a} S R, 10 \mathrm{a} S R, 1^{\prime} S R\right)$ Methyl 5-(1'-t.-

Butyldimethylsilyloxypropyl)-8-methoxmethoxy-1,7-dimethyl-2-oxo-

$4 a, 4 b, 5,6,7,8,8 a, 9,10,10 a-d e c a h y d r o p h e n a n t h r e n e-1(2 H)$-carboxylate $(3.36)$

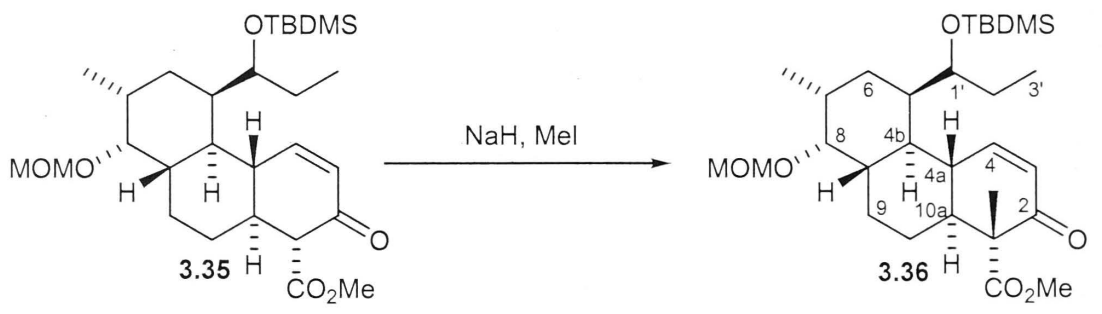

Sodium hydride $(0.007 \mathrm{~g}, 0.29 \mathrm{mmol})$ was added to $\beta$-keto ester 3.35 (0.12 g, 0.24 $\mathrm{mmol}$ ) in THF ( $2 \mathrm{~mL}$ ) at room temperature under nitrogen. After $5 \mathrm{~min}$, iodomethane $(0.018 \mathrm{~mL}, 0.29 \mathrm{mmol})$ was added and the resulting reaction mixture stirred for $18 \mathrm{~h}$. The reaction was quenched with water, poured into $1 M$ hydrochloric acid $(10 \mathrm{~mL})$ and extracted with ethyl acetate $(3 \times 10 \mathrm{~mL})$. The combined organic extracts were washed with water $(5 \mathrm{~mL})$, brine $(5 \mathrm{~mL})$ and dried over $\mathrm{MgSO}_{4}$. Concentration of the organic phase in vacuo gave a yellow oil, which was purified by flash column chromatography on silica gel using ethyl acetate : hexane (1:9) as eluant to give the title compound $\mathbf{3 . 3 6}$ $(0.082 \mathrm{~g}, 65 \%)$ as a white solid. A sample of the title $\beta$-keto ester $\mathbf{3 . 3 6}$ was crystallised from hexane to give white crystals.

m.p: $98-99^{\circ} \mathrm{C}$

IR (thin film) $\mathbf{c m}^{-1}$ : 2931s $(\mathrm{C}-\mathrm{H}), 1744 \mathrm{~s}(\mathrm{C}=\mathrm{O}), 1680 \mathrm{~s}(\mathrm{C}=\mathrm{O}), 1471,1461,1256 \mathrm{~s}$, $1151,1035 \mathrm{~s}$.

${ }^{1} \mathrm{H}$ NMR (300 MHz, $\left.\mathbf{C D C l}_{3}\right)$ \&: $0.01\left(\mathrm{~s}, 3 \mathrm{H},-\mathrm{SiCH}_{3}\right), 0.06\left(\mathrm{~s}, 3 \mathrm{H},-\mathrm{SiCH}_{3}\right), 0.87(\mathrm{~s}$, 9H, - $\left.\mathrm{Si}^{\mathrm{t}} \mathrm{Bu}\right), 0.89$ (d, $\left.J=6.0 \mathrm{~Hz}, 3 \mathrm{H}, 7-\mathrm{CH}_{3}\right), 0.90$ (t, $\left.J_{3^{\prime}, 2^{\prime}}=6.9 \mathrm{~Hz}, 3 \mathrm{H}, \mathrm{H}-3^{\prime}\right), 1.25$ (s, $\left.3 \mathrm{H}, 1-\mathrm{CH}_{3}\right), 1.20-1.83(\mathrm{~m}, 11 \mathrm{H}), 2.35(\mathrm{~m}, 1 \mathrm{H}), 2.27(\mathrm{~m}, 1 \mathrm{H}), 2.51(\mathrm{~m}, 1 \mathrm{H}, \mathrm{H}-4 \mathrm{a}), 3.33$ 
(m, 1H, H-8), 3.37 (s, 3H, 8- $\left.\mathrm{OCH}_{2} \mathrm{OCH}_{3}\right), 3.70$ (s, 3H, 1- $\left.\mathrm{CO}_{2} \mathrm{CH}_{3}\right), 4.07$ (m, 1H, H-1'), 4.58, $4.61\left(2 \times \mathrm{ABd}, J=6.6 \mathrm{~Hz}, 2 \mathrm{H}, 8-\mathrm{OCH}_{2} \mathrm{OCH}_{3}\right), 5.93(\mathrm{dd}, J=10.5 \mathrm{~Hz}, J=2.4 \mathrm{~Hz}$, $1 \mathrm{H}, \mathrm{H}-3), 7.18$ (d, $J=10.5 \mathrm{~Hz}, 1 \mathrm{H}, \mathrm{H}-4)$.

${ }^{13} \mathrm{C}$ NMR (75 MHz, $\left.\mathbf{C D C l}_{3}\right)$ ) : $-3.6\left(\mathrm{SiCH}_{3}\right),-3.2\left(\mathrm{SiCH}_{3}\right), 8.0\left(\mathrm{CH}_{3}, \mathrm{C}-3^{\prime}\right), 14.0$ (1$\left.\mathrm{CH}_{3}\right), 18.4(\mathrm{SiC}), 18.9\left(7-\mathrm{CH}_{3}\right), 26.3\left(\mathrm{Si}{ }^{\mathrm{t}} \mathrm{Bu}\right.$ and $\left.\mathrm{CH}_{2}\right), 28.0\left(\mathrm{CH}_{2}\right), 29.3\left(\mathrm{CH}_{2}\right), 31.2$ $\left(\mathrm{CH}_{2}\right), 32.6(\mathrm{CH}), 36.3(\mathrm{CH}), 38.3(\mathrm{CH}), 41.1(\mathrm{CH}), 41.4(\mathrm{CH}), 46.6(\mathrm{CH}), 52.3(1-$ $\left.\mathrm{CO}_{2} \mathrm{CH}_{3}\right), 56.2\left(8-\mathrm{OCH}_{2} \mathrm{OCH}_{3}\right), 58.8(\mathrm{C}, \mathrm{C}-1), 72.9\left(\mathrm{CH}, \mathrm{C}-1^{\prime}\right), 83.4(\mathrm{CH}, \mathrm{C}-8), 99.0$ $\left(8-\mathrm{OCH}_{2} \mathrm{OCH}_{3}\right), 126.5(\mathrm{CH}, \mathrm{C}-3), 152.7(\mathrm{CH}, \mathrm{C}-4), 173.3\left(1-\mathrm{CO}_{2} \mathrm{CH}_{3}\right), 199.2(2-\mathrm{CO})$.

LRMS (m/z): $465\left(\left(\mathrm{M}-{ }^{\mathrm{t}} \mathrm{Bu}\right)^{+}, 17 \%\right), 403$ (15), 385 (10), 345 (5), 253 (16), 227 (5), 173 (100), 133 (15), 73 (70).

HRMS: $\mathrm{C}_{25} \mathrm{H}_{41} \mathrm{O}_{6} \mathrm{Si}\left(\left(\mathrm{M}-{ }^{\mathrm{t}} \mathrm{Bu}\right)^{+}\right)$requires 465.2672, found 465.2678.

Microanalysis: Calcd. for $\mathrm{C}_{29} \mathrm{H}_{50} \mathrm{O}_{6} \mathrm{Si}: \mathrm{C}, 66.63 \%, \mathrm{H}, 9.64 \%$. Found: $\mathrm{C}, 66.63 \%$, $\mathrm{H}$, $9.75 \%$.

\subsection{Chapter 4 Experimental}

$\left(2^{\prime} R S, 4^{\prime} R S, 4 a^{\prime} S R, 10 a^{\prime} S R, 1 S R\right)$ 1-[7'-Methoxy-1'-methoxymethylene-2'-methyl1', 2', 4a', 9', 10', 10a'-hexahydrophenanthrene-4' (3'H)-yl]-propan-1-yl Benzoate (1.96)
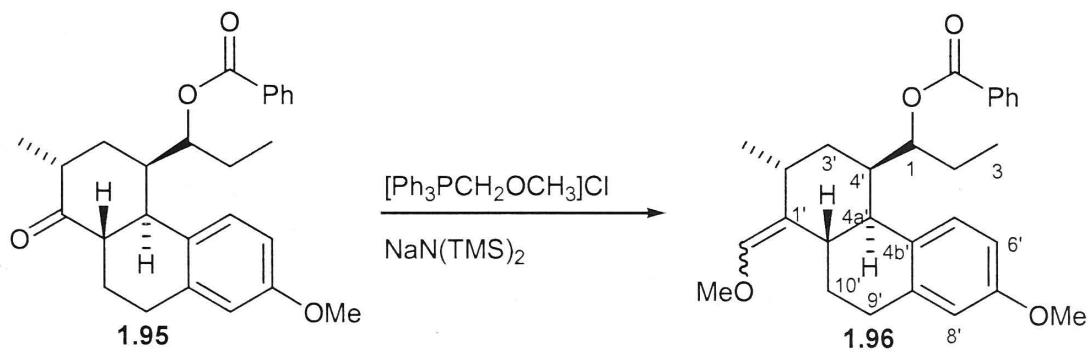

Sodium bis(trimethylsilyl)amide (40.5 mL of a $1 M$ solution in THF, $40.5 \mathrm{mmol}$ ) was added drop wise to a stirred solution of (methoxymethyl)triphenyl phosphonium chloride $(13.9 \mathrm{~g}, 40.5 \mathrm{mmol})$ in dry THF $(50 \mathrm{~mL})$ at $0{ }^{\circ} \mathrm{C}$ under nitrogen. After $15 \mathrm{~min}$, a solution of ketone 1.95 (3.29 g, $8.09 \mathrm{mmol})$ in THF (50 mL) was added drop wise to the red solution and the reaction mixture was stirred at room temperature. After $4 \mathrm{~h}$, the reaction was quenched with water $(20 \mathrm{~mL})$ and extracted with ethyl acetate $(4 \times 50 \mathrm{~mL})$. The combined organic extracts were washed with water $(20 \mathrm{~mL})$, brine $(20 \mathrm{~mL})$, dried 
over anhydrous $\mathrm{MgSO}_{4}$, and concentrated in vacuo to give a yellow oil. Purification by flash column chromatography using ether : hexane $(5: 95)$ as eluant gave the title compound $1.96(2.96 \mathrm{~g}, 87 \%)$ as a colourless oil, a mixture of $E$ and $Z$ isomers.

IR (thin film) $\mathbf{c m}^{-1}$ : 2931s $(\mathrm{C}-\mathrm{H}), 1709 \mathrm{~s}(\mathrm{C}=\mathrm{O}), 1672 \mathrm{~s}, 1610 \mathrm{~s}, 1584,1502 \mathrm{~s}, 1452 \mathrm{~s}$, $1315,1274 \mathrm{~s}, 1224,1146,1112,1045,1026$.

${ }^{1} \mathbf{H}$ NMR (300 $\mathbf{M H z}, \mathbf{C D C l}_{\mathbf{3}}$; * indicates peaks belonging to minor isomer) $\delta: 0.84(\mathrm{t}$, $\left.J_{3,2}=7.5 \mathrm{~Hz}, 3 \mathrm{H}, \mathrm{H}-3\right), 0.87^{*}\left(\mathrm{t}, J_{3,2}=7.5 \mathrm{~Hz}, 3 \mathrm{H}, \mathrm{H}-3\right), 1.04$ (d, $J=6.6 \mathrm{~Hz}, 3 \mathrm{H}, 2^{\prime}-$ $\left.\mathrm{CH}_{3}\right), 1.34^{*}\left(\mathrm{~d}, J=6.6 \mathrm{~Hz}, 3 \mathrm{H}, 2^{\prime}-\mathrm{CH}_{3}\right), 1.45$ (m, 1H, H-10'), 1.59-2.03 (m, 4H), 2.31 2.67 (m, 5H), 2.80-2.96 (m, 2H, H-4a', H-4'), 3.45 (s, 3H, 1'-CHOCH H $^{\prime}, 3.46$ (s, 3H, 7'$\left.\mathrm{OCH}_{3}\right), 3.50^{*}\left(\mathrm{~s}, 3 \mathrm{H}, 1^{\prime}-\mathrm{CHOCH}_{3}\right), 3.51^{*}\left(\mathrm{~s}, 3 \mathrm{H}, 7^{\prime}-\mathrm{OCH}_{3}\right), 5.63\left(\mathrm{~s}, 1 \mathrm{H}, 1^{\prime}-\mathrm{CHOCH}_{3}\right)$, 5.70* (s, 1H, 1'-CHOCH 3$), 5.71(\mathrm{~m}, 1 \mathrm{H}, \mathrm{H}-1), 6.01\left(\mathrm{~d}, J_{8^{\prime}, 6^{\prime}}=2.7 \mathrm{~Hz}, 1 \mathrm{H}, \mathrm{H}-8^{\prime}\right), 6.10^{*}$ $\left(\mathrm{d}, J_{8^{\prime}, 6^{\prime}}=2.7 \mathrm{~Hz}, 1 \mathrm{H}, \mathrm{H}-8^{\prime}\right), 6.50\left(\mathrm{dd}, J_{6}{ }^{\prime}, 5^{\prime}=8.4 \mathrm{~Hz}, J_{6}{ }^{\prime}, 8^{\prime}=2.7 \mathrm{~Hz}, 1 \mathrm{H}, \mathrm{H}-6^{\prime}\right), 6.55^{*}$ $\left(\mathrm{dd}, J_{6}{ }^{\prime},^{\prime}=8.4 \mathrm{~Hz}, J_{6}{ }^{\prime}, 8^{\prime}=2.7 \mathrm{~Hz}, 1 \mathrm{H}, \mathrm{H}-6^{\prime}\right), 7.12\left(\mathrm{~d}, J_{5}{ }^{\prime}, 6^{\prime}=8.4 \mathrm{~Hz}, 1 \mathrm{H}, \mathrm{H}-5^{\prime}\right), 7.18^{*}(\mathrm{~d}$, $\left.J_{5^{\prime}, 6^{\prime}}=8.4 \mathrm{~Hz}, 1 \mathrm{H}, \mathrm{H}-5^{\prime}\right), 7.18-7.52$ (m, 5H, H-2", H-3", H-4").

${ }^{13} \mathbf{C ~ N M R}\left(75 \mathbf{~ M H z}, \mathbf{C D C l}_{\mathbf{3}}\right.$ * indicates peaks belonging to minor isomer) $\delta$ : $9.2\left(\mathrm{CH}_{3}\right.$, C-3), 9.4* $\left(\mathrm{CH}_{3}, \mathrm{C}-3\right), 19.0\left(2^{\prime}-\mathrm{CH}_{3}\right), 21.0^{*}\left(2^{\prime}-\mathrm{CH}_{3}\right), 26.2\left(\mathrm{CH}_{2}\right), 26.3^{*}\left(\mathrm{CH}_{2}\right), 26.9$ $\left(\mathrm{CH}_{2}\right), 27.8^{*}\left(\mathrm{CH}_{2}\right), 30.5\left(\mathrm{CH}_{2}\right), 31.3 *\left(\mathrm{CH}_{2}\right), 31.6\left(\mathrm{CH}_{2}\right), 32.2 *\left(\mathrm{CH}_{2}\right), 37.9(\mathrm{CH})$, 38.8* $(\mathrm{CH}), 40.2(\mathrm{CH}), 40.4^{*}(\mathrm{CH}), 41.0(\mathrm{CH}), 41.4^{*}(\mathrm{CH}), 47.3(\mathrm{CH}), 47.6^{*}(\mathrm{CH})$, $54.6\left(7^{\prime}-\mathrm{OCH}_{3}\right), 54.7^{*}\left(7^{\prime}-\mathrm{OCH}_{3}\right), 59.6\left(1^{\prime}-\mathrm{CHOCH}_{3}\right), 73.6(\mathrm{CH}, \mathrm{C}-1), 74.3^{*}(\mathrm{CH}, \mathrm{C}-1)$, $112.0\left(\mathrm{CH}, \mathrm{C}-6^{\prime}\right), 112.5\left(\mathrm{CH}, \mathrm{C}-8^{\prime}\right), 112.6^{*}\left(\mathrm{CH}, \mathrm{C}-8^{\prime}\right), 123.8\left(\mathrm{CH}, 1^{\prime}-\mathrm{CHOCH}_{3}\right)$, 123.9* $\left(\mathrm{CH}, 1^{\prime}-\mathrm{CHOCH}_{3}\right), 127.2\left(\mathrm{CH}, \mathrm{C}-5^{\prime}\right), 127.3^{*}\left(\mathrm{CH}, \mathrm{C}-5^{\prime}\right), 127.9(\mathrm{Ar}), 128.0^{*}$ (Ar), 129.3 (Ar), 129.6* (Ar), 129.7 (Ar), 130.8 (Ar), 131.2* (Ar), 131.9 (C, C-4b'), 132.0* (C, C-4b'), $137.6\left(\mathrm{C}, \mathrm{C}-8 \mathrm{a}^{\prime}\right), 138.2 *\left(\mathrm{C}, \mathrm{C}-8 \mathrm{a}^{\prime}\right), 139.4\left(\mathrm{C}, \mathrm{C}-1^{\prime}\right), 139.6^{*}\left(\mathrm{C}, \mathrm{C}-1^{\prime}\right)$, $156.0\left(\mathrm{C}, \mathrm{C}-7^{\prime}\right), 156.1^{*}\left(\mathrm{C}, \mathrm{C}-7^{\prime}\right), 165.6(1-\mathrm{OC}(\mathrm{O}) \mathrm{Ph}), 165.7^{*}(1-\mathrm{OC}(\mathrm{O}) \mathrm{Ph})$.

LRMS (m/z): $434\left(\mathrm{M}^{+}, 9 \%\right), 312$ (100), 297 (2), 280 (7), 267 (10), 243 (53), 225 (4), 211 (9), 185 (4), $158(9)$.

HRMS: $\mathrm{C}_{28} \mathrm{H}_{35} \mathrm{O}_{4}\left(\mathrm{MH}^{+}\right)$requires 435.2535 , found 435.2541 . 
(1'RS, 2'RS, 4'RS, 4a'SR, 10a'SR, 1SR) 1-[7'-Methoxy-1"'-methoxy-

spiro[cyclopropane-1', $\left.1^{\prime}\right]-2^{\prime}-$ methyl-1', 2', 4a', 9', 10', 10a'-

hexahydrophenanthrene-4' (3'H)-yl]-propan-1-yl Benzoate (1.99)
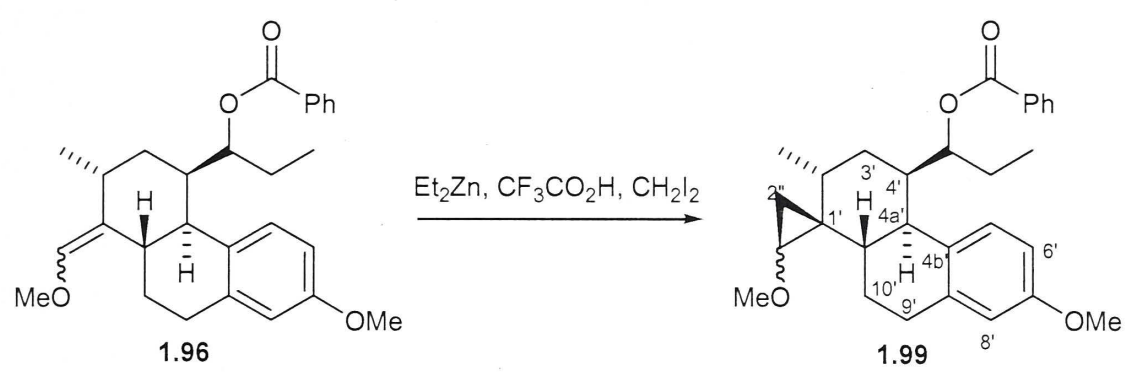

Diethyl zinc (24.5 $\mathrm{mL}$ of a $1 \mathrm{M}$ solution in hexanes, $24.5 \mathrm{mmol})$ was added to DCM (20 $\mathrm{mL})$ at $0{ }^{\circ} \mathrm{C}$ under nitrogen. Trifluoroacetic acid $(1.89 \mathrm{~mL}, 24.5 \mathrm{mmol})$ in DCM (10 $\mathrm{mL}$ ) was then added drop wise and the resulting reaction mixture stirred for $20 \mathrm{~min}$. Diiodomethane $(1.98 \mathrm{~mL}, 24.5 \mathrm{mmol})$ in DCM $(10 \mathrm{~mL})$ was then added and after 20 min enol ether 1.96 (2.96 g, $7.01 \mathrm{mmol})$ was added. The reaction mixture was warmed to room temperature and stirred for a further $20 \mathrm{~min}$. The reaction was quenched with a saturated solution of ammonium chloride and extracted with DCM $(3 \times 50 \mathrm{~mL})$. The combined organic extracts were washed with water, dried over $\mathrm{MgSO}_{4}$ and concentrated in vacuo to give the title compound 1.99 (ca. $3 \mathrm{~g}$ ) as a yellow oil. The crude product was used directly in the next step without any further purification. A sample was purified by flash column chromatography using ether : petroleum spirit $(0.5: 9.5)$ for characterization purposes.

IR (thin film) $\mathbf{c m}^{-1}$ : 2929s $(\mathrm{C}-\mathrm{H}), 1709 \mathrm{~s}(\mathrm{C}=\mathrm{O}), 1503 \mathrm{~s}, 1455,1273 \mathrm{~s}, 1112,1067,1042$, 1020.

${ }^{1} \mathbf{H}$ NMR (300 MHz, $\mathbf{C D C l}_{3} *$ indicates peaks belonging to minor isomer) $\delta: 0.59(\mathrm{~d}, J$ $\left.=7.1 \mathrm{~Hz}, 3 \mathrm{H}, 2^{\prime}-\mathrm{CH}_{3}\right), 0.64\left(\mathrm{~m}, 1 \mathrm{H}, \mathrm{H}-2^{\prime \prime}\right), 0.86\left(\mathrm{t}, J_{3,2}=7.2 \mathrm{~Hz}, 3 \mathrm{H}, \mathrm{H}-3\right), 0.88^{*}\left(\mathrm{t}, J_{3,2}\right.$ $=7.2 \mathrm{~Hz}, 3 \mathrm{H}, \mathrm{H}-3), 0.81\left(\mathrm{~m}, 1 \mathrm{H}, \mathrm{H}^{\prime}-2^{\prime \prime}\right), 0.97^{*}\left(\mathrm{~d}, J=7.1 \mathrm{~Hz}, 3 \mathrm{H}, 2^{\prime}-\mathrm{CH}_{3}\right), 1.57(\mathrm{~m}, 1 \mathrm{H}$, H-10') 1.62-1.89 (m, 4H), 2.11-2.54 (m, 5H), 2.89 (m, 1H, H-4'), 3.10-3.23 (m, 2H, H$\left.4 \mathrm{a}^{\prime}, \mathrm{H}-1^{\prime \prime}\right), 3.22\left(\mathrm{~s}, 3 \mathrm{H}, 1^{\prime}-\mathrm{CHOCH}_{3}\right), 3.30 *\left(\mathrm{~s}, 3 \mathrm{H}, 1^{\prime}-\mathrm{CHOCH}_{3}\right), 3.43\left(\mathrm{~s}, 3 \mathrm{H}, 7^{\prime}-\mathrm{OCH}_{3}\right)$, $3.45^{*}\left(\mathrm{~s}, 3 \mathrm{H}, 7^{\prime}-\mathrm{OCH}_{3}\right), 5.75(\mathrm{ddd}, J=11.1 \mathrm{~Hz}, J=7.8 \mathrm{~Hz}, J=3.3 \mathrm{~Hz}, 1 \mathrm{H}, \mathrm{H}-1), 5.97$ $\left(\mathrm{d}, J_{8^{\prime}, 6^{\prime}}=2.9 \mathrm{~Hz}, 1 \mathrm{H}, \mathrm{H}-8^{\prime}\right), 6.49\left(\mathrm{dd}, J_{6^{\prime}, 5^{\prime}}=8.4 \mathrm{~Hz}, J_{6}^{\prime}, 8^{\prime}=2.9 \mathrm{~Hz}, 1 \mathrm{H}, \mathrm{H}-6^{\prime}\right), 6.52^{*}$ $\left(\mathrm{dd}, J_{6^{\prime}, 5^{\prime}}=8.4 \mathrm{~Hz}, J_{6^{\prime}, 8^{\prime}}=2.9 \mathrm{~Hz}, 1 \mathrm{H}, \mathrm{H}-6^{\prime}\right), 7.14\left(\mathrm{~d}, J_{5^{\prime}, 6^{\prime}}=8.4 \mathrm{~Hz}, 1 \mathrm{H}, \mathrm{H}-5^{\prime}\right), 7.17-7.45$ $(\mathrm{m}, 5 \mathrm{H})$. 
${ }^{13} \mathrm{C}$ NMR (75 $\mathbf{~ M H z}, \mathbf{C D C l}_{3}$ * indicates peaks belonging to minor isomer) $\delta: 9.2\left(\mathrm{CH}_{3}\right.$, C-3), 9.8* $\left(\mathrm{CH}_{3}, \mathrm{C}-3\right), 10.8\left(\mathrm{CH}_{2}, 1^{\prime}-\mathrm{CH}_{2}\right), 16.6\left(2^{\prime}-\mathrm{CH}_{3}\right), 18.4 *\left(2^{\prime}-\mathrm{CH}_{3}\right), 25.3\left(\mathrm{CH}_{2}\right)$, $27.0\left(\mathrm{CH}_{2}\right), 29.8\left(\mathrm{CH}_{2}\right), 30.5\left(\mathrm{CH}_{2}\right), 31.3\left(\mathrm{CH}_{2}\right), 32.1^{*}\left(\mathrm{CH}_{2}\right), 32.9\left(\mathrm{C}, \mathrm{C}-1^{\prime}\right), 33.1 *(\mathrm{C}$, C-1'), $38.6(\mathrm{CH}), 38.9^{*}(\mathrm{CH}), 38.4(\mathrm{CH}), 41.8(\mathrm{CH}), 42.0^{*}(\mathrm{CH}), 45.7(\mathrm{CH}), 46.0 *$ $(\mathrm{CH}), 54.6\left(7^{\prime}-\mathrm{OCH}_{3}\right), 54.7 *\left(7^{\prime}-\mathrm{OCH}_{3}\right), 57.8\left(1^{\prime}-\mathrm{CHOCH}_{3}\right), 58.1 *\left(1^{\prime}-\mathrm{CHOCH}_{3}\right), 59.7$ $\left(1^{\prime}-\mathrm{CHOCH}_{3}\right), 60.0 *\left(1^{\prime}-\mathrm{CHOCH}_{3}\right), 73.7(\mathrm{CH}, \mathrm{C}-1), 74.0 *(\mathrm{CH}, \mathrm{C}-1), 112.0\left(\mathrm{CH}, \mathrm{C}-6^{\prime}\right)$, $112.2\left(\mathrm{CH}, \mathrm{C}-8^{\prime}\right), 112.4 *\left(\mathrm{CH}, \mathrm{C}-8^{\prime}\right), 127.2\left(\mathrm{CH}, \mathrm{C}-5^{\prime}\right), 127.4 *\left(\mathrm{CH}, \mathrm{C}-5^{\prime}\right), 127.9$ (Ar), 128.1* (Ar), 129.3 (Ar), 129.7* (Ar), 131.6 (C, C-4b'), 131.9* (C, C-4b'), 137.5 (C, C$\left.8 \mathrm{a}^{\prime}\right), 138.2 *\left(\mathrm{C}, \mathrm{C}-8 \mathrm{a}^{\prime}\right), 155.9$ (C, C-7'), 156.0* (C, C-7'), 165.7 (1-OC(O)Ph).

LRMS (m/z): $448\left(\mathrm{M}^{+}, 15 \%\right), 326$ (68), 294 (11), 284 (65), 268 (85), 251 (21), 239 (34) 225 (100), 211 (23), 197 (20), 185 (14).

HRMS: $\mathrm{C}_{29} \mathrm{H}_{36} \mathrm{O}_{4}\left(\mathrm{M}^{+}\right)$requires 448.2614 , found 448.2615 .

(1RS, 2RS, 4RS, 4aSR, 10aSR, 1'SR) 4-(1'-Benzoyloxypropyl)-7-methoxy-1,2methyl-3,4,4a,9,10,10a-hexahydrophenanthrene-1 $(2 H)$-carbaldehyde $(1.98)$
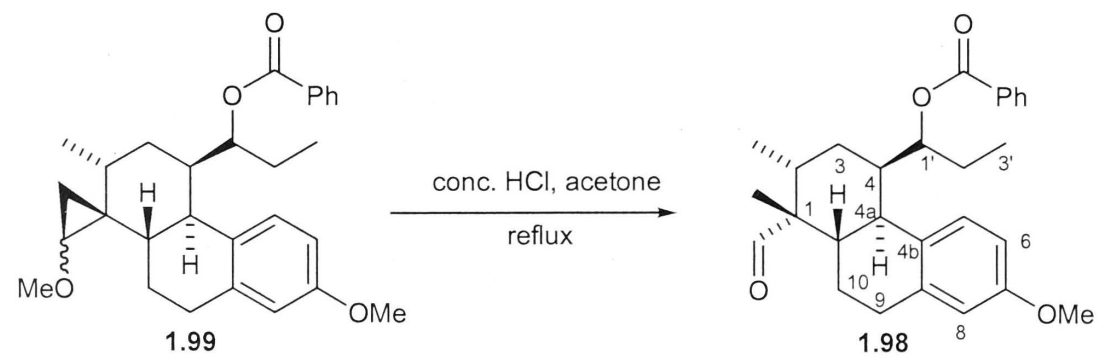

Concentrated hydrochloric acid (4 mL) was added to cyclopropane 1.99 (3 g, $7 \mathrm{mmol}$ ) in acetone $(80 \mathrm{~mL})$ and heated at reflux for $10 \mathrm{~h}$. Water $(10 \mathrm{~mL})$ was then added and the acetone removed in vacuo. The mixture was extracted with ethyl acetate $(4 \times 10 \mathrm{~mL})$ and the combined organic extracts washed with brine $(10 \mathrm{~mL})$, saturated sodium bicarbonate $(10 \mathrm{~mL})$ then water $(10 \mathrm{~mL})$. The organic phase was dried over anhydrous $\mathrm{MgSO}_{4}$ and concentrated in vacuo to give the title compound $\mathbf{1 . 9 8}(3 \mathrm{~g})$ as a yellow oil which was used in the next step without further purification. A sample was purified by flash column chromatography for characterization purposes, on silica gel using ether : hexane (5:95) as eluant to give the title compound as a white solid. A sample was crystallised from ethyl acetate : hexane to give white crystals. 
IR (thin film) $\mathbf{c m}^{-1}$ : 2917s (C-H),1709s (C=O), 1610s, 1503s, 1453, $1273 \mathrm{~s}, 1108$.

${ }^{1} \mathbf{H}$ NMR (300 MHz, $\left.\mathbf{C D C l}_{3}\right)$ ): $0.90\left(\mathrm{t}, J_{3^{\prime}, 2^{\prime}}=7.3 \mathrm{~Hz}, 3 \mathrm{H}, \mathrm{H}-3^{\prime}\right), 1.01(\mathrm{~d}, J=6.7 \mathrm{~Hz}$, $\left.3 \mathrm{H}, 2-\mathrm{CH}_{3}\right), 1.35$ (s, 3H, 1- $\left.\mathrm{CH}_{3}\right), 1.26$ (m, 1H, H-10), 1.65 (m, 1H, H-2'), 1.77-1.93 (m, $3 \mathrm{H}, \mathrm{H}^{\prime}-2$ ', H-3, H-2), 2.07-2.20 (m, 3H, H'-3, H'-10, H-10a), 2.47-2.50 (m, 2H, H-9), 2.98 (m, 1H, H-4), 3.40 (m, 1H, H-4a), 3.44 (s, 3H, 7-OCH $), 5.72$ (ddd, $J=10.8 \mathrm{~Hz}, J$ $\left.=7.8 \mathrm{~Hz}, J=2.7 \mathrm{~Hz}, 1 \mathrm{H}, \mathrm{H}-1^{\prime}\right), 5.99\left(\mathrm{~d}, J_{8,6}=2.7 \mathrm{~Hz}, 1 \mathrm{H}, \mathrm{H}-8\right), 6.50\left(\mathrm{dd}, J_{6,5}=8.4 \mathrm{~Hz}\right.$, $J_{6,8}=2.7$ Hz, 1H, H-6), 7.17-7.42 (m, 6H, H-5, H-2", H-3", H-4"), 9.93 (s, 1H, 1-CHO).

${ }^{13} \mathbf{C}$ NMR (75 MHz, $\left.\mathbf{C D C l}_{3}\right)$ 8: $9.1\left(\mathrm{CH}_{3}, \mathrm{C}-3^{\prime}\right), 17.2\left(2-\mathrm{CH}_{3}\right), 19.9\left(1-\mathrm{CH}_{3}\right), 24.0$ $\left(\mathrm{CH}_{2}, \mathrm{C}-10\right), 26.8\left(\mathrm{CH}_{2}, \mathrm{C}-2^{\prime}\right), 31.1\left(\mathrm{CH}_{2}, \mathrm{C}-9\right), 35.5\left(\mathrm{CH}_{2}, \mathrm{C}-3\right), 35.6(\mathrm{CH}, \mathrm{C}-2), 40.6$ (CH, C-4), 41.7 (CH, C-4a), $43.3(\mathrm{CH}, \mathrm{C}-10 \mathrm{a}), 51.9(\mathrm{C}, \mathrm{C}-1), 54.7\left(7-\mathrm{OCH}_{3}\right), 72.8$ (CH, C-1'), 112.3 (CH, C-6), 112.4 (CH, C-8), 127.3 (CH, C-5), 127.9 (Ar), 129.3 (Ar), 129.4 (Ar), 132.0 (C, C-4b), 137.3 (C, C-8a), 156.3 (C, C-7), 165.7 (1'-OC(O)Ph), 207.7 (1-CHO).

LRMS (m/z): $434\left(\mathrm{M}^{+}, 10 \%\right), 336$ (68), 312 (12), 283 (11), 231 (74), 215 (100), 199 (24), 185 (23).

HRMS: $\mathrm{C}_{28} \mathrm{H}_{34} \mathrm{O}_{4}\left(\mathrm{M}^{+}\right)$requires 434.2457 , found 434.2452 .

(1RS, 2RS, 4RS, 4aSR, 10aSR, 1'SR) 4-(1'-Benzoyloxypropyl)-7-methoxy-1,2methyl-3,4,4a,9,10,10a-hexahydrophenanthrene-1(2H)-carboxylic acid (4.2)

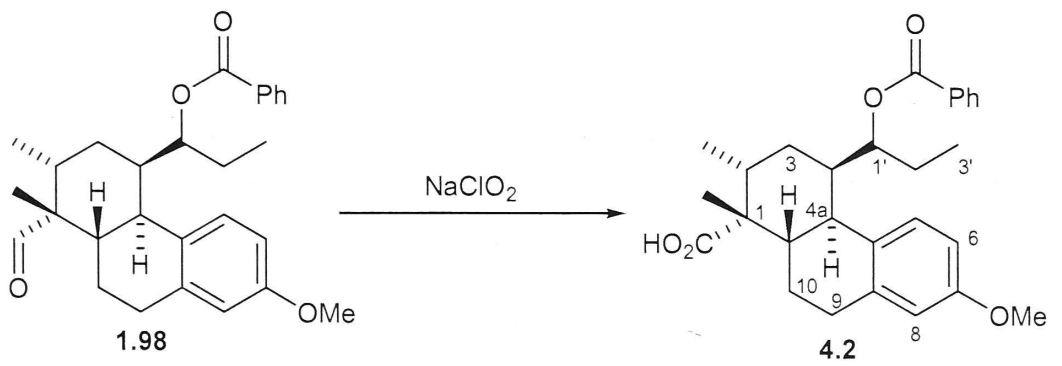

Aldehyde 1.98 (3.25 g, $7.02 \mathrm{mmol}$ ) was dissolved in a mixture of acetonitrile (200 mL), hydrogen peroxide ( $24 \mathrm{~mL}$ of a $30 \% \mathrm{w} / \mathrm{v}$ solution) and sodium hydrogen phosphate buffer $(24 \mathrm{~mL}, \mathrm{pH} 2)$. The solution was cooled to $0{ }^{\circ} \mathrm{C}$ and sodium chlorite $(1.27 \mathrm{~g}$, $14.0 \mathrm{mmol}$ ) was added. The resulting reaction mixture was stirred for $5 \mathrm{~h}$ then diluted with ethyl acetate $(150 \mathrm{~mL})$ and washed with water $(100 \mathrm{~mL})$. The organic phase was 
separated and the aqueous layer extracted with ethyl acetate $(2 \times 50 \mathrm{~mL})$. The combined organic extracts were washed with water $(50 \mathrm{~mL})$, brine $(50 \mathrm{~mL})$, dried over $\mathrm{MgSO}_{4}$ and concentrated in vacuo to give a yellow solid. Purification by flash column chromatography using ethyl acetate : petroleum spirit (1:4) with $1 \%$ acetic acid as eluant gave the title compound 4.2 (2.52 g, 80\% over three steps) as a white solid. A sample was crystallised from ether : hexane to give white crystals.

m.p: $203-205^{\circ} \mathrm{C}$

IR (thin film) $\mathbf{c m}^{-1}$ : 3289 br $(\mathrm{C}-\mathrm{OH}), 2938 \mathrm{~s}(\mathrm{C}-\mathrm{H}), 1709 \mathrm{~s}(\mathrm{C}=\mathrm{O}), 1689 \mathrm{~s}(\mathrm{C}=\mathrm{O}), 1606$, $1503,1450,1275$ s, 1109.

${ }^{1} \mathbf{H}$ NMR (300 MHz, $\left.\mathbf{C D C l}_{\mathbf{3}}\right)$ 8: $0.87\left(\mathrm{t}, J_{3^{\prime}, 2^{\prime}}=7.5 \mathrm{~Hz}, 3 \mathrm{H}, \mathrm{H}-3^{\prime}\right), 1.00(\mathrm{~d}, J=6.6 \mathrm{~Hz}$, $\left.3 \mathrm{H}, 2-\mathrm{CH}_{3}\right), 1.39$ (s, 3H, 1-CH $\mathrm{CH}_{3}, 1.09-2.34$ (m, 8H, H-2', H-3, H-2, H-10, H-10a), 2.372.58 (m, 2H, H-9), 2.86 (m, 1H, H-4), 3.44 (s, 3H, 7--OCH $), 3.55$ (m, 1H, H-4a), 5.64 (ddd, $\left.J=10.5 \mathrm{~Hz}, J=7.5 \mathrm{~Hz}, J=2.7 \mathrm{~Hz}, 1 \mathrm{H}, \mathrm{H}-1^{\prime}\right), 5.99$ (d, $\left.J_{8,6}=2.7 \mathrm{~Hz}, 1 \mathrm{H}, \mathrm{H}-8\right)$, $6.51\left(\mathrm{dd}, J_{6,5}=8.4 \mathrm{~Hz}, J_{6,8}=2.7 \mathrm{~Hz}, 1 \mathrm{H}, \mathrm{H}-6\right), 7.15-7.41$ (m, 6H, H-5, H-2", H-3", H$\left.4^{\prime \prime}\right)$.

${ }^{13} \mathrm{C}$ NMR (75 MHz, $\left.\mathbf{C D C l}_{3}\right)$ 8: $9.0\left(\mathrm{CH}_{3}, \mathrm{C}-3^{\prime}\right), 17.4\left(2-\mathrm{CH}_{3}\right), 23.2\left(1-\mathrm{CH}_{3}\right), 24.6$ $\left(\mathrm{CH}_{2}, \mathrm{C} 10\right), 26.6\left(\mathrm{CH}_{2}, \mathrm{C}-2^{\prime}\right), 30.9\left(\mathrm{CH}_{2}, \mathrm{C}-9\right), 34.5\left(\mathrm{CH}_{2}, \mathrm{C}-3\right), 35.4(\mathrm{CH}, \mathrm{C}-2), 39.8$ (CH, C-4), 39.9 (CH, C-4a), 42.5 (CH, C-10a), 49.9 (C, C-1), $54.6\left(7-\mathrm{OCH}_{3}\right), 73.2(\mathrm{CH}$, C-1'), 112.2 (CH, C-6), 112.4 (CH, C-8), 127.3 (CH, C-5), 127.9 (Ar), 129.3 (Ar), 129.5 (Ar), 131.4 (Ar), 132.0 (C, C-4b), 137.2 (C, C-8a), 156.1 (C, C-7), 165.9 (1'-OC(O)Ph), $181.1\left(1-\mathrm{CO}_{2} \mathrm{H}\right)$.

LRMS (m/z): $450\left(\mathrm{M}^{+}, 90 \%\right), 328$ (68), 283 (30), 240 (46), 231 (42), 213 (31), 159 (26), 105 (100).

HRMS: $\mathrm{C}_{28} \mathrm{H}_{34} \mathrm{O}_{5}\left(\mathrm{M}^{+}\right)$requires 450.2406 , found 450.2406 .

Microanalysis: Calcd. for $\mathrm{C}_{28} \mathrm{H}_{34} \mathrm{O}_{5}$ : C, 74.64\%, H, 7.61\%. Found: C, $74.43 \%$, H, $7.67 \%$. 
(1RS, 2RS, 4RS, 4aSR, 10aSR, 1'SR) 4-(1'-hydroxypropyl)-7-methoxy-1,2-methyl$3,4,4 a, 9,10,10 \mathrm{a}-h e x a h y d r o p h e n a n t h r e n e-1(2 H)$-carboxylic acid (4.4)

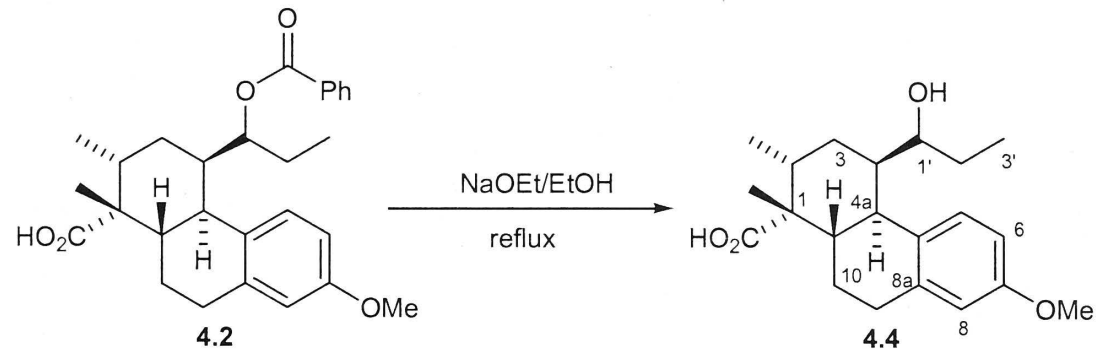

Sodium (2 g) was slowly added to the benzoate 4.2 (2.52 g, $5.62 \mathrm{mmol})$ in ethanol (120 $\mathrm{mL}$ ) at room temperature under nitrogen. The reaction mixture was heated at reflux for $2 \mathrm{~d}$, then water $(50 \mathrm{~mL})$ was added and the ethanol removed in vacuo. The residue was treated with $1 M$ hydrochloric acid until pH 5 and extracted with ethyl acetate $(3 \times 50$ $\mathrm{mL}$ ). The combined organic extracts were dried over $\mathrm{MgSO}_{4}$ and concentrated in vacuo to give the crude product as a yellow solid. Purification by flash column chromatography using ethyl acetate : petroleum spirit $(1: 9)$ with $1 \%$ acetic acid as eluant gave the title compound $4.4(1.24 \mathrm{~g}, 65 \%)$ as a white foam and recovered starting material $4.2(0.97 \mathrm{~g}, 35 \%)$ which was re-submitted to the reaction conditions and purified as above to give more of the title compound 4.4 (1.38 g total, $73 \%)$.

IR (thin film) $\mathbf{c m}^{-1}: 3546 \mathrm{br}(\mathrm{C}-\mathrm{OH}), 2934 \mathrm{~s}(\mathrm{C}-\mathrm{H}), 1694 \mathrm{~s}(\mathrm{C}=\mathrm{O}), 1610 \mathrm{~s}, 1500 \mathrm{~s}, 1464$, $1256 \mathrm{~s}, 1157$.

${ }^{1} \mathbf{H}$ NMR (300 MHz, CDCl$\left.)_{3}\right)$ 8: $0.92\left(\mathrm{t}, J_{3^{\prime}, 2^{\prime}}=7.5 \mathrm{~Hz}, 3 \mathrm{H}, \mathrm{H}-3^{\prime}\right), 0.96(\mathrm{~d}, J=6.6 \mathrm{~Hz}$, $\left.3 \mathrm{H}, 2-\mathrm{CH}_{3}\right), 1.26-1.67(\mathrm{~m}, 6 \mathrm{H}), 1.34\left(\mathrm{~s}, 3 \mathrm{H}, 1-\mathrm{CH}_{3}\right), 1.97(\mathrm{td}, J=12.0 \mathrm{~Hz}, J=1.5 \mathrm{~Hz}$, 1H), 2.08 (m, 1H), 2.57 (m, 1H, H-4), 2.68-2.89 (m, 2H, H-9), 3.59 (m, 1H, H-4a), 3.74 $\left(\mathrm{s}, 3 \mathrm{H}, 7-\mathrm{OCH}_{3}\right), 3.94\left(\mathrm{~m}, 1 \mathrm{H}, \mathrm{H}-1^{\prime}\right), 6.58\left(\mathrm{~d}, J_{8,6}=2.7 \mathrm{~Hz}, 1 \mathrm{H}, \mathrm{H}-8\right), 6.73\left(\mathrm{dd}, J_{6,5}=8.7\right.$ $\left.\mathrm{Hz}, J_{6,8}=2.7 \mathrm{~Hz}, 1 \mathrm{H}, \mathrm{H}-6\right), 7.29\left(\mathrm{~d}, J_{5,6}=8.7 \mathrm{~Hz}, 1 \mathrm{H}, \mathrm{H}-5\right)$.

${ }^{13} \mathrm{C}$ NMR (75 MHz, $\left.\mathbf{C D C l}_{3}\right)$ 8: $9.5\left(\mathrm{CH}_{3}, \mathrm{C}-3{ }^{\prime}\right), 17.3\left(2-\mathrm{CH}_{3}\right), 23.2\left(1-\mathrm{CH}_{3}\right), 24.5$ $\left(\mathrm{CH}_{2}\right), 29.0\left(\mathrm{CH}_{2}\right), 31.3\left(\mathrm{CH}_{2}\right), 34.4\left(\mathrm{CH}_{2}\right), 35.4(\mathrm{CH}), 39.8(\mathrm{CH}), 42.0(\mathrm{CH}), 43.1$ $(\mathrm{CH}), 49.7(\mathrm{C}, \mathrm{C}-1), 55.0\left(7-\mathrm{OCH}_{3}\right), 72.8\left(\mathrm{CH}, \mathrm{C}-1^{\prime}\right), 112.3(\mathrm{CH}, \mathrm{C}-6), 114.1(\mathrm{CH}, \mathrm{C}-$ 8), 128.0 (CH, C-5), 130.9 (C, C-4b), 138.5 (C, C-8a), 157.2 (C, C-7), $180.7\left(1-\mathrm{CO}_{2} \mathrm{H}\right)$. 
LRMS (m/z): $346\left(\mathrm{M}^{+}, 75 \%\right), 328$ (15), 283 (11), 241 (25), 199 (26), 187 (66), 174 (100), $161(37)$.

HRMS: $\mathrm{C}_{21} \mathrm{H}_{30} \mathrm{O}_{4}\left(\mathrm{M}^{+}\right)$requires 346.2144, found 346.2143 .

(1RS, 2RS, 4RS, 4aSR, 10aSR, 1'SR) 4-(1'-t.-butyldimethylsilyloxyproyl)-7methoxy-1,2-methyl-3,4,4a,9,10,10a-hexahydrophenanthrene-1(2H)-carboxylic acid (4.7)

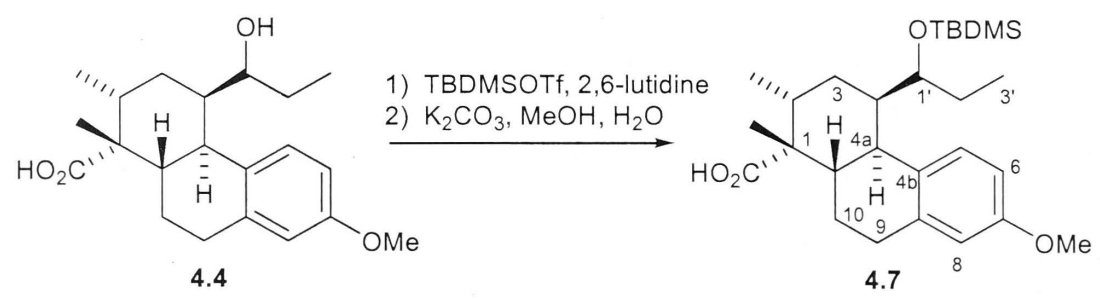

t.-Butyldimethylsilyl trifluoromethanesulfonate $(1.43 \mathrm{~mL}, 6.23 \mathrm{mmol})$ was added drop wise to alcohol $4.4(0.72 \mathrm{~g}, 2.08 \mathrm{mmol})$ and 2,6-lutidine $(0.97 \mathrm{~mL}, 8.32 \mathrm{mmol})$ in DCM $(20 \mathrm{~mL})$ at room temperature under nitrogen. After 15 min water $(20 \mathrm{~mL})$ was added and the organic phase was separated then the aqueous layer extracted with DCM $(2 \times 20$ $\mathrm{mL}$ ). The combined organic extracts were washed with brine, dried over anhydrous $\mathrm{MgSO}_{4}$ and concentrated in vacuo to give the crude bis-protected product as a yellow gum.

Potassium carbonate $(10 \%$ in water $10 \mathrm{~mL})$ was added to a solution of the TBDMS ester in $\mathrm{THF}: \mathrm{MeOH}(1: 3,40 \mathrm{~mL})$ and stirred at room temperature for $1 \mathrm{~h} 45 \mathrm{~min}$. The methanol was removed in vacuo, the residue treated with $1 M$ hydrochloric acid until pH 5 and then extracted with ethyl acetate $(3 \times 20 \mathrm{~mL})$. The combined organic extracts were washed with brine $(10 \mathrm{~mL})$, dried over $\mathrm{MgSO}_{4}$ and concentrated in vacuo to give a yellow oil. Purification by flash column chromatography on silica gel using ethyl acetate : hexane $(1: 9)$ with $1 \%$ acetic acid as eluant gave the title compound $4.7(0.78$ g, $81 \%$ ) as a white solid. A sample was crystallised from hexane to give white crystals.

m.p: $172-173^{\circ} \mathrm{C}$

IR (thin film) $\mathbf{c m}^{-1}$ : $3500 \mathrm{br}(\mathrm{C}-\mathrm{OH}), 2929 \mathrm{~s}(\mathrm{C}-\mathrm{H}), 1692 \mathrm{~s}(\mathrm{C}=\mathrm{O}), 1611,1502 \mathrm{~s}, 1472$, $1255 \mathrm{~s}, 1079$. 
${ }^{1}$ H NMR (300 MHz, $\mathbf{C D C l}_{3}$ ) $\mathbf{~}$ : $-0.11\left(\mathrm{~s}, 3 \mathrm{H},-\mathrm{SiCH}_{3}\right),-0.07$ (s, 3H, $\left.-\mathrm{SiCH}_{3}\right), 0.80$ (s, $\left.9 \mathrm{H},-\mathrm{Si}{ }^{\mathrm{t}} \mathrm{Bu}\right), 0.75-0.84\left(\mathrm{~m}, 3 \mathrm{H}, \mathrm{H}-3^{\prime}\right), 0.98\left(\mathrm{~d}, J=6.6 \mathrm{~Hz}, 3 \mathrm{H}, 2-\mathrm{CH}_{3}\right), 1.87-2.16(\mathrm{~m}$, $8 \mathrm{H}), 1.33\left(\mathrm{~s}, 3 \mathrm{H}, 1-\mathrm{CH}_{3}\right), 2.68-2.84(\mathrm{~m}, 3 \mathrm{H}), 3.53\left(\mathrm{dd}, J_{4 \mathrm{a}, 10 \mathrm{a}}=12.0 \mathrm{~Hz}, J_{4 \mathrm{a}, 4}=4.5 \mathrm{~Hz}\right.$, 1H, H-4a), 3.77 (s, 3H, 7-OCH $), 3.87$ (m, 1H, H-1'), 6.54 (d, J J,6 $=2.7$ Hz, 1H, H-8), $6.70\left(\mathrm{dd}, J_{6,5}=8.7 \mathrm{~Hz}, J_{6,8}=2.7 \mathrm{~Hz}, 1 \mathrm{H}, \mathrm{H}-6\right), 7.23$ (d, $\left.J_{5,6}=8.7 \mathrm{~Hz}, 1 \mathrm{H}, \mathrm{H}-5\right)$.

${ }^{13} \mathrm{C}$ NMR (75 MHz, $\left.\mathbf{C D C l}_{3}\right)$ ): $-4.5\left(\mathrm{SiCH}_{3}\right),-3.9\left(\mathrm{SiCH}_{3}\right), 9.8\left(\mathrm{CH}_{3}, \mathrm{C}-3\right), 17.7$ (2$\left.\mathrm{CH}_{3}\right), 18.2(\mathrm{SiC}), 23.5\left(1-\mathrm{CH}_{3}\right), 25.2\left(\mathrm{CH}_{2}\right), 26.1\left(\mathrm{Si}{ }^{\mathrm{t}} \mathrm{Bu}\right), 28.7\left(\mathrm{CH}_{2}\right), 31.4\left(\mathrm{CH}_{2}\right), 31.9$ $\left(\mathrm{CH}_{2}\right), 36.8(\mathrm{CH}), 39.2(\mathrm{CH}), 39.4(\mathrm{CH}), 43.6(\mathrm{CH}), 49.6(\mathrm{C}, \mathrm{C}-1), 55.2\left(7-\mathrm{OCH}_{3}\right), 72.7$ (CH, C-1'), 111.8 (CH, C-6), 113.2 (CH, C-8), 128.4 (CH, C-5), 131.1 (C, C-4b), 137.4 (C, C-8a), 156.7 (C, C-7), $181.4\left(1-\mathrm{CO}_{2} \mathrm{H}\right)$.

LRMS (m/z): $460\left(\mathrm{M}^{+}, 15 \%\right), 437$ (17), 405 (50), 403 (98), 283 (23), 241 (23), 173 (100), $117(70)$.

HRMS: $\mathrm{C}_{27} \mathrm{H}_{44} \mathrm{O}_{4} \mathrm{Si}\left(\mathrm{M}^{+}\right)$requires 460.3009 , found 460.3007 .

Microanalysis: Calcd. for $\mathrm{C}_{27} \mathrm{H}_{44} \mathrm{O}_{4} \mathrm{Si}: \mathrm{C}, 70.39 \%, \mathrm{H}, 9.63 \%$. Found: $\mathrm{C}, 70.06 \%, \mathrm{H}$, $9.49 \%$.

(1RS, 2RS, 4RS, 4aSR, 4bSR, 10aSR, 1'SR) 4-(1'-t.-Butyldimethylsilyloxypropyl)-2methyl-7-oxo-3,4,4a,4b,5,6,7,9,10,10a-decahydrophenanthrene-1(2H)-carboxylic acid (4.9)

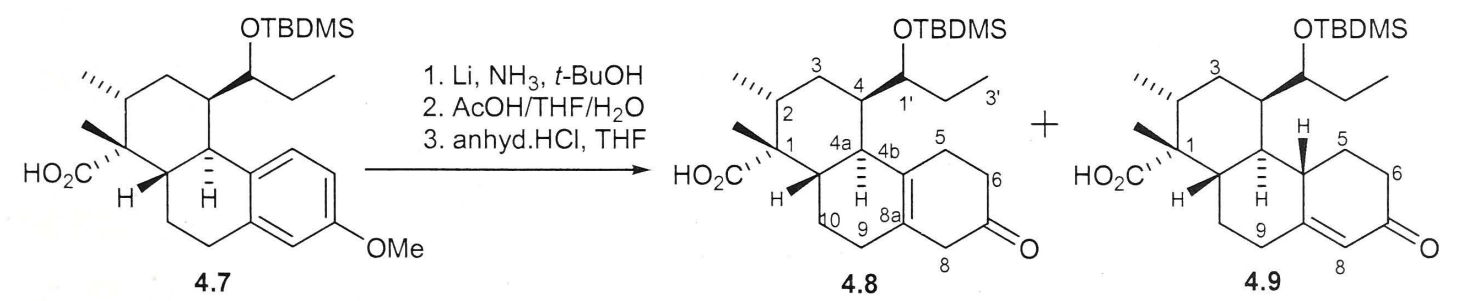

Dry ammonia $(200 \mathrm{~mL})$ was distilled into a 3-necked flask fitted with a dry ice condenser under nitrogen. Small pieces of freshly cleaned lithium wire (1.65 g, 245.3 mmol) were added at $-78{ }^{\circ} \mathrm{C}$ and the resulting blue solution was stirred for $15 \mathrm{~min}$. Silyl ether 4.7 (2.26 g, $4.91 \mathrm{mmol})$ in THF (50 mL) was added over $10 \mathrm{~min}$, stirred for 15 min, then $t$-butanol $(50 \mathrm{~mL})$ was added. The blue reaction mixture was warmed to -40 ${ }^{\circ} \mathrm{C}$ and stirred for $3 \mathrm{~h}$. The reaction was then quenched with methanol and the ammonia 
allowed to boil off under a stream of nitrogen before a saturated aqueous solution of ammonium chloride $(80 \mathrm{~mL})$ was added. After 15 min water $(50 \mathrm{~mL})$ was added and the aqueous phase adjusted to $\mathrm{pH} 5$ with $1 M$ hydrochloric acid then extracted with ethyl acetate $(3 \times 100 \mathrm{~mL})$. The combined organic extracts were washed with water $(50 \mathrm{~mL})$, brine $(50 \mathrm{~mL})$ and dried over anhydrous $\mathrm{MgSO}_{4}$. Concentration of the organic phase in vacuo gave a colourless oil, which was taken up in a solution of acetic acid : THF : water $(4: 2: 1,50 \mathrm{~mL})$ and stirred for $2 \mathrm{~h}$ under nitrogen. The solvent was removed in vacuo and the aqueous residue was extracted with ethyl acetate $(3 \times 50 \mathrm{~mL})$ then dried over anhydrous $\mathrm{MgSO}_{4}$. Concentration of the organic phase in vacuo gave the crude $\beta \gamma$-enone 4.8 as a colourless oil, which was used directly in the next reaction without purification. Concentrated sulfuric acid was added drop wise to sodium chloride. The resulting hydrogen chloride gas was passed through concentrated sulfuric acid and then bubbled through THF (35 mL) for $1 \mathrm{~min}$. The crude $\beta \gamma$-enone 4.8 in THF (35 mL) was then added to the acidic THF then the reaction was monitored by TLC until half of the starting material had been consumed, and a new UV active spot was observed. Concentration of the organic phase in vacuo gave a yellow gum, which was purified by flash column chromatography on silica gel using ethyl acetate : hexane $(1: 9-1: 4)$ with $1 \%$ acetic acid as eluant to give the $\beta \gamma$-enone 4.8 (1.31 g, 39\%) as a colourless oil, and the $\alpha \beta$-enone $4.9(1.20 \mathrm{~g}, 35 \%)$ as a white foam (74\% combined yield).

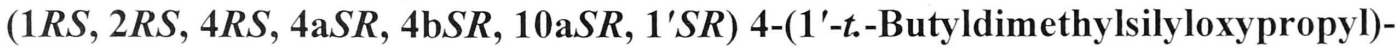

1,2-dimethyl-7-oxo-3,4,4a,4b,5,6,7,9,10,10a-decahydrophenanthrene-1(2H)carboxylic acid (4.9)

IR (thin film) $\mathbf{c m}^{-1}$ : 2932s (C-H), 1694s $(\mathrm{C}=\mathrm{O}), 1671(\mathrm{C}=\mathrm{O}), 1472,1462,1256 \mathrm{~s}, 1208$.

${ }^{1} \mathrm{H}$ NMR (300 MHz, $\left.\mathbf{C D C l}_{\mathbf{3}}\right)$ ): $0.07\left(\mathrm{~s}, 3 \mathrm{H},-\mathrm{SiCH}_{3}\right), 0.08\left(\mathrm{~s}, 3 \mathrm{H},-\mathrm{SiCH}_{3}\right), 0.89$ (s, $\left.9 \mathrm{H},-\mathrm{Si}^{\mathrm{t}} \mathrm{Bu}\right), 0.91\left(\mathrm{t}, J_{3^{\prime}, 2^{\prime}}=7.5 \mathrm{~Hz}, 3 \mathrm{H}, \mathrm{H}-3^{\prime}\right), 0.86-0.94\left(\mathrm{~m}, 3 \mathrm{H}, 2-\mathrm{CH}_{3}\right), 1.26(\mathrm{~s}, 3 \mathrm{H}, 1-$ $\left.\mathrm{CH}_{3}\right), 1.05-2.31$ (m, 14H), 2.34-2.45 (m, 2H, H-6), 2.91 (m, 1H, H-4b), 4.16 (dt, J=8.4 $\left.\mathrm{Hz}, J=3.9 \mathrm{~Hz}, 1 \mathrm{H}, \mathrm{H}-1^{\prime}\right), 5.79$ (s, 1H, H-8).

${ }^{13} \mathrm{C}$ NMR (75MHz, $\left.\mathbf{C D C l}_{3}\right)$ 8: $-3.8\left(\mathrm{SiCH}_{3}\right),-3.3\left(\mathrm{SiCH}_{3}\right), 7.4\left(\mathrm{CH}_{3}, \mathrm{C} 3{ }^{\prime}\right), 17.6$ (2$\left.\mathrm{CH}_{3}\right), 18.2(\mathrm{SiC}), 23.9\left(1-\mathrm{CH}_{3}\right), 26.1\left(\mathrm{Si}{ }^{\mathrm{t}} \mathrm{Bu}\right), 27.0\left(\mathrm{CH}_{2}\right), 28.0\left(\mathrm{CH}_{2}\right), 28.4\left(\mathrm{CH}_{2}\right), 33.1$ $\left(\mathrm{CH}_{2}\right), 35.2(\mathrm{CH}), 35.3(\mathrm{CH}), 35.7\left(\mathrm{CH}_{2}\right), 36.2\left(\mathrm{CH}_{2}\right), 39.0(\mathrm{CH}), 43.5(\mathrm{CH}), 46.3(\mathrm{CH})$, 
50.1 (C, C-1), $72.3\left(\mathrm{CH}, \mathrm{C}-1^{\prime}\right), 123.7(\mathrm{CH}, \mathrm{C}-8), 167.8$ (C, C-8a), $180.2\left(1-\mathrm{CO}_{2} \mathrm{H}\right)$, 200.9 (7-CO).

LRMS (m/z): $448\left(\mathrm{M}^{+}, 1 \%\right), 319$ (80), 345 (15), 316 (100), 273 (21), 224 (48), 173 (91).

HRMS: $\mathrm{C}_{26} \mathrm{H}_{44} \mathrm{O}_{4} \mathrm{Si}\left(\mathrm{M}^{+}\right)$requires 448.3009, found 448.3010.

(1RS, 2RS, 4RS, 4aSR, 10aSR, 1'SR) 4-(1'-t.-Butyldimethylsilyloxypropyl)-1,2dimethyl-7-oxo-3,4,4a,5,6,7,8,9,10,10a-decahydrophenanthrene-1(2H)-carboxylic acid (4.8)

IR (thin film) $\mathbf{c m}^{-1}:$ 2931s $(\mathrm{C}-\mathrm{H}), 1721 \mathrm{~s}(\mathrm{C}=\mathrm{O}), 1694(\mathrm{C}=\mathrm{O}), 1472,1463,1254 \mathrm{~s}$, 1075 s.

${ }^{1} \mathrm{H}$ NMR (300 MHz, $\left.\mathbf{C D C l}_{3}\right)$ \&: $-0.10\left(\mathrm{~s}, 3 \mathrm{H},-\mathrm{SiCH}_{3}\right),-0.01\left(\mathrm{~s}, 3 \mathrm{H},-\mathrm{SiCH}_{3}\right), 0.82$ (s, $\left.9 \mathrm{H},-\mathrm{Si}{ }^{\mathrm{t}} \mathrm{Bu}\right), 0.87\left(\mathrm{t}, J_{3^{\prime}, 2^{\prime}}=7.5 \mathrm{~Hz}, 3 \mathrm{H}, \mathrm{H}-3^{\prime}\right), 0.91\left(\mathrm{~d}, J=6.6 \mathrm{~Hz}, 3 \mathrm{H}, 2-\mathrm{CH}_{3}\right), 1.28$ (s, $\left.3 \mathrm{H}, 1-\mathrm{CH}_{3}\right), 1.44-2.20(\mathrm{~m}, 11 \mathrm{H}), 2.26-2.38(\mathrm{~m}, 2 \mathrm{H}), 2.41-2.46(\mathrm{~m}, 2 \mathrm{H}), 2.67(\mathrm{~s}(\mathrm{br}), 2 \mathrm{H}$, H-8), 2.70-2.90 (m, 2H), 4.05 (dt, $\left.J=9.9 \mathrm{~Hz}, J=3.3 \mathrm{~Hz}, 1 \mathrm{H}, \mathrm{H}-1^{\prime}\right)$.

${ }^{13} \mathrm{C}$ NMR (75 MHz, $\left.\mathbf{C D C l}_{3}\right)$ 8: -4.6 $\left(\mathrm{SiCH}_{3}\right),-3.4\left(\mathrm{SiCH}_{3}\right), 6.6\left(\mathrm{CH}_{3}, \mathrm{C}-3{ }^{\prime}\right), 17.5$ (2$\left.\mathrm{CH}_{3}\right), 18.2(\mathrm{SiC}), 23.6\left(1-\mathrm{CH}_{3}\right), 24.6\left(\mathrm{CH}_{2}\right), 26.2\left(\mathrm{Si}{ }^{\mathrm{t}} \mathrm{Bu}\right), 27.5\left(\mathrm{CH}_{2}\right), 28.2\left(\mathrm{CH}_{2}\right), 30.5$ $\left(\mathrm{CH}_{2}\right), 34.3\left(\mathrm{CH}_{2}\right), 35.3(\mathrm{CH}), 36.0(\mathrm{CH}), 39.1\left(\mathrm{CH}_{2}\right), 41.7(\mathrm{CH}), 42.2(\mathrm{CH}), 44.7\left(\mathrm{CH}_{2}\right.$, C-8), $49.8(\mathrm{C}), 70.7\left(\mathrm{CH}, \mathrm{C}-1^{\prime}\right), 122.8$ (C, C-8a), 133.0 (C, C-4b), $181.2\left(1-\mathrm{CO}_{2} \mathrm{H}\right)$, 212.2 (7-CO).

LRMS (m/z): $391\left(\left(\mathrm{M}-{ }^{\mathrm{t}} \mathrm{Bu}\right)^{+}, 50 \%\right), 316(70), 277$ (22), 224 (21), 173 (100), 147 (43), $73(79)$.

HRMS: $\mathrm{C}_{22} \mathrm{H}_{35} \mathrm{O}_{4} \mathrm{Si}\left(\left(\mathrm{M}-{ }^{\mathrm{t}} \mathrm{Bu}\right)^{+}\right)$requires 391.2305, found 391.2304. 
(1RS, 2RS, 4RS, 4aSR, 4bRS, 8aRS, 10aSR, 1'SR) 4-(1'-t.-

Butyldimethylsilyloxypropyl)-1,2-dimethyl-7-oxo-3,4,4a,4b,5,6,7,8,8a,9,10,10a-

dodecahydrophenanthrene-1(2H)-carboxylic acid (8.5)

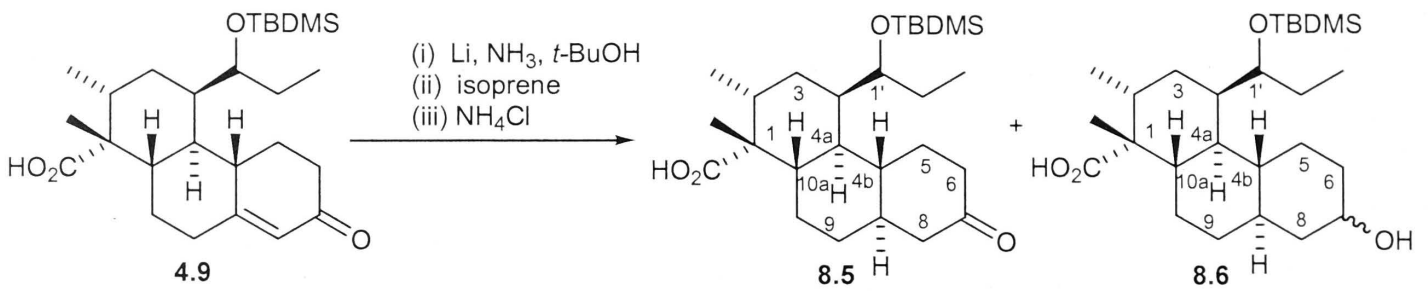

Dry ammonia $(70 \mathrm{~mL})$ was distilled into a 3-necked flask fitted with a dry ice condenser under nitrogen. Small pieces of freshly cleaned lithium wire $(0.056 \mathrm{~g}, 8.22 \mathrm{mmol})$ were added at $-78{ }^{\circ} \mathrm{C}$ and the resulting blue solution was stirred for $10 \mathrm{~min}$. A solution of enone $4.9(1.23 \mathrm{~g}, 2.74 \mathrm{mmol})$ in $t$-butanol $(0.26 \mathrm{~mL}, 2.74 \mathrm{mmol})$ and THF $(40 \mathrm{~mL})$ was added drop wise, and the resulting reaction mixture was stirred for $30 \mathrm{~min}$ at $-33{ }^{\circ} \mathrm{C}$. The reaction was quenched with isoprene until the blue colour dispersed, and the ammonia was allowed to boil off under a stream of nitrogen. A saturated solution of aqueous ammonium chloride $(40 \mathrm{~mL})$ was then added and stirring continued for a further $15 \mathrm{~min}$. Water $(10 \mathrm{~mL})$ was added and the aqueous phase adjusted to $\mathrm{pH} 5$ with $1 M$ hydrochloric acid then extracted with ethyl acetate $(3 \times 40 \mathrm{~mL})$. The combined organic extracts were washed with water $(20 \mathrm{~mL})$, brine $(20 \mathrm{~mL})$ and dried over anhydrous $\mathrm{MgSO}_{4}$. Concentration of the organic phase in vacuo gave a yellow oil (1.24 g, a mixture of the title compound 8.5 and alcohol 8.6) which was used directly in the next step without further purification. A sample of $\mathbf{8 . 5}$ was purified by flash column chromatography for characterization purposes, on silica gel using ether : hexane (1:9) with $1 \%$ acetic acid as eluant to give the title compound as a white solid.

m.p: $181-184^{\circ} \mathrm{C}$

IR (thin film) $\mathbf{c m}^{-1}$ : 3300 br $(\mathrm{C}-\mathrm{OH}), 2931 \mathrm{~s}(\mathrm{C}-\mathrm{H}), 1716 \mathrm{~s}(\mathrm{C}=\mathrm{O}), 1695(\mathrm{C}=\mathrm{O}), 1472$, $1462,1254 \mathrm{~s}, 1079$.

${ }^{1} \mathrm{H}$ NMR (300 MHz, $\left.\mathbf{C D C l}_{3}\right) \delta: 0.08\left(\mathrm{~s}, 6 \mathrm{H},-\mathrm{SiCH}_{3}\right), 0.86\left(\mathrm{~d}, J=6.6 \mathrm{~Hz}, 3 \mathrm{H}, 2-\mathrm{CH}_{3}\right)$, $0.91\left(\mathrm{~s}, 9 \mathrm{H},-\mathrm{Si}{ }^{\mathrm{t}} \mathrm{Bu}\right), 0.92\left(\mathrm{t}, J_{3^{\prime}, 2^{\prime}}=7.5 \mathrm{~Hz}, 3 \mathrm{H}, \mathrm{H}-3^{\prime}\right), 1.23\left(\mathrm{~s}, 3 \mathrm{H}, 1-\mathrm{CH}_{3}\right), 0.98-2.45(\mathrm{~m}$, 20H), 4.02 (m, 1H, H-1'). 
${ }^{13} \mathbf{C}$ NMR (75 MHz, $\left.\mathbf{C D C l}_{3}\right)$ 8: -4.2 $\left(\mathrm{SiCH}_{3}\right),-3.0\left(\mathrm{SiCH}_{3}\right), 8.9\left(\mathrm{CH}_{3}, \mathrm{C}-3^{\prime}\right), 17.8$ (2$\left.\mathrm{CH}_{3}\right), 18.4(\mathrm{SiC}), 23.7\left(1-\mathrm{CH}_{3}\right), 26.2\left(\mathrm{Si}^{\mathrm{t}} \mathrm{Bu}\right), 28.0\left(\mathrm{CH}_{2}\right), 28.7\left(\mathrm{CH}_{2}\right), 30.9\left(\mathrm{CH}_{2}\right), 32.1$ $\left(\mathrm{CH}_{2}\right), 33.7\left(\mathrm{CH}_{2}\right), 35.6(\mathrm{CH}), 36.1(\mathrm{CH}), 40.9(\mathrm{CH}), 42.0(\mathrm{CH}), 43.4(\mathrm{CH}), 43.7(\mathrm{CH})$, $44.1\left(\mathrm{CH}_{2}, \mathrm{C}-5\right), 48.4\left(\mathrm{CH}_{2}, \mathrm{C}-8\right), 50.1$ (C, C-1), $72.9\left(\mathrm{CH}, \mathrm{C}-1^{\prime}\right), 181.2\left(1-\mathrm{CO}_{2} \mathrm{H}\right)$, $212.3(7-\mathrm{CO})$.

LRMS (m/z): $393\left(\left(\mathrm{M}^{\mathrm{t}}{ }^{\mathrm{Bu}}\right)^{+}, 67 \%\right), 255$ (12), 215 (13), 173 (100), 145 (11), 115 (19).

HRMS: $\mathrm{C}_{22} \mathrm{H}_{37} \mathrm{O}_{4} \mathrm{Si}\left(\left(\mathrm{M}-{ }^{\mathrm{t}} \mathrm{Bu}\right)^{+}\right)$requires 393.2461, found 393.2466.

(1RS, 2RS, 4RS, 4aSR, 4bRS, 8aRS, 10aSR, 1'SR) Methyl 4-(1'-t.-

Butyldimethylsilyloxypropyl)-7-1,2-dimethyl-7-oxo-3,4,4a,4b,5,6,7,8,8a,9,10,10adodecahydrophenanthrene-1(2H)-carboxylate (4.10)

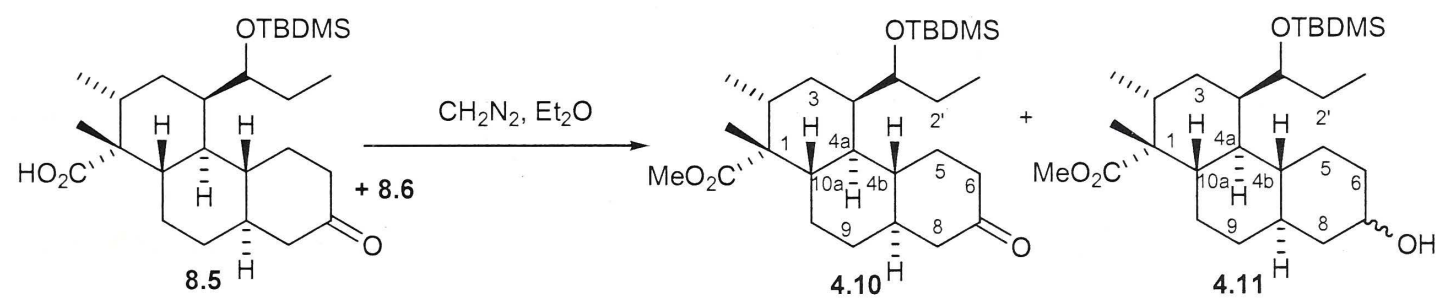

A freshly prepared solution of diazomethane in ether $(120 \mathrm{~mL})$ was added to the crude carboxylic acids $\mathbf{8 . 5}$ and $\mathbf{8 . 6}(2 \mathrm{~g})$ in ether $(50 \mathrm{~mL})$ at $0{ }^{\circ} \mathrm{C}$. The yellow reaction mixture was stirred for $30 \mathrm{~min}$, and the excess diazomethane and ether blown off with a stream of nitrogen. Purification by flash column chromatography using ethyl acetate : petroleum spirit $(1: 9)$ as eluant gave the title compound 4.10 (1.2 g, 55\% over two steps) as a colourless oil, and alcohol 4.11 ( $0.45 \mathrm{~g}, 21 \%$ over the two steps) which was subsequently converted to $\mathbf{4 . 1 0}$ by oxidation with DMP (a total of $76 \%$ yield over two steps).

(1RS, 2RS, 4RS, 4aSR, 4bRS, 8aRS, 10aSR, 1'SR) Methyl 4-(1'-t.-

Butyldimethylsilyloxypropyl)-1,2-dimethyl-7-oxo-3,4,4a,4b,5,6,7,8,8a,9,10,10adodecahydrophenanthrene-1(2H)-carboxylate (4.10)

IR (thin film) $\mathbf{c m}^{-1}:$ 2952s (C-H), 1721s $(\mathrm{C}=\mathrm{O}), 1472,1462,1255,1145$.

${ }^{1} \mathbf{H}$ NMR (600 MHz, $\left.\mathbf{C D C l}_{3}\right)$ ): $0.08\left(\mathrm{~s}, 3 \mathrm{H},-\mathrm{SiCH}_{3}\right), 0.09\left(\mathrm{~s}, 3 \mathrm{H},-\mathrm{SiCH}_{3}\right), 0.78$ (d, J $\left.=7.2 \mathrm{~Hz}, 3 \mathrm{H}, 2-\mathrm{CH}_{3}\right), 0.92\left(\mathrm{~s}, 9 \mathrm{H},-\mathrm{Si}^{\mathrm{t}} \mathrm{Bu}\right), 0.93\left(\mathrm{t}, J_{3^{\prime}, 2^{\prime}}=7.2 \mathrm{~Hz}, 3 \mathrm{H}, \mathrm{H}-3^{\prime}\right), 0.79(\mathrm{~m}$, 
1H, H-10), 1.09 (m, 1H, H-9), 1.24 (s, 3H, 1-CH3), 1.26-1.35 (m, 2H, H-8a, H-5), 1.481.75 (m, 8H, H-2', H-4b, H-3, H-2, H-10a, H'-9), 1.85 (m, 1H, H-4a), 1.95 (m, 1H, H'10), 2.06 (m, 1H, H-8), 2.18 (m, 1H, H-4), 2.27 (m, 1H, H'-8), 2.30-2.34 (m, 2H, H-6), $2.44\left(\mathrm{~m}, 1 \mathrm{H}, \mathrm{H}^{\prime}-5\right), 3.62\left(\mathrm{~s}, 3 \mathrm{H}, 1-\mathrm{CO}_{2} \mathrm{CH}_{3}\right), 4.03$ (dt, J=7.2 Hz, J=4.2 Hz, 1H, H-1').

${ }^{13} \mathrm{C}$ NMR (75 MHz, $\left.\mathbf{C D C l}_{3}\right)$ 8: -4.2 $\left(\mathrm{SiCH}_{3}\right),-3.0\left(\mathrm{SiCH}_{3}\right), 8.7\left(\mathrm{CH}_{3}, \mathrm{C}-3^{\prime}\right), 17.8(2-$ $\left.\mathrm{CH}_{3}\right), 18.2(\mathrm{SiC}), 23.9\left(2-\mathrm{CH}_{3}\right), 26.2\left(\mathrm{Si}{ }^{\mathrm{t}} \mathrm{Bu}\right), 28.1\left(\mathrm{CH}_{2}, \mathrm{C}-10\right), 28.6\left(\mathrm{CH}_{2}, \mathrm{C}-2^{\prime}\right), 30.9$ $\left(\mathrm{CH}_{2}, \mathrm{C}-5\right), 32.4\left(\mathrm{CH}_{2}, \mathrm{C}-3\right), 33.7\left(\mathrm{CH}_{2}, \mathrm{C}-9\right), 35.7(\mathrm{CH}), 36.1(\mathrm{CH}, \mathrm{C}-4), 40.9\left(\mathrm{CH}_{2}, \mathrm{C}-\right.$ 6), $42.0(\mathrm{CH}, \mathrm{C}-4 \mathrm{~b}), 43.5(\mathrm{CH}, \mathrm{C}-8 \mathrm{a}), 44.0(\mathrm{CH}, \mathrm{C}-4 \mathrm{a}), 44.3(\mathrm{CH}), 48.5\left(\mathrm{CH}_{2}, \mathrm{C}-8\right)$, $50.3(\mathrm{C}, \mathrm{C}-1), 50.6\left(1-\mathrm{CO}_{2} \mathrm{CH}_{3}\right), 72.9\left(\mathrm{CH}, \mathrm{C}-1^{\prime}\right), 175.0\left(1-\mathrm{CO}_{2} \mathrm{CH}_{3}\right), 211.8$ (7-CO).

LRMS (m/z): $407\left(\left(\mathrm{M}-{ }^{\mathrm{t}} \mathrm{Bu}\right)^{+}, 91 \%\right), 255$ (28), 215 (18), 173 (100), 145 (13), 115 (27).

HRMS: $\mathrm{C}_{23} \mathrm{H}_{39} \mathrm{O}_{4} \mathrm{Si}\left(\left(\mathrm{M}-{ }^{\mathrm{t}} \mathrm{Bu}\right)^{+}\right)$requires 407.2618, found 407.2621.

$\left(1 R S, 2 R S, 4 R S, 4 \mathrm{a} S R, 4 \mathrm{~b} R, 8 \mathrm{a} R S, 10 \mathrm{a} S R, 1^{\prime} S R\right)$ Methyl 4-(1'-t.-

Butyldimethylsilyloxypropyl)-1,2-dimethyl-7-hydroxy-3,4,4a,4b,5,6,7,8,8a,9,10,10adodecahydrophenanthrene-1(2H)-carboxylate (4.11)

IR (thin film) $\mathbf{c m}^{-1}$ : 3411 br $(\mathrm{C}-\mathrm{OH}), 2929 \mathrm{~s}(\mathrm{C}-\mathrm{H}), 1720 \mathrm{~s}(\mathrm{C}=\mathrm{O}), 1461,1387,1254$, 1079.

${ }^{1} \mathrm{H}$ NMR (300 MHz, $\left.\mathbf{C D C l}_{3}\right) \delta: 0.06\left(\mathrm{~s}, 6 \mathrm{H},-\mathrm{SiCH}_{3}\right), 0.77\left(\mathrm{~d}, J=6.3 \mathrm{~Hz}, 3 \mathrm{H}, 2-\mathrm{CH}_{3}\right)$, $0.90\left(\mathrm{~s}, 9 \mathrm{H},-\mathrm{Si}{ }^{\mathrm{t}} \mathrm{Bu}\right), 0.88-0.92\left(\mathrm{~m}, 3 \mathrm{H}, \mathrm{H}-3{ }^{\prime}\right), 0.86-2.20(\mathrm{~m}, 24 \mathrm{H}), 3.61(\mathrm{~s}, 3 \mathrm{H}, 1-$ $\left.\mathrm{CO}_{2} \mathrm{CH}_{3}\right), 3.90\left(\mathrm{~m}, 1 \mathrm{H}, \mathrm{H}-1^{\prime}\right)$.

${ }^{13} \mathrm{C}$ NMR (75 MHz, $\left.\mathbf{C D C l}_{3}\right)$ 8: -4.4 $\left(\mathrm{SiCH}_{3}\right),-3.2\left(\mathrm{SiCH}_{3}\right), 9.7\left(\mathrm{CH}_{3}, \mathrm{C}-3^{\prime}\right), 17.9$ (2$\left.\mathrm{CH}_{3}\right), 18.3(\mathrm{SiC}), 23.9\left(1-\mathrm{CH}_{3}\right), 26.1\left(\mathrm{Si}{ }^{\mathrm{t}} \mathrm{Bu}\right), 28.4\left(\mathrm{CH}_{2}\right), 28.8\left(\mathrm{CH}_{2}\right), 30.3\left(\mathrm{CH}_{2}\right), 31.6$, $33.4,35.4,36.0,36.6,41.1,42.6,43.1,43.6,44.7,50.3\left(1-\mathrm{CO}_{2} \mathrm{CH}_{3}\right), 50.5(\mathrm{C}, \mathrm{C}-1), 70.5$ $(\mathrm{CH}, \mathrm{C}-7), 73.1\left(\mathrm{CH}, \mathrm{C}-1^{\prime}\right), 175.4\left(1-\mathrm{CO}_{2} \mathrm{CH}_{3}\right)$.

LRMS (m/z): $466\left(\mathrm{M}^{+}, 2 \%\right), 465$ (5), 437 (96), 421 (28), 409 (78), 407 (83), 393 (44), $351(89), 330(100)$.

HRMS: $\mathrm{C}_{27} \mathrm{H}_{50} \mathrm{O}_{4} \mathrm{Si}\left(\mathrm{M}^{+}\right)$requires 466.3478 , found 466.3465 . 
(1RS, 2RS, 4RS, 4aSR, 4bSR, 8aRS, 10aSR, 1'SR) Methyl 4-(1'-t. -

Butyldimethylsilyloxypropyl)-1,2-dimethyl-7-oxo-3,4,4a,4b,7,8,8a,9,10,10adecahydrophenanthrene-1(2H)-carboxylate (4.12)

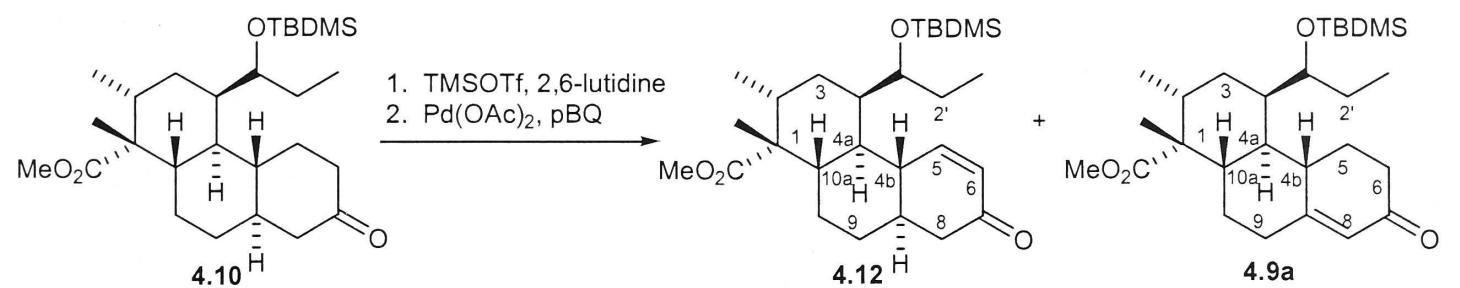

Trimethylsilyl trifluoromethanesulfonate $(1.52 \mathrm{~mL}, 8.39 \mathrm{mmol})$ was added drop wise to ketone $4.10(1.30 \mathrm{~g}, 2.80 \mathrm{mmol})$ and 2,6-lutidine $(1.30 \mathrm{~mL}, 11.19 \mathrm{mmol})$ in DCM (30 $\mathrm{mL})$ at $0{ }^{\circ} \mathrm{C}$ under nitrogen. Water $(15 \mathrm{~mL})$ was added and the organic phase was separated before further extraction of the aqueous layer with DCM $(2 \times 15 \mathrm{~mL})$. The combined organic extracts were then washed with brine and dried over anhydrous $\mathrm{MgSO}_{4}$. Concentration of the organic phase in vacuo gave a mixture of two silyl enol ethers (20:1,6,7-enol ether : 7,8-enol ether). The crude silyl enol ethers in acetonitrile $(30 \mathrm{~mL})$ were added to palladium acetate $(0.63 \mathrm{~g}, 2.80 \mathrm{mmol})$ and $p$-benzoquinone $(0.15$ $\mathrm{g}, 1.40 \mathrm{mmol})$ in acetonitrile $(30 \mathrm{~mL})$ at room temperature under nitrogen. The resulting reaction mixture was stirred for $30 \mathrm{~h}$, then filtered through a plug of Celite ${ }^{\circledR}$ and washed with ether $(60 \mathrm{~mL})$. Concentration in vacuo gave a black gum, which was purified by flash column chromatography on silica gel using ethyl acetate : petroleum spirit (1:9) as eluant to give the title $\alpha \beta$-enone 4.12 (1.03 g, 79\%) as a white solid, and $\alpha \beta$-enone $4.9 \mathrm{a}(0.051 \mathrm{~g}, 4 \%)$ as a white foam (83\% combined yield). A sample of the title $\alpha \beta$-enone $\mathbf{4 . 1 2}$ was crystallised from hexane to give white crystals.

(1RS, 2RS, 4RS, 4aSR, 4bSR, 8aRS, 10aSR, 1'SR) Methyl 4-(1'-t.-

Butyldimethylsilyloxypropyl)-1,2-dimethyl-7-oxo-3,4,4a,4b,7,8,8a,9,10,10adecahydrophenanthrene- $1(2 H)$-carboxylate $(4.12)$

m.p: $99-101^{\circ} \mathrm{C}$

IR (thin film) $\mathbf{c m}^{-1}$ : 2933s $(\mathrm{C}-\mathrm{H}), 1722 \mathrm{~s}(\mathrm{C}=\mathrm{O}), 1684 \mathrm{~s}(\mathrm{C}=\mathrm{O}), 1472 \mathrm{~s}, 1463,1253 \mathrm{~s}$, 1195.

${ }^{1} \mathbf{H}$ NMR (300 MHz, $\mathbf{C D C l}_{\mathbf{3}}$ ) $\mathbf{8 :} 0.05$ (s, 3H, - $\left.\mathrm{SiCH}_{3}\right), 0.08$ (s, 3H, - $\left.\mathrm{SiCH}_{3}\right), 0.79$ (d, J $\left.=6.6 \mathrm{~Hz}, 3 \mathrm{H}, 2-\mathrm{CH}_{3}\right), 0.87\left(\mathrm{~s}, 9 \mathrm{H},-\mathrm{Si}^{\mathrm{t}} \mathrm{Bu}\right), 0.93\left(\mathrm{t}, J_{3^{\prime}, 2^{\prime}}=7.2 \mathrm{~Hz}, 3 \mathrm{H}, \mathrm{H}-3^{\prime}\right), 0.87(\mathrm{~m}$, 
1H, H-10), 1.25 (s, 3H, 1-CH3), 1.18 (m, 1H, H-9), 1.46-1.69 (m, 8H), $1.80(\mathrm{~m}, 1 \mathrm{H})$, 1.96-2.14 (m, 2H, H-8, H-10), 2.35-2.41 (m, 2H, H-8, H-4), 2.55 (m, 1H, H-4b), 3.62 (s, $\left.3 \mathrm{H}, 1-\mathrm{CO}_{2} \mathrm{CH}_{3}\right), 4.17\left(\mathrm{dt}, J=8.7 \mathrm{~Hz}, J=3.9 \mathrm{~Hz}, 1 \mathrm{H}, \mathrm{H}-1^{\prime}\right), 5.97$ (m, 1H, H-6), 7.27 (dd, $J=9.0 \mathrm{~Hz}, J=1.8 \mathrm{~Hz}, 1 \mathrm{H}, \mathrm{H}-5)$.

${ }^{13} \mathrm{C}$ NMR (75 MHz, $\left.\mathbf{C D C l}_{3}\right)$ 8: -3.7 $\left(\mathrm{SiCH}_{3}\right),-3.3\left(\mathrm{SiCH}_{3}\right), 6.9\left(\mathrm{CH}_{3}, \mathrm{C}-3^{\prime}\right), 17.7$ (2$\left.\mathrm{CH}_{3}\right), 18.3(\mathrm{SiC}), 23.9\left(1-\mathrm{CH}_{3}\right), 26.2\left(\mathrm{Si}{ }^{\mathrm{t}} \mathrm{Bu}\right), 27.4\left(\mathrm{CH}_{2}\right), 27.7\left(\mathrm{CH}_{2}\right), 32.4\left(\mathrm{CH}_{2}\right), 33.1$ $\left(\mathrm{CH}_{2}\right), 35.1(\mathrm{CH}), 35.4(\mathrm{CH}), 41.6(\mathrm{CH}), 42.3(\mathrm{CH}), 43.7(\mathrm{CH}), 44.7(\mathrm{CH}), 45.3\left(\mathrm{CH}_{2}\right.$, C-8), $50.5(\mathrm{C}, \mathrm{C}-1), 50.7\left(1-\mathrm{CO}_{2} \mathrm{CH}_{3}\right), 71.6\left(\mathrm{CH}, \mathrm{C}-1^{\prime}\right), 128.7(\mathrm{CH}, \mathrm{C}-6), 154.1(\mathrm{CH}, \mathrm{C}-$ 5), $175.0\left(1-\mathrm{CO}_{2} \mathrm{CH}_{3}\right), 200.2(7-\mathrm{CO})$.

LRMS (m/z): $405\left(\left(\mathrm{M}-{ }^{\mathrm{t}} \mathrm{Bu}\right)^{+}, 93 \%\right), 330$ (22), 270 (25), 213 (14), 173 (100), 115 (33).

HRMS: $\mathrm{C}_{23} \mathrm{H}_{37} \mathrm{O}_{4} \mathrm{Si}\left(\left(\mathrm{M}-{ }^{\mathrm{t}} \mathrm{Bu}\right)^{+}\right)$requires 405.2461, found 405.2459.

(1RS, 2RS, 4RS, 4aSR, 4bSR, 10aSR, 1'SR) Methyl 4-(1'-t.-

Butyldimethylsilyloxypropyl)-1,2-dimethyl-7-oxo-3,4,4a,4b,5,6,7,9,10,10adecahydrophenanthrene-1(2H)-carboxylate (4.9a)

IR (thin film) $\mathbf{c m}^{-1}$ : 2952s $(\mathrm{C}-\mathrm{H}), 1722 \mathrm{~s}(\mathrm{C}=\mathrm{O}), 1676 \mathrm{~s}(\mathrm{C}=\mathrm{O}), 1472 \mathrm{~s}, 1388,1256 \mathrm{~s}$, 1206.

${ }^{1} \mathrm{H}$ NMR (300 MHz, $\left.\mathbf{C D C l}_{\mathbf{3}}\right) \boldsymbol{\delta}: 0.08\left(\mathrm{~s}, 3 \mathrm{H},-\mathrm{SiCH}_{3}\right), 0.09\left(\mathrm{~s}, 3 \mathrm{H},-\mathrm{SiCH}_{3}\right), 0.78$ (d, $J$ $\left.=6.3 \mathrm{~Hz}, 3 \mathrm{H}, 2-\mathrm{CH}_{3}\right), 0.90\left(\mathrm{~s}, 9 \mathrm{H},-\mathrm{Si}^{\mathrm{t}} \mathrm{Bu}\right), 0.92\left(\mathrm{t}, J_{3^{\prime}, 2^{\prime}}=7.2 \mathrm{~Hz}, 3 \mathrm{H}, \mathrm{H}-3^{\prime}\right), 1.28(\mathrm{~s}, 3 \mathrm{H}$, $\left.1-\mathrm{CH}_{3}\right), 0.86-2.48(\mathrm{~m}, 16 \mathrm{H}), 2.91(\mathrm{~m}, 1 \mathrm{H}, \mathrm{H}-4 \mathrm{~b}), 3.61$ (s, 3H, 1- $\left.\mathrm{CO}_{2} \mathrm{CH}_{3}\right), 4.18$ (dt, $J=$ $\left.9.0 \mathrm{~Hz}, J=3.6 \mathrm{~Hz}, 1 \mathrm{H}, \mathrm{H}-1^{\prime}\right), 5.77$ (s, 1H, H-8).

${ }^{13} \mathrm{C}$ NMR (75 MHz, $\left.\mathbf{C D C l}_{3}\right)$ 8: $-3.8\left(\mathrm{SiCH}_{3}\right),-3.3\left(\mathrm{SiCH}_{3}\right), 7.4\left(\mathrm{CH}_{3}, \mathrm{C}-3^{\prime}\right), 17.6(2-$ $\left.\mathrm{CH}_{3}\right), 18.2(\mathrm{SiC}), 24.1\left(1-\mathrm{CH}_{3}\right), 26.1\left(\mathrm{Si}{ }^{\mathrm{t}} \mathrm{Bu}\right), 27.1\left(\mathrm{CH}_{2}\right), 28.0\left(\mathrm{CH}_{2}\right), 28.5\left(\mathrm{CH}_{2}\right), 33.3$ $\left(\mathrm{CH}_{2}\right), 35.3\left(\mathrm{CH}_{2}\right), 35.3(\mathrm{CH}), 35.7(\mathrm{CH}), 36.4\left(\mathrm{CH}_{2}, \mathrm{C}-6\right), 39.0(\mathrm{CH}), 43.7(\mathrm{CH}), 46.6$ $(\mathrm{CH}), 50.3(\mathrm{C}, \mathrm{C}-1), 50.8\left(1-\mathrm{CO}_{2} \mathrm{CH}_{3}\right), 72.3\left(\mathrm{CH}, \mathrm{C}-1^{\prime}\right), 123.8(\mathrm{CH}, \mathrm{C}-8), 167.2(\mathrm{C}$, $\mathrm{C} 8 \mathrm{a}), 174.7\left(1-\mathrm{CO}_{2} \mathrm{CH}_{3}\right), 200.3(7-\mathrm{CO})$.

LRMS (m/z): $405\left(\left(\mathrm{M}^{\mathrm{t}}{ }^{\mathrm{t}} \mathrm{Bu}\right)^{+}, 95 \%\right), 330$ (94), 270 (92), 224 (94), 173 (100), 115 (89). 
HRMS: $\mathrm{C}_{23} \mathrm{H}_{37} \mathrm{O}_{4} \mathrm{Si}\left(\left(\mathrm{M}-{ }^{\mathrm{t}} \mathrm{Bu}\right)^{+}\right)$requires 405.2461, found 405.2460.

(1RS, 4aRS, 4bSR, 5RS, 7RS, 8RS, 8aSR, 10aSR, 1'SR) Dimethyl 5-(1'-t. -

Butyldimethylsilyloxypropyl)-7,8-dimethyl-2-oxo-4a,4b,5,6,7,9,10,10a-

octahydrophenanthrene-1,8(2H,8aH)-dicarboxylate (4.16)

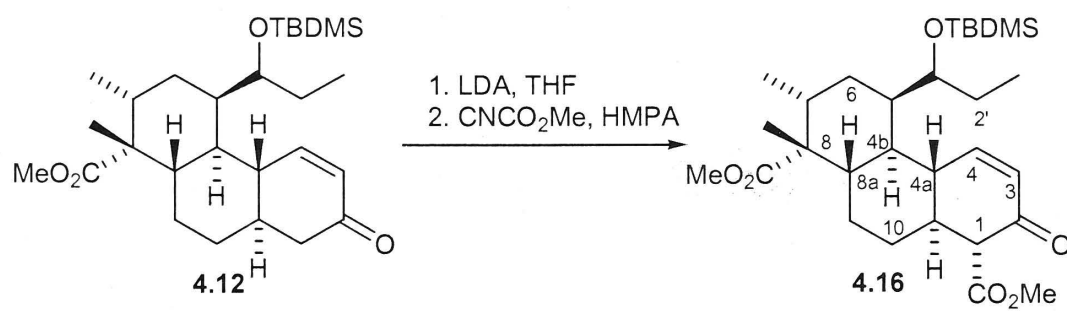

$n$-Butyllithium $(1.0 \mathrm{~mL}$ of a $1.6 \mathrm{M}$ solution in hexanes, $1.60 \mathrm{mmol})$ was added to diisopropylamine $(0.22 \mathrm{~mL}, 1.60 \mathrm{mmol})$ in THF $(10 \mathrm{~mL})$ at $-20{ }^{\circ} \mathrm{C}$ under nitrogen. The reaction mixture was stirred for $20 \mathrm{~min}$, warmed to $0{ }^{\circ} \mathrm{C}$ and stirred for a further $30 \mathrm{~min}$. The solution was cooled to $-78^{\circ} \mathrm{C}$, ketone 4.12 (0.37 g, $\left.0.80 \mathrm{mmol}\right)$ in THF (10 mL) was added, and then 'stirred for $1 \mathrm{~h}$ at $0{ }^{\circ} \mathrm{C}$. The reaction mixture was then cooled to $-78{ }^{\circ} \mathrm{C}$, HMPA $(0.14 \mathrm{~mL}, 0.80 \mathrm{mmol})$ was added followed by methyl cyanoformate $(0.12 \mathrm{~mL}, 1.60 \mathrm{mmol})$. After $20 \mathrm{~min}$ the mixture was poured into water and extracted with ether $(3 \times 15 \mathrm{~mL})$. The combined organic extracts were washed with water (10 $\mathrm{mL})$, brine $(10 \mathrm{~mL})$ and dried over anhydrous $\mathrm{MgSO}_{4}$. Concentration of the organic phase in vacuo gave a yellow oil, which was purified by flash column chromatography on silica gel using ethyl acetate : hexane (1:9) as eluant to give the title compound $\mathbf{4 . 1 6}$ $(0.35 \mathrm{~g}, 83 \%)$ as a colourless oil.

IR (thin film) $\mathbf{c m}^{-1}$ : 2952s $(\mathrm{C}-\mathrm{H}), 1746 \mathrm{~s}(\mathrm{C}=\mathrm{O}), 1722 \mathrm{~s}(\mathrm{C}=\mathrm{O}), 1681 \mathrm{~s}(\mathrm{C}=\mathrm{O}), 1472 \mathrm{~s}$, $1462 \mathrm{~s}, 1254 \mathrm{~s}, 1149$.

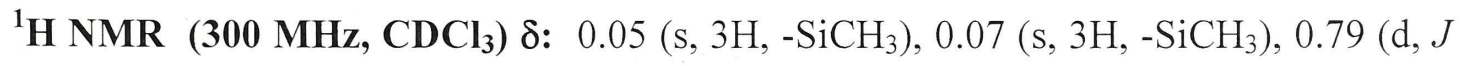
$\left.=6.6 \mathrm{~Hz}, 3 \mathrm{H}, 7-\mathrm{CH}_{3}\right), 0.86\left(\mathrm{~s}, 9 \mathrm{H},-\mathrm{Si}^{\mathrm{t}} \mathrm{Bu}\right), 0.93\left(\mathrm{t}, J_{3^{\prime}, 2^{\prime}}=7.2 \mathrm{~Hz}, 3 \mathrm{H}, \mathrm{H}-3^{\prime}\right), 1.26(\mathrm{~s}, 3 \mathrm{H}$, 8- $\left.\mathrm{CH}_{3}\right), 0.90$ (m, 1H, H-9), 1.17 (m, 1H, H-10), 1.47-1.72 (m, 6H), 1.82 (m, 1H), $1.95-$ 2.14 (m, 3H, H-4b, H-9, H-10), 2.38 (m, 1H, H-5), 2.69 (m, 1H, H-4a), 3.10 (d, J1,10a = $12.9 \mathrm{~Hz}, 1 \mathrm{H}, \mathrm{H}-1), 3.62\left(\mathrm{~s}, 3 \mathrm{H}, 8-\mathrm{CO}_{2} \mathrm{CH}_{3}\right), 3.76\left(\mathrm{~s}, 3 \mathrm{H}, 1-\mathrm{CO}_{2} \mathrm{CH}_{3}\right), 4.22$ (dt, $J=9.3$ $\left.\mathrm{Hz}, J=3.6 \mathrm{~Hz}, 1 \mathrm{H}, \mathrm{H}-1^{\prime}\right), 6.03(\mathrm{dd}, J=10.2 \mathrm{~Hz}, J=2.7 \mathrm{~Hz}, 1 \mathrm{H}, \mathrm{H}-3), 7.33$ (dd, $J=$ $10.2 \mathrm{~Hz}, J=1.8 \mathrm{~Hz}, 1 \mathrm{H}, \mathrm{H}-4)$. 
${ }^{13} \mathrm{C}$ NMR (75 MHz, $\left.\mathbf{C D C l}_{3}\right)$ 8: $-3.6\left(\mathrm{SiCH}_{3}\right),-3.2\left(\mathrm{SiCH}_{3}\right), 6.4\left(\mathrm{CH}_{3}, \mathrm{C}-3{ }^{\prime}\right), 17.7$ (7$\left.\mathrm{CH}_{3}\right), 18.3(\mathrm{SiC}), 23.9\left(8-\mathrm{CH}_{3}\right), 26.2\left(\mathrm{Si}{ }^{\mathrm{t}} \mathrm{Bu}\right), 27.1\left(\mathrm{CH}_{2}, \mathrm{C}-9\right), 27.4\left(\mathrm{CH}_{2}\right), 30.4\left(\mathrm{CH}_{2}\right)$, $33.3\left(\mathrm{CH}_{2}\right), 34.8(\mathrm{CH}), 35.2(\mathrm{CH}), 42.6(\mathrm{CH}), 42.7(\mathrm{CH}), 43.6(\mathrm{CH}), 44.4(\mathrm{CH}), 50.5$ $(\mathrm{C}, \mathrm{C}-8), 50.8\left(8-\mathrm{CO}_{2} \mathrm{CH}_{3}\right), 52.0\left(1-\mathrm{CO}_{2} \mathrm{CH}_{3}\right), 60.9(\mathrm{CH}, \mathrm{C}-1), 71.4\left(\mathrm{CH}, \mathrm{C}-1^{\prime}\right), 127.5$ $(\mathrm{CH}, \mathrm{C}-3), 154.3(\mathrm{CH}, \mathrm{C}-4), 170.5\left(1-\mathrm{CO}_{2} \mathrm{CH}_{3}\right), 174.7\left(8-\mathrm{CO}_{2} \mathrm{CH}_{3}\right), 194.6$ (2-CO).

LRMS (m/z): $463\left(\left(\mathrm{M}^{\mathrm{t}}{ }^{\mathrm{Bu}}\right)^{+}, 93 \%\right), 405$ (49), 388 (50), 329 (67), 269 (47), 213 (40), $173(100)$.

HRMS: $\mathrm{C}_{25} \mathrm{H}_{39} \mathrm{O}_{6} \mathrm{Si}\left(\left(\mathrm{M}-{ }^{\mathrm{t}} \mathrm{Bu}\right)^{+}\right)$requires 463.2516, found 463.2514 .

(1RS, 4aRS, 4bSR, 5RS, 7RS, 8RS, 8aSR, 10aSR, 1'SR) Dimethyl 5-(1'-t.Butyldimethylsilyloxypropyl)-2-oxo-1,7,8-trimethyl-4a,4b,5,6,7,9,10,10aoctahydrophenanthrene-1,8(2H,8aH)-dicarboxylate $(4.17)$

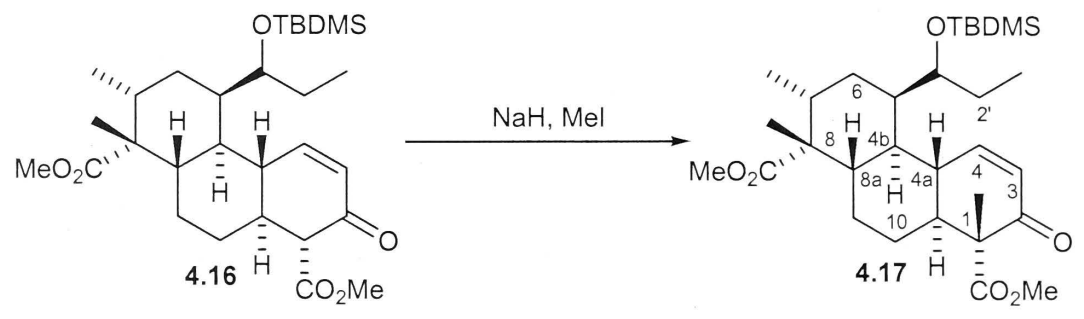

Sodium hydride $(0.018 \mathrm{~g}, 0.76 \mathrm{mmol})$ was added to the $\beta$-keto ester $4.16(0.33 \mathrm{~g}, 0.64$ $\mathrm{mmol})$ in THF $(10 \mathrm{~mL})$ at room temperature under nitrogen. After $5 \mathrm{~min}$ iodomethane $(0.048 \mathrm{~mL}, 0.76 \mathrm{mmol})$ was added and the reaction mixture stirred for $18 \mathrm{~h}$. The reaction was quenched with water and extracted with ethyl acetate $(4 \times 10 \mathrm{~mL})$. The combined organic extracts were washed with water $(5 \mathrm{~mL})$, brine $(5 \mathrm{~mL})$ and dried over $\mathrm{MgSO}_{4}$. Concentration of the organic phase in vacuo gave a yellow oil which was purified by flash column chromatography on silica gel using ethyl acetate : petroleum spirit (1 : 9) as eluant to give the title compound $\mathbf{4 . 1 7}(0.30 \mathrm{~g}, 88 \%)$ as a white solid. A sample was crystallized from hexane to give white crystals.

m.p: $47-50{ }^{\circ} \mathrm{C}$

IR (thin film) $\mathbf{c m}^{-1}$ : 2950s $(\mathrm{C}-\mathrm{H}), 1741 \mathrm{~s}(\mathrm{C}=\mathrm{O}), 1721 \mathrm{~s}(\mathrm{C}=\mathrm{O}), 1679 \mathrm{~s}(\mathrm{C}=\mathrm{O}), 1461$, $1258 \mathrm{~s}, 1212$. 
${ }^{1}$ H NMR (300 MHz, $\left.\mathbf{C D C l}_{3}\right)$ ): 0.04 (s, 3H, - $\left.\mathrm{SiCH}_{3}\right), 0.09$ (s, 3H, - $\left.\mathrm{SiCH}_{3}\right), 0.79$ (d, J $\left.=6.6 \mathrm{~Hz}, 3 \mathrm{H}, 7-\mathrm{CH}_{3}\right), 0.89\left(\mathrm{~s}, 9 \mathrm{H},-\mathrm{Si}{ }^{\mathrm{t}} \mathrm{Bu}\right), 0.93\left(\mathrm{t}, J_{3^{\prime}, 2^{\prime}}=7.2 \mathrm{~Hz}, 3 \mathrm{H}, \mathrm{H}-3^{\prime}\right), 1.26(\mathrm{~s}, 6 \mathrm{H}$, 1- $\left.\mathrm{CH}_{3}, 8-\mathrm{CH}_{3}\right), 0.91$ (m, 1H, H-9), 1.25 (m, 1H, H-10), 1.47-1.68 (m, 6H), 1.81 (m, 1H), 2.01 (m, 1H, H-9), 2.08-2.26 (m, 2H, H-10, H-4b), 2.38 (m, 1H, H-5), 2.56 (m, $1 \mathrm{H}, \mathrm{H}-4 \mathrm{a}), 3.64$ (s, 3H, 8- $\left.\mathrm{CO}_{2} \mathrm{CH}_{3}\right), 3.72$ (s, 3H, 1- $\left.\mathrm{CO}_{2} \mathrm{CH}_{3}\right), 4.19$ (dt, $J=8.7 \mathrm{~Hz}, J=$ $\left.3.9 \mathrm{~Hz}, 1 \mathrm{H}, \mathrm{H}-1^{\prime}\right), 5.96$ (dd, $\left.J=10.4 \mathrm{~Hz}, J=2.7 \mathrm{~Hz}, 1 \mathrm{H}, \mathrm{H}-3\right), 7.28$ (dd, $J=10.4 \mathrm{~Hz}, J$ $=1.5 \mathrm{~Hz}, 1 \mathrm{H}, \mathrm{H}-4)$.

${ }^{13} \mathbf{C}$ NMR (75 MHz, $\left.\mathbf{C D C l}_{3}\right)$ 8: -3.6 $\left.\left(\mathrm{SiCH}_{3}\right),-2.9\left(\mathrm{SiCH}_{3}\right), 6.9\left(\mathrm{CH}_{3}, \mathrm{C}-3\right)^{\prime}\right), 14.1$ (1$\left.\mathrm{CH}_{3}\right), 17.6\left(7-\mathrm{CH}_{3}\right), 18.4(\mathrm{SiC}), 23.8\left(8-\mathrm{CH}_{3}\right), 26.3\left(\mathrm{Si}^{\mathrm{t}} \mathrm{Bu}\right), 26.7\left(\mathrm{CH}_{2}, \mathrm{C}-9\right), 27.4$ $\left(\mathrm{CH}_{2}\right), 27.9\left(\mathrm{CH}_{2}\right), 33.3\left(\mathrm{CH}_{2}\right), 35.1(\mathrm{CH}), 35.2(\mathrm{CH}), 39.3(\mathrm{CH}), 43.5(\mathrm{CH}), 44.5$ $(\mathrm{CH}), 46.2(\mathrm{CH}), 50.6(\mathrm{C}, \mathrm{C}-8), 50.8\left(8-\mathrm{CO}_{2} \mathrm{CH}_{3}\right), 52.2\left(1-\mathrm{CO}_{2} \mathrm{CH}_{3}\right), 58.6(\mathrm{C}, \mathrm{C}-1), 72.0$ $\left(\mathrm{CH}, \mathrm{C}-1^{\prime}\right), 126.3(\mathrm{CH}, \mathrm{C}-3), 152.8(\mathrm{CH}, \mathrm{C}-4), 173.2\left(1-\mathrm{CO}_{2} \mathrm{CH}_{3}\right), 174.8\left(8-\mathrm{CO}_{2} \mathrm{CH}_{3}\right)$, 199.1 (2-CO).

LRMS (m/z): $477\left(\left(\mathrm{M}^{\mathrm{t}} \mathrm{Bu}\right)^{+}, 84 \%\right), 459$ (22), 419 (37), 357 (38), 343 (53), 283 (22), $173(100)$.

HRMS: $\mathrm{C}_{26} \mathrm{H}_{41} \mathrm{O}_{6} \mathrm{Si}\left(\mathrm{M}-{ }^{\mathrm{t}} \mathrm{Bu}\right)^{+}$requires 477.2672, found 477.2669.

\subsection{Chapter 5 Experimental}

$(1 R S, 4 \mathrm{a} R S, 4 \mathrm{~b} R S, 5 R S, 7 R S, 8 R S, 8 \mathrm{a} S R, 10 \mathrm{a} S R, 1 ' S R)$ 4,1'-Epoxy-7-methyl-1methoxycarbonyl-8-methoxmethoxy-5-(1'-propyl)-2-oxo-

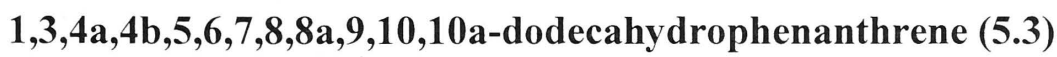
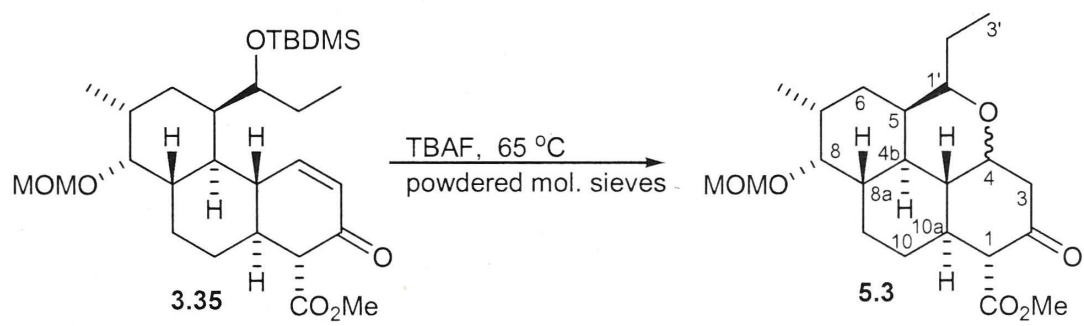

Tetrabutyl ammonium fluoride $(0.30 \mathrm{~mL}$ of a $1 M$ solution in THF, $0.30 \mathrm{mmol})$ was added to a solution of silyl ether $\mathbf{3 . 3 5}(0.022 \mathrm{~g}, 0.043 \mathrm{mmol})$ in THF (1 mL) containing powdered $4 \AA$ molecular sieves at room temperature under nitrogen. The reaction mixture was stirred overnight, then water $(5 \mathrm{~mL})$ was added and the mixture extracted with ethyl acetate $(3 \times 10 \mathrm{~mL})$. The combined organic extracts were washed with water 
$(5 \mathrm{~mL})$, brine $(5 \mathrm{~mL})$ and dried over $\mathrm{MgSO}_{4}$. Concentration of the organic phase in vacuo gave a yellow oil which was purified by flash column chromatography on silica gel using ether : hexane $(1: 1)$ as eluant to give the title compound $\mathbf{5 . 3}(0.002 \mathrm{~g}, 12 \%)$ as a white foam.

IR (thin film) $\mathbf{c m}^{-1}:$ 2926s $(\mathrm{C}-\mathrm{H}), 1747 \mathrm{~s}(\mathrm{C}=\mathrm{O}), 1715(\mathrm{C}=\mathrm{O}), 1455,1257,1151,1091$, 1037.

${ }^{1} \mathbf{H}$ NMR (300 MHz, CDCl $\left.\mathbf{3}_{3}\right)$ 8: $0.90\left(\mathrm{t}, J_{3^{\prime}, 2^{\prime}}=7.5 \mathrm{~Hz}, 3 \mathrm{H}, \mathrm{H}-3^{\prime}\right), 0.96(\mathrm{~d}, J=6.9 \mathrm{~Hz}$, $\left.3 \mathrm{H}, 7-\mathrm{CH}_{3}\right) 1.15-2.01(\mathrm{~m}, 14 \mathrm{H}), 2.40(\mathrm{~m}, 1 \mathrm{H}, \mathrm{H}-3), 2.81(\mathrm{dd}, J=13.2 \mathrm{~Hz}, J=5.1 \mathrm{~Hz}$, $\left.1 \mathrm{H}, \mathrm{H}^{\prime}-3\right), 3.08\left(\mathrm{~d}, J_{1,10 \mathrm{a}}=11.4 \mathrm{~Hz}, 1 \mathrm{H}, \mathrm{H}-1\right), 3.39\left(\mathrm{~s}, 3 \mathrm{H}, 8-\mathrm{OCH}_{2} \mathrm{OCH}_{3}\right), 3.50(\mathrm{~m}, 1 \mathrm{H}$, $\mathrm{H}-8), 3.65-3.75$ (m, 2H, H-4, H-1'), 3.76 (s, 3H, 1- $\left.\mathrm{CO}_{2} \mathrm{CH}_{3}\right), 4.60$ (s, 2H, 8$\left.\mathrm{OCH}_{2} \mathrm{OCH}_{3}\right)$.

${ }^{13} \mathrm{C}$ NMR (75 MHz, $\left.\mathbf{C D C l}_{3}\right)$ 8: $9.3\left(\mathrm{CH}_{3}, \mathrm{C}-3{ }^{\prime}\right), 18.3\left(7-\mathrm{CH}_{3}\right), 26.2\left(\mathrm{CH}_{2}\right), 28.5\left(\mathrm{CH}_{2}\right)$, $29.7\left(\mathrm{CH}_{2}\right), 32.7\left(\mathrm{CH}_{2}\right), 33.0,33.4,37.0,40.3,44.5,45.9,48.6,52.1\left(1-\mathrm{CO}_{2} \mathrm{CH}_{3}\right), 56.1$ $\left(8-\mathrm{OCH}_{2} \mathrm{OCH}_{3}\right), 63.5(\mathrm{CH}, \mathrm{C}-1), 71.3(\mathrm{CH}, \mathrm{C}-4), 75.3\left(\mathrm{CH}, \mathrm{C}-1^{\prime}\right), 80.4(\mathrm{CH}, \mathrm{C}-8), 98.2$ $\left(8-\mathrm{OCH}_{2} \mathrm{OCH}_{3}\right), 169.7\left(1-\mathrm{CO}_{2} \mathrm{CH}_{3}\right), 202.9$ (2-CO).

LRMS (m/z): $394\left(\mathrm{M}^{+}, 5 \%\right), 365$ (38), 319 (25), 303 (85), 173 (20), 45 (100).

HRMS: $\mathrm{C}_{22} \mathrm{H}_{34} \mathrm{O}_{6}\left(\mathrm{M}^{+}\right)$requires 394.2355, found 394.2361.

$(1 R S, 4 \mathrm{a} S R, 4 \mathrm{~b} S R, 5 R S, 7 R S, 8 R S, 8 \mathrm{a} S R, 10 \mathrm{a} S R, 1 ' S R)$ Methyl 5-(1'-t.-

Butyldimethylsilyloxypropyl)-1,7-dimethyl-2-hydroxy-8-methoxmethoxy$4 a, 4 b, 5,6,7,8,8 a, 9,10,10 a-d e c a h y d r o p h e n a n t h r e n e-1(2 H)$-carboxylate $(5.4)$

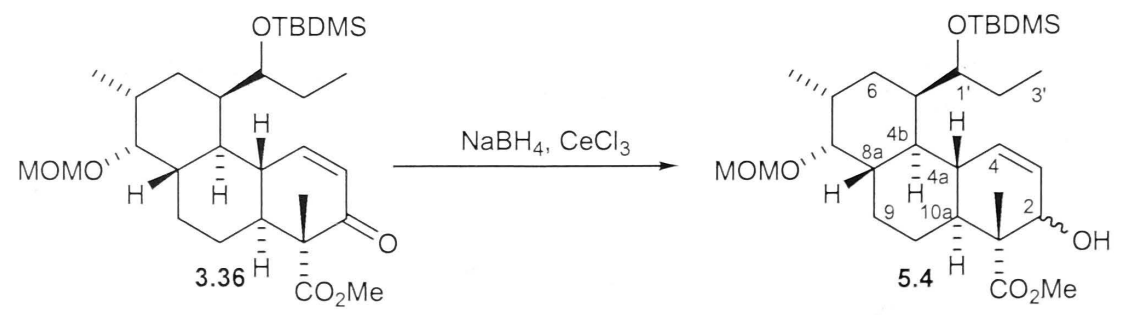

Cerium (III) chloride heptahydrate $(4.8 \mathrm{~mL}$ of a $0.1 \mathrm{M}$ solution in $\mathrm{MeOH}, 0.48 \mathrm{mmol}$ ) was added to ketone $3.36(0.23 \mathrm{~g}, 0.44 \mathrm{mmol})$ in $\mathrm{MeOH}(3 \mathrm{~mL})$ at $-78{ }^{\circ} \mathrm{C}$ under nitrogen. Sodium borohydride $(0.05 \mathrm{~g}, 0.44 \mathrm{mmol})$ was added portion wise over 40 min, allowing the reaction mixture to warm to $0{ }^{\circ} \mathrm{C}$. The reaction was quenched with 
water $(2 \mathrm{~mL})$, and the methanol removed in vacuo. The aqueous residue was then extracted with ethyl acetate $(4 \times 20 \mathrm{~mL})$. The combined organic extracts were washed with saturated sodium bicarbonate solution $(10 \mathrm{~mL})$, brine $(10 \mathrm{~mL})$, and dried over $\mathrm{MgSO}_{4}$. Concentration of the organic phase in vacuo gave the epimeric alcohols $\mathbf{5 . 4}$ $(0.21 \mathrm{~g}, 91 \%)$ as a white foam, which was used without further purification.

IR (thin film) $\mathbf{c m}^{-1}: 3464 b r(\mathrm{C}-\mathrm{OH}), 2928 \mathrm{~s}(\mathrm{C}-\mathrm{H}), 1726 \mathrm{~s}(\mathrm{C}=\mathrm{O}), 1463,1387,1257 \mathrm{~s}$, $1152,1038 \mathrm{~s}$.

${ }^{1}$ H NMR (300 MHz, $\mathbf{C D C l}_{3}$, major epimer) $\delta$ : 0.05 (s, 3H, OSiCH $\left.{ }_{3}\right), 0.06$ (s, 3H, $\left.\mathrm{OSiCH}_{3}\right), \quad 0.90\left(\mathrm{~s}, 9 \mathrm{H}, \mathrm{OSi}^{\mathrm{t}} \mathrm{Bu}\right), 0.85-0.93\left(\mathrm{~m}, 6 \mathrm{H}, 7-\mathrm{CH}_{3}, \mathrm{H}-3{ }^{\prime}\right), 1.09\left(\mathrm{~s}, 3 \mathrm{H}, 1-\mathrm{CH}_{3}\right)$, 1.10-1.75 (m, 12H), $2.00(\mathrm{~m}, 1 \mathrm{H}), 2.17$ (m, 1H), 3.30 (m, 1H, H-8), 3.39 (s, 3H, 8$\left.\mathrm{OCH}_{2} \mathrm{OCH}_{3}\right), 3.72\left(\mathrm{~s}, 3 \mathrm{H}, 1-\mathrm{CO}_{2} \mathrm{CH}_{3}\right), 3.94\left(\mathrm{~m}, 1 \mathrm{H}, \mathrm{H}-1^{\prime}\right), 4.58,4.62(2 \times \mathrm{ABd}, J=6.9$ $\left.\mathrm{Hz}, 2 \mathrm{H}, 8-\mathrm{OCH}_{2} \mathrm{OCH}_{3}\right), 4.73(\mathrm{~m}, 1 \mathrm{H}, \mathrm{H}-2), 5.52$ (m, 1H, H-3), 5.96 (m, 1H, H-4).

${ }^{13} \mathbf{C}$ NMR (75 MHz, $\mathbf{C D C l}_{3}$, major epimer) 8 : $-4.0\left(\mathrm{SiCH}_{3}\right),-3.4\left(\mathrm{SiCH}_{3}\right), 9.2\left(\mathrm{CH}_{3}\right.$, C-3'), $9.4\left(1-\mathrm{CH}_{3}\right), 18.4(\mathrm{SiC}), 19.0\left(7-\mathrm{CH}_{3}\right), 26.2\left(\mathrm{Si}{ }^{\mathrm{t}} \mathrm{Bu}\right), 26.5\left(\mathrm{CH}_{2}\right), 28.5\left(\mathrm{CH}_{2}\right), 29.7$ $\left(\mathrm{CH}_{2}\right), 30.1\left(\mathrm{CH}_{2}\right), 33.0(\mathrm{CH}), 37.4(\mathrm{CH}), 38.3(\mathrm{CH}), 41.3(\mathrm{CH}), 41.7(\mathrm{CH}), 46.5(\mathrm{CH})$, $51.9\left(1-\mathrm{CO}_{2} \mathrm{CH}_{3}\right.$ and $\left.\mathrm{C} 1\right), 56.2\left(8-\mathrm{OCH}_{2} \mathrm{OCH}_{3}\right), 73.3\left(\mathrm{CH}, \mathrm{C}-1^{\prime}\right), 73.4(\mathrm{CH}, \mathrm{C}-2), 83.7$ (CH, C-8), $99.0\left(8-\mathrm{OCH}_{2} \mathrm{OCH}_{3}\right), 129.1(\mathrm{CH}, \mathrm{C}-3), 130.3(\mathrm{CH}, \mathrm{C}-4), 177.1\left(1-\mathrm{CO}_{2} \mathrm{CH}_{3}\right)$.

LRMS (m/z): $467\left(\left(\mathrm{M}^{\mathrm{t}}{ }^{\mathrm{Bu}}\right)^{+}, 2 \%\right), 405$ (8), 347 (11), 313 (15), 253 (31), 204 (17), 173 (100), 133 (29), 73 (52).

HRMS: $\mathrm{C}_{25} \mathrm{H}_{43} \mathrm{O}_{6} \mathrm{Si}\left(\left(\mathrm{M}-{ }^{\mathrm{t}} \mathrm{Bu}\right)^{+}\right)$requires 467.2829 , found 467.2825.

(1RS, 4aSR, 4bSR, 5RS, 7RS, 8RS, 8aSR, 10aSR, 1'SR) Methyl 5-(1'Hydroxypropyl)- 1,7-dimethyl-2-hydroxy-8-methoxmethoxy$4 a, 4 b, 5,6,7,8,8 a, 9,10,10 a-d e c a h y d r o p h e n a n t h r e n e-1(2 H)$-carboxylate $(5.5)$
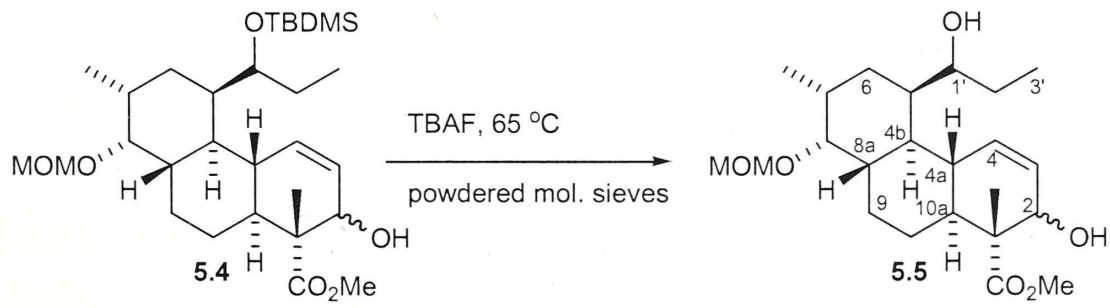
Tetrabutyl ammonium fluoride $(0.97 \mathrm{~mL}$ of a $1 M$ solution in THF, $0.97 \mathrm{mmol})$ was added to a solution of silyl ether $5.4(0.17 \mathrm{~g}, 0.32 \mathrm{mmol})$ in THF $(10 \mathrm{~mL})$ containing powdered $4 \AA$ molecular sieves at room temperature under nitrogen, then heated to 65 ${ }^{\circ} \mathrm{C}$ overnight. The reaction mixture was cooled to room temperature, water $(5 \mathrm{~mL})$ added and the mixture extracted with ethyl acetate $(3 \times 10 \mathrm{~mL})$. The combined organic extracts were washed with water $(5 \mathrm{~mL})$, brine $(5 \mathrm{~mL})$ and dried over $\mathrm{MgSO}_{4}$. Concentration of the organic phase in vacuo gave a yellow oil which was purified by flash column chromatography on silica gel using ethyl acetate : hexane $(2: 3-4: 1)$ as eluant to give the epimeric diols $\mathbf{5 . 5}(0.096 \mathrm{~g}, 73 \%)$ as a white foam.

IR (thin film) $\mathbf{c m}^{-1}$ : 3469br $(\mathrm{C}-\mathrm{OH}), 2928 \mathrm{~s}(\mathrm{C}-\mathrm{H}), 1720 \mathrm{~s}(\mathrm{C}=\mathrm{O}), 1455,1381,1259$, $1150,1037 \mathrm{~s}$.

${ }^{1} \mathbf{H}$ NMR (300 MHz, $\mathbf{C D C l}_{3}$, major epimer) $\delta: 0.87$ (d, $J=4.8 \mathrm{~Hz}, 3 \mathrm{H}, 7-\mathrm{CH}_{3}$ ), 0.98 $\left(\mathrm{t}, J_{3^{\prime}, 2^{\prime}}=7.2 \mathrm{~Hz}, 3 \mathrm{H}, \mathrm{H}-3^{\prime}\right), 1.07\left(\mathrm{~s}, 3 \mathrm{H}, 1-\mathrm{CH}_{3}\right), 0.88-1.71(\mathrm{~m}, 12 \mathrm{H}), 2.07(\mathrm{~m}, 1 \mathrm{H}), 2.23$ (m, 1H, H-4a), 3.32 (m, 1H, H-8), 3.38 (s, 3H, 8- $\left.\mathrm{OCH}_{2} \mathrm{OCH}_{3}\right), 3.71$ (s, 3H, 1-CO $\mathrm{CH}_{3}$ ), $3.86\left(\mathrm{~m}, 1 \mathrm{H}, \mathrm{H}-1^{\prime}\right), 4.58,4.61\left(2 \times \mathrm{ABd}, J=6.7 \mathrm{~Hz}, 2 \mathrm{H}, 8-\mathrm{OCH}_{2} \mathrm{OCH}_{3}\right), 4.72(\mathrm{~m}, 1 \mathrm{H}$, $\mathrm{H}-2), 5.47$ (m, 1H, H-3), 6.06 (m, 1H, H-4).

${ }^{13} \mathbf{C}$ NMR (75 MHz, $\mathbf{C D C l}_{3}$, major epimer) $\delta$ : $9.0\left(\mathrm{CH}_{3}, \mathrm{C}-3^{\prime}\right), 9.5\left(1-\mathrm{CH}_{3}\right), 18.8$ (7$\left.\mathrm{CH}_{3}\right), 26.5\left(\mathrm{CH}_{2}\right), 28.5\left(\mathrm{CH}_{2}\right), 29.7\left(\mathrm{CH}_{2}\right), 31.4\left(\mathrm{CH}_{2}\right), 32.4(\mathrm{CH}), 38.9(\mathrm{CH}), 39.4$ $(\mathrm{CH}), 41.5(\mathrm{CH}), 42.1(\mathrm{CH}), 46.2(\mathrm{CH}), 51.9\left(1-\mathrm{CO}_{2} \mathrm{CH}_{3}\right.$ and $\left.\mathrm{C} 1\right), 56.2\left(8-\mathrm{OCH}_{2} \mathrm{OCH}_{3}\right)$, $71.8\left(\mathrm{CH}, \mathrm{C}-1^{\prime}\right), 73.4(\mathrm{CH}, \mathrm{C}-2), 83.5(\mathrm{CH}, \mathrm{C}-8), 99.0\left(8-\mathrm{OCH}_{2} \mathrm{OCH}_{3}\right), 128.3(\mathrm{CH}, \mathrm{C}-$ 3), $131.2(\mathrm{CH}, \mathrm{C}-4), 177.2\left(1-\mathrm{CO}_{2} \mathrm{CH}_{3}\right)$.

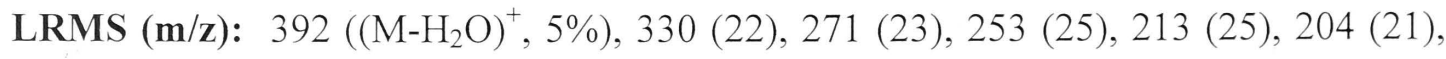
145 (72), 131 (25), 105 (26), 45 (100).

HRMS: $\mathrm{C}_{23} \mathrm{H}_{36} \mathrm{O}_{5}\left(\mathrm{M}-\mathrm{H}_{2} \mathrm{O}\right)^{+}$requires 392.2563, found 392.2560 . 
$(1 R S, 4 \mathrm{a} S R, 4 \mathrm{~b} S R, 5 R S, 7 R S, 8 R S, 8 \mathrm{a} S R, 10 \mathrm{a} S R)$ Methyl 5-(1'-oxopropyl)-1,7-

dimethyl-8-methoxmethoxy-2-oxo-4a,4b,5,6,7,8,8a,9,10,10a-

decahydrophenanthrene- $1(2 H)$-carboxylate $(5.1)$

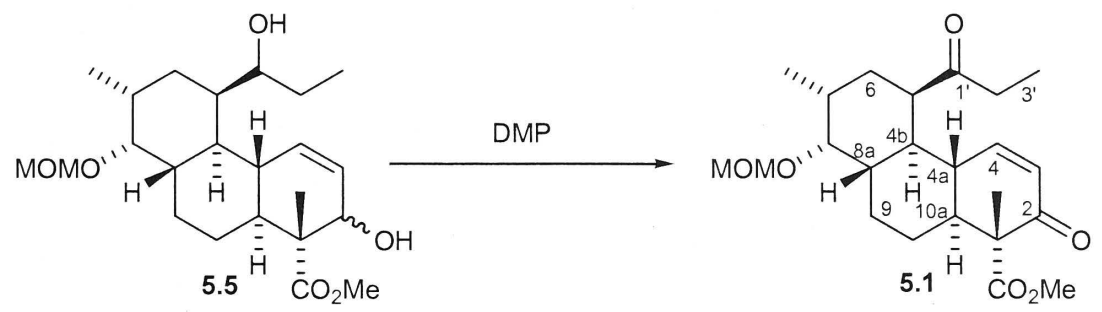

Dess-Martin periodinane $(0.50 \mathrm{~g}, 1.17 \mathrm{mmol})$ was added to diol $\mathbf{5 . 5}(0.12 \mathrm{~g}, 0.29 \mathrm{mmol})$ in DCM $(10 \mathrm{~mL})$ at room temperature under nitrogen. After $1.5 \mathrm{~h}$, the reaction mixture was stirred with $1 M$ sodium thiosulfate $(5 \mathrm{~mL})$ and a saturated solution of sodium bicarbonate $(5 \mathrm{~mL})$ until the cloudiness disappeared. The organic phase was separated and the aqueous phase extracted with $\operatorname{DCM}(3 \times 10 \mathrm{~mL})$. The combined organic extracts were dried over anhydrous $\mathrm{MgSO}_{4}$ and concentrated in vacuo to give a white solid. Purification by flash column chromatography on silica gel using ethyl acetate : hexane $(1: 9)$ as eluant gave the title compound $\mathbf{5 . 1}(0.096 \mathrm{~g}, 81 \%)$ as a white foam.

IR (thin film) $\mathbf{c m}^{-1}$ : 2931s $(\mathrm{C}-\mathrm{H}), 1741 \mathrm{~s}(\mathrm{C}=\mathrm{O}), 1703 \mathrm{~s}(\mathrm{C}=\mathrm{O}), 1678 \mathrm{~s}(\mathrm{C}=\mathrm{O}), 1456$, 1254,11491032 s.

${ }^{1} \mathbf{H}$ NMR (300 MHz, $\left.\mathbf{C D C l}_{3}\right)$ ): $0.93\left(\mathrm{~d}, J=6.6 \mathrm{~Hz}, 3 \mathrm{H}, 7-\mathrm{CH}_{3}\right), 1.04\left(\mathrm{t}, J_{3^{\prime}, 2^{\prime}}=7.2 \mathrm{~Hz}\right.$, $\left.3 \mathrm{H}, \mathrm{H}-3^{\prime}\right), 1.24\left(\mathrm{~s}, 3 \mathrm{H}, 1-\mathrm{CH}_{3}\right), 1.22-1.46(\mathrm{~m}, 3 \mathrm{H}), 1.55-1.66(\mathrm{~m}, 4 \mathrm{H}), 1.87(\mathrm{~m}, 1 \mathrm{H})$, 2.24-2.44 (m, 4H), 2.69 (m, 1H, H2'), 3.27 (m, 1H, H-5), 3.60 (m, 1H, H-8), 3.38 (s, $\left.3 \mathrm{H}, 8-\mathrm{OCH}_{2} \mathrm{OCH}_{3}\right), 3.72\left(\mathrm{~s}, 3 \mathrm{H}, 1-\mathrm{CO}_{2} \mathrm{CH}_{3}\right), 4.60$ (s, 2H, 8-OCH $\left.\mathrm{OCH}_{3}\right), 5.95(\mathrm{dd}, J=$ $10.4 \mathrm{~Hz}, J=3.0 \mathrm{~Hz}, 1 \mathrm{H}, \mathrm{H}-3), 6.85$ (d, $J=10.4 \mathrm{~Hz}, 1 \mathrm{H}, \mathrm{H}-4)$.

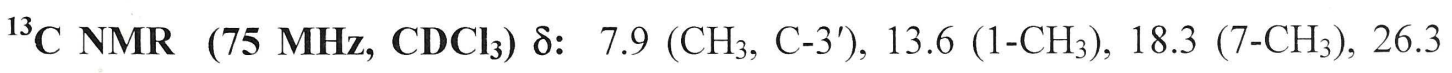
$\left(\mathrm{CH}_{2}\right), 28.5\left(\mathrm{CH}_{2}\right), 30.5\left(\mathrm{CH}_{2}\right), 32.2\left(\mathrm{CH}_{2}\right), 35.7(\mathrm{CH}), 38.2(\mathrm{CH}), 39.7(\mathrm{CH}), 41.7$ $(\mathrm{CH}), 46.3(\mathrm{CH}), 46.4(\mathrm{CH}), 52.3\left(1-\mathrm{CO}_{2} \mathrm{CH}_{3}\right), 56.2\left(8-\mathrm{OCH}_{2} \mathrm{OCH}_{3}\right), 58.9(\mathrm{C}, \mathrm{C}-1)$, $82.9(\mathrm{CH}, \mathrm{C}-8), 98.9\left(8-\mathrm{OCH}_{2} \mathrm{OCH}_{3}\right), 127.6(\mathrm{CH}, \mathrm{C}-3), 149.6(\mathrm{CH}, \mathrm{C}-4), 173.0$ (1$\left.\mathrm{CO}_{2} \mathrm{CH}_{3}\right), 198.9$ (2-CO), $213.6\left(1^{\prime}-\mathrm{CO}\right)$.

LRMS (m/z): $406\left(\mathrm{M}^{+}, 10 \%\right), 344$ (38), 285 (27), 255 (11), 227 (50), 213 (13), 57 (89), 45 (100). 
HRMS: $\mathrm{C}_{23} \mathrm{H}_{34} \mathrm{O}_{6}\left(\mathrm{M}^{+}\right)$requires 406.2355, found 406.2353.

(3RS, 3aSR, 5a $R R, 5 \mathrm{~b} S R, 5 \mathrm{c} S R, 6 R S, 7 R S, 8 \mathrm{a} S R, 10 R S, 10 \mathrm{a} S R)$ Methyl 2,9-dioxo-6methoxmethoxy-1,3a,4,5,5a,5b,5c,6,7,8,8a,10,10a-tridecahydro-3,7,10trimethylpyrene-3(2H)-carboxylate $(5.2)$

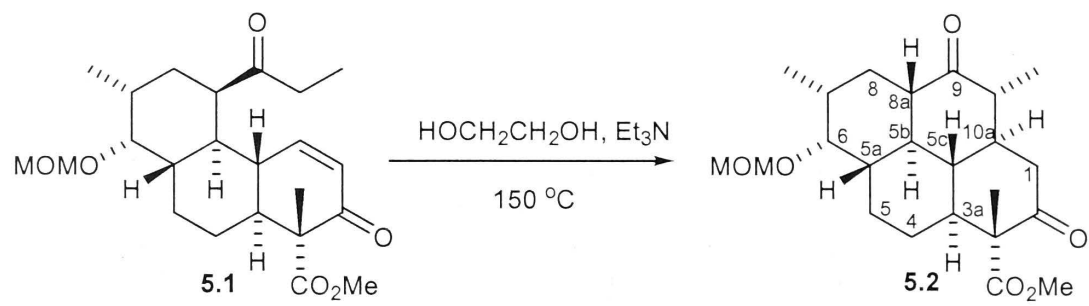

Enone $5.1(0.048 \mathrm{~g}, 0.12 \mathrm{mmol})$ in ethylene glycol $(5 \mathrm{~mL})$ and triethylamine $(0.5 \mathrm{~mL})$ was heated to $150^{\circ} \mathrm{C}$ under nitrogen for $20 \mathrm{~h}$. Water was then added and the resulting emulsion extracted with pentane : DCM $(2: 1,5 \times 10 \mathrm{~mL})$. The combined organic extracts were washed with brine $(5 \mathrm{~mL})$, dried over $\mathrm{MgSO}_{4}$ and concentrated in vacuo to give the crude product mixture as a yellow oil. Purification by flash column chromatography on silica gel using ethyl acetate : hexane (1:9-2:3) as eluant gave the title compound $\mathbf{5 . 2}(0.011 \mathrm{~g}, 31 \%$ based on recovered starting material) as a white solid. A sample was crystallized from methanol to give white needle like crystals.

m.p: $127-129^{\circ} \mathrm{C}$

IR (thin film) $\mathbf{c m}^{-1}$ : 2929s $(\mathrm{C}-\mathrm{H}), 1738 \mathrm{~s}(\mathrm{C}=\mathrm{O}), 1709 \mathrm{~s}(\mathrm{C}=\mathrm{O}), 1678 \mathrm{~s}(\mathrm{C}=\mathrm{O}), 1455$, $1363,1271,1244,1032$.

${ }^{1} \mathbf{H}$ NMR (800 MHz, $\left.\mathbf{C D C l}_{3}\right)$ 8: $1.01\left(\mathrm{~d}, J=6.4 \mathrm{~Hz}, 6 \mathrm{H}, 7-\mathrm{CH}_{3}, 10-\mathrm{CH}_{3}\right), 1.37-1.68$ (m, 11H, H-4, H-5, H-5a, H5b, H-5c, H-7, H-8, H-10a), 1.40 (s, 3H, 3-CH3), 2.14-2.21 (m, 2H, H-8a, H-3a), 2.26 (m, 1H, H-10), 2.36 (m, 1H, H-1), 2.58 (dd, $J=14.4$ Hz, $J=$ $4.0 \mathrm{~Hz}, 1 \mathrm{H}, \mathrm{H}-1), 3.39$ (m, 1H, H-6), 3.38 (s, 3H, 6- $\left.\mathrm{OCH}_{2} \mathrm{OCH}_{3}\right), 3.76$ (s, 3H, 3$\left.\mathrm{CO}_{2} \mathrm{CH}_{3}\right), 4.59,4.61\left(2 \times \mathrm{ABd}, J=7.2 \mathrm{~Hz}, 2 \mathrm{H}, 8-\mathrm{OCH}_{2} \mathrm{OCH}_{3}\right)$.

${ }^{13} \mathrm{C}$ NMR (75 MHz, CDCl 3 ) 8: $11.1\left(10-\mathrm{CH}_{3}\right), 15.5\left(3-\mathrm{CH}_{3}\right), 18.7\left(7-\mathrm{CH}_{3}\right), 27.0\left(\mathrm{CH}_{2}\right.$, C-5), $27.5\left(\mathrm{CH}_{2}, \mathrm{C}-4\right), 28.3\left(\mathrm{CH}_{2}, \mathrm{C}-8\right), 35.8(\mathrm{CH}, \mathrm{C}-7), 42.4\left(\mathrm{CH}_{2}, \mathrm{C}-1\right), 43.9(\mathrm{CH})$, $44.5(\mathrm{CH}), 45.3(\mathrm{CH}), 46.4(\mathrm{CH}), 48.8(\mathrm{CH}), 49.8(\mathrm{CH}, \mathrm{C}-10), 52.4(\mathrm{CH}), 52.8$ (3$\left.\mathrm{CO}_{2} \mathrm{CH}_{3}\right), 56.2\left(6-\mathrm{OCH}_{2} \mathrm{OCH}_{3}\right), 61.6(\mathrm{C}, \mathrm{C}-3), 81.9(\mathrm{CH}, \mathrm{C}-6), 98.7\left(6-\mathrm{OCH}_{2} \mathrm{OCH}_{3}\right)$, $172.8\left(3-\mathrm{CO}_{2} \mathrm{CH}_{3}\right), 208.1$ (2-CO), 209.9 (9-CO). 
LRMS (m/z): $406\left(\mathrm{M}^{+}, 5 \%\right), 344$ (10), 285 (8), 277 (12), 245 (34), 215 (31), 130 (26), 55 (27), 45 (100).

HRMS: $\mathrm{C}_{23} \mathrm{H}_{34} \mathrm{O}_{6}\left(\mathrm{M}^{+}\right)$requires 406.2355 , found 406.2345 .

(4aSR, 4bSR, 5RS, 7RS, 8RS, 8aSR, 10a RS, 1'SR) 5-(1'-to-

Butyldimethylsilyloxypropyl)-8-methoxmethoxy-7-methyl-

4a,4b,5,6,7,8,8a,9,10,10a-decahydrophenanthrene-2(1H)-ol (5.8)

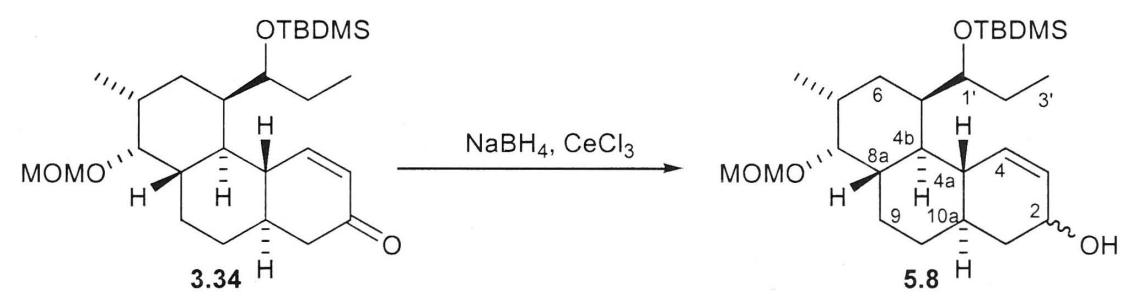

Cerium (III) chloride heptahydrate $(9.3 \mathrm{~mL}$ of a $0.1 \mathrm{M}$ solution in $\mathrm{MeOH}, 0.93 \mathrm{mmol})$ was added to ketone $3.34(0.38 \mathrm{~g}, 0.84 \mathrm{mmol})$ at $-78{ }^{\circ} \mathrm{C}$ under nitrogen. Sodium borohydride $(0.064 \mathrm{~g}, 1.68 \mathrm{mmol})$ was added portion-wise over $40 \mathrm{~min}$, allowing the reaction mixture to warm to $0{ }^{\circ} \mathrm{C}$. The reaction was quenched with water $(2 \mathrm{~mL})$, and the methanol removed in vacuo. The aqueous residue was then extracted with ethyl acetate $(4 \times 20 \mathrm{~mL})$. The combined organic extracts were washed with saturated sodium bicarbonate solution $(10 \mathrm{~mL})$, brine $(10 \mathrm{~mL})$, and dried over $\mathrm{MgSO}_{4}$. Concentration of the organic phase in vacuo gave the title compound $\mathbf{5 . 8}(0.38 \mathrm{~g}, 100 \%)$ as a white foam, which was used without further purification.

IR (thin film) $\mathbf{c m}^{-1}: 3401 \mathrm{br}(\mathrm{C}-\mathrm{OH}), 2928 \mathrm{~s}(\mathrm{C}-\mathrm{H}), 1471,1462,1387,1253,1150,1039$.

${ }^{1} \mathrm{H}$ NMR $\left(300 \mathrm{MHz}, \mathbf{C D C l}_{3}\right)$ ): $0.04\left(\mathrm{~s}, 3 \mathrm{H},-\mathrm{SiCH}_{3}\right), 0.05\left(\mathrm{~s}, 3 \mathrm{H},-\mathrm{SiCH}_{3}\right), 0.88(\mathrm{~s}$, 9H, - $\mathrm{Si} \mathrm{t}^{\mathrm{B} u}$ ), 0.87-0.92 (m, 6H, 7-CH, $\left.\mathrm{CH}^{\prime}{ }^{\prime}\right), 1.10-1.70(\mathrm{~m}, 14 \mathrm{H}), 1.90(\mathrm{~m}, 1 \mathrm{H}), 2.00(\mathrm{~m}$, 1H), $2.19(\mathrm{~m}, 1 \mathrm{H}), 3.32$ (m, 1H, H-8), 3.39 (s, 3H, 8- $\left.\mathrm{OCH}_{2} \mathrm{OCH}_{3}\right), 3.89$ (m, 1H, H-1'), $4.33(\mathrm{~m}, 1 \mathrm{H}, \mathrm{H}-2), 4.60,4.62\left(2 \mathrm{x} \mathrm{ABd}, J=6.6 \mathrm{~Hz}, 2 \mathrm{H}, 8-\mathrm{OCH}_{2} \mathrm{OCH}_{3}\right), 5.63(\mathrm{~m}, 1 \mathrm{H}$, $\mathrm{H}-3), 5.95$ (m, 1H, H-4).

${ }^{13} \mathbf{C}$ NMR (75 MHz, $\left.\mathbf{C D C l}_{3}\right)$ 8: $\left.\quad-4.1\left(\mathrm{SiCH}_{3}\right),-3.8\left(\mathrm{SiCH}_{3}\right), 9.9\left(\mathrm{CH}_{3}, \mathrm{C}^{\prime}\right)^{\prime}\right), 18.2$ ( $\mathrm{SiC}), 19.0\left(7-\mathrm{CH}_{3}\right), 26.0\left(\mathrm{CH}_{2}\right), 26.1\left(\mathrm{Si}{ }^{\mathrm{B}} \mathrm{Bu}\right), 28.3\left(\mathrm{CH}_{2}\right), 29.0\left(\mathrm{CH}_{2}\right), 30.0\left(\mathrm{CH}_{2}\right), 32.1$ 33.4, 37.4, $40.1(\mathrm{CH}), 40.5(\mathrm{CH}), 42.0(\mathrm{CH}), 42.4(\mathrm{CH}), 56.0\left(8-\mathrm{OCH}_{2} \mathrm{OCH}_{3}\right), 68.2$ 
$(\mathrm{CH}, \mathrm{C}-2), 73.2\left(\mathrm{CH}, \mathrm{C}-1^{\prime}\right), 84.0(\mathrm{CH}, \mathrm{C}-8), 98.8\left(8-\mathrm{OCH}_{2} \mathrm{OCH}_{3}\right), 130.8(\mathrm{CH}, \mathrm{C}-3)$, $131.5(\mathrm{CH}, \mathrm{C}-4)$.

LRMS (m/z): $452\left(\mathrm{M}^{+}, 5 \%\right), 423$ (22), 402 (100), 391 (54), 372 (84), 361 (25), 333 (51), $315(12)$.

HRMS: $\mathrm{C}_{26} \mathrm{H}_{48} \mathrm{O}_{4} \mathrm{Si}\left(\mathrm{M}^{+}\right)$requires 452.3322 , found 452.3318 .

(4aSR, 4bRS, 5RS, 7RS, 8RS, 8aSR, 10a $R S, 1$ 'SR) 5-(1'-hydroxypropyl)-8methoxmethoxy-7-methyl-4a,4b,5,6,7,8,8a,9,10,10a-decahydrophenanthrene2(1H)-ol (5.9)
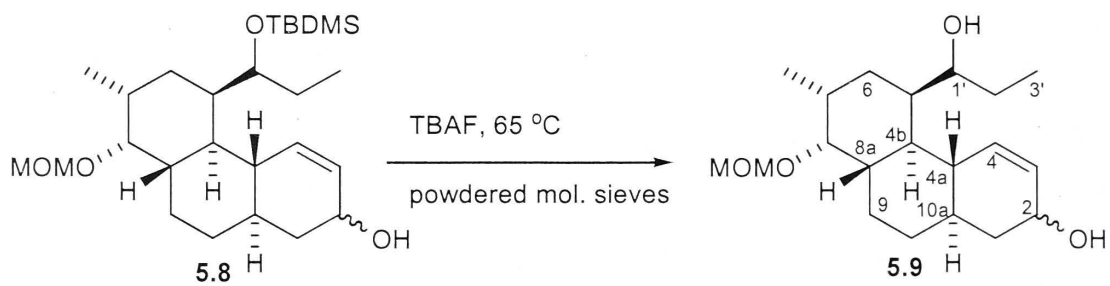

Tetrabutyl ammonium fluoride $(2.52 \mathrm{~mL}$ of a $1 \mathrm{M}$ solution in THF, $2.52 \mathrm{mmol})$ was added to a solution of silyl ether $5.8(0.38 \mathrm{~g}, 0.84 \mathrm{mmol})$ in THF (20 mL) containing powdered $4 \AA$ molecular sieves at room temperature under nitrogen, then heated to 65 ${ }^{\circ} \mathrm{C}$ overnight. The reaction mixture was cooled to room temperature, water $(10 \mathrm{~mL})$ added and the mixture extracted with ethyl acetate $(3 \times 20 \mathrm{~mL})$. The combined organic extracts were washed with water $(10 \mathrm{~mL})$, brine $(10 \mathrm{~mL})$ and dried over $\mathrm{MgSO}_{4}$. Concentration of the organic phase in vacuo gave a yellow oil which was purified by flash column chromatography on silica gel using ethyl acetate : hexane $(2: 3-4: 1)$ as eluant to give the title compound $\mathbf{5 . 9}$ (0.24 g, 87\% over two steps) as a white foam.

IR (thin film) $\mathbf{c m}^{-1}$ : 3396 br (C-OH), 2906s (C-H), 1463, 1450, 1442, 1148, 1143, 1044, 1039.

${ }^{1} \mathrm{H}$ NMR $\left(300 \mathrm{MHz}, \mathbf{C D C l}_{3}\right) \delta: 0.88\left(\mathrm{~d}, J=5.7 \mathrm{~Hz}, 3 \mathrm{H}, 7-\mathrm{CH}_{3}\right), 0.98\left(\mathrm{t}, J_{3^{\prime}, 2^{\prime}}=7.5 \mathrm{~Hz}\right.$, $\left.3 \mathrm{H}, \mathrm{H}-3^{\prime}\right), 1.13-1.68(\mathrm{~m}, 15 \mathrm{H}), 1.96-2.14(\mathrm{~m}, 3 \mathrm{H}), 3.32$ (m, 1H, H-8), 3.40 (s, 3H, 8$\left.\mathrm{OCH}_{2} \mathrm{OCH}_{3}\right), 3.86\left(\mathrm{td}, J_{1,2}=8.6 \mathrm{~Hz}, J_{1,4^{\prime}}=2.7 \mathrm{~Hz}, 1 \mathrm{H}, \mathrm{H}-1^{\prime}\right), 4.31(\mathrm{~m}, 1 \mathrm{H}, \mathrm{H}-2), 4.62$ (s, 2H, 8- $\left.\mathrm{OCH}_{2} \mathrm{OCH}_{3}\right), 5.61$ (m, 1H, H-3), 6.07 (m, 1H, H-4). 
${ }^{13}$ C NMR (75 MHz, $\left.\mathbf{C D C l}_{3}\right)$ 8: $9.7\left(\mathrm{CH}_{3}, \mathrm{C}-3^{\prime}\right), 18.9\left(7-\mathrm{CH}_{3}\right), 28.4\left(\mathrm{CH}_{2}\right), 29.9\left(\mathrm{CH}_{2}\right)$, $31.2\left(\mathrm{CH}_{2}\right), 32.2\left(\mathrm{CH}_{2}\right), 32.7,39.4,40.4,41.0(\mathrm{CH}), 41.7(\mathrm{CH}), 41.8(\mathrm{CH}), 43.5(\mathrm{CH})$, $56.2\left(8-\mathrm{OCH}_{2} \mathrm{OCH}_{3}\right), 68.6(\mathrm{CH}, \mathrm{C}-2), 71.9\left(\mathrm{CH}, \mathrm{C}-1^{\prime}\right), 83.8(\mathrm{CH}, \mathrm{C}-8), 99.0(8-$ $\left.\mathrm{OCH}_{2} \mathrm{OCH}_{3}\right), 130.2(\mathrm{CH}, \mathrm{C}-3), 132.3(\mathrm{CH}, \mathrm{C}-4)$.

LRMS (m/z): $320\left(\left(\mathrm{M}-\mathrm{H}_{2} \mathrm{O}\right)^{+}, 7 \%\right), 288$ (7), 258 (50), 240 (29), 201 (42), 69 (68), 57 (79), 45 (100).

HRMS: $\mathrm{C}_{20} \mathrm{H}_{32} \mathrm{O}_{3}\left(\mathrm{M}-\mathrm{H}_{2} \mathrm{O}\right)^{+}$requires 320.2351 , found 320.2356 .

(4aSR, 4bSR, 5RS, 7RS, 8RS, 8a SR, 10a RS, 1'SR) 5-(1'-oxopropyl)-8methoxmethoxy-7-methyl-4a,4b,5,6,7,8,8a,9,10,10a-decahydro-2(1H)phenanthrenone (5.10)

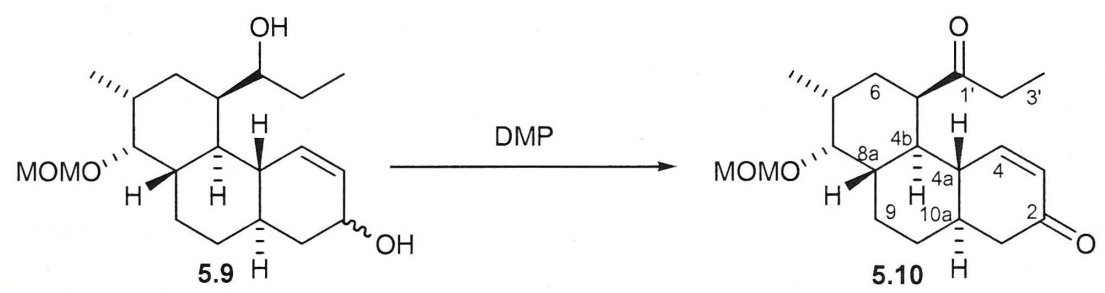

Dess-Martin periodinane $(1.20 \mathrm{~g}, 2.84 \mathrm{mmol})$ was added to diol $\mathbf{5 . 9}(0.24 \mathrm{~g}, 0.71 \mathrm{mmol})$ in DCM $(40 \mathrm{~mL})$ at room temperature under nitrogen. After $1.5 \mathrm{~h}$, the reaction mixture was stirred with a mixture of $1 M$ sodium thiosulfate $(10 \mathrm{~mL})$ and a saturated solution of sodium bicarbonate $(10 \mathrm{~mL})$ until the cloudiness disappeared. The organic phase was separated and the aqueous phase extracted with DCM $(3 \times 20 \mathrm{~mL})$. The combined organic extracts were dried over anhydrous $\mathrm{MgSO}_{4}$ and concentrated in vacuo to give a white solid. Purification by flash column chromatography on silica gel using ethyl acetate : hexane $(3: 7)$ as eluant gave the title compound $\mathbf{5 . 1 0}(0.18 \mathrm{~g}, 76 \%)$ as a white solid.

m.p: $109-111^{\circ} \mathrm{C}$

IR (thin film) $\mathbf{c m}^{-1}:$ 2929s $(\mathrm{C}-\mathrm{H}), 1700 \mathrm{~s}(\mathrm{C}=\mathrm{O}), 1682 \mathrm{~s}(\mathrm{C}=\mathrm{O}), 1460,1445,1403,1222$, 1150, 1089, 1031. 
${ }^{1} \mathbf{H}$ NMR $\left(300 \mathrm{MHz}, \mathbf{C D C l}_{3}\right) \boldsymbol{\delta}: 0.93\left(\mathrm{~d}, J=6.6 \mathrm{~Hz}, 3 \mathrm{H}, 7-\mathrm{CH}_{3}\right), 1.03\left(\mathrm{t}, J_{3^{\prime}, 2^{\prime}}=7.2 \mathrm{~Hz}\right.$, $\left.3 \mathrm{H}, \mathrm{H}-3^{\prime}\right), 1.27-1.77$ (m, 9H), $1.86(\mathrm{~m}, 1 \mathrm{H}), 2.11-2.44(\mathrm{~m}, 4 \mathrm{H}), 2.67$ (m, 1H, H2'), 3.27 $(\mathrm{m}, 1 \mathrm{H}, \mathrm{H}-5), 3.40(\mathrm{~m}, 1 \mathrm{H}, \mathrm{H}-8), 3.40\left(\mathrm{~s}, 3 \mathrm{H}, 8-\mathrm{OCH}_{2} \mathrm{OCH}_{3}\right), 4.62(\mathrm{~s}, 2 \mathrm{H}, 8-$ $\mathrm{OCH}_{2} \mathrm{OCH}_{3}$ ), 5.97 (dd, $\left.J=10.2 \mathrm{~Hz}, J=3.0 \mathrm{~Hz}, 1 \mathrm{H}, \mathrm{H}-3\right), 6.91$ (dd, $J=10.2 \mathrm{~Hz}, J=$ $1.7 \mathrm{~Hz}, 1 \mathrm{H}, \mathrm{H}-4)$.

${ }^{13} \mathrm{C}$ NMR (75 MHz, CDCl 3 ) 8: $7.8\left(\mathrm{CH}_{3}, \mathrm{C}-3^{\prime}\right), 18.3\left(7-\mathrm{CH}_{3}\right), 29.4\left(\mathrm{CH}_{2}\right), 30.3\left(\mathrm{CH}_{2}\right)$, $31.9\left(\mathrm{CH}_{2}\right), 32.1\left(\mathrm{CH}_{2}\right), 35.9,39.1,41.6,41.8,42.9,45.4,46.1,56.1\left(8-\mathrm{OCH}_{2} \mathrm{OCH}_{3}\right)$, 83.1 (CH, C-8), 98.8 (8-OCH $\left.2 \mathrm{OCH}_{3}\right), 129.8$ (CH, C-3), 150.6 (CH, C-4), 199.9 (2-CO), $213.8\left(1^{\prime}-\mathrm{CO}\right)$.

LRMS (m/z): $334\left(\mathrm{M}^{+}, 20 \%\right), 272$ (49), 215 (30), 200 (48), 188 (19), 57 (50), 45 (100).

HRMS: $\mathrm{C}_{20} \mathrm{H}_{30} \mathrm{O}_{4}\left(\mathrm{M}^{+}\right)$requires 334.2144 , found 334.2146 .

(3a $R S, 5 \mathrm{a} S R, 5 \mathrm{~b} S R, 5 \mathrm{c} S R, 6 R S, 7 R S, 8 \mathrm{a} S R, 10 R S, 10 \mathrm{a} S R)$ 6-Methoxmethoxy1,3a,4,5,5a,5b,5c,6,7,8,8a,10a-dodecahydro-7,10-dimethylpyrene-2,9(3H, 10H)dione (5.11)

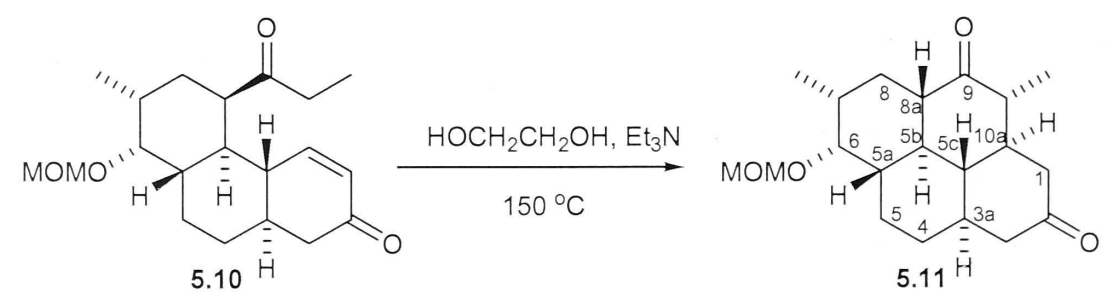

Enone $\mathbf{5 . 1 0}(0.069 \mathrm{~g}, 0.21 \mathrm{mmol})$ in ethylene glycol $(6 \mathrm{~mL})$ and triethylamine $(0.6 \mathrm{~mL})$ was heated to $150{ }^{\circ} \mathrm{C}$ under nitrogen for $20 \mathrm{~h}$. Water was then added and the resulting emulsion extracted with pentane : $\operatorname{DCM}(2: 1,5 \times 10 \mathrm{~mL})$. The combined organic extracts were washed with brine $(5 \mathrm{~mL})$, dried over $\mathrm{MgSO}_{4}$ and concentrated in vacuo to give a yellow oil. Purification by flash column chromatography on silica gel using ethyl acetate : hexane $(4: 6)$ as eluant gave the title compound $\mathbf{5 . 1 1}(0.047 \mathrm{~g}, 68 \%)$ as a white foam.

IR (thin film) $\mathbf{c m}^{-1}$ : 2930s (C-H), 1711s (C=O), 1447, 1365, 1252, 1150, 1044. 
${ }^{1} \mathbf{H}$ NMR (300 MHz, $\left.\mathbf{C D C l}_{3}\right)$ ): $0.99\left(\mathrm{~d}, J=6.6 \mathrm{~Hz}, 6 \mathrm{H}, 7-\mathrm{CH}_{3}, 10-\mathrm{CH}_{3}\right), 1.16-1.89$ $(\mathrm{m}, 12 \mathrm{H}), 2.07-2.46(\mathrm{~m}, 5 \mathrm{H}), 2.62(\mathrm{~m}, 1 \mathrm{H}, \mathrm{H}-1), 3.36\left(\mathrm{~s}, 3 \mathrm{H}, 6-\mathrm{OCH}_{2} \mathrm{OCH}_{3}\right), 3.38$ (m, $1 \mathrm{H}, \mathrm{H}-6), 4.59$ (s, 2H, 8- $\mathrm{OCH}_{2} \mathrm{OCH}_{3}$ ).

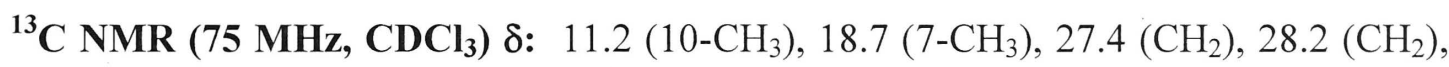
$33.3\left(\mathrm{CH}_{2}\right), 35.8,40.7,43.8,46.5,47.3,48.1,49.3,49.4,49.9,54.5,56.1$ (6$\mathrm{OCH}_{2} \mathrm{OCH}_{3}$ ), 82.1 ( $\left.\mathrm{CH}, \mathrm{C}-6\right), 98.7$ (6-OCH $\mathrm{OCH}_{3}$ ), 209.2 (2-CO), 210.5 (9-CO).

LRMS (m/z): $334\left(\mathrm{M}^{+}, 40 \%\right), 302$ (15), 272 (57), 193 (10), 186 (11), 124 (12), 45 (100).

HRMS: $\mathrm{C}_{20} \mathrm{H}_{30} \mathrm{O}_{4}\left(\mathrm{M}^{+}\right)$requires 334.2144 , found 334.2143 .

(3RS, 3aSR, 5aSR, 5bSR, 5cSR, 6RS, 7RS, 8aSR, 10RS, 10aSR) Methyl 2,9-dioxo-6methoxmethoxy-1,3a,4,5,5a,5b,5c,6,7,8,8a,9a,10,10a-tetradecahydro-7,10dimethylpyrene-3(2H)-carboxylate (5.12)
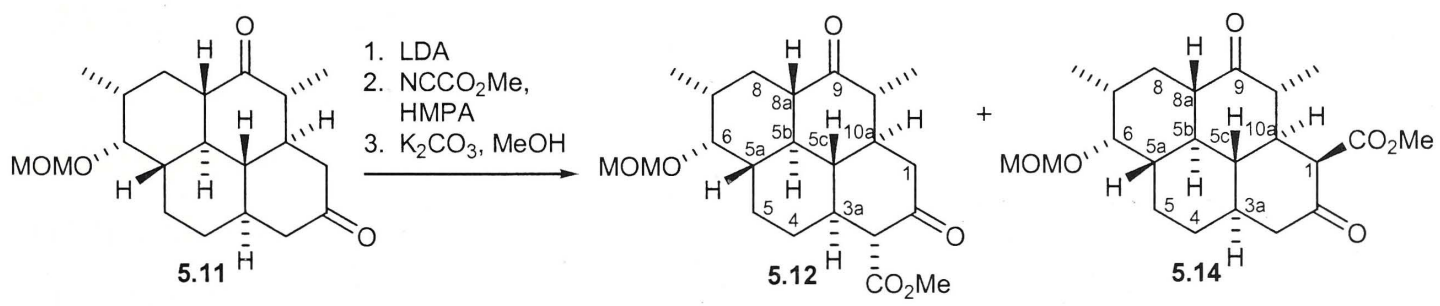

$n$-Butyllithium $(0.12 \mathrm{~mL}$ of a $1.6 \mathrm{M}$ solution in hexanes, $0.20 \mathrm{mmol})$ was added to diisopropylamine $(0.0 .28 \mathrm{~mL}, 0.20 \mathrm{mmol})$ in THF $(2 \mathrm{~mL})$ at $-20^{\circ} \mathrm{C}$ under nitrogen. The reaction mixture was stirred for $20 \mathrm{~min}$, warmed to $0^{\circ} \mathrm{C}$ and stirred for a further $30 \mathrm{~min}$. The solution was then cooled to $-78^{\circ} \mathrm{C}$, ketone $\mathbf{5 . 1 1}(0.044 \mathrm{~g}, 0.13 \mathrm{mmol})$ was added, and the reaction mixture warmed to $0{ }^{\circ} \mathrm{C}$ for $1 \mathrm{~h}$. After cooling to $-78{ }^{\circ} \mathrm{C}$, HMPA $(0.024 \mathrm{~mL}, 0.13 \mathrm{mmol})$ and methyl cyanoformate $(0.016 \mathrm{~mL}, 0.20 \mathrm{mmol})$ were added. After 20 min the reaction mixture was poured into water and extracted with ether $(3 \mathrm{x}$ $10 \mathrm{~mL})$. The combined organic extracts were washed with water $(5 \mathrm{~mL})$, brine $(5 \mathrm{~mL})$ and dried over anhydrous $\mathrm{MgSO}_{4}$. Concentration of the organic phase in vacuo gave a yellow oil which was purified by flash column chromatography on silica gel using ethyl acetate : hexane (1:9) as eluant to give compounds $\mathbf{5 . 1 2}$ and $\mathbf{5 . 1 3}(0.016 \mathrm{~g}, 37 \%)$ as an inseparable mixture. The mixture of $\mathbf{5 . 1 2}$ and $\mathbf{5 . 1 3}$ was then treated with potassium carbonate $(0.20 \mathrm{~g})$ in methanol $(2 \mathrm{~mL})$ overnight. Water was then added and the methanol removed in vacuo. The aqueous residue was extracted with ether $(3 \times 5 \mathrm{~mL})$ 
and dried over $\mathrm{MgSO}_{4}$. Concentration of the organic phase in vacuo gave a colourless oil which was purified by flash column chromatography on silica gel using ethyl acetate : hexane (1 : 9) as eluant to give methyl esters $\mathbf{5 . 1 2}(0.014 \mathrm{~g}, 88 \%)$ and $\mathbf{5 . 1 4}(1.9 \mathrm{mg}$, $12 \%)$.

(3RS, 3aSR, 5aSR, 5bSR, 5cSR, 6RS, 7RS, 8a $R R, 10 R S, 10 \mathrm{a} S R)$ Methyl 2,9-dioxo-6methoxmethoxy-1,3a,4,5,5a,5b,5c,6,7,8,8a,9a,10,10a-tetradecahydro-7,10dimethylpyrene-3(2H)-carboxylate (5.12)

IR (thin film) $\mathbf{c m}^{-1}$ : 2928s $(\mathrm{C}-\mathrm{H}), 1745 \mathrm{~s}(\mathrm{C}=\mathrm{O}), 1710 \mathrm{~s}(\mathrm{C}=\mathrm{O}), 1456,1366,1252,1151$, 1033.

${ }^{1} \mathbf{H}$ NMR (600 MHz, $\left.\mathbf{C D C l}_{3}\right)$ 8: $0.99\left(\mathrm{~d}, J=6.0 \mathrm{~Hz}, 3 \mathrm{H}, 7-\mathrm{CH}_{3}\right) 1.00,(\mathrm{~d}, J=6.6 \mathrm{~Hz}$, $\left.3 \mathrm{H}, 10-\mathrm{CH}_{3}\right), 1.19-1.70(\mathrm{~m}, 11 \mathrm{H}), 1.80-1.91(\mathrm{~m}, 2 \mathrm{H}), 2.13-2.20(\mathrm{~m}, 2 \mathrm{H}), 2.74(\mathrm{dd}, J=$ $13.8 \mathrm{~Hz}, J=4.2 \mathrm{~Hz}, 1 \mathrm{H}, \mathrm{H}-1), 3.19$ (d, $J=12.6 \mathrm{~Hz}, 1 \mathrm{H}, \mathrm{H}-3), 3.37$ (s, 3H, 6$\left.\mathrm{OCH}_{2} \mathrm{OCH}_{3}\right), 3.39(\mathrm{~m}, 1 \mathrm{H}, \mathrm{H}-6), 3.77$ (s, 3H, 3- $\left.\mathrm{CO}_{2} \mathrm{CH}_{3}\right), 4.59,4.60$ (2 x ABd, $J=6.6$ $\mathrm{Hz}, 2 \mathrm{H}, 8-\mathrm{OCH}_{2} \mathrm{OCH}_{3}$ ).

${ }^{13} \mathbf{C}$ NMR (150 MHz, $\left.\mathbf{C D C l}_{3}\right)$ 8: $11.2\left(10-\mathrm{CH}_{3}\right), 18.7\left(7-\mathrm{CH}_{3}\right), 27.4\left(\mathrm{CH}_{2}\right), 27.9\left(\mathrm{CH}_{2}\right)$, $31.8\left(\mathrm{CH}_{2}\right), 35.8(\mathrm{CH}), 43.0(\mathrm{CH}), 43.8(\mathrm{CH}), 46.2\left(\mathrm{CH}_{2}, \mathrm{C}-1\right), 47.2(\mathrm{CH}), 48.2(\mathrm{CH})$, $48.8(\mathrm{CH}), 49.7(\mathrm{CH}), 52.1\left(3-\mathrm{CO}_{2} \mathrm{CH}_{3}\right), 52.6(\mathrm{CH}), 56.3\left(6-\mathrm{OCH}_{2} \mathrm{OCH}_{3}\right), 63.3(\mathrm{CH}, \mathrm{C}-$ 3), $81.9(\mathrm{CH}, \mathrm{C}-6), 98.7$ (6- $\left.\mathrm{OCH}_{2} \mathrm{OCH}_{3}\right), 169.7$ (3- $\left.\mathrm{CO}_{2} \mathrm{CH}_{3}\right), 203.6$ (2-CO), 209.9 (9$\mathrm{CO})$.

LRMS (m/z): $392\left(\mathrm{M}^{+}, 19 \%\right), 360$ (5), 330 (22), 244 (18), 215 (6), 124 (6), 45 (100).

HRMS: $\mathrm{C}_{22} \mathrm{H}_{32} \mathrm{O}_{6}\left(\mathrm{M}^{+}\right)$requires 392.2199, found 392.2194.

$(1 R S, 3 \mathrm{a} R S, 5 \mathrm{a} S R, 5 \mathrm{~b} S R, 5 \mathrm{c} R S, 6 R S, 7 R S, 8 \mathrm{a} S R, 10 R S, 10 \mathrm{a} S R)$ Methyl 2,9-dioxo-6methoxmethoxy-3,3a,4,5,5a,5b,5c,6,7,8,8a,9a,10,10a-tetradecahydro-7,10dimethylpyrene-1(2H)-carboxylate (5.14)

IR (thin film) $\mathrm{cm}^{-1}$ : 2928s (C-H), 1712s (C=O), 1449, 1357, 1252, 1165, 1041. 
${ }^{1} \mathbf{H}$ NMR $\left(\mathbf{6 0 0} \mathbf{M H z}, \mathbf{C D C l}_{3}\right) \delta: 1.00\left(\mathrm{~d}, J=6.0 \mathrm{~Hz}, 3 \mathrm{H}, 7-\mathrm{CH}_{3}\right) 1.02,(\mathrm{~d}, J=6.6 \mathrm{~Hz}$, $3 \mathrm{H}, 10-\mathrm{CH}_{3}$ ), 1.21-1.71 (m, 10H, H-3a, H-4, H-5, H-5a, H-5b, H-7, H-8, H-10a), 1.80 (m, 1H, H'-4), 2.15 (q, $J=10.6$ Hz, 1H, H-5c), 2.21 (m, 1H, H-8a), 2.35 (m, 1H, H-3), 2.58 (m, 1H, H-10), 2.64 (m, 1H, H'-3), 3.37 (s, 3H, 6- $\left.\mathrm{OCH}_{2} \mathrm{OCH}_{3}\right), 3.38$ (m, 1H, H-6), $3.62(\mathrm{dd}, J=4.8 \mathrm{~Hz}, J=1.2 \mathrm{~Hz}, 1 \mathrm{H}, \mathrm{H}-1), 3.73\left(\mathrm{~s}, 3 \mathrm{H}, 1-\mathrm{CO}_{2} \mathrm{CH}_{3}\right), 4.59,4.61(2 \times$ $\left.\mathrm{ABd}, J=6.9 \mathrm{~Hz}, 2 \mathrm{H}, 8-\mathrm{OCH}_{2} \mathrm{OCH}_{3}\right)$.

${ }^{13} \mathrm{C}$ NMR (150 MHz, $\left.\mathbf{C D C l}_{3}\right) \delta$ : $11.2\left(10-\mathrm{CH}_{3}\right), 18.7\left(7-\mathrm{CH}_{3}\right), 27.3\left(\mathrm{CH}_{2}\right), 28.3\left(\mathrm{CH}_{2}\right)$, $33.2\left(\mathrm{CH}_{2}\right), 35.7(\mathrm{CH}), 41.4(\mathrm{CH}), 43.7(\mathrm{CH}), 43.8(\mathrm{CH}), 45.8\left(\mathrm{CH}_{2}, \mathrm{C}-3\right), 46.2(\mathrm{CH})$, $47.3(\mathrm{CH}), 52.1(2 \times \mathrm{CH}), 52.4\left(3-\mathrm{CO}_{2} \mathrm{CH}_{3}\right), 56.2\left(6-\mathrm{OCH}_{2} \mathrm{OCH}_{3}\right), 59.3(\mathrm{CH}, \mathrm{C}-1), 82.2$ (CH, C-6), 98.8 (6-OCH $\left.\mathrm{OCH}_{3}\right), 168.9$ (1- $\left.\mathrm{CO}_{2} \mathrm{CH}_{3}\right), 204.1$ (2-CO), 210.5 (9-CO).

LRMS (m/z): $392\left(\mathrm{M}^{+}, 34 \%\right), 330$ (19), 215 (51), 170 (20), 45 (100).

HRMS: $\mathrm{C}_{22} \mathrm{H}_{32} \mathrm{O}_{6}\left(\mathrm{M}^{+}\right)$requires 392.2199, found 392.2200.

(3RS, 3a $S R, 5 \mathrm{a} S R, 5 \mathrm{~b} S R, 5 \mathrm{c} S R, 6 R S, 7 R S, 8 \mathrm{a} S R, 10 R S, 10 \mathrm{a} S R)$ Methyl 2,9-dioxo-6methoxmethoxy-1,3a,4,5,5a,5b,5c,6,7,8,8a,9a,10,10a-tetradecahydro-7,10dimethylpyrene-3(2H)-carboxylate $(5.12)$

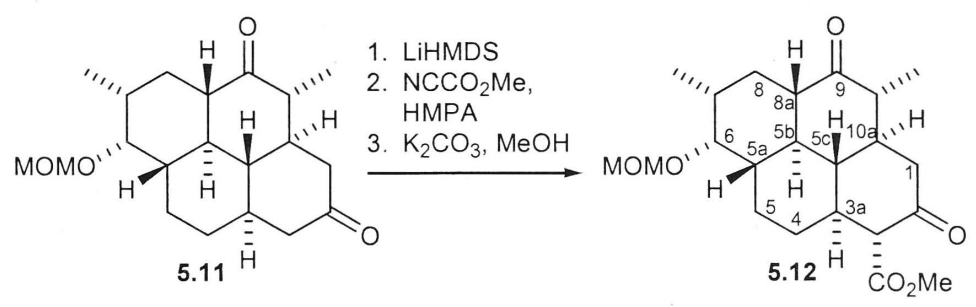

Lithium bis(trimethylsilyl)amide $(0.13 \mathrm{~mL}$ of a $1 \mathrm{M}$ solution in THF, $0.13 \mathrm{mmol})$ was added to ketone $5.11(0.029 \mathrm{~g}, 0.087 \mathrm{mmol})$ at $-78{ }^{\circ} \mathrm{C}$ under nitrogen. The reaction mixture was then warmed to $0{ }^{\circ} \mathrm{C}$ for $1 \mathrm{~h}$, then cooled to $-78^{\circ} \mathrm{C}$ before adding HMPA $(0.015 \mathrm{~mL}, 0.087 \mathrm{mmol})$ and methyl cyanoformate $(0.010 \mathrm{~mL}, 0.13 \mathrm{mmol})$. After 20 min the reaction mixture was poured into water and extracted with ether $(3 \times 10 \mathrm{~mL})$. The combined organic extracts were washed with water $(5 \mathrm{~mL})$, brine $(5 \mathrm{~mL})$ and dried over anhydrous $\mathrm{MgSO}_{4}$. Concentration of the organic phase in vacuo gave a yellow oil which was treated with potassium carbonate $(0.20 \mathrm{~g})$ in methanol $(2 \mathrm{~mL})$ overnight. Water was then added and the methanol removed in vacuo. The aqueous residue was extracted with ether $(3 \times 5 \mathrm{~mL})$ and dried over $\mathrm{MgSO}_{4}$. Concentration of the organic 
phase in vacuo gave the title compound $\mathbf{5 . 1 2}(\sim 0.02 \mathrm{~g})$ as a colourless oil which was not purified further.

(1RS, 4aSR, 4bSR, 5RS, 7RS, 8RS, 8aSR, 10aSR, 1'SR) Dimethyl 5-(1'-t.-

Butyldimethylsilyloxypropyl)-2-hydroxy-1,7,8-trimethyl-4a,4b,5,6,7,9,10,10aoctahydrophenanthrene-1,8(2H,8aH)-dicarboxylate (5.15)

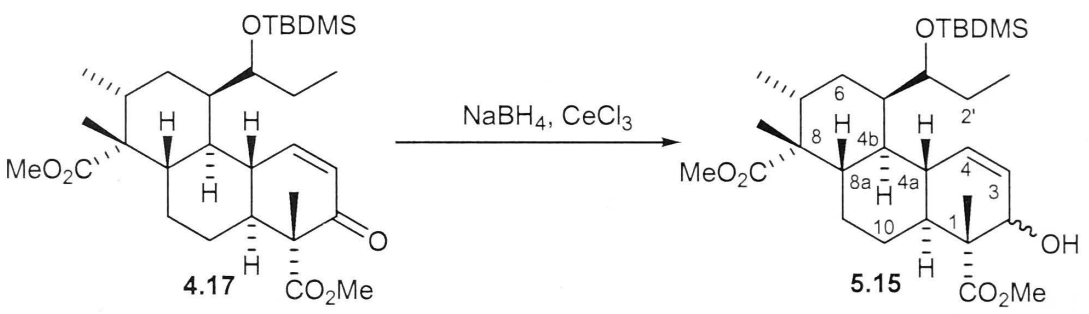

Ketone 4.17 (0.36 g, $0.67 \mathrm{mmol})$ in $\mathrm{MeOH}(10 \mathrm{~mL})$ was added to cerium (III) chloride heptahydrate $(0.28 \mathrm{~g}, 0.74 \mathrm{mmol})$ under nitrogen. The solution was cooled to $-78{ }^{\circ} \mathrm{C}$, sodium borohydride $(0.03 \mathrm{~g}, 0.74 \mathrm{mmol})$ was added and the mixture gradually warmed to $0{ }^{\circ} \mathrm{C}$ over $50 \mathrm{~min}$. The reaction was quenched with water and the methanol was removed in vacuo. The aqueous residue was extracted with ethyl acetate $(4 \times 30 \mathrm{~mL})$, then the combined organic extracts washed with brine $(10 \mathrm{~mL})$, back-extracted with ethyl acetate $(2 \times 10 \mathrm{~mL})$ and dried over $\mathrm{MgSO}_{4}$. Concentration of the organic phase in vacuo gave two epimeric products, which were purified by flash column chromatography on silica gel using ethyl acetate : petroleum spirit $(1.5: 8.5)$ as eluant to give the major alcohol $(0.27 \mathrm{~g}, 75 \%)$ and the minor alcohol $(0.02 \mathrm{~g}, 5 \%)$ as white solids. A sample of the major alcohol $\mathbf{5 . 1 5}$ was crystallised from ether to give white crystals.

m.p: $133-136^{\circ} \mathrm{C}$

IR (thin film) $\mathbf{c m}^{-1}$ : $3497 \mathrm{br}(\mathrm{C}-\mathrm{OH}), 2951 \mathrm{~s}(\mathrm{C}-\mathrm{H}), 1723 \mathrm{~s}(\mathrm{C}=\mathrm{O}), 1468 \mathrm{~s}, 1387,1255 \mathrm{~s}$, 1212.

${ }^{1} \mathrm{H}$ NMR (300 MHz, $\mathbf{C D C l}_{3}$, major epimer) $\delta: 0.05$ (s, 3H, - $\left.\mathrm{SiCH}_{3}\right), 0.08(\mathrm{~s}, 3 \mathrm{H}$, $\left.\mathrm{SiCH}_{3}\right), 0.76\left(\mathrm{~d}, J=6.6 \mathrm{~Hz}, 3 \mathrm{H}, 7-\mathrm{CH}_{3}\right), 0.88\left(\mathrm{~s}, 9 \mathrm{H},-\mathrm{Si}^{\mathrm{t}} \mathrm{Bu}\right), 0.91\left(\mathrm{t}, J_{3^{\prime}, 2^{\prime}}=7.2 \mathrm{~Hz}, 3 \mathrm{H}\right.$, H-3') 0.85 (m, 1H, H-9), 1.06 (s, 3H, 1-CH3), 1.22 (s, 3H, 8-CH3), 1.18 (m, 1H, H-10), 1.46-1.77 (m, 8H), 1.89-2.10 (m, 3H), 2.31 (m, 1H, H-5), $3.63\left(\mathrm{~s}, 3 \mathrm{H}, 8-\mathrm{CO}_{2} \mathrm{CH}_{3}\right), 3.70$ (s, 3H, 1- $\left.\mathrm{CO}_{2} \mathrm{CH}_{3}\right), 4.09$ (m, 1H, H-1'), 4.73 (m, 1H, H-2), 5.51 (m, 1H, H-3), 6.05 (m, $1 \mathrm{H}, \mathrm{H}-4)$. 
${ }^{13} \mathbf{C}$ NMR (75 MHz, $\mathbf{C D C l}_{3}$, major epimer) $\delta$ : $-3.9\left(\mathrm{SiCH}_{3}\right),-3.0\left(\mathrm{SiCH}_{3}\right), 7.9\left(\mathrm{CH}_{3}\right.$, C-3'), $9.1\left(1-\mathrm{CH}_{3}\right), 17.7\left(7-\mathrm{CH}_{3}\right), 18.4(\mathrm{SiC}), 23.9\left(8-\mathrm{CH}_{3}\right), 26.3\left(\mathrm{Si}^{\mathrm{t}} \mathrm{Bu}\right), 26.9\left(\mathrm{CH}_{2}\right)$, $28.0\left(\mathrm{CH}_{2}\right), 28.4\left(\mathrm{CH}_{2}\right), 32.8\left(\mathrm{CH}_{2}\right), 35.4(\mathrm{CH}), 36.0(\mathrm{CH}), 39.5(\mathrm{CH}), 44.0(\mathrm{CH}), 44.5$ $(\mathrm{CH}), 46.2(\mathrm{CH}), 50.6(2 \times \mathrm{C}, \mathrm{C}-8$ and $\mathrm{C}-1), 50.8\left(8-\mathrm{CO}_{2} \mathrm{CH}_{3}\right), 51.9\left(1-\mathrm{CO}_{2} \mathrm{CH}_{3}\right), 72.2$ $\left(\mathrm{CH}, \mathrm{C}-1^{\prime}\right), 73.2(\mathrm{CH}, \mathrm{C}-2), 128.8(\mathrm{CH}, \mathrm{C}-3), 130.6(\mathrm{CH}, \mathrm{C}-4), 175.2\left(1-\mathrm{CO}_{2} \mathrm{CH}_{3}\right)$, $177.1\left(8-\mathrm{CO}_{2} \mathrm{CH}_{3}\right)$.

LRMS (m/z): $479\left(\left(\mathrm{M}^{\mathrm{t}}{ }^{\mathrm{Bu}}\right)^{+}, 53 \%\right), 419(82), 404$ (79), 387 (80), 361 (41), 355 (33), $345(100)$.

HRMS: $\mathrm{C}_{26} \mathrm{H}_{43} \mathrm{O}_{6} \mathrm{Si}\left(\left(\mathrm{M}-{ }^{\mathrm{t}} \mathrm{Bu}\right)^{+}\right)$requires 479.2829 , found 479.2830 .

Microanalysis: Calcd. for $\mathrm{C}_{30} \mathrm{H}_{52} \mathrm{O}_{6} \mathrm{Si}: \mathrm{C}, 67.12 \%, \mathrm{H}, 9.76 \%$. Found: $\mathrm{C}, 67.43 \%$, H, $10.00 \%$.

$(1 R S, 4 \mathrm{a} S R, 4 \mathrm{~b} S R, 5 R S, 7 R S, 8 R S, 8 \mathrm{a} S R, 10 \mathrm{a} S R, 1 ' S R)$ Dimethyl 5-(1'Hydroxypropyl)-2-hydroxy-1,7,8-trimethyl-4a,4b,5,6,7,9,10,10aoctahydrophenanthrene-1,8(2H,8aH)-dicarboxylate $(5.16)$

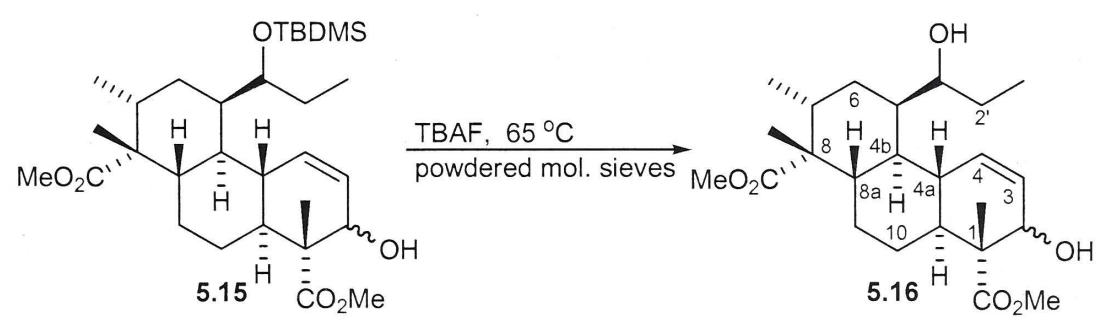

Tetrabutyl ammonium fluoride $(1.51 \mathrm{~mL}$ of a $1 M$ solution in THF, $1.51 \mathrm{mmol})$ was added to the TBDMS ether $5.15(0.27 \mathrm{~g}, 0.50 \mathrm{mmol})$ in THF $(20 \mathrm{~mL})$ containing powdered $4 \AA$ molecular sieves at room temperature under nitrogen, then the mixture was heated to $65^{\circ} \mathrm{C}$ for $36 \mathrm{~h}$. The reaction mixture was cooled to room temperature, water $(5 \mathrm{~mL})$ was added and the mixture extracted with ethyl acetate $(4 \times 20 \mathrm{~mL})$. The combined organic extracts were washed with water $(10 \mathrm{~mL})$, brine $(10 \mathrm{~mL})$ and dried over $\mathrm{MgSO}_{4}$. Concentration of the organic phase in vacuo gave a yellow oil, which was purified by flash column chromatography on silica gel using ethyl acetate : hexane $(2: 3$ - $4: 1)$ as eluant to give the title compound $\mathbf{5 . 1 6}(0.15 \mathrm{~g}, 84 \%$ based on recovered starting material) as a white solid. 
IR (thin film) $\mathbf{c m}^{-1}$ : $3497 \mathrm{br}(\mathrm{C}-\mathrm{OH}), 2948 \mathrm{~s}(\mathrm{C}-\mathrm{H}), 1718 \mathrm{~s}(\mathrm{C}=\mathrm{O}), 1459,1387,1256$, 1211.

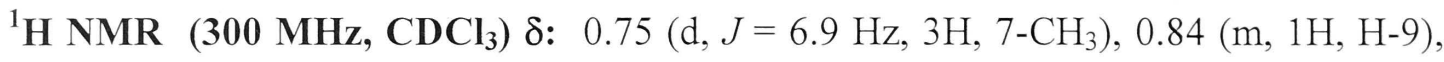
$0.98\left(\mathrm{t}, J_{3^{\prime}, 2^{\prime}}=7.5 \mathrm{~Hz}, 3 \mathrm{H}, \mathrm{H}-3^{\prime}\right), 1.05\left(\mathrm{~s}, 3 \mathrm{H}, 1-\mathrm{CH}_{3}\right), 1.21\left(\mathrm{~s}, 3 \mathrm{H}, 8-\mathrm{CH}_{3}\right), 1.20(\mathrm{~m}, 1 \mathrm{H}$, H-10), 1.31-1.99 (m, 10H), 2.14 (m, 1H, H-5), 2.26 (m, 1H, H-4a), 3.63 (s, 3H, 8$\left.\mathrm{CO}_{2} \mathrm{CH}_{3}\right), 3.69\left(\mathrm{~s}, 3 \mathrm{H}, 1-\mathrm{CO}_{2} \mathrm{CH}_{3}\right), 3.91\left(\mathrm{td}, J=8.7 \mathrm{~Hz}, J=2.7 \mathrm{~Hz}, 1 \mathrm{H}, \mathrm{H}-1^{\prime}\right), 4.72(\mathrm{~m}$, 1H, H-2), 5.49 (m, 1H, H-3), 6.10 (m, 1H, H-4).

${ }^{13} \mathrm{C}$ NMR (75 MHz, $\left.\mathbf{C D C l}_{3}\right)$ 8: $9.2\left(1-\mathrm{CH}_{3}\right), 9.5\left(\mathrm{CH}_{3}, \mathrm{C}-3^{\prime}\right), 17.9\left(7-\mathrm{CH}_{3}\right), 24.1$ (8$\left.\mathrm{CH}_{3}\right), 27.2\left(\mathrm{CH}_{2}\right), 28.3\left(\mathrm{CH}_{2}\right), 28.6\left(\mathrm{CH}_{2}\right), 33.6\left(\mathrm{CH}_{2}\right), 35.4(\mathrm{CH}), 38.6(\mathrm{CH}), 40.1$ $(\mathrm{CH}), 44.4(\mathrm{CH}), 44.8(\mathrm{CH}), 46.2(\mathrm{CH}), 50.7(\mathrm{C}, \mathrm{C}-8$ or $\mathrm{C}-1), 51.1\left(8-\mathrm{CO}_{2} \mathrm{CH}_{3}\right), 52.1$ (C, C-8 or C-1), $52.2\left(1-\mathrm{CO}_{2} \mathrm{CH}_{3}\right), 71.9\left(\mathrm{CH}, \mathrm{C}-1^{\prime}\right), 73.5(\mathrm{CH}, \mathrm{C}-2), 128.7(\mathrm{CH}, \mathrm{C}-3)$, $131.4(\mathrm{CH}, \mathrm{C}-4), 175.4\left(1-\mathrm{CO}_{2} \mathrm{CH}_{3}\right), 177.5\left(8-\mathrm{CO}_{2} \mathrm{CH}_{3}\right)$.

LRMS (m/z): $404\left(\left(\mathrm{M}-\mathrm{H}_{2} \mathrm{O}\right)^{+}, 20 \%\right), 386(20), 345$ (41), 327 (44), 285 (51), 278 (56), $221(70), 189$ (67), 161 (100).

HRMS: $\mathrm{C}_{24} \mathrm{H}_{36} \mathrm{O}_{5}\left(\left(\mathrm{M}-\mathrm{H}_{2} \mathrm{O}\right)^{+}\right)$requires 404.2563, found 404.2562.

(1RS, 4aSR, 4bSR, 5RS, 7RS, 8RS, 8aSR, 10aSR) Dimethyl 5-(1'-Oxopropyl)- 2-oxo1,7,8-trimethyl-4a,4b,5,6,7,9,10,10a-octahydrophenanthrene-1,8(2H,8aH)dicarboxylate (1.86)

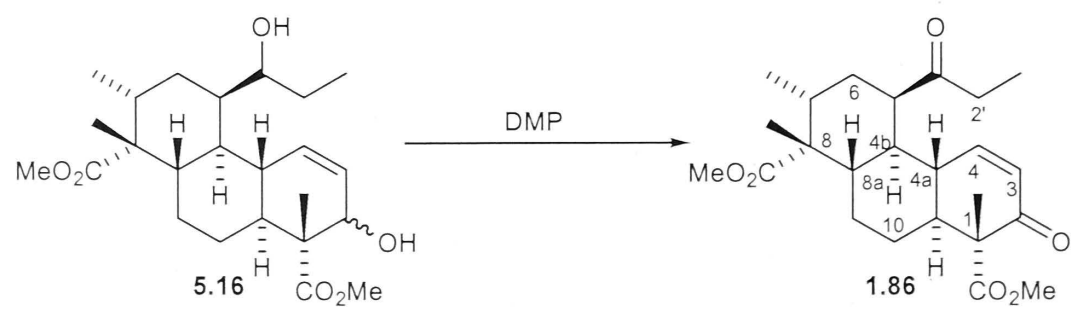

Dess-Martin periodinane $(0.45 \mathrm{~g}, 1.07 \mathrm{mmol})$ was added to diol $5.16(0.15 \mathrm{~g}, 0.36$ $\mathrm{mmol})$ in DCM $(10 \mathrm{~mL})$ at $0{ }^{\circ} \mathrm{C}$ under nitrogen. After $1.5 \mathrm{~h}$, the reaction mixture was stirred with $1 \mathrm{M}$ sodium thiosulfate $(5 \mathrm{~mL})$ and a saturated aqueous solution of sodium bicarbonate $(5 \mathrm{~mL})$ until the cloudiness disappeared. The organic phase was separated and the aqueous phase extracted with DCM $(3 \times 15 \mathrm{~mL})$. The combined organic extracts were dried over anhydrous $\mathrm{MgSO}_{4}$ and concentrated in vacuo to give a white solid. Purification by flash column chromatography on silica gel using ethyl acetate : 
hexane (1:9) as eluant gave the title compound $\mathbf{1 . 8 6}(0.12 \mathrm{~g}, 81 \%)$ as a white solid. A sample was crystallised from ether/hexane to give white crystals.

m.p: $143-145^{\circ} \mathrm{C}$

IR (thin film) $\mathbf{~ m m}^{-1}$ : 2947s $(\mathrm{C}-\mathrm{H}), 1736 \mathrm{~s}(\mathrm{C}=\mathrm{O}), 1720 \mathrm{~s}(\mathrm{C}=\mathrm{O}), 1678 \mathrm{~s}(\mathrm{C}=\mathrm{O}), 1458$, $1377,1263$.

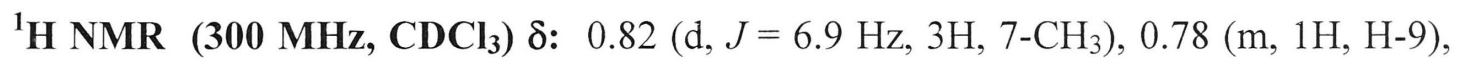
$1.04\left(\mathrm{t}, J_{3^{\prime}, 2^{\prime}}=7.2 \mathrm{~Hz}, 3 \mathrm{H}, \mathrm{H}-3^{\prime}\right), 1.23\left(\mathrm{~s}, 6 \mathrm{H}, 1-\mathrm{CH}_{3}, 8-\mathrm{CH}_{3}\right), 1.17-1.51(\mathrm{~m}, 2 \mathrm{H}), 1.68-$ 1.75 (m, 2H), 1.93-2.44 (m, 7H), 2.69 (m, 1H, H-2'), 3.35 (m, 1H, H-5), 3.63 (s, 3H, 8$\left.\mathrm{CO}_{2} \mathrm{CH}_{3}\right), 3.71\left(\mathrm{~s}, 3 \mathrm{H}, 1-\mathrm{CO}_{2} \mathrm{CH}_{3}\right), 5.96(\mathrm{dd}, J=10.5 \mathrm{~Hz}, J=2.7 \mathrm{~Hz}, 1 \mathrm{H}, \mathrm{H}-3), 6.88$ (dd, $J=10.5 \mathrm{~Hz}, J=1.5 \mathrm{~Hz}, 1 \mathrm{H}, \mathrm{H}-4$ ).

${ }^{13} \mathbf{C}$ NMR $\left(75 \mathbf{~ M H z}, \mathbf{C D C l}_{3}\right)$ 8: $7.9\left(\mathrm{CH}_{3}, \mathrm{C}-3^{\prime}\right), 13.5\left(1-\mathrm{CH}_{3}\right), 17.2\left(7-\mathrm{CH}_{3}\right), 22.9(8-$ $\left.\mathrm{CH}_{3}\right), 26.7\left(\mathrm{CH}_{2}, \mathrm{C}-9\right), 27.5\left(\mathrm{CH}_{2}, \mathrm{C}-10\right), 32.2\left(\mathrm{CH}_{2}, \mathrm{C}-6\right), 35.4(\mathrm{CH}), 35.5\left(\mathrm{CH}_{2}, \mathrm{C}-2\right)$, $38.9(\mathrm{CH}), 41.5(\mathrm{CH}), 44.6(\mathrm{CH}), 46.0(\mathrm{CH}), 46.1(\mathrm{CH}, \mathrm{C}-5), 49.9(\mathrm{C}, \mathrm{C}-8), 50.9(8-$ $\left.\mathrm{CO}_{2} \mathrm{CH}_{3}\right), 52.3\left(1-\mathrm{CO}_{2} \mathrm{CH}_{3}\right), 58.7(\mathrm{C}, \mathrm{C}-1), 127.6(\mathrm{CH}, \mathrm{C}-3), 149.5(\mathrm{CH}, \mathrm{C}-4), 172.9$ (1$\left.\mathrm{CO}_{2} \mathrm{CH}_{3}\right), 174.8\left(8-\mathrm{CO}_{2} \mathrm{CH}_{3}\right), 198.8$ (2-CO), 213.9 (1'-CO).

LRMS (m/z): $418\left(\mathrm{M}^{+}, 94 \%\right), 358$ (58), 299 (59), 241 (61), 213 (20), 159 (22), 121 (21), 57 (100).

HRMS: $\mathrm{C}_{24} \mathrm{H}_{34} \mathrm{O}_{6}\left(\mathrm{M}^{+}\right)$requires 418.2355 , found 418.2354 .

Microanalysis: Calcd. for $\mathrm{C}_{24} \mathrm{H}_{34} \mathrm{O}_{6}$ : C, $68.88 \%, \mathrm{H}, 8.19 \%$. Found: $\mathrm{C}, 68.89 \%, \mathrm{H}$, $8.12 \%$.

( \pm -Dimethyl 2,6-Dioxo-isocycloamphilectan-7,20-dicarboxylate (1.87)

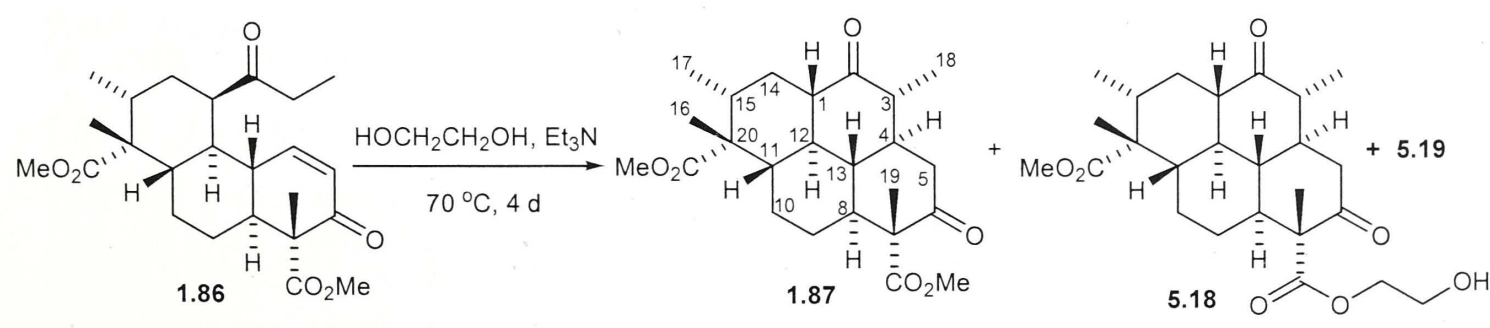


Enone $1.86(0.058 \mathrm{~g}, 0.14 \mathrm{mmol})$ in ethylene glycol $(3 \mathrm{~mL})$ and triethylamine $(0.3 \mathrm{~mL})$ was heated to $70{ }^{\circ} \mathrm{C}$ under nitrogen for $4 \mathrm{~d}$. Water was then added and the resulting mixture extracted with pentane : DCM $(2: 1,3 \times 10 \mathrm{~mL})$. The aqueous phase was then saturated with sodium chloride and further extracted with pentane : DCM $(2: 1,3 \times 10$ $\mathrm{mL})$. The combined organic extracts were washed with water $(5 \mathrm{~mL})$, brine $(5 \mathrm{~mL})$, dried over $\mathrm{MgSO}_{4}$ and concentrated in vacuo to give the crude product mixture as a yellow oil. Purification by flash column chromatography on silica gel using ethyl acetate : petroleum spirit $(1.5: 8.5)$ as eluant gave the title compound $\mathbf{1 . 8 7}$ (0.013 g, $30 \%$ based on recovered starting material) as a white solid and an inseparable mixture of $\mathbf{5 . 1 8}$ and $\mathbf{5 . 1 9}$ (0.018 g, 41\% based on recovered starting material) as a colourless oil. A sample of $\mathbf{1 . 8 7}$ was crystallised from methanol to give white needle like crystals.

m.p: $174-175^{\circ} \mathrm{C}$

IR (thin film) $\mathbf{c m}^{-1}$ : 2950s $(\mathrm{C}-\mathrm{H}), 1732 \mathrm{~s}(\mathrm{C}=\mathrm{O}), 1712 \mathrm{~s}(\mathrm{C}=\mathrm{O}), 1456,1434,1380,1235$, 1091.

${ }^{1}$ H NMR (800 MHz, $\left.\mathbf{C D C l}_{3}\right)$ ): $0.92\left(\mathrm{~d}, J=6.4 \mathrm{~Hz}, 3 \mathrm{H}, 17-\mathrm{CH}_{3}\right), 0.91(\mathrm{~m}, 1 \mathrm{H}, \mathrm{H}-10)$, $1.02\left(\mathrm{~d}, J=7.2 \mathrm{~Hz}, 3 \mathrm{H}, 18-\mathrm{CH}_{3}\right), 1.17$ (m, 1H, H-11), 1.24 (m, 1H, H-14), 1.25 (s, 3H, 16- $\mathrm{CH}_{3}$ ), 1.33 (m, 1H, H-9), 1.39 (s, 3H, 19- $\mathrm{CH}_{3}$ ), 1.39-1.44 (m, 2H, H'-9, H-15), 1.59 (m, 1H, H-13), 1.66 (m, 1H, H-4), 1.74 (m, 1H, H'-14), 1.84 (m, 1H, H-12), 1.95 (dq, J $\left.=13.6 \mathrm{~Hz}, J=2.4 \mathrm{~Hz}, 1 \mathrm{H}, \mathrm{H}^{\prime}-10\right), 2.15-2.19$ (m, 2H, H-8, H-1), 2.28 (m, 1H, H-3), 2.35 (m, 1H, H-5), 2.56 (dd, $\left.J=14.4 \mathrm{~Hz} J=4.0 \mathrm{~Hz}, 1 \mathrm{H}, \mathrm{H}^{\prime}-5\right), 3.63$ (s, 3H, 20-CO $\mathrm{CH}_{3}$ ), $3.75\left(\mathrm{~s}, 3 \mathrm{H}, 7-\mathrm{CO}_{2} \mathrm{CH}_{3}\right)$.

${ }^{13} \mathrm{C}$ NMR (150 MHz, $\left.\mathbf{C D C l}_{3}\right)$ 8: $11.1\left(18-\mathrm{CH}_{3}\right), 15.5\left(19-\mathrm{CH}_{3}\right), 17.4\left(17-\mathrm{CH}_{3}\right), 23.3$ (16- $\left.\mathrm{CH}_{3}\right), 26.4\left(\mathrm{CH}_{2}, \mathrm{C}-10\right), 27.4\left(\mathrm{CH}_{2}, \mathrm{C}-9\right), 29.5\left(\mathrm{CH}_{2}, \mathrm{C}-14\right), 39.6(\mathrm{CH}, \mathrm{C}-15), 42.3$ $\left(\mathrm{CH}_{2}, \mathrm{C}-5\right), 44.6(\mathrm{CH}, \mathrm{C}-13), 45.1$ (CH, C-8), 46.3 (CH, C-12), 48.4 (CH, C-4), 49.5 (C, $\mathrm{C}-20), 49.6(\mathrm{CH}, \mathrm{C}-3), 51.0(\mathrm{CH}, \mathrm{C}-11), 51.1\left(20-\mathrm{CO}_{2} \mathrm{CH}_{3}\right), 52.4\left(7-\mathrm{CO}_{2} \mathrm{CH}_{3}\right), 52.4$ (CH, C-1), 61.4 (C, C-7), 172.7 (7- $\left.\mathrm{CO}_{2} \mathrm{CH}_{3}\right), 174.4$ (20- $\left.\mathrm{CO}_{2} \mathrm{CH}_{3}\right), 207.9$ (6-CO), 209.9 $(2-\mathrm{CO})$.

LRMS (m/z): $418\left(\mathrm{M}^{+}, 40 \%\right), 400$ (78), 358 (51), 341 (100), 281 (60), 229 (50), 211 (54). 
HRMS: $\mathrm{C}_{24} \mathrm{H}_{34} \mathrm{O}_{6}\left(\mathrm{M}^{+}\right)$requires 418.2355 , found 418.2354 .

Microanalysis: Calcd. for $\mathrm{C}_{24} \mathrm{H}_{34} \mathrm{O}_{6}: \mathrm{C}, 68.88 \%, \mathrm{H}, 8.19 \%$. Found: $\mathrm{C}, 68.65 \%, \mathrm{H}$, $7.91 \%$.

( \pm -7-(2'-Methoxmethoxyethyl) 20-Methyl 2,6-Dioxo-isocycloamphilectan-7, 20dicarboxylate (5.20)

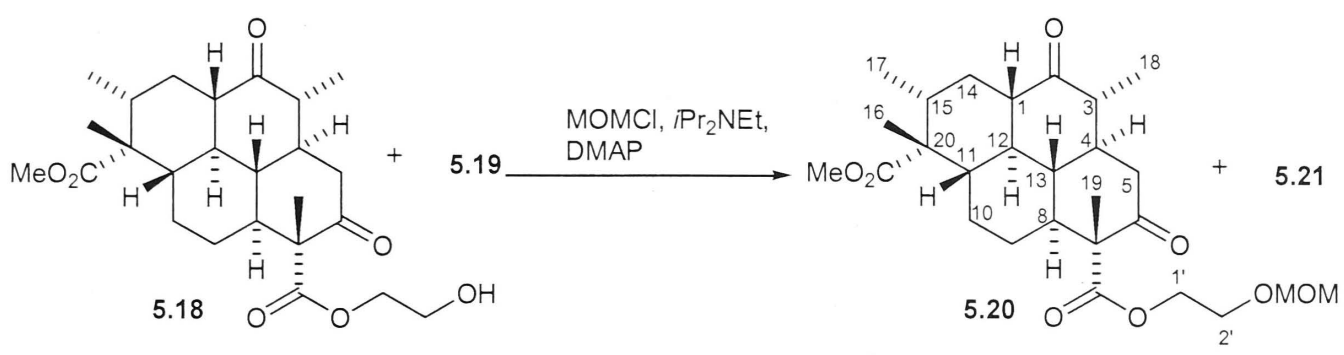

Hünig's base $(0.15 \mathrm{~mL}, 0.86 \mathrm{mmol})$ was added to a mixture of alcohols $\mathbf{5 . 1 8}$ and $\mathbf{5 . 1 9}$ $(0.077 \mathrm{~g}, 0.17 \mathrm{mmol})$ in $\mathrm{DCM}(5 \mathrm{~mL})$ at $0{ }^{\circ} \mathrm{C}$ under nitrogen. Chloromethyl methyl ether $(0.065 \mathrm{~mL}, 0.86 \mathrm{mmol})$ was added drop wise and the reaction mixture was warmed to room temperature. A catalytic amount of DMAP was then added and the reaction mixture stirred for $24 \mathrm{~h}$. The reaction mixture was cooled to $0{ }^{\circ} \mathrm{C}$, saturated aqueous sodium bicarbonate $(5 \mathrm{~mL})$ was added, and the resulting mixture stirred for 10 min. The organic phase was separated and the aqueous phase was extracted with DCM $(3 \times 10 \mathrm{~mL})$. The combined organic extracts were washed with water $(5 \mathrm{~mL}), 1 \mathrm{M}$ hydrochloric acid $(5 \mathrm{~mL})$, saturated aqueous sodium bicarbonate $(5 \mathrm{~mL})$, brine $(5 \mathrm{~mL})$ and dried over anhydrous $\mathrm{MgSO}_{4}$. Concentration of the organic phase in vacuo gave a yellow gum which was purified by flash column chromatography on silica gel using ethyl acetate : hexane $(1: 4)$ as eluant to give the title compound $\mathbf{5 . 2 0}(0.036 \mathrm{~g}, 43 \%)$ as a colourless oil and a mixture of esters $\mathbf{5 . 2 1}$ and $\mathbf{5 . 2 0}(0.026,31 \%)$ as a colourless oil.

IR (thin film) $\mathbf{c m}^{-1}$ : 2931s (C-H), 1736s $(\mathrm{C}=\mathrm{O}), 1712 \mathrm{~s}(\mathrm{C}=\mathrm{O}), 1459,1380,1254,1091$.

${ }^{1} \mathrm{H}$ NMR $\left(\mathbf{3 0 0} \mathbf{~ M H z}, \mathbf{C D C l}_{3}\right)$ \&: $0.91\left(\mathrm{~d}, J=6.9 \mathrm{~Hz}, 3 \mathrm{H}, 17-\mathrm{CH}_{3}\right), 0.87$ (m, 1H, H-10), $1.01\left(\mathrm{~d}, J=6.6 \mathrm{~Hz}, 3 \mathrm{H}, 18-\mathrm{CH}_{3}\right), 1.12-2.04(\mathrm{~m}, 10 \mathrm{H}), 1.24\left(\mathrm{~s}, 3 \mathrm{H}, 16-\mathrm{CH}_{3}\right), 1.38$ (s, 3H, 19- $\mathrm{CH}_{3}$ ), 2.11-2.40 (m, 4H), 2.57 (dd, $\left.J=14.4 \mathrm{~Hz} J=3.9 \mathrm{~Hz}, 1 \mathrm{H}, \mathrm{H}-5\right), 3.35$ (s, 3H, 2'$\left.\mathrm{OCH}_{2} \mathrm{OCH}_{3}\right), 3.61\left(\mathrm{~s}, 3 \mathrm{H}, 20-\mathrm{CO}_{2} \mathrm{CH}_{3}\right), 3.72-3.75\left(\mathrm{~m}, 2 \mathrm{H}, 2^{\prime}-\mathrm{H}\right), 4.33-4.36\left(\mathrm{~m}, 2 \mathrm{H}, 1^{\prime}-\right.$ $\mathrm{H}), 4.62\left(\mathrm{~s}, 2 \mathrm{H}, 2^{\prime}-\mathrm{OCH}_{2} \mathrm{OCH}_{3}\right)$. 
${ }^{13} \mathrm{C}$ NMR (75 MHz, $\left.\mathbf{C D C l}_{3}\right)$ 8: $11.1\left(\mathrm{CH}_{3}\right), 15.4\left(\mathrm{CH}_{3}\right), 17.4\left(\mathrm{CH}_{3}\right), 23.3\left(\mathrm{CH}_{3}\right), 26.3$ $\left(\mathrm{CH}_{2}\right), 27.4\left(\mathrm{CH}_{2}\right), 29.5\left(\mathrm{CH}_{2}\right), 39.6(\mathrm{CH}), 42.2\left(\mathrm{CH}_{2}\right), 44.5(\mathrm{CH}), 45.0(\mathrm{CH}), 46.3$ $(\mathrm{CH}), 48.3(\mathrm{CH}), 49.5(\mathrm{C}), 49.6(\mathrm{CH}), 50.9(\mathrm{CH}), 51.0\left(20-\mathrm{CO}_{2} \mathrm{CH}_{3}\right), 52.4(\mathrm{CH}), 55.2$ $\left(2^{\prime}-\mathrm{OCH}_{2} \mathrm{OCH}_{3}\right), 61.4(\mathrm{C}), 64.2\left(\mathrm{CH}_{2}, \mathrm{C}^{\prime} 1^{\prime}\right), 65.5\left(\mathrm{CH}_{2}, \mathrm{C}-2^{\prime}\right), 96.4\left(2^{\prime}-\mathrm{OCH}_{2} \mathrm{OCH}_{3}\right)$, $172.1\left(7-\mathrm{CO}_{2} \mathrm{R}\right), 174.4\left(20-\mathrm{CO}_{2} \mathrm{CH}_{3}\right), 207.8$ (6-CO), 209.9 (2-CO).

LRMS (m/z): $492\left(\mathrm{M}^{+}, 4 \%\right), 460$ (19), 386 (20), 358 (41), 299 (37), 281 (38), 229 (30), 45 (100).

HRMS: $\mathrm{C}_{27} \mathrm{H}_{40} \mathrm{O}_{8}\left(\mathrm{M}^{+}\right)$requires 492.2723, found 492.2726.

\subsection{Chapter 6 Model Studies Experimental}

(1SR, 4aRS, 8aSR)-Methyl decahydro-1-methylnaphthalene-1-carboxylate (6.6)

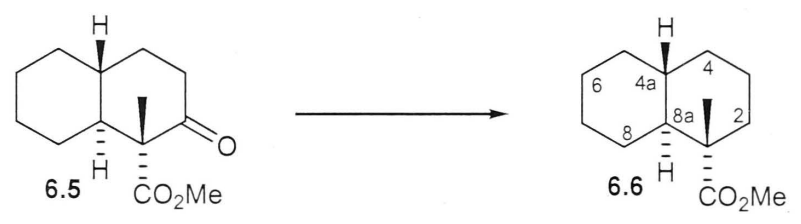

Method A: Tosylhydrazine (0.65 g, $3.48 \mathrm{mmol})$ was added to ketone 6.5 (0.65 g, 2.90 $\mathrm{mmol})$ in THF $(15 \mathrm{~mL})$ under nitrogen. The resulting mixture was heated at reflux for $18 \mathrm{~h}$. The reaction was then cooled to room temperature before adding zinc chloride (0.55 g, $4.06 \mathrm{mmol})$ and sodium cyanoborohydride $(0.26 \mathrm{~g}, 4.06 \mathrm{mmol})$. The suspension was then heated to reflux for $24 \mathrm{~h}$. The mixture was cooled to room temperature and saturated sodium bicarbonate was added. The residue was extracted with ether $(4 \times 20 \mathrm{~mL})$ then the combined organic extracts were washed with $1 \mathrm{M}$ hydrochloric acid $(5 \mathrm{~mL})$, water $(5 \mathrm{~mL})$ and dried over $\mathrm{MgSO}_{4}$. Concentration in vacuo gave the crude product as a colourless oil, which was purified by flash column chromatography using ether : petroleum spirit (1:9) as eluant to give the title compound $6.6(0.40 \mathrm{~g}, 66 \%)$ as a colourless oil.

Method B: ketone 6.5 (0.10 g, $0.45 \mathrm{mmol})$ in $\mathrm{MeOH}(5 \mathrm{~mL})$ was added to cerium (III) chloride heptahydrate $(0.18 \mathrm{~g}, 0.49 \mathrm{mmol})$ under nitrogen. The solution was cooled to $0{ }^{\circ} \mathrm{C}$, and sodium borohydride $(0.02 \mathrm{~g}, 0.49 \mathrm{mmol})$ was added. The reaction was stirred for $30 \mathrm{~min}$ then quenched with water, and the methanol removed in vacuo. The aqueous 
residue was extracted with ethyl acetate $(3 \times 10 \mathrm{~mL})$ then the aqueous phase saturated with sodium chloride, and further extracted with ethyl acetate $(2 \times 10 \mathrm{~mL})$. The combined organic extracts were washed with brine $(10 \mathrm{~mL})$, dried over $\mathrm{MgSO}_{4}$ and concentrated in vacuo to give a mixture of two epimeric alcohols $6.7(0.11 \mathrm{~g})$, which were used directly in the next step without purification.

The crude alcohols 6.7 (0.11 g, $0.49 \mathrm{mmol})$ were dissolved in THF (5 mL) and Sodium bis(trimethylsilyl)amide $(0.97 \mathrm{~mL}$ of a $1 \mathrm{M}$ solution in THF, $0.97 \mathrm{mmol})$ was added at room temperature under nitrogen. The resulting reaction mixture was stirred for $2 \mathrm{~h}$ then carbon disulfide $(0.058 \mathrm{~mL}, 0.97 \mathrm{mmol})$ was added. The reaction mixture was stirred for $2 \mathrm{~h}$ then iodomethane $(0.06 \mathrm{~mL}, 0.97 \mathrm{mmol})$ was added. The mixture was stirred for an additional $2 \mathrm{~h}$ then quenched with acetic acid $(0.5 \mathrm{~mL})$ and diluted with saturated ammonium chloride solution $(5 \mathrm{~mL})$. The resulting aqueous mixture was extracted with ethyl acetate $(4 \times 10 \mathrm{~mL})$. The combined organic extracts were dried over $\mathrm{MgSO}_{4}$ and concentrated in vacuo to give a mixture of two epimeric xanthate esters $6.8(0.13 \mathrm{~g})$, which were used directly in the next step without purification.

The crude xanthate esters $6.8(0.13 \mathrm{~g}, 0.41 \mathrm{mmol})$ were dissolved in toluene $(5 \mathrm{~mL})$ then tributyl tin hydride $(0.22 \mathrm{~mL}, 0.82 \mathrm{mmol})$ and a catalytic amount of AIBN was added. The reaction mixture was heated to a $100{ }^{\circ} \mathrm{C}$ for $1 \mathrm{~h}$, after which time starting material remained so excess tributyl tin hydride $(0.15 \mathrm{~mL}, 0.56 \mathrm{mmol})$ and AIBN (catalytic) were added. After $1 \mathrm{~h}$ at $100{ }^{\circ} \mathrm{C}$ the toluene was removed in vacuo and the residue purified by flash column chromatography on silica gel using ether : petroleum spirit (5 : $95)$ as eluant to give the title compound $\mathbf{6 . 6}(0.062 \mathrm{~g}, \sim 70 \%$ over 3 steps $)$ as a colouless oil.

IR (thin film) $\mathbf{c m}^{-1}:$ 2924s (C-H), 1730s (C=O), 1447, 1383, 1263, 1227, 1142, 1105.

${ }^{1} \mathbf{H}$ NMR (300 MHz, $\left.\mathbf{C D C l}_{3}\right)$ 8: 0.87-1.78 (m, 16H, H-2, H-3, H-4, H-4a, H-5, H-6, H7, H-8, H-8a), 1.11 (s, 3H, 1-CH3), 3.65 (s, 3H, 1- $\mathrm{CO}_{2} \mathrm{CH}_{3}$ ).

${ }^{13}$ C NMR (75 MHz, $\left.\mathbf{C D C l}_{3}\right)$ 8: $15.0\left(1-\mathrm{CH}_{3}\right), 21.0\left(\mathrm{CH}_{2}, \mathrm{C}-3\right), 26.4,26.7,28.4\left(\mathrm{CH}_{2}\right.$, C-6, C-7 and C-8), 34.0, $34.8\left(\mathrm{CH}_{2}, \mathrm{C}-4\right.$ and C-5), $36.4(\mathrm{CH}, \mathrm{C}-4 \mathrm{a}), 37.4\left(\mathrm{CH}_{2}, \mathrm{C}-2\right)$, 46.7 (C, C-1), $47.1(\mathrm{CH}, \mathrm{C}-8 \mathrm{a}), 51.6\left(1-\mathrm{CO}_{2} \mathrm{CH}_{3}\right), 179.0\left(1-\mathrm{CO}_{2} \mathrm{CH}_{3}\right)$.

LRMS (m/z): $210\left(\mathrm{M}^{+}, 52 \%\right), 178$ (50), 151 (91), 123 (31), 101 (38), 95 (100). 
HRMS: $\mathrm{C}_{13} \mathrm{H}_{22} \mathrm{O}_{2}\left(\mathrm{M}^{+}\right)$requires 210.1620, found 210.1619 .

(1SR, 4aRS, 8aSR)-decahydro-1-methylnapthalene-1-carboxylic acid (6.10)
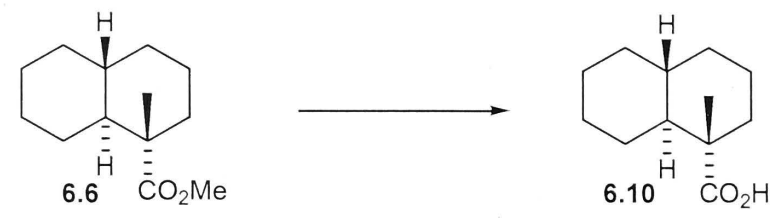

Method A: Lithium hydroxide $(0.28 \mathrm{~g}, 6.71 \mathrm{mmol})$ was added to a solution of ester $\mathbf{6 . 6}$ $(0.28 \mathrm{~g}, 1.34 \mathrm{mmol})$ in methanol : water $(3: 1,10 \mathrm{~mL})$ and the resulting reaction mixture was heated at reflux for $24 \mathrm{~h}$. The methanol was then removed in vacuo, and the aqueous residue extracted with ethyl acetate $(3 \times 5 \mathrm{~mL})$. The combined organic extracts were washed with brine, dried over $\mathrm{MgSO}_{4}$ and concentrated in vacuo to give a colourless oil. Purification by flash column chromatography using ethyl acetate : petroleum spirit $(5: 95)$ with $1 \%$ acetic acid as eluant gave the title compound $\mathbf{6 . 1 0}$ $(0.11 \mathrm{~g}, 42 \%)$ as a colourless oil.

Method B: Freshly distilled propane thiol $(0.70 \mathrm{~mL}, 7.72 \mathrm{mmol})$ was added to a degassed suspension of sodium hydride $(0.24 \mathrm{~g}, 10 \mathrm{mmol})$ in HMPA $(5 \mathrm{~mL})$ at room temperature under nitrogen. The resulting reaction mixture was stirred for $2 \mathrm{~h}$, then left to stand for $1 \mathrm{~h}$.

An aliquot of the thiolate solution prepared above $(0.38 \mathrm{~mL}, 0.57 \mathrm{mmol})$ was added to a solution of ester $\mathbf{6 . 6}(0.039 \mathrm{~g}, 0.19 \mathrm{mmol})$ in HMPA $(0.4 \mathrm{~mL})$ at room temperature under nitrogen. The reaction mixture was stirred for $14 \mathrm{~h}$, after which time ethyl acetate $(5 \mathrm{~mL})$ was added and the crude carboxylic acid was extracted with water : saturated sodium bicarbonate $(2: 1,3 \times 10 \mathrm{~mL})$. The combined aqueous washings were treated with $1 M$ hydrochloric acid until pH 2 then the solution was extracted with ethyl acetate $(4 \times 5 \mathrm{~mL})$. The combined organic extracts were washed with a saturated copper (II) chloride solution $(2 \times 5 \mathrm{~mL})$, brine $(5 \mathrm{~mL})$ and dried over $\mathrm{MgSO}_{4}$. Concentration of the organic phase in vacuo gave a yellow gum, which was purified by flash column chromatography on silica gel using ethyl acetate : petroleum spirit (1:9) as eluant to give the title compound $\mathbf{6 . 1 0}(0.031 \mathrm{~g}, 83 \%)$ as a colourless oil.

IR (thin film) $\mathbf{c m}^{-1}$ : 3000 br $(\mathrm{C}-\mathrm{OH}), 2923 \mathrm{~s}(\mathrm{C}-\mathrm{H}), 1696 \mathrm{~s}(\mathrm{C}=\mathrm{O}), 1447,1404,1294$, $1277,1244,1164$. 
${ }^{1}$ H NMR (300 MHz, $\left.\mathbf{C D C l}_{3}\right)$ 8: 0.85-1.82 (m, 16H, H-2, H-3, H-4, H-4a, H-5, H-6, H-

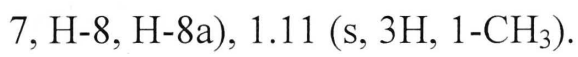

${ }^{13}$ C NMR (75 MHz, $\left.\mathbf{C D C l}_{3}\right)$ 8: $14.8\left(1-\mathrm{CH}_{3}\right), 21.0\left(\mathrm{CH}_{2}, \mathrm{C}-3\right), 26.4,26.8,28.4\left(\mathrm{CH}_{2}\right.$, C-6, C-7 and C-8), 34.0, $34.9\left(\mathrm{CH}_{2}, \mathrm{C}-4\right.$ and C-5), $36.4(\mathrm{CH}, \mathrm{C}-4 \mathrm{a}), 37.4\left(\mathrm{CH}_{2}, \mathrm{C}-2\right)$, $46.5(\mathrm{C}, \mathrm{C}-1), 46.9(\mathrm{CH}, \mathrm{C}-8 \mathrm{a}), 185.5\left(1-\mathrm{CO}_{2} \mathrm{H}\right)$.

LRMS (m/z): $196\left(\mathrm{M}^{+}, 63 \%\right), 178$ (46), 151 (72), 123 (54), 110 (49), 96 (52), 95 (100).

HRMS: $\mathrm{C}_{12} \mathrm{H}_{20} \mathrm{O}_{2}\left(\mathrm{M}^{+}\right)$requires 196.1463, found 196.1466 .

\section{(1SR, 4aRS, 8aSR)-decahydro-1-methylnaphthalen-1-amine (6.13)}
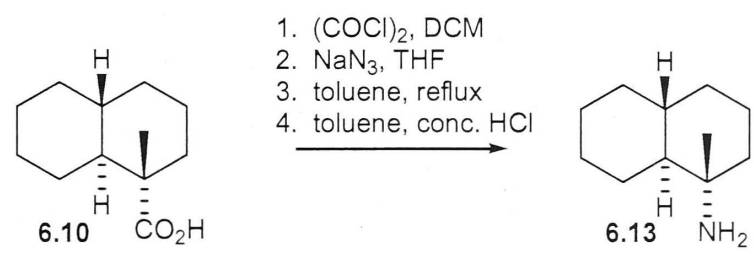

Oxalyl chloride $(0.13 \mathrm{~mL}, 1.50 \mathrm{mmol})$ was added to the dicarboxylic acid $\mathbf{6 . 1 0}(0.029 \mathrm{~g}$, $0.15 \mathrm{mmol})$ in DCM (3 mL) at room temperature under nitrogen. After $1.5 \mathrm{~h}$, analysis by IR spectroscopy revealed a peak at $1783 \mathrm{~cm}^{-1}$, due to the formation of an acid chloride. The reaction mixture was concentrated in vacuo and dried under high vacuum for $5 \mathrm{~min}$.

The crude acid chloride was taken up in THF $(3 \mathrm{~mL})$ and sodium azide $(0.098 \mathrm{~g} 1.50$ mmol) was added. The resulting reaction mixture was stirred for $18 \mathrm{~h}$, after which time analysis by IR spectroscopy revealed the disappearance of the peak at $1783 \mathrm{~cm}^{-1}$, and the formation of a peak at $2130 \mathrm{~cm}^{-1}$, due to the formation of an acyl azide. The reaction mixture was then diluted with water $(5 \mathrm{~mL})$ and extracted with ethyl acetate $(5$ x $5 \mathrm{~mL}$ ). The combined organic extracts were then dried over $\mathrm{MgSO}_{4}$ and concentrated in vacuo to give the crude acyl azide 6.11 as a yellow oil.

Toluene $(3 \mathrm{~mL})$ was added to the crude acyl azide 6.11 and the resulting solution was heated to reflux for $15 \mathrm{~min}$ then cooled to room temperature. Analysis by IR spectoscopy revealed a new peak at $2256 \mathrm{~cm}^{-1}$, and the disappearance of the peak at $2130 \mathrm{~cm}^{-1}$, indicating that the desired isocyanate 6.12 had formed. Concentrated hydrochloric acid $(0.3 \mathrm{~mL})$ was then added to the isocyanate in toluene and the mixture 
heated to $100{ }^{\circ} \mathrm{C}$ for $20 \mathrm{~h}$. After cooling the solution to room temperature, the mixture was extracted with water $(2 \times 10 \mathrm{~mL})$. The combined aqueous layers were treated with $10 \%$ aqueous sodium hydroxide until $\mathrm{pH} 10$, then extracted with chloroform $(3 \times 15$ $\mathrm{mL}$ ). The combined organic extracts were dried over $\mathrm{MgSO}_{4}$ and concentrated to give the title compound $\mathbf{6 . 1 3}$ (0.012 g, 48\% over four steps) as a white wax.

IR (thin film) $\mathbf{c m}^{-1}$ : 3351 br $\left(\mathrm{NH}_{2}\right), 2922(\mathrm{C}-\mathrm{H}), 1715,1598,1448,1378,1260,1171$, 1092.

${ }^{1}$ H NMR (300MHz, $\mathbf{C D C l}_{3}$ ) : : 0.76-1.85 (m, 18H, 1-NH $2, \mathrm{H}-2, \mathrm{H}-3, \mathrm{H}-4, \mathrm{H}-4 \mathrm{a}, \mathrm{H} 5$, H-6, H-7, H-8, H-8a), 0.97 (s, 3H, 1- $\mathrm{CH}_{3}$ ).

LRMS (m/z): $167\left(\mathrm{M}^{+}, 18 \%\right), 149$ (37), 124 (58), 105 (34), 81 (26), 70 (100).

HRMS: $\mathrm{C}_{11} \mathrm{H}_{21} \mathrm{~N}\left(\mathrm{M}^{+}\right)$requires 167.1674, found 167.1676.

(1RS, 2RS, 4RS, 4aSR, 10aSR, 1'SR) 4-(1'-Benzoyloxypropyl)-7-methoxy-1,2methyl-3,4,4a,9,10,10a-hexahydrophenanthrene-1(2H)-amine (6.16)

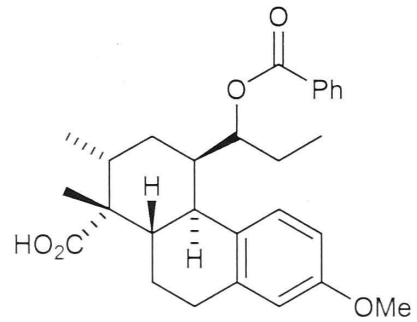

4.2
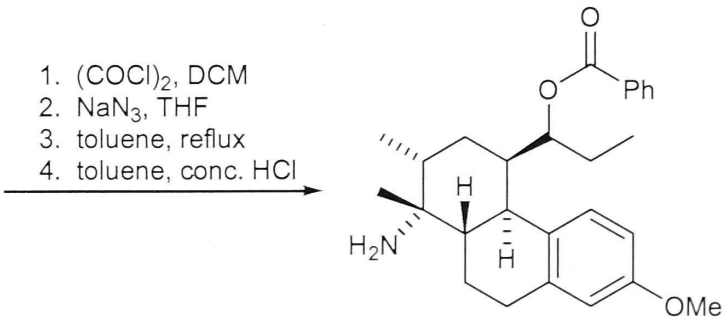

6.16

Oxalyl chloride $(0.11 \mathrm{~mL}, 1.30 \mathrm{mmol})$ was added to the dicarboxylic acid 4.2 (0.056 g, $0.13 \mathrm{mmol})$ in DCM (3 mL) at room temperature under nitrogen. After $1.5 \mathrm{~h}$, analysis by IR spectroscopy revealed a peak at $1779 \mathrm{~cm}^{-1}$, due to the formation of an acid chloride. The reaction mixture was concentrated in vacuo and dried under high vacuum for $5 \mathrm{~min}$.

The crude acid chloride was taken up in THF $(3 \mathrm{~mL})$ and sodium azide $(0.081 \mathrm{~g} 1.30$ mmol) was added. The resulting reaction mixture was stirred for $18 \mathrm{~h}$, after which time analysis by IR spectroscopy revealed the disappearance of the peak at $1779 \mathrm{~cm}^{-1}$, and the formation of a peak at $2129 \mathrm{~cm}^{-1}$, due to the formation of an acyl azide. The reaction mixture was then diluted with water $(5 \mathrm{~mL})$ and extracted with ethyl acetate $(5$ 
x $5 \mathrm{~mL}$ ). The combined organic extracts were then dried over $\mathrm{MgSO}_{4}$ and concentrated in vacuo to give the crude acyl azide $\mathbf{6 . 1 4}$ as a yellow oil.

Toluene $(3 \mathrm{~mL})$ was added to the crude acyl azide $\mathbf{6 . 1 4}$ and the resulting solution was heated to reflux for $15 \mathrm{~min}$ then cooled to room temperature. Analysis by IR spectoscopy revealed a new peak at $2259 \mathrm{~cm}^{-1}$, and the disappearance of the peak at $2129 \mathrm{~cm}^{-1}$, indicating that the desired isocyanate $\mathbf{6 . 1 5}$ had formed. Concentrated hydrochloric acid $(0.3 \mathrm{~mL})$ was then added to the isocyanate in toluene and the mixture heated to $100{ }^{\circ} \mathrm{C}$ for $24 \mathrm{~h}$. After cooling the solution to room temperature, the mixture was extracted with water $(2 \times 10 \mathrm{~mL})$. The combined aqueous layers were treated with $10 \%$ aqueous sodium hydroxide until $\mathrm{pH} 10$, then extracted with chloroform $(3 \times 15$ $\mathrm{mL}$ ). The combined organic extracts were dried over $\mathrm{MgSO}_{4}$ and concentrated to give the title compound $\mathbf{6 . 1 6}$ (0.015 g, 29\% over four steps) as a white wax and recovered isocyanate $6.15(\sim 0.04 \mathrm{~g})$.

(1RS, 2RS, 4RS, 4aSR, 10a $R$, 1'SR) 4-(1'-Benzoyloxypropyl)-7-methoxy-1,2methyl-3,4,4a,9,10,10a-hexahydrophenanthrene-1(2H)-isocyanate $(6.15)$

IR (thin film) $\mathbf{c m}^{-1}: 2924(\mathrm{C}-\mathrm{H}), 2260(\mathrm{~N}=\mathrm{C}=\mathrm{O}), 1709,1611,1502,1463,1273$.

${ }^{1} \mathbf{H}$ NMR (300 MHz, $\left.\mathbf{C D C l}_{3}\right)$ 8: $0.87\left(\mathrm{t}, J_{3^{\prime}, 2^{\prime}}=7.2 \mathrm{~Hz}, 3 \mathrm{H}, \mathrm{H}-3^{\prime}\right), 1.04(\mathrm{~d}, J=5.7 \mathrm{~Hz}$, 3H, 2- $\mathrm{CH}_{3}$ ), 1.11-2.59 (m, 13H, 1- $\mathrm{CH}_{3}, \mathrm{H}-2$ ', H-3, H-2, H-10, H-10a, H-9), 3.12 (m, $1 \mathrm{H}, \mathrm{H}-4), 3.42$ (s, 3H, 7-OCH $), 3.55$ (m, 1H, H-4a), 5.57 (ddd, $J=10.5 \mathrm{~Hz}, J=8.1 \mathrm{~Hz}$, $\left.J=3.0 \mathrm{~Hz}, 1 \mathrm{H}, \mathrm{H}-1^{\prime}\right), 5.99\left(\mathrm{~d}, J_{8,6}=3.0 \mathrm{~Hz}, 1 \mathrm{H}, \mathrm{H}-8\right), 6.51\left(\mathrm{dd}, J_{6,5}=8.7 \mathrm{~Hz}, J_{6,8}=3.0\right.$ Hz, 1H, H-6), 7.16-7.42 (m, 6H, H-5, H-2", H-3", H-4").

LRMS (m/z): $447\left(\mathrm{M}^{+}, 65 \%\right), 404$ (10), $316(20), 282$ (82), 240 (100), 228 (60), 225 (41).

HRMS: $\mathrm{C}_{28} \mathrm{H}_{33} \mathrm{NO}_{4}\left(\mathrm{M}^{+}\right)$requires 447.2410, found 447.2406.

(1RS, 2RS, 4RS, 4aSR, 10aSR, 1'SR) 4-(1'-Benzoyloxypropyl)-7-methoxy-1,2methyl-3,4,4a,9,10,10a-hexahydrophenanthrene-1 $(2 H)$-amine $(6.16)$

LRMS (m/z): $421\left(\mathrm{M}^{+}, 10 \%\right), 404$ (10), 282 (52), 240 (100), 225 (12), 105 (37). 
HRMS: $\mathrm{C}_{27} \mathrm{H}_{35} \mathrm{NO}_{3}\left(\mathrm{M}^{+}\right)$requires 421.2619, found 421.2617 .

\subsection{Chapter 6 Experimental}

\section{$( \pm)$-Dimethyl Isocycloamphilectane-7,20-dicarboxylate (6.1)}

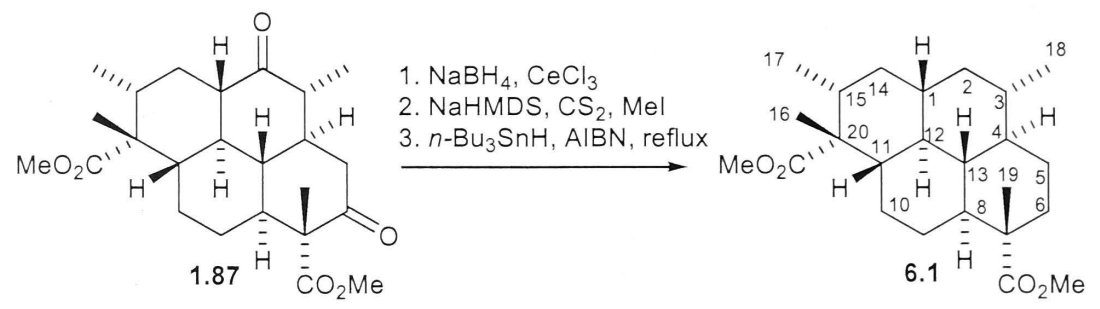

Dione 1.87 (0.028 g, $0.067 \mathrm{mmol})$ in $\mathrm{MeOH}(2 \mathrm{~mL})$ was added to cerium (III) chloride heptahydrate $(0.056 \mathrm{~g}, 0.15 \mathrm{mmol})$ under nitrogen. The solution was cooled to $0{ }^{\circ} \mathrm{C}$, and sodium borohydride $(0.01 \mathrm{~g}, 0.26 \mathrm{mmol})$ was added in four batches over $2 \mathrm{~h}$, until TLC revealed the consumption of all starting material. The reaction was quenched with water and the methanol was removed in vacuo. The aqueous residue was extracted with ethyl acetate $(3 \times 10 \mathrm{~mL})$, then the aqueous phase saturated with sodium chloride, and extracted with ethyl acetate $(2 \times 10 \mathrm{~mL})$. The combined organic extracts were washed with brine $(10 \mathrm{~mL})$ and dried over $\mathrm{MgSO}_{4}$. Concentration of the organic phase in vacuo gave the desired product as a mixture of four epimeric alcohols $(0.028 \mathrm{~g})$, which was used directly in the next step without further purification.

The crude diols $(0.028 \mathrm{~g}, 0.066 \mathrm{mmol})$ were dissolved in THF ( $3 \mathrm{~mL})$ and Sodium bis(trimethylsilyl)amide $(0.26 \mathrm{~mL}$ of a $1 \mathrm{M}$ solution in THF, $0.26 \mathrm{mmol})$ was added at room temperature under nitrogen. The resulting reaction mixture was stirred for $2 \mathrm{~h}$ then carbon disulfide $(0.016 \mathrm{~mL}, 0.26 \mathrm{mmol})$ was added. The reaction mixture was stirred for $2 \mathrm{~h}$ and then iodomethane $(0.016 \mathrm{~mL}, 0.26 \mathrm{mmol})$ was added. After a further $2 \mathrm{~h}$, the reaction was quenched with acetic acid $(0.5 \mathrm{~mL})$ and diluted with a saturated aqueous ammonium chloride solution, before extracting with ethyl acetate $(4 \times 10 \mathrm{~mL})$. The combined organic extracts were dried over $\mathrm{MgSO}_{4}$ and concentrated in vacuo to give the crude product as a mixture of four epimeric xanthates $(\sim 0.40 \mathrm{~g})$, which was used directly in the next step without further purification.

The crude xanthate esters $(\sim 0.40 \mathrm{~g}, 0.066 \mathrm{mmol})$ were dissolved in toluene ( $3 \mathrm{~mL})$ and tributyl tin hydride $(0.071 \mathrm{~mL}, 0.26 \mathrm{mmol})$ was added under nitrogen. A catalytic amount of AIBN was added and the reaction mixture heated to $80{ }^{\circ} \mathrm{C}$ for $2.5 \mathrm{~h}$, after which time starting material remained so excess tribuyl tin hydride $(0.03 \mathrm{~mL}, 0.11$ 
mmol) and AIBN (catalytic) were added. After $1 \mathrm{~h}$ at $80{ }^{\circ} \mathrm{C}$ TLC revealed the consumption of all starting material. The toluene was removed in vacuo and the residue purified by flash column chromatography on silica gel using ethyl acetate : petroleum spirit ( $5: 95)$ as eluant to give the title compound $\mathbf{6 . 1}(7.1 \mathrm{mg}, 27 \%$ over 3 steps) as a white oil, and a mono-deoxygenated product (11 mg, $40 \%$ over 3 steps), which was recycled to give the title compound $\mathbf{6 . 1}(5.1 \mathrm{mg}),(12.2 \mathrm{mg}, 47 \%$ total yield of the title compound over three steps).

IR (thin film) $\mathbf{c m}^{-\mathbf{1}}$ : 2925s (C-H), 1726s (C=O), 1456, 1260, 1160, 1097.

${ }^{1} \mathbf{H}$ NMR (600 MHz, $\left.\mathbf{C D C l}_{3}\right)$ ): $0.68(\mathrm{ddd}, 3 \mathrm{x} J=10.8 \mathrm{~Hz}, 1 \mathrm{H}), 0.83(\mathrm{~d}, J=6.6 \mathrm{~Hz}$, $\left.3 \mathrm{H}, 17-\mathrm{CH}_{3}\right), 0.86\left(\mathrm{~d}, J=6.6 \mathrm{~Hz}, 3 \mathrm{H}, 18-\mathrm{CH}_{3}\right), 0.74-0.91(\mathrm{~m}, 4 \mathrm{H}), 1.08(\mathrm{~s}, 3 \mathrm{H}, 16-$ $\left.\mathrm{CH}_{3}\right), 1.19\left(\mathrm{~s}, 3 \mathrm{H}, 19-\mathrm{CH}_{3}\right), 0.96-1.21(\mathrm{~m}, 4 \mathrm{H}), 1.23-1.45(\mathrm{~m}, 5 \mathrm{H}), 1.53-1.63(\mathrm{~m}, 3 \mathrm{H})$, $1.72-1.85(\mathrm{~m}, 3 \mathrm{H}), 3.62\left(\mathrm{~s}, 3 \mathrm{H}, 20-\mathrm{CO}_{2} \mathrm{CH}_{3}\right), 3.64\left(\mathrm{~s}, 3 \mathrm{H}, 7-\mathrm{CO}_{2} \mathrm{CH}_{3}\right)$.

${ }^{13}$ C NMR (150 MHz, $\left.\mathbf{C D C l}_{3}\right)$ 8: $15.1\left(16-\mathrm{CH}_{3}\right), 17.4\left(17-\mathrm{CH}_{3}\right), 19.9\left(18-\mathrm{CH}_{3}\right), 23.4$ (19- $\left.\mathrm{CH}_{3}\right), 25.2\left(\mathrm{CH}_{2}\right), 27.2\left(\mathrm{CH}_{2}\right), 28.5\left(\mathrm{CH}_{2}\right), 36.7\left(\mathrm{CH}_{2}\right.$ and $\left.\mathrm{CH}\right), 38.4\left(\mathrm{CH}_{2}\right), 40.5$ $(\mathrm{CH}), 41.0(\mathrm{CH}), 42.7\left(\mathrm{CH}_{2}, \mathrm{C}-6\right), 45.0(\mathrm{CH}), 45.4(\mathrm{CH}), 46.2(\mathrm{CH}), 46.6(\mathrm{C}), 48.2$ $(\mathrm{CH}), 50.2(\mathrm{C}), 50.3(\mathrm{CH}), 50.7\left(\mathrm{CO}_{2} \mathrm{CH}_{3}\right), 51.7\left(\mathrm{CO}_{2} \mathrm{CH}_{3}\right), 175.3\left(20-\mathrm{CO}_{2} \mathrm{CH}_{3}\right), 179.1$ $\left(7-\mathrm{CO}_{2} \mathrm{CH}_{3}\right)$.

LRMS (m/z): $390\left(\mathrm{M}^{+}, 25 \%\right), 330$ (100), 271 (92), 217 (24), 201 (20), 149 (34), 81 (53), 69 (98).

HRMS: $\mathrm{C}_{24} \mathrm{H}_{38} \mathrm{O}_{4}\left(\mathrm{M}^{+}\right)$requires 390.2770 , found 390.2763 .

( \pm )-7-(2'-Methoxmethoxyethyl) 20-Methyl-isocycloamphilectan-7,20-dicarboxylate (6.2)

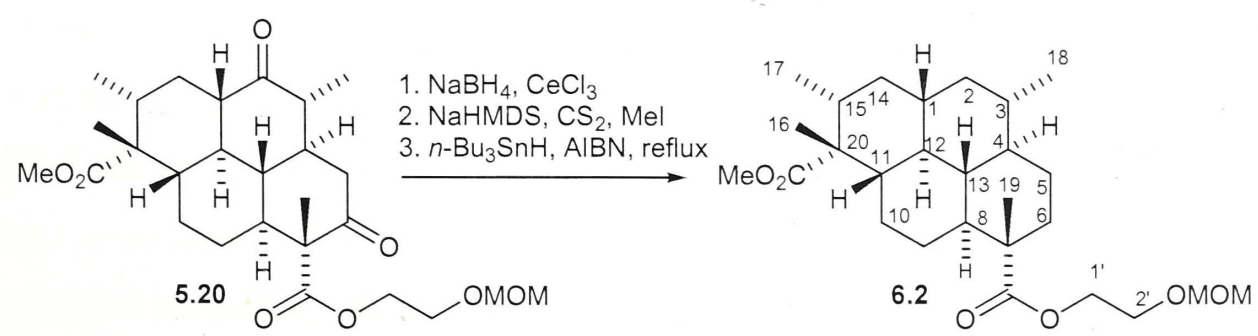


Dione 5.20 (0.019 g, $0.039 \mathrm{mmol})$ in $\mathrm{MeOH}(2 \mathrm{~mL})$ was added to cerium (III) chloride heptahydrate $(0.032 \mathrm{~g}, 0.085 \mathrm{mmol})$ under nitrogen. The solution was cooled to $0{ }^{\circ} \mathrm{C}$, and sodium borohydride $(0.006 \mathrm{~g}, 0.16 \mathrm{mmol})$ was added in four batches over $2 \mathrm{~h}$, until TLC revealed the consumption of all starting material. The reaction was quenched with water and the methanol was removed in vacuo. The aqueous residue was extracted with ethyl acetate $(3 \times 10 \mathrm{~mL})$, then the aqueous phase saturated with sodium chloride, and extracted with ethyl acetate $(2 \times 10 \mathrm{~mL})$. The combined organic extracts were washed with brine $(10 \mathrm{~mL})$ and dried over $\mathrm{MgSO}_{4}$. Concentration of the organic phase in vacuo gave the desired product as a mixture of four epimeric alcohols $(0.019 \mathrm{~g})$, which was used directly in the next step without further purification.

The crude diols (0.019 g, $0.038 \mathrm{mmol})$ were dissolved in THF (3 mL) and Sodium bis(trimethylsilyl)amide $(0.23 \mathrm{~mL}$ of a $1 \mathrm{M}$ solution in THF, $0.23 \mathrm{mmol})$ was added at room temperature under nitrogen. The resulting reaction mixture was stirred for $2 \mathrm{~h}$ then carbon disulfide $(0.017 \mathrm{~mL}, 0.23 \mathrm{mmol})$ was added. The reaction mixture was stirred for $2 \mathrm{~h}$ and then iodomethane $(0.014 \mathrm{~mL}, 0.23 \mathrm{mmol})$ was added. After a further $2 \mathrm{~h}$, the reaction was quenched with acetic acid $(0.5 \mathrm{~mL})$ and diluted with a saturated aqueous ammonium chloride solution, before extracting with ethyl acetate $(4 \times 10 \mathrm{~mL})$. The combined organic extracts were dried over $\mathrm{MgSO}_{4}$ and concentrated in vacuo to give the crude product as a mixture of four epimeric xanthates $(\sim 0.03 \mathrm{~g})$, which was used directly in the next step without further purification.

The crude xanthate esters $(\sim 0.03 \mathrm{~g})$ were dissolved in toluene $(3 \mathrm{~mL})$ and tributyl tin hydride $(0.049 \mathrm{~mL}, 0.18 \mathrm{mmol})$ was added under nitrogen. A catalytic amount of AIBN was added and the reaction mixture heated to $80^{\circ} \mathrm{C}$ for $2.5 \mathrm{~h}$, after which time starting material remained so excess tributyl tin hydride $(0.025 \mathrm{~mL}, 0.09 \mathrm{mmol})$ and AIBN (catalytic) were added. After $1 \mathrm{~h}$ at $80{ }^{\circ} \mathrm{C}$ TLC revealed the consumption of all starting material. The toluene was removed in vacuo and the residue purified by flash column chromatography on silica gel using ethyl acetate : petroleum spirit (1:9) as eluant to give the title compound $\mathbf{6 . 2}$ (7 mg, 39\% over 3 steps) as a white oil, and a monodeoxygenated product (6 mg, 33\% over 3 steps).

IR (thin film) $\mathbf{c m}^{-1}$ : 2926s (C-H), 1725s (C=O), 1459, 1382, 1255, 1230, 1157, 1042.

${ }^{1} \mathrm{H}$ NMR $\left(300 \mathrm{MHz}, \mathbf{C D C l}_{3}\right) \delta: 0.68(\mathrm{ddd}, 3 \mathrm{x} J=9.9 \mathrm{~Hz}, 1 \mathrm{H}), 0.83(\mathrm{~d}, J=6.0 \mathrm{~Hz}, 3 \mathrm{H}$, $\left.17-\mathrm{CH}_{3}\right), 0.86\left(\mathrm{~d}, J=6.3 \mathrm{~Hz}, 3 \mathrm{H}, 18-\mathrm{CH}_{3}\right), 1.09$ (s, 3H, 16- $\left.\mathrm{CH}_{3}\right), 1.19$ (s, 3H, 19- $\left.\mathrm{CH}_{3}\right)$, 0.73-1.43 (m, 12H), 1.51-1.67 (m, 4H), 1.72-1.84 (m, 3H), $3.36\left(\mathrm{~s}, 3 \mathrm{H}, 2\right.$ '- $\left.\mathrm{OCH}_{2} \mathrm{OCH}_{3}\right)$, 
$3.61\left(\mathrm{~s}, 3 \mathrm{H}, 20-\mathrm{CO}_{2} \mathrm{CH}_{3}\right), 3.69-3.73\left(\mathrm{~m}, 2 \mathrm{H}, 2^{\prime}-\mathrm{H}\right), 4.22-4.25\left(\mathrm{~m}, 2 \mathrm{H}, 1^{\prime}-\mathrm{H}\right), 4.62(\mathrm{~s}, 2 \mathrm{H}$, $\left.2^{\prime}-\mathrm{OCH}_{2} \mathrm{OCH}_{3}\right)$.

${ }^{13} \mathbf{C}$ NMR (75 MHz, $\left.\mathbf{C D C l}_{3}\right)$ 8: $15.1\left(16-\mathrm{CH}_{3}\right), 17.4\left(17-\mathrm{CH}_{3}\right), 19.9\left(18-\mathrm{CH}_{3}\right), 23.4$ (19- $\left.\mathrm{CH}_{3}\right), 25.2\left(\mathrm{CH}_{2}\right), 27.2\left(\mathrm{CH}_{2}\right), 28.5\left(\mathrm{CH}_{2}\right), 36.7\left(\mathrm{CH}_{2}\right.$ and $\left.\mathrm{CH}\right), 38.4\left(\mathrm{CH}_{2}\right), 40.5$ $(\mathrm{CH}), 41.0(\mathrm{CH}), 42.7\left(\mathrm{CH}_{2}, \mathrm{C}-6\right), 44.9(\mathrm{CH}), 45.4(\mathrm{CH}), 46.2(\mathrm{CH}), 46.6(\mathrm{C}), 48.2$ $(\mathrm{CH}), 50.2(\mathrm{C}), 50.3(\mathrm{CH}), 50.7\left(20-\mathrm{CO}_{2} \mathrm{CH}_{3}\right), 55.2\left(2^{\prime}-\mathrm{OCH}_{2} \mathrm{OCH}_{3}\right), 63.4\left(\mathrm{CH}_{2}, \mathrm{C}-1^{\prime}\right)$, $65.6\left(\mathrm{CH}_{2}, \mathrm{C}-2^{\prime}\right), 96.4\left(2^{\prime}-\mathrm{OCH}_{2} \mathrm{OCH}_{3}\right), 175.3\left(20-\mathrm{CO}_{2} \mathrm{CH}_{3}\right), 178.5\left(7-\mathrm{CO}_{2} \mathrm{R}\right)$.

LRMS (m/z): $464\left(\mathrm{M}^{+}, 5 \%\right), 419$ (15), 372 (10), 359 (12), 331 (31), 271 (100), 215 (15), 201 (15).

HRMS: $\mathrm{C}_{27} \mathrm{H}_{44} \mathrm{O}_{6}\left(\mathrm{M}^{+}\right)$requires 464.3138 , found 464.3142 .

\section{( \pm )-Isocycloamphilectane-7,20-dicarboxylic Acid (1.62)}

\section{Method A:}
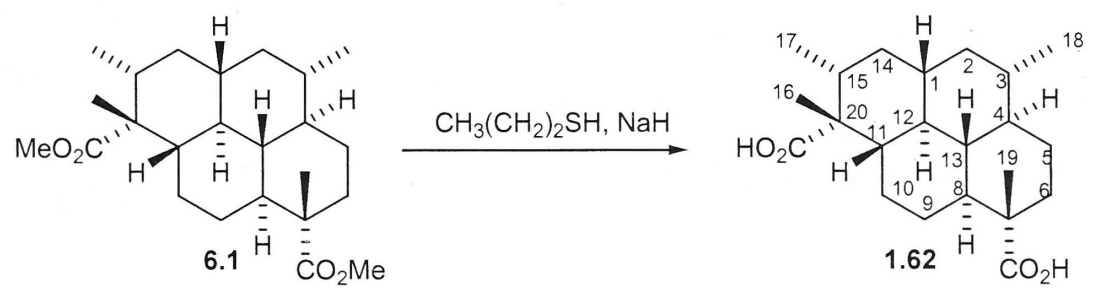

Freshly distilled propane thiol $(0.35 \mathrm{~mL}, 3.87 \mathrm{mmol})$ was added to a degassed suspension of sodium hydride $(0.12 \mathrm{~g}, 5.0 \mathrm{mmol})$ in HMPA $(2.5 \mathrm{~mL})$ under nitrogen. The reaction mixture was stirred for $2 \mathrm{~h}$ then left to stand for $1 \mathrm{~h}$ at room temperature.

An aliquot of the thiolate solution prepared above $(0.19 \mathrm{~mL}, 0.30 \mathrm{mmol})$ was added to a solution of diester $6.1(0.015 \mathrm{~g}, 0.038 \mathrm{mmol})$ in HMPA $(0.3 \mathrm{~mL})$ at room temperature under nitrogen. The reaction mixture was stirred for $1.5 \mathrm{~d}$, after which time ethyl acetate $(5 \mathrm{~mL})$ was added and the crude carboxylic acid was extracted with a solution of water and saturated sodium bicarbonate $(2: 1,3 \times 10 \mathrm{~mL})$. The combined aqueous washings were treated with $1 M$ hydrochloric acid until $\mathrm{pH} 2$, then the resulting mixture was extracted with ethyl acetate $(4 \times 5 \mathrm{~mL})$. The combined organic extracts were washed with saturated copper (II) chloride solution $(2 \times 5 \mathrm{~mL})$, brine and dried over $\mathrm{MgSO}_{4}$. Concentration of the organic phase in vacuo gave a yellow gum, which was 
purified by flash column chromatography on silica gel using ethyl acetate : petroleum spirit (1:4) as eluant to give the title compound $\mathbf{1 . 6 2}(0.012 \mathrm{~g}, 87 \%)$ as a white solid

\section{Method B:}
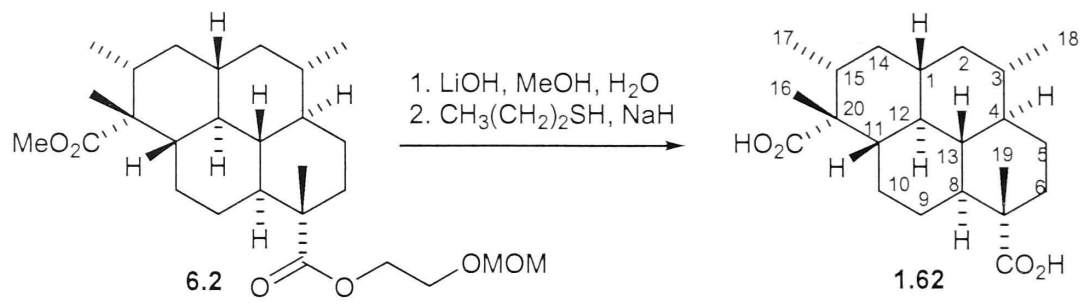

Lithium hydroxide $(13 \mathrm{mg}, 0.30 \mathrm{mmol})$ was added to ester $6.2(7 \mathrm{mg}, 0.015 \mathrm{mmol})$ in methanol : water $(3: 1,4 \mathrm{~mL})$ and the reaction mixture was heated at reflux for $24 \mathrm{~h}$. The reaction mixture was cooled to room temperature and the methanol removed in vacuo. The aqueous residue was then extracted with ethyl acetate $(3 \times 5 \mathrm{~mL})$ and the combined organic extracts dried over $\mathrm{MgSO}_{4}$. Concentration of the organic phase in vacuo gave the crude mixture ( $\sim 6 \mathrm{mg}$ ) as a colourless oil.

An aliquot of the thiolate solution prepared in method $\mathrm{A}(0.10 \mathrm{~mL}, 0.15 \mathrm{mmol})$ was added to a solution of crude mixture $(\sim 6 \mathrm{mg}, 0.015 \mathrm{mmol})$ in HMPA $(0.3 \mathrm{~mL})$ at room temperature under nitrogen. The reaction mixture was stirred for $1.5 \mathrm{~d}$, after which time ethyl acetate $(5 \mathrm{~mL})$ was added and the crude carboxylic acid was extracted with water: saturated sodium bicarbonate solution (2:1,3 x $10 \mathrm{~mL})$. The combined aqueous washings were treated with $1 M$ hydrochloric acid until $\mathrm{pH} 2$ then the residue was extracted with ethyl acetate $(4 \times 5 \mathrm{~mL})$. The combined organic extracts were washed with a saturated copper (II) chloride solution ( 2 x $5 \mathrm{~mL}$ ), brine and dried over $\mathrm{MgSO}_{4}$. Concentration of the organic phase in vacuo gave a yellow gum, which was purified by flash column chromatography on silica gel using ethyl acetate : petroleum spirit $(1: 4)$ as eluant to give the title compound $\mathbf{1 . 6 2}(\sim 1 \mathrm{mg}, \sim 20 \%$ over two steps $)$ as a white solid.

m.p: decomposed at $280^{\circ} \mathrm{C}$

IR (thin film) $\mathrm{cm}^{-1}$ : $3200 \mathrm{br}(\mathrm{C}-\mathrm{OH}), 2924 \mathrm{~s}(\mathrm{C}-\mathrm{H}), 1693 \mathrm{~s}(\mathrm{C}=\mathrm{O}), 1456,1379,1261$.

${ }^{1} \mathrm{H}$ NMR $\left(600 \mathrm{MHz}, \mathrm{CDCl}_{3}\right) \delta: 0.83\left(\mathrm{~d}, J=6.3 \mathrm{~Hz}, 3 \mathrm{H}, 17-\mathrm{CH}_{3}\right), 0.88(\mathrm{~d}, J=6.6 \mathrm{~Hz}$, $\left.3 \mathrm{H}, 18-\mathrm{CH}_{3}\right), 1.05$ (s, 3H, 16- $\left.\mathrm{CH}_{3}\right), 1.16$ (s, 3H, 19- $\left.\mathrm{CH}_{3}\right)$.

See dimethyl ester derivative 6.1 for full ${ }^{1} \mathrm{H}$ NMR characterisation. 
${ }^{13} \mathrm{C}$ NMR (75 MHz, $\left.\mathbf{C D C l}_{3}\right)$ 8: $14.9\left(16-\mathrm{CH}_{3}\right), 17.3 \cdot\left(17-\mathrm{CH}_{3}\right), 19.8\left(18-\mathrm{CH}_{3}\right), 23.4$ (19- $\left.\mathrm{CH}_{3}\right), 25.1\left(\mathrm{CH}_{2}\right), 27.0\left(\mathrm{CH}_{2}\right), 28.4\left(\mathrm{CH}_{2}\right), 36.6\left(\mathrm{CH}_{2}\right), 36.7(\mathrm{CH}), 38.2\left(\mathrm{CH}_{2}\right), 40.2$ $(\mathrm{CH}), 40.9(\mathrm{CH}), 42.7\left(\mathrm{CH}_{2}, \mathrm{C}-6\right), 44.9(\mathrm{CH}), 45.4(\mathrm{CH}), 46.0(\mathrm{CH}), 46.2(\mathrm{C}), 48.2$ $(\mathrm{CH}), 49.8,50.1,178.4\left(20-\mathrm{CO}_{2} \mathrm{H}\right), 182.1\left(7-\mathrm{CO}_{2} \mathrm{H}\right)$.

LRMS (m/z): $362\left(\mathrm{M}^{+}, 18 \%\right), 316$ (100), 298 (12), 271 (75), 262 (50), 217 (43), 201 (25), $161(20)$.

HRMS: $\mathrm{C}_{22} \mathrm{H}_{34} \mathrm{O}_{4}\left(\mathrm{M}^{+}\right)$requires 362.2457, found 362.2465.

\section{$( \pm)$-Isocycloamphilectane-7,20-diamine (1.63)}
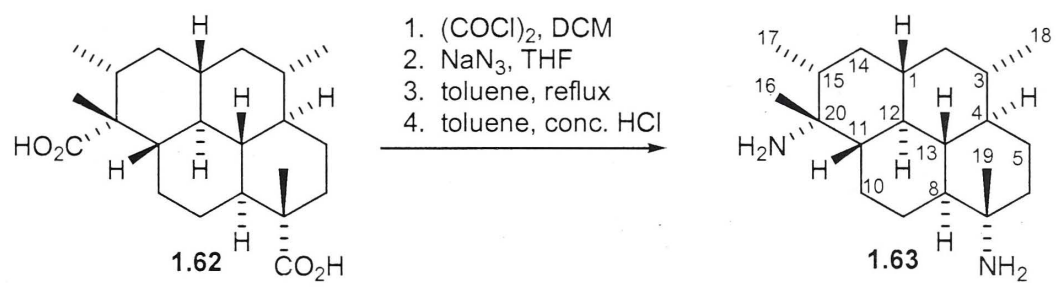

Oxalyl chloride $(0.072 \mathrm{~mL}, 0.83 \mathrm{mmol})$ was added to the dicarboxylic acid $\mathbf{1 . 6 2}(0.015$ $\mathrm{g}, 0.041 \mathrm{mmol})$ in DCM $(3 \mathrm{~mL})$ at room temperature under nitrogen. After $3 \mathrm{~h}$, analysis by IR spectroscopy revealed a peak at $1781 \mathrm{~cm}^{-1}$, due to the formation of an acid chloride. The reaction mixture was concentrated in vacuo and dried under high vacuum for $5 \mathrm{~min}$.

The crude acid chloride was taken up in THF $(3 \mathrm{~mL})$ and sodium azide $(0.054 \mathrm{~g} 0.83$ mmol) was added. The resulting reaction mixture was stirred for $18 \mathrm{~h}$, after which time analysis by IR spectroscopy revealed the disappearance of the peak at $1781 \mathrm{~cm}^{-1}$, and the formation of a peak at $2131 \mathrm{~cm}^{-1}$, due to the formation of an acyl azide. The reaction mixture was then diluted with water $(5 \mathrm{~mL})$ and extracted with ethyl acetate $(5$ x $5 \mathrm{~mL}$ ). The combined organic extracts were dried over $\mathrm{MgSO}_{4}$ and concentrated in vacuo to give the crude acyl azide $\mathbf{6 . 1 7}$ as a yellow oil.

Toluene $(3 \mathrm{~mL})$ was added to the crude acyl azide $\mathbf{6 . 1 7}$ and the resulting solution was heated to reflux for $15 \mathrm{~min}$ then cooled to room temperature. Analysis by IR spectoscopy revealed a new peak at $2260 \mathrm{~cm}^{-1}$, and the disappearance of the peak at $2131 \mathrm{~cm}^{-1}$, indicating that the desired isocyanate $\mathbf{6 . 1 8}$ had formed. Concentrated hydrochloric acid $(2 \mathrm{~mL})$ was then added to the isocyanate in toluene and the mixture heated to $100{ }^{\circ} \mathrm{C}$ for $18 \mathrm{~h}$. After cooling the solution to room temperature, the mixture was extracted with water $(2 \times 10 \mathrm{~mL})$. The combined aqueous layers were treated with 
$10 \%$ aqueous sodium hydroxide until $\mathrm{pH} 10$, then extracted with chloroform $(5 \times 10$ $\mathrm{mL}$ ). The combined organic extracts were dried over $\mathrm{MgSO}_{4}$ and concentrated to give the title compound $\mathbf{1 . 6 3}$ (4.70 mg, 39\% over three steps) as a white solid, which was further purified by reverse-phase HPLC on C-18 stationary phase heated to $40{ }^{\circ} \mathrm{C}(5$ $100 \%$ acetonitrile and $100-5 \%$ water gradient containing $0.1 \%$ TFA),

IR (thin film) $\mathbf{c m}^{-1}$ : 3368br (N-H), 2920s (C-H), 1729, 1642, 1544, 1455, 1378, 1261, 1101.

${ }^{1} \mathrm{H}$ NMR (600 MHz, CD 3 OD, measured on TFA salt) $\delta: 0.78$ (m, 1H), 0.86 (ddd, 3xJ $=10.2 \mathrm{~Hz}, 1 \mathrm{H}), 0.86-0.91(\mathrm{~m}, 1 \mathrm{H}), 0.92(\mathrm{~d}, J=6.6 \mathrm{~Hz}, 3 \mathrm{H}), 0.95(\mathrm{ddd}, 3 \mathrm{x} J=10.2 \mathrm{~Hz}$, $1 \mathrm{H}), 1.03(\mathrm{~d}, J=7.2 \mathrm{~Hz}, 3 \mathrm{H}), 1.03(\mathrm{~m}, 1 \mathrm{H}), 1.09-1.15(\mathrm{~m}, 2 \mathrm{H}), 1.20-1.28(\mathrm{~m}, 2 \mathrm{H}), 1.25$ $(\mathrm{s}, 3 \mathrm{H}), 1.30-1.35(\mathrm{~m}, 3 \mathrm{H}), 1.35(\mathrm{~s}, 3 \mathrm{H}), 1.53-1.63(\mathrm{~m}, 3 \mathrm{H}), 1.75(\mathrm{~m}, 1 \mathrm{H}), 1.86-1.91(\mathrm{~m}$, 2H), $1.99(\mathrm{~m}, 1 \mathrm{H}), 2.10(\mathrm{~m}, 1 \mathrm{H})$.

${ }^{13} \mathrm{C}$ NMR (200 MHz, CD $\mathbf{C D}_{3} \mathrm{OD}$ ) measured on TFA salt $\delta$ : 15.6, 18.0, 20.0, 22.2, 25.8, $26.1,26.8,37.6,37.8,38.6,40.4,41.9,43.1,46.8,47.2,48.2,58.0,60.4$. Two peaks obscured by $\mathrm{CD}_{3} \mathrm{OD}$.

LRMS (m/z): $304\left(M^{+}, 32 \%\right), 289$ (37), 256 (9), 221 (12), 204 (25), 105 (20), 84 (100).

HRMS: $\mathrm{C}_{20} \mathrm{H}_{36} \mathrm{~N}_{2}\left(\mathrm{M}^{+}\right)$requires 304.2878 , found 304.2876 . 
References 


\section{References}

(1) Wright, A. D.; König, G. J. Nat. Prod. 1996, 59, 710.

(2) Angerhofer, C. K.; Pezzuto, J. M.; König, G. M.; Wright, A. D.; Sticher, O. J. J. Nat. Prod. 1992, 55, 1787.

(3) Chang, C. W. J. In Progress in the Chemistry of Organic Natural Products; Springer Wien: New York, 2000; Vol. 80.

(4) Burreson, B. J.; Christophersen, C.; Scheuer, P. J. Tetrahedron 1975, 31, 2015.

(5) Patra, A.; Chang, C. W. J.; Scheuer, P. J. J. Am. Chem. Soc. 1984, 106, 7981.

(6) Chang, C. W. J.; Patra, A.; Roll, D. M.; Scheuer, P. J. J. Am. Chem. Soc. $\mathbf{1 9 8 4 , ~ 1 0 6 , ~} 4644$.

(7) Mijaoka, H.; Shimomura, M.; Kimura, H.; Yamada, Y. Tetrahedron 1998, 54, 4644.

(8) Baker, J. T.; Wells, R. J.; Oberhänsli, W. E.; Hawes, G. B. J. Am. Chem. Soc. 1976, 98, 4010.

(9) Kazlauskas, R.; Murphy, P. T.; Wells, R. J. Tetrahedron Lett. 1980, 21, 315.

(10) Garson, M. J. J. Chem. Soc., Chem. Commun. 1986, 35.

(11) König, G. M.; Wright, A. D.; Angerhofer, C. K. J. Org. Chem. 1996, 61, 3259 .

(12) Ciasullo, L.; Cutignano, A.; Casapullo, A.; Puliti, R.; Mattia, C. A.;

Debitus, C.; Riccio, R.; Gomez-Paloma, L. J. Nat. Prod. 2002, 65, 1210.

(13) Wright, A. D.; Wang, H.; Gurrath, M.; König, G. M.; Kocak, G.;

Newmann, G.; Loria, P.; Florey, M.; Tilley, L. J. Med. Chem. 2001, 44, 873.

(14) Schwarz, O.; Brun, R.; Bats, J. W.; Schmalz, J. G. Tetrahedron Lett. 2002, 43, 1009.

(15) Fookes, C. J. R.; Garson, M. J.; Macleod, J. K.; Skelton, B. W.; White, A. H. J. Chem. Soc., Perkin Trans. 1 1988, 1003.

(16) Simpson, J. S.; Garson, M. J. Tetrahedron Lett. 1999, 40, 3909.

(17) Garson, M. J. Nat. Prod. Rep. 1989, 6, 143.

(18) Piers, E.; Llinas-Brunet, M. J. J. Org. Chem. 1989, 54, 1483. 
(19) White, R. D.; Keaney, G. F.; Slown, C. D.; Wood, J. L. Organic Letters 2004, 6, 1123.

(20) Corey, E. J.; Magriotis, P. A. J. Am. Chem. Soc. 1987, 109, 287.

(21) Simpson, J. S.; Garson, M. J. Organic Biomolecular Chemistry 2004, 2, 939.

(22) Cossey, A. L.; Gunter, M. J.; Mander, L. N. Tetrahedron Lett. 1980, 21, 3309.

(23) Hook, J. M.; Mander, L. N.; Urech, R. Synthesis 1979, 374.

(24) Crabtree, S. R., PhD Thesis, Australian National University 1990.

(25) Caine, D. Organic Reactions 1976, 23, 1.

(26) Crabtree, S. R.; Chu, W. L. A.; Mander, L. N. Synlett 1990, 169.

(27) Spencer, T. A.; Weaver, T. D.; Villarica, R. M.; Friary, R. J.; Posler, J.;

Schwartz, M. A. J. Org. Chem. 1968, 33, 712.

(28) Kuehne, M. E. J. Org. Chem. 1970, 35, 171.

(29) Kuehne, M. E.; Nelson, J. A. J. Org. Chem. 1970, 35, 161.

(30) Fairweather, K. A., Honours Thesis, Australian National University 2002.

(31) Eliel, L. L.; Wilen, S. H.; Mander, L. N. Stereochemistry of Organic Compounds; Wiley Interscience: New York, 1994.

(32) Wenkert, E. Acc. Chem. Res. 1980, 13, 27.

(33) Dess, D. B.; Martin, J. C. J. Org. Chem. 1983, 48, 4155.

(34) Jorgensen, M.; Krebs, F. C.; Bechgaard, K. J. Org. Chem. 2000, 65, 8783.

(35) Faure, R.; Pommier, A.; Pons, J. M.; Rajzmann, M.; Santelli, M. Tetrahedron 1992, 48, 8419.

(36) Baddeley, G. V.; Jefferies, P. R.; Retallack, R. W. Tetrahedron 1964, 20, 1983.

(37) Hubbard, J. L. Encyclopedia of Reagents for Organic Synthesis; Wiley: Chichester, 1995.

(38) Greene, T. W.; Wuts, P. G. M. Protective Groups in Organic Synthesis; Second Edition ed.; Wiley: New York, 1991.

(39) Corey, E. J.; Cho, H.; Rucker, C.; Hua, D. H. Tetrahedron Lett. 1981, 22, 3455 .

(40) O'Connor, P. D., PhD thesis, Australian National University 2004.

(41) Crabtree, S. R.; Mander, L. N.; Sethi, S. P. Org. Synth. 1992, 256. 
(42) Trost, Barry M.; Hiemstra, H. Tetrahedron 1986, 42, 3323.

(43) Paquette, L. A.; Belmont, D. T.; Hsu, Y. L. J. Org. Chem. 1985, 50, 4667.

(44) Ye, B.; Yao, Z. J.; Terrence, R.; Burke, J. J. Org. Chem. 1997, 62, 5428.

(45) Nagata, W.; Sugasawa, T.; Narisada, M.; Wakabayashi, T.; Hayase, Y. J. Am. Chem. Soc. 1967, 89, 1483.

(46) Mander, L. N.; Sethi, S. P. Tetrahedron Lett. 1983, 24, 5425.

(47) Llera, J. M.; Fraser-Reid, B. J. Org. Chem. 1989, 54, 5544.

(48) Ito, Y.; Hirao, T.; Saegusa, T. J. Org. Chem. 1978, 43, 1011.

(49) Charette, A. B.; Beauchemine, Z. Organic Reactions 2001, 58, 1.

(50) Furukawa, J.; Kawabata, N.; Nishimura, J. Tetrahedron 1968, 24, 53.

(51) Furukawa, J.; Kawabata, N.; Nishimura, J. Tetrahedron Lett. 1966, 28, 3353.

(52) Suda, M. Synthesis 1981, 714.

(53) Yang, Z.; Lorenz, J. C.; Shi, Y. Tetrahedron Lett. 1998, 39, 8621.

(54) Dalcanale, E.; Montanari, F. J. Org. Chem. 1986, 51, 567.

(55) Corey, E. J.; Gross, A. W. Tetrahedron Lett. 1984, 25, 495.

(56) Luche, J. L. J. Am. Chem. Soc. 1978, 100, 2226.

(57) Corey, E. J.; Ohno, R. B.; Mitra, R. B.; Vatakencherry, P. A. J. Am. Chem. Soc. 1964, 86, 478.

(58) Jenner, G. Tetrahedron 2002, 58, 5185.

(59) Kishner, N. J. Russ. Phys. Chem. Soc., 1911, 43, 582.

(60) Wolff, L. Justus Liebigs Ann. Chem. 1912, 394, 86.

(61) Todd, D. Organic Reactions 1948, 4, 378.

(62) Huang-Minlon J. Am. Chem. Soc. 1946, 68, 2487.

(63) Cram, D. J.; Sahyun, M. R. V.; Knox, G. R. J. Am. Chem. Soc. 1962, 84, 1734.

(64) Henbest, H. B.; Grundon, M. F.; Scott, M. D. J. Chem. Soc. 1963, 1855.

(65) Furrow, M. E.; Myers, A. G. J. Am. Chem. Soc. 2004, 126, 5436.

(66) Hutchins, R. O.; Maryanoff, B. E.; Milewski, C. A. J. Am. Chem. Soc. 1971, 93, 1793.

(67) Kim, S.; Ho Oh, C.; Ko, J. S.; Ahn, K. H.; Kim, Y. J. J. Org. Chem. 1985, 50, 1927.

(68) Taber, D. F.; Wang, Y.; Stachel, S. J. Tetrahedron Lett. 1993, 34, 6209. 
(69) Barton, D. H. R.; McCombie, S. W. J. Chem. Soc., Perkin Trans. 1 1975, 1574.

(70) Bartlett, P. A.; Johnson, W. S. Tetrahedron Lett. 1970, 4459.

(71) Smith, P. A. S. Organic Reactions 1946, 3, 337.

(72) Simpson, J. S.; Garson, M. J. Organic Biomolecular Chemistry 2004, 2, 939.

(73) Schultz, A. G.; Pettus, L. Tetrahedron Lett. 1997, 38, 5433.

(74) Sato, Y.; Sodeoka, M.; Shibasaki, M. J. Org. Chem. 1989, 54, 4738.

(75) Sato, Y.; Honda, T.; Shibasaki, M. Tetrahedron Lett. 1992, 33, 2593.

(76) Still, W. C.; Kahn, M.; Mitra, A. J. Org. Chem. 1978, 43, 2923.

(77) Dess, D. B.; Martin, J. C. J. Am. Chem. Soc. 1991, 113, 7277.

(78) Meyer, S. D.; Schreiber, S. L. J. Org. Chem. 1994, 59, 7549.

(79) Frigerio, M.; Santagostino, S. L. J. Org. Chem. 1999, 64, 4537.

(80) Furniss, B. S.; Hannaford, A. J.; Smith, P. N. G.; Tatchell, A. R. Vogel's Textbook of Practical Organic Chemistry; 5 ed.; Longman: London, 1991. 


\section{APPENDIX ONE}

\section{Organic Letters Publication}


Appendix 


\title{
A Formal Total Synthesis of the Marine Diterpenoid Diisocyanoadociane
}

XXXXX

Vol. 0, No. 0

$\mathrm{A}-\mathrm{D}$

\author{
Kelly A. Fairweather and Lewis N. Mander* \\ Research School of Chemistry, Australian National University, \\ Canberra, ACT 0200, Australia
}

mander@rsc.anu.edu.au

Received May 19, 2006

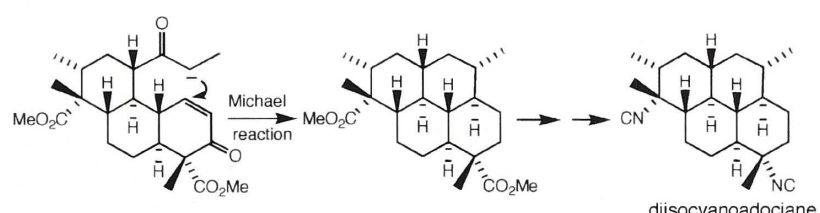

A formal total synthesis of diisocyanoadociane, a marine diterpenoid with potent antimalarial properties, has been completed. The synthesis begins with a phenanthrenoid precursor that is transformed into a pyrene-derived intermediate by means of an intramolecular Michael reaction. Nitrogen functionality is introduced via a double Curtius reaction.

Numerous diterpenes based on a wide range of carbon skeletons possessing one or more isonitrile substituents have been isolated from marine sponges. ${ }^{1}$ Many have been shown to have significant in vitro anti-malarial activity with the most potent being diisocyanoadociane (1), isolated originally from an Amphimedon species ${ }^{2}$ and subsequently from Cymbastela hooperi. ${ }^{3}$ The combination of biological activity ${ }^{4}$ with the unusual pyrene-based structure $\mathbf{2}$ has aroused the interest of synthetic chemists, and an elegant enantioselective synthesis (60\% ee) based on sequential Diels-Alder cycloadditions has been reported by Corey and Magriotis. ${ }^{5}$ In the final stages of their synthesis, however, the isonitrile groups were introduced without diastereochemical control. This intriguing molecule had also captured our attention, and we now disclose an alternative formal synthesis of $( \pm)-\mathbf{1}$ in which all 10 stereogenic centers have been introduced with complete diastereoselectivity. ${ }^{6}$ An outline of our strategy is

(1) Chang, W. C. Progress in the Chemistry of Natural Products; Springer, Wien: New York, 2000; Vol. 80

(2) Baker, J. T.; Wells, R. J.; Oberhänsli, W. E.; Hawes, G. B. J. Am. Chem. Soc. 1976, 98, 4010.

(3) Wright, A. D.; König, G. J. Nat. Prod. 1996, 59, 710.

(4) Wright, A. D.; Wang, H.; Gurrath, M.; König, G. M.; Kocak, G.; Newmann, G.; Loria, P.; Florey, M.; Tilley, L. J. Med. Chem. 2001, 44, 873

(5) Corey, E. J.; Magriotis, P. A. J. Am. Chem. Soc. 1987, I09, 287 provided in Scheme 1 and begins with the proposed construction of the phenanthrene derived structure $\mathbf{3}$ as illustrated. ${ }^{7}$
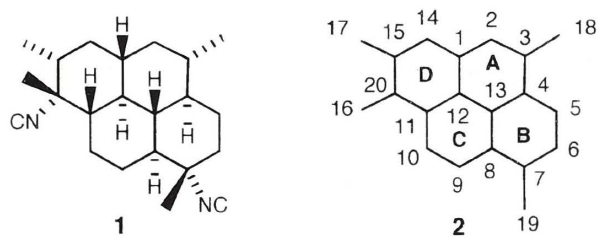

Thus, Birch reductive alkylation, then Lewis acid induced cyclization, following earlier precedents, could be expected to furnish $\mathbf{3}$ in good yield. ${ }^{8}$ We envisaged completion of the pyrene structure by means of the intramolecular Michael reaction $\mathbf{7} \rightarrow \mathbf{8}$, and in anticipation of this step we hoped to introduce a propionyl side chain into 3 by means of a

(6) The numbering system of the parent structure, namely "isocycloamphilectane" (2) is based on its presumed biogenetic relationship to the amphilectane skeleton (cf. ref 1) and will be used throughout this Letter

(7) (a) Hook, J. M.; Mander, L. N.; Urech, R. Synthesis 1979, 374. (b) Cossey, A. L.; Gunter, M. J.; Mander, L. N. Tetrahedron Lett. 1980, 21, 3309. (c) Rogers, D. H.; Frey, B.; Roden, F. R.; Russkamp, F.-W.; Willis, A. C.; Mander, L. N. Aust. J. Chem. 1999, 52, 1093.

(8) Crabtree, S. R. Ph.D. Dissertation, Australian National University, 1990 


\section{Scheme 1}

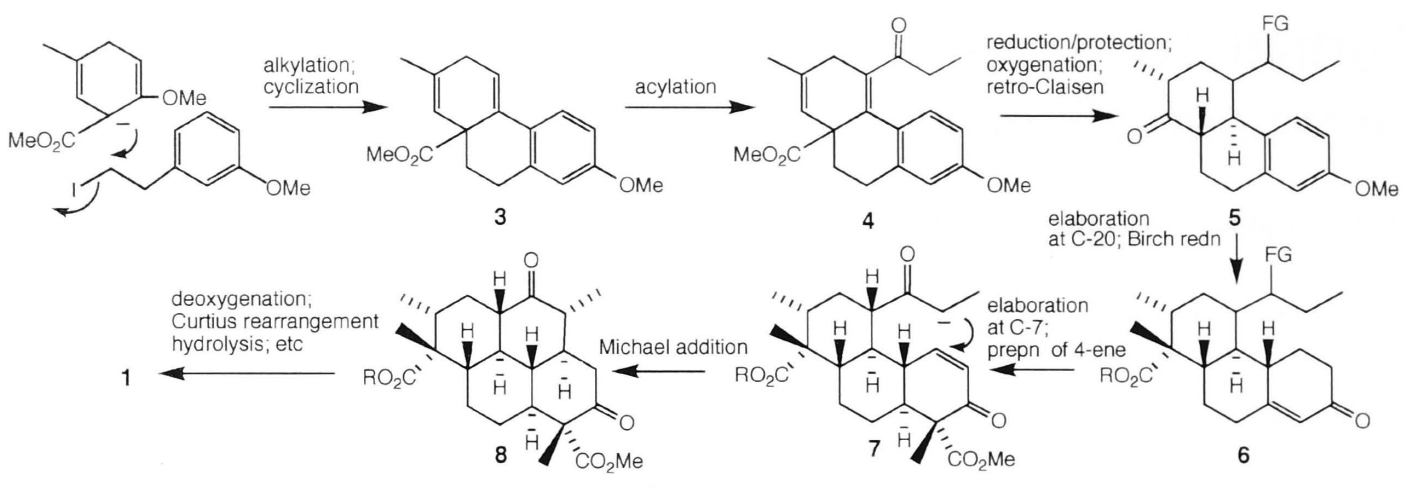

Friedel-Crafts-type acylation of the styrene double bond. To maintain stereochemical control in the introduction of the isonitrile groups, we planned to establish the quaternary centers at C-7 and C-20 by stereochemically controlled $\alpha$-methylation of methoxycarbonyl or formyl substituents at these loci and then apply the Curtius rearrangement to the corresponding acyl azides. ${ }^{9}$ As illustrated in Figure 1, we
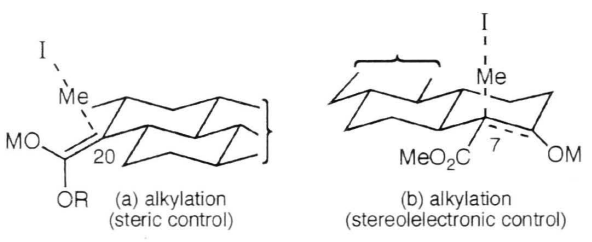

Figure 1. Stereocontrolled elaboration of the C-7 and C-20 quaternary centers.

expected simple alkylation at C-20 to proceed along the equatorial vector (steric control), whereas to achieve "axial" alkylation at $\mathrm{C}-7$, we anticipated that the involvement of the C-6 carbonyl group (stereoelectronic control) would be necessary. ${ }^{10}$

Elaboration of these two centers would necessarily be under kinetic control, as would be the stereochemistry at C-8 following $\mathrm{Li} / \mathrm{NH}_{3}$ reduction of enone 6 . The remaining stereogenic centers, however, should be subjected to thermodynamic control by virtue of their relationship to carbonyl groups at C-2, C-6, and C-20, respectively, at the appropriate stage of the sequence.

The first stage of the synthesis is outlined in Scheme 2. Thus, Birch reduction of methyl 2-methoxy-5-methylbenzoate with lithium and in situ alkylation followed by $\mathrm{BF}_{3}$. $\mathrm{Et}_{2} \mathrm{O}$-induced cyclization afforded 3 in good yield. Then, $\mathrm{AlCl}_{3}$-catalyzed acylation of the styrene alkene bond with propionyl chloride afforded $\mathbf{4}$, provided that this last reaction

(9) Cf. Piers, E.: Llinas-Brunet, M. J. Org. Chem. 1989, 54, 1483.

(10) Eliel, L. L.; Wilen, S. H.; Mander, L. N. Stereochemistry of Organic Compounds: Wiley-Interscience: New York, 1994; p 901. was carried out at $-78^{\circ} \mathrm{C}$; at higher temperatures, the newly formed carbonyl function underwent intramolecular cyclization onto the aromatic ring $\mathrm{B}$. To reduce the styrene bond, 4 was submitted to reduction by lithium in liquid ammonia, affording hydroxy ketone 9, a somewhat surprising result given the absence of a proton source (other than ammonia). The all-cis structure was provisionally assigned as indicated from extensive NMR studies and is consistent with subsequent analyses. After masking the hydroxyl as a MOM ether, the carbonyl function was reduced $\left(\mathrm{LiAlH}_{4}\right)$ to give an epimerically pure alcohol of unspecified configuration that was protected as the benzoate 10. Hydroboration proved to be unsatisfactory for the introduction of oxygen at C-20, so we examined epoxidation with a view to subsequent rearrangement to the 20-one. When the MOM group was found to interfere with epoxidation, it was replaced by acetate, and then the reaction proceeded smoothly to afford $\mathbf{1 1}$ as a mixture of epimers. $\mathrm{BF}_{3} \cdot \mathrm{Et}_{2} \mathrm{O}$-induced rearrangement then gave 12, again as a mixture of diastereomers. However, subsequent base-catalyzed hydrolysis of the acetate function with concomitant loss of the superfluous angular substituent (retro-aldol as planned) led to a single diastereomer, presumed to be $\mathbf{1 3}$ in the expectation that the product would possess the more stable trans-fused ring system with the 16methyl group equatorial. To elaborate the quaternary center at $\mathrm{C}-20$, a Wittig reaction was carried out with methoxymethylenetriphenyl phosphorane, followed by hydrolysis to aldehyde 15. C-Methylation of the aldehyde was unsuccessful, however, and so we abandoned the original strategy (Figure 1a) and submitted the enol ether 14 to a modified Simmons-Smith methylenation. ${ }^{11}$ The resulting cyclopropane derivative 16 was then treated with acid at reflux to give the desired aldehyde $17 .^{12}$ NMR analysis again established the stereochemical relationships between the substituents on ring-D, the most salient feature of which was the cis relationship between the formyl group and $\mathrm{H}-12$ as established by NOE difference spectra. It was thus established that methylenation had taken place on the more exposed exo face, leading to the desired diastereomer.

(11) Yang, Z.; Lorenz, J. C.; Shi, Y. Tetrahedron Lett. 1984, 39, 8621. (12) Wenkert, E. Acc. Chem. Res. 1980, 13, 27 
Scheme 2

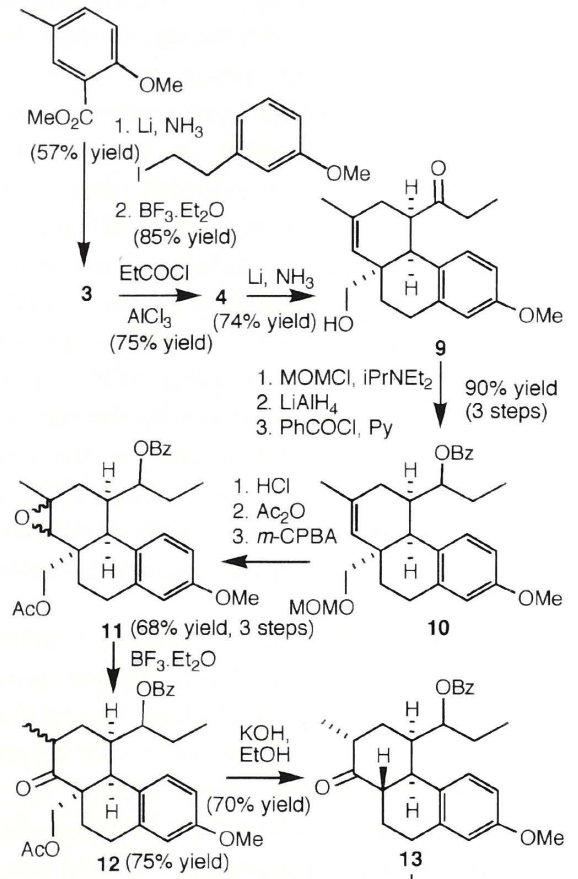

$\mathrm{Ph}_{3} \mathrm{P}=\mathrm{CHOMe} \downarrow 87 \%$ yield
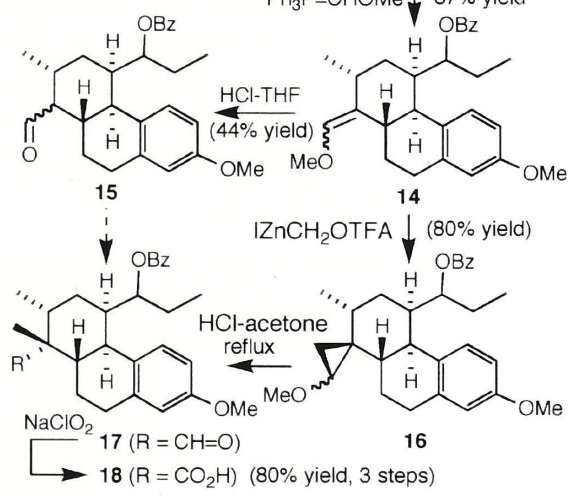

The next stage of the synthesis, as outlined in Scheme 3, involved extensive functional group manipulation, including repeated lithium in ammonia reductions and establishment of the second quaternary center at C-7. Thus, aldehyde $\mathbf{1 7}$ was oxidized to acid $18\left(\mathrm{NaClO}_{2}, 80 \% \text { yield from } 14\right)^{13}$ and the benzoate group replaced with a TBDMS function, following which, Birch reduction and hydrolysis in acetic acid of the dihydroanisole product afforded the expected $\beta, \gamma$ unsaturated enone which could be isomerized by anhydrous $\mathrm{HCl}$ in $\mathrm{THF}$ to enone 20. A second lithium/ammonia reduction with trapping of the resulting lithium enolate by methyl cyanoformate ${ }^{14}$ afforded a modest yield of the $\beta$-keto ester $\mathbf{2 1}$, but $\mathrm{C}$-methylation of this intermediate using a variety of bases gave none of the desired product.

Alternatively, enone $\mathbf{2 0}$ was simply reduced with $\mathrm{Li} / \mathrm{NH}_{3}$ to $\mathbf{2 2}$ and the isomeric enone $\mathbf{2 3}$ prepared using the Saegusa

(13) Dalcanale, E.; Montanari, F. J. Org. Chem. 1986, 51, 567.

(14) Crabtree, S. R.; Chu, W. L. A.; Mander L. N. Synlett 1990, 169

\section{Scheme 3}

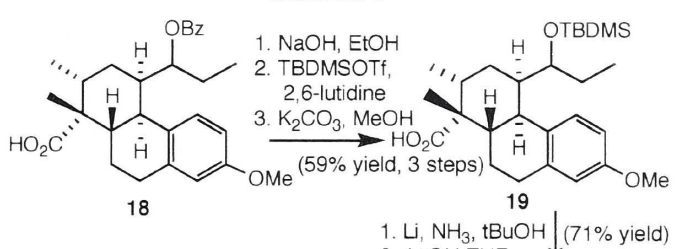

1. $\mathrm{Li}, \mathrm{NH}_{3}, \mathrm{tBuOH} \mid(71 \%$ yield $)$

2. AcOH-THF

3. $\mathrm{HCl}$ (anhyd) OTBDMS
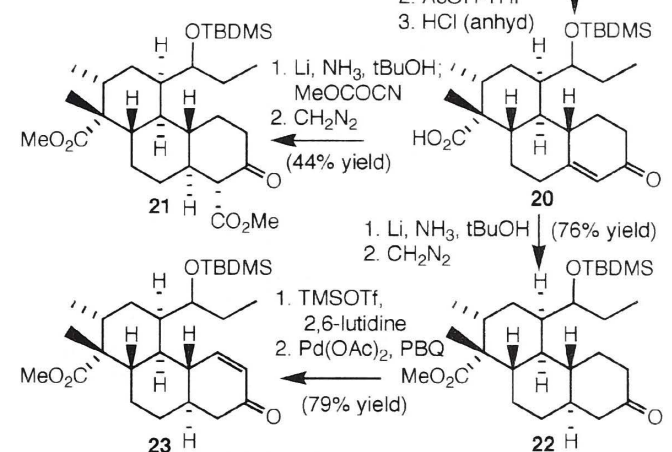

$23 \overline{\mathrm{H}}$

1. LDA, HMPA; MeOCOCN ( $83 \%$ yield)

2. $\mathrm{NaH}, \mathrm{Mel}(88 \%$ yield)

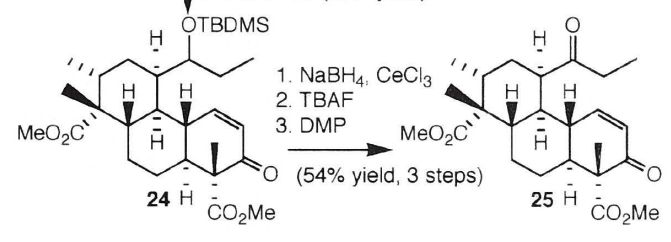

procedure. ${ }^{15}$ Subsequent acylation with methyl cyanoformate, ${ }^{16}$ followed by C-methylation, then proceeded in excellent yield to afford 24. From model studies, we expected that removal of the TBDMS group with TBAF would almost certainly result in cyclization of the liberated hydroxyl onto the enone function. The enone was therefore reduced with $\mathrm{NaBH}_{4} / \mathrm{CeCl}_{3}{ }^{17}$ prior to deprotection. After desilylation, a double oxidation with the Dess-Martin periodinane ${ }^{18}$ afforded dione $\mathbf{2 5}$ in preparation for the pivotal Michael reaction (Scheme 4 ).

An inspection of molecular models indicated that the Michael reaction was unlikely to take place with $\mathbf{2 5}$ since it would require the D-ring to adopt a boat conformation to bring the participating functions within bonding distance, and even then orbital overlap between the reacting centers would be poor. It appeared that an $\alpha$-configured side chain could assume the necessary geometry, however. When treatment of $\mathbf{2 5}$ with a variety of bases returned starting material, it seemed that the axially oriented side chain was more stable in the $\beta$-configuration, despite its axial nature. Nevertheless, one could expect there to be a sufficient amount of the $\alpha$-epimer in equilibrium to undergo the desired cyclization. After extensive experimentation, it was found that heating a solution of $\mathbf{2 5}$ in ethanediol and triethylamine for 4 days at $70{ }^{\circ} \mathrm{C}$ effected cyclization, conditions that were selected in

(15) Ito, Y.; Hirao, T.; Saegusa, T. J. Org. Chem. 1978, 43, 1011 (16) Mander, L. N.; Sethi, P. A. Tetrahedron Lett. 1983, 24, 5425 (17) Luche, J. L. J. Am. Chem. Soc. 1978, 100, 2226

(18) Dess, D. B.; Martin, J. C.J. Org. Chem. 1983, 48, 4155 


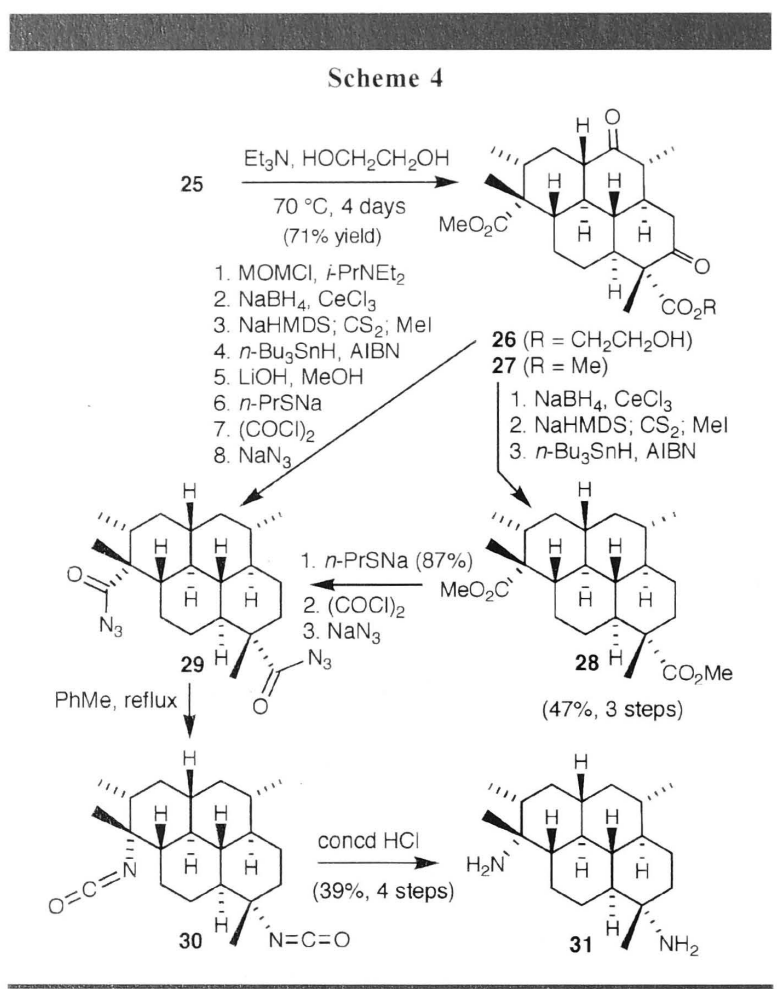

view of those reported by Corey et al. for a difficult intramolecular Michael reaction during the synthesis of longifolene. ${ }^{19}$ No other solvent was effective, and unfortunately, trans-esterification of the 7-ester function with the glycol had occurred, resulting in a $4: 3$ mixture of $\mathbf{2 6}$ and 27, complicating subsequent manipulations. After confirming the structure of the latter compound by single-crystal X-ray analysis, ${ }^{20}$ the diketone was converted into the deoxy derivative $\mathbf{2 8}$ by applying the Barton-McCombie deoxygenation procedure to the dixanthate derived from the 2,6diol. ${ }^{21}$ After protecting $\mathbf{2 6}$ as the MOM ether, this product was similarly deoxygenated. Demethylation of both ester

(19) Corey, E. J.; Ohno, M.; Mitra, R. B.; Vatakencherry, P. A. J. Am. Chem. Soc. $1964,86,478$

(20) Willis, A. C. Unpublished results groups in $\mathbf{2 8}$ was effected with sodium propanethiolate, ${ }^{22}$ while the deoxygenated ester from 26 was treated with lithium hydroxide to hydrolyze the C-7 ester function before liberating the $\mathrm{C}-20$ carboxyl with propanethiolate. Preparation of the diacyl chloride and thence the diacyl azide 29 proceeded smoothly, as did the Curtius rearrangement to $\mathbf{3 0}$, which was effected by heating in toluene at reflux..$^{23}$ Hydrolysis in concd $\mathrm{HCl}$ then afforded diamine 31, which gave identical mass spectra as well as ${ }^{1} \mathrm{H}$ and ${ }^{13} \mathrm{C}$ NMR spectra (measured on the TFA salts) to those obtained from an authentic sample obtaineded by hydrolysis of $\mathbf{1}$. Since $\mathbf{3 1}$ has been reconstituted to $\mathbf{1},{ }^{24}$ the formal total synthesis of diisocyanoadociane (1) is complete. While all 10 stereogenic centers have been introduced with the correct relative stereochemistry, we have yet to address the question of enantioselectivity. However, the initial Birch reductive alkylation, if carried out on an appropriate chiral benzamide, ${ }^{25}$ should resolve this remaining stereochemical issue.

Acknowledgment. We are indebted to Professor Mary Garson (University of Queensland) for the provision of authentic samples of diisocyanoadociane (1) and diamine $\mathbf{3 1}$; to Dr Jamie Simpson (Monash University) for helpful advice; to Bruce Twitchin and Tony Herlt (ANU) for technical assistance; to Tony Willis (ANU) for X-ray studies; and to Chris Blake (ANU) for assistance with high-field NMR spectra. Funding for an Avance $800 \mathrm{MHz}$ NMR spectrometer by the Australian Research Council (LIEF grant LE0346876) and the provision of an Australian Postgraduate Award plus an Alan Sargeson Ph.D. Supplementary Scholarship in Chemical Sciences to K.A.F. are also gratefully acknowledged.

Supporting Information Available: Experimental details and copies of selected ${ }^{1} \mathrm{H}$ and ${ }^{13} \mathrm{C}$ NMR spectra. This material is available free of charge via the Internet at http://pubs.acs.org.

OL061228F

(21) Barton, D. H. R.; McCombie, S. W. J. Chem. Soc., Perkin Trans $1 \mathbf{1 9 7 5}, 1574$

(22) Bartlett, P. A.; Johnson, W. S. Tetrahedron Lett. 1970, 4459

(23) Smith, P. A. S. Org. React. 1946, 3, 337

(24) Simpson, J. S.; Garson, M. J. Org. Biomol. Chem. 2004, 2, 939

(25) Schultz, A. G.; Macielag, M.; Podhorez, D. E.; Suhadolnik, J. C. Kullnig, R. K. J. Org. Chem. 1988, 53, 2456. 


\section{APPENDIX TWO}

\section{X-Ray Crystal Structure Reports}


Figure 1. Anisotropic displacement ellipsoid plot of $\mathrm{C}_{23} \mathrm{H}_{34} \mathrm{O}_{6}$ with labelling of selected atoms. Ellipsoids show $30 \%$ probability levels. Hydrogen atoms are drawn as circles with small radii.

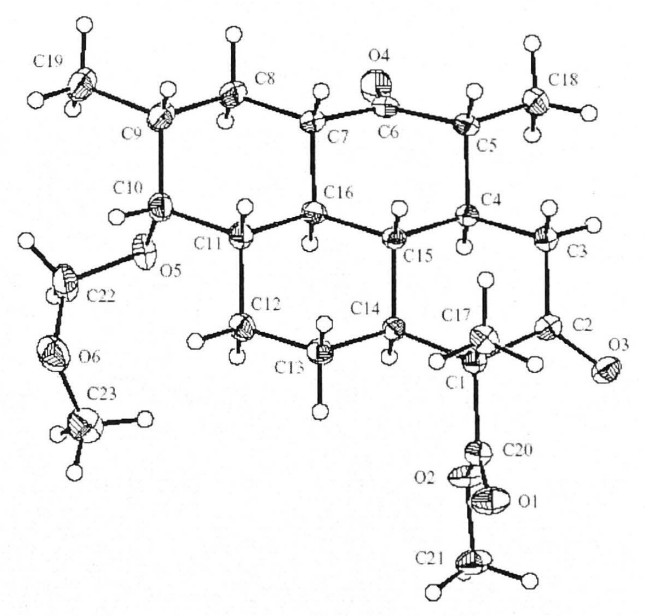

Figure 2. Unit cell packing diagram of $\mathrm{C}_{23} \mathrm{H}_{34} \mathrm{O}_{6}$. solvate projected down the $a$ axis. Hydrogen atoms have been deleted for clarity.

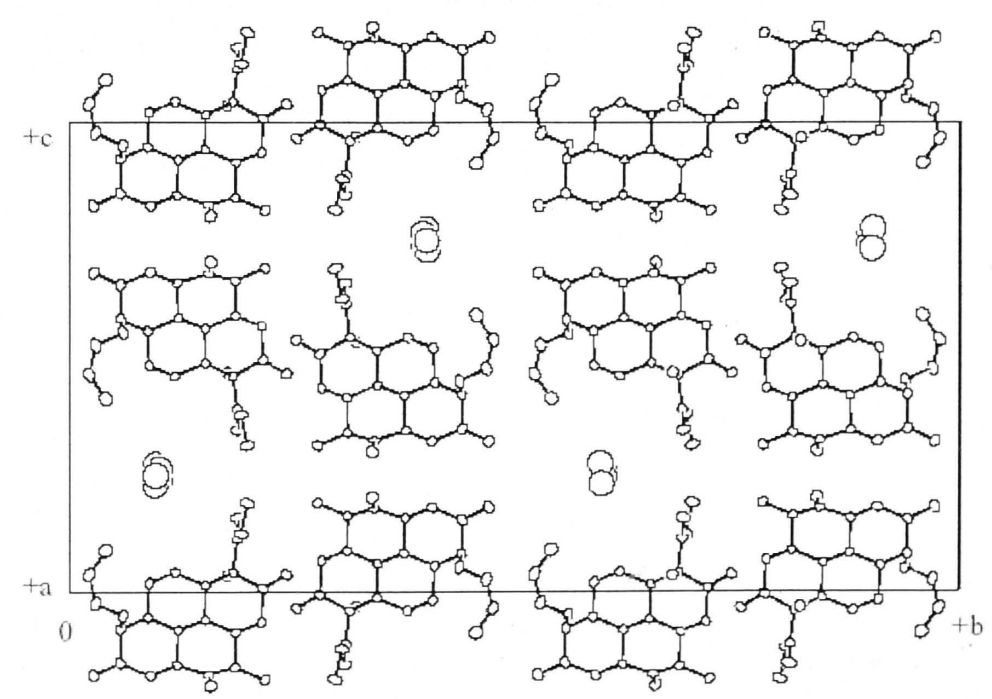




\title{
Crystal structure of $\mathrm{C}_{23} \mathrm{H}_{34} \mathrm{O}_{6}$. solvate -lnm041
}

\author{
Kelly A. Fairweather, Lewis N. Mander and Anthony C. Willis \\ Research School of Chemistry, Australian National University, Canberra, A. C. T. 0200, \\ Australia.E-mail: willis@rsc.anu.edu.au
}

\begin{abstract}
The crystal structure of $\mathrm{C}_{23} \mathrm{H}_{34} \mathrm{O}_{6}$. solvate is reported. The solvate is most probably methanol in 1:1 ratio with $\mathrm{C}_{23} \mathrm{H}_{34} \mathrm{O}_{6}$.
\end{abstract}

\section{Comment}

The crystallographic asymmetric unit consists of one $\mathrm{C}_{23} \mathrm{H}_{34} \mathrm{O}_{6}$ molecule and disordered molecules of solvation. The solvate molecules give rise to an infinite chain of atomic sites running through the unit cell in the a direction. The sample was recystallized from methanol, so the electron density has been modelled assuming two disordered methanol molecules of halfoccupancy. As $\mathrm{C}$ and $\mathrm{O}$ sites can not be differentiated, $\mathrm{C}$ atom sites of occupancy 0.58 (i.e. $(8+6) /(6 \times 4))$ were used. These sites were refined with a common isotropic displacement parameter and with restraints on bonding distances.

In other structures we have successfully used the computer program SQUEEZE within PLATON to account for the electron density in ill-defined regions of the unit cell. [Sluis, $\mathrm{P}$. van der and Spek, A. L. (1990) Acta Crystallogr., Sect. A, 46, 194-201.] In this case the program fails: when the solvate sites are omitted from the model, solvent accessible voids are located but no positive electron density is recovered.

$\mathrm{H}$ atoms of the $\mathrm{C}_{23} \mathrm{H}_{34} \mathrm{O}_{6}$ molecule were included at calculated positions and ride on the atoms to which they are bonded. $\mathrm{H}$ atoms of the solvation molecules were not located.

The biggest peaks in the final difference electron density map are located within the disordered solvate channel.

\section{Experimental}

The compound was prepared by KAF and recrystallized from methanol. The sample ID is KF11181c. 


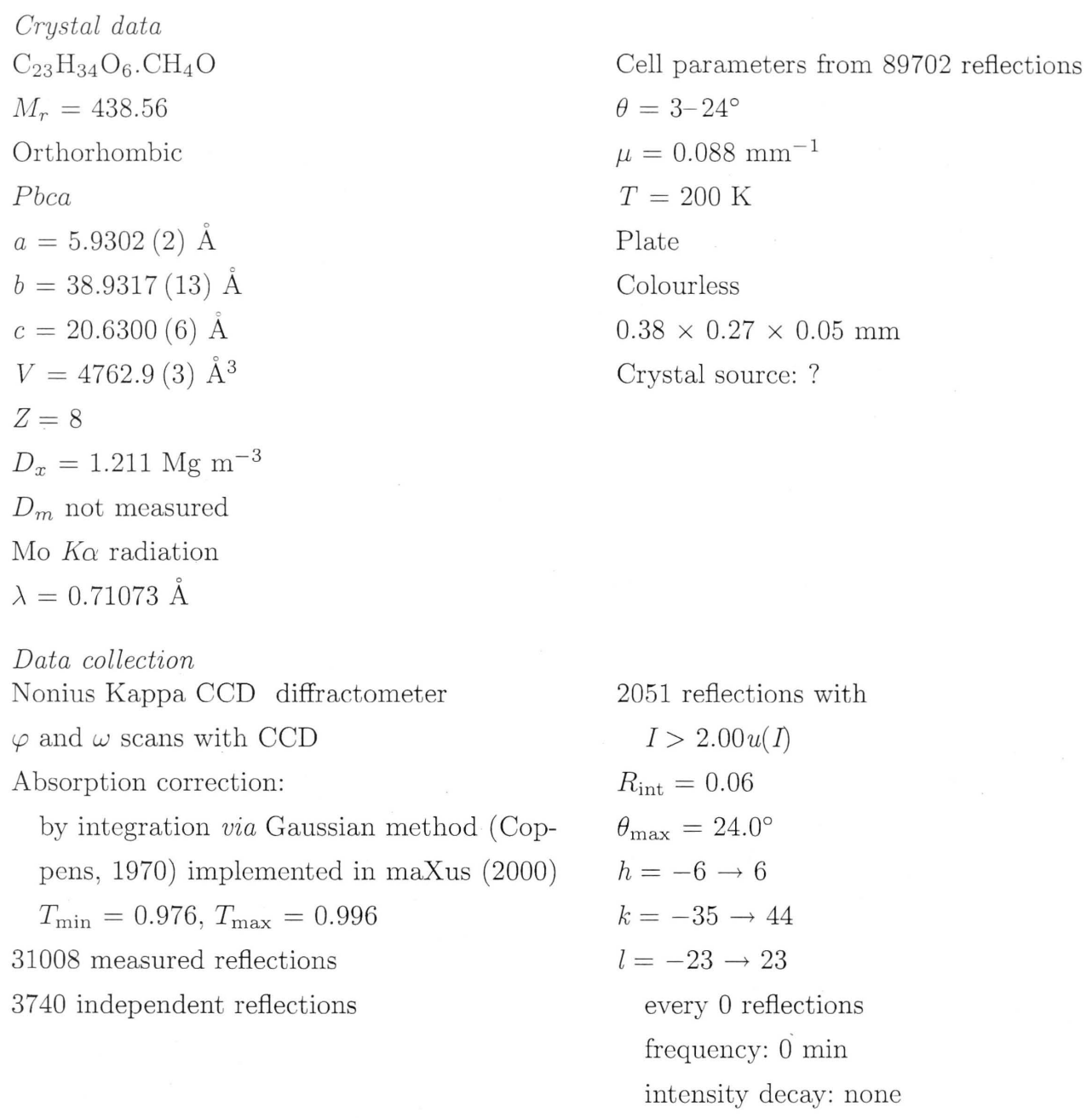




\section{Refinement}

Refinement on $F$

$R=0.0683$

$w R=0.0551$

$S=0.9497$

2051 reflections

275 parameters

$\mathrm{H}$-atom parameters not refined
Method, part 1, Chebychev polynomial, (Watkin, 1994, Prince, 1982) [weight $]=1.0 /\left[A_{0} * T_{0}(x)+A_{1} * T_{1}(x) \ldots\right.$ $\left.\left.+A_{n-1}\right]^{*} T_{n-1}(x)\right]$ where $A_{i}$ are the Chebychev coefficients listed below and $x=$ Fcalc/Fmax Method = Robust Weighting (Prince, 1982) $W=$ [weight] $*\left[1-\left(\operatorname{deltaF} / 6^{*} \operatorname{sigmaF}\right)^{2}\right]^{2} A_{i}$ are: 1.600 .1411 .25

$(\Delta / \sigma)_{\max }=0.084634$

$\Delta \rho_{\max }=0.38 \mathrm{e}^{-3}$

$\Delta \rho_{\min }=-0.39{\mathrm{e} \AA^{-3}}^{-3}$

Extinction correction: none

Scattering factors from International Tables for X-ray Crystallography (Vol. IV)
$\mathrm{O} 1-\mathrm{C} 20$
$\mathrm{O} 2-\mathrm{C} 20$
$\mathrm{O} 2-\mathrm{C} 21$
$\mathrm{O} 3-\mathrm{C} 2$
$\mathrm{O} 4-\mathrm{C} 6$
$\mathrm{O} 5-\mathrm{C} 10$
$\mathrm{O} 5-\mathrm{C} 22$
$\mathrm{O} 6-\mathrm{C} 22$
$\mathrm{O} 6-\mathrm{C} 23$
$\mathrm{C} 1-\mathrm{C} 2$
$\mathrm{C} 1-\mathrm{C} 14$
$\mathrm{C} 1-\mathrm{C} 17$
$\mathrm{C} 1-\mathrm{C} 20$
$\mathrm{C} 2-\mathrm{C} 3$
$\mathrm{C} 3-\mathrm{C} 4$
$\mathrm{C} 4-\mathrm{C} 5$
$\mathrm{C} 4-\mathrm{C} 15$

Table 1. Selected geometric parameters $\left(\AA,^{\circ}\right)$

\begin{tabular}{|c|c|c|}
\hline $1.200(4)$ & $\mathrm{C} 5-\mathrm{C} 6$ & $1.499(5)$ \\
\hline $1.343(4)$ & $\mathrm{C} 5-\mathrm{C} 18$ & $1.528(5)$ \\
\hline $1.445(4)$ & $\mathrm{C} 6-\mathrm{C} 7$ & $1.523(5)$ \\
\hline 1.209 (4) & $\mathrm{C} 7-\mathrm{C} 8$ & $1.512(5)$ \\
\hline $1.216(5)$ & $\mathrm{C} 7-\mathrm{C} 16$ & $1.549(5)$ \\
\hline $1.462(4)$ & C8-C9 & $1.531(6)$ \\
\hline 1.397 (4) & $\mathrm{C} 9-\mathrm{C} 10$ & $1.526(6)$ \\
\hline $1.416(5)$ & C9-C19 & $1.522(6)$ \\
\hline $1.421(5)$ & $\mathrm{C} 10-\mathrm{C} 11$ & $1.525(5)$ \\
\hline $1.529(5)$ & $\mathrm{C} 11-\mathrm{C} 12$ & $1.531(5)$ \\
\hline $1.552(5)$ & $\mathrm{C} 11-\mathrm{C} 16$ & $1.532(5)$ \\
\hline $1.550(5)$ & $\mathrm{C} 12-\mathrm{C} 13$ & $1.511(5)$ \\
\hline $1.519(5)$ & $\mathrm{C} 13-\mathrm{C} 14$ & $1.532(5)$ \\
\hline $1.501(5)$ & $\mathrm{C} 14-\mathrm{C} 15$ & $1.533(5)$ \\
\hline $1.529(5)$ & $\mathrm{C} 15-\mathrm{C} 16$ & $1.529(5)$ \\
\hline $1.554(5)$ & $\mathrm{C} 51-\mathrm{C} 52$ & $1.467(10)$ \\
\hline $1.542(4)$ & $\mathrm{C} 53-\mathrm{C} 54$ & $1.452(9)$ \\
\hline
\end{tabular}




\begin{tabular}{|c|c|c|c|}
\hline $\mathrm{C} 20-\mathrm{O} 2-\mathrm{C} 21$ & $116.8(3)$ & $\mathrm{C} 7-\mathrm{C} 8-\mathrm{C} 9$ & $111.7(3)$ \\
\hline $\mathrm{C} 10-\mathrm{O} 5-\mathrm{C} 22$ & $114.3(3)$ & $\mathrm{C} 8-\mathrm{C} 9-\mathrm{C} 10$ & $111.1(3)$ \\
\hline $\mathrm{C} 22-\mathrm{O} 6-\mathrm{C} 23$ & $114.1(3)$ & $\mathrm{C} 8-\mathrm{C} 9-\mathrm{C} 19$ & 110.9 (4) \\
\hline $\mathrm{C} 2-\mathrm{C} 1-\mathrm{C} 14$ & $111.8(3)$ & $\mathrm{C} 10-\mathrm{C} 9-\mathrm{C} 19$ & $113.6(4)$ \\
\hline $\mathrm{C} 2-\mathrm{C} 1-\mathrm{C} 17$ & $107.1(3)$ & $\mathrm{C} 9-\mathrm{C} 10-\mathrm{O} 5$ & $109.8(3)$ \\
\hline $\mathrm{C} 14-\mathrm{C} 1-\mathrm{C} 17$ & $111.7(3)$ & $\mathrm{C} 9-\mathrm{C} 10-\mathrm{C} 11$ & $111.6(3)$ \\
\hline $\mathrm{C} 2-\mathrm{C} 1-\mathrm{C} 20$ & $107.7(3)$ & $\mathrm{O} 5-\mathrm{C} 10-\mathrm{C} 11$ & $109.0(3)$ \\
\hline $\mathrm{C} 14-\mathrm{C} 1-\mathrm{C} 20$ & $110.3(3)$ & $\mathrm{C} 10-\mathrm{C} 11-\mathrm{C} 12$ & $112.6(3)$ \\
\hline $\mathrm{C} 17-\mathrm{C} 1-\mathrm{C} 20$ & $108.0(3)$ & $\mathrm{C} 10-\mathrm{C} 11-\mathrm{C} 16$ & $113.2(3)$ \\
\hline $\mathrm{C} 1-\mathrm{C} 2-\mathrm{O} 3$ & $120.7(3)$ & $\mathrm{C} 12-\mathrm{C} 11-\mathrm{C} 16$ & $109.4(3)$ \\
\hline $\mathrm{C} 1-\mathrm{C} 2-\mathrm{C} 3$ & $116.3(3)$ & $\mathrm{C} 11-\mathrm{C} 12-\mathrm{C} 13$ & $110.8(3)$ \\
\hline $\mathrm{O} 3-\mathrm{C} 2-\mathrm{C} 3$ & $122.9(3)$ & $\mathrm{C} 12-\mathrm{C} 13-\mathrm{C} 14$ & $111.1(3)$ \\
\hline $\mathrm{C} 2-\mathrm{C} 3-\mathrm{C} 4$ & $111.2(3)$ & $\mathrm{C} 13-\mathrm{C} 14-\mathrm{C} 1$ & $112.4(3)$ \\
\hline $\mathrm{C} 3-\mathrm{C} 4-\mathrm{C} 5$ & $111.8(3)$ & $\mathrm{C} 13-\mathrm{C} 14-\mathrm{C} 15$ & $110.7(3)$ \\
\hline $\mathrm{C} 3-\mathrm{C} 4-\mathrm{C} 15$ & $109.6(3)$ & $\mathrm{C} 1-\mathrm{C} 14-\mathrm{C} 15$ & $114.2(3)$ \\
\hline $\mathrm{C} 5-\mathrm{C} 4-\mathrm{C} 15$ & $112.0(3)$ & $\mathrm{C} 4-\mathrm{C} 15-\mathrm{C} 14$ & $110.7(3)$ \\
\hline $\mathrm{C} 4-\mathrm{C} 5-\mathrm{C} 6$ & $107.6(3)$ & $\mathrm{C} 4-\mathrm{C} 15-\mathrm{C} 16$ & $111.7(3)$ \\
\hline $\mathrm{C} 4-\mathrm{C} 5-\mathrm{C} 18$ & $112.9(3)$ & $\mathrm{C} 14-\mathrm{C} 15-\mathrm{C} 16$ & $110.1(3)$ \\
\hline $\mathrm{C} 6-\mathrm{C} 5-\mathrm{C} 18$ & $111.8(3)$ & $\mathrm{C} 11-\mathrm{C} 16-\mathrm{C} 7$ & $110.8(3)$ \\
\hline $\mathrm{C} 5-\mathrm{C} 6-\mathrm{O} 4$ & 124.0 & $\mathrm{C} 11-\mathrm{C} 16-\mathrm{C} 15$ & $112.1(3)$ \\
\hline $\mathrm{C} 5-\mathrm{C} 6-\mathrm{C} 7$ & $115.3(3)$ & $\mathrm{C} 7-\mathrm{C} 16-\mathrm{C} 15$ & $111.5(3)$ \\
\hline $\mathrm{O} 4-\mathrm{C} 6-\mathrm{C} 7$ & $120.6(4)$ & $\mathrm{C} 1-\mathrm{C} 20-\mathrm{O} 2$ & $111.0(3)$ \\
\hline $\mathrm{C} 6-\mathrm{C} 7-\mathrm{C} 8$ & $114.0(3)$ & $\mathrm{C} 1-\mathrm{C} 20-\mathrm{O} 1$ & $126.6(3)$ \\
\hline $\mathrm{C} 6-\mathrm{C} 7-\mathrm{C} 16$ & $106.1(3)$ & $\mathrm{O} 2-\mathrm{C} 20-\mathrm{O} 1$ & $122.4(3)$ \\
\hline $\mathrm{C} 8-\mathrm{C} 7-\mathrm{C} 16$ & 112.5 & $\mathrm{O} 6-\mathrm{C} 22-\mathrm{O} 5$ & $113.2(3)$ \\
\hline
\end{tabular}

$\mathrm{H}$ atoms bonded to $\mathrm{C}$ atoms of the $\mathrm{C}_{23} \mathrm{H}_{34} \mathrm{O}_{6}$ molecule were included at calculated positions and ride on the atoms to which they are bonded. $\mathrm{H}$ atoms of the solvation molecules were not located.

Data collection: COLLECT (Nonius BV, 1997) . Cell refinement: Denzo/Scalepack (Otwinowski \& Minor, 1996) . Data reduction: Denzo/Scalepack (Otwinowski \& Minor, 1996) . Program(s) used to solve structure: SIR92 (Altomare et al. 1994). Program(s) used to refine structure: CRYSTALS (Watkin et al.2003). Molecular graphics: ORTEP-II (Johnson 1976) in teXsan (MSC, 1992-1997) . Software used to prepare material for publication: CRYSTALS (Watkin et al.2003) . 


\section{References}

Mackay, S., Gilmore, C. J.,Edwards, C., Stewart, N. \& Shankland, K. (2000). maXus Computer Program for the Solution and Refinement of Crystal Structures. Nonius, The Netherlands, MacScience, Japan \& The University of Glasgow.

Coppens, P. (1970). The Evaluation of Absorption and Extinction in Single-Crystal Structure Analysis. Crystallographic Computing. F. R. Ahmed, S. R. Hall and C. P. Huber, Editors., Munksgaard. Copenhagen. pp 255-270.

Altomare, A., Cascarano, G., Giacovazzo C., Guagliardi A., Burla M. C., Polidori, G. \& Camalli, M. (1994). SIR92 - a program for automatic solution of crystal structures by direct methods. J. Appl. Cryst. (27), 435-435

Spek, A. L. (2001) PLATON, A Multipurpose Crystallographic Tool, Utrecht University, Utrecht, The Netherlands.

Betteridge, P. W., Carruthers, J. R., Cooper, R. I., Prout, K., Watkin, D. J. (2003). J. Appl. Cryst. 36, 1487.

Nonius BV, COLLECT Software, 1997-2001)

Otwinowski, Z. \& Minor, W. (1996). Processing of X-ray Diffraction Data Collected in Oscillation Mode. Methods Enzymol. 276, 1997, 307-326. Ed Carter, C. W. \& Sweet, R. M., Academic Press.

Prince, E. Mathematical Techniques in Crystallography and Materials Science Springer-Verlag, New York, 1982.

Watkin D. J. (1994). Acta Cryst, A50, 411-437

Molecular Structure Corporation. (1992-1997). teXsan. Single Crystal Structure Analysis Software. Version 1.8. MSC, 3200 Research Forest Drive, The Woodlands, TX 77381, USA. 


\section{Supplementary data}

Table S1. Fractional atomic coordinates and equivalent isotropic displacement parameters $\left(\AA^{2}\right)$

\begin{tabular}{|c|c|c|c|c|c|}
\hline & Occupancy & $x$ & $y$ & $z$ & $U_{\text {eq }}$ \\
\hline O1 & 1.0000 & $0.9587(4)$ & $0.69060(8)$ & $0.34405(13)$ & 0.0484 \\
\hline $\mathrm{O} 2$ & 1.0000 & $0.6012(4)$ & $0.69338(7)$ & $0.37714(11)$ & 0.0399 \\
\hline $\mathrm{O} 3$ & 1.0000 & $0.8015(4)$ & $0.74467(6)$ & $0.46386(12)$ & 0.0391 \\
\hline $\mathrm{O} 4$ & 1.0000 & $0.2678(5)$ & $0.65959(7)$ & $0.70109(14)$ & 0.0515 \\
\hline O5 & 1.0000 & $0.2802(4)$ & $0.56099(6)$ & 0.55139 (13) & 0.0440 \\
\hline O6 & 1.0000 & $0.2904(5)$ & $0.52300(7)$ & $0.46300(15)$ & 0.0579 \\
\hline $\mathrm{C} 1$ & 1.0000 & $0.8734(6)$ & $0.68447(8)$ & $0.45886(16)$ & 0.0269 \\
\hline $\mathrm{C} 2$ & 1.0000 & $0.8184(6)$ & $0.71809(10)$ & $0.49373(16)$ & 0.0295 \\
\hline C3 & 1.0000 & $0.7989(6)$ & $0.71619(9)$ & $0.56620(16)$ & 0.0326 \\
\hline $\mathrm{C} 4$ & 1.0000 & $0.6362(6)$ & $0.68777(8)$ & $0.58686(15)$ & 0.0274 \\
\hline C5 & 1.0000 & $0.6036(7)$ & $0.68691(9)$ & $0.66157(16)$ & 0.0341 \\
\hline C6 & 1.0000 & $0.4543(7)$ & 0.65696 (10) & $0.67716(17)$ & 0.0365 \\
\hline $\mathrm{C} 7$ & 1.0000 & $0.5450(7)$ & $0.62203(9)$ & $0.65659(17)$ & 0.0343 \\
\hline $\mathrm{C} 8$ & 1.0000 & $0.4034(8)$ & $0.59204(10)$ & 0.67931 (19) & 0.0468 \\
\hline C9 & 1.0000 & $0.4920(8)$ & $0.55787(10)$ & $0.6529(2)$ & 0.0466 \\
\hline C10 & 1.0000 & $0.5067(6)$ & $0.55854(9)$ & $0.57904(18)$ & 0.0368 \\
\hline C11 & 1.0000 & $0.6472(6)$ & $0.58878(9)$ & $0.55505(17)$ & 0.0333 \\
\hline C12 & 1.0000 & $0.6585(7)$ & 0.59061 (9) & $0.48100(18)$ & 0.0381 \\
\hline $\mathrm{C} 13$ & 1.0000 & $0.8130(6)$ & $0.61926(8)$ & $0.45939(17)$ & 0.0347 \\
\hline C14 & 1.0000 & $0.7338(6)$ & $0.65397(8)$ & $0.48602(16)$ & 0.0267 \\
\hline C15 & 1.0000 & $0.7190(6)$ & $0.65300(8)$ & $0.56020(16)$ & 0.0258 \\
\hline $\mathrm{C} 16$ & 1.0000 & $0.5673(6)$ & $0.62340(9)$ & $0.58184(16)$ & 0.0292 \\
\hline $\mathrm{C} 17$ & 1.0000 & $1.1302(6)$ & 0.67831 (10) & $0.46643(19)$ & 0.0368 \\
\hline C18 & 1.0000 & $0.5092(8)$ & $0.72049(10)$ & $0.68863(18)$ & 0.0441 \\
\hline C19 & 1.0000 & $0.3552(9)$ & $0.52787(11)$ & $0.6792(2)$ & 0.0635 \\
\hline $\mathrm{C} 20$ & 1.0000 & $0.8235(6)$ & $0.68957(9)$ & $0.38731(18)$ & 0.0316 \\
\hline $\mathrm{C} 21$ & 1.0000 & $0.5311(7)$ & 0.70077 (12) & $0.31155(18)$ & 0.0480 \\
\hline $\mathrm{C} 22$ & 1.0000 & $0.1993(8)$ & $0.53034(10)$ & $0.5249(2)$ & 0.0545 \\
\hline $\mathrm{C} 23$ & 1.0000 & $0.1897(9)$ & $0.54188(12)$ & $0.4116(2)$ & 0.0628 \\
\hline C51 & 0.5800 & $0.252(6)$ & $0.5980(9)$ & $0.2473(17)$ & $0.214(5)$ \\
\hline C52 & 0.5800 & $0.489(6)$ & $0.5973(8)$ & $0.2272(12)$ & $0.214(5)$ \\
\hline C53 & 0.5800 & $0.346(6)$ & $0.6021(9)$ & $0.2608(15)$ & $0.214(5)$ \\
\hline C54 & 0.5800 & $0.587(7)$ & $0.5983(7)$ & $0.2706(13)$ & $0.214(5)$ \\
\hline H31 & 1.0000 & $0.7423(6)$ & $0.73871(9)$ & $0.58291(16)$ & 0.0391 \\
\hline H32 & 1.0000 & $0.9511(6)$ & $0.71139(9)$ & $0.58502(16)$ & 0.0391 \\
\hline H41 & 1.0000 & $0.4842(6)$ & $0.69270(8)$ & $0.56800(15)$ & 0.0329 \\
\hline H51 & 1.0000 & $0.7539(7)$ & $0.68418(9)$ & $0.68293(16)$ & 0.0409 \\
\hline $\mathrm{H} 71$ & 1.0000 & $0.7003(7)$ & $0.61933(9)$ & $0.67474(17)$ & 0.0412 \\
\hline H81 & 1.0000 & $0.4062(8)$ & $0.59126(10)$ & 0.72776 (19) & 0.0562 \\
\hline H82 & 1.0000 & $0.2448(8)$ & $0.59538(10)$ & 0.66409 (19) & 0.0562 \\
\hline H91 & 1.0000 & $0.6498(8)$ & $0.55438(10)$ & $0.6686(2)$ & 0.0560 \\
\hline H101 & 1.0000 & $0.5814(6)$ & $0.53678(9)$ & $0.56483(18)$ & 0.0442 \\
\hline H111 & 1.0000 & $0.8021(6)$ & $0.58429(9)$ & 0.57221 (17) & 0.0400 \\
\hline H121 & 1.0000 & $0.5037(7)$ & $0.59486(9)$ & $0.46350(18)$ & 0.0457 \\
\hline $\mathrm{H} 122$ & 1.0000 & $0.7168(7)$ & $0.56829(9)$ & $0.46385(18)$ & 0.0457 \\
\hline H131 & 1.0000 & $0.9690(6)$ & $0.61453(8)$ & 0.47551 (17) & 0.0416 \\
\hline H132 & 1.0000 & $0.8141(6)$ & $0.62023(8)$ & $0.41096(17)$ & 0.0416 \\
\hline H141 & 1.0000 & $0.5772(6)$ & $0.65828(8)$ & $0.46998(16)$ & 0.0320 \\
\hline H151 & 1.0000 & $0.8730(6)$ & $0.64890(8)$ & $0.57839(16)$ & 0.0310 \\
\hline H161 & 1.0000 & $0.4145(6)$ & $0.62799(9)$ & $0.56329(16)$ & 0.0350 \\
\hline H171 & 1.0000 & $1.1728(6)$ & $0.65644(10)$ & $0.44413(19)$ & 0.0441 \\
\hline
\end{tabular}




$\begin{array}{llllll}\mathrm{H} 172 & 1.0000 & 1.2147(6) & 0.69788(10) & 0.44653(19) & 0.0441 \\ \mathrm{H} 173 & 1.0000 & 1.1689(6) & 0.67664(10) & 0.51350(19) & 0.0441 \\ \mathrm{H} 181 & 0.4918(8) & 0.71847(10) & 0.73670(18) & 0.0529 \\ \mathrm{H} 182 & 1.0000 & 0.6151(8) & 0.73972(10) & 0.67837(18) & 0.0529 \\ \mathrm{H} 183 & 1.0000 & 0.3589(8) & 0.72523(10) & 0.66855(18) & 0.0529 \\ \mathrm{H} 191 & 1.0000 & 0.4160(9) & 0.50586(11) & 0.6614(2) & 0.0762 \\ \mathrm{H} 192 & 1.0000 & 0.3660(9) & 0.52751(11) & 0.7276(2) & 0.0762 \\ \mathrm{H} 193 & 1.0000 & 0.1939(9) & 0.53053(11) & 0.6661(2) & 0.0762 \\ \mathrm{H} 211 & 1.0000 & 0.3632(7) & 0.70304(12) & 0.31004(18) & 0.0576 \\ \mathrm{H} 212 & 1.0000 & 0.6019(7) & 0.72275(12) & 0.29687(18) & 0.0576 \\ \mathrm{H} 213 & 1.0000 & 0.5796(7) & 0.68165(12) & 0.28234(18) & 0.0576 \\ \mathrm{H} 221 & 1.0000 & 0.0317(8) & 0.53201(10) & 0.5209(2) & 0.0654 \\ \mathrm{H} 222 & 1.0000 & 0.2389(8) & 0.51109(10) & 0.5549(2) & 0.0654 \\ \mathrm{H} 231 & 1.0000 & 0.2623(9) & 0.53536(12) & 0.3697(2) & 0.0754 \\ \mathrm{H} 232 & 1.0000 & 0.2110(9) & 0.56703(12) & 0.4194(2) & 0.0754 \\ \mathrm{H} 233 & 1.0000 & 0.0249(9) & 0.53654(12) & 0.4097(2) & 0.0754\end{array}$

Table S2. Anisotropic displacement parameters $\left(\AA^{2}\right)$

$\mathrm{O} 1$

$\mathrm{O} 2$

$\mathrm{O} 3$

$\mathrm{O} 4$

O5

O6

$\mathrm{C} 1$

$\mathrm{C} 2$

$\mathrm{C} 3$

$\mathrm{C} 4$

C5

C6

$\mathrm{C} 7$

$\mathrm{C} 8$

C9

$\mathrm{C} 10$

$\mathrm{C} 11$

$\mathrm{C} 12$

C13

C14

C15

C16

C17

C18

C19

C20

$\mathrm{C} 21$

$\mathrm{C} 22$

C23

$U_{22}$
$0.075(2)$
$0.0677(19)$
$0.0381(15)$
$0.0481(17)$
$0.0291(14)$
$0.0458(17)$
$0.029(2)$
$0.035(2)$
$0.0273(19)$
$0.029(2)$
$0.032(2)$
$0.038(2)$
$0.033(2)$
$0.038(2)$
$0.034(2)$
$0.029(2)$
$0.028(2)$
$0.031(2)$
$0.035(2)$
$0.0277(19)$
$0.028(2)$
$0.029(2)$
$0.043(2)$
$0.033(2)$
$0.039(3)$
$0.037(2)$
$0.069(3)$
$0.035(2)$
$0.062(3)$

\begin{tabular}{l}
\multicolumn{1}{c}{$U_{33}$} \\
$0.0332(15)$ \\
$0.0232(14)$ \\
$0.0344(14)$ \\
$0.0468(17)$ \\
$0.0604(18)$ \\
$0.062(2)$ \\
$0.0254(19)$ \\
$0.032(2)$ \\
$0.031(2)$ \\
$0.0233(19)$ \\
$0.0226(19)$ \\
$0.0204(19)$ \\
$0.0248(19)$ \\
$0.031(2)$ \\
$0.039(2)$ \\
$0.040(2)$ \\
$0.034(2)$ \\
$0.035(2)$ \\
$0.030(2)$ \\
$0.0246(19)$ \\
$0.0232(19)$ \\
$0.0250(19)$ \\
$0.042(2)$ \\
$0.034(2)$ \\
$0.048(3)$ \\
$0.029(2)$ \\
$0.033(2)$ \\
$0.066(3)$ \\
$0.058(3)$
\end{tabular}

$0.062(3)$
$U_{13}$

0.0088 (13)

$-0.0013(11)$

$0.0062(13)$

0.059 (2)

0.0424 (16)

0.066 (2)

$0.0265(19)$

0.0207 (18)

0.039 (2)

$0.030(2)$

$0.048(2)$

0.051 (3)

$0.045(2)$

$0.072(3)$

0.067 (3)

$0.041(2)$

0.037 (2)

$0.048(2)$

$0.039(2)$

0.0276 (19)

$0.0258(19)$

0.034 (2)

$0.025(2)$

$0.065(3)$

$0.104(4)$

$0.028(2)$

$0.042(2)$

$0.063(3)$

0.069 (3)
$0.0009(15)$

$0.0010(13)$

$0.0025(13)$

$-0.0038(16)$

$-0.0053(13)$

0.0085 (16)

$-0.0001(16)$

0.0009 (18)

-0.0007 (19)

$-0.0016(17)$

0.0017 (19)

$-0.004(2)$

$-0.0015(19)$

$-0.006(2)$

$0.000(2)$

$0.000(2)$

$0.0001(18)$

$0.002(2)$

$-0.0020(19)$

$-0.0023(16)$

0.0011 (17)

$0.0028(18)$

-0.0005 (17)

$-0.002(2)$

$-0.009(3)$

$0.0001(18)$

$-0.009(2)$

$-0.012(2)$

$0.000(3)$
(14) $\quad-0.0089(13)$

$-0.0060(17) \quad-0.0146(15)$

$-0.0009(15) \quad 0.0008(15)$

$-0.0003(16) \quad 0.0059(18)$

$-0.0036(18) \quad-0.0008(16)$

$-0.0019(15) \quad 0.0002(15)$

$-0.0011(17) \quad-0.0036(16)$

$0.0001(19) \quad-0.0011(17)$

$-0.0004(17) \quad 0.0032(17)$

$0.011(2) \quad 0.0037(17)$

$0.007(2) \quad 0.0071(19)$

$0.0016(19) \quad-0.0013(17)$

$-0.0039(17) \quad-0.0004(16)$

$0.0073(19) \quad-0.0062(17)$

$0.0064(18) \quad-0.0039(16)$

$0.0021(16) \quad 0.0007(14)$

$-0.0032(16) \quad 0.0003(14)$

$-0.0020(16) \quad-0.0012(16)$

$-0.0020(17) \quad-0.0015(19)$

$0.005(2) \quad-0.0058(18)$

$0.019(3) \quad 0.007(2)$

$0.0004(18) \quad-0.0008(17)$

$-0.0087(19) \quad 0.012(2)$

$0.004(3) \quad-0.010(2)$

$-0.001(3) \quad-0.007(2)$ 


\begin{tabular}{|c|c|}
\hline $\mathrm{O} 1-\mathrm{C} 20$ & $1.200(4)$ \\
\hline $\mathrm{O} 2-\mathrm{C} 20$ & $1.343(4)$ \\
\hline $\mathrm{O} 2-\mathrm{C} 21$ & $1.445(4)$ \\
\hline $\mathrm{O} 3-\mathrm{C} 2$ & 1.209 (4) \\
\hline $\mathrm{O} 4-\mathrm{C} 6$ & $1.216(5)$ \\
\hline $\mathrm{O} 5-\mathrm{C} 10$ & $1.462(4)$ \\
\hline $\mathrm{O} 5-\mathrm{C} 22$ & $1.397(4)$ \\
\hline $\mathrm{O} 6-\mathrm{C} 22$ & $1.416(5)$ \\
\hline $\mathrm{O} 6-\mathrm{C} 23$ & $1.421(5)$ \\
\hline $\mathrm{C} 1-\mathrm{C} 2$ & $1.529(5)$ \\
\hline $\mathrm{C} 1-\mathrm{C} 14$ & $1.552(5)$ \\
\hline $\mathrm{C} 1-\mathrm{C} 17$ & $1.550(5)$ \\
\hline $\mathrm{C} 1-\mathrm{C} 20$ & $1.519(5)$ \\
\hline $\mathrm{C} 2-\mathrm{C} 3$ & $1.501(5)$ \\
\hline $\mathrm{C} 3-\mathrm{C} 4$ & $1.529(5)$ \\
\hline C3-H31 & 1.000 \\
\hline C3-H32 & 1.000 \\
\hline $\mathrm{C} 4-\mathrm{C} 5$ & $1.554(5)$ \\
\hline $\mathrm{C} 4-\mathrm{C} 15$ & $1.542(4)$ \\
\hline $\mathrm{C} 4-\mathrm{H} 41$ & 1.000 \\
\hline $\mathrm{C} 5-\mathrm{C} 6$ & $1.499(5)$ \\
\hline $\mathrm{C} 5-\mathrm{C} 18$ & $1.528(5)$ \\
\hline $\mathrm{C} 5-\mathrm{H} 51$ & 1.000 \\
\hline $\mathrm{C} 6-\mathrm{C} 7$ & $1.523(5)$ \\
\hline $\mathrm{C} 7-\mathrm{C} 8$ & $1.512(5)$ \\
\hline $\mathrm{C} 7-\mathrm{C} 16$ & $1.549(5)$ \\
\hline $\mathrm{C} 7-\mathrm{H} 71$ & 1.000 \\
\hline $\mathrm{C} 8-\mathrm{C} 9$ & $1.531(6)$ \\
\hline $\mathrm{C} 8-\mathrm{H} 81$ & 1.000 \\
\hline $\mathrm{C} 8-\mathrm{H} 82$ & 1.000 \\
\hline $\mathrm{C} 9-\mathrm{C} 10$ & $1.526(6)$ \\
\hline C9-C19 & $1.522(6)$ \\
\hline C9-H91 & 1.000 \\
\hline $\mathrm{C} 10-\mathrm{C} 11$ & $1.525(5)$ \\
\hline $\mathrm{C} 20-\mathrm{O} 2-\mathrm{C} 21$ & $116.8(3)$ \\
\hline $\mathrm{C} 10-\mathrm{O} 5-\mathrm{C} 22$ & $114.3(3)$ \\
\hline $\mathrm{C} 22-\mathrm{O} 6-\mathrm{C} 23$ & 114.1 (3) \\
\hline $\mathrm{C} 2-\mathrm{C} 1-\mathrm{C} 14$ & 111.8 (3) \\
\hline $\mathrm{C} 2-\mathrm{C} 1-\mathrm{C} 17$ & $107.1(3)$ \\
\hline $\mathrm{C} 14-\mathrm{C} 1-\mathrm{C} 17$ & $111.7(3)$ \\
\hline $\mathrm{C} 2-\mathrm{C} 1-\mathrm{C} 20$ & $107.7(3)$ \\
\hline $\mathrm{C} 14-\mathrm{C} 1-\mathrm{C} 20$ & $110.3(3)$ \\
\hline $\mathrm{C} 17-\mathrm{C} 1-\mathrm{C} 20$ & $108.0(3)$ \\
\hline $\mathrm{C} 1-\mathrm{C} 2-\mathrm{O} 3$ & $120.7(3)$ \\
\hline $\mathrm{C} 1-\mathrm{C} 2-\mathrm{C} 3$ & $116.3(3)$ \\
\hline $\mathrm{O} 3-\mathrm{C} 2-\mathrm{C} 3$ & $122.9(3)$ \\
\hline $\mathrm{C} 2-\mathrm{C} 3-\mathrm{C} 4$ & $111.2(3)$ \\
\hline $\mathrm{C} 2-\mathrm{C} 3-\mathrm{H} 31$ & 109.032 \\
\hline $\mathrm{C} 4-\mathrm{C} 3-\mathrm{H} 31$ & 109.034 \\
\hline $\mathrm{C} 2-\mathrm{C} 3-\mathrm{H} 32$ & 109.039 \\
\hline $\mathrm{C} 4-\mathrm{C} 3-\mathrm{H} 32$ & 109.038 \\
\hline $\mathrm{H} 31-\mathrm{C} 3-\mathrm{H} 32$ & 109.466 \\
\hline $\mathrm{C} 3-\mathrm{C} 4-\mathrm{C} 5$ & $111.8(3)$ \\
\hline $\mathrm{C} 3-\mathrm{C} 4-\mathrm{C} 15$ & $109.6(3)$ \\
\hline $\mathrm{C} 5-\mathrm{C} 4-\mathrm{C} 15$ & $112.0(3)$ \\
\hline $\mathrm{C} 3-\mathrm{C} 4-\mathrm{H} 41$ & 108.747 \\
\hline $\mathrm{C} 5-\mathrm{C} 4-\mathrm{H} 41$ & 106.134 \\
\hline $\mathrm{C} 15-\mathrm{C} 4-\mathrm{H} 41$ & 108.479 \\
\hline $\mathrm{C} 4-\mathrm{C} 5-\mathrm{C} 6$ & $107.6(3)$ \\
\hline $\mathrm{C} 4-\mathrm{C} 5-\mathrm{C} 18$ & $112.9(3)$ \\
\hline $\mathrm{C} 6-\mathrm{C} 5-\mathrm{C} 18$ & $111.8(3)$ \\
\hline
\end{tabular}

Table S3. Geometric parameters $(\AA, \circ)$

C10-H101

C11-C12

$\mathrm{C} 11-\mathrm{C} 16$

C11-H111

$\mathrm{C} 12-\mathrm{C} 13$

C12-H121

C12-H122

C13-C14

C13-H131

C13-H132

C14-C15

C14-H141

C15-C16

$\mathrm{C} 15-\mathrm{H} 151$

C16-H161

$\mathrm{C} 17-\mathrm{H} 171$

C17-H172

C17-H173

C18-H181

C18-H182

C18-H183

C19-H191

C19- $\mathrm{H} 192$

C19-H193

$\mathrm{C} 21-\mathrm{H} 211$

C21- $\mathrm{H} 212$

C21-H213

$\mathrm{C} 22-\mathrm{H} 221$

$\mathrm{C} 22-\mathrm{H} 222$

$\mathrm{C} 23-\mathrm{H} 231$

$\mathrm{C} 23-\mathrm{H} 232$

C23- $\mathrm{H} 233$

C51-C52

C53-C54

C4-C5-H51

C6- C5- 551

$\mathrm{C} 18-\mathrm{C} 5-\mathrm{H} 51$

$\mathrm{C} 5-\mathrm{C} 6-\mathrm{O} 4$

$\mathrm{C} 5-\mathrm{C} 6-\mathrm{C} 7$

$\mathrm{O} 4-\mathrm{C} 6-\mathrm{C} 7$

$\mathrm{C} 6-\mathrm{C} 7-\mathrm{C} 8$

$\mathrm{C} 6-\mathrm{C} 7-\mathrm{C} 16$

$\mathrm{C} 8-\mathrm{C} 7-\mathrm{C} 16$

$\mathrm{C} 6-\mathrm{C} 7-\mathrm{H} 71$

$\mathrm{C} 8-\mathrm{C} 7-\mathrm{H} 71$

$\mathrm{C} 16-\mathrm{C} 7-\mathrm{H} 71$

$\mathrm{C} 7-\mathrm{C} 8-\mathrm{C} 9$

$\mathrm{C} 7-\mathrm{C} 8-\mathrm{H} 81$

$\mathrm{C} 9-\mathrm{C} 8-\mathrm{H} 81$

$\mathrm{C} 7-\mathrm{C} 8-\mathrm{H} 82$

$\mathrm{C} 9-\mathrm{C} 8-\mathrm{H} 82$

$\mathrm{H} 81-\mathrm{C} 8-\mathrm{H} 82$

$\mathrm{C} 8-\mathrm{C} 9-\mathrm{C} 10$

$\mathrm{C} 8-\mathrm{C} 9-\mathrm{C} 19$

$\mathrm{C} 10-\mathrm{C} 9-\mathrm{C} 19$

C8-C9-H91

$\mathrm{C} 10-\mathrm{C} 9-\mathrm{H} 91$

C19-C9-H91

$\mathrm{C} 9-\mathrm{C} 10-\mathrm{O} 5$

$\mathrm{C} 9-\mathrm{C} 10-\mathrm{C} 11$

$\mathrm{O} 5-\mathrm{C} 10-\mathrm{C} 11$
1.000

$1.531(5)$

$1.532(5)$

1.000

$1.511(5)$

1.000

1.000

1.532 (5)

1.000

1.000

1.533 (5)

1.000

1.529 (5)

1.000

1.000

1.000

1.000

1.000

1.000

1.000

1.000

1.000

1.000

1.000

1.000

1.000

1.000

1.000

1.000

1.000

1.000

1.000

1.467 (10)

$1.452(9)$

109.179

110.438

104.856

124.0 (4)

115.3 (3)

120.6 (4)

114.0 (3)

106.1 (3)

112.5 (3)

108.322

108.324

107.318

111.7 (3)

108.908

108.912

108.912

108.908

109.467

111.1 (3)

110.9 (4)

113.6 (4)

108.872

105.883

106.138

109.8 (3)

111.6 (3)

109.0 (3) 


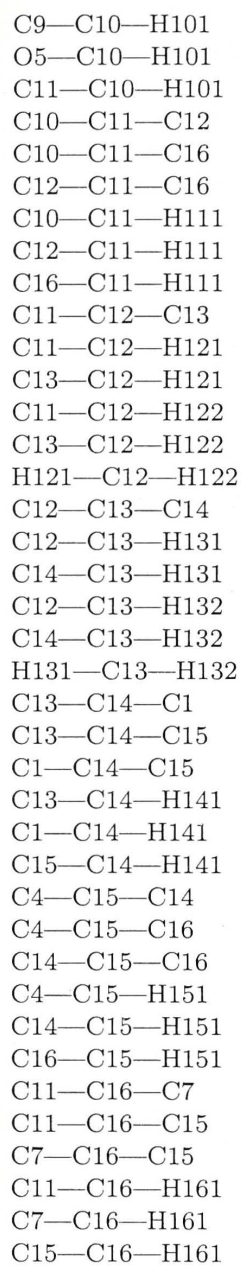

\begin{tabular}{|c|c|c|}
\hline 107.658 & $\mathrm{C} 1-\mathrm{C} 17-\mathrm{H} 171$ & 109.466 \\
\hline 110.354 & $\mathrm{C} 1-\mathrm{C} 17-\mathrm{H} 172$ & 109.468 \\
\hline 108.473 & $\mathrm{H} 171-\mathrm{C} 17-\mathrm{H} 172$ & 109.475 \\
\hline $112.6(3)$ & $\mathrm{C} 1-\mathrm{C} 17-\mathrm{H} 173$ & 109.466 \\
\hline $113.2(3)$ & $\mathrm{H} 171-\mathrm{C} 17-\mathrm{H} 173$ & 109.477 \\
\hline $109.4(3)$ & $\mathrm{H} 172-\mathrm{C} 17-\mathrm{H} 173$ & 109.476 \\
\hline 104.624 & $\mathrm{C} 5-\mathrm{C} 18-\mathrm{H} 181$ & 109.459 \\
\hline 108.725 & $\mathrm{C} 5-\mathrm{C} 18-\mathrm{H} 182$ & 109.476 \\
\hline 108.075 & $\mathrm{H} 181-\mathrm{C} 18-\mathrm{H} 182$ & 109.476 \\
\hline $110.8(3)$ & $\mathrm{C} 5-\mathrm{C} 18-\mathrm{H} 183$ & 109.466 \\
\hline 109.137 & $\mathrm{H} 181-\mathrm{C} 18-\mathrm{H} 183$ & 109.474 \\
\hline 109.135 & $\mathrm{H} 182-\mathrm{C} 18-\mathrm{H} 183$ & 109.476 \\
\hline 109.129 & C9-C19-H191 & 109.471 \\
\hline 109.133 & C9-C19-H192 & 109.470 \\
\hline 109.467 & $\mathrm{H} 191-\mathrm{C} 19-\mathrm{H} 192$ & 109.476 \\
\hline $111.1(3)$ & C9-C19--H193 & 109.459 \\
\hline 109.074 & $\mathrm{H} 191-\mathrm{C} 19-\mathrm{H} 193$ & 109.475 \\
\hline 109.068 & H192-C19-H193 & 109.477 \\
\hline 109.072 & $\mathrm{C} 1-\mathrm{C} 20-\mathrm{O} 2$ & $111.0(3)$ \\
\hline 109.075 & $\mathrm{C} 1-\mathrm{C} 20-\mathrm{O} 1$ & $126.6(3)$ \\
\hline 109.467 & $\mathrm{O} 2-\mathrm{C} 20-\mathrm{O} 1$ & $122.4(3)$ \\
\hline $112.4(3)$ & $\mathrm{O} 2-\mathrm{C} 21-\mathrm{H} 211$ & 109.472 \\
\hline $110.7(3)$ & $\mathrm{O} 2-\mathrm{C} 21-\mathrm{H} 212$ & 109.462 \\
\hline $114.2(3)$ & $\mathrm{H} 211-\mathrm{C} 21-\mathrm{H} 212$ & 109.476 \\
\hline 108.301 & $\mathrm{O} 2-\mathrm{C} 21-\mathrm{H} 213$ & 109.467 \\
\hline 104.336 & $\mathrm{H} 211-\mathrm{C} 21-\mathrm{H} 213$ & 109.476 \\
\hline 106.325 & $\mathrm{H} 212-\mathrm{C} 21-\mathrm{H} 213$ & 109.476 \\
\hline $110.7(3)$ & $\mathrm{O} 6-\mathrm{C} 22-\mathrm{O} 5$ & $113.2(3)$ \\
\hline $111.7(3)$ & $\mathrm{O} 6-\mathrm{C} 22-\mathrm{H} 221$ & 108.539 \\
\hline $110.1(3)$ & $\mathrm{O} 5-\mathrm{C} 22-\mathrm{H} 221$ & 108.534 \\
\hline 107.306 & $\mathrm{O} 6-\mathrm{C} 22-\mathrm{H} 222$ & 108.528 \\
\hline 109.035 & $\mathrm{O} 5-\mathrm{C} 22-\mathrm{H} 222$ & 108.526 \\
\hline 107.892 & $\mathrm{H} 221-\mathrm{C} 22-\mathrm{H} 222$ & 109.467 \\
\hline $110.8(3)$ & O6-C23-H231 & 109.464 \\
\hline $112.1(3)$ & $\mathrm{O} 6-\mathrm{C} 23-\mathrm{H} 232$ & 109.469 \\
\hline $111.5(3)$ & $\mathrm{H} 231-\mathrm{C} 23-\mathrm{H} 232$ & 109.476 \\
\hline 107.447 & $\mathrm{O} 6-\mathrm{C} 23-\mathrm{H} 233$ & 109.467 \\
\hline 108.041 & $\mathrm{H} 231-\mathrm{C} 23-\mathrm{H} 233$ & 109.476 \\
\hline 106.657 & $\mathrm{H} 232-\mathrm{C} 23-\mathrm{H} 233$ & 109.476 \\
\hline
\end{tabular}


$\mathrm{C} 4-\mathrm{C} 15-\mathrm{C} 16-\mathrm{C} 7$

$\mathrm{C} 4-\mathrm{C} 15-\mathrm{C} 16-\mathrm{C} 11$

C5- C4-C15-C14

$\mathrm{C} 5-\mathrm{C} 4-\mathrm{C} 15-\mathrm{C} 16$

$\mathrm{C} 5-\mathrm{C} 6-\mathrm{C} 7-\mathrm{C} 8$

$\mathrm{C} 5-\mathrm{C} 6-\mathrm{C} 7-\mathrm{C} 16$

$\mathrm{C} 6-\mathrm{C} 5-\mathrm{C} 4-\mathrm{C} 15$

C6- $7-\mathrm{C} 8-\mathrm{C} 9$

C6- 7 - $-\mathrm{C} 16-\mathrm{C} 11$

C6-C7-C16-C15

$\mathrm{C} 7-\mathrm{C} 6-\mathrm{C} 5-\mathrm{C} 18$

$\mathrm{C} 7-\mathrm{C} 8-\mathrm{C} 9-\mathrm{C} 10$

$\mathrm{C} 7-\mathrm{C} 8-\mathrm{C} 9-\mathrm{C} 19$

C7-C16-C11-C10

$\mathrm{C} 7-\mathrm{C} 16-\mathrm{C} 11-\mathrm{C} 12$

$\mathrm{C} 7-\mathrm{C} 16-\mathrm{C} 15-\mathrm{C} 14$

$\mathrm{C} 8-\mathrm{C} 7-\mathrm{C} 16-\mathrm{C} 11$

$\mathrm{C} 8-\mathrm{C} 7-\mathrm{C} 16-\mathrm{C} 15$

$\mathrm{C} 8-\mathrm{C} 9-\mathrm{C} 10-\mathrm{C} 11$

$\mathrm{C} 9-\mathrm{C} 8-\mathrm{C} 7-\mathrm{C} 16$

$\mathrm{C} 9-\mathrm{C} 10-\mathrm{O} 5-\mathrm{C} 22$

C9-C10-C11-C12

C9- $110-\mathrm{C} 11-\mathrm{C} 16$

$\mathrm{C} 10-\mathrm{C} 11-\mathrm{C} 12-\mathrm{C} 13$

$\mathrm{C} 10-\mathrm{C} 11-\mathrm{C} 16-\mathrm{C} 15$

$\mathrm{C} 11-\mathrm{C} 10-\mathrm{O} 5-\mathrm{C} 22$

$\mathrm{C} 11-\mathrm{C} 10-\mathrm{C} 9-\mathrm{C} 19$

$\mathrm{C} 11-\mathrm{C} 12-\mathrm{C} 13-\mathrm{C} 14$

$\mathrm{C} 11-\mathrm{C} 16-\mathrm{C} 15-\mathrm{C} 14$

$\mathrm{C} 12-\mathrm{C} 11-\mathrm{C} 16-\mathrm{C} 15$

$\mathrm{C} 12-\mathrm{C} 13-\mathrm{C} 14-\mathrm{C} 15$

$\mathrm{C} 13-\mathrm{C} 12-\mathrm{C} 11-\mathrm{C} 16$

$\mathrm{C} 13-\mathrm{C} 14-\mathrm{C} 1-\mathrm{C} 17$

$\mathrm{C} 13-\mathrm{C} 14-\mathrm{C} 1-\mathrm{C} 2 \mathrm{O}$

C13-C14-C15-C16

$\mathrm{C} 15-\mathrm{C} 4-\mathrm{C} 5-\mathrm{C} 18$

C15-C14-C1-C17

$\mathrm{C} 15-\mathrm{C} 14-\mathrm{C} 1-\mathrm{C} 20$
$-55.6(4)$

$179.5(3)$

$176.1(3)$

$53.0(4)$

173.7 (3)

$-61.9(4)$

$-53.0(4)$

$175.6(3)$

$-177.3(3)$

57.1 (4)

-175.4 (3)

-55.8 (5)

176.9 (3)

$51.4(4)$

177.8 (3)

-179.0 (3)

$-52.0(4)$

$-177.6(3)$

54.7 (4)

54.8 (4)

-104.6 (3)

$-178.3(3)$

$-53.6(4)$

-175.8 (3)

176.7 (3)

132.9 (3)

$-179.4(3)$

$-58.3(4)$

56.1 (4)

$-56.9(4)$

57.1 (4)

$57.5(4)$

-50.8 (4)

$69.3(4)$

-55.2 (4)

$-176.8(3)$

76.4 (4)

$-163.4(3)$ 
Sample: man0503a

Compound: $\mathrm{C}_{24} \mathrm{H}_{34} \mathrm{O}_{6}$.

X-ray Structure Report

for

Kelly A. Fairweather and Lewis N. Mander

by

Anthony C. Willis

Research School of Chemistry, Institute of Advanced Studies

Australian National University, Canberra, ACT 0200, Australia

Thursday, 18th May 2005 
Figure 1. Anisotropic displacement ellipsoid plot of $\mathrm{C}_{24} \mathrm{H}_{34} \mathrm{O}_{6}$. with labelling of selected atoms. Ellipsoids show $30 \%$ probability levels. Hydrogen atoms are drawn as circles with small radii.

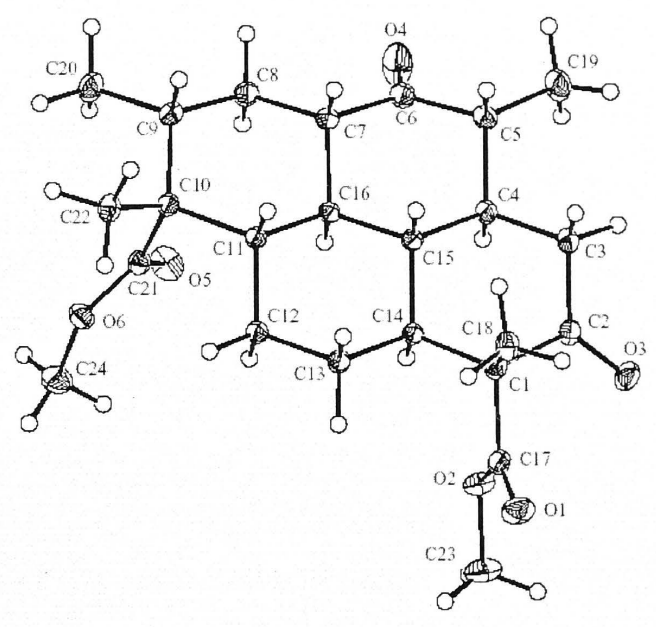

Figure 2. Unit cell packing diagram of $\mathrm{C}_{24} \mathrm{H}_{34} \mathrm{O}_{6}$. projected down the $b$ axis. Hydrogen atoms have been deleted for clarity.

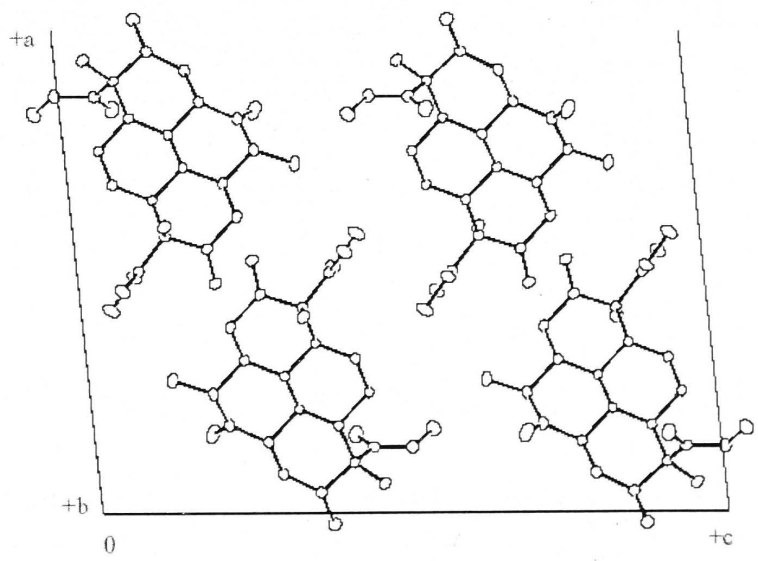




\section{Crystal structure of $\mathrm{C}_{24} \mathrm{H}_{34} \mathrm{O}_{6}-$ man0503a}

Kelly A. Fairweather, Lewis N. Mander and Anthony C. Willis

Research School of Chemistry, Australian National University, Canberra, A. C. T. 0200, Australia.E-mail: willis@rsc.anu.edu.au

\section{Abstract}

The crystal structure of $\mathrm{C}_{24} \mathrm{H}_{34} \mathrm{O}_{6}$ is reported.

\section{Comment}

The crystallographic asymmetric unit consists of one $\mathrm{C}_{24} \mathrm{H}_{34} \mathrm{O}_{6}$ molecule.

$\mathrm{H}$ atoms were observed in difference electron density maps prior to their inclusion. They were included at calculated positions and then refined positionally.

The final difference electron density map was generally featureless with peaks having no chemical significance.

\section{Experimental}

The compound was prepared by KAF and recrystallized from methanol. The sample ID is KFIX79c. 
Crystal data

$\mathrm{C}_{24} \mathrm{H}_{34} \mathrm{O}_{6}$

$M_{r}=418.53$

Monoclinic

$P 2_{1} / c$

$a=16.5386$ (2) §

$b=6.21980$ (10) $\AA$

$c=21.3466(3) \AA$

$\beta=96.1116(7)^{\circ}$

$V=2183.38(5) \AA^{3}$

$Z=4$

$D_{x}=1.273 \mathrm{Mg} \mathrm{m}^{-3}$

$D_{m}$ not measured

Mo $K \alpha$ radiation

$\lambda=0.71073 \AA$

Data collection

Nonius Kappa CCD diffractometer $\varphi$ and $\omega$ scans with CCD

Absorption correction:

by integration via Gaussian method (Coppens, 1970) implemented in maXus (2000)

$T_{\min }=0.969, T_{\max }=0.992$

43217 measured reflections

4962 independent reflections
Cell parameters from 32292 reflections

$\theta=3-27^{\circ}$

$\mu=0.090 \mathrm{~mm}^{-1}$

$T=200 \mathrm{~K}$

Plate

Colourless

$0.40 \times 0.25 \times 0.09 \mathrm{~mm}$

Crystal source: ?
3711 reflections with

$$
\begin{aligned}
& \quad I>2.00 u(I) \\
& R_{\text {int }}=0.04 \\
& \theta_{\max }=27.5^{\circ} \\
& h=-21 \rightarrow 21 \\
& k=-7 \rightarrow 8 \\
& l=-27 \rightarrow 27
\end{aligned}
$$

every 0 reflections

frequency: $0 \mathrm{~min}$

intensity decay: none 


\section{Refinement}

Refinement on $F$

$R=0.0343$

$w R=0.0432$

$S=1.0610$

3711 reflections

373 parameters

Only coordinates of $\mathrm{H}$ atoms refined
Method, part 1, Chebychev polyno-

mial, (Watkin, 1994, Prince, 1982)

$[$ weight $]=1.0 /\left[A_{0} * T_{0}(x)+A_{1} * T_{1}(x) \ldots\right.$

$\left.\left.+A_{n-1}\right]^{*} T_{n-1}(x)\right]$

where $A_{i}$ are the Chebychev coefficients listed below and $x=$ Fcalc/Fmax Method $=$ Robust Weighting (Prince, 1982) $W=$ [weight] $*\left[1-\left(\operatorname{deltaF} / 6^{*} \operatorname{sigmaF}\right)^{2}\right]^{2} A_{i}$ are: 0.9920 .5480 .626

$(\Delta / \sigma)_{\max }=0.002381$

$\Delta \rho_{\max }=0.29 \mathrm{e}^{-3}$

$\Delta \rho_{\min }=-0.18{\mathrm{e} \AA^{-3}}^{-3}$

Extinction correction: none

Scattering factors from International Tables for X-ray Crystallography (Vol. IV)
$\mathrm{O} 1-\mathrm{C} 17$
$\mathrm{O} 2-\mathrm{C} 17$
$\mathrm{O} 2-\mathrm{C} 23$
$\mathrm{O} 3-\mathrm{C} 2$
$\mathrm{O} 4-\mathrm{C} 6$
$\mathrm{O} 5-\mathrm{C} 21$
$\mathrm{O} 6-\mathrm{C} 21$
$\mathrm{O} 6-\mathrm{C} 24$
$\mathrm{C} 1-\mathrm{C} 2$
C1-C14
$\mathrm{C} 1-\mathrm{C} 17$
$\mathrm{C} 1-\mathrm{C} 18$
$\mathrm{C} 2-\mathrm{C} 3$
$\mathrm{C} 3-\mathrm{C} 4$
$\mathrm{C} 4-\mathrm{C} 5$
$\mathrm{C} 4-\mathrm{C} 15$
$\mathrm{C} 5-\mathrm{C} 6$

Table 1. Selected geometric parameters $(\AA, \circ)$

$\begin{array}{ll}1.1991(13) & \mathrm{C} 5-\mathrm{C} 19 \\ 1.3392(14) & \mathrm{C} 6-\mathrm{C} 7 \\ 1.4383(15) & \mathrm{C} 7-\mathrm{C} 8 \\ 1.2130(13) & \mathrm{C} 7-\mathrm{C} 16 \\ 1.2124(16) & \mathrm{C} 8-\mathrm{C} 9 \\ 1.2049(14) & \mathrm{C} 9-\mathrm{C} 10 \\ 1.3421(13) & \mathrm{C} 9-\mathrm{C} 20 \\ 1.4418(15) & \mathrm{C} 10-\mathrm{C} 11 \\ 1.5344(14) & \mathrm{C} 10-\mathrm{C} 21 \\ 1.5560(13) & \mathrm{C} 10-\mathrm{C} 22 \\ 1.5297(14) & \mathrm{C} 11-\mathrm{C} 12 \\ 1.5420(15) & \mathrm{C} 11-\mathrm{C} 16 \\ 1.5055(15) & \mathrm{C} 12-\mathrm{C} 13 \\ 1.5345(15) & \mathrm{C} 13-\mathrm{C} 14 \\ 1.5495(14) & \mathrm{C} 14-\mathrm{C} 15 \\ 1.5380(13) & \mathrm{C} 15-\mathrm{C} 16 \\ 1.5185(17) & \end{array}$




\begin{tabular}{|c|c|}
\hline $\mathrm{C} 17-\mathrm{O} 2-\mathrm{C} 23$ & $116.55(10)$ \\
\hline $\mathrm{C} 21-\mathrm{O} 6-\mathrm{C} 24$ & $116.72(9)$ \\
\hline $\mathrm{C} 2-\mathrm{C} 1-\mathrm{C} 14$ & $110.92(8)$ \\
\hline $\mathrm{C} 2-\mathrm{C} 1-\mathrm{C} 17$ & $106.90(8)$ \\
\hline $\mathrm{C} 14-\mathrm{C} 1-\mathrm{C} 17$ & $109.87(8)$ \\
\hline $\mathrm{C} 2-\mathrm{C} 1-\mathrm{C} 18$ & $106.89(9)$ \\
\hline $\mathrm{C} 14-\mathrm{C} 1-\mathrm{C} 18$ & $112.83(8)$ \\
\hline $\mathrm{C} 17-\mathrm{C} 1-\mathrm{C} 18$ & $109.22(9)$ \\
\hline $\mathrm{C} 1-\mathrm{C} 2-\mathrm{O} 3$ & $121.20(10)$ \\
\hline $\mathrm{C} 1-\mathrm{C} 2-\mathrm{C} 3$ & $116.10(8)$ \\
\hline $\mathrm{O} 3-\mathrm{C} 2-\mathrm{C} 3$ & $122.67(9)$ \\
\hline $\mathrm{C} 2-\mathrm{C} 3-\mathrm{C} 4$ & $112.17(9)$ \\
\hline $\mathrm{C} 3-\mathrm{C} 4-\mathrm{C} 5$ & $111.14(9)$ \\
\hline $\mathrm{C} 3-\mathrm{C} 4-\mathrm{C} 15$ & $110.88(9)$ \\
\hline $\mathrm{C} 5-\mathrm{C} 4-\mathrm{C} 15$ & $111.12(8)$ \\
\hline $\mathrm{C} 4-\mathrm{C} 5-\mathrm{C} 6$ & $107.11(9)$ \\
\hline $\mathrm{C} 4-\mathrm{C} 5-\mathrm{C} 19$ & $114.06(11)$ \\
\hline $\mathrm{C} 6-\mathrm{C} 5-\mathrm{C} 19$ & $111.80(11)$ \\
\hline $\mathrm{C} 5-\mathrm{C} 6-\mathrm{O} 4$ & $122.51(11)$ \\
\hline $\mathrm{C} 5-\mathrm{C} 6-\mathrm{C} 7$ & $115.26(10)$ \\
\hline $\mathrm{O} 4-\mathrm{C} 6-\mathrm{C} 7$ & $122.16(11)$ \\
\hline $\mathrm{C} 6-\mathrm{C} 7-\mathrm{C} 8$ & $113.31(10)$ \\
\hline $\mathrm{C} 6-\mathrm{C} 7-\mathrm{C} 16$ & $109.31(9)$ \\
\hline $\mathrm{C} 8-\mathrm{C} 7-\mathrm{C} 16$ & $110.57(9)$ \\
\hline $\mathrm{C} 7-\mathrm{C} 8-\mathrm{C} 9$ & $111.59(10)$ \\
\hline $\mathrm{C} 8-\mathrm{C} 9-\mathrm{C} 10$ & $114.43(9)$ \\
\hline $\mathrm{C} 8-\mathrm{C} 9-\mathrm{C} 20$ & $109.98(10)$ \\
\hline
\end{tabular}

\begin{tabular}{|c|c|}
\hline $\mathrm{C} 10-\mathrm{C} 9-\mathrm{C} 20$ & $112.57(9)$ \\
\hline $\mathrm{C} 9-\mathrm{C} 10-\mathrm{C} 11$ & $112.21(8)$ \\
\hline $\mathrm{C} 9-\mathrm{C} 10-\mathrm{C} 21$ & $110.57(9)$ \\
\hline $\mathrm{C} 11-\mathrm{C} 10-\mathrm{C} 21$ & $106.38(8)$ \\
\hline $\mathrm{C} 9-\mathrm{C} 10-\mathrm{C} 22$ & $107.88(9)$ \\
\hline $\mathrm{C} 11-\mathrm{C} 10-\mathrm{C} 22$ & $108.40(8)$ \\
\hline $\mathrm{C} 21-\mathrm{C} 10-\mathrm{C} 22$ & $111.42(8)$ \\
\hline $\mathrm{C} 10-\mathrm{C} 11-\mathrm{C} 12$ & $112.12(8)$ \\
\hline $\mathrm{C} 10-\mathrm{C} 11-\mathrm{C} 16$ & $115.76(8)$ \\
\hline $\mathrm{C} 12-\mathrm{C} 11-\mathrm{C} 16$ & $108.78(8)$ \\
\hline $\mathrm{C} 11-\mathrm{C} 12-\mathrm{C} 13$ & $111.38(8)$ \\
\hline $\mathrm{C} 12-\mathrm{C} 13-\mathrm{C} 14$ & $111.19(8)$ \\
\hline $\mathrm{C} 13-\mathrm{C} 14-\mathrm{C} 1$ & $111.01(8)$ \\
\hline $\mathrm{C} 13-\mathrm{C} 14-\mathrm{C} 15$ & $111.13(8)$ \\
\hline $\mathrm{C} 1-\mathrm{C} 14-\mathrm{C} 15$ & $113.66(8)$ \\
\hline $\mathrm{C} 4-\mathrm{C} 15-\mathrm{C} 14$ & $111.02(8)$ \\
\hline $\mathrm{C} 4-\mathrm{C} 15-\mathrm{C} 16$ & $111.39(8)$ \\
\hline $\mathrm{C} 14-\mathrm{C} 15-\mathrm{C} 16$ & $109.45(8)$ \\
\hline $\mathrm{C} 7-\mathrm{C} 16-\mathrm{C} 11$ & $110.45(8)$ \\
\hline $\mathrm{C} 7-\mathrm{C} 16-\mathrm{C} 15$ & $111.23(8)$ \\
\hline $\mathrm{C} 11-\mathrm{C} 16-\mathrm{C} 15$ & $110.52(8)$ \\
\hline $\mathrm{C} 1-\mathrm{C} 17-\mathrm{O} 2$ & $110.62(8)$ \\
\hline $\mathrm{C} 1-\mathrm{C} 17-\mathrm{O} 1$ & $125.49(10)$ \\
\hline $\mathrm{O} 2-\mathrm{C} 17-\mathrm{O} 1$ & $123.89(10)$ \\
\hline $\mathrm{C} 10-\mathrm{C} 21-\mathrm{O} 6$ & $112.47(9)$ \\
\hline $\mathrm{C} 10-\mathrm{C} 21-\mathrm{O} 5$ & $124.99(10)$ \\
\hline $\mathrm{O} 6-\mathrm{C} 21-\mathrm{O} 5$ & $122.43(10)$ \\
\hline
\end{tabular}

$\mathrm{H}$ atoms were refined positionally.

Data collection: COLLECT (Nonius BV, 1997). Cell refinement: Denzo/Scalepack (Otwinowski \& Minor, 1996). Data reduction: Denzo/Scalepack (Otwinowski \& Minor, 1996) . Program(s) used to solve structure: SIR92 (Altomare et al. 1994). Program(s) used to refine structure: CRYSTALS (Watkin et al.2003). Molecular graphics: ORTEP-II (Johnson 1976) in teXsan (MSC, 1992-1997) . Software used to prepare material for publication: CRYSTALS (Watkin et al.2003) . 


\section{References}

Mackay, S., Gilmore, C. J.,Edwards, C., Stewart, N. \& Shankland, K. (2000). maXus Computer Program for the Solution and Refinement of Crystal Structures. Nonius, The Netherlands, MacScience, Japan \& The University of Glasgow.

Coppens, P. (1970). The Evaluation of Absorption and Extinction in Single-Crystal Structure Analysis. Crystallographic Computing. F. R. Ahmed, S. R. Hall and C. P. Huber, Editors., Munksgaard. Copenhagen. pp 255-270.

Altomare, A., Cascarano, G., Giacovazzo C., Guagliardi A., Burla M. C., Polidori, G. \& Camalli, M. (1994). SIR92 - a program for automatic solution of crystal structures by direct methods. J. Appl. Cryst. (27), 435-435

Betteridge, P. W., Carruthers, J. R., Cooper, R. I., Prout, K., Watkin, D. J. (2003). J. Appl. Cryst. 36, 1487.

Nonius BV, COLLECT Software, 1997-2001)

Otwinowski, Z. \& Minor, W. (1996). Processing of X-ray Diffraction Data Collected in Oscillation Mode. Methods Enzymol. 276, 1997, 307-326. Ed Carter, C. W. \& Sweet, R. M., Academic Press.

Prince, E. Mathematical Techniques in Crystallography and Materials Science Springer-Verlag, New York, 1982.

Watkin D. J. (1994). Acta Cryst, A50, 411-437

Molecular Structure Corporation. (1992-1997). teXsan. Single Crystal Structure Analysis Software. Version 1.8. MSC, 3200 Research Forest Drive, The Woodlands, TX 77381, USA.

Johnson, C. K. (1976). ORTEP-II, A Fortran Thermal-Ellipsoid Plot Program, Report ORNL5138, Oak Ridge National Laboratory, Oak Ridge, Tennessee, USA. 


\section{Supplementary data}

Table S1. Fractional atomic coordinates and equivalent isotropic displacement parameters $\left(\AA^{2}\right)$

$$
U_{\text {eq }}=(1 / 3) \Sigma_{i} \Sigma_{j} U^{i j} a^{i} a^{j} \mathbf{a}_{i} \cdot \mathbf{a}_{j} .
$$

\begin{tabular}{|c|c|c|c|c|}
\hline & $x$ & $y$ & $z$ & \\
\hline O1 & $0.54043(5)$ & $1.06092(15)$ & $0.43004(4)$ & 0.0426 \\
\hline $\mathrm{O} 2$ & $0.51053(5)$ & 0.71520 & $0.40902(4)$ & 0.0352 \\
\hline $\mathrm{O} 3$ & $0.52369(5)$ & $0.89611(16)$ & $0.28110(4)$ & 0.0382 \\
\hline $\mathrm{O} 4$ & $0.16522(7)$ & $0.4199(2)$ & $0.18955(5)$ & 0.0658 \\
\hline O5 & $0.16307(6)$ & $0.27103(14)$ & $0.41668(4)$ & 0.0417 \\
\hline O6 & $0.13636(5)$ & $0.43413(13)$ & $0.50538(4)$ & 0.0316 \\
\hline $\mathrm{C} 1$ & $0.42590(6)$ & $0.97247(17)$ & $0.35339(5)$ & 0.0236 \\
\hline $\mathrm{C} 2$ & $0.45244(6)$ & $0.91753(17)$ & $0.28855(5)$ & 0.0268 \\
\hline C3 & $0.38542(7)$ & 0.8989 (2) & $0.23529(5)$ & 0.0306 \\
\hline $\mathrm{C} 4$ & $0.31669(6)$ & $0.75032(18)$ & $0.25174(5)$ & 0.0258 \\
\hline C5 & $0.24762(7)$ & $0.7381(2)$ & $0.19680(5)$ & 0.0355 \\
\hline C6 & $0.18355(7)$ & $0.5860(2)$ & $0.21720(5)$ & 0.0373 \\
\hline $\mathrm{C} 7$ & $0.14735(6)$ & $0.6501(2)$ & $0.27648(5)$ & 0.0287 \\
\hline $\mathrm{C} 8$ & $0.08219(7)$ & $0.4962(2)$ & $0.29407(5)$ & 0.0359 \\
\hline C9 & $0.04325(6)$ & $0.5748(2)$ & $0.35170(5)$ & 0.0312 \\
\hline C10 & $0.10493(6)$ & $0.62843(17)$ & $0.40981(5)$ & 0.0229 \\
\hline C11 & $0.18140(6)$ & $0.75177(16)$ & $0.39091(4)$ & 0.0210 \\
\hline $\mathrm{C} 12$ & $0.25046(6)$ & $0.75844(18)$ & $0.44487(5)$ & 0.0254 \\
\hline $\mathrm{C} 13$ & $0.31970(6)$ & $0.90321(18)$ & $0.42883(5)$ & 0.0257 \\
\hline $\mathrm{C} 14$ & $0.35223(6)$ & $0.83192(16)$ & $0.36769(4)$ & 0.0208 \\
\hline C15 & $0.28384(6)$ & $0.82260(16)$ & $0.31312(4)$ & 0.0214 \\
\hline C16 & $0.21577(6)$ & $0.67137(16)$ & $0.33096(4)$ & 0.0214 \\
\hline $\mathrm{C} 17$ & $0.49871(6)$ & $0.92722(18)$ & $0.40200(5)$ & 0.0276 \\
\hline C18 & $0.40691(7)$ & $1.21522(18)$ & $0.35297(6)$ & 0.0306 \\
\hline C19 & $0.27599(10)$ & $0.6711(4)$ & $0.13403(6)$ & 0.0562 \\
\hline $\mathrm{C} 20$ & $-0.02270(8)$ & $0.4164(3)$ & $0.36748(7)$ & 0.0455 \\
\hline $\mathrm{C} 21$ & $0.13647(6)$ & $0.42360(17)$ & $0.44259(5)$ & 0.0255 \\
\hline $\mathrm{C} 22$ & $0.06142(7)$ & $0.77291(19)$ & $0.45432(5)$ & 0.0296 \\
\hline $\mathrm{C} 23$ & $0.57919(9)$ & $0.6494(3)$ & $0.45177(8)$ & 0.0491 \\
\hline $\mathrm{C} 24$ & $0.17421(9)$ & $0.2583(2)$ & $0.54145(7)$ & 0.0417 \\
\hline H31 & $0.3640(9)$ & $1.039(3)$ & $0.2264(7)$ & 0.0373 \\
\hline H32 & $0.4095(9)$ & $0.854(2)$ & $0.1959(7)$ & 0.0373 \\
\hline $\mathrm{H} 41$ & $0.3402(8)$ & $0.606(2)$ & $0.2581(6)$ & 0.0312 \\
\hline H51 & $0.2217(9)$ & $0.894(3)$ & $0.1924(7)$ & 0.0424 \\
\hline H71 & $0.1243(9)$ & $0.795(2)$ & $0.2671(7)$ & 0.0345 \\
\hline H81 & $0.1082(10)$ & $0.352(3)$ & $0.3022(7)$ & 0.0430 \\
\hline H82 & $0.0393(9)$ & 0.485 & $0.2584(7)$ & 0.0430 \\
\hline H91 & $0.0172(9)$ & $0.717(2)$ & $0.3387(7)$ & 0.0374 \\
\hline H111 & $0.1630(8)$ & $0.902(2)$ & $0.3812(6)$ & 0.0255 \\
\hline H121 & $0.2307(8)$ & $0.808(2)$ & $0.4854(7)$ & 0.0310 \\
\hline $\mathrm{H} 122$ & $0.2713(8)$ & $0.609(2)$ & $0.4528(6)$ & 0.0310 \\
\hline H131 & $0.3650(8)$ & $0.900(2)$ & $0.4649(7)$ & 0.0311 \\
\hline H132 & $0.2978(8)$ & $1.051(2)$ & $0.4237(6)$ & 0.0311 \\
\hline H141 & $0.3718(8)$ & $0.686(2)$ & $0.3738(6)$ & 0.0254 \\
\hline H151 & $0.2587(8)$ & $0.970(2)$ & $0.3058(6)$ & 0.0260 \\
\hline H161 & $0.2407(8)$ & $0.525(2)$ & $0.3394(6)$ & 0.0261 \\
\hline H181 & $0.4005(9)$ & $1.262(2)$ & $0.3952(7)$ & 0.0378 \\
\hline H182 & $0.4506(9)$ & $1.295(2)$ & $0.3380(7)$ & 0.0378 \\
\hline H183 & $0.3567(9)$ & $1.245(2)$ & $0.3256(7)$ & 0.0378 \\
\hline H191 & $0.2279(12)$ & $0.654(3)$ & $0.1037(10)$ & 0.0687 \\
\hline H192 & $0.3108(12)$ & $0.782(3)$ & $0.1179(9)$ & 0.0687 \\
\hline
\end{tabular}




$\begin{array}{lr}\text { H193 } & 0.3070(13) \\ \text { H201 } & -0.0463(10) \\ \text { H202 } & -0.0006(11) \\ \text { H203 } & -0.0658(11) \\ \text { H221 } & 0.0978(9) \\ \text { H222 } & 0.0141(9) \\ \text { H223 } & 0.0417(9) \\ \text { H231 } & 0.5796(11) \\ \text { H232 } & 0.5738(11) \\ \text { H233 } & 0.6286(12) \\ \text { H241 } & 0.1852(10) \\ \text { H242 } & 0.2242(11) \\ \text { H243 } & 0.1399(10)\end{array}$

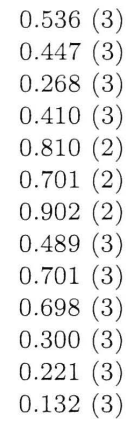

$0.1395(10)$
$0.4064(9)$
$0.3701(8)$
$0.3323(8)$
$0.4923(7)$
$0.4692(7)$
$0.4310(7)$
$0.4497(8)$
$0.4938(9)$
$0.4383(8)$
$0.5844(9)$
$0.5276(8)$
$0.5352(8)$

Table S2. Anisotropic displacement parameters $\left(\AA^{2}\right)$

O1

$\mathrm{O} 2$

$\mathrm{O} 3$

$\mathrm{O} 4$

O5

O6

C1

C2

C3

C4

C5

C6

$\mathrm{C} 7$

C8

C9

C10

C11

C12

C13

C14

C15

C16

$\mathrm{C} 17$

C18

C19

C20

$\mathrm{C} 21$

C22

$\mathrm{C} 23$

C24

$U_{22}$
$0.0440(5)$
$0.0354(4)$
$0.0541(5)$
$0.0825(8)$
$0.0249(4)$
$0.0329(4)$
$0.0258(5)$
$0.0281(5)$
$0.0407(6)$
$0.0327(5)$
$0.0546(8)$
$0.0562(8)$
$0.0410(6)$
$0.0530(7)$
$0.0428(6)$
$0.0243(5)$
$0.0224(5)$
$0.0333(6)$
$0.0323(6)$
$0.0221(5)$
$0.0242(5)$
$0.0240(5)$
$0.0342(5)$
$0.0239(5)$
$0.0963(13)$
$0.0675(10)$
$0.0237(5)$
$0.0296(5)$
$0.0547(9)$
$0.0401(7)$

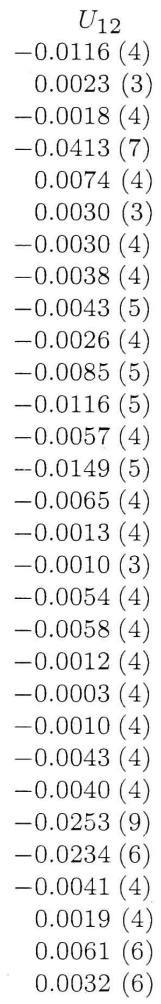

$U_{12}$ $-0.0116(4)$ $0.0023(3)$

$-0.0018(4)$

$-0.0413(7)$

$0.0074(4)$ $0.0030(3)$

$-0.0030(4)$

$-0.0038(4)$

$-0.0043(5)$

$-0.0026(4)$

$-0.0085(5)$

$-0.0116(5)$

$-0.0057(4)$

$-0.0149(5)$

$-0.0065(4)$

$-0.0013(4)$

-0.0010 (3)

-0.0054 (4)

-0.0058 (4)

$-0.0012(4)$

-0.0003 (4)

$-0.0010(4)$

-0.0043 (4)

$-0.0040(4)$

$-0.0253(9)$

$-0.0234(6)$

-0.0041 (4)

0.0019 (4)

0.0061 (6)

0.0032 (6)

\begin{tabular}{rr}
$U_{13}$ & \multicolumn{1}{c}{$U_{23}$} \\
$-0.0073(4)$ & $-0.0073(4)$ \\
$-0.0072(3)$ & $-0.0010(3)$ \\
$0.0097(3)$ & $-0.0091(4)$ \\
$0.0245(5)$ & $-0.0359(6)$ \\
$0.0100(4)$ & $-0.0033(3)$ \\
$0.0039(3)$ & $0.0055(3)$ \\
$0.0032(4)$ & $-0.0027(4)$ \\
$0.0072(4)$ & $-0.0025(4)$ \\
$0.0068(4)$ & $-0.0003(4)$ \\
$0.0043(4)$ & $-0.0033(4)$ \\
$0.0022(4)$ & $-0.0033(5)$ \\
$0.0017(4)$ & $-0.0091(5)$ \\
$-0.0003(4)$ & $-0.0027(4)$ \\
$0.0008(4)$ & $-0.0077(5)$ \\
$0.0014(4)$ & $-0.0009(5)$ \\
$0.0036(3)$ & $-0.0007(4)$ \\
$0.0025(3)$ & $-0.0014(3)$ \\
$0.0024(4)$ & $-0.0029(4)$ \\
$0.0029(4)$ & $-0.0053(4)$ \\
$0.0021(3)$ & $-0.0017(4)$ \\
$0.0020(3)$ & $-0.0017(4)$ \\
$0.0014(3)$ & $-0.0025(4)$ \\
$0.0043(4)$ & $-0.0038(4)$ \\
$0.0094(5)$ & $-0.0008(4)$ \\
$0.0092(6)$ & $-0.0149(7)$ \\
$0.0052(5)$ & $-0.0074(6)$ \\
$0.0043(4)$ & $-0.0006(4)$ \\
$0.0103(4)$ & $-0.0011(4)$ \\
$-0.0144(6)$ & $0.0039(7)$ \\
$-0.0020(5)$ & $0.0131(6)$ \\
&
\end{tabular}




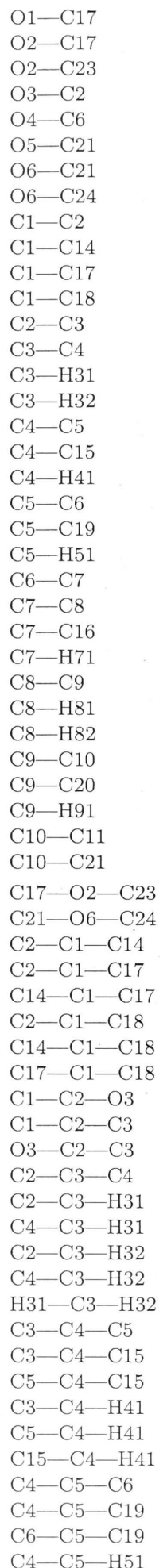

Table S3. Geometric parameters $\left(\AA,^{\circ}\right)$

\begin{tabular}{|c|c|c|}
\hline 1.1991 (13) & $\mathrm{C} 10-\mathrm{C} 22$ & $1.5407(14)$ \\
\hline $1.3392(14)$ & $\mathrm{C} 11-\mathrm{C} 12$ & $1.5338(13)$ \\
\hline $1.4383(15)$ & $\mathrm{C} 11-\mathrm{C} 16$ & $1.5381(13)$ \\
\hline $1.2130(13)$ & $\mathrm{C} 11-\mathrm{H} 111$ & $0.998(13)$ \\
\hline $1.2124(16)$ & $\mathrm{C} 12-\mathrm{C} 13$ & $1.5240(14)$ \\
\hline $1.2049(14)$ & $\mathrm{C} 12-\mathrm{H} 121$ & $1.006(14)$ \\
\hline $1.3421(13)$ & $\mathrm{C} 12-\mathrm{H} 122$ & $0.998(15)$ \\
\hline $1.4418(15)$ & $\mathrm{C} 13-\mathrm{C} 14$ & $1.5294(13)$ \\
\hline $1.5344(14)$ & C13-H131 & $1.016(14)$ \\
\hline $1.5560(13)$ & $\mathrm{C} 13-\mathrm{H} 132$ & $0.992(14)$ \\
\hline $1.5297(14)$ & $\mathrm{C} 14-\mathrm{C} 15$ & 1.5359 (13) \\
\hline $1.5420(15)$ & $\mathrm{C} 14-\mathrm{H} 141$ & $0.965(14)$ \\
\hline $1.5055(15)$ & $\mathrm{C} 15-\mathrm{C} 16$ & $1.5455(13)$ \\
\hline $1.5345(15)$ & $\mathrm{C} 15-\mathrm{H} 151$ & $1.012(13)$ \\
\hline $0.950(16)$ & $\mathrm{C} 16-\mathrm{H} 161$ & $1.006(13)$ \\
\hline $1.008(15)$ & $\mathrm{C} 18-\mathrm{H} 181$ & $0.965(15)$ \\
\hline $1.5495(14)$ & C18-H182 & 0.960 (15) \\
\hline $1.5380(13)$ & $\mathrm{C} 18-\mathrm{H} 183$ & $0.981(15)$ \\
\hline $0.979(14)$ & C19-H191 & $0.98(2)$ \\
\hline $1.5185(17)$ & C19-H192 & $0.98(2)$ \\
\hline $1.5243(17)$ & C19-H193 & $0.98(2)$ \\
\hline $1.060(16)$ & $\mathrm{C} 20-\mathrm{H} 201$ & $0.974(18)$ \\
\hline $1.5100(15)$ & $\mathrm{C} 20-\mathrm{H} 202$ & $0.991(19)$ \\
\hline $1.5185(16)$ & $\mathrm{C} 20-\mathrm{H} 203$ & $0.979(18)$ \\
\hline $1.5395(13)$ & $\mathrm{C} 22-\mathrm{H} 221$ & $0.985(15)$ \\
\hline $0.992(15)$ & $\mathrm{C} 22-\mathrm{H} 222$ & $0.983(15)$ \\
\hline $1.5286(16)$ & $\mathrm{C} 22-\mathrm{H} 223$ & $0.984(15)$ \\
\hline $1.001(17)$ & $\mathrm{C} 23-\mathrm{H} 231$ & $0.997(19)$ \\
\hline $0.986(16)$ & $\mathrm{C} 23-\mathrm{H} 232$ & 0.967 (19) \\
\hline $1.5560(14)$ & $\mathrm{C} 23-\mathrm{H} 233$ & $0.944(19)$ \\
\hline $1.5335(17)$ & $\mathrm{C} 24-\mathrm{H} 241$ & 0.950 (18) \\
\hline $1.011(15)$ & $\mathrm{C} 24-\mathrm{H} 242$ & 0.937 (18) \\
\hline $1.5682(13)$ & $\mathrm{C} 24-\mathrm{H} 243$ & 0.969 (18) \\
\hline $1.5189(14)$ & & \\
\hline $116.55(10)$ & $\mathrm{C} 6-\mathrm{C} 5-\mathrm{H} 51$ & $107.9(8)$ \\
\hline $116.72(9)$ & $\mathrm{C} 19-\mathrm{C} 5-\mathrm{H} 51$ & $109.4(8)$ \\
\hline $110.92(8)$ & $\mathrm{C} 5-\mathrm{C} 6-\mathrm{O} 4$ & $122.51(11)$ \\
\hline $106.90(8)$ & $\mathrm{C} 5-\mathrm{C} 6-\mathrm{C} 7$ & 115.26 (10) \\
\hline $109.87(8)$ & $\mathrm{O} 4-\mathrm{C} 6-\mathrm{C} 7$ & $122.16(11)$ \\
\hline $106.89(9)$ & $\mathrm{C} 6-\mathrm{C} 7-\mathrm{C} 8$ & $113.31(10)$ \\
\hline $112.83(8)$ & $\mathrm{C} 6-\mathrm{C} 7-\mathrm{C} 16$ & $109.31(9)$ \\
\hline 109.22 (9) & $\mathrm{C} 8-\mathrm{C} 7-\mathrm{C} 16$ & $110.57(9)$ \\
\hline $121.20(10)$ & $\mathrm{C} 6-\mathrm{C} 7-\mathrm{H} 71$ & $104.5(8)$ \\
\hline $116.10(8)$ & $\mathrm{C} 8-\mathrm{C} 7-\mathrm{H} 71$ & $110.9(8)$ \\
\hline $122.67(9)$ & $\mathrm{C} 16-\mathrm{C} 7-\mathrm{H} 71$ & $108.0(8)$ \\
\hline $112.17(9)$ & $\mathrm{C} 7-\mathrm{C} 8-\mathrm{C} 9$ & $111.59(10)$ \\
\hline $108.1(9)$ & $\mathrm{C} 7-\mathrm{C} 8-\mathrm{H} 81$ & $107.7(9)$ \\
\hline 109.1 (9) & $\mathrm{C} 9-\mathrm{C} 8-\mathrm{H} 81$ & 110.9 (9) \\
\hline $109.1(8)$ & $\mathrm{C} 7-\mathrm{C} 8-\mathrm{H} 82$ & $109.0(9)$ \\
\hline $113.0(8)$ & $\mathrm{C} 9-\mathrm{C} 8-\mathrm{H} 82$ & $108.3(9)$ \\
\hline $105.1(12)$ & $\mathrm{H} 81-\mathrm{C} 8-\mathrm{H} 82$ & $109.3(13)$ \\
\hline $111.14(9)$ & $\mathrm{C} 8-\mathrm{C} 9-\mathrm{C} 10$ & $114.43(9)$ \\
\hline $110.88(9)$ & $\mathrm{C} 8-\mathrm{C} 9-\mathrm{C} 20$ & $109.98(10)$ \\
\hline $111.12(8)$ & $\mathrm{C} 10-\mathrm{C} 9-\mathrm{C} 20$ & $112.57(9)$ \\
\hline $106.8(8)$ & С $8-\mathrm{C} 9-\mathrm{H} 91$ & $105.2(8)$ \\
\hline $108.1(8)$ & $\mathrm{C} 10-\mathrm{C} 9-\mathrm{H} 91$ & $104.8(8)$ \\
\hline $108.7(8)$ & $\mathrm{C} 20-\mathrm{C} 9-\mathrm{H} 91$ & $109.3(8)$ \\
\hline $107.11(9)$ & $\mathrm{C} 9-\mathrm{C} 10-\mathrm{C} 11$ & $112.21(8)$ \\
\hline 114.06 (11) & $\mathrm{C} 9-\mathrm{C} 10-\mathrm{C} 21$ & 110.57 (9) \\
\hline 111.80 (11) & $\mathrm{C} 11-\mathrm{C} 10-\mathrm{C} 21$ & $106.38(8)$ \\
\hline $106.2(8)$ & $\mathrm{C} 9-\mathrm{C} 10-\mathrm{C} 22$ & $107.88(9)$ \\
\hline
\end{tabular}




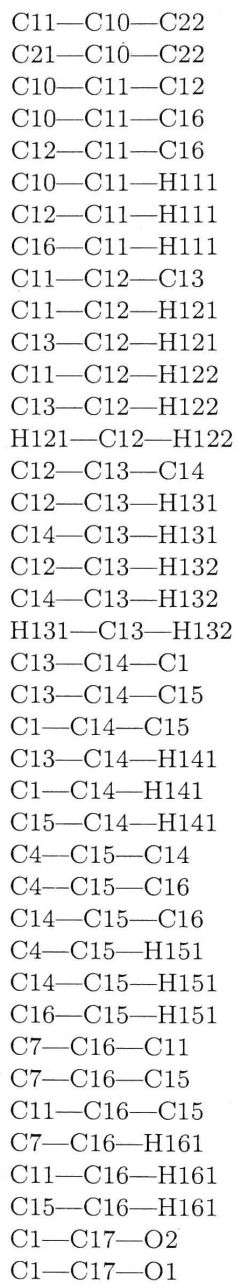

$108.40(8)$

$111.42(8)$ $112.12(8)$ 115.76 (8) 108.78 (8) $106.0(7)$ $108.5(7)$ $105.2(7)$ 111.38 (8) 111.7 (8) 109.4 (8) $108.6(8)$ 109.5 (8) 106.2 (11) 111.19 (8) 109.3 (8) 110.1 (8) $107.5(8)$ 109.4 (8) 109.3 (11) 111.01 (8) $111.13(8)$ 113.66 (8) 107.4 (8) $107.2(7)$ $106.0(8)$ $111.02(8)$ 111.39 (8) 109.45 (8) 108.0 (7) $109.9(7)$ $107.0(7)$ $110.45(8)$ $111.23(8)$ $110.52(8)$ 108.1 (7) $109.0(7)$ $107.3(7)$ $110.62(8)$ $125.49(10)$
$\mathrm{O} 2-\mathrm{C} 17-\mathrm{O} 1$

$\mathrm{C} 1-\mathrm{C} 18-\mathrm{H} 181$

C1-C18-H182 $\mathrm{H} 181-\mathrm{C} 18-\mathrm{H} 182$ $\mathrm{C} 1-\mathrm{C} 18-\mathrm{H} 183$ H181-C18-H183 H182-C18-H183 C5-C19-H191 C5-C19-H192 H191-C19-H192 C5-C19-H193 H191-C19-H193 H192-C19-H193 $\mathrm{C} 9-\mathrm{C} 20-\mathrm{H} 201$ $\mathrm{C} 9-\mathrm{C} 20-\mathrm{H} 202$ $\mathrm{H} 201-\mathrm{C} 20-\mathrm{H} 202$ $\mathrm{C} 9-\mathrm{C} 20-\mathrm{H} 203$ $\mathrm{H} 201-\mathrm{C} 20-\mathrm{H} 203$ H202-C20-H203 $\mathrm{C} 10-\mathrm{C} 21-\mathrm{O} 6$ $\mathrm{C} 10-\mathrm{C} 21-\mathrm{O} 5$ $\mathrm{O} 6-\mathrm{C} 21-\mathrm{O} 5$ $\mathrm{C} 10-\mathrm{C} 22-\mathrm{H} 221$ $\mathrm{C} 10-\mathrm{C} 22-\mathrm{H} 222$ $\mathrm{H} 221-\mathrm{C} 22-\mathrm{H} 222$ $\mathrm{C} 10-\mathrm{C} 22-\mathrm{H} 223$ $\mathrm{H} 221-\mathrm{C} 22-\mathrm{H} 223$ $\mathrm{H} 222-\mathrm{C} 22-\mathrm{H} 223$ $\mathrm{O} 2-\mathrm{C} 23-\mathrm{H} 231$ $\mathrm{O} 2-\mathrm{C} 23-\mathrm{H} 232$ H231-C23-H232 $\mathrm{O} 2-\mathrm{C} 23-\mathrm{H} 233$ $\mathrm{H} 231-\mathrm{C} 23-\mathrm{H} 233$ H232- C23-H233 O6- $244-\mathrm{H} 241$ O6- $224-\mathrm{H} 242$ $\mathrm{H} 241-\mathrm{C} 24-\mathrm{H} 242$ O6- $24-\mathrm{H} 243$ $\mathrm{H} 241-\mathrm{C} 24-\mathrm{H} 243$ $\mathrm{H} 242-\mathrm{C} 24-\mathrm{H} 243$
$123.89(10)$ 109.5 (9) $110.5(9)$ 108.4 (13) $110.4(9)$ $109.3(12)$ $108.8(12)$ 107.9 (12) 111.2 (12) 108.0 (16) 109.5 (12) $111.3(17)$ 108.8 (17) $114.9(10)$ 110.1 (10) 108.1 (15) 109.5 (10) 109.7 (14) 103.9 (15) 112.47 (9) $124.99(10)$ 122.43 (10) $111.2(8)$ 112.0 (9) 106.2 (12) 108.4 (8) 111.4 (12) 107.7 (12) 105.3 (10) 110.5 (11) 112.2 (15) 111.5 (11) 107.1 (16) 110.2 (16) 109.7 (10) $111.4(10)$ 106.7 (14) $109.0(10)$ 113.7 (15) $106.4(14)$ 


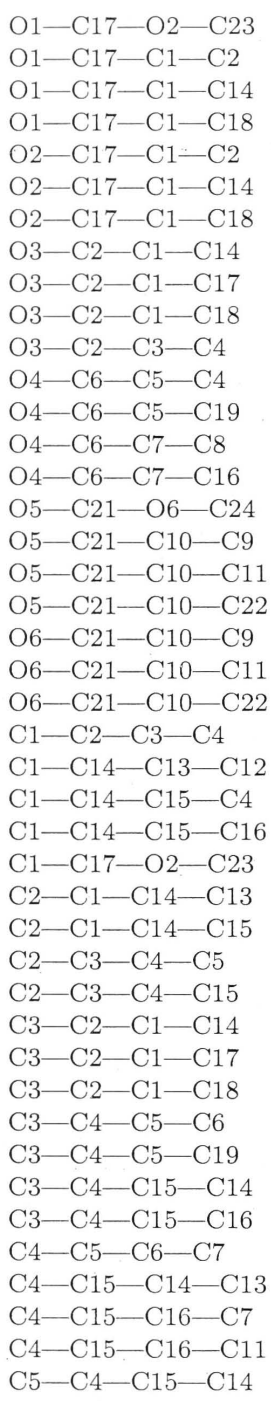

$\mathrm{O} 1 \ldots \mathrm{O} 1^{\mathrm{i}}$

$\mathrm{O} 1 \cdots \mathrm{C} 19^{\mathrm{ii}}$

O3...C2 $2^{\text {iii }}$

$\mathrm{O} 3 \cdots \mathrm{C} 18^{\mathrm{iii}}$

$\mathrm{O} 3 \ldots \mathrm{O}^{\mathrm{ii}}$

O3...O $3^{\text {iii }}$

O3...C3 $3^{\text {iii }}$

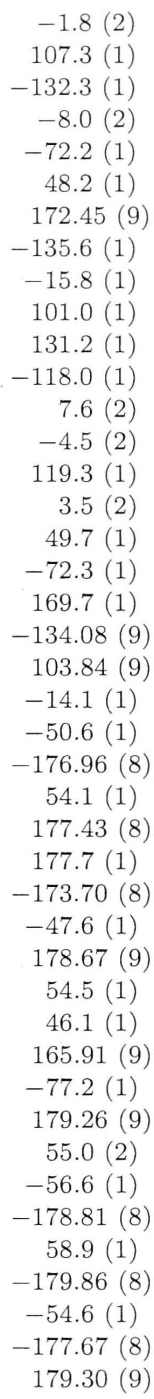

Table S4. Contact distances $(\AA)$

$3.483(2)$
$3.527(2)$
$3.369(1)$
$3.387(2)$
$3.4390(7)$
$3.4390(7)$
$3.472(2)$

$\mathrm{O} 3 . \cdot \mathrm{C} 3^{\text {ii }}$

$\mathrm{O} 3 \cdots \mathrm{C} 4^{\mathrm{ii}}$

Symmetry codes: (i) $1-x, 2-y, 1-z$; (ii) $1-x, \frac{1}{2}+y, \frac{1}{2}-z$; (iii) $1-x, y-\frac{1}{2}, \frac{1}{2}-z$; (iv) $x, \frac{1}{2}-y, z-\frac{1}{2}$; (v) $x, y-1, z ;(\mathrm{vi})-x, 1-y, 1-z$. 


\section{Corrections}

Page xi LiHMDS = lithium hexamethyldisilazide

Page 13 Scheme 1.3, replace $\mathrm{CH}_{2} \mathrm{Br}$ with $\mathrm{CH}_{2} \mathrm{Br}_{2}$

Page $14 \quad$ Scheme 1.4 , replace $\mathrm{Cu}(\mathrm{OT})_{2}$ with $\mathrm{Cu}(\mathrm{OTf})_{2}$

Page 15 Replace R-CN at C-20 in structure $\mathbf{1 . 1 0}$ with R-NC

Page 23 Replace $\mathrm{Pd}(\mathrm{OAc})_{4}$ with $\mathrm{Pd}(\mathrm{OAc})_{2}$, and also on page 53

Page 32 Reduction of the alcohol function in 2.2 (MOM ether derivative) gave an epimerically pure alcohol of unspecified stereochemistry

Page 67 Invert stereochemistry at C-8 in structures $\mathbf{5 . 1}$ and $\mathbf{5 . 2}$, table 5.1

Page 73 Figure 5.5, replace C-12 with C-13

Page 74 line 7 , replace $3.2 \mathrm{~Hz}$ with $13.2 \mathrm{~Hz}$ 